\title{
ADVANCED VITRIFICATION SYSTEM (RIC AVS) RESEARCH AND DEVELOPMENT PROJECT
}

\section{Additional Tests of an Advanced Vitrification System (DE-AC26-00NT40801) Technical Progress Report}

\section{Final Report}

(Revision 2)

\author{
Performance Period: September 1, 2000 to June 30, 2003
}

J.R. Powell and M. Reich, Co-Principal Investigators

\author{
R.E. Barletta \\ E. Bohannan \\ M. Bricka \\ W.R. Grossman \\ B. Kauffman \\ A. Kumar \\ G. Maise \\ B. Manowitz \\ T. Meaker \\ M. McCarthy \\ J. McCown \\ S. Miller \\ L. Pearson \\ M.J. Plodinec \\ A.A. Ramsey \\ W.G. Ramsey \\ F. Salzano \\ J. Smith \\ M. Steinberg \\ S.F. Woodberry
}

RADIOACTIVE ISOLATION CONSORTIUM, LLC (RIC, LLC) 708 East Broad Street, Falls Church, VA 22046

Tel: 703-241-8711

Fax: 703-241-8714

http://www.ricllc.com 


\section{DISCLAIMER}

This report was prepared as an account of work sponsored by an agency of the United States Government. Neither the United States Government nor any agency thereof, nor any of their employees, makes any warranty, express or implied, or assumes any legal liability or responsibility for the accuracy, completeness, or usefulness of any information, apparatus, product, or process disclosed, or represents that its use would not infringe privately owned rights. Reference herein to any specific commercial product, process, or service by trade name, trademark, manufacturer, or otherwise does not necessarily constitute or imply its endorsement, recommendation, or favoring by the United States Government or any agency thereof. The views and opinions of the authors expressed herein do not necessarily state or reflect those of the United States Government or any agency thereof.

Available to the public from the National Technical Information Service, U.S. Department of Commerce, 5285 Port Royal Road, Springfield, VA 22161; phone orders accepted at (703) 4874650. 


\begin{abstract}
The objective of this AVS testing program is to use bench-scale test equipment to produce a vitrified product at maximum waste loading from the specified AZ-101 waste simulant and conduct a TTT analysis using laboratory scale melts to show compliance with the DOE Waste Acceptance Product Specifications for Vitrified High-Level Waste Forms (WAPS).

The vitrified product complies with the following WAPS. A borosilicate glass with a waste loading of $60.9-\mathrm{wt} \%$ was produced from a slurry feed of AZ101 simulant. Glass durability testing, glass characterization testing, and testing methodology were performed in accordance with the Department of Energy approved Test Plan. The glass has two crystalline phases and good uniformity of composition. The Product Consistency Test on the 6 location-specific samples are at least 1 to 2 orders of magnitude below the mean PCT results for the EA glass. Standard deviations were less than $10 \%$ of measured values. The glass transition temperature averaged 658 $\pm 9^{\circ} \mathrm{C}$. A TTT diagram was produced. There was measured cesium loss of about $2 \%$, and compliance with the Universal Treatment Standards.
\end{abstract}




\section{ACRONYMS}

$\begin{array}{ll}\text { AA } & \text { Atomic Absorption } \\ \text { ANSI } & \text { American National Standards Institute } \\ \text { ASTM } & \text { American Society for the Testing of Materials } \\ \text { AVS } & \text { Advanced Vitrification System } \\ \text { BEI } & \text { Backscattered Electron Imaging } \\ \text { COFFEE } & \text { Continuous Feed Fill Experimental Equipment } \\ \text { DIAL } & \text { Diagnostic Instrumentation and Analysis Laboratory } \\ \text { DOE } & \text { Department of Energy } \\ \text { DTA } & \text { Differential Thermal Analysis } \\ \text { EDS } & \text { Energy Dispersive Spectroscopy } \\ \text { ES\&H } & \text { Environmental Safety and Health } \\ \text { HEME } & \text { High Efficiency Mist Eliminator } \\ \text { HEPA } & \text { High Efficiency Particulate Arrestor } \\ \text { HLW } & \text { High Level Waste } \\ \text { IC } & \text { Ion Chromatography } \\ \text { ICP-ES } & \text { Inductively Coupled Plasma Emission Spectroscopy } \\ \text { JCPDF } & \text { Joint Committee on Powder Diffraction Files } \\ \text { MSDS } & \text { Material Safety Data Sheets } \\ \text { MSU } & \text { Mississippi State University } \\ \text { NA } & \text { Neutron Activation } \\ \text { PCT } & \text { Product Consistency Test } \\ \text { PLC } & \text { Programmable Logic Controller } \\ \text { RCRA } & \text { Resource Conservation and Recovery Act } \\ \text { RD\&D } & \text { Research, Demonstration, and Development } \\ \text { RIC } & \text { Radioactive Isolation Consortium } \\ \text { SCADA } & \text { Supervisory Control and Acquisition System } \\ \text { SEE } & \text { Safety, Excellence, and Environment } \\ \text { SEM } & \text { Scanning Electron Microscopy } \\ \text { SOW } & \text { Statement of Work (see Glossary) } \\ \text { SPCC } & \text { Spill Prevention, Control and Countermeasures } \\ \text { TCLP } & \text { Toxicity Characteristic Leaching Procedure } \\ \text { TGA } & \text { Thermo-Gravimetric Analysis } \\ \text { TIC TOC } & \text { Total Inorganic Carbon, Total Organic Carbon } \\ \text { TTT } & \text { Time, Temperature, Transformation } \\ \text { UMR } & \text { University of Missouri - Rolla } \\ \text { Universal Treatment Standards } \\ \text { WAste Acceptance Product Specifications } \\ \text { X-raction }\end{array}$




\section{GLOSSARY}

COFFEE Continuous Feed Form Experimental Equipment

Dryer A device to de-water slurry, e.g., Troy Dryer, Porcupine Processor

Feed A mixture of simulant plus additives, e.g., dryer feed, melter feed, etc.

Feed Form Slurry, powder or tablets

M-1 Waste loading calculation, Method 1 wherein all silica and sodium chemicals are subtracted when calculating waste loading.

M-2 Waste loading calculation, Method 2 wherein only chemicals added to the waste simulant to facilitate vitrification are subtracted when calculating waste loading.

Melter The AVS bench-scale test stand

Powder Dried melter feed

Simulant A waste material prepared from a DOE recipe, designed to chemically simulate high-level radioactive waste sludge, e.g., AZ-101 simulant

SOW Statement of Work (January 2002) Revised 3/14/02 for Additional Tests of the Advanced Vitrification System DE-AC26-00NT40801, Attachment A, Modification A008.

Slurry A liquid-solid mixture, e.g., simulant slurry, feed slurry, etc.

Tablets $\quad$ Pellets of dried melter feed

TR21 First simulant provided by NOAH

TR23 Second simulant provided by NOAH

TR26 Second simulant provided by NOAH after remediation by DIAL

Trim chemicals Simulant additives to meet waste loading requirements, or promote melting and glass making, or to comply with glass content requirements, e.g., silica, boric acid, and sodium carbonate.

Waste Form - Vitrified waste feed product 


\section{TABLE OF CONTENTS}

DISCLAIMER.....................................................................................................................................

ABSTRACT .................................................................................................................................................ii

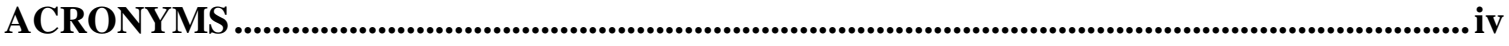

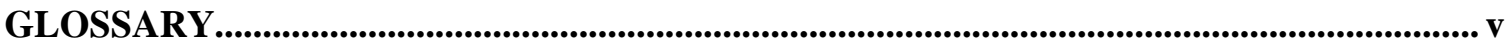

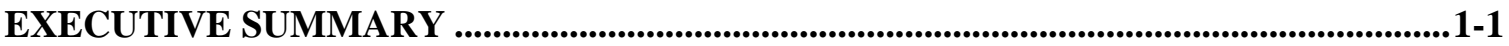

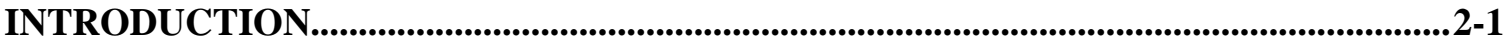

EXPERIMENTAL METHOD.................................................................................................................3-1

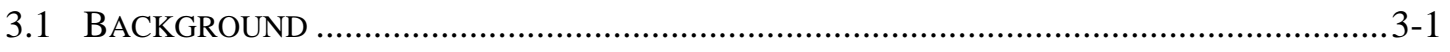

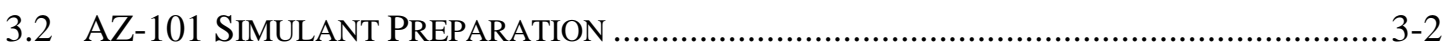

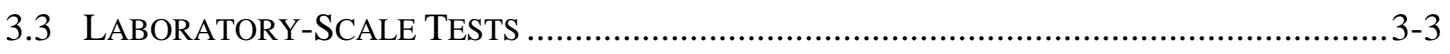

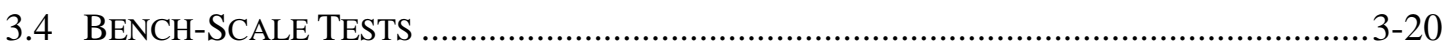

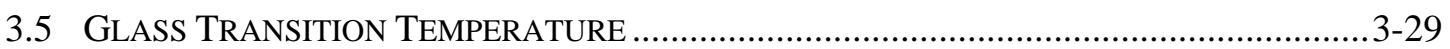

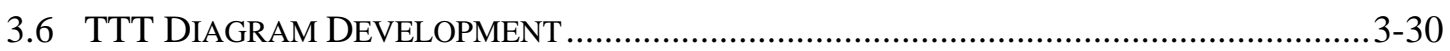

EXPERIMENTAL RESULTS AND DISCUSSION..........................................................4-1

4.1 AZ-101 SIMULANT ACCEPTANCE …….......................................................... 4

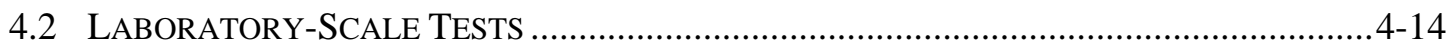

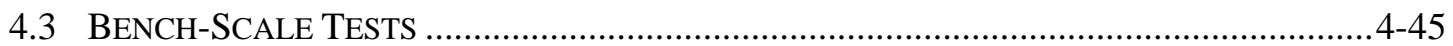

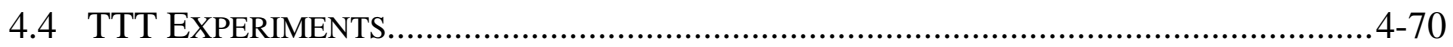

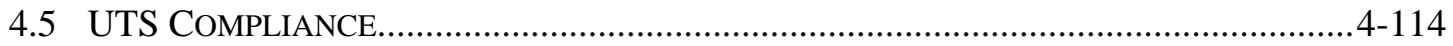

RESULTS AND DISCUSSION - WAPS COMPLIANCE .......................................................5-1

EXTRAPOLATION OF EXPERIMENTAL RESULTS TO A FULL-SCALE AVS

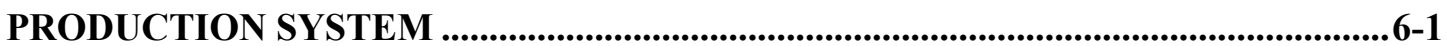

6.1 PRocess Flow SHEET MASS BALANCE ….................................................................... $6-1$

6.2 Extrapolating Test Results to Full-Scale AVS Vitrified Product CoOling

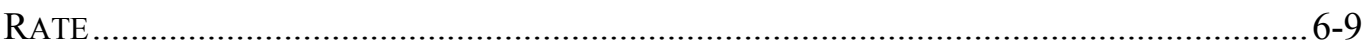

6.3 COMPARISON OF VITRIFIED PRODUCTS FROM RIC-AVS AND CATHOLIC UNIVERSITYVSL

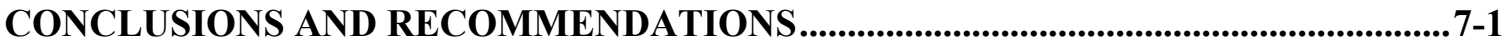

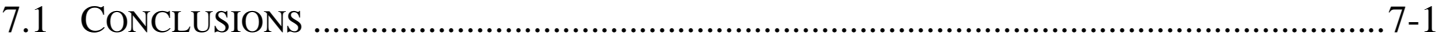

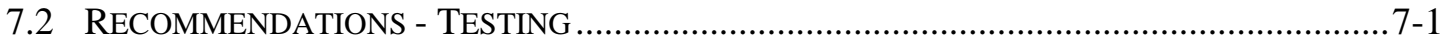

7.3 RECOMMENDATIONS - ENVIRONMENTAL …….........................................................

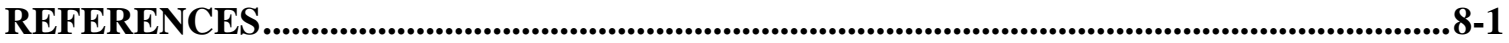




\section{Summary}

The objective of this AVS testing program ${ }^{1}$ is to use bench-scale test equipment to produce a vitrified product at maximum waste loading ${ }^{2}$ from the specified AZ-101 waste simulant and conduct a TTT analysis using laboratory scale melts to show compliance with the DOE Waste Acceptance Product Specifications for Vitrified High-Level Waste Forms (WAPS). ${ }^{3}$

The vitrified product complies with the following WAPS, as required:

1. WAPS Section 1.1.1 Chemical Composition Projections

2. WAPS Section 1.1.2 Chemical Composition During Production

3. WAPS Section 1.3 Specification for Product Consistency

4. WAPS Section 1.4 Specification for Phase Stability

5. WAPS Section 1.5 Hazardous Waste Specification

A borosilicate glass having more than 5 -wt $\%$ boron, namely $5.5 \pm 0.2 \mathrm{wt} \%$, was produced in Bench-Scale 4. Two crystalline phases, zirconia and spinel, were identified in the sectioned product. The average weight percentage of spinel is $10 \% \pm 2 \%$ and zirconia $4 \% \pm 1 \%$. Volume percentage is estimated to be $6 \%$ for spinel and $2 \%$ for zirconia.

The AVS Bench-Scale 4 vitrified product was sampled for composition at 6 sampling locations. There is good uniformity of composition across all the samples.

The Bench-Scale 4 vitrified product had a waste loading of $60.9-\mathrm{wt} \%$. The target waste loading was $60-\mathrm{wt} \%$. This is close to the $60.9-\mathrm{wt} \%$ achieved confirming that the benchscale process produces a product with a predictable waste loading.

The Product Consistency Test (PCT) was run on the 6 location-specific samples from Bench-Scale 4. For all samples, the mean PCT results are at least 1 to 2 orders of magnitude below the mean PCT results for the EA glass. Standard deviations were less than $10 \%$ of measured values. Thus, the result for each element is well below two standard deviations of the mean PCT results for the EA glass.

\footnotetext{
${ }^{1}$ This project is an extension of the testing performed on the Envelope D waste form to include a second waste form using AZ-101 simulant. The SOW references both waste forms, but this testing and report is directed to a simulant of AZ-101 and the single waste form deliverable resulting from testing AZ-101 simulant: "The specific objective of the testing is to unambiguously establish whether these bench-scale tests, using waste simulant recipes provided by the DOE, can produce borosilicate glass waste forms that fully comply with the current revision of Waste Acceptance Product Specifications for Vitrified High-Level Waste Forms (WAPS)."

${ }^{2}$ The SOW at page 1 states, "conduct one qualification bench-scale test at maximum waste loading."

3 U.S. Department of Energy Office of Environmental Management, Waste Acceptance Product Specifications for Vitrified High-Level Waste Forms - WAPS, EM-WAPS Rev. 02, December 1996.
} 
The glass transition temperature, $\mathrm{Tg}$, was measured for the 6 location-specific samples from Bench-Scale 4. The Tg values are uniform throughout the glass to $\pm 10^{\circ} \mathrm{C}$. The average value was $658 \pm 9^{\circ} \mathrm{C}$.

A time temperature phase diagram follows:
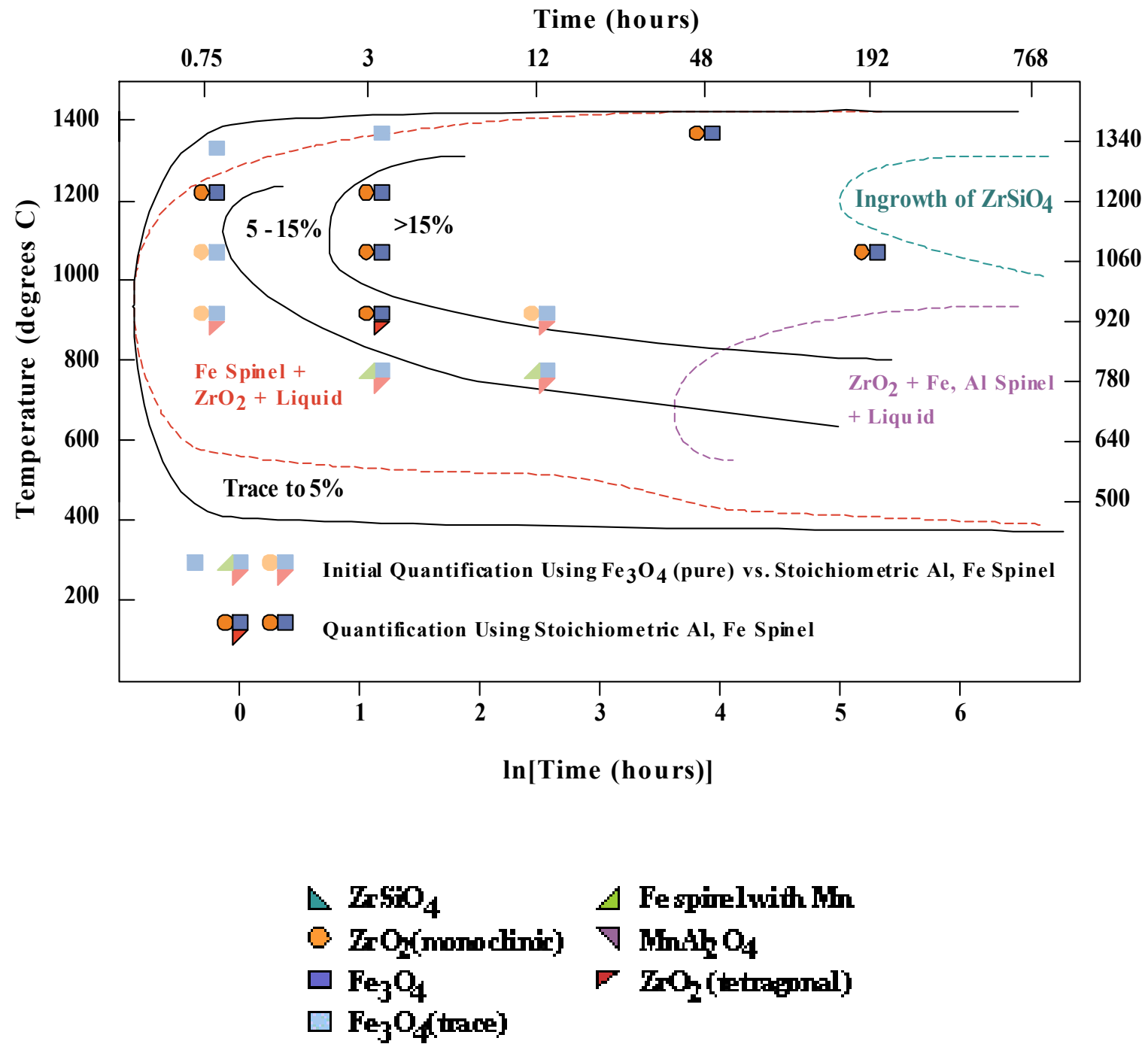

The "appropriate tests and procedures, as described in 40CFR261.20 through 40CFR261.24" were performed on the Bench-Scale 4 vitrified product and it is projected that the waste that would be received by DOE/RW, for transportation and disposal, has no hazardous characteristics as per the EPA regulations specified in the WAPS.

Other accomplishments include demonstration of a slurry feed to the Bench-Scale Test Stand, instead of a dry feed, a measured cesium loss of about $2 \%$, and compliance with the Universal Treatment Standards. 
In addition to WAPS compliance, other conclusions reached are (1) it is possible to prepare a vitrified AZ-101 borosilicate glass at both the laboratory-scale and the AVS bench scale with a waste loading of $\sim 60$-wt $\%$ and melting temperatures at about $1500^{\circ} \mathrm{C}$; (2) better process controls should be implemented to ensure that the feed rate is controlled so that the inner melt temperature remains at the intended melt temperature; (3) with respect to process scale-up of the AZ-101 waste formulation, it was projected that a $1.5 \mathrm{MT} /$ day production rate can be met; and, (4) that the AVS canister would contain 1.8 times more waste than a pour-type canister from the Joule melter at the same fill level, in spite of the lower internal volume of the AVS canister.

Recommendations include (1) proceeding with AVS process development in accordance with the February 2002 Work Plan; (2) a specific method to prepare TCLP samples should be created for use in glass compliance analysis to give comparable results for different researchers; and (3) the standard analytical regimen should be changed because it potentially leads to decisions compromising the commitment to defense-in-depth concerning waste form environmental performance. The deficiency also eliminates the potential for higher waste loaded glass and the attendant cost savings from producing even fewer canisters than is possible with the AVS glass under the standard analytical regimen.

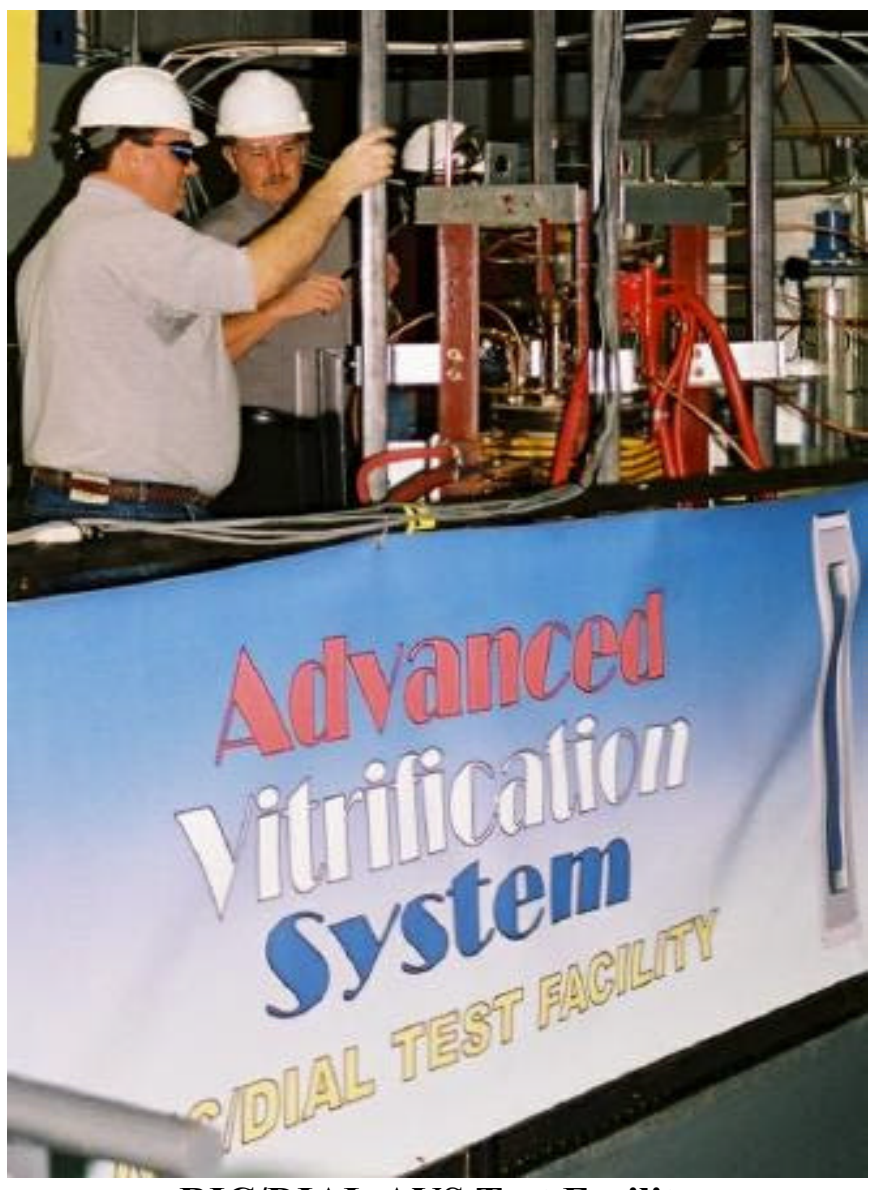

RIC/DIAL AVS Test Facility DOE Witnessed Test - Nov. 6-8, 2002 
The DOE required, as part of its contract with RIC, that an independent review the AVS test results related to WAPS compliance be carried out. The results of this review are contained in Independent Evaluation of Test Results from Waste Forms Produced from Hanford Tank AZ-101 Waste Simulant Using the Advanced Vitrification System (AVS) of the Radioactive Isolation Consortium (RIC), Final Report, prepared for the National Energy Technology Laboratory, under Task No. FT50503, DOE Contract No. DEAM26-99FT40465, June 2003.

The DOE also required, as part of its contract with RIC, that information on the AVS technology be provided in response to a DOE Request for Information on the Advanced Vitrification System Technology and Its Applicability to the Solidification of High-Level Waste (HLW) from Tanks at the Hanford Site. The DOE, through the Assistant Secretary for Environmental Management and the Office of River Protection at Richland, Washington, then evaluated four alternative technologies, including the AVS, to reduce the cost of processing HLW stored in underground tanks at the Hanford Site. Summary results of this DOE evaluation are contained in Alternatives for Hanford High-Level Waste Vitrification/Solidification: Report of the Immobilization Alternative Project Technical Working Group, June 2003. 


\section{Introduction}

This report presents the results from HLW glass formulation work that was conducted under Department of Energy (DOE) Contract DE-AC26-00NT40801 for Additional Tests of an Advanced Vitrification System. The work was conducted at the Diagnostic Instrumentation and Analysis Laboratory at Mississippi State University under a subcontract from the Radioactive Isolation Consortium, LLC (RIC). Supporting work was also performed at RIC's laboratory in New York and University of Missouri at Rolla.

Laboratory and bench-scale vitrification tests were conducted using a Phase I, Hanford waste simulant recipe for AZ-101. The recipe for the simulant was provided by DOE. The purpose was to demonstrate the ability of the existing design Advanced Vitrification System (AVS) test equipment to produce a borosilicate glass waste form that fully complies with the current revision (Rev. 2) of Waste Acceptance Product Specifications for Vitrified High-Level Waste Forms.11

\section{Needs/Issues}

The AVS is a potential option for immobilizing the Department of Energy's high-level radioactive waste (HLW) at Hanford that offers an opportunity for accelerating the Hanford Cleanup program while reducing costs and risks.

An illustration of the risk reduction benefits available with AVS in-can, single-use, melter technology is it potential performance in a risk assessment of the uncertainty in the Hanford waste tank composition on vitrification technology.

The Hanford tank farm comprises 177 tanks containing approximately 60 million gallons of waste sludge and supernate. Most of the tanks are 75 feet in diameter and approximately 30 feet deep. These tanks contain a mixture of chemicals produced by at least four different processes. The contents of the tanks are heterogeneous both because they have been filled in different stratigraphic layers and because over the years various tank contents have been mixed. There have been attempts to characterize the waste over the last ten years most recently by sampling each tank in a major characterization study. There are many inherent problems in obtaining a reliable waste characterization from each of the tanks.

There are relatively few access points (or risers) for sampling and they are located primarily at the periphery of a 75 feet diameter tank. The sampling devices are generally around 3 inches in diameter and can sample a few liters of the million liters of waste in each tank. The risers were used for additions or withdrawals and do not necessarily represent the composition at all points with in the tank. The sampling devices cannot

\footnotetext{
${ }^{1}$ Waste Acceptance Product Specifications for Vitrified High-Level Waste Forms, US Department of Energy, Office of Environmental Management, USDOE Document EM-WAPS Rev. 02, Washington, DC $(12 / 96)$.
} 
reach the bottom of the tank. During the sampling campaign, there were two samples taken from each tank. The results, generally given as "best available," are the average of the sample results but no variance in sample composition is given. In addition to the variance due to lack of a representative sample, there will also be an analytical variance depending on the method used to dissolve solids in the sample.

There is an attempt to address this problem by assigning waste composition envelopes. In reality we will not know what the composition of the waste feed will be until a feed batch is made, homogenized, sampled and analyzed. The overall problem can be managed by producing "maxi-batches", i.e., batches of $\sim 500,000$ gallons which will have to be homogenized and kept segregated for the duration of the vitrification campaign. Even on this basis, however, approximately 100 "maxi-batches" will be required to treat the entire tank farm.

In addition to the uncertainties in the composition due to poor sampling, there will be changes in the chemical species due to reactions at elevated temperatures for long periods of time. Sulphur may be present in a polymer form that does not dissolve in the glass even at low concentrations; foaming agents may be generated that are not present in any of the surrogates. Mercury may be present in compounds that dissolve with the glass and are subsequently leachable. Many other chemical changes are possible which can be recognized only after a feed batch is fully analyzed.

The impact of uncertainties will be felt both in the pre-treatment plant and the vitrification plant. Chemical separation factors and radiochemical decontamination factors may be less then achieved with simulants if the chemical and radiochemical species are different or are in different concentration than the simulants. The vitrification plant has put its entire reliance on joule melters which have constraints in viscosity, conductivity, corrosion, and foaming that are sensitive to composition. It would be prudent to have another melter technology available that is less sensitive to composition variations.

The AVS is an in-canister HLW immobilization system. The baseline full-scale AVS process uses a module that consists of an alumina-lined, graphite crucible contained within a DOE approved conventional stainless steel canister.

In the full-scale AVS, the graphite susceptor within the module is preferentially heated using a low-frequency inductive coil surrounding the outer stainless steel canister. The susceptor heats the waste within. The stainless-steel canister is thermally insulated from the susceptor and the graphite crucible is chemically isolated from the melt by an alumina lining or coating.

The existing AVS test stand operates without the stainless steel outer container. The AVS is a single-use melter system, intended to permit the use of varying waste

\footnotetext{
${ }^{2}$ The term "single-use melter" is intended to describe a melter that is used once and then used to contain the vitrified waste for storage or disposal. In this sense, a single use melter is a single-cycle melter in contrast to a "continuous" melter. The term "single use" is not intended to describe a melter used for a single purpose or a single waste. See the National Research Council's explanation of the benefits of single-
} 
chemistries and waste formulations with melting temperatures up to about $1500^{\circ} \mathrm{C}$.

The Department of Energy determined that the existing AVS technology test stand should demonstrate an ability to produce a vitrified borosilicate glass waste form that meets the technical criteria for immobilized high-level waste (HLW) at the DOE Hanford site.

\section{Background}

During a previous phase of the contract, glass was produced on the same test stand that was used for the DOE-supplied Envelope D waste simulant. Two glasses: $35-w t \%$ and $50-\mathrm{wt} \%$ were produced.

The glasses passed the Product Consistency Test (PCT) and the EPA's UTS standards using the prescribed Toxicity Characteristic Leaching Procedure (TCLP).

A DOE created Independent Review Team (IRT) found that RIC had demonstrated compliance with four of the six WAPS applied to this effort; but was not satisfied with the Tg determination, the determination of crystallinity and the preparation of the TTT diagram. As a result of this review, DOE extended the contract and required additional testing on a new simulant to complete demonstration of WAPS compliance.

\section{Specific Objectives Relating to Needs and Issues}

The Statement of Work (SOW) states, "The specific objective of the testing is to unambiguously establish whether these bench-scale tests, using waste simulant recipes provided by the DOE, can produce borosilicate glass waste forms that fully comply with the current revision of Waste Acceptance Product Specifications for Vitrified High-Level Waste Forms (WAPS)."

\section{Report Structure}

Summary of Results (Section 1) is a summary statement of testing program.

Introduction (Section 2) is an explanation of needs/issues, background and context of the testing. The report structure is outlined and a diagram of the major work efforts that led to the deliverables required by the approved Test Plan and the SOW.

Experimental Method (Section 3) describes the test objectives, methods, and equipment and test parameters for the testing program.

Experimental Results and Discussion (Section 4) details the crystallinity study, including descriptions of the Rietveld method as applied to AZ-101 glass and the TTT diagram; glass formulation, AZ-101 characterization, feed form, feed system design and off gas, including cesium retention studies.

use melters in "Alternative High-Level Waste Treatments at the INEEL," National Research Council, December 16, 1999, pp.68-70.

${ }^{3}$ Toxicity Characteristic Leaching Procedure, test Method 1311 in 'Test Methods for Evaluating Solid Waste, Physical Chemical Methods,' EPA Publication SW-846. 
Results and Discussion - WAPS Compliance (Section 5) presents and analyzes the testing results in terms of compliance with the WAPS.

Extrapolation of Experimental Results to a Full Scale AVS Production Process (Section 6) extrapolates testing results to (1) a full-scale AVS flowsheet including an analysis of production impacting factors, e.g., feed form, melting and cooling rates, and testing and innovation in meeting environmental safety requirements; (2) a 1 dimensional analysis that projects a full-scale AVS vitrified product cooling rate; and (3) compares the experimental results to those obtained by a DOE study, ${ }^{4}$ which examined waste form performance in crucibles heated with lab-scale resistance ovens guided by the operational parameters of the Joule melter.

Conclusions and Recommendations (Section 7) --- (1) makes recommendations for future AVS process development and testing and discusses observations made in this testing program about the need for improved environmental testing standards and suggests approaches to improving environmental safety.

References (Section 8). Provides references consulted and relevant to this program.

\footnotetext{
${ }^{4}$ The Department of Energy provided the Vitreous State Laboratory study for comparison, "Glass Formulation And Testing With RPP-WTP HLW Simulants,” W. K. Kot and I. L. Pegg, Vitreous State Laboratory, The Catholic University of America, Washington, D.C. 20064, February 16, 2001, Rev.0
} 


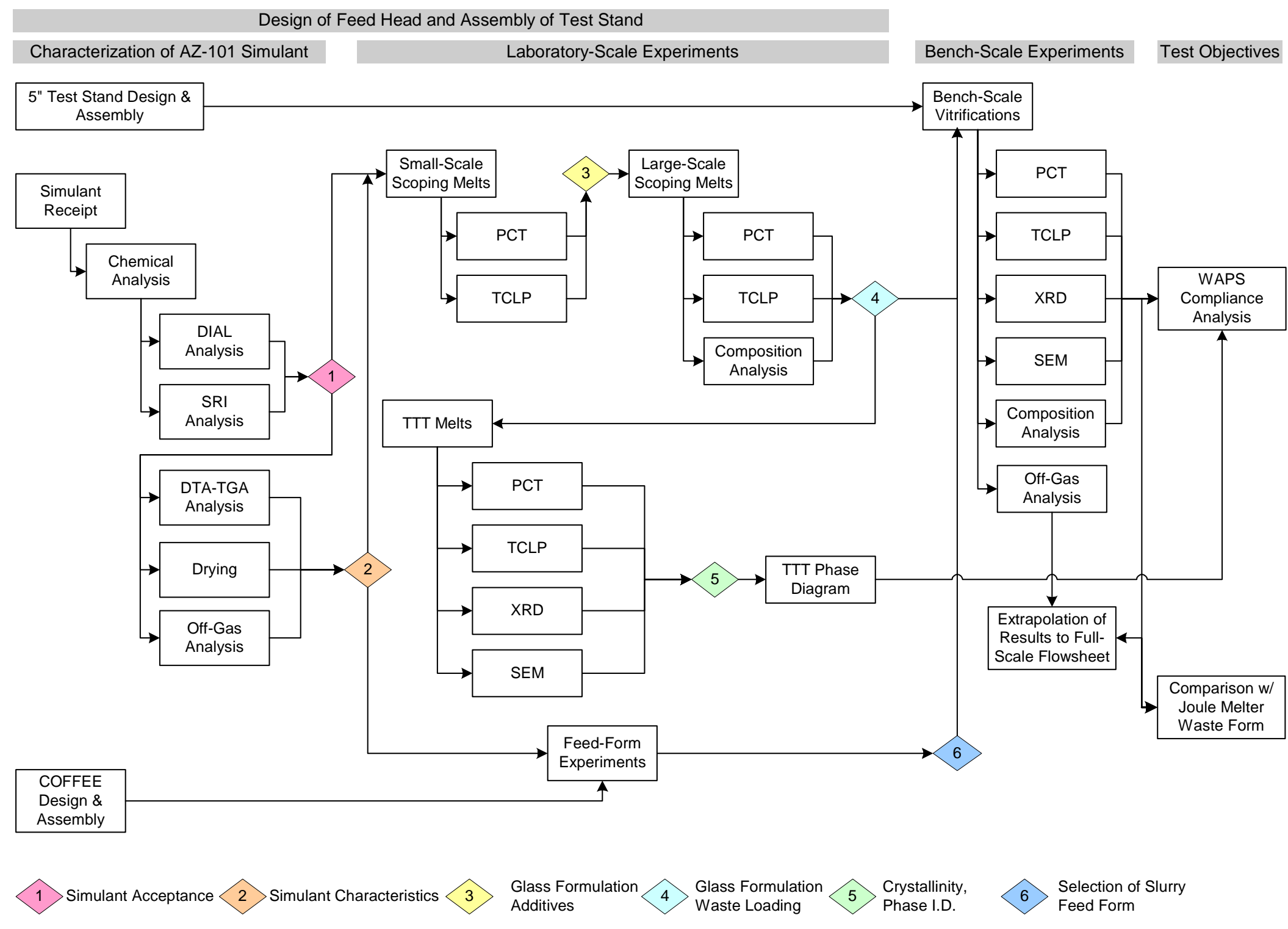




\section{Experimental Method}

This section describes the methodology used in the experimental program. The experimental method is described in four sections: Analytical Methodology, AZ-101 Simulant Preparation, Laboratory scale tests, and Bench-Scale Test.

\subsection{Analytical Methodology}

The experimental methods used during the conduct of this project are in accordance with the DOE Statement of Work and the RIC Detailed Test Plan. The test plan was submitted to and approved by DOE prior to the initiation of the work.

\section{Waste Loading}

The reported waste loading is expressed as weight percent (wt $\%)$ and, in accordance with the SOW, was calculated by two methods:

- Method-1 (M-1): Waste loading (wt\%) $=[$ (mass of the glass $)-(($ mass of glass formers added $)+($ mass of sodium oxide in the waste, expressed as $\mathrm{Na2O})+$ (mass of silicon in the waste, expressed as $\mathrm{SiO} 2)$ )]/ (mass of the glass).

- Method-2 (M-2): Waste loading ( $\mathrm{wt} \%)=[$ (mass of the glass $)-($ mass of glass formers added) $] /$ (mass of the glass).

M-1 yields a lower waste loading of the two methods described. Method-1 does not allow glass-forming chemicals to be considered when calculating waste loading percentages. Excluded are $\mathrm{SiO}_{2}$ and $\mathrm{Na}_{2} \mathrm{O}$ added during feed preparation or which may be present in the waste simulant prior to feed preparation.

M-2 allows all original constituents of the waste simulant to be considered part of the waste loading. Only those chemicals added to the waste simulant to facilitate vitrification are not included in the waste loading. While yielding a higher waste loading value than M-1, M-2 may provide a more accurate gauge as to the quantity and speed of waste removal from the storage tanks.

\section{Leaching and Product Consistency Tests}

The WAPS require Waste Producers to demonstrate control of the consistency of the final waste form using the Product Consistency Test (PCT). ${ }^{1}$ In compliance with the WAPS this report demonstrates control of waste form production by comparing production samples to the Environmental Assessment (EA) benchmark glass.

In addition to the WAPS, the SOW requires a determination of the leachability of any RCRA-listed components using the prescribed Toxicity Characteristic Leaching Procedure (TCLP) relative to the Universal Treatment Standards specified by the Environmental Protection Agency.

\footnotetext{
${ }^{1}$ ASTM C 1285-97
} 


\section{Glass Analysis}

In accordance with the SOW: XRD and SEM were used to measure the extent and nature of crystallinity within the bench-scale vitrified product; Differential Thermal Analysis was used to determine the glass transition temperature (Tg); a Time-TemperatureTransformation (TTT) diagram was prepared using the Rietveld method and the TTT samples were characterized with respect to PCT and TCLP performance; the glass performance results were compared to results obtained by Vitreous State Laboratory on the AZ-101 simulant; a flowsheet was prepared for a full-size AVS process; and a DOEsupplied blind sample was characterized for composition, crystallinity, PCT durability, TCLP performance.

\subsection{AZ-101 Simulant Preparation}

The AZ-101 simulant material was provided by NOAH Technologies, Inc. They provided three, 55-gallon drums of simulant material in slurry form.

\section{Test Objectives}

The objective of this effort is to prepare a simulant that meets the target specifications set by DOE in the SOW. The intent is to use a material that chemically simulates the radioactive high-level waste sludge found in Hanford waste tank AZ-101. Meeting this objective entails both the preparation and acceptance testing of the simulant. The DOE target composition is found in Table 3-1.

\section{Method/Approach}

The AZ-101 simulant material was provided by NOAH Technologies, Inc. NOAH was provided the AZ-101 simulant composition and recipe as specified by DOE. NOAH provided three, 55-gallon drums of simulant material in slurry form. Per the SOW, the chemical composition of the simulant was required to match the AZ-101 target composition prior to initiation of testing.

Upon receipt of the material from NOAH, each drum was subjected to the acceptance protocol at DIAL. Chemical analysis was conducted for cations, anions, and total organic carbon using the DIAL chemical analysis procedures. In addition, an analysis of the material was conducted by an independent laboratory using a sample of the simulant provided to them by NOAH. Finally, the resulting chemical analysis was compared with the target composition and was either accepted, rejected, or remediated, as appropriate. 


\section{Test Equipment}

State-of-the-art analytical equipment was used in the chemical composition verification of AZ-101. This equipment included:

- Perkin Elmer ICP-AES, Optima 4300 DV.

- Perkin Elmer AA, Analyst 800 with both flame and graphite furnace capability.

- Dionex IC, $D X-500$.

- Tekmar-Dohrman TIC-TOC, Phoenix 800, that uses Pb oxidation UV/per sulfate technique.

- Perkin Elmer TG-DTA 6300, Pyris Diamond.

\section{Description of Test Matrix}

Three simulant formulations were analyzed during the chemical composition verification process. TR-21 was the first simulant provided by NOAH. TR-23 was the second simulant provided by NOAH. TR-26 was the second simulant after remediation. The number designators reference DIAL reports detailing the simulant evaluation process.

\begin{tabular}{|c|c|c|c|c|}
\hline \multirow[t]{2}{*}{ Simulant ID } & \multicolumn{3}{|c|}{ DIAL Analysis } & \multirow{2}{*}{$\begin{array}{c}\text { Independent } \\
\text { Analysis }\end{array}$} \\
\hline & Preparation & Instrument & Species & \\
\hline \multirow[t]{6}{*}{ TR-21 } & Alkali Fusions & ICP-ES & Cations $^{2}$ & \multirow[t]{6}{*}{ Yes } \\
\hline & & AA & $\mathrm{Cs}$ & \\
\hline & Microwave & ICP-ES & Cations & \\
\hline & Sonicate & IC & Anions $^{3}$ & \\
\hline & \multirow[t]{2}{*}{ None } & NA & $\mathrm{F}, \mathrm{Cl}$ & \\
\hline & & TIC TOC & TOC & \\
\hline \multirow[t]{6}{*}{ TR-23 } & Alkali Fusions & ICP-ES & Cations & \multirow[t]{6}{*}{ Yes } \\
\hline & & AA & $\mathrm{Cs}$ & \\
\hline & Microwave & ICP-ES & Cations & \\
\hline & Sonicate & IC & Anions & \\
\hline & \multirow[t]{2}{*}{ None } & NA & $\mathrm{F}, \mathrm{Cl}$ & \\
\hline & & TIC TOC & TOC & \\
\hline \multirow[t]{6}{*}{ TR-26 } & Alkali Fusions & ICP-ES & Cations & \multirow[t]{6}{*}{ No } \\
\hline & & $\mathrm{AA}$ & $\mathrm{Cs}$ & \\
\hline & Microwave & ICP-ES & Cations & \\
\hline & Sonicate & $\mathrm{IC}$ & Anions & \\
\hline & \multirow[t]{2}{*}{ None } & NA & $\mathrm{F}, \mathrm{Cl}$ & \\
\hline & & TIC TOC & TOC & \\
\hline
\end{tabular}

\subsection{Laboratory-Scale Tests}

Laboratory scale tests were performed to define the experimental protocols and design parameters for AZ-101 glass. These experiments included, as follows:

\footnotetext{
${ }^{2}$ As, Al, B, Ba, Ca, Cd, Ce, Cr, Cs, Cu, Fe, K, La, Mg, Mn, Na, Ni, P, Pb, S, Sb, Se, Si, Sr, Te, Ti, Zn, Zr

${ }^{3}$ sulfate, phosphate, nitrate, nitrite and carbonate
} 
- Drying tests to prepare the simulant for glass melting and monitor gas evolution as determined by thermogravimetric analysis (Thermogravimetric Analysis of the Simulant, below).

- Evaluation of Cs-retention in the glass (Cs Retention Tests, below).

- Small-scale crucible melts to identify the appropriate glass forming chemicals to facilitate vitrification of AZ-101 (Small Crucible Tests, below).

- Large-scale crucible melts to optimize waste loading of AZ-101 (Large Crucible Tests, below)

- Testing and Analysis of Blind Sample (Blind Sample, below). And,

- Feed form experiments to investigate the appropriate physical feed form and feed equipment for conducting the bench-scale experiments (Feed-Form Experiments, below).

\section{Thermogravimetric Analysis of the Simulant}

\section{Test Objectives}

Experiments in this area have as an objective defining the baseline drying properties of the simulant itself as well as the simulant plus any additives necessary to prepare the product glass. While the major focus of this effort was determining the weight loss and gas release anticipated during feed preparation, the weight loss due to off-gassing of glass forming materials and sludge carbonates, nitrates and sulfates; gaseous release through the melting phase of processing is also of interest. The data obtained determined the anticipated melting profile for the bench-scale tests and the anticipated releases during processing of the simulant.

Method/Approach

Per the SOW, the drying parameters and the gas evolution properties of the simulant were determined. Thorough mixing of the simulant slurry using a hand paddle and mechanical mixer was prerequisite to sampling for these tests. The simulant was extracted from the drum by a vacuum air lift into a stainless steel drying pan. The tare weight was recorded and the pan of simulant was placed in a drying oven. An iterative process was used to determine the optimal drying time and temperature. Three hundred Celsius $\left(300^{\circ} \mathrm{C}\right)$ was selected as the appropriate drying temperature. After drying was complete, the simulant was ground using a V-blender and zirconia grinding media $(1 / 2$ " $\mathrm{x} 1 / 2$ " right circle cylindrical shape). Chemical composition of the simulant slurry was compared to chemical composition of the dried simulant to determine the effect of drying on simulant properties. Thermogravimetric analysis (TGA) was performed on simulant as well as simulant plus additives as part of the sludge/batch evaluation testing. Ground, dried sample was placed in the sample cup and heated to $1450^{\circ} \mathrm{C}$. Various rates (from $10-30^{\circ} \mathrm{C}$ per minute) for sample heat-up and cool down were evaluated.

\section{Test Equipment}

The equipment used during the drying experiments include:

- Perkin Elmer TG-DTA 6300, Pyris Diamond.

- Lightning mixer 
- Stainless steel drying trays

- Laboratory balance

- Drying oven

- V-blender

- Zirconia grinding media

Description of Test Matrix

Test matrix variables included:

- TGA/DTA program to determine gas evolution rate and foaming potential of the simulant.

\section{Cs Retention Tests}

\section{Test Objectives}

The objective of this test was to measure the volatility of Cs at the laboratory scale. These Cs-volatility measurements were then compared with Cs volatility at the benchscale.

\section{Method/Approach}

Small-scale tests were performed in order to determine the loss of cesium, through volatilization, from the AZ-101 waste form. For each test, dry batch materials were placed in a crucible and subsequently heated to $1450{ }^{\circ} \mathrm{C}$ using a resistance heated $C M$ vertical tube furnace and held at temperature for three hours. Figure 3-1 is a schematic of the testing apparatus.

Two test runs were performed. During the first test, the off-gas from the furnace was directed through a Kaowool filter using a vacuum pump. The flow then passed through a condensing unit filled with water, that was placed in an ice-bath. Finally, the tube furnace off-gas was routed to the DIAL off-gas system. The chilled condensate water from the condensing unit was collected, measured, and analyzed to determine the concentration of cesium. The off-gas tubing, condensate tube, and Kaowool filter were each rinsed using a known quantity of dilute hydrochloric acid. The rinseate was collected and analyzed to determine the cesium concentration.

During the second test, the furnace off-gas was vented through the Kaowool ${ }^{\mathrm{TM}}$ filter using the convective heat currents. A dilute solution of hydrochloric acid was used to rinse the filter media. The rinseate was analyzed to determine the amount of cesium collected on the filter. The Cs Retention Study rinseate samples were analyzed for B, Fe, $\mathrm{Na}, \mathrm{Ni}, \mathrm{Sr}$, and Cs.

\section{Test Equipment}

The test equipment for the Cs retention tests included, as follows:

- CM electric vertical tube furnace

- ceramic tubing

- filter media

- off-gas quencher 
- DIAL off-gas system

- $250 \mathrm{~mL}$ high form alumina crucible

- $60-w t \%$ AZ-101 glass batch material.

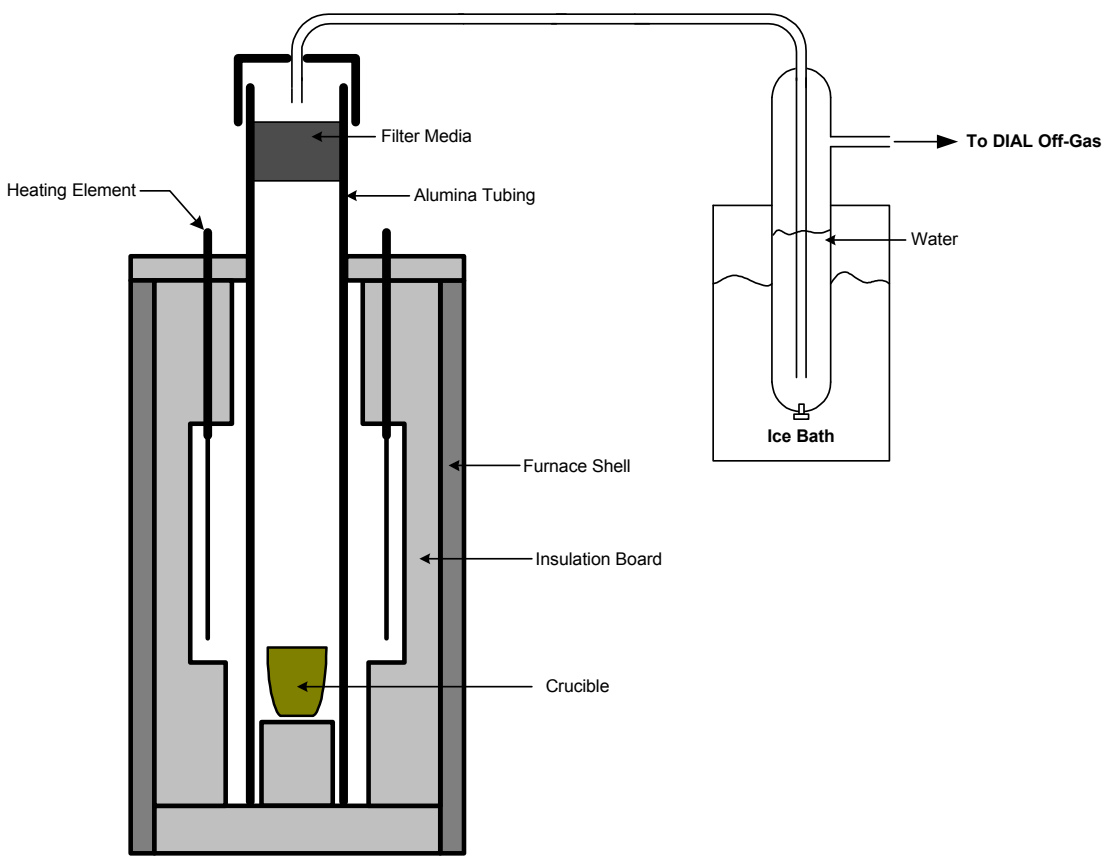

Figure 3-1. Laboratory-Scale Cs-Retention Apparatus.

Description of Test Matrix

\begin{tabular}{|c|c|c|}
\hline Cs Retention Experiments & Test 1 & Test 2 \\
\hline Test Parameters & $\begin{array}{l}\text { Off-gas directed through } \\
\text { Kaowool filter using a vacuum } \\
\text { pump }\end{array}$ & $\begin{array}{l}\text { Off-gas directed through } \\
\text { Kaowool filter using } \\
\text { convective currents }\end{array}$ \\
\hline Analyses Performed For: & $\begin{array}{l}\text { Rinsate from the tube furnace } \\
\text { off-gas pipe, filter, and steel } \\
\text { cap. } \\
\text { - Rinsate from the condenser. } \\
\text { - Water from the condenser } \\
\text { tube. }\end{array}$ & - Rinsate from the Test 2 filter. \\
\hline Analytes & $\mathrm{B}, \mathrm{Fe}, \mathrm{Na}, \mathrm{Ni}, \mathrm{Sr}$, and $\mathrm{Cs}$ & \\
\hline
\end{tabular}

\section{Small Crucible Tests}

\section{Test Objectives}

The objective of this effort was to conduct scoping experiments to define the target composition and feed additives for the bench-scale vitrification of AZ-101 simulant. These scoping tests were also meant to begin waste loading optimization, and to evaluate cooling as a function of crystallinity. The acceptance criteria for the bench-scale process (primarily TCLP, PCT and, to a lesser extent degree crystallinity) defined the selection 
process along with the goal of maximizing the waste loading. Based on the data derived in these experiments, a target formulation was selected for further laboratory-scale tests.

\section{Method/Approach}

According to the definition given in ASTM C162, glass is an inorganic product of fusion that has been cooled to a rigid condition without crystallizing. Borosilicate glass is any glass having at least $5 \%$ boron oxide by weight. However, high-level waste glasses can contain small quantities of crystalline phases, per the SOW.

Design of the glass formulation was based upon these constraints. Equipment processing parameters, and glass durability properties were also included in the experimental design. Glass science was used to guide initial melt experiments. The formulations were then adjusted based upon the results of these test melts, until a suitable formulation was defined. Melting behavior, chemical composition analysis, PCT and TCLP testing were used as measures of acceptability.

\section{Test Equipment}

The following equipment and supplies were used for the small-scale crucible melts.

- $250 \mathrm{ml}$ high form alumina crucibles

- Lindbergh high temperature glass melting furnace

- Laboratory balance

- Dried AZ-101 simulant

- Frit $200^{4}$

- Trim chemicals, i.e. silica, boric acid, and sodium carbonate

\section{Description of Test Matrix}

The small-scale scoping melts were made using 100-200 g of glass. The experimental matrix for these tests is given below. These data were used to determine experimental parameters for the large-scale melts. The sample designation nomenclature is assigned to describe the experiment, e.g. RIC-2002-Small Melt-45 wt\% waste loading.

\begin{tabular}{|c|c|c|c|c|}
\hline $\begin{array}{c}\text { Sample } \\
\text { Designation }\end{array}$ & $\begin{array}{c}\text { Target Loading } \\
\text { wt } \%[M-1]\end{array}$ & $\begin{array}{c}\text { Composition } \\
\text { Analysis }^{\text {a }}\end{array}$ & PCT & TCLP \\
\hline R-O2-SM-45 & 45 & $\mathrm{X}$ & $\mathrm{X}$ & $\mathrm{X}$ \\
\hline R-O2-SM-50 & 50 & $\mathrm{X}$ & $\mathrm{X}$ & $\mathrm{X}$ \\
\hline R-O2-SM-55 & 55 & $\mathrm{X}$ & $\mathrm{X}$ & $\mathrm{X}$ \\
\hline R-O2-SM-60 & 60 & $\mathrm{X}$ & $\mathrm{X}$ & $\mathrm{X}$ \\
\hline R-O2-SM-65 & 65 & $\mathrm{X}$ & $\mathrm{X}$ & $\mathrm{X}$ \\
\hline
\end{tabular}

${ }^{\mathrm{a}} \mathrm{As}, \mathrm{Al}, \mathrm{B}, \mathrm{Ba}, \mathrm{Ca}, \mathrm{Cd}, \mathrm{Ce}, \mathrm{Cr}, \mathrm{Cs}, \mathrm{Cu}, \mathrm{Fe}, \mathrm{K}, \mathrm{La}, \mathrm{Mg}, \mathrm{Mn}, \mathrm{Na}, \mathrm{Ni}, \mathrm{P}, \mathrm{Pb}, \mathrm{S}, \mathrm{Sb}$, $\mathrm{Se}, \mathrm{Si}, \mathrm{Sr}, \mathrm{Te}, \mathrm{Ti}, \mathrm{Zn}, \mathrm{Zr}$

\section{Large Crucible Tests}

\section{Test Objectives}

Based upon the results of small crucible tests, the properties (TCLP, PCT, and crystallinity) of vitrified TR-26 were determined at target waste loadings of 54-, 57-, 60-,

\footnotetext{
${ }^{4}$ Frit 200 is a premelted glass additive with the composition as follows: $70 \% \mathrm{SiO}_{2}, 11 \% \mathrm{~N}_{\mathrm{a} 2} \mathrm{O}, 5 \% \mathrm{Li}_{2} \mathrm{O}$, $12 \% \mathrm{~B}_{2} \mathrm{O}_{3}, 2 \% \mathrm{MgO}$. All percentages are weight-based.
} 
63-, and 66-wt $\%$. The glass transition temperature, $\mathrm{T}_{\mathrm{g}}$, was also determined using dilatometry for the $60-\mathrm{wt} \%$ Large Melt. Tg was also determined for the bench-scale using Simultaneous Thermal Analysis (STA).

The objective of the large-scale crucible tests was to:

- Provide sufficient material for laboratory testing,

- Identify a glass composition, with optimized waste loading, to be used as a reference glass for the TTT study,

- Determine the variation in physical properties,

- Define the bench-scale melt protocols,

- Provide confidence that bench-scale vitrification of the reference glass would produce an acceptable product (in advance of conducting that test).

- Provide baseline information for the TTT study.

\section{Method/Approach}

All process melts were performed in $500 \mathrm{cc}$ alumina crucibles. All batch material was provided by DIAL-MSU $\left(\mathrm{SiO}_{2}, \mathrm{H}_{3} \mathrm{BO}_{3}\right.$, and $\left.\mathrm{ZnO}\right)$ with the exception of the vendor supplied Hanford simulant, TR-26. TR-26 was added in dried, ground powder form.

Based on surrogate sampling and analysis effort performed by DIAL, the conversion factors from "wet" simulant (as received) to dried simulant to oxide calcine were:

$$
\begin{array}{ll}
\text { Sludge specific gravity } & =1.20 \\
\text { Dry }\left(300^{\circ} \mathrm{C}\right) \text { sludge } & =0.21 \cdot \text { wet sludge } \\
\text { Sludge oxide } & =0.84 \cdot \text { dry sludge }
\end{array}
$$

Melt batch was prepared by adding measured amounts of glass additives and ground, dried simulant to a polyethylene bottle. The batch was mixed by hand; shaken inside the polyethylene bottle. For 500 g glass batches, approximately 200 grams of batch were added to the crucible and the crucible was placed inside the furnace. The remainder of batch was split into approximately $100 \mathrm{~g}$ sub-samples for addition to the crucible at the melting temperature. In turn, the alumina crucible was placed inside a protective quartz "catch" crucible. This combination of crucibles is hereafter referred to as an assembly. Initial foaming of the batch material was observed at approximately $1250^{\circ} \mathrm{C}$. The initial batch foaming subsided between $1325^{\circ} \mathrm{C}$ and $1350^{\circ} \mathrm{C}$.

Each melt was given a unique designation as follows.

\section{RIC-LM-00X}

Where: " $\boldsymbol{X}$ ' corresponding to the number ascribed to the specific sample and LM corresponds to Large Melt Series.

Each alumina crucible was given a permanent mark with red iron oxide paint identifying the batch number that corresponds to the unique sample designation defined above. 
All melt experiments were conducted in a programmable front-loading furnace. The following heating profile and batching schedule were used for both the large and small crucible tests:

1. Ramp at $10^{\circ} \mathrm{C} / \mathrm{min}$ to $700^{\circ} \mathrm{C}$

2. Idle at $700^{\circ} \mathrm{C}$ for 60 minutes

3. Ramp at $5^{\circ} \mathrm{C} / \mathrm{min}$ to $1000 \mathrm{C}$

4. Idle at $1000^{\circ} \mathrm{C}$ for 60 minutes

5. Ramp at $5^{\circ} \mathrm{C} / \mathrm{min}$ to $1450^{\circ} \mathrm{C}$

Once at melt temperature, the assembly was removed from the furnace at 15 - 20 minute intervals, approximately 100 gram batch charges were added to the crucibles. The assembly was then returned to the furnace. Initial small-scale scoping samples were held at melting temperature between two and four hours. It was determined that idling for three hours at the melting temperature was sufficient to ensure a thoroughly melted, homogenous glassy product. Therefore, after the last batch addition was made, the assemblies completed the heat treatment as follows:

1. Idle at $1450^{\circ} \mathrm{C}$ for approximately 180 minutes

2. Remove the assembly from the furnace and place on a steel plate

3. Allow the assembly to cool to room temperature

All large and small-scale batches were melted at $1450^{\circ} \mathrm{C}$.

The PCT was performed on all five large-melt glasses. The DWPF EA glass was the standard glass tested alongside the LM series.

\section{Test Equipment}

- $500 \mathrm{ml}$ high form alumina crucibles

- Lindbergh high temperature glass melting furnace

- Laboratory balance

- dried AZ-101 simulant

- trim chemicals, i.e. silica, boric acid and zinc oxide

- Glass Dilatometer

- Perkin Elmer ICP-AES, Optima 4300 DV

- Perkin Elmer AA, Analyst 800 with both flame and graphite furnace capability

- Dionex IC, $D X-500$

- Tekmar-Dohrman TIC-TOC, Phoenix 800, that uses Pb oxidation UV/per sulfate technique

- Scintag 2000 Diffractometer

- JEOL T33A Scanning Electron Microscope

\section{Description of Test Matrix}

The large crucible test samples are nominally 500 gram melts. During the melting process and after cooling to room temperature, general observations were made. In addition, product characterization tests were conducted as shown in the Test Matrix below. Note that the number of replicates is indicated in parenthesis. 


\begin{tabular}{|c|c|c|c|c|c|}
\hline \multirow{2}{*}{$\begin{array}{c}\text { Waste Loading } \\
\text { Wt\%[M-1] }\end{array}$} & $\begin{array}{c}\text { Chemical } \\
\text { Analysis } \\
\text { a }\end{array}$ & $\begin{array}{c}\text { TCLP } \\
(3)\end{array}$ & $\begin{array}{c}\text { PCT } \\
(3)\end{array}$ & $\begin{array}{c}\text { Qualitative } \\
\text { SEM } \\
(1)\end{array}$ & $\begin{array}{c}\text { Qualitative } \\
\text { XRD } \\
(1)\end{array}$ \\
\hline 54 & $\mathrm{X}$ & $\mathrm{X}$ & $\mathrm{X}$ & $\mathrm{X}$ & $\mathrm{X}$ \\
\hline 57 & $\mathrm{X}$ & $\mathrm{X}$ & $\mathrm{X}$ & $\mathrm{X}$ & $\mathrm{X}$ \\
\hline 60 & $\mathrm{X}$ & $\mathrm{X}$ & $\mathrm{X}$ & $\mathrm{X}$ & $\mathrm{X}$ \\
\hline 63 & $\mathrm{X}$ & $\mathrm{X}$ & $\mathrm{X}$ & $\mathrm{X}$ & $\mathrm{X}$ \\
\hline 67 & $\mathrm{X}$ & $\mathrm{X}$ & $\mathrm{X}$ & $\mathrm{X}$ & $\mathrm{X}$ \\
\hline
\end{tabular}

${ }^{\mathrm{a}} \mathrm{As}, \mathrm{Al}, \mathrm{B}, \mathrm{Ba}, \mathrm{Ca}, \mathrm{Cd}, \mathrm{Ce}, \mathrm{Cr}, \mathrm{Cs}, \mathrm{Cu}, \mathrm{Fe}, \mathrm{K}, \mathrm{La}, \mathrm{Mg}, \mathrm{Mn}, \mathrm{Na}, \mathrm{Ni}, \mathrm{P}, \mathrm{Pb}, \mathrm{S}, \mathrm{Sb}, \mathrm{Se}, \mathrm{Si}, \mathrm{Sr}, \mathrm{Te}, \mathrm{Ti}, \mathrm{Zn}, \mathrm{Zr}$

The glass transition temperature, $\mathrm{T}_{\mathrm{g}}$, was also measured for the 60 -wt $\%$ glass using dilatometry. This measurement was performed at UMR.

\section{Blind Sample}

A "Blind" sample was received at DIAL on September 1, 2002. The blind sample is a comparison standard for AZ-101 glass.

\section{Test Objectives}

The objective of these tests was to characterize a blind sample provided by DOE using the same procedures and equipment used for the characterization of the bench-scale vitrified product.

\section{Method/Approach}

The Blind sample underwent chemical composition analysis, PCT and TCLP testing. In addition, the glass transition temperature, $\mathrm{T}_{\mathrm{g}}$, was determined by Simultaneous Thermal Analysis (STA). All test methods were consistent with those used for the AZ-101 glasses.

The chemical composition analysis included all the required elements, inlcuding additional elements detected during elemental analysis. These additional elements included ruthenium, lithium, molybdenum and neodymium. Additional standards and preparatory chemicals were required to complete quantitative chemical analysis.

\section{Test Equipment}

- Perkin Elmer ICP-AES, Optima 4300 DV

- Perkin Elmer AA, Analyst 800 with both flame and graphite furnace capability

- Dionex IC, $D X-500$

- Tekmar-Dohrman TIC-TOC, Phoenix 800, that uses Pb oxidation UV/persulfate technique

- Perkin Elmer TG-DTA 6300, Pyris Diamond. 


\section{Description of Test Matrix}

The blind sample underwent testing to determine chemical composition, glass transition temperature, and PCT and TCLP response.

\begin{tabular}{|c|c|c|c|c|}
\hline $\begin{array}{c}\text { Sample } \\
\text { Designation }\end{array}$ & $\begin{array}{c}\text { Composition } \\
\text { Analysis }\end{array}$ & PCT & TCLP & $\begin{array}{c}\mathrm{T}_{\mathrm{g}} \text {, Glass } \\
\text { Transition } \\
\text { Temperature }\end{array}$ \\
\hline Blind & $\mathrm{x}^{\mathrm{a}}$ & $\mathrm{x}$ & $\mathrm{x}$ & $\mathrm{x}^{\mathrm{b}}$ \\
\hline
\end{tabular}

${ }^{a} \mathrm{As}, \mathrm{Al}, \mathrm{B}, \mathrm{Ba}, \mathrm{Ca}, \mathrm{Cd}, \mathrm{Ce}, \mathrm{Cr}, \mathrm{Cs}, \mathrm{Cu}, \mathrm{Fe}, \mathrm{K}, \mathrm{La}, \mathrm{Li}, \mathrm{Mg}, \mathrm{Mn}, \mathrm{Mo}, \mathrm{Na}, \mathrm{Nd}, \mathrm{Ni}, \mathrm{P}, \mathrm{Pb}$, $\mathrm{Ru}, \mathrm{S}, \mathrm{Sb}, \mathrm{Se}, \mathrm{Si}, \mathrm{Sr}, \mathrm{Te}, \mathrm{Ti}, \mathrm{Zn}, \mathrm{Zr}$

${ }^{\mathrm{b}} \mathrm{T}_{\mathrm{g}}$ was determined using Simultaneous Thermal Analysis.

\section{Feed-Form Experiments}

\section{Test Objectives}

The objective of the feed-form experiments was to determine the physical form of the melter feed (e.g., slurry, tablets, powder, etc.) that is optimum for use in the available bench-scale vitrification equipment. The range of acceptable feed rates for the selected feed form was also determined. Finally, methods for producing bench-scale feed were investigated and the releases from any processing steps determined.

\section{Method/Approach}

Work performed under this subtask had two components: (1) feed form identification and production, and (2) feed form testing. In the former, commercial available technologies were surveyed and vendors selected. These vendors were supplied with AZ-101 simulant plus glass formers in a physical form appropriate to the technology. The vendors then used the supplied simulant to produce feed for evaluation. This material was returned to RIC where it was examined and where selected material was subjected to feed testing in the COFFEE apparatus modified to accommodate the particular characteristics of the feed. The details of the experimental approach in these areas are summarized below.

\section{Feed Form Production}

Two methods of feed-form production were investigated: direct drying of simulant feed to a powder capable of being fed directly into the bench-scale unit, and drying of the simulant followed by further processing into a pelletized form. The starting material for each of these approaches was an AZ-101 simulant slurry to which the appropriate process chemicals were added in order to achieve a waste loading of $60 \mathrm{wt} \%$ [M-1]. One vendor was selected for the direct drying approach, Bethlehem Corporation, Easton PA, who accomplished the drying using a Porcupine Processor. Two vendors, Cargille TAB-PRO Corporation and Mars Mineral Company, were selected to produce pelletized feed. The production process experiments conducted by these vendors are summarized below.

\section{Porcupine Processor}

The Porcupine Processor is a mechanically agitated, indirectly heated device that provides high heat transfer capabilities in a confined volume. Thirty-five (35) gallons of AZ-101 simulant plus additives was prepared by NOAH and sent to Bethlehem 
Corporation. This material was used in a pilot-scale processor to conduct testing in order to obtain process design data. These data include information necessary to obtain the overall simulant drying rate, heat transfer coefficients, handling conditions and retention times in the processor. In addition, as a result of this test, sufficient material was obtained to provide a potential dry feed for the bench-scale process. This material, along with the condensate obtained from the Porcupine Processor was sent to DIAL for chemical analysis and storage and/or for use in bench-scale tests.

\section{Cargille Tablets}

The AZ-101 Surrogate Waste starting material was processed and formed into tablets by Cargille. NOAH Tech received the starting material from DIAL with the glass formers already added to the ground powder. The batch make-up (RIC Batch \#9) was as follows:

\begin{tabular}{|c|c|c|c|}
\hline Compound & $\begin{array}{c}\text { Total batch } \\
(\mathbf{g})\end{array}$ & $\begin{array}{c}\text { Oxide } \\
(\mathbf{g})\end{array}$ & $\begin{array}{c}\text { Oxide } \\
\mathbf{W t} \mathbf{\%}\end{array}$ \\
\hline $\mathrm{SiO}_{2}$ & 512.00 & 512.00 & 32.0 \\
\hline $\mathrm{B}_{2} \mathrm{O}_{3}$ & 170.10 & 95.80 & 6.0 \\
\hline $\mathrm{Na}_{2} \mathrm{O}$ & 0.00 & 0.00 & 0.0 \\
\hline $\mathrm{Frit} 200$ & 32.06 & 32.06 & 2.0 \\
\hline $\mathrm{AZ}-101$ Simulant & 1200.11 & 960.09 & 60.0 \\
\hline Total: & $\mathbf{1 9 1 4 . 2 7}$ & $\mathbf{1 5 9 9 . 9 5}$ & $\mathbf{1 0 0 . 0}$ \\
\hline
\end{tabular}

The powder was determined to be too fine to be used in the process of making tablets. The material was then screened with a 100-mesh screen. The material that stayed on top of the screen $(1.0 \mathrm{~kg})$ was packaged, designated NOA-01, and sent to Cargille TAB-PRO Corporation.

Using this material, Cargille formulated tablets in a trial formulation (S W AZ101 Tablet Trial, Cargille Lot: 080802) using the screened material plus additives. Magnesium stearate was used as a binder. Calcium silicate was used to improve flow into the die. This formulation is given below.

\begin{tabular}{||l|l|l|l||}
\hline Ingredient & Source & Wt\% & $\begin{array}{l}\text { Mass } \\
(\mathbf{g})\end{array}$ \\
\hline NOA-01 & Noah & 66.33 & 500.00 \\
\hline NOA-01 & Noah & 33.17 & 250.00 \\
\hline Magnesium stearate & & 0.25 & 1.88 \\
\hline Calcium silicate & & 0.25 & 1.88 \\
\hline
\end{tabular}

As "Slug and grind" - Imperfect tablets were first formed and then forced through a 20-mesh screen to make the powder granular for better flow into the die.

The powders were then blended in a plastic bag and tablets were formed by compression on a Colton 216 rotary press fitted with $3 / 8$ " flat faced tooling to $125 \mathrm{mg} \times 0.130$ " x 1.9 $\mathrm{Kp}$. "Kp" (kiloponds), is a measurement of the strength of the tablets formed. This is 
determined when a force is applied by two teeth, one on each side of the tablet, until the tablet is crushed. This process made tablets which were firm and held together well during shipment.

\section{MARS Pellets}

Five tests were conducted on material provided by RIC to MARS Mineral Corporation. The material supplied consisted of dried AZ-101 simulant plus frit dried in a manner similar to that provided to Cargille and described above, except that the particle mesh was $<100$-mesh. MARS pelletized the material using their Model DP-14 Disco Pelletizer. Five different binding agents were used to make pellets as given below:

$\begin{array}{cl}\text { Test Number } & \text { Binding Agent } \\ 1 & \text { Water } \\ 2 & \text { 22\% sodium silicate in water } \\ 3 & \text { Corn starch (3\% dry mix) } \\ 4 & \text { Western bentonite (3\% dry mix) } \\ 5 & \text { Celvol 205 (polyvinyl alcohol) }\end{array}$

The pellets produced with the binders used in tests 2 through 5 produced pellets with a physical strength great enough to be tested, as compared to water alone (test 1), which did not. The pellets from test 5 (Celvol binder) showed the best results in that they survived 13 drops from a height of 18 inches and had a crush strength of 1.9 pounds after oven drying. There was $18.7 \%$ loss on attrition in test 5 , however, which indicates that the pellets would not survive most handling practices such as being fed through a volumetric feeder.

In general, the AZ-101 simulant plus frit did not pelletize well with any of the binders tested. This material could not be evaluated in the MARS pin-mixer pelletizer due to insufficient material volume. This pelletizer has the potential of producing a stronger, more durable pellet, because the pin mixer shearing action applies much more energy to the material.

\section{Feed Form Testing}

Since results from the feed-form experiments were used to help guide the feed protocol for the 5" diameter bench-scale tests, it was desirable to test and evaluate different feed forms using an approach that would match, as closely as possible, the conditions that would be present in the 5" bench-scale tests. Accordingly, the COFFEE (Continuous Feed Form Experimental Equipment) apparatus, which was available at the RIC Laboratory at the Polytechnic Institute in Brooklyn, New York, was used to carry out the feed experiments.

In the 5" bench-scale test stand at DIAL, the graphite/alumina crucible was heated by a set of inductive coils enclosing it. The primary heating zone is above the melt surface, as planned by the Hot Hohlraum method. In the COFFEE test apparatus, the inductive heating method was not available. Instead, an electronically-heated furnace encloses the outside of the cylindrical crucible creating a hot zone several inches in length. The 
furnace is vertically movable allowing the hot zone to be moved upwards as the interior of the crucible is filled with molten simulant HLW/frit mixture.

The COFFEE experiments were carried out to investigate the effect of four operating variables on the ability to continuously the 5 " diameter bench-scale apparatus. The four operating variables were:

1. Nature of the feed (e.g., solid vs. liquid slurry)

2. Particle size of feed (e.g., pellets vs. powder; small vs. large droplets)

3. Type of feeder (e.g., vibratory or screw-feeder, peristaltic or centrifugal pump)

4. Rate of feed (e.g., inches per hour)

The effect of these operating variables was observed with respect to the following performance areas:

1. Amount of particulate entrainment in the off-gas

2. Amount of HLW simulant/frit material adhering to the crucible wall

3. Quality and homogeneity of the vitrified HLW simulant/frit product

4. Crucible fill-rate capability

5. Reliability and consistency of feed rate 
Figure 3-2 shows the criteria applied next to the above performance areas.

\begin{tabular}{|c|c|c|}
\hline \multicolumn{3}{|c|}{$\begin{array}{l}\text { Figure 3-2. Criteria for Evaluation of Feed Operations in the AVS Module } \\
\text { Performance Areas }\end{array}$} \\
\hline Unfavorable Response & $\begin{array}{c}\text { Performance } \\
\text { Area }\end{array}$ & Favorable Response \\
\hline $\begin{array}{l}\text { - Dark smoke in off-gas } \\
\text { - Large amounts of particulate } \\
\text { in off gas }\end{array}$ & $\begin{array}{l}\text { Fine particles in } \\
\text { off-gases }\end{array}$ & $\begin{array}{l}\cdot \text { Little or no particulates in off- } \\
\text { gases } \\
\cdot \text { No smoke emitted }\end{array}$ \\
\hline $\begin{array}{l}\text { - Substantial amounts of feed } \\
\text { adherence } \\
\text { - Partial blockage of crucible } \\
\text { cross-section by adherent feed }\end{array}$ & $\begin{array}{l}\text { Amount of feed } \\
\text { adhering to wall }\end{array}$ & $\begin{array}{l}\text { - Little or no feed particles on wall } \\
\text { above melt surface } \\
\cdot \text { No blockage of crucible cross- } \\
\text { section by adherent feed }\end{array}$ \\
\hline $\begin{array}{l}\text { Substantial bubble content } \\
\text { and undissolved particles in } \\
\text { glass } \\
\text { - Crust of unreacted feed on } \\
\text { top of glass }\end{array}$ & $\begin{array}{l}\text { Quality and } \\
\text { homogeneity of } \\
\text { feed }\end{array}$ & $\begin{array}{l}\text { - Glass product is bubble free and } \\
\text { homogeneous } \\
\text { - No undissolved particles in glass } \\
\text { - No crust of unreacted feed on top } \\
\text { of glass }\end{array}$ \\
\hline $\begin{array}{l}\cdot \text { Feed rate }<6 \text { inches per hour } \\
\cdot \text { Dark cap forms on top of } \\
\text { melt surface }\end{array}$ & $\begin{array}{l}\text { Crucible fill rate } \\
\text { capability }\end{array}$ & $\begin{array}{l}\cdot \text { Feed rate }=6 \text { inches per hour } \\
\cdot \text { Melt surface remains bright and } \\
\text { clear, i.e. no cold cap }\end{array}$ \\
\hline $\begin{array}{l}\text { Feed rate varies substantially } \\
\text { during fill process }\end{array}$ & $\begin{array}{l}\text { Reliability and } \\
\text { Consistency of } \\
\text { feed rate }\end{array}$ & $\begin{array}{l}\text { Feed rate does not vary } \\
\text { consistently during fill process }\end{array}$ \\
\hline
\end{tabular}

A wide range of operating options was considered for possible testing in the COFFEE apparatus, as summarized in Figure 3-3. Not all of these options were actually tested, in part because funding resources were limited and also because the slurry feed was found to perform very well in early tests. 


\section{Figure 3-3. Operating options considered for COFFEE feed tests.}
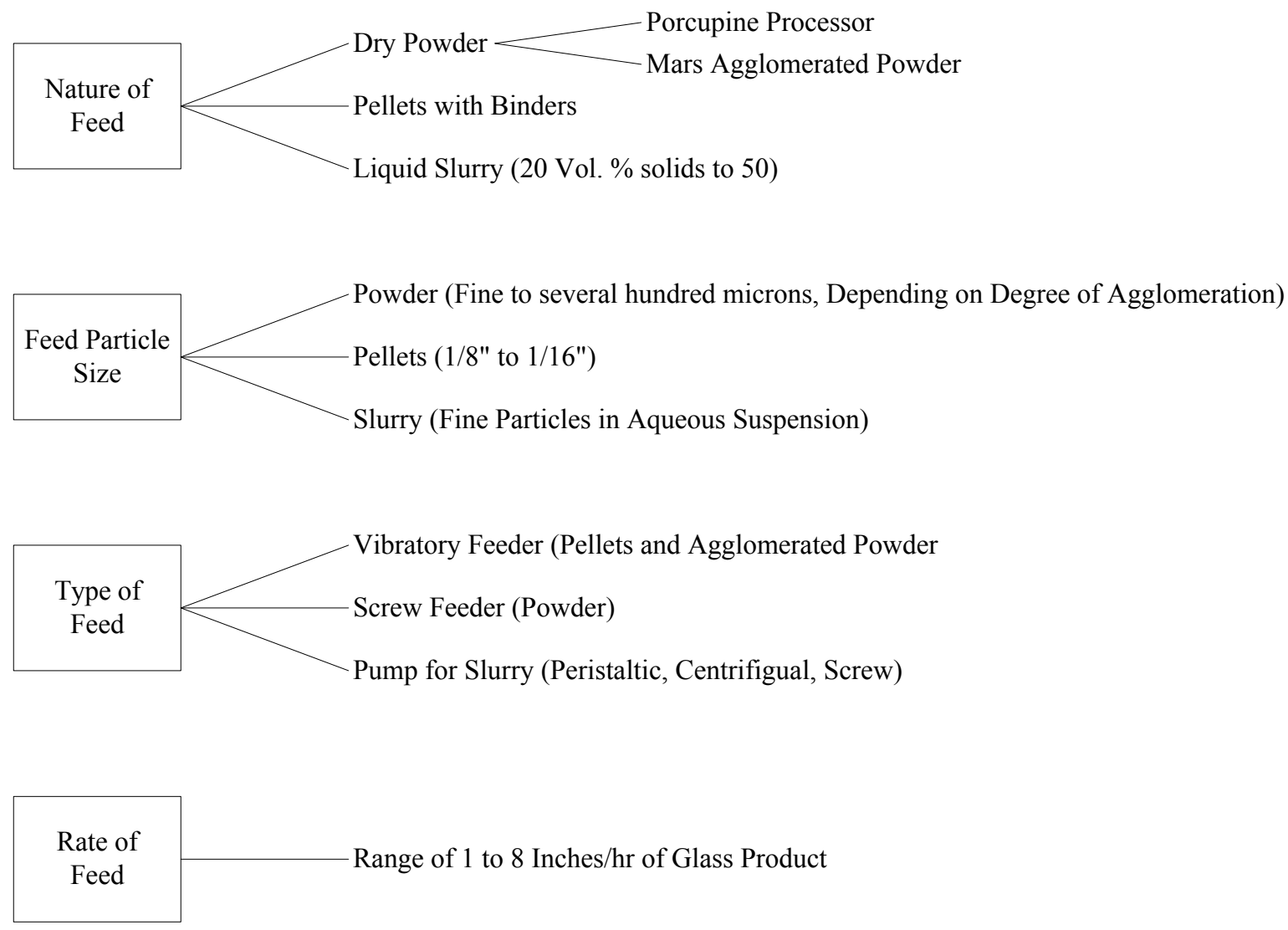

Test Equipment

Figure 3-4 shows a schematic of the COFFEE apparatus and feed/heat transfer process, and compares it to the feed/heat transfer process in the 5" diameter bench-scale test stand and the full-scale AVS module. The COFFEE apparatus used for the series of tests described in this report is essentially the same as that used in the previous AVS test program on the Envelope D simulant. ${ }^{5}$ The only modification is the addition of a continuous feed unit instead of intermittently adding feed in discrete batches.

\footnotetext{
5 "Additional Tests of an Advanced Vitrification System Final Report," RIC Report provided to DOE, July 18, 2001.
} 
Figure 3-4. Comparison of COFFEE Heat Transfer/Feed Process with 5 inch Diameter Bench-Scale and Full-Scale AVS.

COFFEE Process

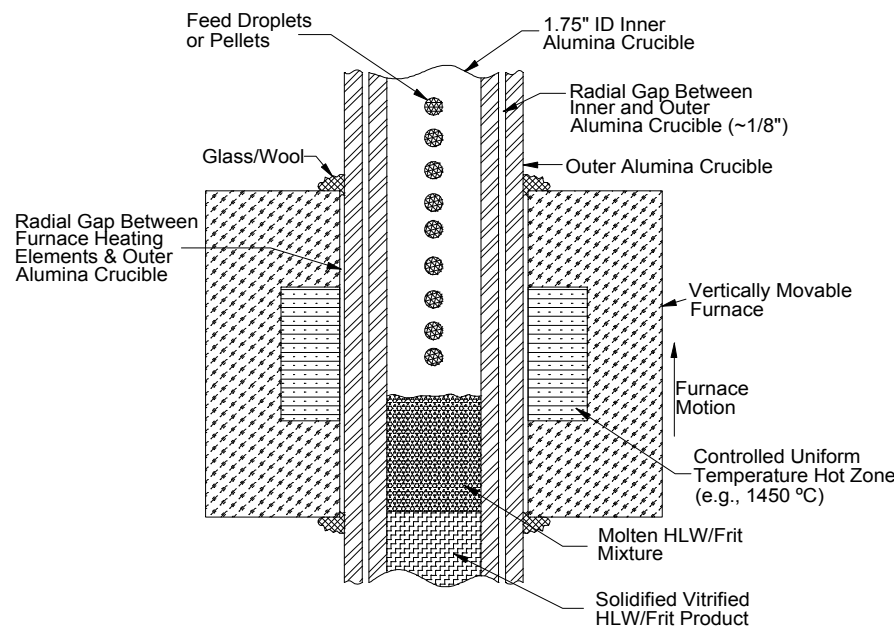

Bench-Scale/AVS Module Process

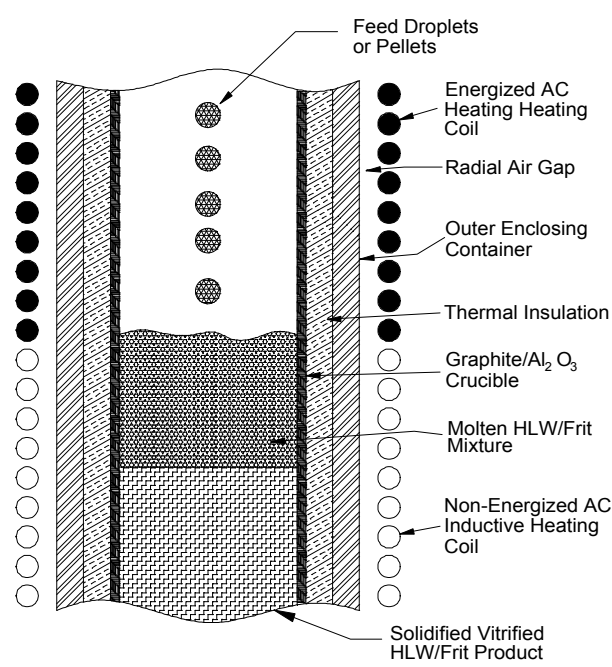

The principle differences between the COFFEE and bench-scale/full-scale AVS module heat-transfer processes are:

1. Heat transfer to the inner crucible is very inefficient in the COFFEE test, in contrast to the bench-scale/full-scale AVS module units, where the heat is directly generated in the inner crucible by the AC inductive heating coils.

2. Heat losses from the inner crucible are considerably greater in the COFFEE test.

3. The length of the hot zone in the COFFEE test is considerably shorter, proportionately, than in the AVS bench-scale test stand.

As a result of these differences, the rate at which heat can be delivered to the melt surface in the COFFEE test is substantially smaller than the bench-scale/full-scale AVS module apparatus. This inherently constrains the fill rate in the COFFEE tests, so that a finding that a certain fill rate was limiting in a COFFEE test does not mean that a faster rate is not possible for the bench-scale apparatus.

Figure 3-5 illustrates how the above differences constrain heat-transfer in the COFFEE apparatus. The maximum temperature capability the COFFEE furnace wall in the uniform, 5" high hot zone is $1550^{\circ} \mathrm{C}$. There are two sequential radial air gaps between the furnace wall and the inner alumina crucible, which leads to a substantial temperature drop between the melt zone and the furnace wall. This constrains the rate at which thermal energy can be delivered to the melt region, which in turn constrains the feed fill rate. 
In addition, there are substantial radiant thermal losses from the hot sections in the two alumina crucibles to their cooler upper sections. These also reduce the rate at which thermal energy can be delivered to the melt region.

Figure 3-5. Heat Transfer Constraints on the COFFEE apparatus.

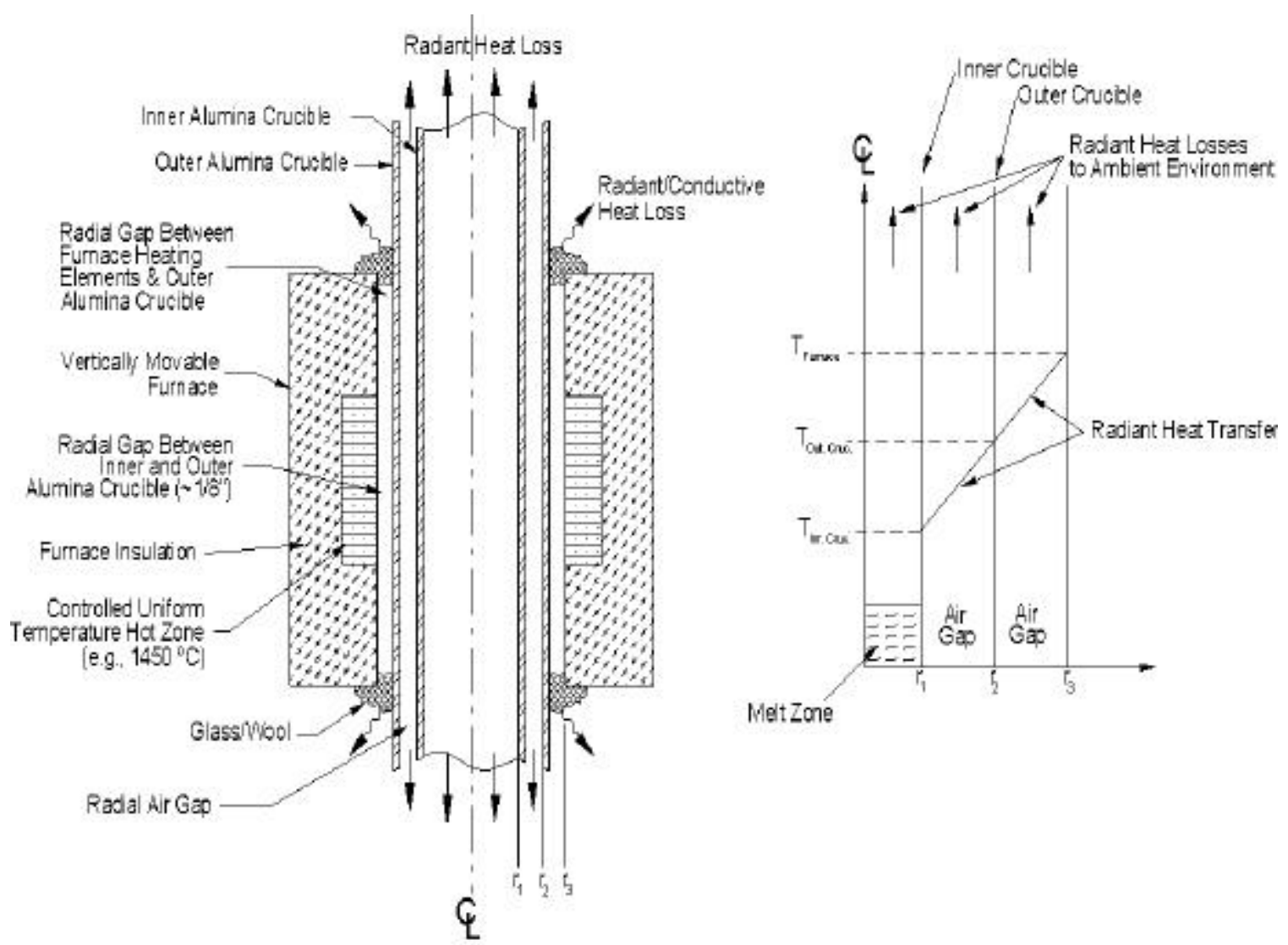

Quantitative values for the temperature differences and radiant heat losses could not be obtained, since funding resources did not allow for purchase of a pyrometer that could optically determine the actual melt temperature as a function of feed rate and furnace control temperature. 
Figure 3-6. COFFEE test apparatus set up in the RIC Laboratory at the Polytechnic Institute in Brooklyn.

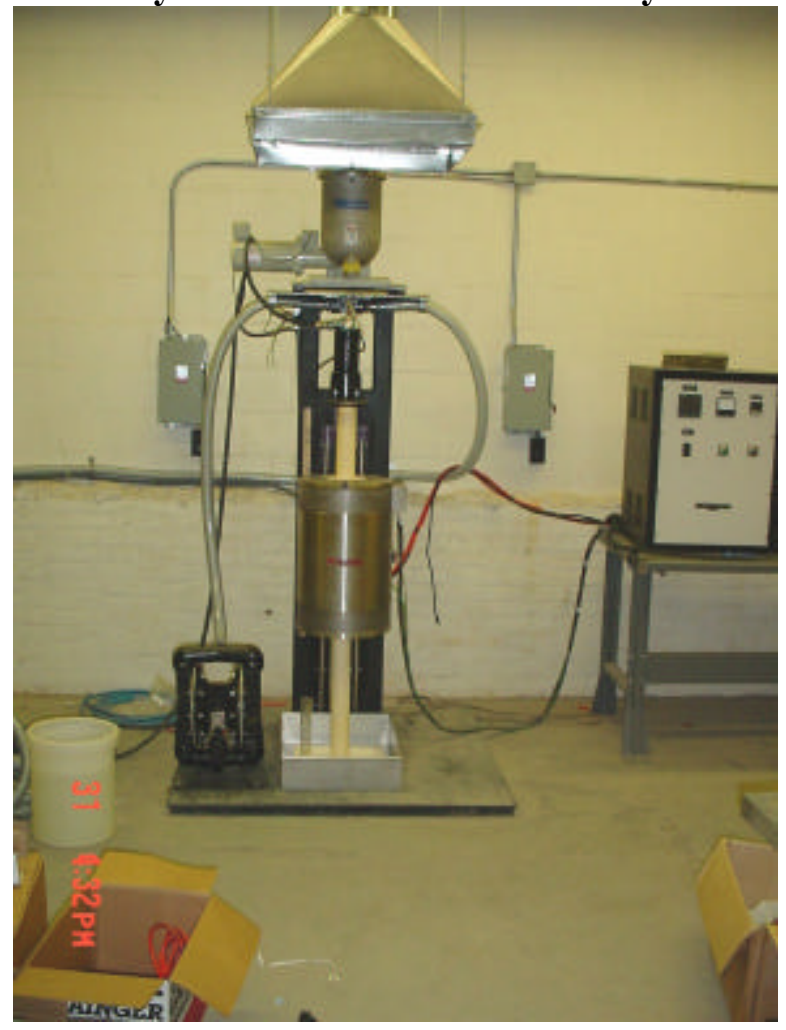

Description of Test Matrix

A number of potential feed forms were evaluated. Each form was evaluated with respect to physical properties and processing considerations. A subset of the feed forms was subjected to further evaluation by conducting one or more vitrification tests in the COFFEE test apparatus. For some of the COFFEE vitrified material was also subjected to chemical analysis to determine product uniformity. The test matrix for feed form experiments is given below.

\begin{tabular}{|l|c|c|c||}
\hline \multicolumn{1}{|c|}{ Feed Form } & $\begin{array}{c}\text { Feed Drying } \\
\text { Temperature } \\
\left({ }^{\circ} \mathbf{C}\right)\end{array}$ & $\begin{array}{c}\text { COFFEE } \\
\text { Vitrification } \\
\text { (number of tests) }\end{array}$ & Glass Analysis \\
\hline Slurry & Not applicable & $\mathrm{X}(3)$ & \\
\hline Dried Simulant & & $\mathrm{X}(1)$ & $\mathrm{X}$ \\
1. Porcupine Processor ${ }^{\mathrm{a}}$ & & - & - \\
\hline Pellets & & $\mathrm{X}(1)$ & $\mathrm{X}$ \\
1. Cargille ${ }^{\mathrm{a}}$ Large & & $\mathrm{X}(1)$ & $\mathrm{X}$ \\
2. Cargille Small & & $\mathrm{X}(1)$ & \\
3. MARS ${ }^{\mathrm{a}}$ & & $\mathrm{X}(1)$ & \\
a. Binder 1 & & $\mathrm{X}(1)$ & \\
b. Binder 2 & & \\
c. Binder 3 & &
\end{tabular}




\subsection{Bench-Scale Tests}

The bench-scale tests are intended to demonstrate "one qualification bench-scale test at maximum waste loading." A melt run sequence was defined using the information gained during the large-scale crucible runs and the feed-form experiments. It included feed preparation, feed transfer, controlled inductive heating, off gas collection and analysis and sampling.

\section{Test Objectives}

The primary goal of the bench-scale testing is to produce a vitrified product, at maximum waste loading using the AZ-101 simulant processed, in the existing, re-assembled benchscale AVS equipment. This vitrified AZ-101 product must also meet the technical criteria for immobilized HLW at Hanford as defined in the SOW. The properties of the bench-scale product were compared with available information on AZ-101 simulant vitrified using other processes by DOE or DOE-subcontractors. In addition, bench-scale process effluents were determined and used as a guide in defining the AVS flow sheet. Finally, the properties (TCLP, PCT and crystallinity) for a DOE-supplied blind sample of glass were determined. Specifically, the objectives of the bench-scale tests are:

- Produce a borosilicate glass using AZ-101 simulant, at the highest possible waste loading that meets the WAPS waste form specifications.

- Determine minimum residence time for complete waste dissolution. Minimizing time at melt temperature also helps to minimize chemical volatility.

- Characterize the effluents generated during vitrification.

- Measure surrogate radionuclide ( $\mathrm{Sr}$ and $\mathrm{Cs}$ ) volatilization/carryover during vitrification.

- Determine product homogeneity.

- Determine the interaction between the melt and the crucible.

- Obtain information relevant to AVS process design.

- Provide sufficient volume of vitrified product to perform analyses required by the SOW as well as archival samples.

\section{Method/Approach}

The prototypic melt run sequence for simulant AZ-101 was defined upon the completion of the laboratory-scale experiments. In general, it included the following procedures:

1. Preparing feed. Sufficient melter feed to produce sufficient crucible glass for testing was generated. The feed was sampled and analyzed.

2. Measuring initial crucible wall thickness. Prior to the test, the crucible wall thickness was determined by sampling.

3. Transferring feed to crucible. The simulant/feed mixture was fed to the AVS for conversion to a borosilicate glass product.

\footnotetext{
${ }^{6}$ Statement of Work
} 
4. Heating as profiled. The heating profile was determined from the laboratoryscale tests.

5. Collecting and analyzing off-gas. The bench-scale test apparatus was equipped with an off-gas system, redesigned to accommodate the experimental requirements of this investigation.

6. Recording heating and cooling profile.

7. Removing crucible.

8. Sampling and analyzing vitrified product and measuring crucible wall thickness. The final production run at the maximum achievable waste loading was sampled and analyzed. The crucible wall thickness was determined at glass contact locations and compared with the pre-test measurements to determine the extent of melt corrosion.

The bench-scale experiments were performed on reassembled equipment used in the prior effort described in "Additional Tests of an Advanced Vitrification System," Appendix I, Section I-8. Modifications to the feed system, off-gas system and the induction coil have been made to accommodate $\mathrm{SOW}$ requirements and to incorporate lessons learned from the previous experiments

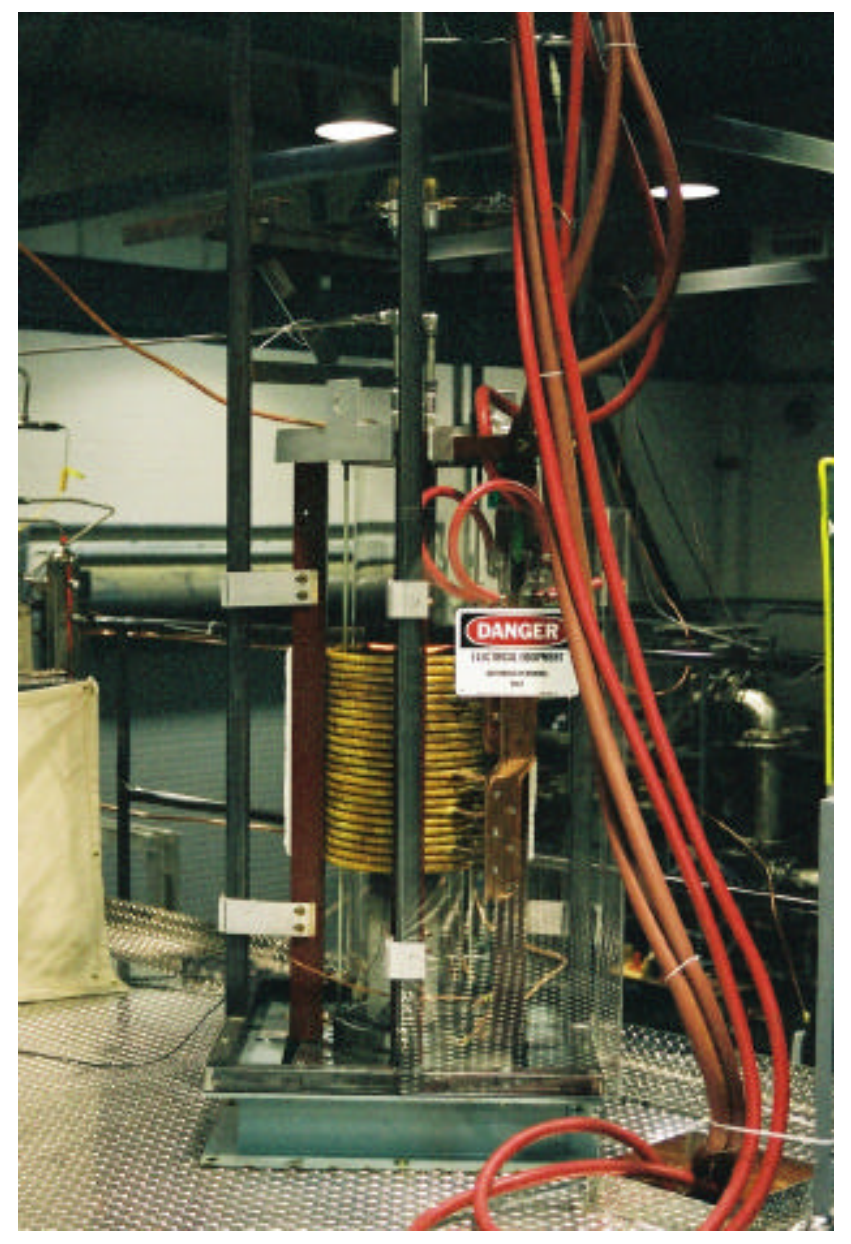

Figure 3-6a. Bench-Scale Test Stand 
Figure 3-7 is a comprehensive representation of the bench-scale system that was used for these tests. A simple feed system was designed and used to deliver the slurry feed to the system. A motor equipped with an agitating shaft was mounted to the top of the thirtygallon feed drum and was used during the testing activities to ensure the batch slurry remained well mixed. Slurry was fed from the drum using a variable speed peristaltic pump through santoprene tubing, which was connected to the copper feed tube. This configuration is shown in Figure 3-7. Individual subsystems are discussed below.

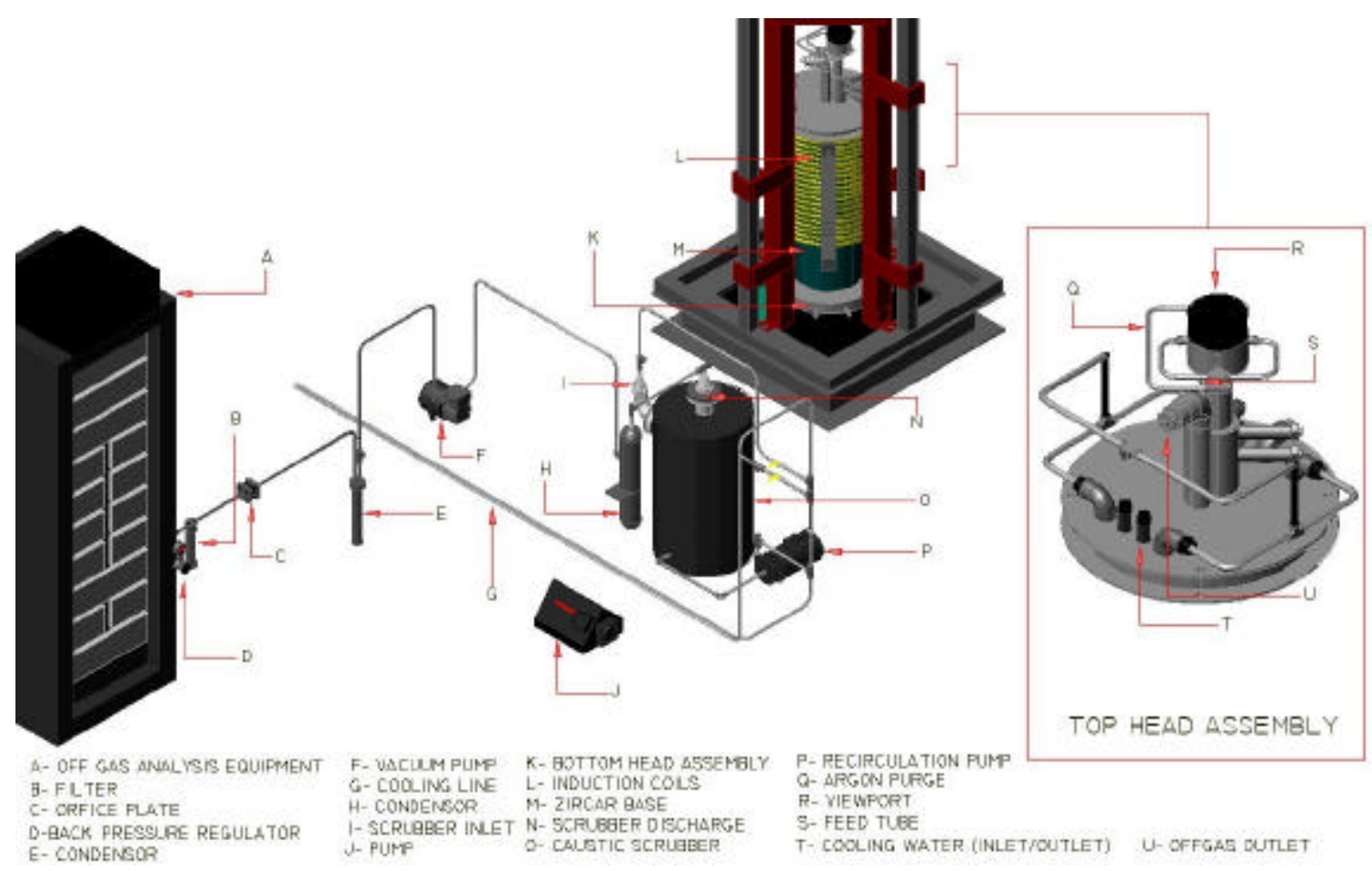

Figure 3-7. Advanced Vitrification System Bench-Scale Apparatus

\section{Feed System}

The feed system has been modified, as indicated by the results of laboratory-scale and COFFEE experiments, to enhance glass production rate and to accommodate a redesigned off-gas system. The modifications include a new upper head and watercooled feed tube design. The primary feed tube pipe penetration is constructed of copper, rather than brass or stainless steel, based upon the results of a heat transfer analysis. Slurry feed is introduced through the side of the copper feed tube pipe through a 1/4" copper tube that then runs along its interior wall. This ancillary feed tube is positioned as closely as possible to the center of the bench-scale crucible. The slurry feed is pumped, via a controllable peristaltic device, making use of the water-cooled section of the primary feed pipe, to prevent the feed from drying along the inside wall of the feed tube. The primary feed tube pipe is also fitted with a sight glass port to visually monitor feeding behavior. 
The module interface schematic is shown in Figure 3-8.

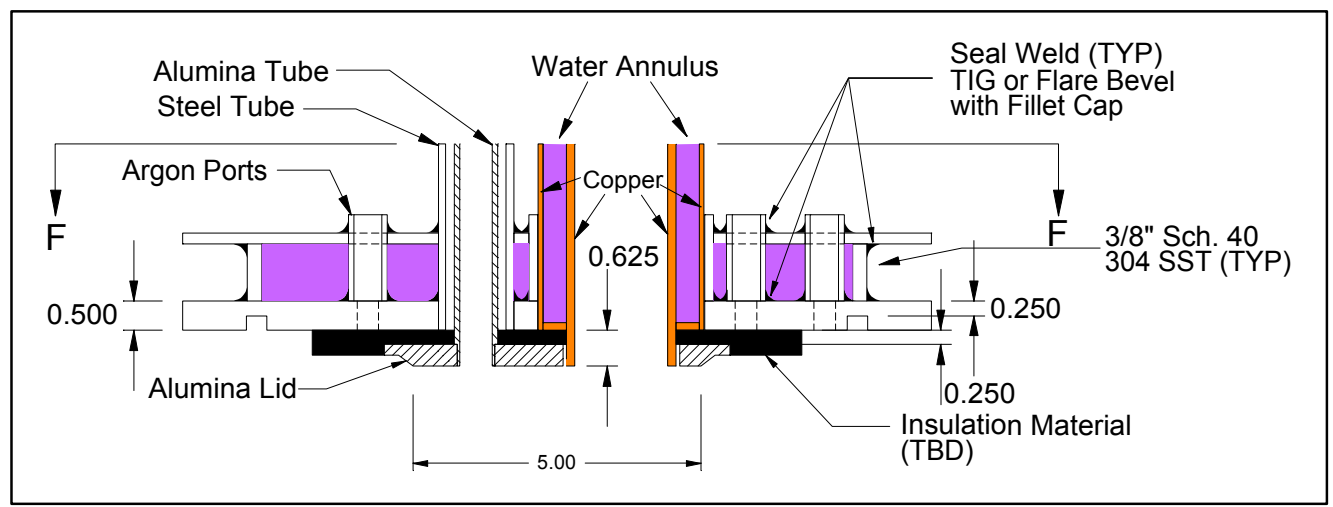

Figure 3-8. Design of Module/Feed System Interface

The feed tube configuration is shown in Figure 3.9.

Figure 3-9. Feed Tube Configuration for AVS Bench-Scale Apparatus

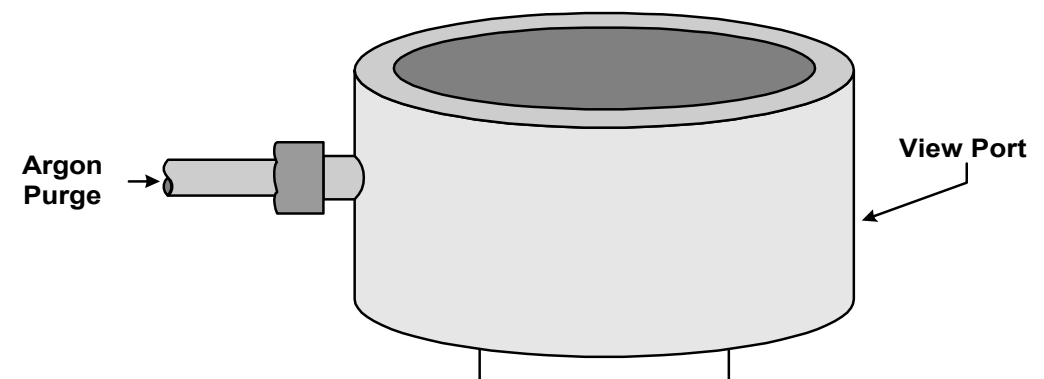


A 30-gallon drum was used for the bench-scale apparatus feed tank. Prior to initiating each bench-scale test run, the batch amount was determined to ensure a minimum of 20 liters was available.

The system was precharged with batch material prior to energizing the induction coil. This material safeguarded the alumina crucible from thermal shock upon introduction of the cold feed. Feeding did not commence until the system had reached operational temperature, i.e. $1450^{\circ} \mathrm{C}$. An argon carrier gas was introduced with the simulant material, into the feeder to assist in material movement into the AVS crucible. The carrier gas was diverted to the purge gas line when the system was not in feed mode.

Off-gas from the RIC AVS bench-scale melter is treated by an off-gas treatment system consisting of a film cooler, contacting condensate removal vessel, HEME (high efficiency mist eliminator), and HEPA (high efficiency particulate arrestor). The film cooler, located at the melter exhaust port, is a simple low pressure drop fitting in which off-gas exiting the RIC AVS melter is mixed with a controlled flow of argon gas. This mixing quickly reduces the off-gas temperature to under $200^{\circ} \mathrm{F}$ and increases the gas velocity above 25 feet per second. The higher velocity is necessary to minimize the total travel time from the melter to the condensate vessel. In this manner, particulate matter lay-down in the process piping can be avoided.

The condensate system consists of a condensate vessel (approximately 10 gallons), a recirculation pump, recirculation piping, a condensate/cooling water cross exchanger, temperature, level, and pressure instrumentation, and provisions for sampling of the solution during system operation. The condensate system is filled with a scrubbing solution or $\mathrm{pH}$-adjusted demineralized water such that a level is maintained in the condensate vessel. The solution was slightly caustic to facilitate scrubbing of $\mathrm{F}$ and $\mathrm{Cl}$ $(\mathrm{pH} \sim 10)$. The off-gas enters the condensate vessel through a diptube, which ensures contact between the gas and the scrubbing solution. This cools the off-gas to approximately $70^{\circ} \mathrm{F}$ and removes any condensate or particulate matter present in the gas. The cool, clean off-gas then exits the condensate system through a HEME. The scrubbing solution is continuously circulated and cooled to maintain a constant system temperature of $70^{\circ} \mathrm{F}$. Off-gas condensate and solids are allowed to accumulate within the condensate vessel throughout the entire test. The level is monitored to quantify the condensation versus run time. In addition, at pre-determined time intervals, condensate samples were collected for analysis.

A HEME is installed at the exit of the condensate vessel. This device removes both liquid aerosols generated by the bubbling action in the condensate vessel, and particulate matter that has penetrated the contacting condensate. The de-misted HEME exhaust enters the diaphragm-sampling pump. Suction is maintained at a slight vacuum $(\sim 2$ inches of $\mathrm{H}_{2} \mathrm{O}$ column). The pump discharge passes through a HEPA filter to remove any remaining particulate matter before being routed through the DIAL analyzer system. 
Figure 3-10 is a schematic of the AVS off-gas system that illustrates its interface with the AVS apparatus and where (and what) measurements are taken during operation. Figure 3-11 further details the AVS off-gas flow configuration. The purpose of the off-gas system is to measure gas flow rate as well as to quantitatively determine composition of the AZ-101 volatile off-gases versus time and temperature.

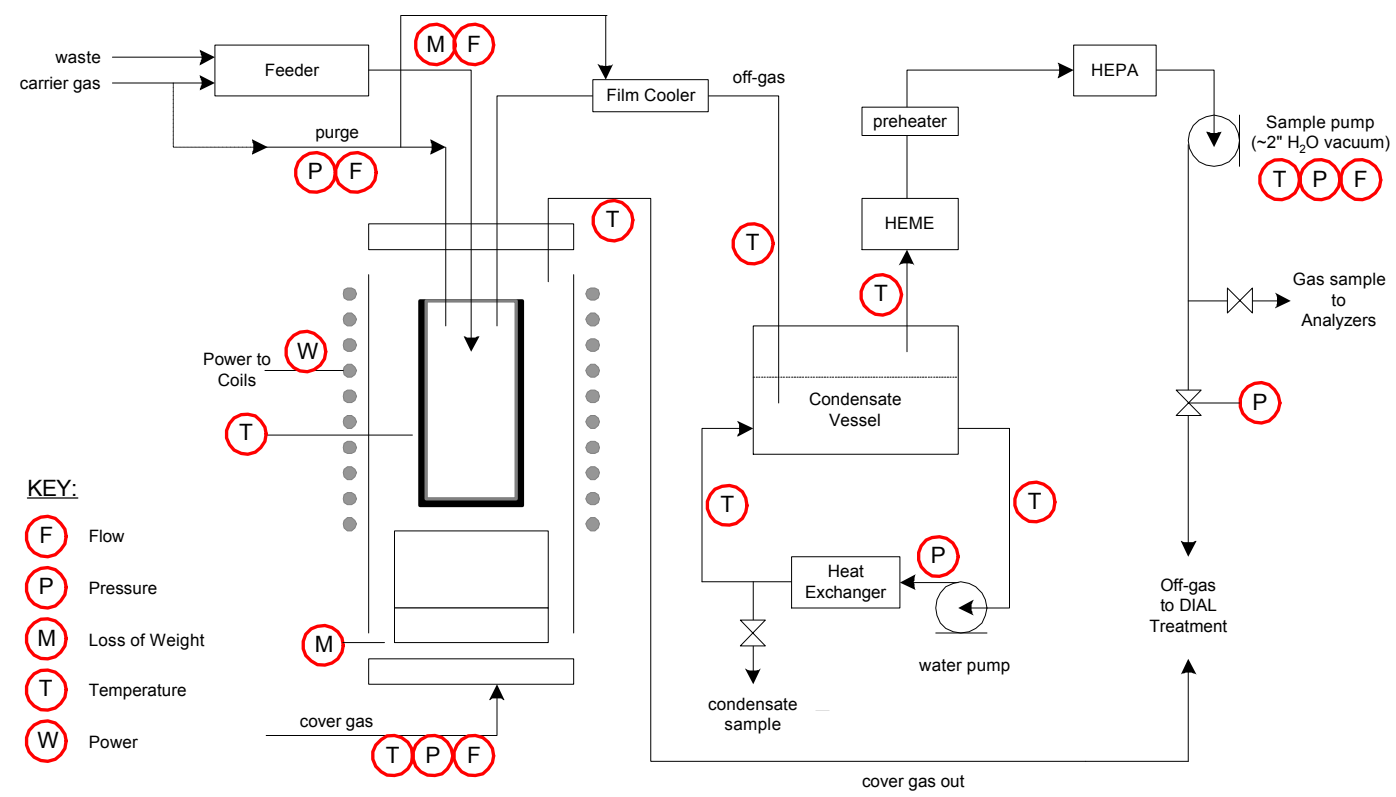

Figure 3-10. Advanced Vitrification System Off-Gas Schematic

Gases exiting the system, as well as the crucible cover gas, are routed to and treated in the DIAL facility off-gas treatment unit. This unit is comprised of a water supplied Venturi scrubber, a water-washed packed column and a HEPA. The off-gas engineering components are off-the-shelf items and assembled according to AVS bench-scale requirements. 


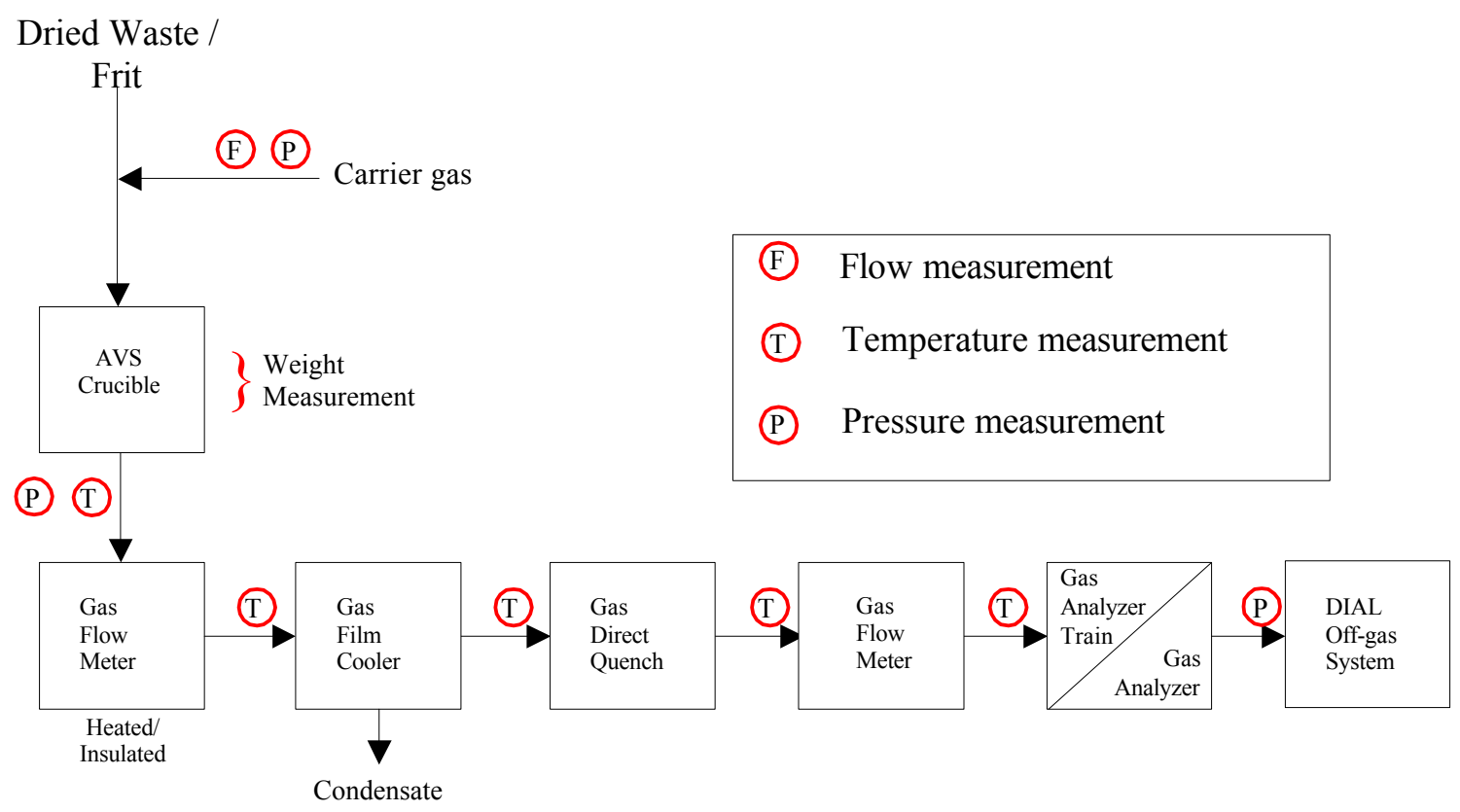

Figure 3-11. Analysis / Measurement Train for AVS Crucible Off-Gas

Argon is used as both a feed material carrier gas and outer cavity cover gas. Gases evolved from the melt exited the crucible and were quenched to remove condensables. Waste material carry-over in the condensate or in the pre-quench piping appeared as deposits. The cool, non-condensable gases exiting the quench section consisted of carbon oxides, nitrogen oxides, and sulfur oxides. This stream passed through the assembled DIAL process gas analyzers and a temperature-pressure-corrected flow meter. IR and chemiluminescence instruments with low ppm detection limits were used. 


\begin{tabular}{|c|c|c|c|c|}
\hline \multicolumn{5}{|c|}{ Table 3-2. DIAL Facility Process Analyzers } \\
\hline Species & Manufacturer & $\begin{array}{l}\text { Analytical } \\
\text { Method }\end{array}$ & Range 1 & Range 2 \\
\hline $\begin{array}{l}\mathrm{CO} \\
\mathrm{CO}_{2}\end{array}$ & Infrared Ind. & Infrared & $\begin{array}{c}0-5 \% \\
0-20 \%\end{array}$ & $\begin{array}{l}0-100 \mathrm{ppm} \\
0-100 \mathrm{ppm}\end{array}$ \\
\hline $\begin{array}{l}\mathrm{CO} \\
\mathrm{CO}_{2}\end{array}$ & $\begin{array}{l}\text { Summit } \\
\text { Analyzers }\end{array}$ & Infrared & $\begin{array}{c}0-1000 \mathrm{ppm} \\
0-10 \%\end{array}$ & $\begin{array}{c}0-3000 \mathrm{ppm} \\
0-20 \%\end{array}$ \\
\hline $\mathrm{O}_{2}$ & Teledyne & & $0-20 \%$ & $0-5 \%$ \\
\hline Combustibles & Teledyne & & $0-5 \%$ & \\
\hline $\mathrm{SO}_{2}$ & $\begin{array}{l}\text { Thermo } \\
\text { Electron } \\
\text { Series } 40\end{array}$ & $\begin{array}{c}\text { Pulsed } \\
\text { Fluorescent }\end{array}$ & $0-5000 \mathrm{ppm}$ & $0-100 \mathrm{ppm}$ \\
\hline $\begin{array}{c}\text { Total } \\
\text { Hydrocarbons }\end{array}$ & $\begin{array}{l}\text { Baseline Ind. } \\
\text { Series } 8800\end{array}$ & Flame Ionization & 0-2000 ppm & \\
\hline $\mathrm{NOx}$ & $\begin{array}{l}\text { Thermo } \\
\text { Electron } \\
\text { Series } 10\end{array}$ & Chemiluminescent & $0-1000 \mathrm{ppm}$ & $0-100 \mathrm{ppm}$ \\
\hline NO & Land Analyzer & Electrochemical & $0-1000 \mathrm{ppm}$ & \\
\hline $\mathrm{CO}$ & Series II & & $\begin{array}{c}0-2000 \mathrm{ppm} \\
0-25 \mathrm{p}\end{array}$ & $0-40,000 \mathrm{ppm}$ \\
\hline $\mathrm{O}_{2}$ & & & $0-25 \%$ & $0-100 \mathrm{ppm}$ \\
\hline $\mathrm{H}_{2}$ & Teledyne & $\begin{array}{c}\text { Thermal } \\
\text { conductivity }\end{array}$ & 0 to $500 \mathrm{ppm}$ & $0-100 \mathrm{ppm}$ \\
\hline
\end{tabular}

Following the AVS off-gas system, the remaining gases can enter the DIAL facility offgas system (Figure-3-12) at one of two locations (A or B); however, the upstream location, at the combination quench and venturi scrubber, is where it entered for these tests. The DIAL system is designed to accept a variety of stream conditions including combustion, incineration, and plasma vitrification. The system typically operates at 500 $\mathrm{lbs} / \mathrm{hr}, 750^{\circ} \mathrm{F}$, and $10-20^{\prime} \mathrm{H}_{2} \mathrm{O}$ vacuum. System equipment includes a combination quench and variable throat Venturi scrubber, a counter-current packed bed column, and a HEPA filter with inlet re-heater. 


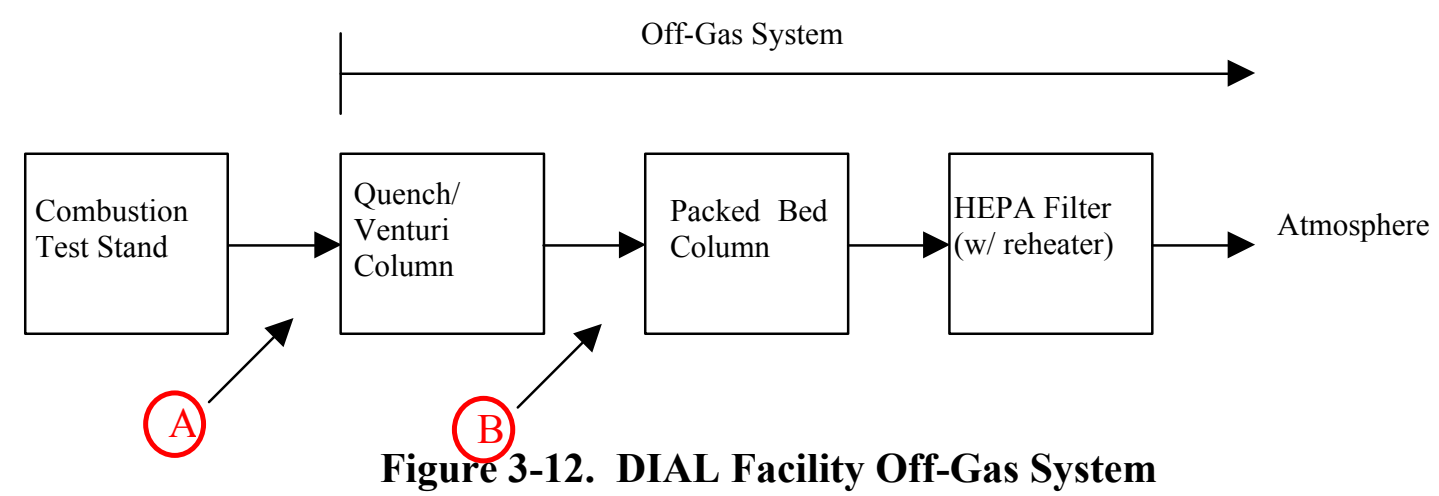

\section{Induction Coil}

The feed-form tests indicated a requirement for improved crucible temperature control. The bench-scale apparatus power input configuration has been modified to meet this requirement. This modification enhances the capabilities of the existing induction coil design by providing the ability to apply power to discrete sections of the vitrification column, producing a narrow heating band. This flexible heatup capability also enables the bench-scale experiments to better model the Hot Hohlraum AVS process model.

To facilitate this mode of operation, additional inductance was needed to maintain coil current within the range of the power supply. This modification enables the test operator to quickly and safely change or move the point of connection and/or the height of the heated section during a test run and provide the additional output impedance to accommodate the existing power supply. Figure 3-13 illustrates the new power input configuration.

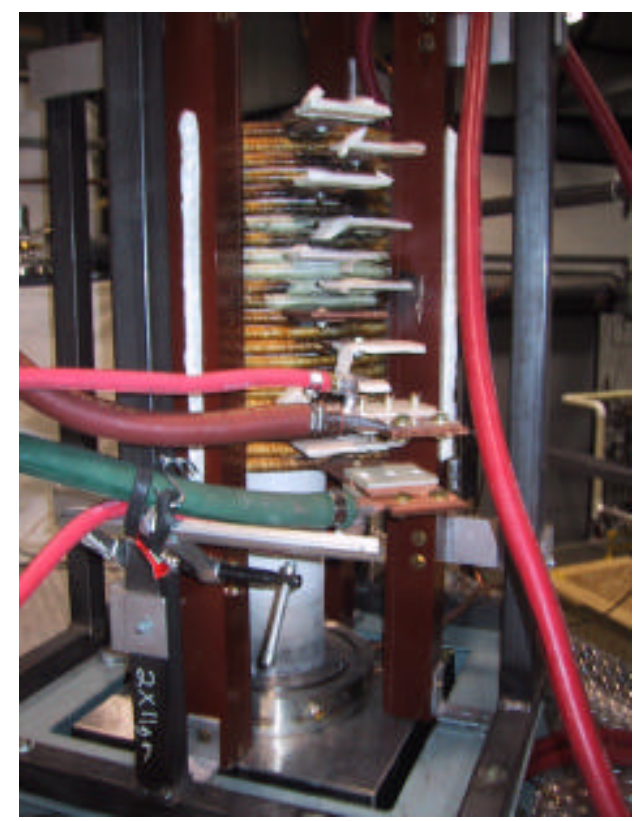

Figure 3-13. AVS power input configuration. 


\section{Description of Test Matrix}

Testing was performed on the AVS bench-scale product processed during the trial and demonstration runs. The blind reference material was analyzed as a comparison control standard.

\begin{tabular}{|llc|}
\hline Testing and Analyses & \multicolumn{1}{c|}{ AVS Demonstration } & DOE Blind \\
Composition & 6 samples, 3 replicates & Yes \\
PCT & 6 samples, 3 replicates & Yes \\
TCLP & 6 samples, 3 replicates & Yes \\
$T_{\mathrm{g}}$ & 6 samples & Yes \\
XRD (Qualitative) & $\mathrm{No}^{\mathrm{a}}$ & No \\
XRD (Quantitative) & 6 samples, 1 replicates & No \\
SEM (Qualitative) & 6 samples, 1 replicates & No \\
\hline
\end{tabular}

${ }^{a}$ Quantitative XRD incorporated qualitative determinations.

\subsection{Glass Transition Temperature}

The glass transition temperature, $T_{\mathrm{g}}$, was determined for the waste forms produced during the bench-scale runs and the corresponding LM series glass (LM 60). The transformation temperature range is the thermal region wherein glass behavior transitions from an undercooled liquid to a solid. The $\mathrm{T}_{\mathrm{g}}$ range is defined by viscosity. Glass crystallization kinetics at or below $\mathrm{T}_{\mathrm{g}}$ are usually extremely slow.

\section{Test Objectives}

The objective was to determine the glass transition temperature of the AZ-101 benchscale material. A $T_{g}$ was determined for 6 samples of glass from the bench-scale run. The samples correspond to radial and edge locations at three elevations in the crucible (top, center, and bottom). This was compared with the transition temperature of the LM 60 glass, confirming that the $T_{\mathrm{g}}$ could be adequately predicted from crucible testing.

\section{Method/Approach}

The $\mathrm{T}_{\mathrm{g}}$ was determined using Differential Thermal Analysis. A Perkin Elmer TG-DTA 6300, Pyris Diamond instrument was used. Powdered glass samples were placed in the sample cup and given a constant rate $\left(10^{\circ} \mathrm{C}\right.$ per minute) heat up to $1400^{\circ} \mathrm{C}$ and cooled at the same rate $\left(10^{\circ} \mathrm{C}\right.$ per minute $)$. The $\mathrm{T}_{\mathrm{g}}$ was determined by analyzing the derivative of the DTA curve (DDTA).

Samples of the LM 60 glass were also cast into $1 / 4$ " by 1/4" by 1" samples and analyzed by dilatometry. These values were compared with those obtained by DTA. This was performed as an independent check. It was not practical to obtain representative AVS glass pieces for dilatometry due to the nature of the bench-scale system.

\section{Test Equipment}

- Perkin Elmer TG-DTA 6300, Pyris Diamond. TTT Experiments 


\subsection{TTT Diagram Development}

\section{Test Objectives}

The objective of these experiments is to develop a Time-Temperature-Transformation (TTT) diagram for the AZ-101 simulant vitrified at the target bench-scale waste loading. The TTT experiments were defined to provide the evidence needed to demonstrate compliance with the WAPS 1.4, Specification for Phase Stability. The effort has the goal of identifying "the duration exposure at any temperature that causes significant changes in either the phase structure or phase properties in order to provide phase stability information." In particular, a "nose-diagram" was developed to define the crystalline fields (identity and extent) at temperatures between the liquidus temperature and glass transition temperature, and the TCLP and PCT properties of each sample were determined.

\section{Method/Approach}

There are multiple elements required to generate the data needed to construct a TTT diagram, i.e. heat treatments, sampling, and crystalline phase identification and quantification.

During the laboratory scale testing, 36 heat treatments were identified. Six heat treatment times and six treatment temperatures (located between the glass liquidus and glass transition temperature) were chosen. All testing was conducted on the $60-\mathrm{wt} \%$ [M-1] AZ-101 reference glass, using the TR-26 simulant. In addition, 6 samples were added to the test matrix for additional information regarding crystallization behavior at higher temperatures.

All TTT samples were batched and melted in the same manner as Large Melt samples, using a molybdenum disilicide element resistance furnace in an air atmosphere. One third of the $294 \mathrm{~g}$ dry batch was added (by visual inspection) to the $500 \mathrm{cc}$ high-form alumina $(99.8 \%$ corundum) crucible and placed in the room temperature melt furnace. The furnace was heated to $700^{\circ} \mathrm{C}$ at $10^{\circ} \mathrm{C}$ per minute and held at $700^{\circ} \mathrm{C}$ for one hour. The furnace was then ramped to $1000^{\circ} \mathrm{C}$ at $5^{\circ} \mathrm{C}$ per minute and held at $1000^{\circ} \mathrm{C}$ for one hour. The furnace was then ramped to $1450^{\circ} \mathrm{C}$ at $5^{\circ} \mathrm{C}$ per minute. As soon as the furnace reached $1450^{\circ} \mathrm{C}, 50 \mathrm{~g}$ (visual estimate) batch charges were added at 20 minute intervals. One hour after the final batch addition, the crucible was removed from the furnace and stirred with a 1/2" diameter quartz rod for 5-10 seconds and then replaced in the furnace. The $1450^{\circ} \mathrm{C}$ dwell period was continued for a total of 3 hours post batch addition. After the 3-hour dwell at $1450^{\circ} \mathrm{C}$, the alumina crucible was removed from the catch crucible and immediately placed in a pre-heated annealing furnace. All annealing furnaces were equipped with calibrated thermocouples - all of which were electronically connected to a PC platform temperature recorder.

Upon completion of the heat treatment, the samples were removed from the annealing furnaces and cooled to room temperature on a steel plate.

\footnotetext{
${ }^{7}$ Statement of Work (January 2002) Revised 3/14/02 for Additional Tests of the Advanced Vitrification System DE-AC26-00NT40801, Attachment A, Modification A008, p. 10
} 
The alumina crucible containing the heat-treated sample was visually examined for corrosion, batch/mass loss due to foam overflow, or fractures. Any crucible exhibiting foam overflow or fractures that resulted in mass loss, i.e. fractures that occurred during the melting/heat treatment, was discarded and the experiment repeated. All acceptable samples were then bisected vertically with a diamond saw. As can be observed from the photographs, none of the sample crucibles were shown to have been visibly corroded at the glass melt line.

Sampling of the crucible sections was performed with video record. The crucible sections were placed in two plastic bags and the wasteform was removed by striking the outer edges of the crucible. The resulting pieces with no visible crucible contact were separated from those with visible crucible adhesion. The SEM samples, one oriented near the top center of the melt, one oriented near the bottom center of the melt, were extracted at this point. This selection was made by mandating a portion of the top melt surface be attached for the "top" sample and a portion of the crucible contact area be attached for the "bottom" sample. The SEM samples were oriented normal to the crucible or melt surface prior to polishing in order to minimize surface phenomena impact on analysis. The pieces with crucible contamination were then placed in two plastic bags and the separation process was repeated as necessary to maximize sample recovery.

The resulting pieces were placed on white paper and mixed thoroughly with metallic forceps. The resulting mound of sample pieces was separated into quadrants. One quadrant was selected for the PCT experiment; the remaining three quadrants were combined for TCLP size grading. All samples extracted were placed in pre-marked plastic bags.

Sample obtained for TCLP was further size reduced with a hammer (in a plastic bag) prior to initiation of the EPA test protocol. Sample obtained for the PCT was also size reduced with a hammer (to reduce the potential for tungsten carbide contamination from the grinder).

Sub-samples analyzed by PCT and TCLP protocols were processed solely at Mississippi State University (MSU). XRD powder was initially sampled and size reduced at MSU, with standard addition, final sample grinding, along with actual XRD analysis at University of Missouri-Rolla (UMR). SEM samples were selected at MSU, with sample mounting and polishing being performed at Graftech (Parma, Ohio) and SEM analysis at UMR.

For the purposes of the TTT diagram construction, the XRD detection limit was used to define absence/presence of crystallinity. Calibration experiments, using aluminum oxide as a peak height standard, were performed to facilitate the Rietveld method of quantifying crystalline character of the samples. In addition, SEM-EDS analysis was performed on these samples. SEM-EDS analysis can reveal crystallinity not apparent to XRD. SEMEDS is also useful in identifying the composition of individual crystallites. 
The data collected from this battery of tests was analyzed, interpreted and correlated to define and construct a TTT diagram. This process is detailed in Section 4.

\section{Test Equipment}

- $250 \mathrm{ml}$ high form alumina crucibles

- Lindbergh high temperature glass melting furnace

- Laboratory balance

- Dried AZ-101 simulant

- Trim chemicals, i.e. silica, boric acid and zinc oxide

- Annealing lehrs

- Polishing equipment

- Scintag 2000 Diffractometer

- JEOL T33A Scanning Electron Microscope

\section{Description of Test Matrix}

The TTT experiments were conducted on 36 heat-treated samples of TR-26 reference glass. PCT, TCLP, XRD and SEM have been conducted on all 36 to determine chemical durability and crystalline character with respect to temperature and heat treatment exposure time. In addition, 6 extra samples were included, to examine the effects of higher temperatures on crystallization character and TCLP Cd response. The shaded regions in the matrix below indicate the samples that were tested. These data have been used to construct a TTT diagram. In addition, detailed compositional analysis and $\mathrm{T}_{\mathrm{g}}$ were performed on the TR-26 reference glass, to provide baseline information regarding the glass matrix. The data and results from this study are detailed in Section 4. 


\begin{tabular}{|c|c|c|c|c|c|c||}
\hline $\begin{array}{c}\text { Temperature } \\
\left({ }^{\circ} \mathbf{C}\right)\end{array}$ & \multicolumn{7}{|c||}{ TTT Testing Matrix } \\
\hline 1340 & $\mathrm{X}$ & $\mathrm{X}$ & & $\mathrm{X}$ & & \\
\hline 1300 & $\mathrm{X}$ & $\mathrm{X}$ & & $\mathrm{X}$ & & \\
\hline 1200 & $\mathrm{X}$ & $\mathrm{X}$ & $\mathrm{X}$ & $\mathrm{X}$ & $\mathrm{X}$ & $\mathrm{X}$ \\
\hline 1060 & $\mathrm{X}$ & $\mathrm{X}$ & $\mathrm{X}$ & $\mathrm{X}$ & $\mathrm{X}$ & $\mathrm{X}$ \\
\hline 920 & $\mathrm{X}$ & $\mathrm{X}$ & $\mathrm{X}$ & $\mathrm{X}$ & $\mathrm{X}$ & $\mathrm{X}$ \\
\hline 780 & $\mathrm{X}$ & $\mathrm{X}$ & $\mathrm{X}$ & $\mathrm{X}$ & $\mathrm{X}$ & $\mathrm{X}$ \\
\hline 640 & $\mathrm{X}$ & $\mathrm{X}$ & $\mathrm{X}$ & $\mathrm{X}$ & $\mathrm{X}$ & $\mathrm{X}$ \\
\hline 500 & $\mathrm{X}$ & $\mathrm{X}$ & $\mathrm{X}$ & $\mathrm{X}$ & $\mathrm{X}$ & $\mathrm{X}$ \\
\hline \hline Time (hours) & 0.75 & 3 & 12 & 48 & 192 & 768 \\
\hline
\end{tabular}

All the TTT samples, as indicated by an X in shaded cells, underwent analyses as follows:

\begin{tabular}{|c|c|c|}
\hline Test & Numbers of Samples & Replicates \\
\hline \hline PCT & 1 & 3 \\
\hline TCLP & 1 & 1 \\
\hline XRD & 1 & 1 \\
\hline SEM & 2 & 3 \\
\hline
\end{tabular}




\section{Experimental Results and Discussion}

\subsection{AZ-101 Simulant}

\section{Simulant Acceptance}

Obtaining an acceptable chemical simulant for Hanford AZ-101 high-level tank waste was prerequisite to initiating this test program. The AZ-101 simulant was prepared by NOAH Technologies and was received at DIAL in the form of three, 55-gallon drums. The chemical composition of the simulant must closely match the targeted composition of AZ-101 given in Section 3. In the case of AZ-101 simulant, the critical elements that need to match targeted values include the major components (Al, Cd, Fe, $\mathrm{La}, \mathrm{Mn}, \mathrm{Na}, \mathrm{Sr}$, and $\mathrm{Zr}$ ) and the RCRA elements (As, $\mathrm{Se}, \mathrm{Ba}, \mathrm{Pb}, \mathrm{Te}$, and $\mathrm{Cr}$ ). For this document, $\mathrm{Cd}$ is listed as a major constituent (versus RCRA) as it is present above one oxide weight percent. Major deviations from the expected value for any component must be identified and appropriately quantified. In some cases, the composition discrepancies may be adjusted to bring the overall formulation into an acceptable range.

\section{Preparation of AZ-101 Samples for Analysis and Approach to Analysis}

Prior to undergoing chemical analysis, the simulant was prepared for testing. Multiple samples of simulant were taken, dried, ground and then sub-sampled for cation analysis. Three digestion protocols were performed on each replicate. These replicates were analyzed in triplicate for cationic species. The data is reported as weight percent oxide. Anion analysis was performed on wet (as-taken) samples of simulant. The anion concentrations are reported as ppm or weight percent (in anionic form). These same test protocols were used for all of the simulant samples that were analyzed at DIAL.

\section{Simulant Acceptance Testing - Highlights and General Observations}

The first batch of AZ-101 simulant material provided by NOAH Technologies is designated TR-21. This material was found to be unacceptable due to its extremely high silica content. It was also low in lead and high in magnesium oxide. This material was rejected. The second batch of AZ-101, designated TR-23, was also found to have chemical discrepancies from the target composition; however, upon successful remediation of the lead content, this material was accepted. The lead-remediated material is designated TR-26, and is the material that was used for the TTT testing. The data and rationale for the simulant acceptance process is found in the following section.

\section{Simulant Acceptance Testing - Data, Discussion and Results}

A comparison of the DIAL TR-21 analysis with the target values for AZ-101 is given in Table 4-1. An independent laboratory, Southwest Research Institute (SWRI) also analyzed the material. This analysis is provided in Table 4-2. A comparison of the DIAL and SWRI analysis of TR-21 is provided in Table 4-3. Overall, the DIAL and SWRI results were in good agreement.

TR-21 was judged unacceptable for three reasons. First, the $\mathrm{SiO}_{2}$ content was found to be in excess of 100 times what it should have been. As silica content is a primary factor in processing waste, this was a major concern. High $\mathrm{SiO}_{2}$ would favor processing. In 
addition, the $\mathrm{PbO}$ content was only $40 \%$ of the targeted value and the $\mathrm{MgO}$ content was 10 times higher than it should have been. None of these discrepancies would have negatively impacted processing of the simulant; however, RIC felt they were too far outside of the DOE guidelines for the simulant composition to be acceptable. It was not possible to remediate the $\mathrm{SiO}_{2}$ and $\mathrm{MgO}$ as they were present in excessive amounts. Thus, TR-21 was rejected and it was requested that NOAH reformulate the simulant. 
Section 4

Experimental Results and Discussion

Additional Tests of an Advanced Vitrification System (DE-AC26-00NT40801)
Radioactive Isolation Consortium, LLC

Falls Church, VA 22046

www.ricllc.com

The simulant formulation specified by DOE follows:

Table 4-1. Composition of AZ-101 Waste Simulant

(All Compositions Expressed as wt\% Oxide, Except F, Cl and TOC)

\begin{tabular}{|c|c|c|c|}
\hline Oxide & AZ-101 Simulant & Starting Materials & $\begin{array}{c}\text { Amount in Simulant } \\
(\mathrm{kg})\end{array}$ \\
\hline $\mathrm{Ag}_{2} \mathrm{O}$ & - & - & - \\
\hline $\mathrm{Al}_{2} \mathrm{O}_{3}$ & $24.27 \%$ & $\mathrm{Al}(\mathrm{OH})_{3}$ & 41.94 \\
\hline $\mathrm{As}_{2} \mathrm{O}_{3}$ & $0.13 \%$ & $\mathrm{Na}_{2} \mathrm{HAsO}_{4}$ & 0.30 \\
\hline $\mathrm{BaO}$ & $0.14 \%$ & $\mathrm{Ba}(\mathrm{OH})_{2} * 8 \mathrm{H}_{2} \mathrm{O}$ & 0.30 \\
\hline $\mathrm{CaO}$ & $0.81 \%$ & $\mathrm{CaCO}_{3}$ & 1.62 \\
\hline $\mathrm{CdO}$ & $1.22 \%$ & $\mathrm{CdO}$ & 1.38 \\
\hline $\mathrm{CeO}_{2}$ & $0.27 \%$ & $\mathrm{Ce}(\mathrm{OH})_{4}$ & 0.36 \\
\hline $\mathrm{Cl}$ & $0.02 \%$ & $\mathrm{KCl}$ & 0.06 \\
\hline $\mathrm{Cr}_{2} \mathrm{O}_{3}$ & $0.14 \%$ & $\mathrm{Cr}_{2} \mathrm{O}_{3} * 1.5 \mathrm{H}_{2} \mathrm{O}$ & 0.18 \\
\hline $\mathrm{Cs}_{2} \mathrm{O}$ & $0.27 \%$ & $\mathrm{CsOH}(50 \%$ Solution $)$ & 0.66 \\
\hline $\mathrm{CuO}$ & $0.09 \%$ & $\mathrm{CuSO}_{4} * 5 \mathrm{H}_{2} \mathrm{O}$ & 0.30 \\
\hline $\mathrm{F}$ & $0.12 \%$ & $\mathrm{NaF}$ & 0.30 \\
\hline $\mathrm{Fe}_{2} \mathrm{O}_{3}$ & $34.08 \%$ & $\mathrm{Fe}(\mathrm{OH})_{3}$ Slurry $(13 \%)$ & 391.30 \\
\hline $\mathrm{Fe}_{2} \mathrm{O}_{3}$ & & $\mathrm{FePO}_{4}(80 \%)$ & \\
\hline $\mathrm{K}_{2} \mathrm{O}$ & $0.55 \%$ & $\mathrm{KNO}_{3}$ & 1.32 \\
\hline $\mathrm{K}_{2} \mathrm{O}$ & & $\mathrm{KCl}$ & \\
\hline $\mathrm{La}_{2} \mathrm{O}_{3}$ & $1.06 \%$ & $\mathrm{La}(\mathrm{OH})_{3} * 3 \mathrm{H}_{2} \mathrm{O}$ & 1.80 \\
\hline $\mathrm{MgO}$ & $0.21 \%$ & $4 \mathrm{MgCO}_{3} * \mathrm{Mg}(\mathrm{OH})_{2} * 5 \mathrm{H}_{2} \mathrm{O}$ & 0.54 \\
\hline $\mathrm{MnO}$ & $9.94 \%$ & $\mathrm{MnO}_{2}$ & 13.80 \\
\hline $\mathrm{Na}_{2} \mathrm{O}$ & $1.96 \%$ & $\mathrm{NaOH}(50 \%$ Solution $)$ & 1.44 \\
\hline $\mathrm{Na}_{2} \mathrm{O}$ & & $\mathrm{NaNO}_{2} \& \mathrm{Na}_{2} \mathrm{SO}_{4} \& \mathrm{NaF}$ & \\
\hline $\mathrm{NiO}$ & $1.76 \%$ & $\mathrm{Ni}(\mathrm{OH})_{2}$ & 2.46 \\
\hline $\mathrm{P}_{2} \mathrm{O}_{5}$ & $0.42 \%$ & $\mathrm{FePO}_{4}(80 \%)$ & 1.26 \\
\hline $\mathrm{PbO}$ & $0.50 \%$ & $2 \mathrm{PbCO}_{3} * \mathrm{~Pb}(\mathrm{OH})_{2}$ & 0.66 \\
\hline $\mathrm{Rh}_{2} \mathrm{O}_{3}$ & - & - & - \\
\hline $\mathrm{RuO}_{2}$ & - & - & - \\
\hline $\mathrm{SO}_{3}$ & $0.82 \%$ & $\mathrm{Na}_{2} \mathrm{SO}_{4}$ & 1.44 \\
\hline $\mathrm{SO}_{3}$ & & $\mathrm{CuSO}_{4} * 5 \mathrm{H}_{2} \mathrm{O}$ & \\
\hline $\mathrm{Sb}_{2} \mathrm{O}_{5}$ & $0.69 \%$ & $\mathrm{Sb}_{2} \mathrm{O}_{5}$ & 0.78 \\
\hline $\mathrm{SeO}_{2}$ & $0.49 \%$ & $\mathrm{SeO}_{2}$ & 0.54 \\
\hline $\mathrm{SiO}_{2}$ & $0.07 \%$ & $\mathrm{SiO}_{2}$ & 0.07 \\
\hline $\mathrm{SrO}$ & $7.60 \%$ & $\mathrm{Sr}\left(\mathrm{NO}_{3}\right)_{2}$ & 2.22 \\
\hline $\mathrm{SrO}$ & & $\mathrm{Sr}(\mathrm{OH})_{2} * 8 \mathrm{H}_{2} \mathrm{O}$ & 19.26 \\
\hline $\mathrm{TeO}_{2}$ & $0.47 \%$ & $\mathrm{TeO}_{2}$ & 0.54 \\
\hline $\mathrm{TiO}_{2}$ & $0.21 \%$ & $\mathrm{TiO}_{2}$ & 0.24 \\
\hline $\mathrm{UO}_{2}$ & - & - & - \\
\hline $\mathrm{ZnO}$ & - & - & - \\
\hline $\mathrm{ZrO}_{2}$ & $11.68 \%$ & $\mathrm{ZrOOH}\left(\mathrm{CO}_{3}\right)_{0.5}(50 \%)$ & 21.18 \\
\hline \multirow[t]{2}{*}{$\mathrm{ZrO}_{2}$} & & $\mathrm{Zr}(\mathrm{OH})_{4}(50 \%)$ & 12.24 \\
\hline & & Water & 70.39 \\
\hline TOTAL & $99.99 \%$ & & \\
\hline \multicolumn{3}{|c|}{ Volatiles (g/100 g oxides) } & \\
\hline $\mathrm{CO}_{3}$ & 3 & & \\
\hline $\mathrm{NO}_{2}$ & 0.91 & $\mathrm{NaNO}_{2}$ & 1.56 \\
\hline $\mathrm{NO}_{3}$ & 1.88 & & \\
\hline \multirow[t]{2}{*}{ TOC } & 1.27 & $\mathrm{H}_{2} \mathrm{C}_{2} \mathrm{O}_{4} * 2 \mathrm{H}_{2} \mathrm{O}$ & 7.56 \\
\hline & & Total & 600.00 \\
\hline
\end{tabular}




\begin{tabular}{|c|c|c|c|c|c|c|c|c|c|c|c|}
\hline & & ible 4 & $1 \mathbf{a} A$ & lysis & TR- & Sim & ant & rfor & $\mathbf{d} \mathbf{a}$ & $\mathrm{IAL}^{1}$ & \\
\hline & Eleme & tal wt \% & & & Conv & Oxide & SD & RSD & Norm. & Expected & Deviation \\
\hline Oxide & $\begin{array}{l}\mathrm{mw} \\
\text { ave }\end{array}$ & fcl ave & fn ave & Average & & $\mathrm{Wt} \%$ & & & Wt \% & & \\
\hline $\mathrm{Al}_{2} \mathrm{O}_{3}$ & 3.63 & 10.55 & 11.30 & 10.93 & 1.8895 & 20.64 & 1.00 & 4.85 & 23.89 & 24.27 & -1.58 \\
\hline $\mathrm{As}_{2} \mathrm{O}_{3}$ & .06 & 0.08 & 0.06 & 0.07 & 1.3203 & 0.09 & 0.02 & 19.02 & 0.10 & 0.13 & -22.90 \\
\hline $\mathrm{B}_{2} \mathrm{O}_{3}$ & & & & & 3.2201 & & & & 0.00 & & \\
\hline $\mathrm{BaO}$ & 0.01 & 0.10 & 0.10 & 0.10 & 1.1165 & 0.11 & 0.00 & 3.27 & 0.13 & 0.14 & -10.26 \\
\hline $\mathrm{CaO}$ & 0.23 & 0.51 & 0.54 & 0.52 & 1.3992 & 0.73 & 0.03 & 3.85 & 0.85 & 0.81 & 4.69 \\
\hline $\mathrm{CdO}$ & 0.76 & 0.75 & 0.78 & 0.76 & 1.1423 & 0.87 & 0.02 & 2.03 & 1.01 & 1.22 & -17.30 \\
\hline $\mathrm{CeO}_{2}$ & 0.03 & 0.17 & 0.20 & 0.18 & 1.2284 & 0.22 & 0.03 & 13.35 & 0.26 & 0.27 & -3.79 \\
\hline $\mathrm{Cr}_{2} \mathrm{O}_{3}$ & 0.04 & 0.06 & 0.05 & 0.05 & 1.4616 & 0.07 & 0.01 & 17.36 & 0.09 & 0.14 & -38.32 \\
\hline $\mathrm{Cs}_{2} \mathrm{O}$ & & & & & 1.0602 & & & & & 0.27 & \\
\hline $\mathrm{CuO}$ & 0.04 & 0.04 & 0.04 & 0.04 & 1.2518 & 0.05 & 0.00 & 7.87 & 0.06 & 0.09 & -33.39 \\
\hline$\overline{\mathrm{Fe}_{2} \mathrm{O}_{3}}$ & 17.60 & 18.45 & 19.50 & 18.52 & 1.4297 & 26.47 & 1.36 & 5.14 & 30.63 & 34.08 & -10.12 \\
\hline $\mathrm{K}_{2} \mathrm{O}$ & 0.37 & 0.38 & 0.38 & 0.37 & 1.2046 & 0.45 & 0.01 & 1.95 & 0.52 & 0.55 & -5.02 \\
\hline $\mathrm{La}_{2} \mathrm{O}_{3}$ & 0.14 & 0.51 & 0.53 & 0.52 & 1.1728 & 0.61 & 0.02 & 3.01 & 0.70 & 1.06 & -33.94 \\
\hline $\mathrm{MgO}$ & 0.17 & 1.14 & 1.18 & 1.16 & 1.6583 & 1.92 & 0.05 & 2.44 & 2.23 & 0.21 & 959.93 \\
\hline $\mathrm{MnO}$ & 5.24 & 5.23 & 4.32 & 5.23 & 1.2912 & 6.76 & 0.01 & 0.09 & 7.82 & 9.94 & -21.34 \\
\hline $\mathrm{Na}_{2} \mathrm{O}$ & 0.99 & & & 0.99 & 1.3480 & 1.34 & & & 1.55 & 1.96 & -20.92 \\
\hline $\mathrm{NiO}$ & 1.00 & 0.99 & & 1.00 & 1.2726 & 1.27 & 0.01 & 0.47 & 1.47 & 1.76 & -16.72 \\
\hline $\mathrm{P}_{2} \mathrm{O}_{5}$ & 0.20 & 0.17 & 0.16 & 0.18 & 2.2914 & 0.40 & 0.05 & 12.84 & 0.47 & 0.42 & 11.25 \\
\hline $\mathrm{PbO}$ & 0.12 & 0.16 & 0.16 & 0.15 & 1.0772 & 0.16 & 0.03 & 18.64 & 0.18 & 0.5 & -63.26 \\
\hline $\mathrm{SO}_{3}$ & 0.33 & 0.47 & 0.45 & 0.45 & 2.4971 & 1.04 & 0.18 & \begin{tabular}{|l}
17.56 \\
\end{tabular} & 1.20 & 0.82 & 46.39 \\
\hline $\mathrm{Sb}_{2} \mathrm{O}_{5}$ & 0.32 & 0.32 & 0.28 & 0.31 & 1.3285 & 0.41 & 0.03 & $\begin{array}{l}7.66 \\
\end{array}$ & 0.47 & 0.69 & -31.84 \\
\hline $\mathrm{SeO}_{2}$ & 0.22 & 0.23 & & 0.22 & 1.4053 & 0.31 & 0.01 & 2.78 & 0.36 & 0.49 & -27.03 \\
\hline $\mathrm{SiO}_{2}$ & 3.18 & 3.64 & 3.75 & 3.52 & 2.1393 & 7.54 & 0.65 & 8.58 & 8.72 & 0.07 & 12359.51 \\
\hline $\mathrm{SrO}$ & 1.03 & 4.44 & 4.72 & 4.58 & 1.1826 & 5.42 & 0.23 & 4.32 & 6.27 & 7.6 & -17.54 \\
\hline $\mathrm{TeO}_{2}$ & 0.26 & 0.27 & 0.28 & 0.27 & 1.2508 & 0.34 & 0.01 & 2.82 & 0.39 & 0.47 & -17.11 \\
\hline $\mathrm{TiO}_{2}$ & 0.20 & 0.21 & 0.20 & 0.21 & 1.6680 & 0.34 & 0.01 & 1.68 & 0.40 & 0.21 & 89.33 \\
\hline $\mathrm{ZrO}_{2}$ & 6.79 & 6.85 & 6.65 & 6.76 & 1.3508 & 9.14 & 0.14 & 1.52 & 10.57 & 11.68 & -9.49 \\
\hline Total & 42.96 & 55.73 & 55.61 & 56.84 & & 86.42 & & & 100 & 99.85 & \\
\hline
\end{tabular}

${ }^{1}$ Shaded cells indicate values used for Average, SD and RSD calculations. Unshaded cells indicate that all three elemental $\mathrm{wt} \%$ were used. 
Section 4

Experimental Results and Discussion

Additional Tests of an Advanced Vitrification System (DE-AC26-00NT40801)
Radioactive Isolation Consortium, LLC Falls Church, VA 22046 www.ricllc.com

\begin{tabular}{|c|c|c|c|c|c|c|c|}
\hline \multirow[b]{2}{*}{ Oxide } & \multicolumn{3}{|c|}{ Elemental } & \multirow[t]{2}{*}{ Conv factor } & \multirow{2}{*}{$\begin{array}{l}\text { Oxide } \\
\text { Wt \% }\end{array}$} & \multirow{2}{*}{$\frac{\text { Normalized }}{\mathrm{Wt} \%}$} & \multirow[t]{2}{*}{ Expecteo } \\
\hline & ppm (wet) & Wt \% (wet) & Wt \% (dry) & & & & \\
\hline $\mathrm{Al}_{2} \mathrm{O}_{3}$ & 24396 & 2.44 & 10.29 & 1.8895 & 19.45 & 22.31 & 24.27 \\
\hline $\mathrm{As}_{2} \mathrm{O}_{3}$ & 183 & 0.02 & 0.08 & 1.3203 & 0.10 & 0.12 & 0.13 \\
\hline $\mathrm{B}_{2} \mathrm{O}_{3}$ & & & 0.00 & 3.2201 & 0.00 & 0.00 & \\
\hline $\mathrm{BaO}$ & 217 & 0.02 & 0.09 & 1.1165 & 0.10 & 0.12 & 0.14 \\
\hline $\mathrm{CaO}$ & 1161 & 0.12 & 0.49 & 1.3992 & 0.69 & 0.79 & 0.81 \\
\hline $\mathrm{CdO}$ & 1956 & 0.20 & 0.83 & 1.1423 & 0.94 & 1.08 & 1.22 \\
\hline $\mathrm{CeO}_{2}$ & 396 & 0.04 & 0.17 & 1.2284 & 0.21 & 0.24 & 0.27 \\
\hline $\mathrm{Cr}_{2} \mathrm{O}_{3}$ & 184 & 0.02 & 0.08 & 1.4616 & 0.11 & 0.13 & 0.14 \\
\hline $\mathrm{Cs}_{2} \mathrm{O}$ & 458 & 0.05 & 0.19 & 1.0602 & 0.20 & 0.24 & 0.27 \\
\hline $\mathrm{CuO}$ & 121 & 0.01 & 0.05 & 1.2518 & 0.06 & $\mathbf{0 . 0 7}$ & 0.09 \\
\hline $\mathrm{Fe}_{2} \mathrm{O}_{3}$ & 42215 & 4.22 & 17.81 & 1.4297 & 25.47 & 29.21 & 34.08 \\
\hline $\mathrm{K}_{2} \mathrm{O}$ & 909 & 0.09 & 0.38 & 1.2046 & 0.46 & 0.53 & 0.55 \\
\hline $\mathrm{La}_{2} \mathrm{O}_{3}$ & 1285 & 0.13 & 0.54 & 1.1728 & 0.64 & 0.73 & 1.06 \\
\hline $\mathrm{MgO}$ & 2706 & 0.27 & 1.14 & 1.6583 & 1.89 & 2.17 & 0.21 \\
\hline $\mathrm{MnO}$ & 11376 & 1.14 & 4.80 & 1.2912 & 6.20 & 7.11 & 9.94 \\
\hline $\mathrm{Na}_{2} \mathrm{O}$ & 4851 & 0.49 & 2.05 & 1.3480 & 2.76 & 3.16 & 1.96 \\
\hline $\mathrm{NiO}$ & 2481 & 0.25 & 1.05 & 1.2726 & 1.33 & 1.53 & 1.76 \\
\hline $\mathrm{P}_{2} \mathrm{O}_{5}$ & 622 & 0.06 & 0.26 & 2.2914 & 0.60 & 0.69 & 0.42 \\
\hline $\mathrm{PbO}$ & 380 & 0.04 & 0.16 & 1.0772 & 0.17 & 0.20 & 0.5 \\
\hline $\mathrm{SO}_{3}$ & 840 & 0.08 & 0.35 & 2.4971 & 0.89 & 1.02 & 0.82 \\
\hline $\mathrm{Sb}_{2} \mathrm{O}_{5}$ & 667 & 0.07 & 0.28 & 1.3285 & 0.37 & 0.43 & 0.69 \\
\hline $\mathrm{SeO}_{2}$ & 654 & 0.07 & 0.28 & 1.4053 & 0.39 & 0.44 & 0.49 \\
\hline $\mathrm{SiO}_{2}$ & 9037 & 0.90 & 3.81 & 2.1393 & 8.16 & 9.36 & 0.07 \\
\hline $\mathrm{SrO}$ & 10824 & 1.08 & 4.57 & 1.1826 & 5.40 & 6.20 & 7.6 \\
\hline $\mathrm{TeO}_{2}$ & 732 & 0.07 & 0.31 & 1.2508 & 0.39 & 0.44 & 0.47 \\
\hline $\mathrm{TiO}_{2}$ & 467 & 0.05 & 0.20 & 1.6680 & 0.33 & 0.38 & 0.21 \\
\hline $\mathrm{ZrO}_{2}$ & 17319 & 1.73 & 7.31 & 1.3508 & 9.87 & 11.32 & 11.68 \\
\hline & & & & Total & 87.18159 & 100 & 99.85 \\
\hline
\end{tabular}




\begin{tabular}{|c|c|c|c|}
\hline \multicolumn{4}{|c|}{ Table 4-3. Comparison of SWRI Results to DIAL Results for TR-21 } \\
\hline & SWRI & DIAL & \\
\hline Oxide & Normalized & Normalized & RSD \\
\hline & Oxide Wt \% & Oxide Wt \% & \\
\hline $\mathrm{Al}_{2} \mathrm{O}_{3}$ & 22.31 & 23.89 & 4.39 \\
\hline $\mathrm{As}_{2} \mathrm{O}_{3}$ & 0.12 & 0.10 & 3.52 \\
\hline $\mathrm{B}_{2} \mathrm{O}_{3}$ & & $\mathbf{0 . 0 0}$ & \\
\hline $\mathrm{BaO}$ & 0.12 & $\mathbf{0 . 1 3}$ & 6.94 \\
\hline $\mathrm{CaO}$ & 0.79 & $\mathbf{0 . 8 5}$ & 4.60 \\
\hline $\mathrm{CdO}$ & 1.08 & 1.01 & 3.91 \\
\hline $\mathrm{CeO}_{2}$ & $\mathbf{0 . 2 4}$ & 0.26 & 1.57 \\
\hline $\mathrm{Cr}_{2} \mathrm{O}_{3}$ & 0.13 & 0.09 & 21.70 \\
\hline $\mathrm{Cs}_{2} \mathrm{O}$ & 0.24 & 0.00 & 141.42 \\
\hline $\mathrm{CuO}$ & 0.07 & 0.06 & 13.49 \\
\hline $\mathrm{Fe}_{2} \mathrm{O}_{3}$ & 29.21 & 30.63 & 3.47 \\
\hline $\mathrm{K}_{2} \mathrm{O}$ & 0.53 & 0.52 & 1.57 \\
\hline $\mathrm{La}_{2} \mathrm{O}_{3}$ & 0.73 & 0.70 & 3.18 \\
\hline $\mathrm{MgO}$ & 2.17 & 2.23 & 0.69 \\
\hline $\mathrm{MnO}$ & 7.11 & 7.82 & 7.05 \\
\hline $\mathrm{Na}_{2} \mathrm{O}$ & 3.16 & 1.55 & 39.89 \\
\hline $\mathrm{NiO}$ & 1.53 & 1.47 & 3.83 \\
\hline $\mathrm{P}_{2} \mathrm{O}_{5}$ & 0.69 & 0.47 & 28.16 \\
\hline $\mathrm{PbO}$ & 0.20 & 0.18 & 2.67 \\
\hline $\mathrm{SO}_{3}$ & 1.02 & 1.20 & 9.76 \\
\hline $\mathrm{Sb}_{2} \mathrm{O}_{5}$ & 0.43 & 0.47 & 7.88 \\
\hline $\mathrm{SeO}_{2}$ & 0.44 & 0.36 & 14.90 \\
\hline $\mathrm{SiO}_{2}$ & 9.36 & 8.72 & 5.14 \\
\hline $\mathrm{SrO}$ & 6.20 & 6.27 & 0.26 \\
\hline $\mathrm{TeO}_{2}$ & 0.44 & 0.39 & 0.12 \\
\hline $\mathrm{TiO}_{2}$ & 0.38 & $\begin{array}{l}0.40 \\
\end{array}$ & 1.68 \\
\hline $\mathrm{ZrO}_{2}$ & 11.32 & 10.57 & 4.89 \\
\hline
\end{tabular}

\begin{tabular}{|c|c|c|c|}
\hline \multicolumn{4}{|c|}{ Table 4-4. Anion Data of TR-21 Simulant } \\
\hline Anions & $\begin{array}{c}\text { DIAL } \\
\text { (ppm) }\end{array}$ & $\begin{array}{c}\text { Expected } \\
(\mathbf{p p m})\end{array}$ & $\begin{array}{c}\% \\
\text { Expected }\end{array}$ \\
\hline $\mathbf{F}$ & 158 & 226 & 69.9 \\
\hline $\mathbf{C l}$ & 201 & 48 & 418.8 \\
\hline $\mathbf{N O}_{2}$ & 2360 & 1733 & 136.2 \\
\hline $\mathbf{N O}_{3}$ & 5310 & 3517 & 151.0 \\
\hline $\mathbf{S O}_{4}$ & 1540 & 1815 & 84.8 \\
\hline $\mathbf{P O}_{4}$ & $\mathrm{BDL}$ & 1058 & \\
\hline $\mathbf{C O}_{3}$ & 1039 & 1134 & 92.0 \\
\hline $\mathbf{T O C}$ & 685.5 & 2800 & 24.4 \\
\hline
\end{tabular}

Receipt, Analysis, and Remediation of Second Lot of AZ-101 mixed at NOAA. The second lot of AZ-101 simulant, TR-23, was received and analyzed. A comparison of the results obtained with the target values is given in Table 4-5. Most of the cations are within the target range, although a number of elements are outside of the target range. 
These variations are discussed below. Of particular importance in this regard are the elements denoted to be major elements in Table 4-5 as well as those of importance with respect to TCLP analysis, denoted as RCRA elements in Table 4-5.

\section{Major species.}

Of the major species, all except $\mathrm{Na}$ are within the target range (the analyzed value \pm standard deviation overlaps the target value \pm tolerance). Sodium was slightly low (about $18 \%$ ) versus the target value. Sodium is a common glass-making additive and this deviation was not expected to significantly impact vitrification potential or crystallization.

\section{RCRA Elements.}

With respect to the RCRA elements, both chromium and lead were significantly lower than the target value. In fact, the lead was absent entirely due to an error by a supplier to NOAH. A presumed source of lead carbonate was actually a siliceous material instead of a lead salt. This error was verified by NOAH and contributed to the higher silica values measured in the simulant. Chromium was slightly low, however, the initial TCLP results indicate the chrome release to be approximately 2 orders of magnitude below the UTS limit. Cadmium, which was slightly high, appeared to be the process-limiting factor.

\section{Other Cations}

Calcium, silicon, magnesium, and titanium are significantly higher than the target values, while antimony is lower. These are trace elements and the discrepancies should not affect processing, durability, or crystallinity. Silica is the primary batch additive (and will not be calculated as part of the waste loading in any event). 


\begin{tabular}{|c|c|c|c|c|c|c|c|}
\hline & ole $4-5$. s & ulant $A$ & is of & 101, TR & Perfi & ed at D & \\
\hline & & DIAL & & & Deviation & om Target & \\
\hline Oxide & $\begin{array}{c}\text { Analyzed } \\
\text { Wt \% }\end{array}$ & St. Dev & $\begin{array}{l}\text { Target } \\
\text { Wt \% }\end{array}$ & w/in 1 SD & $<10 \%$ & $10-20 \%$ & $>20 \%$ \\
\hline $\mathrm{Al}_{2} \mathrm{O}_{3}$ & 24.39 & 0.28 & 24.27 & $\mathbf{X}$ & $\mathbf{X}$ & & \\
\hline $\mathrm{As}_{2} \mathrm{O}_{3}$ & 0.12 & 0.01 & 0.13 & $\mathbf{X}$ & $\mathbf{X}$ & & \\
\hline $\mathrm{B}_{2} \mathrm{O}_{3}$ & $\overline{B D L}$ & NA & & & & & \\
\hline $\mathrm{BaO}$ & 0.14 & 0.00 & 0.14 & $\bar{X}$ & $\mathbf{X}$ & & \\
\hline $\mathrm{CaO}$ & 1.12 & 0.01 & 0.81 & & & & $\mathbf{X}$ \\
\hline $\mathrm{CdO}$ & 1.31 & 0.06 & 1.22 & & $\mathbf{X}$ & & \\
\hline $\mathrm{CeO}_{2}$ & 0.26 & 0.01 & 0.27 & $\mathbf{X}$ & $\mathbf{X}$ & & \\
\hline $\mathrm{Cr}_{2} \mathrm{O}_{3}$ & 0.09 & 0.01 & 0.14 & & & & $\bar{X}$ \\
\hline $\mathrm{Cs}_{2} \mathrm{O}$ & 0.27 & 0.02 & 0.27 & $\mathbf{X}$ & $\mathbf{X}$ & & \\
\hline $\mathrm{CuO}$ & 0.08 & 0.01 & 0.09 & $\mathrm{X}$ & $\mathrm{X}$ & & \\
\hline $\mathrm{Fe}_{2} \mathrm{O}_{3}$ & 34.45 & 0.22 & 34.08 & & $\mathbf{X}$ & & \\
\hline $\mathrm{K}_{2} \mathrm{O}$ & 0.57 & 0.01 & 0.55 & & $\mathrm{X}$ & & \\
\hline $\mathrm{La}_{2} \mathrm{O}_{3}$ & 0.99 & 0.02 & 1.06 & & $\mathbf{X}$ & & \\
\hline $\mathrm{MgO}$ & 0.34 & 0.01 & 0.21 & & & & $\mathbf{X}$ \\
\hline MnO & 9.69 & 0.22 & 9.94 & & $\mathbf{X}$ & & \\
\hline $\mathrm{Na}_{2} \mathrm{O}$ & 1.60 & 0.03 & 1.96 & & & $\mathbf{X}$ & \\
\hline $\mathrm{NiO}$ & 1.74 & 0.03 & 1.76 & $\bar{X}$ & $\bar{X}$ & & \\
\hline $\mathrm{P}_{2} \mathrm{O}_{5}$ & 0.32 & 0.03 & 0.42 & & & & $\mathrm{X}$ \\
\hline $\mathrm{PbO}$ & $\overline{\mathrm{BDL}}$ & NA & 0.50 & & & & $\mathbf{X}$ \\
\hline $\mathrm{SO}_{3}$ & 1.55 & 0.06 & 0.82 & & & & $\mathbf{X}$ \\
\hline $\mathrm{Sb}_{2} \mathrm{O}_{5}$ & 0.53 & 0.01 & 0.69 & & & & $\mathbf{X}$ \\
\hline $\mathrm{SeO}_{2}$ & 0.42 & 0.01 & 0.49 & & & $\mathbf{X}$ & \\
\hline $\mathrm{SiO}_{2}$ & 0.92 & 0.25 & 0.07 & & & & $\mathrm{X}$ \\
\hline SrO & 7.43 & 0.08 & 7.60 & & $\mathbf{X}$ & & \\
\hline $\mathrm{TeO}_{2}$ & 0.46 & 0.01 & 0.47 & $\mathbf{X}$ & $\mathbf{X}$ & & \\
\hline $\mathrm{TiO}_{2}$ & 0.27 & 0.01 & 0.21 & & & & $\mathbf{X}$ \\
\hline $\mathrm{ZrO}_{2}$ & 12.81 & 0.47 & 11.68 & & $\mathbf{X}$ & & \\
\hline
\end{tabular}

Major, Target $>1 \mathrm{wt} \%$

RCRA, and Target $<1 \mathrm{wt} \%$

Minor, Non-RCRA, and $0.1<$ Target $<1 \mathrm{wt} \%$

The results of the anion analysis are given in Table 4-6. With the exception of $\mathrm{F}, \mathrm{Cl}, \mathrm{CO}_{3}$ $\mathrm{TOC}$, the anions are reasonably within specification (assuming a 15\% tolerance). The $\mathrm{F}$ is low; the $\mathrm{Cl}$ is elevated. Both species tend to reduce melt viscosity and can affect crystallinity. The sum concentration of $\mathrm{F}$ and $\mathrm{Cl}$ is close to the target value. The level of deviation should not affect glass processing. The total carbonate value is measured (as all anions) from the supernate of dilute, sonicated sludge. Hence, insoluble carbonate material cannot be measured by this technique. Another method of carbonate determination was performed with a TGA for the TR-26. The TGA result was very complex. Individual compounds with carbonate were obtained to attempt translation of the complex TGA analysis. These indicated that different carbonate species evolved 
gases at temperatures ranging from $300^{\circ} \mathrm{C}$ to $900^{\circ} \mathrm{C}$. Other salts also decompose in this region making TGA analysis unusable by itself. A TGA with a Fourier transform infrared reflection (FTIR) attachment would be necessary but is not available at present. A more dilute solution of sludge and water was prepared with extensive sonication. These numbers seem to give the best results for $\mathrm{CO}_{3}$ and TOC. The average of the three $\mathrm{CO}_{3}$ numbers for the individual drums is close to the expected value. The TOC results are very low. This may be due to $\mathrm{CO}_{2}$ from oxalate being evolved during the sonication. However, this is not expected to have an appreciable effect on the vitrification process. All anion results for the individual TR-26 drums are reported in Tables 4-10, 4-11, and 412.

\begin{tabular}{|c|c|c|c|c|c|}
\hline \multicolumn{5}{|c|}{ Table 4-6. Anion Analysis of AZ 101 Simulant, TR-23 } \\
\hline Anions & $\begin{array}{c}\text { Average } \\
(\mathbf{p p m})\end{array}$ & Std. Dev. & $\begin{array}{c}\text { Expected } \\
(\mathbf{p p m})\end{array}$ & Tolerance & \% Expected \\
\hline $\mathbf{F}$ & 161 & 10 & 226 & 30 & 71 \\
\hline $\mathbf{C l}$ & 148 & 4 & 48 & 7 & 308 \\
\hline $\mathbf{N O}_{\mathbf{2}}$ & 2115 & 183 & 1733 & 300 & 122 \\
\hline $\mathbf{N O}_{\mathbf{3}}$ & 4238 & 312 & 3517 & 500 & 121 \\
\hline $\mathbf{S O}_{\mathbf{4}}$ & 1933 & 100 & 1815 & 300 & 107 \\
\hline $\mathbf{C O}$ & 1145 & 193 & 5665 & 800 & $* *$ \\
\hline $\mathbf{T O C}$ & 847 & 401 & 2400 & 400 & $* *$ \\
\hline
\end{tabular}

For the anion analysis of TR-23, It was assumed, given the form of the chemicals added to prepare the simulant, that the carbonate was underestimated by the current analysis. The measured TOC value is considerably lower than the target. However, this is not expected to have an appreciable effect on the vitrification process.

As a result of the analyses performed, and given the project schedule limitations, it was concluded to accept the TR-23 batch, upon successful remediation of the simulant. Only the lead was remediated for the reasons given below. Although, the $\mathrm{SiO}_{2}$ content in TR23 was in excess of the targeted value $(0.07 \%)$, it was felt that since the $\mathrm{SiO}_{2}$ was an additive, and did not affect the M-1 waste loading, remediation was not necessary. A similar rationale may be applied to the sodium discrepancy. It was felt, however, that the absence of lead was a significant omission that could potentially affect the TCLP results, although it would most likely not affect the processing of the simulant. It was therefore decided to remediate the lead in the simulant through the addition of sufficient lead carbonate to achieve a nominal $0.5 \mathrm{wt} \% \mathrm{PbO}$ (normalized calcine oxide basis) level. The three 55 gallon drums, designated TR-26a, TR-26b and TR-26c, were each remediated for lead, and subsequently analyzed. The results of those analyses are presented in Tables 4-7, 4-8, and 4-9. As may be seen from these tables, the lead content was successfully remediated. 


\begin{tabular}{|c|c|c|c|c|c|c|}
\hline \multicolumn{7}{|c|}{ Table 4-7. Simulant Analysis of TR-26a Performed at DIAL } \\
\hline Oxide & $\begin{array}{l}\text { Target } \\
(w t \%)\end{array}$ & $\begin{array}{c}\text { Tolerance } \\
(\%)\end{array}$ & \begin{tabular}{|l} 
Tolerance \\
$( \pm$ wt .\%)
\end{tabular} & $\begin{array}{c}\text { DIAL } \\
\text { Analyzed } \\
(w t \%)\end{array}$ & $\begin{array}{l}\text { Standard } \\
\text { Deviation }\end{array}$ & $\begin{array}{c}\text { Within } \\
\text { Tolerance }\end{array}$ \\
\hline $\mathrm{Al}_{2} \mathrm{O}_{3}$ & 24.3 & 10.0 & 2 & 23.8 & 0.2 & $\mathbf{X}$ \\
\hline $\mathrm{As}_{2} \mathrm{O}_{3}$ & 0.13 & 15.0 & 0.02 & 0.13 & 0.03 & $\mathbf{X}$ \\
\hline $\mathrm{B}_{2} \mathrm{O}_{3}$ & & & & BDL & NA & \\
\hline $\mathrm{BaO}$ & 0.14 & 15 & 0.02 & 0.14 & 0.00 & $\mathbf{X}$ \\
\hline $\mathrm{CaO}$ & 0.81 & 15 & 0.1 & 1.14 & 0.01 & \\
\hline $\mathrm{CdO}$ & 1.22 & 15 & 0.2 & 1.23 & 0.01 & $\mathbf{X}$ \\
\hline $\mathrm{CeO}_{2}$ & 0.27 & 15 & 0.04 & 0.25 & 0.01 & $\mathrm{X}$ \\
\hline $\mathrm{Cr}_{2} \mathrm{O}_{3}$ & 0.14 & 15 & 0.02 & 0.09 & 0.01 & \\
\hline $\mathrm{Cs}_{2} \mathrm{O}$ & 0.27 & 15 & 0.04 & 0.28 & 0.02 & $\mathbf{X}$ \\
\hline $\mathrm{CuO}$ & 0.09 & 15 & 0.01 & 0.09 & 0.01 & $X$ \\
\hline $\mathrm{Fe}_{2} \mathrm{O}_{3}$ & 34.1 & 10 & 3 & 32.9 & 1.8 & $\mathbf{X}$ \\
\hline $\mathrm{K}_{2} \mathrm{O}$ & 0.55 & 15 & 0.1 & 0.56 & 0.01 & $\mathrm{X}$ \\
\hline $\mathrm{La}_{2} \mathrm{O}_{3}$ & 1.06 & 15 & 0.2 & 1.00 & $\begin{array}{l}0.02 \\
\end{array}$ & $\mathbf{X}$ \\
\hline $\mathrm{MgO}$ & 0.21 & 15 & 0.03 & 0.28 & 0.01 & \\
\hline MnO & 9.94 & 10 & 1 & 9.4 & 0.2 & $\mathbf{X}$ \\
\hline $\mathrm{Na}_{2} \mathrm{O}$ & 1.96 & 10 & 0.2 & 1.52 & $\begin{array}{l}0.03 \\
\end{array}$ & \\
\hline $\mathrm{NiO}$ & 1.76 & 10 & 0.2 & 1.95 & 0.03 & $\mathbf{X}$ \\
\hline $\mathrm{P}_{2} \mathrm{O}_{5}$ & 0.42 & 15 & 0.1 & 0.4 & 0.1 & $\mathbf{X}$ \\
\hline $\mathrm{PbO}$ & 0.50 & 15 & .08 & 0.54 & .09 & $\mathrm{X}$ \\
\hline $\mathrm{SO}_{3}$ & 0.82 & 15 & 0.1 & 1.6 & 0.2 & \\
\hline $\mathrm{Sb}_{2} \mathrm{O}_{5}$ & 0.69 & 15 & 0.1 & 0.5 & 0.1 & \\
\hline $\mathrm{SeO}_{2}$ & $\begin{array}{l}0.49 \\
\end{array}$ & 15 & 0.1 & 0.44 & 0.05 & $\mathbf{X}$ \\
\hline $\mathrm{SiO}_{2}$ & 0.07 & 10 & 0.01 & 0.94 & 0.09 & \\
\hline SrO & 7.60 & 10 & 0.8 & 7.54 & 0.01 & $\mathbf{X}$ \\
\hline $\mathrm{TeO}_{2}$ & 0.47 & 15 & 0.1 & 0.47 & 0.01 & $\mathrm{X}$ \\
\hline $\mathrm{TiO}_{2}$ & 0.21 & 15 & 0.03 & 0.28 & 0.01 & \\
\hline $\mathrm{ZrO}_{2}$ & 11.7 & 10 & 1 & 12.6 & 0.1 & $\mathbf{X}$ \\
\hline
\end{tabular}

Major, Target > 1 wt\%

RCRA, and Target $<1 \mathrm{wt} \%$

Minor, Non-RCRA, and $0.1<$ Target $<1 \mathrm{wt} \%$ 


\begin{tabular}{|c|c|c|c|c|c|c|}
\hline \multicolumn{7}{|c|}{ Table 4-8. Simulant Analysis of TR-26b Performed at DIAL } \\
\hline Oxide & $\begin{array}{l}\text { Target } \\
\text { (wt\%) }\end{array}$ & $\begin{array}{c}\text { Tolerance } \\
(\%)\end{array}$ & $\begin{array}{l}\text { Tolerance } \\
( \pm \text { wt .\%) }\end{array}$ & $\begin{array}{c}\text { DIAL } \\
\text { Analyzed } \\
(w t \%)\end{array}$ & $\begin{array}{l}\text { Standard } \\
\text { Deviation }\end{array}$ & $\begin{array}{c}\text { Within } \\
\text { Tolerance }\end{array}$ \\
\hline $\mathrm{Al}_{2} \mathrm{O}_{3}$ & 24.3 & 10.0 & 2 & 24.0 & 0.6 & $\mathbf{X}$ \\
\hline $\mathrm{As}_{2} \mathrm{O}_{3}$ & 0.13 & 15.0 & 0.02 & 0.14 & 0.02 & $\mathbf{X}$ \\
\hline $\mathrm{B}_{2} \mathrm{O}_{3}$ & & & & BDL & NA & \\
\hline $\mathrm{BaO}$ & 0.14 & 15 & 0.02 & 0.14 & 0.01 & $\mathbf{X}$ \\
\hline $\mathrm{CaO}$ & 0.81 & 15 & 0.1 & 1.11 & $\begin{array}{l}0.07 \\
\end{array}$ & \\
\hline $\mathrm{CdO}$ & 1.22 & 15 & 0.2 & 1.21 & 0.02 & $\mathbf{X}$ \\
\hline $\mathrm{CeO}_{2}$ & 0.27 & 15 & 0.04 & 0.25 & 0.01 & $\mathrm{X}$ \\
\hline $\mathrm{Cr}_{2} \mathrm{O}_{3}$ & 0.14 & 15 & 0.02 & 0.13 & 0.01 & $\mathrm{X}$ \\
\hline $\mathrm{Cs}_{2} \mathrm{O}$ & 0.27 & 15 & 0.04 & 0.29 & 0.02 & $\mathrm{X}$ \\
\hline $\mathrm{CuO}$ & 0.09 & 15 & 0.01 & 0.08 & 0.01 & $X$ \\
\hline $\mathrm{Fe}_{2} \mathrm{O}_{3}$ & 34.1 & 10 & 3 & 33.6 & 1.1 & $\mathbf{X}$ \\
\hline $\mathrm{K}_{2} \mathrm{O}$ & 0.55 & 15 & 0.1 & 0.62 & 0.05 & $\mathrm{X}$ \\
\hline $\mathrm{La}_{2} \mathrm{O}_{3}$ & 1.06 & 15 & 0.2 & 0.97 & 0.01 & $\mathbf{X}$ \\
\hline $\mathrm{MgO}$ & 0.21 & 15 & 0.03 & 0.29 & 0.03 & \\
\hline MnO & 9.94 & 10 & 1 & 9.2 & 0.1 & $\mathbf{X}$ \\
\hline $\mathrm{Na}_{2} \mathrm{O}$ & 1.96 & 10 & 0.2 & 1.75 & 0.03 & \\
\hline $\mathrm{NiO}$ & 1.76 & 10 & 0.2 & 1.69 & 0.02 & $\mathbf{X}$ \\
\hline $\mathrm{P}_{2} \mathrm{O}_{5}$ & 0.42 & 15 & 0.1 & $\begin{array}{l}0.35 \\
\end{array}$ & 0.05 & $\mathbf{X}$ \\
\hline $\mathrm{PbO}$ & 0.50 & 15 & .08 & 0.47 & .09 & $\mathrm{X}$ \\
\hline $\mathrm{SO}_{3}$ & 0.82 & 15 & 0.1 & 1.6 & 0.3 & \\
\hline $\mathrm{Sb}_{2} \mathrm{O}_{5}$ & 0.69 & 15 & 0.1 & 0.55 & 0.05 & \\
\hline $\mathrm{SeO}_{2}$ & 0.49 & 15 & 0.1 & 0.45 & 0.03 & $\mathbf{X}$ \\
\hline $\mathrm{SiO}_{2}$ & 0.07 & 10 & 0.01 & 0.2 & 0.1 & \\
\hline SrO & 7.60 & 10 & 0.8 & 7.5 & 0.2 & $\mathbf{X}$ \\
\hline $\mathrm{TeO}_{2}$ & 0.47 & 15 & 0.1 & 0.47 & 0.01 & $\mathrm{X}$ \\
\hline $\mathrm{TiO}_{2}$ & 0.21 & 15 & 0.03 & 0.28 & 0.01 & \\
\hline $\mathrm{ZrO}_{2}$ & 11.7 & 10 & 1 & 12.7 & 0.1 & $\mathbf{X}$ \\
\hline
\end{tabular}

Major, Target $>1$ wt \%

RCRA, and Target $<1 \mathrm{wt} \%$

Minor, Non-RCRA, and $0.1<$ Target $<1 \mathrm{wt} \%$ 


\begin{tabular}{|c|c|c|c|c|c|c|}
\hline \multicolumn{7}{|c|}{ Table 4-9. Simulant Analysis of TR-26c Performed at DIAL } \\
\hline Oxide & $\begin{array}{l}\text { Target } \\
\text { (wt\%) }\end{array}$ & $\begin{array}{c}\text { Tolerance } \\
(\%)\end{array}$ & $\begin{array}{l}\text { Tolerance } \\
( \pm \text { wt .\%) }\end{array}$ & $\begin{array}{c}\text { DIAL } \\
\text { Analyzed } \\
(w t \%)\end{array}$ & $\begin{array}{l}\text { Standard } \\
\text { Deviation }\end{array}$ & $\begin{array}{c}\text { Within } \\
\text { Tolerance }\end{array}$ \\
\hline $\mathrm{Al}_{2} \mathrm{O}_{3}$ & 24.3 & 10.0 & 2 & 23.4 & 0.2 & $\mathbf{X}$ \\
\hline $\mathrm{As}_{2} \mathrm{O}_{3}$ & 0.13 & 15.0 & 0.02 & 0.13 & 0.03 & $\mathbf{X}$ \\
\hline $\mathrm{B}_{2} \mathrm{O}_{3}$ & & & & $\overline{\mathrm{BDL}}$ & NA & \\
\hline $\mathrm{BaO}$ & 0.14 & 15 & 0.02 & 0.14 & 0.01 & $\mathbf{X}$ \\
\hline $\mathrm{CaO}$ & 0.81 & 15 & 0.1 & 1.12 & 0.04 & \\
\hline $\mathrm{CdO}$ & 1.22 & 15 & 0.2 & 1.26 & 0.08 & $\mathbf{X}$ \\
\hline $\mathrm{CeO}_{2}$ & 0.27 & 15 & 0.04 & 0.25 & 0.01 & $\mathrm{X}$ \\
\hline $\mathrm{Cr}_{2} \mathrm{O}_{3}$ & 0.14 & 15 & 0.02 & 0.10 & 0.01 & \\
\hline $\mathrm{Cs}_{2} \mathrm{O}$ & 0.27 & 15 & 0.04 & 0.27 & 0.02 & $\bar{X}$ \\
\hline $\mathrm{CuO}$ & 0.09 & 15 & 0.01 & 0.09 & 0.02 & $\mathrm{X}$ \\
\hline $\mathrm{Fe}_{2} \mathrm{O}_{3}$ & 34.1 & 10 & 3 & 32.5 & 1.4 & $\mathbf{X}$ \\
\hline $\mathrm{K}_{2} \mathrm{O}$ & 0.55 & 15 & 0.1 & 0.57 & 0.03 & $\mathrm{X}$ \\
\hline $\mathrm{La}_{2} \mathrm{O}_{3}$ & 1.06 & 15 & 0.2 & 0.97 & 0.01 & $\mathbf{X}$ \\
\hline $\mathrm{MgO}$ & 0.21 & 15 & 0.03 & 0.27 & 0.01 & \\
\hline MnO & 9.94 & 10 & 1 & 9.6 & 0.4 & $\mathbf{X}$ \\
\hline $\mathrm{Na}_{2} \mathrm{O}$ & 1.96 & 10 & 0.2 & 1.65 & 0.03 & \\
\hline $\mathrm{NiO}$ & 1.76 & 10 & 0.2 & 1.99 & 0.07 & \\
\hline $\mathrm{P}_{2} \mathrm{O}_{5}$ & 0.42 & 15 & 0.1 & 0.4 & 0.2 & $\bar{X}$ \\
\hline $\mathrm{PbO}$ & 0.50 & 15 & .08 & 0.51 & .09 & $\mathrm{X}$ \\
\hline $\mathrm{SO}_{3}$ & 0.82 & 15 & 0.1 & 1.6 & 0.1 & \\
\hline $\mathrm{Sb}_{2} \mathrm{O}_{5}$ & 0.69 & 15 & 0.1 & 0.6 & 0.1 & $\mathbf{X}$ \\
\hline $\mathrm{SeO}_{2}$ & 0.49 & 15 & 0.1 & 0.47 & 0.07 & $\mathbf{X}$ \\
\hline $\mathrm{SiO}_{2}$ & 0.07 & 10 & 0.01 & 0.94 & 0.03 & \\
\hline SrO & 7.60 & 10 & 0.8 & 7.35 & 0.08 & $\bar{X}$ \\
\hline $\mathrm{TeO}_{2}$ & 0.47 & 15 & 0.1 & 0.49 & 0.06 & $\mathbf{X}$ \\
\hline $\mathrm{TiO}_{2}$ & 0.21 & 15 & 0.03 & 0.28 & 0.02 & \\
\hline $\mathrm{ZrO}_{2}$ & 11.7 & 10 & 1 & 13.1 & 0.5 & \\
\hline
\end{tabular}

Major, Target > 1 wt \%

RCRA, and Target $<1 \mathrm{wt} \%$

Minor, Non-RCRA, and $0.1<$ Target $<1 \mathrm{wt} \%$ 
Anion analyses are provided in Tables 4-10, 4-11 and 4-12. TR-26 was accepted, and TTT testing commenced.

\begin{tabular}{|l|l|l|l|l|l|}
\hline \multicolumn{7}{|c|}{ Table 4-10. Average Anion Analysis of TR-26a } \\
\hline Anions & $\begin{array}{l}\text { Average } \\
(\mathbf{p p m})\end{array}$ & Std. Dev. & $\begin{array}{l}\text { Expected } \\
(\mathbf{p p m})\end{array}$ & Tolerance & \% Expected \\
\hline $\mathrm{F}$ & 100 & 6 & 226 & 30 & 44 \\
\hline $\mathrm{Cl}$ & 131 & 1 & 48 & 7 & 273 \\
\hline $\mathrm{NO}_{2}$ & N.A. & N.A. & 1733 & 300 & N.A. \\
\hline $\mathrm{NO}_{3}$ & 3571 & 194 & 3517 & 500 & 102 \\
\hline $\mathrm{SO}_{4}$ & 1940 & 95 & 1815 & 300 & 107 \\
\hline $\mathrm{CO}_{3}$ & 6321 & 196 & 5665 & 800 & 116 \\
\hline $\mathrm{TOC}$ & 692 & 5.8 & 2400 & 400 & 29 \\
\hline
\end{tabular}

\begin{tabular}{|l|l|l|l|l|l|}
\hline \multicolumn{7}{|c|}{ Table 4-11. Average Anion Analysis of TR-26b } \\
\hline Anions & $\begin{array}{l}\text { Average } \\
(\mathbf{p p m})\end{array}$ & Std. Dev. & $\begin{array}{l}\text { Expected } \\
(\mathbf{p p m})\end{array}$ & Tolerance & \% Expected \\
\hline $\mathrm{F}$ & 125 & 3 & 226 & 30 & 55 \\
\hline $\mathrm{Cl}$ & 126 & 3 & 48 & 7 & 263 \\
\hline $\mathrm{NO}_{2}$ & 1721 & 24 & 1733 & 300 & 99 \\
\hline $\mathrm{NO}_{3}$ & 3758 & 167 & 3517 & 500 & 107 \\
\hline $\mathrm{SO}_{4}$ & 1878 & 64 & 1815 & 300 & 103 \\
\hline $\mathrm{CO}_{3}$ & 4180 & 193 & 5665 & 800 & 74 \\
\hline $\mathrm{TOC}$ & 1674 & 9 & 2400 & 400 & 70 \\
\hline
\end{tabular}

\begin{tabular}{|l|l|l|l|l|l|}
\hline \multicolumn{7}{|c|}{ Table 4-12. Average Anion Analysis of TR-26c } \\
\hline Anions & $\begin{array}{l}\text { Average } \\
(\mathbf{p p m})\end{array}$ & Std. Dev. & $\begin{array}{l}\text { Expected } \\
(\mathbf{p p m})\end{array}$ & Tolerance & \% Expected \\
\hline $\mathrm{F}$ & 106 & 1 & 226 & 30 & 47 \\
\hline $\mathrm{Cl}$ & 145 & 4 & 48 & 7 & 302 \\
\hline $\mathrm{NO}_{2}$ & 542 & 20 & 1733 & 300 & 31 \\
\hline $\mathrm{NO}_{3}$ & 3682 & 243 & 3517 & 500 & 105 \\
\hline $\mathrm{SO}_{4}$ & 1954 & 45 & 1815 & 300 & 108 \\
\hline $\mathrm{CO}_{3}$ & 7230 & 39 & 5665 & 800 & 128 \\
\hline $\mathrm{TOC}$ & 106 & 1 & 226 & 30 & 47 \\
\hline
\end{tabular}

TR-26a and TR-26b were used for crucible testing. TR-26c was used for the bench scale runs. As may be seen from Tables 4-4 through 4-12, the measured compositional differences between the drums were negligible. None of the drums was drawn past the $30 \%$ fill level in order to prevent any segregation effects. 


\subsection{Laboratory-Scale Tests}

Lab- scale tests were performed to identify the appropriate experimental protocols and product and process parameters, for the bench scale tests and TTT experiments. Labscale testing included small and large-scale melt tests and feed form experiments.

\section{Thermogravimetric Analysis of Simulant}

TGA/DTA was performed on simulant TR-26a and on a corresponding 60 -wt $\%$ glass batch sample. The corresponding graph is shown in Figure 4-1. The simulant had been dried at $300^{\circ} \mathrm{C}$. The procedure was performed on dried material because the evolution of water that would occur when testing a slurry would overwhelm the system and mask other effects. The samples were kept in a polyethylene container for 24 hours prior to the TGA run. The container was sealed - but not air-evacuated. This was done to determine the amount of water uptake to be expected during AVS batch processing and melting.

Test Highlights and General Observations

The TGA evaluations on the simulant and batch show relatively good agreement with the ICP-ES analyses on the simulant and batch materials. The data indicate the simulant is slightly hydroscopic (water loss was observed below $300^{\circ} \mathrm{C}$ ) and picks up a small amount appreciable amount of water from the atmosphere, post drying. As this simulant is "washed", i.e. the sodium content is quite low compared with tank sludge, it was anticipated that the material would not be extremely hydroscopic. The TGA of the batch was coupled with a DTA analysis (of the cooling profile) to determine the glass transition temperature, $\mathrm{T}_{\mathrm{g}}$, of the vitrified batch. This was performed to provide an evaluation of the $\mathrm{T}_{\mathrm{g}}$ on a glass sample with a known thermal history.

\section{Test Data}

The sludge and batch samples were analyzed using a simultaneous TGA/DTA. The ramp rates and dwell temperatures for the simulant samples were constant as shown in Table 413. The batch samples were given a straight ramp rate of $10^{\circ} \mathrm{C}$ per minute to $1500^{\circ} \mathrm{C}$, no dwell, and a straight ramp rate $\left(-10^{\circ} \mathrm{C}\right.$ per minute) to room temperature. Instrument readings were performed five times every second.

\begin{tabular}{|c|c|c|c|}
\hline \multicolumn{4}{|c|}{ Table 4-13. Temperature Program of TGA/DTA Runs } \\
\hline $\begin{array}{c}\text { Beginning } \\
\text { Temperature }\left({ }^{\mathbf{}}{ }^{\circ} \mathbf{C}\right)\end{array}$ & $\begin{array}{l}\text { Ending Temperature } \\
\left({ }^{\circ} \mathrm{C}\right)\end{array}$ & $\begin{array}{l}\text { Ramp Rate } \\
\left({ }^{\circ} \mathbf{C} / \text { minute }\right)\end{array}$ & $\begin{array}{c}\text { Dwell Time } \\
\text { (minutes) }\end{array}$ \\
\hline 30 & 250 & 30 & 5 \\
\hline 250 & 400 & 30 & 3 \\
\hline 400 & 500 & 30 & 3 \\
\hline 500 & 600 & 30 & 3 \\
\hline 600 & 800 & 30 & 3 \\
\hline 800 & 900 & 30 & 3 \\
\hline 900 & 1100 & 30 & 0 \\
\hline 1100 & 1400 & 30 & 0 \\
\hline 1400 & 300 & 30 & 3 \\
\hline
\end{tabular}

The following graphs were generated during these experiments for both the simulant and the glass batch. 

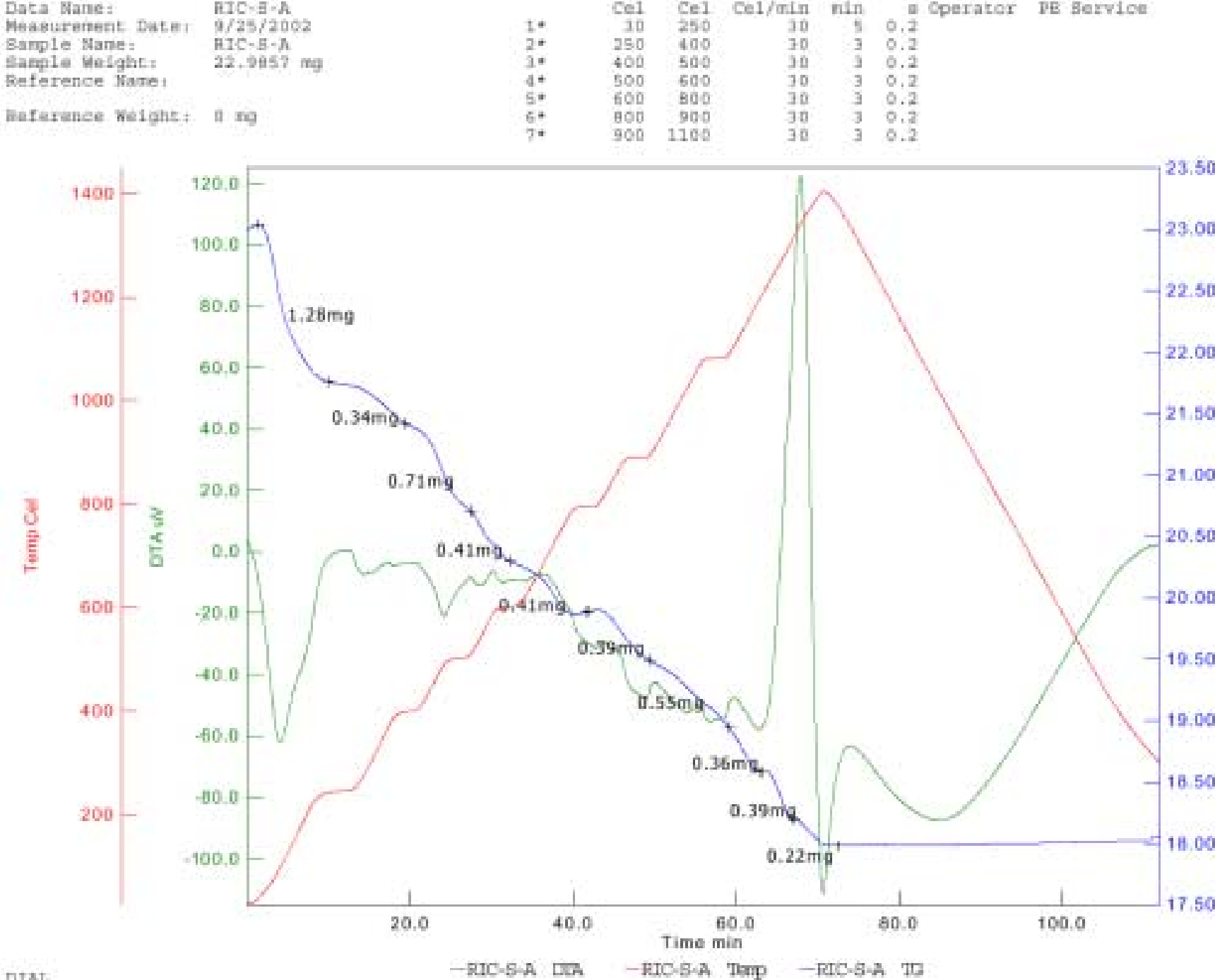

Figure 4-1. TGA/DTA graph of TR-26a simulant material. 

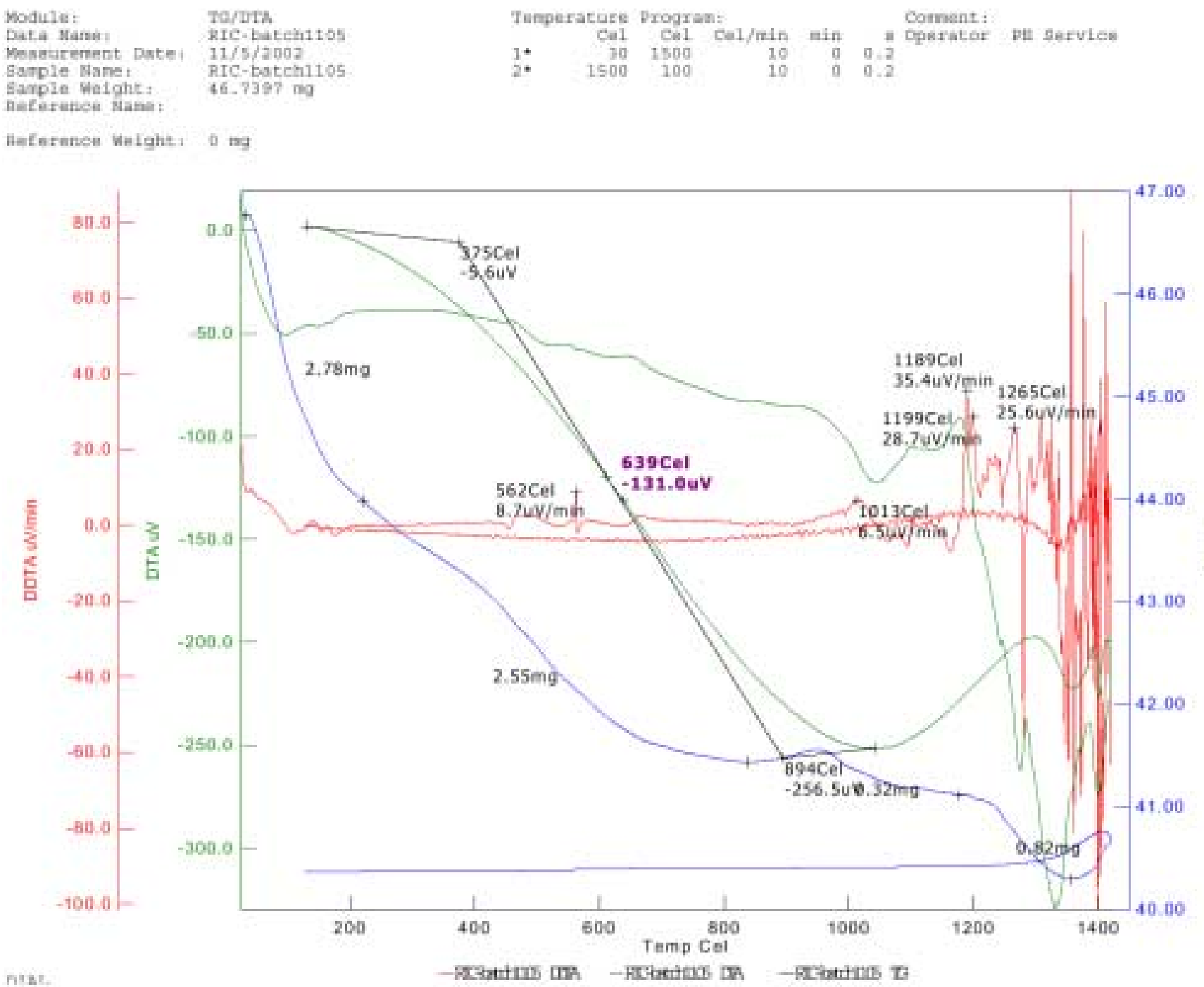

Figure 4-2. TGA/DTA Graph of LM-60 Glass Batch Material 


\section{Discussion and Results}

\section{Simulant}

The initial mass of the simulant sample was measured to be $22.99 \mathrm{mg}$. Total mass loss was calculated to be $5.06 \mathrm{mg}$, or $22 \%$. However, $1.28 \mathrm{mg}$ of that was lost during the first ramp and dwell at $250^{\circ} \mathrm{C}$. This was most likely due to absorption of water vapor from the air during sample archiving. Taking this into account, that is, using a beginning mass of $21.71 \mathrm{mg}$ with a sample loss (after $250^{\circ} \mathrm{C}$ ) of $3.78 \mathrm{mg}$, the percent loss is $17.4 \%$. This matches very closely with oxide weight percent calculated from ICPES analyses (nominally 16 percent weight loss). Table 4-14 shows the actual mass loss for each individual heating step. During the last heating step $\left(1100\right.$ to $\left.1400^{\circ} \mathrm{C}\right)$, there were three appreciable regions of mass loss. These three regions correspond to weight losses of $0.36,0.39$ and $0.22 \mathrm{mg}$, respectively. The total mass is effectively constant above 1380 $1400^{\circ} \mathrm{C}$. This data was later shown to be consistent with the batch foaming observed in all sample melts. Considerable foaming was observed between 1200 and $1350^{\circ} \mathrm{C}$, negligible foaming during the remainder of the vitrification cycle.

\begin{tabular}{|c|c|c|}
\hline \multicolumn{3}{|c|}{ Table 4-14. Mass Loss for TR-26a for Each Individual TGA/DTA Heating Step } \\
\hline Ending Temperature $\left({ }^{\mathbf{0}} \mathbf{C}\right)$ & Weight Loss $(\mathbf{m g})$ & Percent Loss $(\boldsymbol{\%})$ \\
\hline 250 & 1.28 & --- \\
\hline 400 & 0.34 & 1.57 \\
\hline 500 & 0.71 & 3.27 \\
\hline 600 & 0.41 & 1.89 \\
\hline 800 & 0.41 & 1.89 \\
\hline 900 & 0.39 & 1.80 \\
\hline 1100 & 0.55 & 2.53 \\
\hline 1400 & 0.97 & 4.47 \\
\hline
\end{tabular}

\section{LM-60 Glass Batch}

The beginning mass of the sample was measured to be $46.74 \mathrm{mg}$. Total mass loss was calculated to be $6.47 \mathrm{mg}$ or 13.84 percent. A mass loss of $2.78 \mathrm{mg}$ is noted during the ramp to $200^{\circ} \mathrm{C}$. An additional $2.55 \mathrm{mg}$ is lost during the ramp to $820^{\circ} \mathrm{C}$, predominately from the initial off gassing of nitrates, sulfates, carbonates and organics. An additional $0.32 \mathrm{mg}$ is lost during between $820^{\circ} \mathrm{C}$ and $1190^{\circ} \mathrm{C}$ and $0.82 \mathrm{mg}$ lost during the remainder of the heating profile. The total mass loss of 13.8 percent is consistent with the 15.5 percent loss calculated from the ICPES composition analyses. The batch chemical boric acid is slightly hygroscopic; therefore, the initial mass loss cannot be conclusively subscribed to water vapor uptake by the simulant. As per the sludge sample, the small mass loss until the $1350^{\circ} \mathrm{C}$ region is indicative of the slight foaming observed during AVS glass vitrification.

The total mass loss of 13.8 percent is consistent with the 15.5 percent loss calculated from the ICPES composition analyses. It should be noted the batch chemical boric acid is also slightly hydroscopic, therefore the initial mass loss cannot be conclusively or completely subscribed to water vapor uptake by the simulant, as was the case for the sludge sample. Figure 4-2 shows the TGA/DTA graph of LM-60 glass batch material. The liquidus temperature, determined from this curve is approximately $1350^{\circ} \mathrm{C}$. 
This batch sample was run at a fixed ramp rate $\left(10^{\circ} \mathrm{C}\right.$ per minute $)$ to allow glass transition temperature measurements to be taken with the same thermal profile as the AVS bench scale and laboratory scale samples were subject to. This analysis was performed during the sample cooling curve after vitrification during the heat-up.

\begin{tabular}{|l|l|l|}
\hline \multicolumn{2}{|c|}{$\begin{array}{c}\text { Table 4-15. } \\
\text { Mass Loss for LM-60 Glass Batch } \\
\text { for each Individual TGA/DTA Heating Step }\end{array}$} \\
\hline Temperature $\left({ }^{\mathbf{C}} \mathbf{C}\right)$ & Mass Loss $(\mathbf{m g})$ & Percent Loss $(\%)$ \\
\hline Room T to 200 & 2.78 & 5.95 \\
\hline $200-820$ & 2.55 & 5.46 \\
\hline $820-1190$ & 0.32 & 0.68 \\
\hline $1190-1500$ & 0.82 & 1.75 \\
\hline
\end{tabular}

\section{Glass Transition Temperature Analysis}

The glass transition temperature analysis performed on the vitrified batch during the cooling profile yields a value of $640^{\circ} \mathrm{C}$ (analysis by first derivative of the DTA curve, DDTA). The accuracy of this measurement is on the order of $\pm 5^{\circ} \mathrm{C}$. This value is only slightly lower than observed for the cast/annealed LM 60 glass pieces and the benchscale AVS samples (ranging between $646-670^{\circ} \mathrm{C}$ ). This was performed to provide a reference value on a sample with a well-defined thermal history. The glass liquidus appears to be on the order of $1380^{\circ} \mathrm{C}$. This is consistent with the XRD analyses which showed small amounts of crystallization melt samples heat treated at $1340^{\circ} \mathrm{C}$ and lower.

\section{Cs-Retention Tests}

Small-scale tests were performed in order to determine the loss of cesium, through volatilization, from the AZ-101 waste form.

Test Highlights and General Observations

For each test, 75 grams $( \pm 0.01 \mathrm{~g})$ of 60 percent waste loading batch material was placed in a $250 \mathrm{ml}$, high-form alumina crucible. The batch was subsequently heated to $1450^{\circ} \mathrm{C}$ using a $C M 1700^{\circ} \mathrm{C}$ tube furnace and held at temperature for three hours.

During the first test, the off-gas from the furnace was directed through a 3" Kaowool ${ }^{\mathrm{TM}}$ filter (packed mass) using a vacuum pump. Make-up air was added to the off-gas stream through two $1 / 8$ " diameter screw holes. The flow then passed through a condensing unit and was finally routed to the DIAL off-gas system. The condensate from the condensing unit was collected, measured, and analyzed to determine the concentration of cesium. The off-gas tubing and Kaowool ${ }^{\mathrm{TM}}$ filter were each rinsed using a known quantity $(200 \pm 0.1 \mathrm{ml})$ of dilute hydrochloric acid. The rinseate was collected and analyzed to determine the cesium concentration.

During the second test, the furnace off-gas was vented through the Kaowool ${ }^{\mathrm{TM}}$ filter using the convective heat currents. A known volume of dilute solution of hydrochloric acid $(200 \pm 0.1 \mathrm{ml})$ was used to rinse the filter media. The rinseate was analyzed to determine the amount of cesium collected on the filter. 


\section{Test Data}

The $\mathrm{Cs}$ retention study rinseate samples were analyzed for $\mathrm{B}, \mathrm{Fe}, \mathrm{Na}, \mathrm{Ni}, \mathrm{Sr}$, and $\mathrm{Cs}$. The analytical results are provided in Table 4-16 below. The sample designations are as follows:

\begin{tabular}{|l|l|}
\hline R2A Pipe Rinse: & $\begin{array}{l}\text { Rinsate from the tube furnace off-gas pipe, filter, and steel cap } \\
\text { for Test } 1\end{array}$ \\
\hline R2B Cond Rinse: & Rinsate from the condenser for Test 1 \\
\hline R2C Cond Water: & Water from the condenser tube for Test 1 \\
\hline R1 Filter Rinse: & Rinsate from the Test 2 filter \\
\hline
\end{tabular}

\begin{tabular}{|c|c|c|c|c|}
\hline \multicolumn{5}{|c|}{ Table 4-16. Cs Retention Study Analytical Results } \\
\hline Analyte & $\begin{array}{c}\text { R2A Pipe } \\
\text { Rinse }\end{array}$ & $\begin{array}{l}\text { R2B Cond } \\
\text { Rinse }\end{array}$ & $\begin{array}{c}\text { R2C Cond } \\
\text { Water }\end{array}$ & $\begin{array}{c}\text { R1 Filter } \\
\text { Rinse }\end{array}$ \\
\hline $\mathrm{B}$ & 27.50 & 0.47 & 0.11 & 18.10 \\
\hline $\mathrm{Fe}$ & 63.40 & 5.46 & 0.35 & 94.40 \\
\hline $\mathrm{Na}$ & 26.10 & 0.32 & 0.14 & 22.90 \\
\hline $\mathrm{Ni}$ & 0.97 & 0.73 & 0.06 & 0.22 \\
\hline $\mathrm{Sr}$ & 0.51 & 1.76 & 0.38 & 0.41 \\
\hline $\mathrm{Cs}$ & 7.50 & bdl & bdl & 8.61 \\
\hline
\end{tabular}

Cs Retention Discussion and Results

Rinseate analyses were performed on the six species selected to allow qualitative and quantitative comparisons. It is noted that the Cs content is considerably higher than all other species in the filter rinseate relative to the batch compositions. This is true for species which are common impurities in the aluminosilica fiber (Fe and $\mathrm{Na}$ ), semivolatile species in the batch (B and $\mathrm{Na}$ ), and nickel and strontium, which are not common impurities in the fiber or highly volatile. Iron, for instance, is approximately 100 times more prevalent the batch than Cs, but approximately $10 \mathrm{X} \mathrm{Cs}$ in the filter rinseates. The ratio of $\mathrm{Sr}$ to $\mathrm{Cs}$ in the batch is 23 versus 0.6 in the filter rinseates. The Cs present in the rinseates, then, appears to have been volatized from the melt.

Using the 0.8616 batch to glass conversion factor from the TGA data, the 75 grams of batch equate to $64.6 \mathrm{~g}$ glass. The $\mathrm{Cs}_{2} \mathrm{O}$ content in the batch was determined to be 0.18 $\mathrm{wt} \%$ (oxide basis). This equates to a total elemental Cs content of $0.110 \mathrm{~g}$.

Cesium was detected in both rinses of the filer media. Cesium was BDL in rinses of the off-gas piping and in the off-gas condensate tank. It appears, then, that all of the Cs escaping the tube furnace was captured in the filter media. Subsequent rinses of the filtrate and the alumina furnace tube indicate the Cs content to be below 100ppb. Using the available data, the concentrations of Cs in the $200 \mathrm{ml}$ volumes of filter rinseate equate to $1.50 \mathrm{mg}$ (Run 1) and $1.72 \mathrm{mg}$ (Run 2) Cs. With no other loss data available, the total recovered (volatilized) Cs equates to approximately 1.36\% (Run 1) and $1.55 \%$ (Run 2), respectively. These loss values are considerably lower than the calculated value for glass (approximately 10\% for LM 60) and is likely due to the experimental set-up. A more accurate method using radioisotopes Cs-137 or Cs-134 were recommended, but not 
performed due to project expense. Still, all project data (glass analysis and Cs retention studies) indicate the high-temperature glasses utilized retain the dominant fraction of the batch Cs.

\section{Small Crucible Tests}

The objective of the small-scale crucible tests was to conduct scoping experiments to define the target composition and feed additives for the bench-scale vitrification of AZ101 simulant. These scoping tests were also meant to begin waste loading optimization, and to evaluate cooling as a function of crystallinity. The acceptance criteria for the bench-scale process (primarily TCLP, PCT and, to a lesser extent degree of crystallinity) defined the selection process along with the goal of maximizing the waste loading. The data generated by these experiments, was used to choose a target formulation for further laboratory-scale tests as defined in this section.

\section{Test Highlights and General Observations}

Thirteen small-scale melts were completed using a consistent heat-up and batch addition profile. These melts were allowed to air cool in the crucible after melting. An additional five small melts were performed with a prescribed cooling profile. These additional small melts were performed in order to determine how cooling rate affects the performance of the glassy product with regard to the Toxicity Characteristic Leaching Procedure (TCLP).

Glass science, and past experience regarding high-level waste glass compositions was used to guide initial melt experiments. However, as the AVS process operates at higher temperatures than other HLW melters, more flexibility with regard to processing was possible. Initial experiments were conducted using a recipe that included dried AZ-101 simulant, Frit 200, silica, boric acid and sodium carbonate. Various permutations of these ingredients were unable to achieve the desired physical properties and levels of waste loading. The formulations were adjusted. Dried AZ-101 simulant with additions of silica, boric acid and zinc oxide were found to produce a chemically durable, highly waste loaded AZ-101 waste glass product. Chemical composition analysis, PCT and TCLP testing were used as measures of acceptability. Cd-release per the TCLP was found to be the waste loading limiter. Cd-release was greater for the heat-treated samples.

\section{Test Data}

Glass formulation experiments were conducted to establish the best choice of batch additive(s) to achieve a chemically durable, highly waste loaded, AVS-processable glass composition. RIC was directed, per the SOW, that the glass composition be a borosilicate glass. Borosilicate glass is any glass having at least $5 \%$ boron oxide by weight. However, high-level waste glasses can contain small quantities of crystalline phases, per the SOW. Tank AZ-101 is high in Fe, Al, Sr, Mn and Zr. This surrogate material represents washed high-level waste and is correspondingly low in sodium. As a result, the material contains very little flux to reduce melting temperature. High waste loaded borosilicate glasses are relatively refractory. For this study, an upper temperature limit of $1450^{\circ} \mathrm{C}$ was used. 
Appropriate glass formulations were investigated using TR-26. The simulant material was dried and glass compositions representing 45, 50, 55, 60 and $65-\mathrm{wt} \%$ waste loading [M-1] were prepared. The glass trim chemicals used included: silica, SRS frit 200, sodium carbonate, and boric acid. Duplicate samples were prepared. The batch was placed in alumina crucibles and each pair of samples was melted simultaneously in a resistance furnace for at least 2.5 hours. One sample was removed from the oven and the crucible placed onto a room temperature steel plate. The other sample remained in the furnace, which was slowly cooled in a controlled manner $\left(1^{\circ} \mathrm{C}\right.$ per minute) to $600^{\circ} \mathrm{C}$ and held for 24 hours. The quenched samples yielded amorphous material. All heat-treated glass showed apparent crystallization (subsequently determined to be transition metal spinel).

The PCT and TCLP methods were performed on the quenched and heat-treated samples. As expected, the PCT results were significantly (20X or more below the SRS Environmental Assessment glass values) below the maximum allowable values. It was determined that the Cd release per the TCLP appeared to be the limiting factor, i.e. closest to minimum acceptable levels. All other RCRA species were significantly below UTS regulatory levels. However, at about 50 - 55-wt \%, the Cd (and other RCRA species) release increased. It was also noted that for each waste loading tested, the heattreated sample had a higher Cd release than that of the quenched sample.

The glasses were re-formulated using the same waste-loading percentages, but different batch additives, i.e. silica, boric acid and zinc oxide. These formulations also yielded amorphous material. These glasses where more chemically durable as measured by the Product Consistency Test and the TCLP. However, cadmium content remains the wasteloading limiter for AZ-101 glass.

Small-scale melts were performed with target waste loadings ranging from 45 to 70 percent following the heating profile described above. In addition, the small-scale melts were repeated using the same heating profile; however, the duplicate melts were given a prescribed cooling profile. This profile included a $1^{\circ} \mathrm{C}$ per minute ramp from $1450^{\circ} \mathrm{C}$ to $600^{\circ} \mathrm{C}$ with a 24 hour dwell at $600^{\circ} \mathrm{C}$ followed by a rapid cool down (in the crucible) to room temperature on a steel plate. The TCLP was performed on small-scale and smallscale duplicate samples with target waste loadings of 45, 50, 55, 60, and 65 percent and the results of this testing are shown in Table 4-17 and 4-18.

\begin{tabular}{|c|c|c|c|c|c|c|c|c|}
\hline \multicolumn{7}{|c|}{ Table 4-17. Small-scale TCLP Results } \\
\hline \multirow{2}{*}{$\begin{array}{c}\text { Waste } \\
\text { Loading }\end{array}$} & $\mathbf{9}$ Element Concentration in TCLP Extract (ppm) \\
\hline $\mathbf{4 5}$ & 0.0000 & 0.3120 & $\mathbf{0 . 0 2 9 7}$ & 0.0008 & 0.0312 & 0.0105 & 0.0000 & 0.1380 \\
\hline $\mathbf{5 0}$ & 0.0000 & 0.0222 & $\mathbf{0 . 0 3 0 8}$ & 0.0014 & 0.0253 & 0.0083 & 0.0000 & 0.1201 \\
\hline $\mathbf{5 5}$ & 0.0000 & 0.0595 & $\mathbf{0 . 0 2 8 3}$ & 0.0005 & 0.0195 & 0.0068 & 0.0000 & 0.1120 \\
\hline $\mathbf{6 0}$ & 0.0000 & 0.0136 & $\mathbf{0 . 0 3 7 3}$ & 0.0002 & 0.0214 & 0.0087 & 0.0000 & 0.1001 \\
\hline $\mathbf{6 5}$ & 0.0000 & 0.0534 & $\mathbf{0 . 0 4 5 3}$ & 0.0007 & 0.0232 & 0.0118 & 0.0013 & 0.1323 \\
\hline $\begin{array}{c}\text { UTS } \\
\text { Limit }\end{array}$ & $\mathbf{5 . 0}$ & $\mathbf{2 1 . 0}$ & $\mathbf{0 . 1 1}$ & $\mathbf{0 . 6 0}$ & $\mathbf{1 1 . 0}$ & $\mathbf{0 . 7 5}$ & $\mathbf{5 . 7}$ & $\mathbf{4 . 3}$ \\
\hline
\end{tabular}




\begin{tabular}{|c|c|c|c|c|c|c|c|c|}
\hline \multicolumn{7}{|c|}{ Table 4-18. Small-scale TCLP Results - Cooling Profile } \\
\hline \multirow{2}{*}{$\begin{array}{c}\text { Waste } \\
\text { Loading }\end{array}$} & \multicolumn{7}{|c|}{ Element Concentration in TCLP Extract (ppm) } \\
\cline { 2 - 9 } & As & $\mathbf{B a}$ & $\mathbf{C d}$ & $\mathbf{C r}$ & $\mathbf{N i}$ & $\mathbf{P b}$ & $\mathbf{S e}$ & Zn \\
\hline 45 & 0.0027 & 0.0000 & $\mathbf{0 . 0 5 2 7}$ & 0.0016 & 0.0245 & 0.0128 & 0.0000 & 0.1322 \\
\hline $\mathbf{5 0}$ & 0.0044 & 0.0000 & $\mathbf{0 . 0 4 7 7}$ & 0.0055 & 0.0143 & 0.0055 & 0.0034 & 0.0786 \\
\hline $\mathbf{5 5}$ & 0.0000 & 0.0369 & $\mathbf{0 . 0 5 7 0}$ & 0.0000 & 0.0182 & 0.0125 & 0.0000 & 0.0852 \\
\hline $\mathbf{6 0}$ & 0.0012 & 0.0248 & $\mathbf{0 . 0 7 3 1}$ & 0.0004 & 0.0158 & 0.0177 & 0.0000 & 0.0736 \\
\hline $\mathbf{6 5}$ & 0.0026 & 0.0509 & $\mathbf{0 . 0 9 9 9}$ & 0.0003 & 0.0201 & 0.0234 & 0.0000 & 0.1047 \\
\hline $\begin{array}{c}\text { UTS } \\
\text { Limit }\end{array}$ & $\mathbf{5 . 0}$ & $\mathbf{2 1 . 0}$ & $\mathbf{0 . 1 1}$ & $\mathbf{0 . 6 0}$ & $\mathbf{1 1 . 0}$ & $\mathbf{0 . 7 5}$ & $\mathbf{5 . 7}$ & $\mathbf{4 . 3}$ \\
\hline
\end{tabular}

It should be noted that the small scale crucible melts did not undergo PCT testing. These experiments were scoping in nature, and the TCLP was deemed to be the more restrictive test with regard to design of the glass formulation.

Discussion and Results

Based on the small-scale crucible tests, the AVS reference glass formulation range was narrowed by identifying:

- the optimal trim chemical additives, i.e. silica, boric acid and zinc oxide and

- the composition limiter, TCLP - Cd response.

TCLP data for Cd are illustrated in Figure 4-3. Based on the results for the small-scale melts, large-scale melts were performed at target waste loadings of 54, 57, 60, 63, and 66 percent.

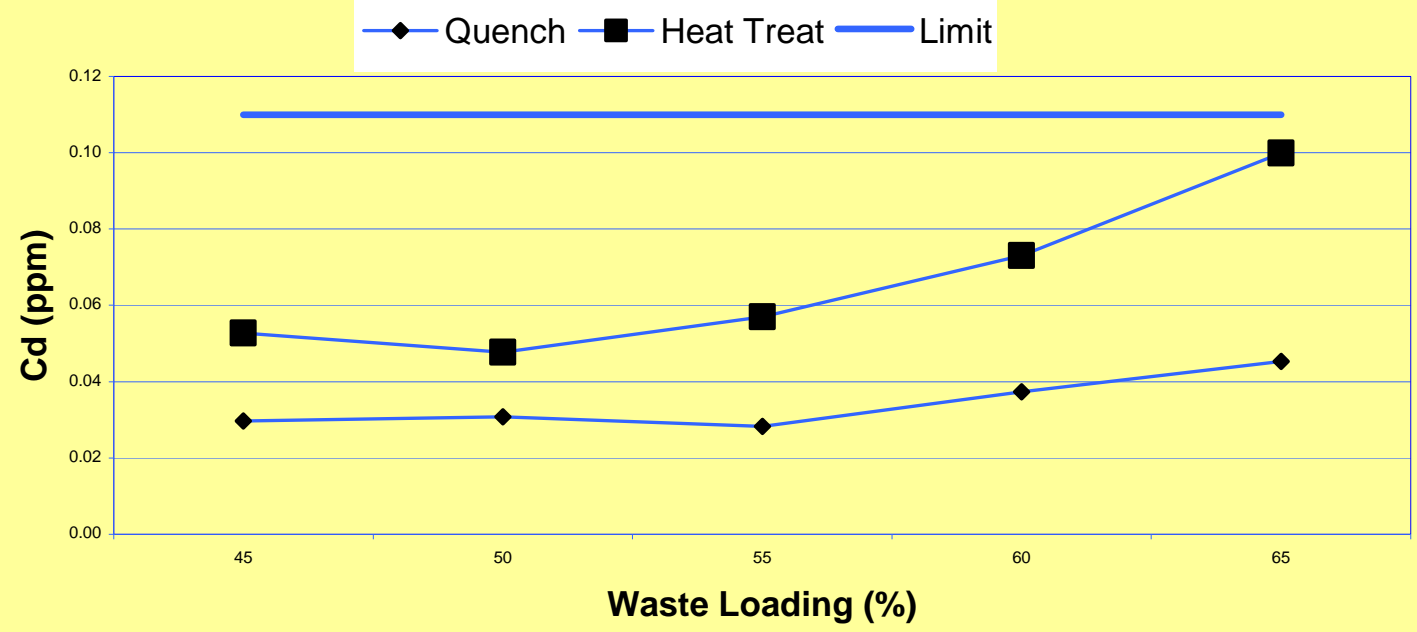

Figure 4-3. TCLP Cd -vs- Waste Loading

\section{Large-Scale-Crucible Scoping Melts}

Based upon the results of small crucible tests, the properties (TCLP, PCT, and 
crystallinity) of vitrified AZ-101 waste glasses were determined at target waste loadings of 54, 57, 60, 63, and 66 percent. The glass transition temperature, $\mathrm{T}_{\mathrm{g}}$, was also determined using dilatometry for the $60-\mathrm{wt} \%$ Large Melt (LM) composition selected for AVS testing and the TTT diagram. $\mathrm{T}_{\mathrm{g}}$ was also determined for the LM 60 composition by Simultaneous Thermal Analysis (STA). These data are provided in the following sections.

\section{Test Highlights and General Observations}

The five large-scale melts were completed using a consistent heat-up and batch addition profile. These melts were allowed to air cool in the crucible after melting. All melts were performed in alumina crucibles as described in Section 3.

The additives $\mathrm{ZnO}$, silica, and boric acid were used for all melts. Zinc oxide was held at 2 percent (oxide weight percent in glass); boric oxide was held at a target of 6 percent. The variation in waste loading was accommodated solely by increase/decrease of silica. All melts were held for three hours at $1450^{\circ} \mathrm{C}$ after the final batch addition. The fluidity of the melts appeared to increase strongly with increased waste loading.

The cooled crucibles were broken and the crucible/glass interface examined -both at the melt cut line and the crucible bottom. No visible corrosion was evident at the cut line of any crucible. Likewise, no visible unmelted material was evident at the bottom of any crucible. Chemical composition analysis indicates the target waste loadings were achieved for all samples. The PCT response was effectively constant as a function of waste loading - there was no change in relative durability from 54-66 percent waste loading. The TCLP response, especially for $\mathrm{Cd}$, was a strong function of waste loading. $\mathrm{Cd}$ release increased as was loading increased - such that the 66 percent target waste glass had a Cd release in excess of the UTS limit.

Crystallinity analysis by XRD identified low concentrations of transition metal spinel phase (most closely compatible with $\mathrm{Fe}_{3} \mathrm{O}_{4}$ ). SEM photomicrographs indicate the presence of large numbers of very small crystalline shapes (well under 1 micron across). These shapes appear to coalesce into primitive spinel crystals as the waste loading increases - i.e. there is a much stronger crystalline character as the loading increases. SEM-EDS analyses were inconclusive for all samples save the 66 percent waste glass. The photomicrographs and EDS spectra for this sample identify two types of crystals, a transition metal-rich spinel phase and a high-zirconia phase. The zirconia rich crystals are needle shape in appearance and were measured to be on the order of 7 microns by 440 nanometers.

\section{Test Data}

Table 4-19 provide the as-analyzed compositions of the Large Melt (LM) series of glasses. The last two digits in the composition designation indicate the target waste loading weight percentage.

The glass composition is reported as the oxide assemblage of the system. The waste loading can be determined directly from the glass composition by at least two methods. 
This study used the more conservative method 1 [M-1] which subtracts all batch additive, soda and silica content from the total glass composition. For this project, the waste loading is considered all sludge oxides except soda and silica. The waste loading was calculated for all large-scale melts by first adding all silica, soda, zinc oxide, and boron oxide. The sum of the normalized concentration of these components was then subtracted from 100 to determine the waste loading (in oxide weight percent). Table 420.lists the TCLP results for the LM series. 


\begin{tabular}{|c|c|c|c|c|c|}
\hline Oxide & R-O2-LM-54 & R-O2-LM-57 & R-O2-LM-60 & R-O2-LM-63 & R-O2-LM-66 \\
\hline $\mathrm{Al}_{2} \mathrm{O}_{3}$ & 16.47 & 17.15 & 16.87 & 18.16 & 19.16 \\
\hline $\mathrm{As}_{2} \mathrm{O}_{3}$ & 0.05 & 0.06 & 0.07 & 0.07 & 0.07 \\
\hline $\mathrm{B}_{2} \mathrm{O}_{3}$ & 6.60 & 6.29 & 6.11 & 5.74 & 5.41 \\
\hline $\mathrm{BaO}$ & 0.07 & 0.07 & 0.08 & 0.08 & 0.09 \\
\hline $\mathrm{CaO}$ & 0.64 & 0.70 & 0.73 & 0.70 & 0.79 \\
\hline $\mathrm{CdO}$ & 0.60 & 0.64 & 0.69 & 0.72 & 0.75 \\
\hline $\mathrm{CeO}_{2}$ & 0.13 & 0.14 & 0.15 & 0.16 & 0.16 \\
\hline $\mathrm{Cr}_{2} \mathrm{O}_{3}$ & 0.16 & 0.15 & 0.16 & 0.17 & 0.17 \\
\hline $\mathrm{Cs}_{2} \mathrm{O}$ & 0.14 & 0.15 & 0.17 & 0.17 & 0.16 \\
\hline $\mathrm{CuO}$ & 0.07 & 0.06 & 0.05 & 0.05 & 0.07 \\
\hline $\mathrm{Fe}_{2} \mathrm{O}_{3}$ & 18.29 & 19.30 & 20.66 & 21.40 & 22.63 \\
\hline $\mathrm{K}_{2} \mathrm{O}$ & 0.32 & 0.35 & 0.37 & 0.37 & 0.37 \\
\hline $\mathrm{La}_{2} \mathrm{O}_{3}$ & 0.53 & 0.57 & 0.60 & 0.63 & 0.66 \\
\hline MgO & 0.15 & 0.15 & 0.16 & 0.17 & 0.17 \\
\hline $\mathrm{MnO}$ & 5.03 & 5.35 & 5.60 & 5.96 & 6.16 \\
\hline $\mathrm{Na}_{2} \mathrm{O}$ & 0.92 & 0.98 & 1.04 & 1.15 & 1.11 \\
\hline $\mathrm{NiO}$ & 1.04 & 1.08 & 1.14 & 1.22 & 1.21 \\
\hline $\mathbf{P}_{2} \mathbf{O}_{5}$ & 0.17 & 0.19 & 0.20 & 0.20 & 0.20 \\
\hline $\mathrm{PbO}$ & 0.28 & 0.29 & 0.32 & 0.34 & 0.32 \\
\hline $\mathrm{Sb}_{2} \mathrm{O}_{5}$ & 0.27 & 0.29 & 0.30 & 0.32 & 0.33 \\
\hline $\mathrm{SeO}_{2}$ & 0.00 & 0.00 & 0.00 & 0.00 & 0.00 \\
\hline $\mathrm{SiO}_{2}$ & 34.74 & 32.01 & 29.94 & 26.94 & 24.00 \\
\hline $\mathrm{SO}_{3}$ & 0.35 & 0.36 & 0.37 & 0.38 & 0.41 \\
\hline SrO & 4.04 & 4.25 & 4.52 & 4.72 & 4.92 \\
\hline $\mathrm{TeO}_{2}$ & 0.11 & 0.11 & 0.14 & 0.12 & 0.14 \\
\hline $\mathrm{TiO}_{2}$ & 0.14 & 0.15 & 0.16 & 0.17 & 0.18 \\
\hline $\mathrm{ZnO}$ & 1.90 & 1.89 & 1.92 & 1.95 & 1.83 \\
\hline $\mathrm{ZrO2}$ & 6.79 & 7.26 & 7.49 & 7.95 & 8.51 \\
\hline
\end{tabular}

\begin{tabular}{|c|c|c|c|c|c|c|c|c|}
\hline \multicolumn{7}{|c|}{ Table 4-20. Large Melt Series TCLP Results } \\
\hline \multirow{2}{*}{$\begin{array}{l}\text { Waste } \\
\text { Loading }\end{array}$} & \multicolumn{7}{c|}{ Element Concentration in TCLP Extract (ppm) } \\
\cline { 2 - 10 } & $\mathbf{A s}$ & $\mathbf{B a}$ & $\mathbf{C d}$ & $\mathbf{C r}$ & $\mathbf{N i}$ & $\mathbf{P b}$ & $\mathbf{S e}$ & Zn \\
\hline $\mathbf{5 4}$ & 0.0074 & 0.0056 & $\mathbf{0 . 0 3 9 0}$ & 0.0008 & 0.0149 & 0.0151 & 0.0017 & 0.0841 \\
\hline $\mathbf{5 7}$ & 0.0112 & bdl & $\mathbf{0 . 0 6 0 0}$ & 0.0008 & 0.0174 & 0.0290 & 0.0018 & bdl \\
\hline $\mathbf{6 0}$ & 0.0074 & bdl & $\mathbf{0 . 0 5 3 0}$ & 0.0007 & 0.0129 & 0.0356 & 0.0010 & bdl \\
\hline $\mathbf{6 3}$ & 0.0127 & bdl & $\mathbf{0 . 0 6 9 0}$ & 0.0006 & 0.0146 & 0.0361 & 0.0030 & bdl \\
\hline $\mathbf{6 6}$ & 0.0180 & bdl & $\mathbf{0 . 1 2 9 0}$ & 0.0007 & 0.0223 & 0.0783 & 0.0036 & bdl \\
\hline $\begin{array}{l}\text { Avg.\% } \\
\text { RSD }\end{array}$ & 22 & NA & 15 & 21 & 10 & 26 & 71 & NA \\
\hline $\begin{array}{l}\text { UTS } \\
\text { Limit }\end{array}$ & $\mathbf{5 . 0}$ & $\mathbf{2 1 . 0}$ & $\mathbf{0 . 1 1}$ & $\mathbf{0 . 6 0}$ & $\mathbf{1 1 . 0}$ & $\mathbf{0 . 7 5}$ & $\mathbf{5 . 7}$ & \multirow{4}{4}{$\mathbf{4 . 3}$} \\
\hline
\end{tabular}

These same data are plotted for both the Large Melt and Small Melt laboratory scale samples in Figure 4-4. 


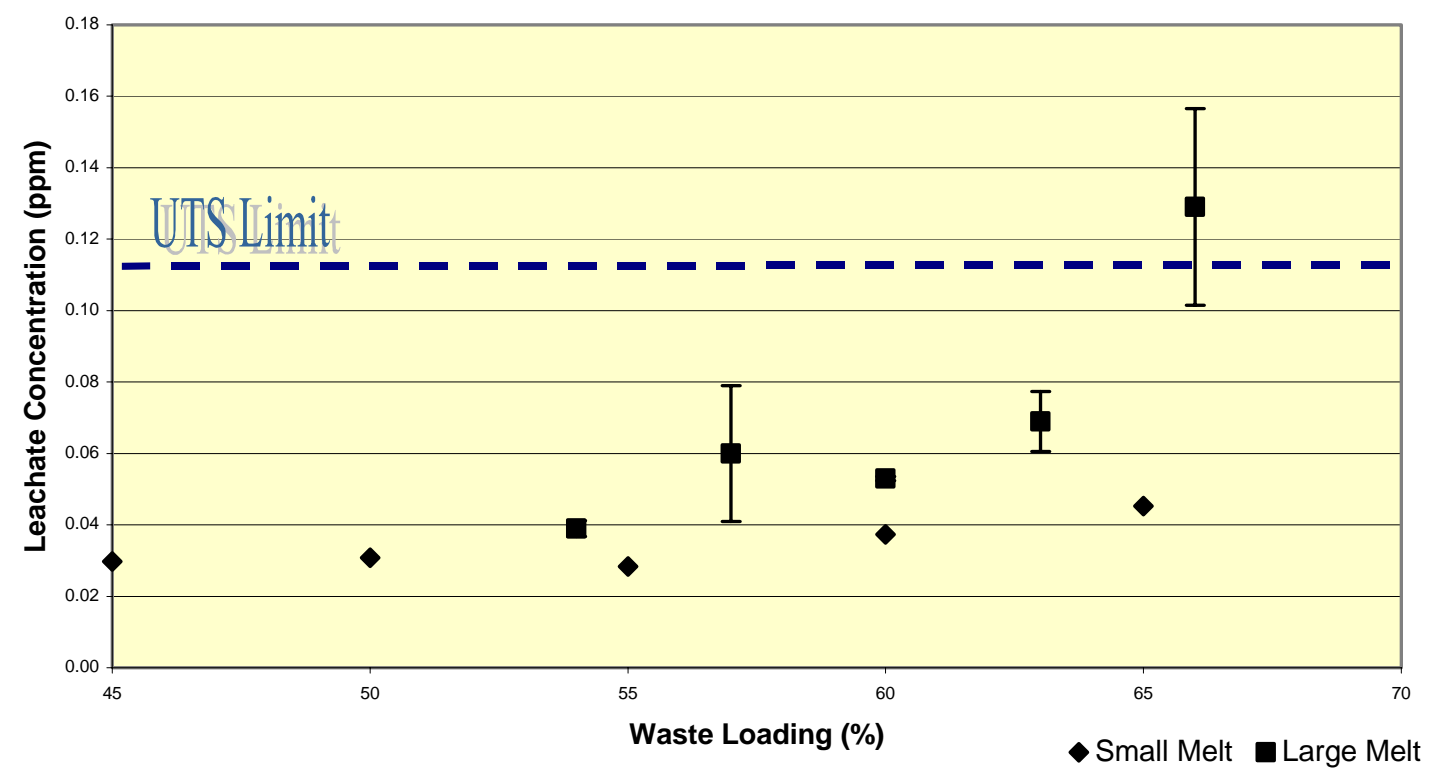

Figure 4-4. Large and Small Melt TCLP: Cd Response

The PCT results for the Large Melt Series (LM-54 to LM-66) are presented in Table 421.

\begin{tabular}{|c|c|c|c|c|c|}
\hline \multicolumn{6}{|c|}{ Table 4-21. Large Melt Series PCT Results } \\
\hline \multirow{2}{*}{$\begin{array}{l}\text { Average } \\
\text { Concentration } \\
(\mathbf{p p m})\end{array}$} & \multicolumn{5}{|c|}{ Sample ID } \\
\hline & LM-54 & LM-57 & LM-60 & LM-63 & LM-66 \\
\hline $\mathrm{Na}$ & 1.45 & 1.83 & 1.71 & 1.56 & 1.61 \\
\hline $\mathbf{S i}$ & 11.73 & 11.77 & 11.63 & 11.37 & 9.96 \\
\hline B & 2.22 & 2.29 & 2.24 & 2.35 & 2.42 \\
\hline $\mathbf{L i}^{*}$ & NA & NA & NA & NA & NA \\
\hline Average $\mathbf{p H}$ & 8.15 & 8.08 & 8.02 & 8.09 & 8.06 \\
\hline
\end{tabular}

* All values were below detection limits.

$\mathrm{T}_{\mathrm{g}}$ is determined by the intersection of two tangents drawn through the expansion versus temperature curves consistent with the transformation of a solid to under-cooled liquid. This technique was used for the LM 60 glass as an independent check of the $\mathrm{T}_{\mathrm{g}}$ determinations by STA. The dilatometry method requires $1 / 4 \times 1 / 4 \times 1$ " pieces - this geometry was not obtainable from the AVS bench-scale waste forms. The STA method determined $\mathrm{T}_{\mathrm{g}}$ to be $657 \pm 7^{\circ} \mathrm{C}$ and $658 \pm 9^{\circ} \mathrm{C}$ for the AVS bench scale waste forms, respectively. Figure 4-5 shows the graph and intersections used to determine the $\mathrm{T}_{\mathrm{g}}$. 


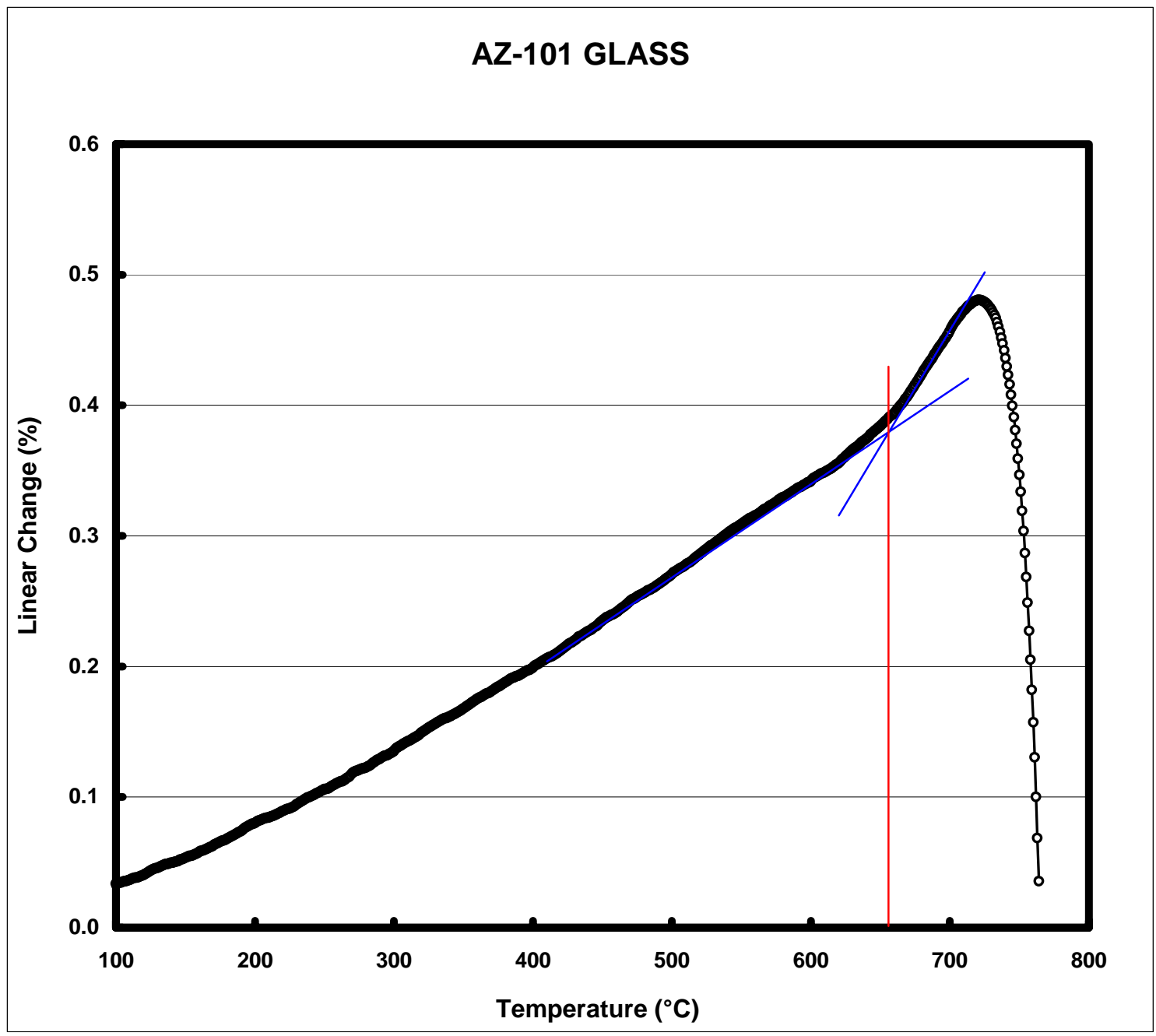

Figure 4-5. Glass Transition Temperature, $T_{g}$, is Equal to $660^{\circ} \mathrm{C} \pm 5^{\circ} \mathrm{C}$ as Measured by Dilatometry for the 60-wt\% Glass

Discussion and Results

The TCLP was performed on the large-scale glassy samples. Results are presented in Table 4-22. The analytical results are compared to the Universal Treatment Standard (UTS) limits. From the small-scale data, cadmium was identified as the limiting element of concern. Figure 4-6 presents the TCLP cadmium results of the large-scale melts and small-scale melts versus waste loading. 


\begin{tabular}{|c|c|c|c|c|c|c|c|c|}
\hline \multicolumn{9}{|c|}{ Table 4-22. Large Scale TCLP Results } \\
\hline \multirow{2}{*}{$\begin{array}{l}\text { Waste } \\
\text { Loading }\end{array}$} & \multicolumn{8}{|c|}{ Element Concentration in TCLP Extract (ppm) } \\
\hline & As & $\mathbf{B a}$ & Cd & $\mathrm{Cr}$ & $\mathrm{Ni}$ & $\mathbf{P b}$ & Se & Zn \\
\hline 54 & 0.0074 & 0.0078 & 0.0390 & 0.0008 & 0.0149 & 0.0151 & 0.0017 & 0.0841 \\
\hline 57 & 0.0112 & 0.0000 & 0.0600 & 0.0008 & 0.0174 & 0.0290 & 0.0018 & 0.0000 \\
\hline 60 & 0.0074 & 0.0000 & 0.0530 & 0.0007 & 0.0129 & 0.0356 & 0.0010 & 0.0000 \\
\hline 63 & 0.0127 & 0.0000 & 0.0690 & 0.0006 & 0.0146 & 0.0361 & 0.0030 & 0.0000 \\
\hline 66 & 0.0180 & 0.0000 & 0.1290 & 0.0007 & 0.0223 & 0.0783 & 0.0036 & 0.0000 \\
\hline $\begin{array}{l}\text { UTS } \\
\text { Limit }\end{array}$ & 5.0 & 21.0 & 0.11 & 0.60 & 11.0 & 0.75 & 5.7 & 4.3 \\
\hline
\end{tabular}

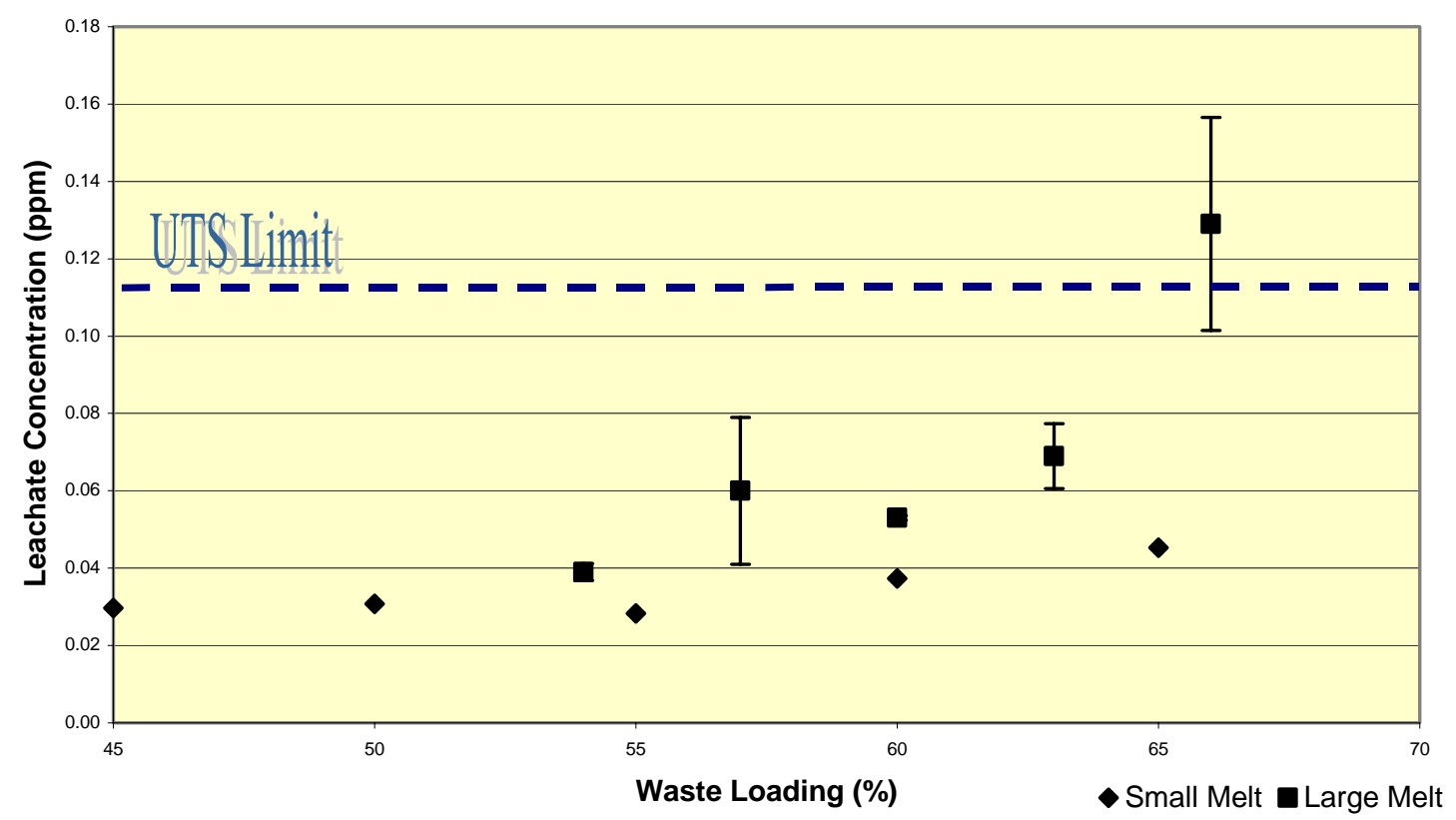

Figure 4-6: Large and Small Melt TCLP: Cd Response

The toxicity characteristic of the RIC glasses is dependent on waste loading, as indicated by the increase in cadmium release over the entire range. In general, the results indicate that an increase in waste loading increases the cadmium leach rate. All RIC glasses met the UTS limit for all analytes with one exception. The large-scale $66-w t \%$ waste loading exceeded the cadmium UTS limit.

Initial observations are:

- Cadmium is the element of concern regarding the TCLP. 
- Cadmium release is dependent on waste loading, crystallization, and begins to notably increase around 55-wt \%. Cadmium release approaches the UTS limit around 65-wt\% loading.

\section{Blind Sample Testing}

\section{Test Highlights and General Observations}

Only two elements ( $\mathrm{Ni}$ and $\mathrm{Cr}$ ) were detected in the TCLP leachate of the blind sample. All other elements tested in the TCLP were determined to be below detection limits (BDL) in the glass itself, therefore not expected to be in the TCLP leachate. All elements found in the glass were also detected in the PCT leachate except Mo, Ru and Nd. These three elements were not included in the PCT leachate analysis. Ru values reported here are believed due to interference caused by iron and are likely inaccurate. The iron interference was discovered after the results were obtained and digestion samples were discarded. If needed, archived samples can be retrieved and re-analyzed with a different $\mathrm{Ru}$ emission line to determine a true $\mathrm{Ru}$ concentration.

\section{Test Data}

Chemical analysis followed methods and protocols are similar in nature to methods developed at the Savannah River Site for analyzing waste glasses and have been used for previous work, involving RIC, for DOE. Table 4-23 reports the chemical analysis of the Blind sample in normalized oxide weight percent. Standard deviations are also reported. Table 4-24 reports the TCLP results and compares those results with UTS limits. Table 4-25 shows the PCT results for all elements tested (excluding Mo, $\mathrm{Li}, \mathrm{Ru}$ and Nd). $\mathrm{T}_{\mathrm{g}}$ was measured to be $463+/-3^{\circ} \mathrm{C}$. The TGA and DTA (as well as the derivative of the DTA curve, or DDTA) curves for the two sub samples are provided in Figures 4-7 and 48.

\section{Discussion and Results}

The Blind sample was analyzed using the same equipment and methodology as the AVS and LM glasses. No out of normal conditions were experienced during any chemical or physical analysis. The known values for the standard glass have not provided for comparison to date. 


\begin{tabular}{|c|c|c|}
\hline Oxide & $\begin{array}{c}\text { Blind } \\
\text { (normalized oxide wt \%) }\end{array}$ & $\begin{array}{c}\text { Standard Deviation } \\
(+/-)\end{array}$ \\
\hline $\mathrm{Al}_{2} \mathrm{O}_{3}$ & 3.51 & 0.08 \\
\hline $\mathrm{As}_{2} \mathrm{O}_{3}$ & BDL & - \\
\hline $\mathrm{B}_{2} \mathrm{O}_{3}$ & 8.32 & 0.03 \\
\hline $\mathrm{BaO}$ & 0.25 & 0.01 \\
\hline $\mathrm{CaO}$ & 0.84 & 0.01 \\
\hline $\mathrm{CdO}$ & BDL & - \\
\hline $\mathrm{CeO}_{2}$ & BDL & - \\
\hline $\mathrm{Cr}_{2} \mathrm{O}_{3}$ & 0.24 & 0.01 \\
\hline $\mathrm{Cs}_{2} \mathrm{O}$ & 0.12 & 0.01 \\
\hline $\mathrm{CuO}$ & 0.46 & 0.01 \\
\hline $\mathrm{Fe}_{2} \mathrm{O}_{3}$ & 12.5 & 0.3 \\
\hline $\mathrm{K}_{2} \mathrm{O}$ & 3.9 & 0.2 \\
\hline $\mathrm{La}_{2} \mathrm{O}_{3}$ & BDL & - \\
\hline $\mathrm{MgO}$ & 1.46 & 0.05 \\
\hline $\mathrm{MnO}$ & 2.62 & 0.02 \\
\hline $\mathrm{Na}_{2} \mathrm{O}$ & 8.2 & 0.1 \\
\hline $\mathrm{NiO}$ & 1.11 & 0.02 \\
\hline $\mathrm{PbO}$ & BDL & - \\
\hline $\mathrm{Sb}_{2} \mathrm{O}_{5}$ & BDL & - \\
\hline $\mathrm{SeO}_{2}$ & BDL & - \\
\hline $\mathrm{SiO}_{2}$ & 50.3 & 1.5 \\
\hline $\mathrm{SrO}$ & 0.05 & 0.03 \\
\hline $\mathrm{TeO}_{2}$ & BDL & - \\
\hline $\mathrm{TiO}_{2}$ & 1.05 & 0.03 \\
\hline $\mathrm{ZnO}$ & BDL & - \\
\hline $\mathrm{ZrO}_{2}$ & 0.23 & 0.03 \\
\hline $\mathrm{P}_{2} \mathrm{O}_{5}$ & BDL & - \\
\hline $\mathrm{SO}_{3}$ & $\mathrm{BDL}$ & - \\
\hline $\mathrm{Li}_{2} \mathrm{O}$ & 4.2 & 0.2 \\
\hline $\mathrm{MoO}_{3}$ & 0.20 & 0.03 \\
\hline
\end{tabular}

\begin{tabular}{|c|c|c|}
\hline \multicolumn{3}{|c|}{ Table 4-24. TCLP Results of Blind } \\
Sample \\
\hline Element & ppm & $\begin{array}{c}\text { UTS } \\
\text { Limits }\end{array}$ \\
\hline $\mathrm{As}$ & bdl & 5.0 \\
\hline $\mathrm{Ba}$ & $\mathrm{bdl}$ & 21 \\
\hline $\mathrm{Cd}$ & $\mathrm{bdl}$ & 0.11 \\
\hline $\mathrm{Cr}$ & 0.0080 & 0.60 \\
\hline $\mathrm{Ni}$ & 0.1250 & 11 \\
\hline $\mathrm{Pb}$ & $\mathrm{bdl}$ & 0.75 \\
\hline $\mathrm{Sb}$ & $\mathrm{bdl}$ & 1.2 \\
\hline $\mathrm{Se}$ & $\mathrm{bdl}$ & 5.7 \\
\hline $\mathrm{Zn}$ & $\mathrm{bdl}$ & 4.3 \\
\hline
\end{tabular}




\begin{tabular}{|c|c|c|c|c|}
\hline \multicolumn{5}{|c|}{ Table 4-25. PCT results of the Blind sample } \\
\hline \multirow{2}{*}{ Element } & \multicolumn{3}{|c|}{ Reported Concentration (ppm) } & \multirow{2}{*}{ Average } \\
\hline & RIC-Blind-PCT-A & RIC-Blind-PCT-B & RIC-Blind-PCT-C & \\
\hline $\mathrm{Al}$ & 3.42 & 3.42 & 3.43 & 3.42 \\
\hline As & BDL & BDL & BDL & \\
\hline $\mathrm{B}$ & 23.8 & 24.5 & 23.6 & 24.0 \\
\hline $\mathrm{Ba}$ & 0.018 & 0.017 & 0.019 & 0.018 \\
\hline $\mathrm{Ca}$ & 0.21 & 0.081 & 0.115 & 0.14 \\
\hline $\mathrm{Cd}$ & BDL & BDL & BDL & \\
\hline $\mathrm{Ce}$ & $\mathrm{BDL}$ & BDL & BDL & \\
\hline $\mathrm{Cr}$ & 0.112 & 0.113 & 0.111 & 0.112 \\
\hline $\mathrm{Cu}$ & 0.103 & 0.082 & 0.099 & 0.095 \\
\hline $\mathrm{Fe}$ & 2.71 & 2.77 & 3.11 & 2.86 \\
\hline $\mathrm{K}$ & 27.7 & 28.8 & 28.0 & 28.2 \\
\hline $\mathrm{La}$ & BDL & BDL & BDL & \\
\hline $\mathrm{Li}$ & 18.3 & 18.7 & 18.4 & 18.5 \\
\hline $\mathrm{Mg}$ & 0.423 & 0.32 & 0.394 & 0.38 \\
\hline $\mathrm{Mn}$ & 0.578 & 0.514 & 0.598 & 0.56 \\
\hline $\mathrm{Na}$ & 61.9 & 62.9 & 61.6 & 62.1 \\
\hline $\mathrm{Ni}$ & 0.165 & 0.136 & 0.167 & 0.16 \\
\hline $\mathrm{P}$ & BDL & BDL & BDL & \\
\hline $\mathrm{Pb}$ & BDL & BDL & BDL & \\
\hline $\mathrm{S}$ & BDL & BDL & BDL & \\
\hline $\mathrm{Sb}$ & BDL & BDL & BDL & \\
\hline $\mathrm{Se}$ & BDL & BDL & $\mathrm{BDL}$ & \\
\hline $\mathrm{Si}$ & 114.0 & 118.0 & 114.0 & 115.3 \\
\hline $\mathrm{Sr}$ & 0.014 & 0.006 & 0.006 & 0.009 \\
\hline $\mathrm{Te}$ & BDL & BDL & BDL & \\
\hline $\mathrm{Ti}$ & 0.148 & 0.145 & 0.144 & 0.146 \\
\hline $\mathrm{Zn}$ & BDL & BDL & BDL & \\
\hline $\mathrm{Zr}$ & 0.055 & 0.056 & 0.074 & 0.062 \\
\hline Cs (AA) & 0.246 & 0.278 & 0.276 & 0.267 \\
\hline
\end{tabular}


Mactule:

$\begin{array}{ll}\text { Moctulei } & \text { TOJDTA } \\ \text { Data Nane: } & \text { RIC-b1ind } \\ \text { Mearurenent Datei } & 10 / 15 / 2002\end{array}$

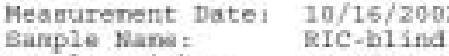

sample weight

$42.0077 \mathrm{mg}$

Temperature Progran!

kefereace darte:

Reference Kelghe: o ng

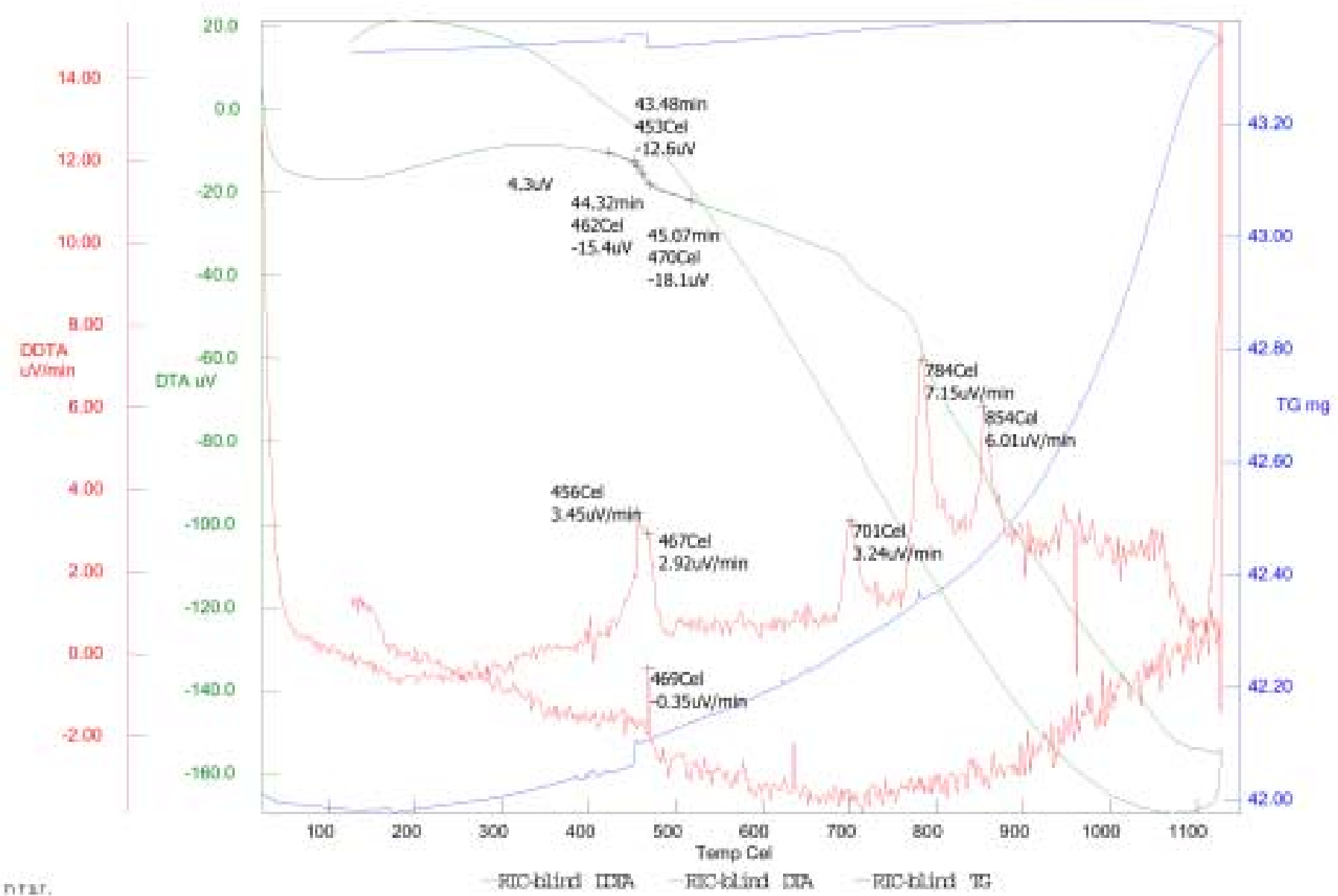

Figure 4-7. The TGA, DTA and DDTA Curves Blind Sub-Sample 1 

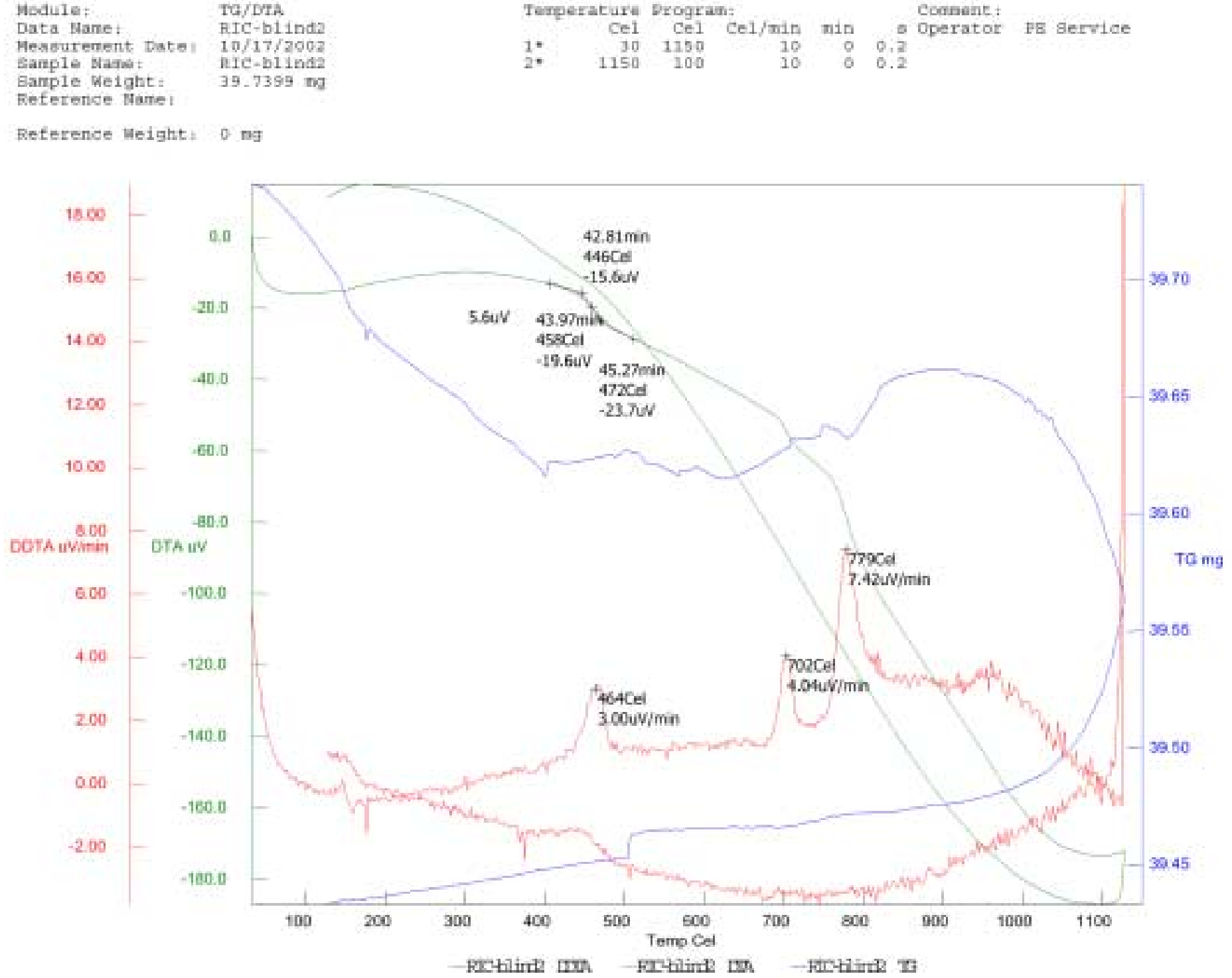

Figure 4-8. The TGA, DTA and DDTA curves Blind Sub-Sample 2 


\section{Feed-Form Experiments}

\section{Porcupine Processor}

The Bethlehem Corporation was able to dry the customer furnished feed slurry to a very low moisture content using a Porcupine Processor. Steam at 50 psig was used as the heat transfer media. Product solids were granular in nature and were free flowing when recycle type drying was used.

Fouling of the heat transfer surface was experienced at the high inlet moisture level. The range of fouling moisture was determined to extend to less than $30 \%$ moisture. As the mass of sample was limited, no efforts were made to find the upper moisture where fouling starts.

The material does follow the classical phases of drying. At the charging moisture, the material exhibited properties of a free boiling liquid. Using recycle, the Bethlehem staff was able to determine that the material entered the wet granular range of 24 to $27 \%$.

Recycle type drying was successful in producing a dry product material at low moisture with no material buildup on accumulation on the heat transfer surface. Operation over the moisture range of $22 \%$ inlet moisture to $0.11 \%$ did provide high heat transfer rates and a granular product of $55-\mathrm{lbs} / \mathrm{ft}^{3}$ density.

\section{Test Highlights and General Observations}

Table 4-26 gives a matrix of all the various tests that would be possible, using the COFFEE test apparatus, taking into account the range of operating variables. However, because of limited funding resources, it was not possible to carry out all of these tests. Instead, a smaller subset (outlined in bold face) was carried out in order to quickly zeroin on a practical and effective method for continuously feeding the 5-inch bench-scale test apparatus as well as the full-scale AVS module.

Table 4-26. Matrix of Possible Feed Tests Using the COFFEE Apparatus ( $\mathbf{P}=$ Possible; NP = Not Possible; Shaded Area = Tests Actually Performed $)$

\begin{tabular}{|l|c|c|c|c|c|c|}
\hline \multirow{2}{*}{} & \multicolumn{6}{|c|}{ Nature of Feed } \\
\cline { 2 - 7 } & \multicolumn{2}{|c|}{ Pellets } & \multicolumn{2}{c|}{ Powder } & \multicolumn{2}{c|}{ Liquid } \\
\cline { 2 - 7 } & Large & Small & Fine & Agglomerated & Dilute & Concentrated \\
\cline { 2 - 7 } & $(5 / 16 ”$ Dia) & $(1 / 8$ ” Dia $)$ & Powder & Powder & $\left(80 \% \mathrm{H}_{2} \mathrm{O}\right.$ Vol $)$ & $\left(50 \% \mathrm{H}_{2} \mathrm{O}\right.$ Vol $)$ \\
\hline $\begin{array}{l}\text { Vibratory } \\
\text { Sheet }\end{array}$ & $\mathbf{P}$ & $\mathbf{P}$ & $\mathbf{P}$ & $\mathrm{P}$ & $\mathrm{NP}$ & $\mathrm{NP}$ \\
\hline $\begin{array}{l}\text { Mechanical } \\
\text { Screws }\end{array}$ & $\mathrm{P}$ & $\mathrm{P}$ & $\mathrm{P}$ & $\mathrm{P}$ & $\mathrm{P}$ & $\mathrm{P}$ \\
\hline $\begin{array}{l}\text { Peristaltic } \\
\text { Pump }\end{array}$ & $\mathrm{NP}$ & $\mathrm{NP}$ & $\mathrm{NP}$ & $\mathrm{NP}$ & $\mathbf{P}$ & $\mathbf{P}$ \\
\hline $\begin{array}{l}\text { Centrifugal } \\
\text { Liquid Pump }\end{array}$ & $\mathrm{NP}$ & $\mathrm{NP}$ & $\mathrm{NP}$ & $\mathrm{NP}$ & $\mathrm{P}$ & $\mathrm{P}$ \\
\hline
\end{tabular}


The following general observations were derived from the 6 COFFEE tests conducted to date. Test \#1 was carried out in the previous AVS program using Envelope D waste simulant ${ }^{1}$ hile tests 2 through 6 were carried out using AZ-101 waste simulant.

1. The slurry feed option provided excellent results - the slurry droplets retained their integrity as they traveled straight downward with virtually none of them impacting on the wall of the alumina crucible, even though it is much smaller in diameter and has a much greater length/diameter ratio than does the 5 inch bench-scale and full-scale AVS Module units. Moreover, the melt surface remained bright and clear during the process, with no visible obscuring smoke. The amount of particulates released during feeding was very small.

2. The slurry feed rate could be precisely set and controlled using a peristaltic pump and remained constant during the feeding period.

3. The pellet feed option, while it worked in principle, had objectionable features. First, the magnesium stearate binder caused a considerable amount of dark smoke when the pellets hit the hot melt surface. This was probably due to the decomposition of the organic stearate ( $\sim 0.25 \%$ by weight $)$. The smoke probably consisted of fine particulates of carbon and various hydrocarbons produced by thermal decomposition. Such particulates could pose problems for the off-gas system. Second, the method of feeding pellets off the edge of a vibratory flat sheet caused the pellets to have erratic trajectories as they traveled downwards through the alumina crucible. As a result, a substantial fraction of the pellets struck the walls of the crucible, causing feed material to adhere to the cooler walls above the melt zone.

These problems could probably be greatly eased, and perhaps eliminated, by using an inorganic binder material, together with a feed tube that directs pellets downwards along the axis of the crucible. However, for a full-scale vitrification application, it still would be necessary to fabricate thousands of tons of HLW/frit material into pellets - a process that would increase the cost and complexity of the vitrification plant.

4. The powder feed method was the least satisfactory of the three options tested. There was significant entrainment of feed powder in the off-gases, and substantial adherence of feed material on the crucible walls. Moreover, the powder was difficult to handle in the feeder. Agglomerated pellets of powder were fabricated, but they broke-up in the feeding process, because of the very weak binding of the powder. The vibratory feeder typically reduced the agglomerated pellets to a fine powder, which then dropped off the vibrating sheet into the alumina crucible in an uncontrolled fashion; however, a positive volume feeding system may alleviate these problems.

5. If the feed rate; whether pellets, powder, or slurry feed, exceeded the rate at which heat could transport from the external furnace into the inner alumina crucible, a "cold cap" of undissolved feed built up on the top of the melt surface. If the "cold cap" became too thick, its upper surface acted as a

\footnotetext{
${ }^{1}$ Appendix H of “Additional Tests of an Advanced Vitrification System,” July 18, 2001.
} 
thermal insulator, inhibiting heat transfer to the melt from the upper hot alumina crucible.

At the proper rate of feed, the melt surface remains bright and clear, and immediately dissolves the feed as it strikes the surface. For the COFFEE tests, this proper fill rate is approximately 4 inches of glass per hour for pellet and powder feed, and about 1.6 inches of glass per hour for the diluted slurry feed $(80 \%$ water by volume). With a concentrated slurry feed $(50 \%$ water by volume), the water/solid volume ratio would be $1: 1$ instead of $4: 1$. This should result in the fill rate for the concentrated slurry approaching that of pellets and powder, since much less heat must be transported into the inner crucible to evaporate the excess water.

6. Due the heat transport in the COFFEE test apparatus (see Section 3.2.4.2), the proper fill rates as determined by the COFFEE tests will be substantially less than those using the hot Hohlraum method in the actual AVS Module. Follow-on tests to determine the fill rate for the actual AVS module should use a true hot hohlraum geometry.

\section{Test Data}

All tests used AZ-101 simulant, with a $60-\mathrm{wt} \%[\mathrm{M}-1]$ waste loading of simulant and $40 \%$ frit. This loading along with the frit composition was determined in the laboratory-scale experiments. The tests were numbered from 2 to 6 (See Table 4-27).

Table 4-27. Outline of COFFEE Series

\begin{tabular}{|c|c|c|}
\hline $\begin{array}{c}\text { Test } \\
\text { Number }\end{array}$ & Feed Type & $\begin{array}{c}\text { Nominal Furnace } \\
\text { Temperature }\left({ }^{\circ} \mathbf{C}\right)\end{array}$ \\
\hline 2 & Pellets (Cargille) & 1450 \\
\hline 3 & Pellets (Mars) & 1450 \\
\hline 4 & Slurry & 1500 \\
\hline 5 & Slurry & 1500 \\
\hline 6 & Slurry & $1475-1535$ \\
\hline
\end{tabular}

\section{$\underline{\text { Test } 1}$}

Test 1 was carried out and is described as per the previous AVS program, using Envelope D waste simulants. Three types of feed form were tested:

1. Pellets $\mathrm{w} / \mathrm{magnesium} \mathrm{stearate} \mathrm{binder} \mathrm{[Test} \mathrm{2]}$

2. Agglomerated powder with various types of binders (starch, bentonite, sodium silicate) [Test 3]

3. Wet slurry feed [Tests 4, 5, and 6]

The wet slurry feed consisted of $37-w t \%$ solids $(20$ vol $\%)$ in aqueous suspension. The slurry was pumped through a Tygon ${ }^{\circledR}$ feed tube that connected to a steel tube at the top of the open inner alumina crucible (1.75 inch diameter). The steel tube ( $3 / 8$ " diameter and 10 inches in length) was located coaxially with the alumina crucible, and extended downwards into the interior. Slurry exiting the steel tube dropped into the heated zone of 
the inner crucible. The slurry was pumped by a peristaltic pump. The pump could be precisely controlled to feed at the desired fill rate. No problems were encountered with the control of the slurry feed. The drops of slurry feed into the crucible mainly fell along the centerline of the crucible with very few exceptions.

The pellet feed [Test 2] used magnesium stearate as a binder. The pellets were relatively strong and retained their integrity during the feed process. Two sizes of pellets were tested ( 0.6 gram and 0.13 gram). The pellets were fed into the top of the inner open alumina crucible by a vibratory feeder. The feed rate varied significantly during the feed process, since there was no way to precisely control the motion of the pellets.

The agglomerated powder [Test 3] typically disintegrated to a fine powder during the feed process, and it was difficult to ensure that it cleanly entered and fell into the hot zone of the alumina crucible.

\section{Test 2}

The run started by feeding 5/16" diameter (0.598 gram) pellets (Cargille Manufacturing supplied) containing $60-\mathrm{wt} \%$ [M-1] waste loaded with frit. The pellets were bound with magnesium stearate binder and formed in a die under pressure. In this experiment, the vibrating feeder rate was approximately 75 grams in 10 minutes. The total weight of pellets introduced during this phase of the experiment was 500 grams.

The second phase of this experiment consisted of feeding $1 / 8$ " diameter $(0.131$ gram $)$ pellets (Cargille supplied) containing $60-\mathrm{wt} \%$ waste loaded with frit. The vibratory feeder rate for these smaller pellets was 120 grams in 8 minutes 20 seconds. The total amount of $1 / 8$ " diameter pellets fed into the crucible was 200 grams. During the experiment the furnace was moved upwards by a total of 6.5 inches (both phases).

\section{Observations:}

Black puffs of smoke were observed during the feeding of both the large and small pellets into the crucible. The smaller pellets seemed to generate more smoke than the larger ones. After cessation of feeding of the pellets, it took 40 to 60 seconds for the black smoke to clear the surface of the melt.

The slug of glass produced from this run was about 5-1/2 to 6 inches long. DIAL reported variations in the glass analysis from the bottom to the top of the glass. The glass also contained substantial amounts of bubbles.

\section{$\underline{\text { Test } 3}$}

Agglomerated powder pellets with starch, bentonite and sodium silicate binders (obtained from MARS, Inc.) were fed into the crucible during this experiment. The initial feed rate consisted of 4 additions of 65 gram lots fed at 3 minute intervals per lot.

A second set of crucible feeds during this experiment consisted of three 130 gram lots containing the three different types of binders (described above) fed into the crucible at 7 minute intervals per lot.

The total amount of agglomerated pellets fed during this experiment was 642 grams. 
Observations:

Large portions of the agglomerated pellets tended to disintegrate during the traverse from the vibrator to the mouth of the crucible. Large amounts of black smoke were observed during the feeding. Plugs developed along the length of the crucible during feeding. Efforts to melt the plugs by moving the furnace up and down were only partially successful. Examination of the product after cooling by DIAL determined that large amounts of feed in the crucible were not vitrified. Results from Test 2 and 3 indicated that the crucible temperature was lower than the furnace temperature (i.e. $<1450^{\circ} \mathrm{C}$ ).

\section{Test 4}

The Slurry Feed AZ-101 from DIAL consisted of $60-\mathrm{wt} \%[\mathrm{M}-1]$ waste simulant with frit. Approximately 3.5 liter ( 2951.2 grams $)$ of slurry was poured into a Hobart mixer and mixed to a "melted chocolate like" consistency. At the beginning of the experiment $5 \mathrm{cc}$ of water was fed into the inner 1.75 " tube. The resultant steam emissions stopped after 1 minute and 5.5 seconds.

A peristaltic pump then delivered the slurry through 3/16" Tygon ${ }^{\circledR}$ tube which in turn fed into a 10 " long steel $3 / 8$ " tube that projected down into the 1.75 " ID alumina tube.

The slurry flow rate was calibrated to $0.25 \mathrm{cc} / \mathrm{sec}$ (setting 1.8 on the peristaltic pump) and only steam was observed coming from tube - no black smoke.

The steel tube clogged after 12 minutes - it was then cleared with a rod and restarted. Slurry was pumped for an additional 32 minutes, the furnace was moved 1 inch upward.

Ran another 32 minutes - moved furnace another inch upwards.

Then ran three more intervals 11 minutes, 17 minutes, and 8 minutes.

Total run time 142 minutes (2 hours 22 minutes)

The total upward movement of the furnace was 6-7/8"

The operation appeared very smooth. The sequence of slurry drops fell directly onto the melt surface without striking the wall of the crucible. At the end of run, a crack was found about 1 " from bottom of crucible. It appeared that molten glass ran out and filled the annulus between outer and inner tube with glass to a length of about 6 inches. The bottom spacer plug supporting inner tube was fused to the bottom of the crucible.

$$
\begin{aligned}
\text { Estimate glass made in annulus } & =437.5 \mathrm{gm} \\
\text { Estimate glass made in crucible } & =116.2 \mathrm{gm} \\
\hline \text { Total } & =553.7 \mathrm{gm}
\end{aligned}
$$

\section{Test 5}

The Test 5 set-up was similar to that for Test 4 except that the SS tube was shortened to 5 " to prevent heating/plugging. In addition, feed would come directly from the slurry jar, with no transfer to an intermediate container. 
Wet AZ-101 slurry with frit was used to feed at $60-\mathrm{wt} \%$ waste loading (based on DOE definition of waste loading). The standard furnace arrangement with a central 1.75" I.D. alumina tube inside a 2.45 " I.D. alumina outer tube was used as before. The annulus (or gap) is 0.20 inches.

The bottom of the inner tube was first filled with $30.3^{\circ} \mathrm{C}$ dried granular AZ-101 material to produce a 1" layer of glass. The furnace took about 5 hours to heat up to $1500^{\circ} \mathrm{C}$ and with a subsequent hold period of about $1-1 / 2$ hours before the run actually started. A peristaltic pumps calibrated to feed at the rate of $0.25 \mathrm{cc} / \mathrm{sec}$ was used to feed the slurry mixture through a Tygon ${ }^{\circledR}$ tube into the inner alumina tube. The Tygon ${ }^{\circledR}$ tube was attached to a 0.340 " I.D. -5 " long stainless steel tube that projected into the top of the alumina tube allowing the drops of slurry to fall directly down the center of the tube. By means of a mirror, we could observe the bright red-yellow glow of glass of the surface of the melt and the drops disappearing into the melt. The melt Hohlraum zone (just above the melt) was centered in the middle of the furnace. The furnace temperature ranged between $1450^{\circ} \mathrm{C}$ and $1500^{\circ} \mathrm{C}$ and the feeding of the slurry was held at a steady rate. The melting operation was very smooth. Small steam puffs issued from the top of the alumina tube with no violent reactions of the released gas. From time to time, there was darkening of the bright molten surface, which disappeared when slurry feeding was stopped. The furnace was moved up 1" every 20 minutes to coincide with each additional inch of glass that was made. We ran at steady state for about 90 minutes. We intended to run longer; however, the furnace shutoff because it was inadvertently programmed to shut-off after 8 hours of operation. The furnace temperature dropped very rapidly after shutdown. We estimate that we were producing glass at about 2.87 " per hour and produced about 4.3 " of glass from the slurry feed on top of the 1 " of glass at the bottom of the crucible from the dried slurry (waste simulant plus frit). Probe measurement down the tube at the end of the run indicated that we made about 4" of glass. A post examination of the tubes revealed that a crack had developed about 5" from the bottom of the inner tube causing some molten glass leak out and run down and glue the supporting tube to the bottom of the crucible. This could have occurred because of the rapid cool-down.

At the end of the run the amount of water remaining in the remaining slurry was measured. The water in this residual slurry was evaporated at $80-90^{\circ} \mathrm{C}$ on a hot plate to measure its solids content. The residual slurry was determined to have $55.3 \%$ as percent of solids, as compared to the as prepared slurry, which had a solids content of $37.0 \%$. However, it is possible all the free water was not evaporated because the slurry could be poured like heavy molasses. At this point, it appeared that the pump might have been feeding more dilute slurry during the run, perhaps on the order $30 \%$ solids by weight.

\section{$\underline{\text { Test } 6}$}

The Test 6 set-up was similar to that for Test 5 except that slurry mixing was improved by using a high-speed turbo mixer in the feed jar. Also, the slurry container was shaken prior to mixing to improve the mixing process.

The slurry was directly fed into the 1.75 " ID heated alumina tube. The vitrification of AZ-101 simulant with frit to produce a $60 \mathrm{wt} \%$ [M-1] borosilicate glass was as follows: 


\begin{tabular}{|ll|}
\hline Component & Mass \\
\hline AZ-101 Simulant $^{(1)}$ & 3050.0 \\
$\mathrm{SiO}_{2}$ & 297.0 \\
$\mathrm{H}_{3} \mathrm{BO}_{3}$ & 99.2 \\
$\mathrm{ZnO}$ & 18.6 \\
\hline Total $^{(2)}$ & 3464.8 \\
\hline
\end{tabular}

(1) Simulant is $28.5 \mathrm{wt} \%$ Solids.

(2) Total is $37 \mathrm{wt} \%$ Solids.

The peristaltic Tygon ${ }^{\circledR}$ pump was used to transfer the slurry from DIAL container \#7 to the crucible. The pump was pre-calibrated with water. A double vane mixer operating at 600 RPM mixed the simulant within Jar \#7 for about 2 hours before the run. The 1.75" alumina tube was pre-loaded with $300^{\circ} \mathrm{C}$ dried simulant supplied by DIAL. The idea was to form a pool of molten glass at the bottom of the crucible so that the liquid slurry would fall onto a molten surface. The furnace was heated at a rate of $5^{\circ} \mathrm{C} / \mathrm{min}$ and required about 5 hours to heat up to the control temperature of $1500^{\circ} \mathrm{C}$. Temperatures were measured inside the furnace and on the exterior of the alumina tube. The furnace was held at $1500^{\circ} \mathrm{C}$ for about 2 hours prior to starting the run. We could observe the red hot glow of the surface of the melt.

The run was started at $12: 17 \mathrm{pm}$ at a pump dial setting of 1.3. Based on the calibration test done during Test $5,0.25 \mathrm{cc} / \mathrm{sec}$ of simulant was being introduced into the alumina crucible. The slurry feed was introduced into the crucible molten pool for about 21 minutes. (This equates to about 1" for the DIAL 5" diameter crucible). After 21 minutes, the furnace was moved up 1" and a darkening of the melt surface was observed.

During this time we observed steam exiting the top of the tube. The flow rate was reduced to a peristaltic pump dial setting of $1.0\left(\sim 0.18 \mathrm{~cm}^{3} / \mathrm{sec}\right)$ and the dark layer receded but did not become bright. The furnace was held in this position for 21 minutes. The furnace temperature displayed $1500^{\circ} \mathrm{C}$ to a low of $1455^{\circ} \mathrm{C}$ during the first 21 minutes then rose to $1475^{\circ} \mathrm{C}$ during the second 21 minutes. The temperature during the third 21 minute period stayed at $1507^{\circ} \mathrm{C}$. We then moved the furnace another 1 " with no change in the dark surface. We then stopped the pump to try to clear up the surface. It appeared that an un-melted crust formed somewhat above the surface of the melt. So we proceeded to raise the furnace to attempt to melt the crust layer. This upward movement was carried out in 3 steps: 1 " and two 0.5 " movements, while the furnace temperature was held at $1500^{\circ} \mathrm{C}$. After the last $0.5^{\prime}$ movement the crust broke into sections and fell into the molten glass. This whole procedure took about 50 minutes. It was then noted that the molten sections of crust did not completely melt and become part of the molten glass. In an attempt to melt the crust, the furnace was again moved up. Finally, with the furnace up about 5" above the initial melting, the furnace temperature setting was increased to about $1550^{\circ} \mathrm{C}$. When the temperature reached about $1530^{\circ} \mathrm{C}$, the crust in the melt disintegrated and the molten glass resumed its normal continuous bright melt surface. At this point, i.e. after a shut-off period that lasted $\sim 140$ minutes, simulant addition at a setting of $0.5(0.085 \mathrm{cc} / \mathrm{sec})$ was resumed. At this rate there was no build-up of unwanted material and the surface was very bright. The temperature dropped from $1550^{\circ} \mathrm{C}$ to $1535^{\circ} \mathrm{C}$ steady and there was a good steady feed versus glass making. This 
lasted for 135 minutes. We then increased the setting of the pumps to $0.7 \mathrm{cc} / \mathrm{sec}$ ) and there was a build-up of black material. We maintained the furnace in this position 24 minutes. We moved the furnace up 1" and reduced simulant flow to $0.11 \mathrm{cc} / \mathrm{sec}$ and ran the rest of the 119 minutes with the temperature at $1520^{\circ} \mathrm{C}$. With slight black material on the surface on shutdown the melt cleared up in 2 minutes, indicating there was very little un-melted material building up on the surface. The feed flow was shut-off at 9:12 PM.

The furnace was shutdown at 9:30 PM and allowed to cool overnight at a cool down rate of $5^{\circ} \mathrm{C} / \mathrm{min}$. Summary of operating data for COFFEE Run \#6 is given in Table 4-32.

We estimated that approximately 6" to 6.25 " of glass was produced. Weighing at the end indicated $\sim 2500$ grams of mixed slurry was added in this run. Observation indicated the inner tube cracked at a level where the first crust was formed (about 7" above bottom of tube) Very little glass leaked out. Measurements indicated there was 6.3" of glass in the tube. The bottom inch was pre-loaded with dry simulant. 5.3" was made, which corresponds for the amount we fed. The glass was broken out of the tube and put together as one sample. Three separate pieces were selected. Each was ground and sieved separately and analyzed for composition. These results are given in Table 4-30 A fourth sample under went TCLP testing and the results are given in Table 4-31. It can be seen from these tables that the glass is relatively homogeneous (see Table 4-30) and passed TCLP for all elements.

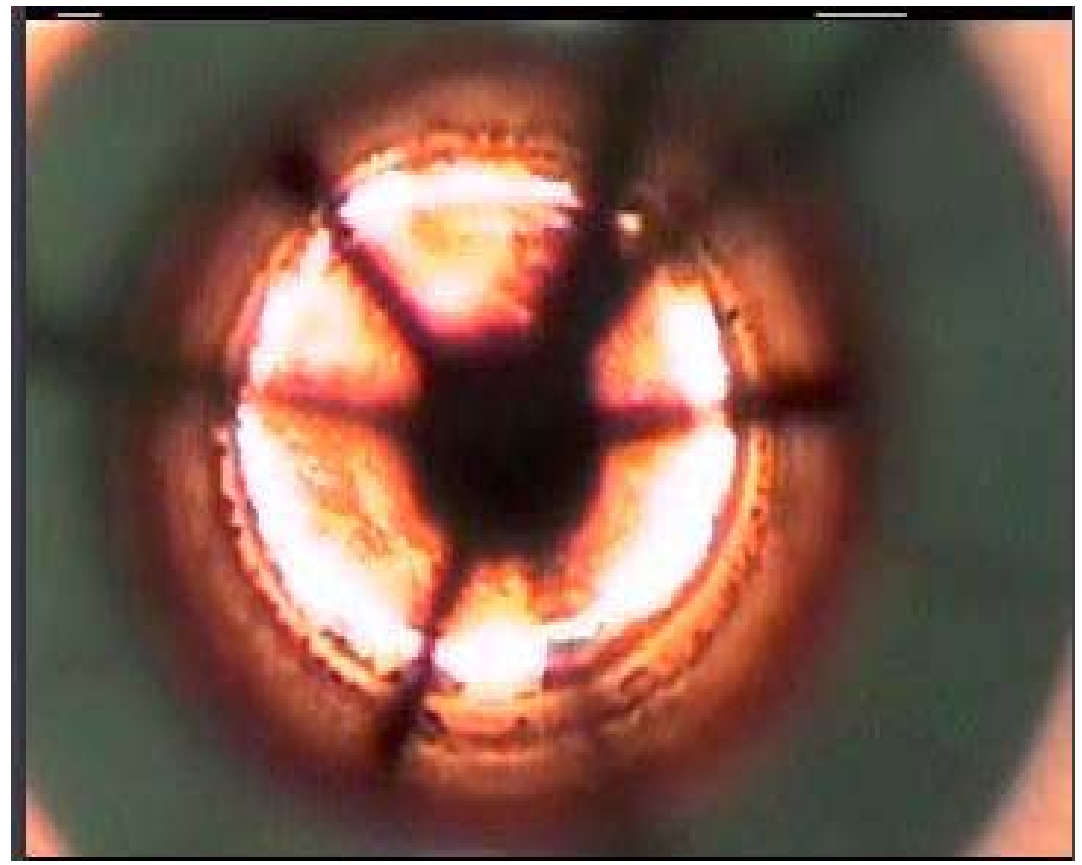

Figure 4-8a. Top Surface of Coffie Melt with Center (Black) Feed Mechanism at Top of Alumina Tube 
Table 4-30. Analytical Results for COFFEE Run-6

\begin{tabular}{|c|c|c|c|c|}
\hline \multirow[b]{2}{*}{ Oxide } & \multicolumn{4}{|c|}{ Normalized Composition } \\
\hline & $\begin{array}{c}\text { Sample } 1 \\
\left(w^{\circ} \%\right)\end{array}$ & $\begin{array}{c}\text { Sample } 2 \\
\left(\mathrm{wt}^{0} \%\right)\end{array}$ & $\begin{array}{c}\text { Sample } 3 \\
(\mathrm{wt} \%)\end{array}$ & $\begin{array}{c}\text { Average } \\
(\mathrm{wt} \%)\end{array}$ \\
\hline $\mathrm{Al}_{2} \mathrm{O}_{3}$ & 21.10 & 19.53 & 18.88 & $20 \pm 1$ \\
\hline $\mathrm{As}_{2} \mathrm{O}_{3}$ & 0.04 & 0.02 & 0.02 & $0.03 \pm 0.01$ \\
\hline $\mathrm{B} 2 \mathrm{O} 3$ & 5.27 & 4.65 & 4.85 & $4.9 \pm 0.3$ \\
\hline $\mathrm{BaO}$ & 0.08 & 0.08 & 0.08 & $0.08 \pm 0.00$ \\
\hline $\mathrm{CaO}$ & 0.66 & 0.64 & 0.67 & $0.66 \pm 0.01$ \\
\hline $\mathrm{CdO}$ & 0.72 & 0.50 & 0.54 & $0.6 \pm 0.1$ \\
\hline $\mathrm{CeO}_{2}$ & 0.15 & 0.14 & 0.15 & $0.15 \pm 0.00$ \\
\hline $\mathrm{Cr}_{2} \mathrm{O}_{3}$ & 0.33 & 0.22 & 0.25 & $0.27 \pm 0.06$ \\
\hline $\mathrm{Cs}_{2} \mathrm{O}$ & 0.17 & 0.16 & 0.16 & $0.16 \pm 0.00$ \\
\hline $\mathrm{CuO}$ & 0.07 & 0.07 & 0.07 & $0.07 \pm 0.00$ \\
\hline $\mathrm{Fe}_{2} \mathrm{O}_{3}$ & 19.67 & 22.02 & 20.31 & $21 \pm 1$ \\
\hline $\mathrm{K}_{2} \mathrm{O}$ & 0.33 & 0.34 & 0.35 & $0.34 \pm 0.01$ \\
\hline $\mathrm{La}_{2} \mathrm{O}_{3}$ & 0.59 & 0.57 & 0.59 & $0.58 \pm 0.01$ \\
\hline $\mathrm{MgO}$ & 0.15 & 0.15 & 0.16 & $0.15 \pm 0.00$ \\
\hline $\mathrm{MnO}$ & 5.34 & 5.54 & 5.63 & $5.5 \pm 0.2$ \\
\hline $\mathrm{Na}_{2} \mathrm{O}$ & 1.04 & 1.04 & 1.15 & $1.08 \pm 0.06$ \\
\hline $\mathrm{NiO}$ & 0.98 & 1.30 & 0.87 & $1.1 \pm 0.2$ \\
\hline $\mathrm{PbO}$ & 0.31 & 0.26 & 0.28 & $0.28 \pm 0.02$ \\
\hline $\mathrm{Sb}_{2} \mathrm{O}_{5}$ & 0.28 & 0.26 & 0.29 & $0.28 \pm 0.02$ \\
\hline $\mathrm{SeO}_{2}$ & BDL & BDL & BDL & BDL \\
\hline $\mathrm{SiO}_{2}$ & 29.92 & 29.48 & 31.51 & $30 \pm 1$ \\
\hline $\mathrm{SrO}$ & 4.34 & 4.26 & 4.30 & $4.30 \pm 0.04$ \\
\hline $\mathrm{TeO}_{2}$ & 0.21 & 0.05 & 0.04 & $0.10 \pm 0.10$ \\
\hline $\mathrm{TiO}_{2}$ & 0.16 & 0.16 & 0.16 & $0.16 \pm 0.00$ \\
\hline $\mathrm{ZnO}$ & 1.84 & 2.09 & 1.84 & $1.9 \pm 0.2$ \\
\hline $\mathrm{ZrO}_{2}$ & 5.70 & 5.91 & 6.28 & $6.0 \pm 0.3$ \\
\hline $\mathrm{P}_{2} \mathrm{O}_{5}$ & 0.17 & 0.16 & 0.21 & $0.18 \pm 0.02$ \\
\hline $\mathrm{SO}_{3}$ & 0.40 & 0.37 & 0.39 & $0.38 \pm 0.01$ \\
\hline Total & 100.00 & 100.00 & 100.00 & 100.00 \\
\hline
\end{tabular}


Table 4-31. TCLP Results for COFFEE Run-6

\begin{tabular}{|c|c|c|}
\hline Element & $\begin{array}{c}\text { UTS Limits } \\
\text { (ppm) }\end{array}$ & $\begin{array}{c}\text { COFFEE Run-6 TCLP } \\
\text { (ppm) }\end{array}$ \\
\hline $\mathrm{As}$ & 5.0 & $0.0120 \pm 0.003$ \\
\hline $\mathrm{Ba}$ & 21 & $0.009 \pm 0.000$ \\
\hline $\mathrm{Cd}$ & 0.11 & $0.101 \pm 0.001$ \\
\hline $\mathrm{Cr}$ & 0.60 & $0.001 \pm 0.000$ \\
\hline $\mathrm{Ni}$ & 11 & $0.022 \pm 0.003$ \\
\hline $\mathrm{Pb}$ & 0.75 & $0.050 \pm 0.001$ \\
\hline $\mathrm{Sb}$ & 1.2 & $0.0180 \pm 0.002$ \\
\hline $\mathrm{Se}$ & 5.7 & $\mathrm{BDL}$ \\
\hline $\mathrm{Zn}$ & 4.3 & $0.075 \pm 0.002$ \\
\hline
\end{tabular}

Table 4-32. Operating Data for Test 6

\begin{tabular}{|c|c|c|c|c|}
\hline $\begin{array}{l}\text { Run Time } \\
\text { (min) }\end{array}$ & $\begin{array}{l}\text { Pump } \\
\text { Setting }\end{array}$ & $\begin{array}{l}\text { Furnace Temp. }\left({ }^{\circ} \mathrm{C}\right) \\
\text { Lowest During Period }\end{array}$ & $\begin{array}{c}\text { Furnace } \\
\text { Position (in) }\end{array}$ & $\begin{array}{l}\text { Melt Surface } \\
\text { Condition }\end{array}$ \\
\hline 120 & 0.00 & 1500 & 0 & Bright \\
\hline 21 & 1.30 & 1455 & 0 & Darkening \\
\hline 21 & 1.30 & 1475 & 1 & Very Dark \\
\hline 17 & 1.00 & 1507 & $\begin{array}{ll}--- \\
\end{array}$ & Very Dark \\
\hline 26 & 0.00 & 1500 & 2 & Very Dark \\
\hline 8 & 0.00 & 1500 & 3 & Dark \\
\hline 20 & 0.00 & 1500 & 4 & $\begin{array}{l}\text { Black Material } \\
\text { Fell onto Melt }\end{array}$ \\
\hline 15 & 0.00 & 1498 & 3 & Melt Clearing \\
\hline 7 & 0.00 & 1500 & 2 & $\begin{array}{l}\text { Chunks (cobble } \\
\text { stone pattern) }\end{array}$ \\
\hline 12 & 0.00 & 1499 & 1 & Chunks \\
\hline 10 & 0.00 & 1500 & 2 & Chunks \\
\hline 5 & 0.00 & 1500 & 3 & Chunks \\
\hline 5 & 0.00 & 1501 & 4 & Clearing \\
\hline 25 & 0.00 & 1534 & 5 & $\begin{array}{l}\text { Bright Clear } \\
\text { Surface }\end{array}$ \\
\hline 5 & 1.00 & 1532 & 5 & Darkening \\
\hline 133 & 0.50 & 1528 & 5 & Clear \\
\hline 241 & 0.60 & 1520 & 5.5 & $\begin{array}{l}\text { Surface Very } \\
\text { Bright }\end{array}$ \\
\hline 119 & 0.58 & 1520 & 6 & $\begin{array}{l}\text { Surface Very } \\
\text { Bright }\end{array}$ \\
\hline
\end{tabular}


Discussion and Results

The limits on program resources constrained testing to a subset of the full matrix of all feed forms, types of feeder, and feed rate. However, the excellent performance and clear advantages of the liquid slurry form, both in the simplicity and reliability of the feeding process, the lack of particulate entrainment and build-up of deposits on the crucible walls, and the favorable properties of the vitrified glass product, lead to the conclusion that it is the best feed option for the current bench-scale AVS Module operations.

The remaining issues are how much water content in the slurry can be reduced and still have it readily pumped into the AVS Module, and what the proper fill rate will be using a true hot hohlraum. These issues can be resolved quickly with further experiments on the pumping capabilities of concentrated slurries, and their performance in a hot hohlraum. 


\subsection{Bench-Scale Tests}

The primary objective of the AVS bench-scale testing is to produce an acceptable borosilicate glass at maximum waste loading 1 from the specified AZ-101 using the glass forming additives identified in the small-scale and large-scale scoping melts. The acceptance criteria for the bench-scale process consist of the PCT, TCLP, and degree of crystallinity. Additional objectives include as follows:

- Determining the minimum residence time for complete waste dissolution,

- Producing a homogenous waste form,

- Characterizing process effluents,

- Determining the extent of component volatilization during vitrification, and

- Obtaining relevant information on process design.

A total of four test runs were conducted of the AVS bench scale system. Table 4-33 provides a description of the testing sequence and the performance variables experienced. Runs 2 and 4 are the tests described in this report.

\begin{tabular}{|l|c|c|c|c|}
\hline \multicolumn{4}{|c|}{ Table 4-33. AVS Bench Scale Testing Matrix of Variables } \\
\hline Run Number & 1 & 2 & 3 & 4 \\
\hline Date Conducted & $10 / 31-11 / 01 / 02$ & $11 / 04-05 / 02$ & $\begin{array}{c}11 / 07 / 02 \\
\text { DOE witnessed }\end{array}$ & $11 / 18-19 / 02$ \\
\hline $\begin{array}{l}\text { Off-gas } \\
\text { analytical } \\
\text { equipment }\end{array}$ & Not Integrated & Integrated & Integrated & Integrated \\
\hline Time fed & 1 hour & 2 hours & $2+$ hours & $2+$ hours \\
\hline $\begin{array}{l}\text { Glass produced } \\
\text { (inches) }\end{array}$ & 2.5 & 3 & 2.9 & 3 \\
\hline $\begin{array}{l}\text { Initial charge } \\
\text { Designation }\end{array}$ & Slurry feed & $\begin{array}{c}\text { dry batch }+ \\
\text { slurry feed }\end{array}$ & $\begin{array}{c}\text { dry batch }+ \\
\text { slurry feed }\end{array}$ & $\begin{array}{c}\text { dry batch }+ \\
\text { slurry feed }\end{array}$ \\
\hline
\end{tabular}

Approximately 40 liters of feed batch was prepared by NOAH Laboratories and shipped to DIAL in a 30-gallon drum. The batch was prepared at 60 -wt $\%$ waste loading according to the formula established by DIAL during the small-scale and large-scale scoping studies. The 60 -wt\% waste loading formulation was determined by subtracting all glass forming chemicals agents. Run 2 was fed with the batch sent from NOAH Laboratories. This material is completely consistent compositionally with feed material prepared using TR-26 simulant. For Run 4, additional feed material was prepared by DIAL using the TR-26 simulant material. The feed was prepared according to the same formula as the feed prepared by NOAH Laboratories. The batch of DIAL feed was mixed with the NOAH feed batch prior to initiating the bench-scale run.

\footnotetext{
${ }^{1}$ The SOW at page 1 states, "conduct one qualification bench-scale test at maximum waste loading."
} 
A feed system, based on the COFFEE feed form slurry experiments, was adapted for the AVS bench-scale test stand. A motor equipped with an agitating shaft was mounted to the top of the thirty-gallon drum and was used during the testing activities to ensure the batch slurry remained well mixed. Slurry was fed from the drum using a variable speed peristaltic pump through santoprene tubing, which was connected to the copper feed tube. Feed rates for the test runs ranged from approximately $40 \mathrm{~mL}$ per minute to $100 \mathrm{~mL}$ per minute.

An initial charge of batch material was made to the crucible before the AVS system power was initiated. After the crucibles reached the prescribed temperature, the feed system was initiated. A camera was positioned over the site port above the top head of the bench scale apparatus. The camera was equipped with a special thermal imaging system that enabled differentiation of temperature within the melt crucible via multicolored thermal regions. Examples of the data output using this thermal imaging system are illustrated in Figure 4-9. Due to the assumption of target surface emissivity = 1, temperatures (so called, apparent blackbody temperature) from the thermal imaging system were a bit cooler then the pyrometer reads.

Process off-gas evolved during the testing activities was monitored and quantified using the DIAL gas analyzer system. Data from the off-gas analysis is presented in Test Data. The product glass was measured and sampled for elemental analysis. The gas data, as well as, the product glass analyses were compared to values predicted by a simple model. An overall mass balance was calculated based on the data collected and the predicted values. 
Section 4

Results and Discussion

Additional Tests of an Advanced Vitrification System (DE-AC26-00NT40801)
Radioactive Isolation Consortium, LLC Falls Church, VA 22046 www.ricllc.com

Figure 4-9 Thermal Images From Different Stages of Bench Scale Testing.
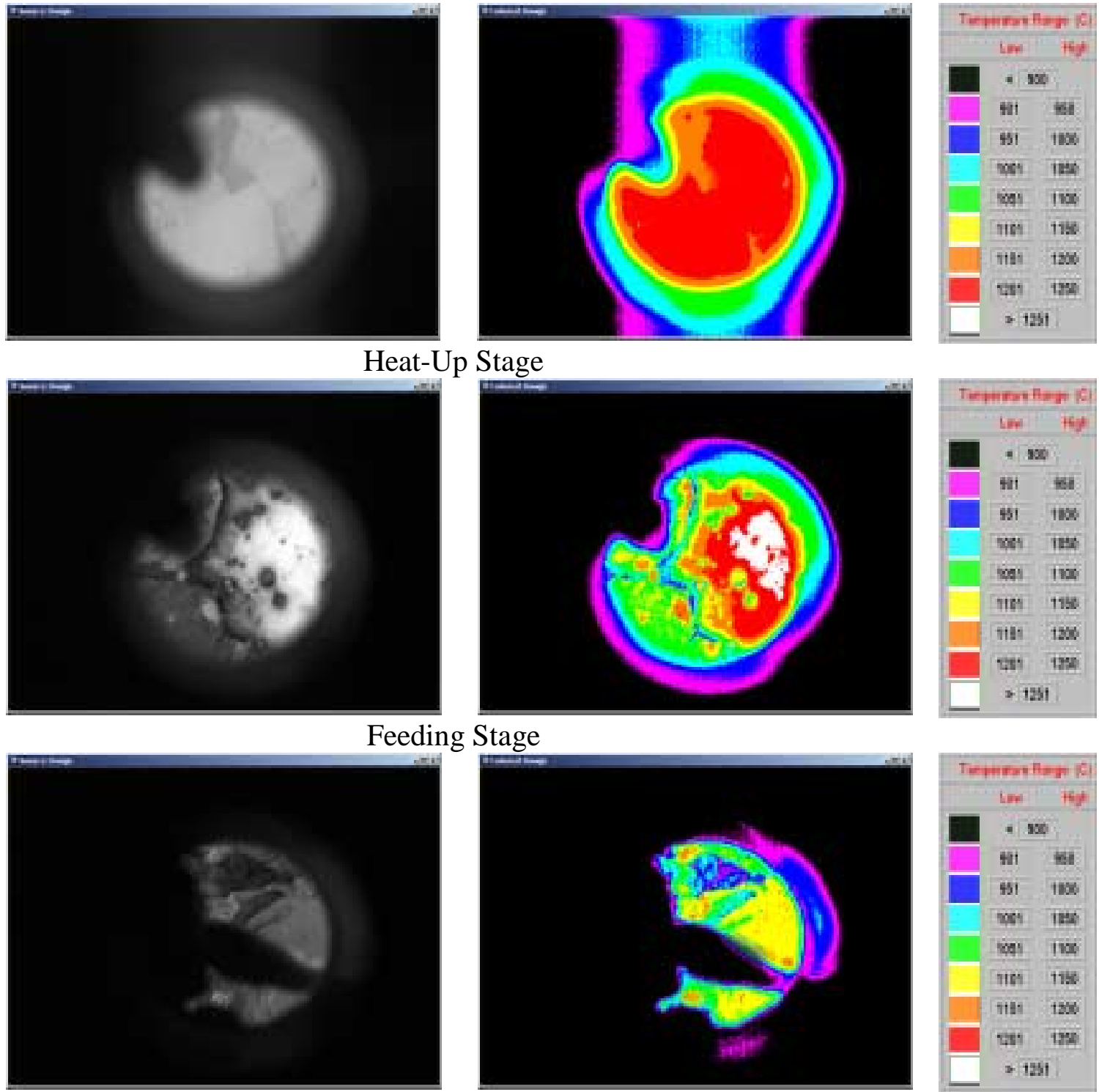

Feeding Stage (Temperature was below the detectable low limit.)
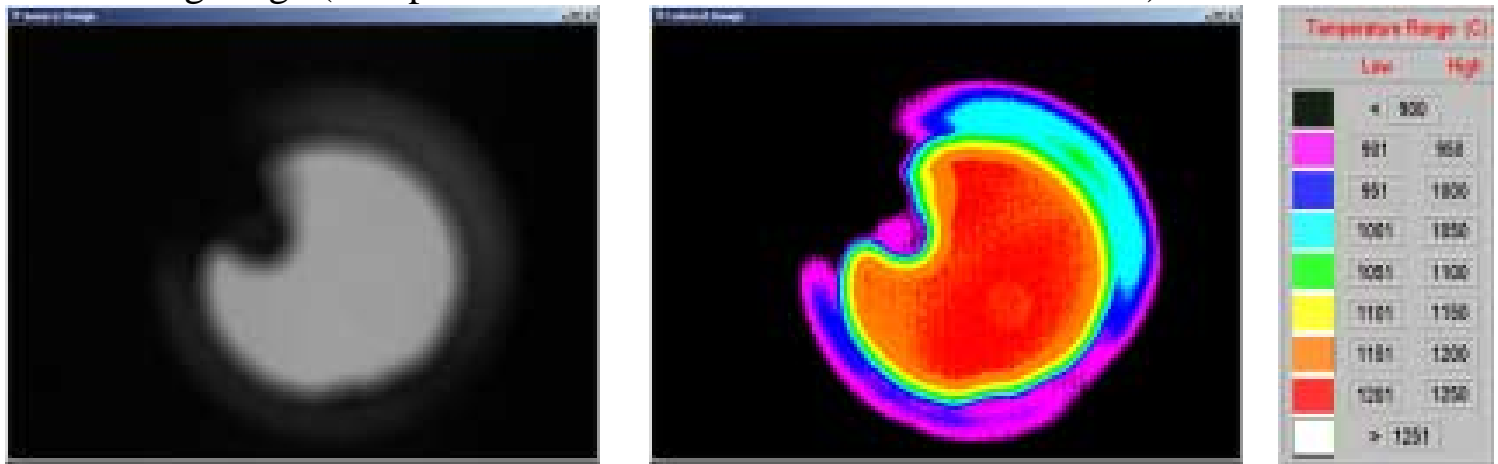

Cool-Down Stage 


\section{Test Highlights and General Observations}

\section{Bench-Scale Run 2}

AVS Bench-Scale Run 2 was performed using the slurry feed system, the off-gas treatment system, and the in-line gas analysis equipment. General information and observations made during the testing activities for AVS Run 2 are provided in this section. The glass analysis and process data are provided in the subsequent sections.

Prior to energizing the induction coil, the crucible was charged with $600 \mathrm{~mL}$ of slurry batch. This protected the bench scale crucible from thermal shock, by ensuring the feed slurry was fed onto a molten glass pool. The solids content of the slurry feed was approximately 30 percent by weight. Subsequent to feeding the $600 \mathrm{~mL}$ pre-charge of slurry and prior to energizing the coil, the feed system was flushed using de-ionized water in order to prevent plugging of the system.

The induction coil was powered to maintain a heating rate of $160^{\circ} \mathrm{C}$ per hour. This heating rate was maintained until the susceptor reached $240^{\circ} \mathrm{C}$, at which point the temperature was held constant for one hour. The power was then increased to sustain a heating rate of $240^{\circ} \mathrm{C}$ per hour. This heating rate was maintained until the crucible assembly reached $600^{\circ} \mathrm{C}$, at which time the heating rate was increased to $360^{\circ} \mathrm{C}$ per hour. This heating rate was maintained until the crucible system reached a final temperature of $1510^{\circ} \mathrm{C}$. The target temperature, the measured temperature and the power profile for this AVS bench-scale test run are provided in the following Figures 4-10 and 4-11.

\section{AVS Run 11/04/02 Temperature Profile}

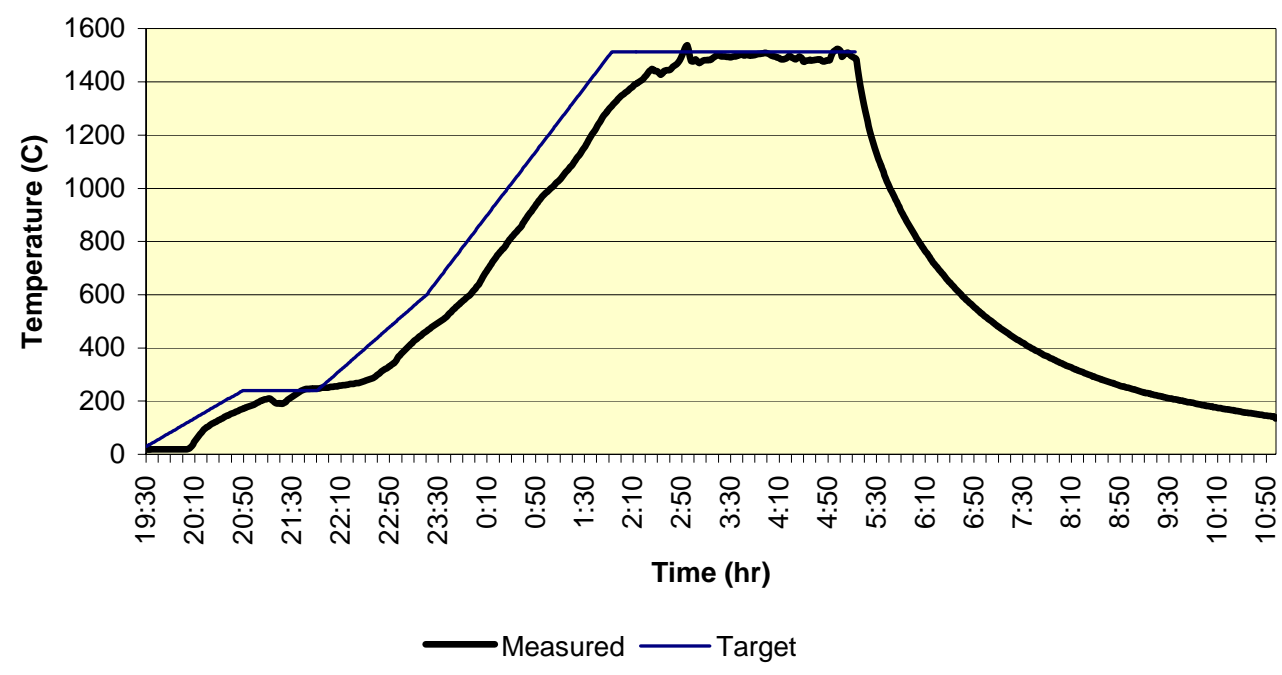

Figure 4-10 AVS Run 2 Temperature Profile 
AVS Run 11/04/02 Power Supply

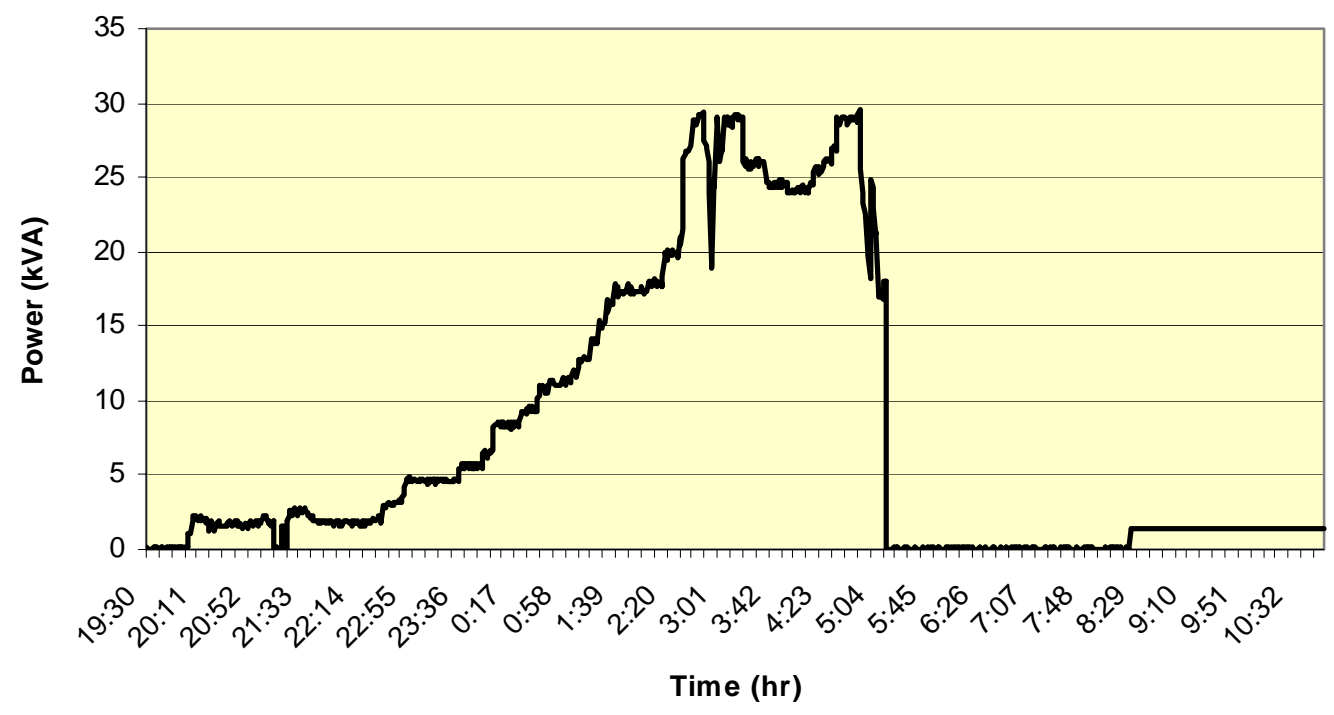

Figure 4-11: AVS Run 2 Power Profile

Approximately one hour after the AVS induction coil was energized, the low water flow alarm signaled and the power was automatically shut down. The water flow was increased and the induction coils were re-energized. The system remained under control during the remainder of the heating schedule. Six hours and twenty minutes were required to reach a temperature of $1450^{\circ} \mathrm{C}$.

Once the temperature reached $1450^{\circ} \mathrm{C}$, the slurry feed was initiated at approximately 40 $\mathrm{mL}$ per minute. Shortly after, the feed rate was increased to approximately $75 \mathrm{~mL}$ per minute. As the slurry was being fed to the crucible, dry material build-up was occurring on the tip of the copper feed tube. The dry material would form a stalagmite shaped mass of material. DIAL personnel noted that the feed flow to the melter diminished as more dry material collected at the end of the feed tube. As a consequence of the blockage, the direction of material flow was not consistent or predictable. Material continued to accumulate on the feed tube until the mass of dry material fell into the glass melt pool. This behavior continued in a cyclical manner throughout the slurry feeding activities. However, as the material blockages became more frequent, one of two actions was taken. Either small amounts of water were intermittently fed to the melter in order to flush the system, or the feed was surged to remove the blockage. Feed to the system was maintained for approximately $2 \frac{1}{2}$ hours, at which time it was noted that the gas analysis system was receiving no flow. Therefore, flow to the AVS was discontinued. The system was held at temperature for an additional 30 minutes before being de-energized.

After the crucible had cooled to room temperature, the lid and off-gas tube were removed and examined. It was evident that the feed material had migrated to the off-gas discharge port and plugged the off-gas line. 
Samples of the caustic scrubber solution were taken on regular intervals during the duration of the feeding activities.

\section{Bench-Scale Run 4}

AVS Bench-Scale Run 4 was performed using the slurry feed system, the in-line gas analysis equipment and the off-gas treatment system. General information and observations made during the testing activities for AVS Run 4 are provided in this section. The glass analysis and process data are provided in the subsequent sections.

Initially, the crucible was charged with $1.8 \mathrm{~kg}$ of dry batch formulated to produce a $60 \%$ waste loading glass product. This batch was prepared in a manner consistent with the dry batch preparation method. Following the dry batch addition, $715 \mathrm{~mL}$ of slurry feed batch was added to the top of the dry batch in order to help compact the dry material. The final height of the dry and slurry batch was approximately 8 inches.

The induction coil was powered to maintain a heating rate of $160^{\circ} \mathrm{C}$ per hour. This heating rate was maintained until the susceptor reached a temperature of $240^{\circ} \mathrm{C}$, at which point the temperature was held constant for one hour. The power was then increased to sustain a heating rate of $240^{\circ} \mathrm{C}$ per hour. This heating rate was maintained until the crucible assembly reached a temperature of $1100^{\circ} \mathrm{C}$, at which time the heating rate was decreased to $90^{\circ} \mathrm{C}$ per hour to reduce the amount of foaming expected. This heating rate was maintained until the crucible system reached a temperature of $1350^{\circ} \mathrm{C}$. After reaching $1350^{\circ} \mathrm{C}$, the heating rate was increased to $240^{\circ} \mathrm{C}$ per hour and this rate was maintained until the thermocouple on the surface of the graphite susceptor read $1510^{\circ} \mathrm{C}$. The system was energized and remained under control during the heating schedule. Nine hours were required to reach a temperature of $1450^{\circ} \mathrm{C}$. The target temperature, the power profile and the measured temperature for this AVS bench-scale test run are provided in Figure 4-12 and Figure 4-13. 
AVS Run 11/18/02: Temperature Profile

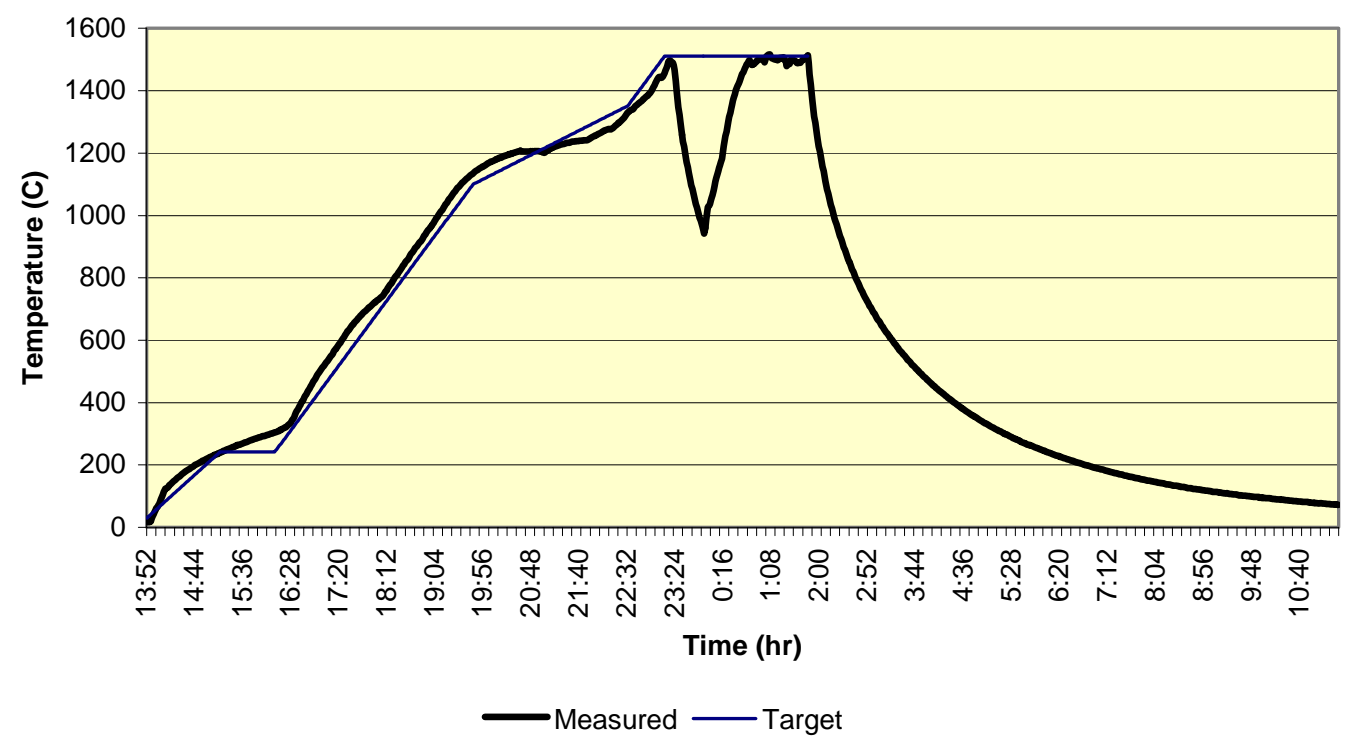

Figure 4-12: AVS Run 11/18/02 Temperature Profile

\section{AVS Run 11/18/02: Power Profile}

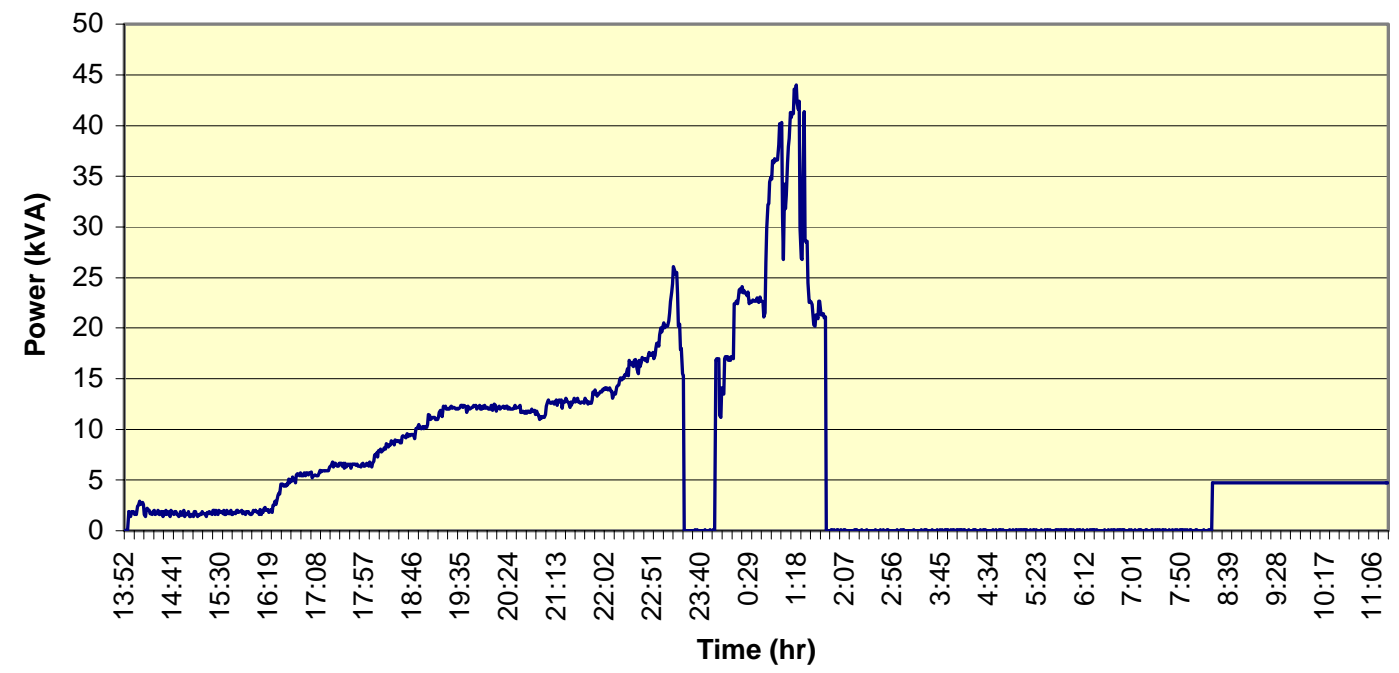

Figure 4-13: AVS Run 4 Power Profile

In order to reduce the amount of foaming, a small amount of water was added to the top of the batch material at $1290^{\circ} \mathrm{C}, 1340^{\circ} \mathrm{C}$, and $1385^{\circ} \mathrm{C}$.

Once the temperature reached $1450^{\circ} \mathrm{C}$, the slurry feed was initiated at approximately 50 $\mathrm{mL}$ per minute. As the slurry was being fed to the crucible, dry material build-up was occurring on the tip of the copper feed tube. The dry material would form a stalactite 
shaped mass of material. DIAL personnel noted that the feed flow to the melter diminished as more dry material collected at the end of the feed tube. As a consequence of the blockage, the direction of material flow was not consistent or predictable. Approximately 10 minutes after feed was initiated, the feed tube became completely obstructed. An effort was made to dislodge the blockage; however, the feed tube ruptured before the blockage was cleared. The induction coils were de-energized and the feed tube was cleared using a rotary hook device. The induction coils were re-energized and feed was re-initiated when the temperature reached $1500^{\circ} \mathrm{C}$. However, material continued to accumulate on the feed tube. The system was therefore flushed with water on a more frequent basis.

Forty minutes after feed was re-initiated, a small flame was observed on the top-head. The feed was immediately discontinued and the argon purge to the outer portion of the assembly was increased to remove the oxygen source and smother the flames. When the feed was restarted, it was determined that the feed tube was again obstructed. At the same time, it was noticed that a small amount of steam was escaping from the top head. It was decided to allow the system to hold at $1510^{\circ} \mathrm{C}$ to ensure a consistent melt and then de-energize the induction coil.

Samples of the caustic scrubber solution were taken on regular intervals during the duration of the feeding activities.

\section{Test Data}

Test Data from both runs will be grouped for a comprehensive perspective on the run campaign. Prior to initiating the AVS Bench-Scale test runs, the NOAH slurry feed was sampled and analyzed for chemical composition, percent solids and specific gravity. Following the operation of the bench scale system, the product glass was sampled and analyzed for chemical composition. Additional samples were taken for the PCT, TCLP, $\mathrm{XRD}$, and SEM analyses. This section includes the analytical results for the analyses mentioned above, as well as analysis of the process data from the AVS bench-scale runs, including off-gas composition and a steady state mass balance.

As directed in the scope of work, the glass product was sectioned horizontally into a top, middle, and bottom section. Each section of glass was then fragmented further, as shown in Figure 4-14 below. Individual samples were taken from the middle and from the perimeter of the three horizontal sections and submitted for analysis.

The section designations for the AVS bench-scale glass samples are as follows:

\section{Location}

Center of Cylinder Vertical Top

Side of Cylinder Vertical Top

Center of Cylinder Vertical Middle

Side of Cylinder Vertical Middle

Center of Cylinder Vertical Bottom

Side of Cylinder Vertical Bottom $\underline{\text { Designation }}$

TC

TS

MC

MS

$\mathrm{BC}$

BS 
The glass analyses were performed in the same manner as the analysis of sludge and dry batch, with three separate dissolutions used for each sample.
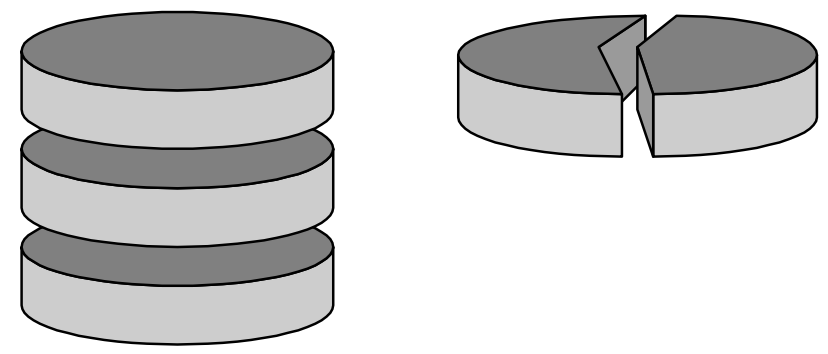

Figure 4-14. Glass Product Sampling Sections 


\section{AVS Bench-Scale Slurry Feed Chemical Composition}

The Chemical composition of the AVS Bench-Scale Slurry Batch Feed was measured and analyzed:

Table 4-34. Analysis of AVS Bench-Scale Slurry Batch Feed

\begin{tabular}{|c|c|c|c|c|c|c|c|c|c|}
\hline \multirow{2}{*}{ Oxide } & \multicolumn{4}{|c|}{ Elemental wt\% } & \multirow{2}{*}{$\begin{array}{l}\text { Conv } \\
\text { factor }\end{array}$} & \multirow{2}{*}{$\begin{array}{l}\text { Oxide } \\
\text { Wt\% }\end{array}$} & \multirow{2}{*}{ SD } & \multirow{2}{*}{ RSD } & \multirow{2}{*}{$\begin{array}{l}\text { Norm. } \\
\text { Wt\% }\end{array}$} \\
\hline & mw ave & fcl ave & fn ave & Average & & & & & \\
\hline $\mathrm{Al}_{2} \mathrm{O}_{3}$ & 3.91 & 6.62 & 6.79 & 6.70 & 1.8895 & 12.66 & 0.23 & 1.79 & 14.96 \\
\hline $\mathrm{As}_{2} \mathrm{O}_{3}$ & 0.02 & 0.06 & 0.05 & 0.06 & 1.3203 & 0.08 & 0.03 & 41.87 & 0.09 \\
\hline $\mathrm{B}_{2} \mathrm{O}_{3}$ & 0.00 & 1.45 & 1.44 & 1.45 & 3.2201 & 4.65 & 2.69 & 57.74 & 5.50 \\
\hline $\mathrm{BaO}$ & 0.02 & 0.06 & 0.06 & 0.06 & 1.1165 & 0.07 & 0.00 & 0.58 & 0.08 \\
\hline $\mathrm{CaO}$ & 0.26 & 0.40 & 0.39 & 0.40 & 1.3992 & 0.56 & 0.01 & 1.69 & 0.66 \\
\hline $\mathrm{CdO}$ & 0.54 & 0.55 & 0.53 & 0.54 & 1.1423 & 0.62 & 0.01 & 1.55 & 0.73 \\
\hline $\mathrm{CeO}_{2}$ & 0.00 & 0.10 & 0.11 & 0.11 & 1.2284 & 0.13 & 0.00 & 1.01 & 0.15 \\
\hline $\mathrm{Cr}_{2} \mathrm{O}_{3}$ & 0.03 & 0.06 & 0.06 & 0.06 & 1.4616 & 0.09 & 0.02 & 26.37 & 0.10 \\
\hline $\mathrm{Cs}_{2} \mathrm{O}$ & 0.00 & 0.00 & 0.15 & 0.15 & 1.0602 & 0.16 & 0.00 & 1.89 & 0.19 \\
\hline $\mathrm{CuO}$ & 0.03 & 0.04 & 0.04 & 0.03 & 1.2518 & 0.04 & 0.01 & 22.28 & 0.05 \\
\hline $\mathrm{Fe}_{2} \mathrm{O}_{3}$ & 12.30 & 12.60 & 12.70 & 12.53 & 1.4297 & 17.92 & 0.30 & 1.66 & 21.17 \\
\hline $\mathrm{K}_{2} \mathrm{O}$ & 0.24 & 0.24 & 0.24 & 0.24 & 1.2046 & 0.29 & 0.00 & 1.11 & 0.34 \\
\hline $\mathrm{La}_{2} \mathrm{O}_{3}$ & 0.02 & 0.56 & 0.56 & 0.56 & 1.1728 & 0.66 & 0.00 & 0.00 & $\begin{array}{l}0.78 \\
\end{array}$ \\
\hline $\mathrm{MgO}$ & 0.01 & 0.08 & 0.08 & 0.08 & 1.6583 & 0.13 & 0.01 & 6.23 & 0.16 \\
\hline $\mathrm{MnO}$ & 3.82 & 3.73 & 3.14 & 3.77 & 1.2912 & 4.87 & 0.08 & 1.72 & 5.75 \\
\hline $\mathrm{Na}_{2} \mathrm{O}$ & 0.67 & 0.00 & 0.00 & 0.67 & 1.3480 & 0.91 & & & 1.07 \\
\hline $\mathrm{NiO}$ & 0.69 & 0.70 & 0.69 & 0.69 & 1.2726 & 0.88 & 0.01 & 1.10 & 1.04 \\
\hline $\mathrm{PbO}$ & 0.18 & 0.22 & 0.23 & 0.22 & 1.0772 & 0.24 & 0.03 & 12.55 & 0.29 \\
\hline $\mathrm{Sb}_{2} \mathrm{O}_{5}$ & 0.26 & 0.27 & 0.23 & 0.26 & 1.3285 & 0.35 & 0.02 & 6.95 & 0.41 \\
\hline $\mathrm{SeO}_{2}$ & 0.12 & 0.15 & 0.15 & 0.14 & 1.4053 & 0.20 & 0.03 & 13.25 & 0.23 \\
\hline $\mathrm{SiO}_{2}$ & 11.43 & 11.70 & 12.20 & 11.95 & 2.1393 & 25.56 & 0.35 & 1.38 & 30.20 \\
\hline $\mathrm{SrO}$ & 2.04 & 3.19 & 3.25 & 3.22 & 1.1826 & 3.81 & 0.05 & 1.43 & 4.50 \\
\hline $\mathrm{TeO}_{2}$ & 0.13 & 0.19 & 0.19 & 0.19 & 1.2508 & 0.23 & 0.04 & 16.02 & 0.27 \\
\hline $\mathrm{TiO}_{2}$ & 0.07 & 0.09 & 0.09 & 0.08 & 1.6680 & 0.14 & 0.02 & 14.11 & 0.17 \\
\hline $\mathrm{ZnO}$ & 1.39 & 1.33 & 1.33 & 1.35 & 1.2446 & 1.68 & & & 1.98 \\
\hline $\mathrm{ZrO}_{2}$ & 4.93 & 5.01 & 4.89 & 4.97 & 1.3508 & 6.71 & 0.08 & 1.19 & 7.93 \\
\hline $\mathrm{P}_{2} \mathrm{O}_{5}$ & 0.08 & 0.11 & 0.07 & 0.09 & 2.2914 & 0.21 & 0.04 & 18.75 & 0.25 \\
\hline $\mathrm{SO}_{3}$ & 0.30 & 0.31 & 0.34 & 0.32 & 2.4971 & 0.81 & 0.05 & 5.77 & 0.96 \\
\hline Total & 43.48 & 49.81 & 49.98 & 50.90 & & 84.64 & & & 100.00 \\
\hline
\end{tabular}

Vitrified Product Chemical Composition

The glass produced in the AVS system testing was measured and analyzed for the generation of an overall mass balance of the process. Predictions were made based on the composition and amount of the slurry feed used in the run. A recovery was not calculated because the ceramic crucible could not be removed from the susceptor, consequently, a final weight of the crucible plus product glass could not be measured. The product glass weight was therefore not available. 
Table 4-35 lists the analyzed values for all prescribed elements for each sample taken and the percent relative standard deviation of the six data sets in AVS Bench-Scale Run 2. The average of the glass compositions is also reported, as is the normalized (of the average) composition. The complete set of analyses is maintained by DIAL.

\begin{tabular}{|c|c|c|c|c|c|}
\hline \multicolumn{6}{|c|}{ Table 4-35 DIAL Analyzed Composition of AVS Bench-Scale Run 2} \\
\hline Oxide & $\begin{array}{c}\text { Oxide wt } \\
\% \\
\end{array}$ & $\begin{array}{l}\text { Standard } \\
\text { Deviation } \\
\end{array}$ & RSD (\%) & \begin{tabular}{|c} 
\# Samples \\
per Run
\end{tabular} & $\begin{array}{l}\text { Normalized } \\
\text { Composition }\end{array}$ \\
\hline $\mathrm{Al}_{2} \mathbf{O}_{3}$ & 16.06 & 0.40 & 2.51 & 24 & 16.29 \\
\hline $\mathbf{A s}_{2} \mathbf{O}_{3}$ & 0.05 & 0.01 & 24.97 & 24 & 0.05 \\
\hline $\mathbf{B}_{2} \mathbf{O}_{3}$ & 5.25 & 0.19 & 3.68 & 24 & 5.33 \\
\hline $\mathrm{BaO}$ & 0.09 & 0.00 & 3.75 & 24 & 0.09 \\
\hline $\mathrm{CaO}$ & 0.67 & 0.03 & 4.58 & 24 & 0.68 \\
\hline CdO & 0.65 & 0.03 & 4.11 & 42 & 0.66 \\
\hline $\mathrm{CeO}_{2}$ & 0.14 & 0.00 & 2.80 & 24 & 0.14 \\
\hline $\mathrm{Cr}_{2} \mathrm{O}_{3}$ & 0.21 & 0.02 & 9.74 & 24 & 0.21 \\
\hline $\mathrm{Cs}_{2} \mathrm{O}$ & 0.15 & 0.01 & 4.15 & 12 & 0.15 \\
\hline $\mathrm{CuO}$ & 0.07 & 0.02 & 23.61 & 42 & 0.07 \\
\hline $\mathrm{Fe}_{2} \mathrm{O}_{3}$ & 20.02 & 0.83 & 4.14 & 24 & 20.30 \\
\hline $\mathrm{K}_{2} \mathrm{O}$ & 0.31 & 0.02 & 6.43 & 30 & 0.31 \\
\hline $\mathrm{La}_{2} \mathrm{O}_{3}$ & 0.70 & 0.02 & 2.90 & 24 & 0.71 \\
\hline MgO & 0.16 & 0.01 & 3.86 & 24 & 0.16 \\
\hline MnO & 5.62 & 0.30 & 5.40 & 30 & 5.70 \\
\hline $\mathrm{Na}_{2} \mathrm{O}$ & 1.13 & 0.03 & 2.39 & 18 & 1.15 \\
\hline $\mathrm{NiO}$ & 1.01 & 0.07 & 6.59 & 30 & 1.03 \\
\hline PbO & 0.29 & 0.01 & 2.89 & 42 & 0.29 \\
\hline $\mathrm{Sb}_{2} \mathrm{O}_{5}$ & 0.35 & 0.05 & 14.56 & 30 & 0.35 \\
\hline $\mathrm{SeO}_{2}$ & 0.00 & & & 42 & 0.00 \\
\hline $\mathrm{SiO}_{2}$ & 30.88 & 0.88 & 2.86 & 24 & 31.32 \\
\hline SrO & 4.42 & 0.16 & 3.74 & 24 & 4.48 \\
\hline $\mathrm{TeO}_{2}$ & 0.12 & 0.01 & 9.30 & 30 & 0.12 \\
\hline $\mathrm{TiO}_{2}$ & 0.17 & 0.01 & 5.12 & 42 & 0.18 \\
\hline $\mathrm{ZnO}$ & 1.88 & 0.14 & 7.71 & 42 & 1.91 \\
\hline $\mathrm{ZrO}_{2}$ & 7.58 & 0.59 & 7.75 & 18 & 7.69 \\
\hline $\mathbf{P}_{2} \mathbf{O}_{5}$ & 0.21 & 0.02 & 7.89 & 18 & 0.21 \\
\hline $\mathrm{SO}_{3}$ & 0.40 & 0.02 & 6.00 & 24 & 0.41 \\
\hline \multicolumn{5}{|l|}{ Total } & 100.00 \\
\hline \multirow{2}{*}{\multicolumn{4}{|c|}{ Waste Loading }} & Method 1 & 60.30 \\
\hline & & & & Method 2 & 62.00 \\
\hline
\end{tabular}

Table 4-36 lists the analyzed values for all prescribed elements for each sample taken and the percent relative standard deviation of the six data sets for Bench Scale Run 4. The average of the glass compositions is also reported, as is the normalized (of the average) composition. 


\begin{tabular}{|c|c|c|c|c|c|}
\hline \multicolumn{6}{|c|}{ Table 4-36 DIAL Analyzed Composition of AVS Bench-Scale Run 4} \\
\hline Oxide & $\begin{array}{c}\text { Oxide wt } \\
\%\end{array}$ & $\begin{array}{l}\text { Standard } \\
\text { Deviation }\end{array}$ & RSD (\%) & $\begin{array}{c}\text { \# Samples } \\
\text { per Run }\end{array}$ & $\begin{array}{c}\text { Normalized } \\
\text { Composition }\end{array}$ \\
\hline $\mathbf{A l}_{2} \mathbf{O}_{3}$ & 17.53 & 0.71 & 4.06 & 24 & 17.69 \\
\hline $\mathrm{As}_{\mathbf{2}} \mathrm{O}_{3}$ & 0.06 & 0.01 & 23.68 & 24 & 0.06 \\
\hline $\mathbf{B}_{2} \mathbf{O}_{3}$ & 5.42 & 0.22 & 3.98 & 24 & 5.47 \\
\hline $\mathrm{BaO}$ & 0.08 & 0.00 & 4.51 & 24 & 0.09 \\
\hline $\mathrm{CaO}$ & 0.65 & 0.03 & 4.61 & 24 & 0.66 \\
\hline $\mathrm{CdO}$ & 0.68 & 0.03 & 4.33 & 42 & 0.69 \\
\hline $\mathrm{CeO}_{2}$ & 0.14 & 0.01 & 4.09 & 24 & 0.14 \\
\hline $\mathrm{Cr}_{2} \mathrm{O}_{3}$ & 0.21 & 0.02 & 10.21 & 24 & 0.21 \\
\hline $\mathrm{Cs}_{2} \mathrm{O}$ & 0.14 & 0.01 & 5.35 & 12 & 0.14 \\
\hline $\mathrm{CuO}$ & 0.07 & 0.02 & 26.63 & 42 & 0.07 \\
\hline $\mathrm{Fe}_{2} \mathrm{O}_{3}$ & 20.02 & 0.91 & 4.57 & 24 & 20.21 \\
\hline $\mathrm{K}_{2} \mathrm{O}$ & 0.27 & 0.01 & 5.32 & 30 & 0.27 \\
\hline $\mathrm{La}_{2} \mathrm{O}_{3}$ & 0.61 & 0.02 & 4.02 & 24 & 0.62 \\
\hline MgO & 0.16 & 0.01 & 5.09 & 24 & 0.16 \\
\hline MnO & 5.57 & 0.25 & 4.44 & 30 & 5.62 \\
\hline $\mathrm{Na}_{2} \mathrm{O}$ & 1.03 & 0.02 & 1.73 & 18 & 1.04 \\
\hline $\mathrm{NiO}$ & 1.01 & 0.06 & 5.93 & 30 & 1.02 \\
\hline PbO & 0.31 & 0.01 & 3.08 & 42 & 0.32 \\
\hline $\mathrm{Sb}_{2} \mathrm{O}_{5}$ & 0.32 & 0.02 & 5.12 & 30 & 0.33 \\
\hline $\mathrm{SeO}_{2}$ & 0.00 & & & 42 & 0.00 \\
\hline $\mathrm{SiO}_{2}$ & 30.38 & 1.21 & 3.98 & 24 & 30.66 \\
\hline $\mathrm{SrO}$ & 4.37 & 0.18 & 4.17 & 24 & 4.41 \\
\hline $\mathrm{TeO}_{2}$ & 0.17 & 0.01 & 8.50 & 30 & 0.17 \\
\hline $\mathrm{TiO}_{2}$ & 0.17 & 0.01 & 7.74 & 42 & 0.17 \\
\hline $\mathrm{ZnO}$ & 1.92 & 0.17 & 8.64 & 42 & 1.94 \\
\hline $\mathrm{ZrO}_{2}$ & 7.15 & 0.10 & 1.39 & 18 & 7.21 \\
\hline $\mathbf{P}_{2} \mathbf{O}_{5}$ & 0.24 & 0.05 & 20.80 & 18 & 0.24 \\
\hline $\mathrm{SO}_{3}$ & 0.38 & 0.03 & 7.20 & 24 & 0.39 \\
\hline \multicolumn{5}{|l|}{ Total } & 100.00 \\
\hline \multirow{2}{*}{\multicolumn{4}{|c|}{ Waste Loading }} & Method 1 & 60.88 \\
\hline & & & & Method 2 & 62.48 \\
\hline
\end{tabular}

TCLP

\begin{tabular}{|l|l|l|l|l|l|l|l|l|}
\hline \multicolumn{7}{|c|}{ Table 4-37 Results of TCLP testing on vitrified product from Run 2 } \\
\hline \hline Element & $\begin{array}{l}\text { Reg. } \\
\text { Limit } \\
\end{array}$ & $\begin{array}{l}\text { Top } \\
\text { ppm) }\end{array}$ & $\begin{array}{l}\text { Top } \\
\text { Side }\end{array}$ & $\begin{array}{l}\text { Middle } \\
\text { Center }\end{array}$ & $\begin{array}{l}\text { Midde } \\
\text { Senter }\end{array}$ & $\begin{array}{l}\text { Bottom } \\
\text { Side }\end{array}$ & $\begin{array}{l}\text { Bottom } \\
\text { Center }\end{array}$ & $\begin{array}{l}\text { Overall } \\
\text { Average }\end{array}$ \\
\hline As & 5.0 & 0.013 & 0.015 & 0.02 & 0.17 & 0.02 & 0.02 & $\begin{array}{l}0.016 \pm \\
0.003\end{array}$ \\
\hline $\mathrm{Ba}$ & 100.0 & 0.19 & 0.17 & 0.19 & 0.27 & 0.15 & 0.05 & $0.15 \pm 0.14$ \\
\hline $\mathrm{Cd}$ & 1 & 0.12 & 0.13 & 0.14 & 0.12 & 0.15 & 0.16 & $0.15 \pm 0.02$ \\
\hline $\mathrm{Cr}$ & 5 & 0.003 & 0.003 & 0.003 & 0.003 & 0.003 & 0.003 & $0.003 \pm$ \\
& & & & & & & & 0.001 \\
\hline $\mathrm{Pb}$ & 5 & 0.061 & 0.073 & 0.063 & 0.50 & 0.26 & 0.18 & $0.14 \pm 0.18$ \\
\hline $\mathrm{Se}$ & 1.0 & bdl & bdl & bdl & bdl & bdl & bdl & NA \\
\hline \hline
\end{tabular}




\begin{tabular}{|c|c|c|c|c|c|c|c|c|}
\hline \multirow[t]{2}{*}{ Element } & \multirow{2}{*}{$\begin{array}{l}\text { Reg. } \\
\text { Limit } \\
(\mathrm{ppm})\end{array}$} & \multicolumn{7}{|c|}{ Concentration (ppm) } \\
\hline & & $\begin{array}{l}\text { Top } \\
\text { Side }\end{array}$ & $\begin{array}{l}\text { Top } \\
\text { Center }\end{array}$ & $\begin{array}{l}\text { Middle } \\
\text { Side }\end{array}$ & $\begin{array}{l}\text { Middle } \\
\text { Center }\end{array}$ & $\begin{array}{l}\text { Bottom } \\
\text { Side }\end{array}$ & $\begin{array}{l}\text { Bottom } \\
\text { Center }\end{array}$ & $\begin{array}{l}\text { Overall } \\
\text { Average }\end{array}$ \\
\hline As & 5.0 & 0.018 & 0.028 & 0.019 & 0.016 & 0.015 & 0.018 & $\begin{array}{l}0.019 \pm \\
0.009\end{array}$ \\
\hline $\mathrm{Ba}$ & 100.0 & 0.45 & 0.15 & 0.15 & 0.19 & 0.19 & 0.14 & $0.17 \pm 0.16$ \\
\hline $\mathrm{Cd}$ & 1 & 0.13 & 0.16 & 0.14 & 0.13 & 0.13 & 0.14 & $0.14 \pm 0.03$ \\
\hline $\mathrm{Cr}$ & 5 & 0.002 & 0.002 & 0.002 & 0.002 & 0.002 & 0.002 & $\begin{array}{l}0.002 \pm \\
0.001\end{array}$ \\
\hline $\mathrm{Pb}$ & 5 & 0.065 & 0.27 & 0.21 & 0.064 & 0.064 & 0.36 & $0.17 \pm 0.25$ \\
\hline $\mathrm{Se}$ & 1.0 & bdl & 0.022 & bdl & 0.011 & bdl & 0.010 & $0.014 \pm 0.007$ \\
\hline
\end{tabular}

PCT

Table 4-39 Results of PCT testing on bench-scale vitrified product from Run 2.

\begin{tabular}{|c|c|c|c|c|c|c|c|c|}
\hline Element & $\begin{array}{c}\text { SRL- } \\
\text { EA }\end{array}$ & $\begin{array}{l}\text { Top } \\
\text { Side }\end{array}$ & $\begin{array}{l}\text { Top } \\
\text { Center }\end{array}$ & $\begin{array}{l}\text { Middle } \\
\text { Side }\end{array}$ & $\begin{array}{l}\text { Middle } \\
\text { Center }\end{array}$ & $\begin{array}{l}\text { Bottom } \\
\text { Side }\end{array}$ & $\begin{array}{l}\text { Bottom } \\
\text { Center }\end{array}$ & $\begin{array}{l}\text { Bench } \\
\text { Scale } 2 \\
\text { Average }\end{array}$ \\
\hline \multicolumn{9}{|c|}{ 7-day PCT Normalized Concentration (g/L) } \\
\hline $\mathrm{B}$ & 15.15 & 0.10 & 0.10 & 0.10 & 0.09 & 0.10 & 0.10 & 0.10 \\
\hline $\mathrm{Li}$ & 8.37 & bdl & bdl & bdl & bdl & bdl & bdl & NA \\
\hline $\mathrm{Na}$ & 10.68 & 0.17 & 0.16 & 0.17 & 0.17 & 0.18 & 0.17 & 0.17 \\
\hline $\mathrm{Si}$ & 3.36 & 0.08 & 0.08 & 0.08 & 0.08 & 0.08 & 0.08 & 0.08 \\
\hline $\begin{array}{l}\mathrm{pH} \text { after } 7 \\
\text { days }\end{array}$ & 11.57 & 7.43 & 7.44 & 7.47 & 7.46 & 7.51 & 7.65 & 7.49 \\
\hline
\end{tabular}

Table 4-40 Results of PCT testing on bench-scale vitrified product from Run 4.

\begin{tabular}{|c|c|c|c|c|c|c|c|c||}
\hline Element & $\begin{array}{c}\text { SRL- } \\
\text { EA }\end{array}$ & $\begin{array}{l}\text { Top } \\
\text { Side }\end{array}$ & $\begin{array}{l}\text { Top } \\
\text { Center }\end{array}$ & $\begin{array}{l}\text { Middle } \\
\text { Side }\end{array}$ & $\begin{array}{l}\text { Middle } \\
\text { Center }\end{array}$ & $\begin{array}{l}\text { Bottom } \\
\text { Side }\end{array}$ & $\begin{array}{l}\text { Bottom } \\
\text { Center }\end{array}$ & $\begin{array}{l}\text { Bench } \\
\text { Scale 4 } \\
\text { Average }\end{array}$ \\
\hline 7-day PCT & \multicolumn{7}{|c|}{} \\
\hline $\mathrm{B}$ & 15.15 & 0.10 & 0.10 & .09 & 0.10 & 0.10 & 0.10 & 0.10 \\
\hline $\mathrm{Li}$ & 8.37 & bdl & bdl & bdl & bdl & bdl & bdl & NA \\
\hline $\mathrm{Na}^{*}$ & 10.68 & 0.53 & 0.27 & 0.27 & 0.31 & 0.26 & 0.26 & 0.32 \\
\hline $\mathrm{Si}$ & 3.36 & 0.08 & 0.09 & 0.08 & 0.09 & 0.08 & 0.08 & 0.08 \\
\hline $\begin{array}{l}\mathrm{pH} \text { after 7 } \\
\text { days }\end{array}$ & 11.57 & 7.64 & 7.57 & 7.55 & 7.59 & 7.57 & 7.59 & 7.59 \\
\hline
\end{tabular}

* Na data were adjusted to account for filter contamination

$\underline{\text { XRD/SEM Analysis }}$

Crystallinity for AVS Bench-Scale 4 is discussed in Section 5. 


\section{Tg Analysis}

The glass transition temperature, $\mathrm{T}_{\mathrm{g}}$, was measured by STA at DIAL. The glass transition temperature data, as measured by Simultaneous Thermal Analysis at DIAL using a Perkin Elmer TG-DTA 6300, Pyris Diamond analytical instrument are reported in Table 4-41-.

\begin{tabular}{|c|c|c|}
\hline Table 4-41 Glass Transition Temperature, $\mathbf{T}_{\mathbf{g}}$, Determinations by STA in $\left({ }^{\mathbf{0}} \mathbf{C}\right)$ \\
\hline Sample Location & Bench Scale Run 2 & Bench Scale Run 4 \\
\hline Top, Center & 650 & 670 \\
\hline Top, Side & 668 & 660 \\
\hline Middle, Center & 651 & 646 \\
\hline Middle Side & 655 & 652 \\
\hline Bottom, Center & 663 & 664 \\
\hline Bottom, Side & 657 & 655 \\
\hline Average & \multirow{6}{*}{$\mathbf{6 5 7}^{\circ} \mathbf{1 1} \mathbf{C}$} & $\mathbf{6 5 8}^{\circ} \mathbf{C}$ \\
\hline
\end{tabular}

\section{Offgas and Mass Balance Analysis}

The AVS vitrification system was operated according to a pre-determined temperature profile. A gas collection and analysis system was operated during processing and the data was recorded. Process gas analyzer results during surrogate feed to the AVS were compared to values calculated from an oxide spreadsheet prepared by DIAL.

During Run 2 the bench scale system was pre-charged with a mixture of slurry feed and dried simulant prior to startup. The system was then heated according to the temperature schedule determined by the laboratory tests. After approximately 400 minutes of heatup, additional waste surrogate was fed to the system. To obtain a mass balance, a portion of the feed period was chosen for analysis. For AVS Run 2, this consisted of 52 minutes of feed operation beginning 11-05-2002 02:25. The slurry feed rate during this time was assumed to be $50 \mathrm{ml} / \mathrm{min}$. For AVS Run 4, this consisted of 10 minutes of feed operation beginning 11-18-2002 23:05. The slurry feed rate during this time was assumed to be 75 $\mathrm{ml} / \mathrm{min}$. 


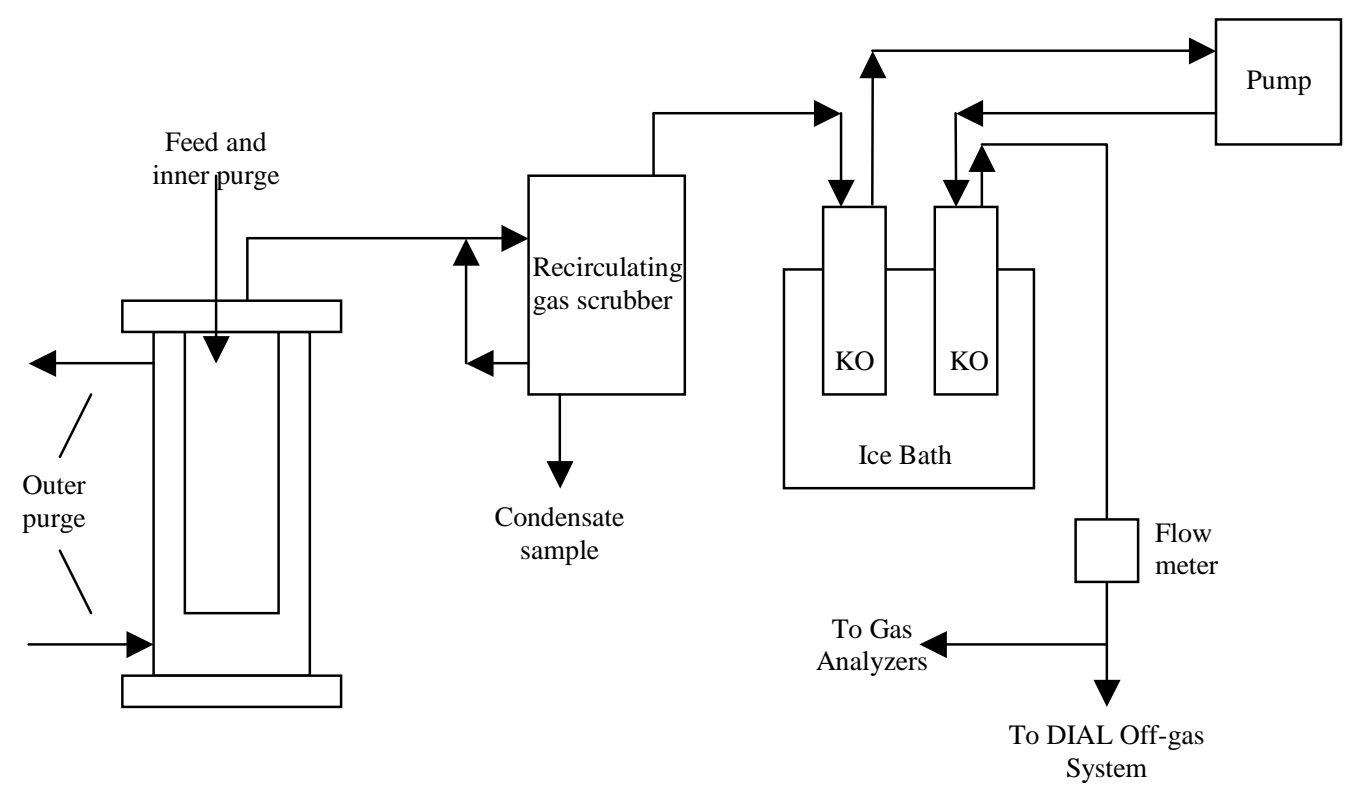

Figure 4-15. Schematic of Bench Scale Apparatus Configuration

\section{$\underline{\text { Run } 2}$}

For Run 2 the gas scrubber system was loaded with 1 liter of $25 \% \mathrm{NaOH}$ mixed with 9 gallons of water. The outer purge was sent to the DIAL off-gas system. Because of the lack of a true seal between the inner and outer purges, the off-gas system pump was run to draw an amount equal to the inner purge. This was an attempt to get a representative sample from the crucible.

As can be seen from Figures 4-16 and 4-17, gases were evolved during the heatup stage as oxides were formed from the pre-charged of waste feed. DIAL's process gas analyzers and data acquisition system were used to determine and record gas concentrations for $\mathrm{CO}, \mathrm{CO}_{2}, \mathrm{NO}, \mathrm{SO}_{2}, \mathrm{O}_{2}$, and $\mathrm{H}_{2}$. All instruments were calibrated prior to the AVS testing with the exception of the $\mathrm{H}_{2}$ analyzer (the hydrogen gas standard failed to arrive in time). 


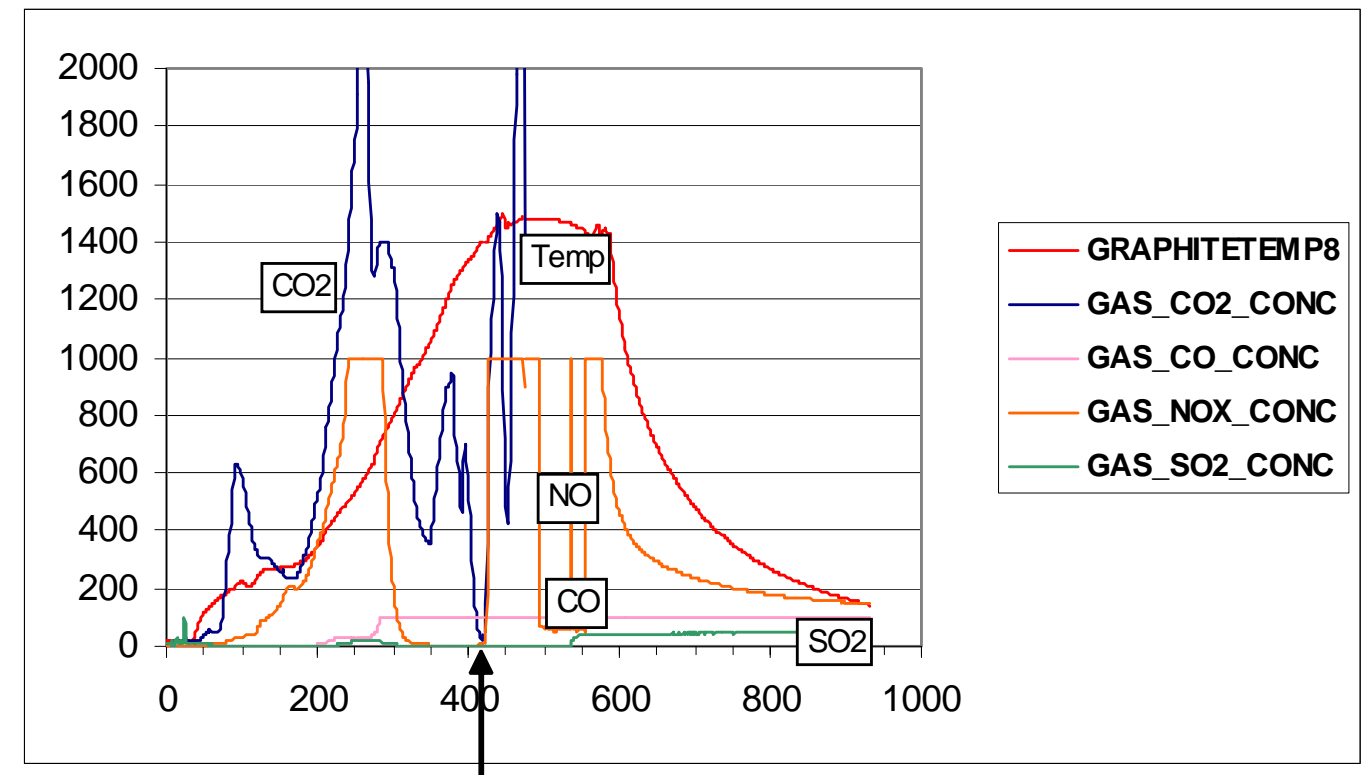

Start Waste

Feed

Figure 4-16. Analysis of $\mathrm{CO}, \mathrm{CO}_{2}, \mathrm{NO}_{\mathrm{x}}$, and $\mathrm{SO}_{2}$ versus Runtime (min) for Run 2

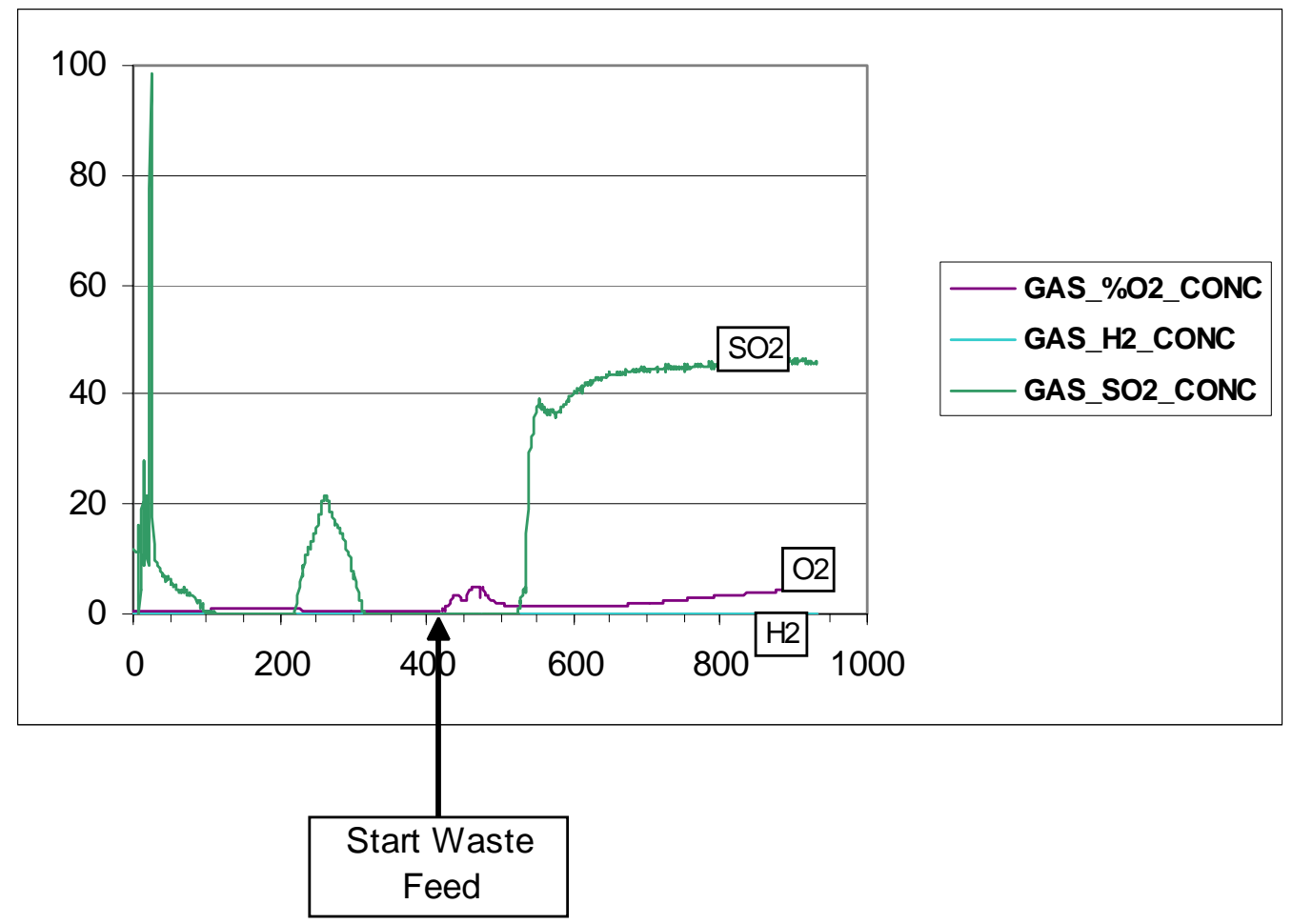

Figure 4-17. Analysis of $\% \mathrm{O}_{2}, \mathrm{H}_{2}, \mathrm{NO}_{\mathrm{x}}$, and $\mathrm{SO}_{2}$ Versus Runtime (min) for Run 2 
Figures 4-18 and 4-19 show data from the actual balance period. With the exception of $\mathrm{CO}$, all of the gas concentrations had returned to zero immediately prior to the start of the waste feed. This was anticipated as the end of gas evolution resulting from the initial waste charge. As the run started, it can be seen that gas evolution began again and continued for the length of the balance period.

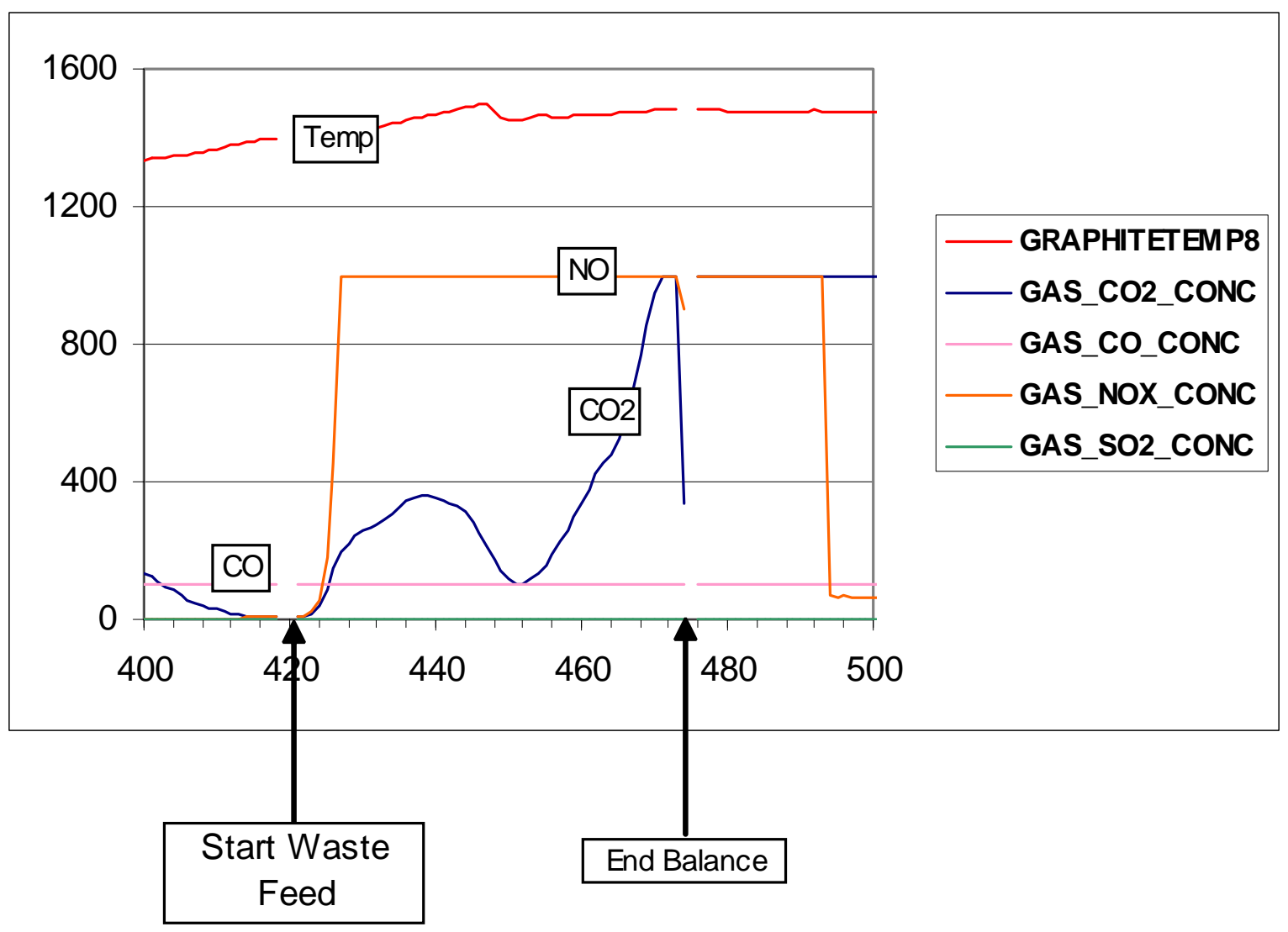

Figure 4-18 Gas Analysis During Balance Period for Run 2 


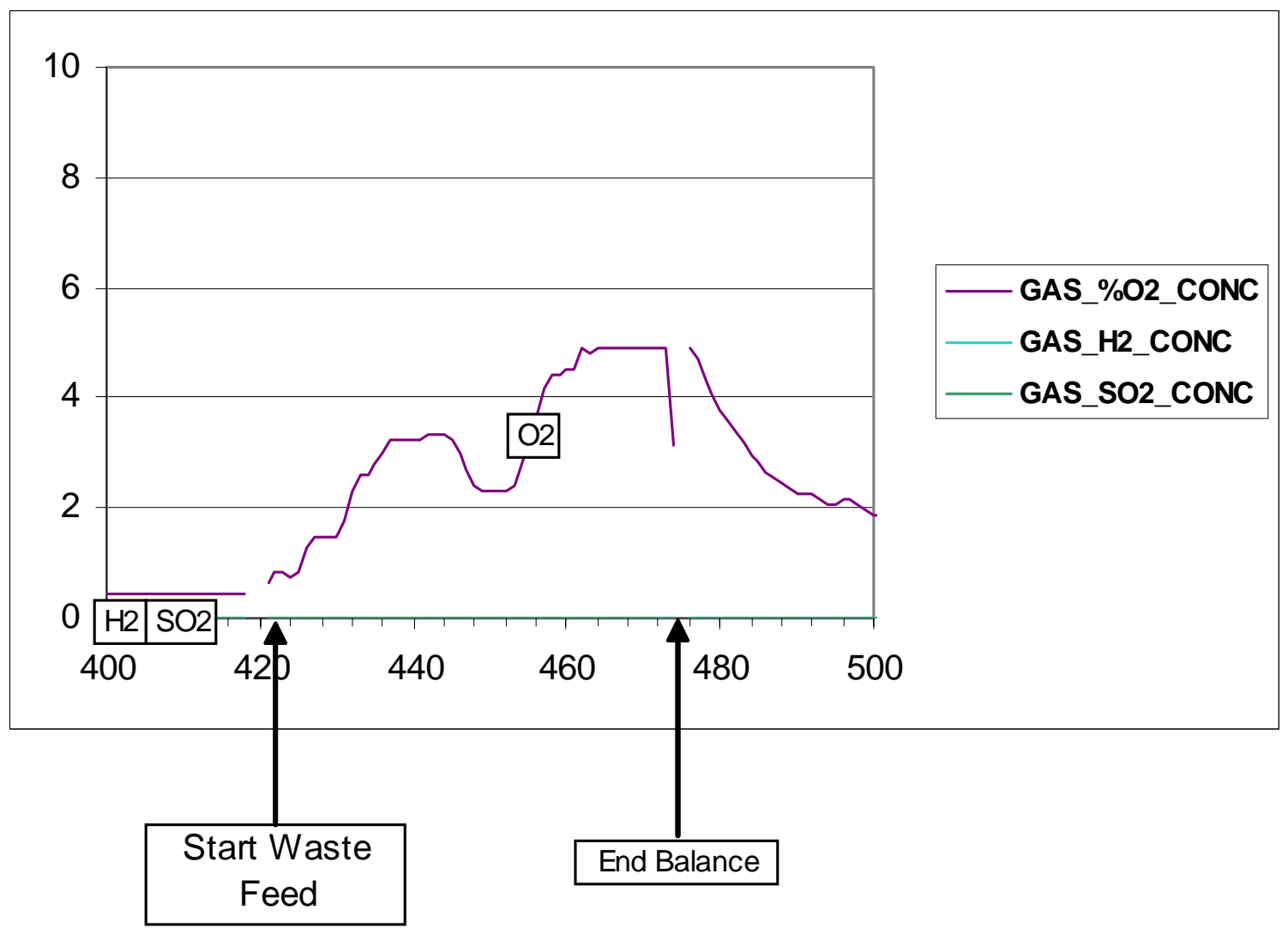

Figure 4-19. Gas Analysis During Balance Period for Run 2

In addition to the process analyzer data, samples were taken of the scrubber water as shown in Table 4-42. This data was converted to equivalent concentrations as shown in Table 4-43. 
Table 4-42. Elemental Scrubber Water Concentrations for Run 2

Elemental Concentrations in Scrubber Water Samples of AVS Run2 in ppm

\begin{tabular}{|c|c|c|c|c|c|c|c|c|c|c|}
\hline \multirow[t]{2}{*}{ Element } & \multirow{2}{*}{$\begin{array}{c}Q L \\
(p p b)\end{array}$} & \multicolumn{5}{|c|}{ AVS-2-2:39 } & \multicolumn{4}{|c|}{ AVS-2-3:30 } \\
\hline & & & -1 & -2 & Average & SD (+/-) & -1 & -2 & Average & SD (+/-) \\
\hline $\mathrm{Al}$ & 92.26 & & 0.42 & 0.48 & 0.45 & 0.04 & 0.63 & 0.73 & 0.68 & 0.07 \\
\hline As & 28.00 & & 0.07 & 0.07 & 0.07 & 0.00 & 0.73 & 0.73 & 0.73 & 0.00 \\
\hline B & 89.14 & & 4.64 & 4.28 & 4.46 & 0.25 & 38.10 & 38.00 & 38.05 & 0.07 \\
\hline $\mathrm{Ba}$ & 3.96 & & 0.02 & 0.02 & 0.02 & 0.01 & 0.02 & 0.02 & 0.02 & 0.00 \\
\hline $\mathrm{Ca}$ & 74.21 & & 0.99 & 0.98 & 0.99 & 0.00 & 0.79 & 0.76 & 0.78 & 0.03 \\
\hline $\mathrm{Cd}$ & 0.50 & & 0.22 & 0.24 & 0.23 & 0.01 & 0.46 & 0.43 & 0.44 & 0.02 \\
\hline $\mathrm{Ce}$ & 11.56 & bdl & bdl & & bdl & & bdl & & bdl & \\
\hline $\mathrm{Cr}$ & 8.69 & bdl & bdl & & bdl & & 0.10 & 0.09 & 0.10 & 0.00 \\
\hline Cs & 3.41 & & 0.48 & 0.48 & 0.48 & 0.00 & 1.02 & 1.00 & 1.01 & 0.01 \\
\hline $\mathrm{Cu}$ & 22.90 & & 0.03 & 0.03 & 0.03 & 0.00 & 0.06 & 0.06 & 0.06 & 0.00 \\
\hline $\mathrm{Fe}$ & 6.61 & & 0.30 & 0.38 & 0.34 & 0.05 & 1.28 & 1.29 & 1.29 & 0.01 \\
\hline K2 & 112.84 & & 8.02 & 8.36 & 8.19 & 0.24 & 9.02 & 9.26 & 9.14 & 0.17 \\
\hline $\mathrm{La}$ & 1.12 & bdl & bdl & & bdl & & bdl & & bdl & \\
\hline $\mathrm{Mg}$ & 10.09 & & 0.04 & 0.06 & 0.05 & 0.02 & 0.06 & 0.08 & 0.07 & 0.01 \\
\hline $\mathrm{Mn}$ & 0.07 & & 0.02 & 0.02 & 0.02 & 0.00 & 0.07 & 0.08 & 0.08 & 0.00 \\
\hline $\mathrm{Ni}$ & 2.89 & bdl & bdl & & bdl & & bdl & & bdl & \\
\hline $\mathrm{Pb}$ & 22.95 & & 0.12 & 0.13 & 0.12 & 0.00 & 0.26 & 0.26 & 0.26 & 0.00 \\
\hline $\mathrm{Sb}$ & 9.12 & & 0.04 & 0.02 & 0.03 & 0.02 & 0.27 & 0.24 & 0.25 & 0.02 \\
\hline $\mathrm{Se}$ & 19.64 & & 5.73 & 5.92 & 5.83 & 0.13 & 23.40 & 22.40 & 22.90 & 0.71 \\
\hline $\mathrm{Si}$ & 216.08 & & 7.73 & 8.30 & 8.02 & 0.40 & 7.56 & 8.29 & 7.93 & 0.52 \\
\hline $\mathrm{Sr}$ & 65.45 & & 0.16 & 0.77 & 0.47 & 0.43 & 0.29 & 0.35 & 0.32 & 0.05 \\
\hline $\mathrm{Te}$ & 17.56 & & 0.81 & 0.80 & 0.81 & 0.01 & 3.47 & 3.28 & 3.38 & 0.13 \\
\hline $\mathrm{Ti}$ & 9.90 & bdl & bdl & & bdl & & 0.01 & 0.01 & 0.01 & 0.00 \\
\hline $\mathrm{Zn}$ & 0.98 & & 0.15 & 0.16 & 0.15 & 0.01 & 0.35 & 0.34 & 0.34 & 0.00 \\
\hline $\mathrm{Zr}$ & 5.36 & & 0.01 & 0.25 & 0.13 & 0.18 & 0.01 & 0.03 & 0.02 & 0.01 \\
\hline$P$ & 5.41 & bdl & bdl & & bdl & & bdl & & bdl & \\
\hline$S$ & 51.92 & & 23.70 & 23.70 & 23.70 & 0.00 & 69.50 & 66.30 & 67.90 & 2.26 \\
\hline
\end{tabular}

\section{Anion Concentrations in Scrubber Water of AVS Run2 Samples in ppm}

\begin{tabular}{|c|c|c|c|c|c|c|c|c|c|}
\hline $\mathrm{F}$ & 0.10 & 3.63 & 3.45 & 3.54 & 0.13 & 14.83 & 14.21 & 14.52 & 0.44 \\
\hline $\mathrm{Cl}$ & 0.20 & 2.82 & 2.90 & 2.86 & 0.06 & 10.02 & 9.44 & 9.73 & 0.41 \\
\hline NO2 & 0.20 & 29.40 & 30.43 & 29.92 & 0.73 & 168.60 & 181.40 & 175.00 & 9.05 \\
\hline NO3 & $0.20 \mathrm{bdl}$ & & & & & bdl & dl & dl & \\
\hline SO4 & 1.00 & 3.24 & 3.30 & 3.27 & 0.04 & 12.25 & 10.86 & 11.56 & 0.98 \\
\hline PO4 & $1.00 \mathrm{bdl}$ & & & & & bdl & dl & dl & \\
\hline $\mathrm{CO} 3$ & 0.47 & & & 122.00 & 0.27 & & & 361.00 & 2.10 \\
\hline TOC & 0.15 & & & 7.20 & 0.05 & & & 7.08 & 0.04 \\
\hline
\end{tabular}

Table 4-43. Scrubber water samples converted to concentration equivalents (ppmv)

\begin{tabular}{|c|c|c|c|c|c|}
\hline \multicolumn{6}{|c|}{ Delta (AVS2:39 - AVS3:30** } \\
\hline & ppm (mg/liter) & system mg & $\mathrm{mg} /$ balance $\mathrm{min}$ & scfm (equiv) & conc (equiv)* \\
\hline NO2 & 145.09 & 4935.79 & 94.92 & $0.0018(\mathrm{NO})$ & 6315.95 \\
\hline S & 44.20 & 1503.68 & 28.92 & 0.0008 (SO2) & 2765.96 \\
\hline $\mathrm{CO} 3$ & 239.00 & 8130.78 & 156.36 & 0.0022 & 7976.65 \\
\hline $\mathrm{F}$ & 10.98 & 373.54 & 7.18 & 0.0003 & 1157.24 \\
\hline & Run 11-04-200 & *purge flow -- & $0.28200 \mathrm{scfm}$ & & \\
\hline
\end{tabular}


A comparison of the calculated predictions for gas concentrations from the DIAL oxide spreadsheet versus the combined process gas analyses and scrubber water sampling is shown in Table 4-44.

Table 4-44. Predicted Gas Concentrations Versus Measured for Run 2.

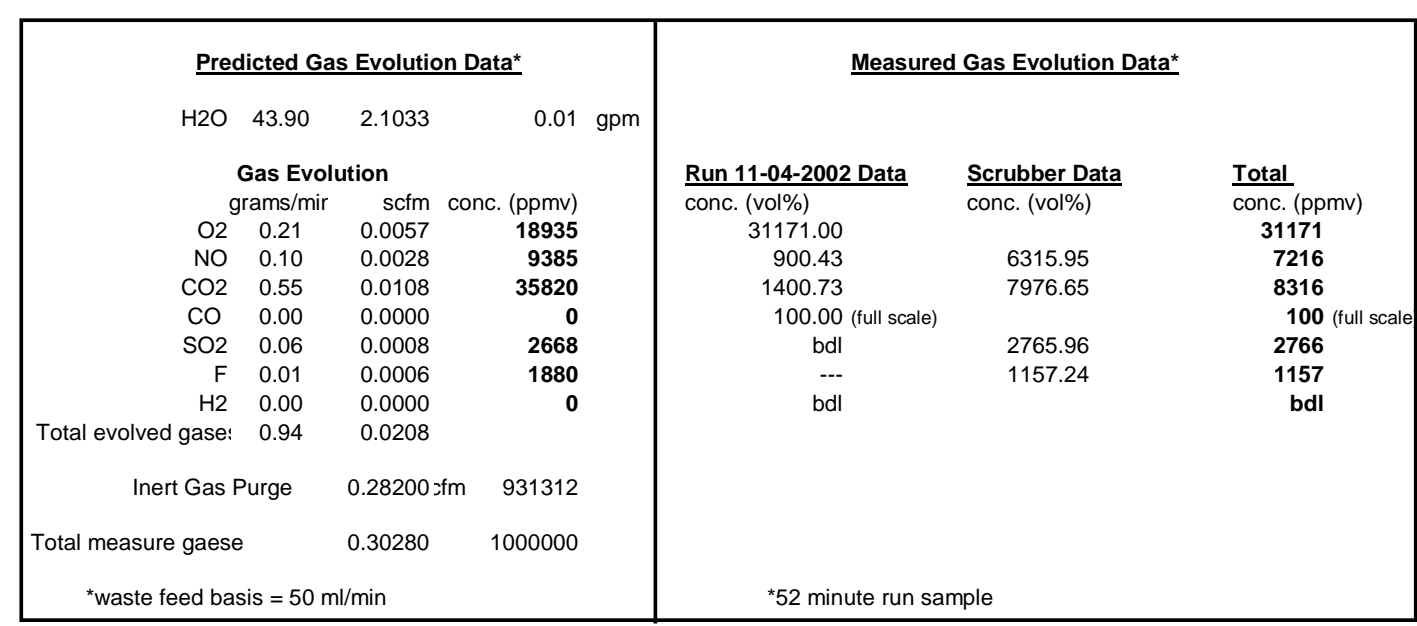

\section{Cs Retention Study}

The scrubber solution generated during Bench-Scale 2 were analyzed for cations as shown in Table 4-42. The Cs concentration reached levels of $1.01 \mathrm{ppm}$ in the 34-liter scrubber solution during the test. An initial dilute $\mathrm{HCl}(1 \%) 200 \mathrm{ml}$ flush of the off-gas piping yielded a concentration of 600ppm. A second flush recovered yield a 10ppm Cs solution concentration; the third flush yielded a $<1 \mathrm{ppm}$ Cs solution. The total recovered Cs from the off-gas system was $34.4 \mathrm{mg}$ from the scrubber plus $122 \mathrm{mg}$ from the off-gas line flushes, or 156mg. The total glass recovered form the crucible was approximately $3 \mathrm{~kg}$. From the target glass composition as reported in Table 4.3.2.1.1 the elemental Cs concentration is $0.18 \mathrm{wt} \%$ - equating to a total Cs feed content of $5400 \mathrm{mg}$. The total amount of Cs recovered (as volatilized and carry over) was approximately $2.9 \%$. This is about twice the value determined for the laboratory-scale furnace tests.

The process gas analyzers performed well during the AVS Run 2 and data was obtained for balance calculations. All species were put on an equivalent concentration basis with respect to the AVS system off-gas flow. CO, which was not expected to be present in the off-gas, exceeded 100ppm. Balance values for the $\mathrm{NO}, \mathrm{SO}_{2}$, and $\mathrm{F}$ compared well with the calculated values. No Hydrogen was observed during the run. The measured $\mathrm{CO}_{2}$ was low compared to the predicted value. The $\% \mathrm{O}_{2}$ was higher than predicted. This observation, along with the elevated $\mathrm{CO}$ reading, tends to suggest the leakage of air into the system. In addition, the level of predicted $\mathrm{O}_{2}$ in the off-gas indicates that there may be a substantial amount of free Oxygen in the off-gas. Combined with the high AVS reaction temperature, this may explain the deterioration of the crucible graphite linings even without leakage of air into the system. In addition, leakage between the crucible and the outer containment cavity may have contributed to inaccuracies in measurements. 


\section{$\underline{\text { Run } 4}$}

To prevent leakage of air into the system, the outer purge was combined with the off-gas and sent to the gas scrubber. This had the added advantage of avoiding inaccuracies due to leakage between the crucible and the outer cavity. The scrubber solution was a continuation of that which was used in prior runs. In order to avoid over-pressure of the quartz tube, the outer purge was reduced from $15 \mathrm{liter} / \mathrm{min}$ to $7.5 \mathrm{liters} / \mathrm{min}$. This also addressed the concern of over-dilution of the process off-gas.

As can be seen from Figure 4-20 and Figure 4-21, gases were evolved during the heatup stage as oxides were formed from the initial charge of waste surrogate. DIAL's process gas analyzers and data acquisition system were used to determine and record gas concentrations for $\mathrm{CO}, \mathrm{CO}_{2}, \mathrm{NO}, \mathrm{SO}_{2}, \mathrm{O}_{2}$, and $\mathrm{H}_{2}$.

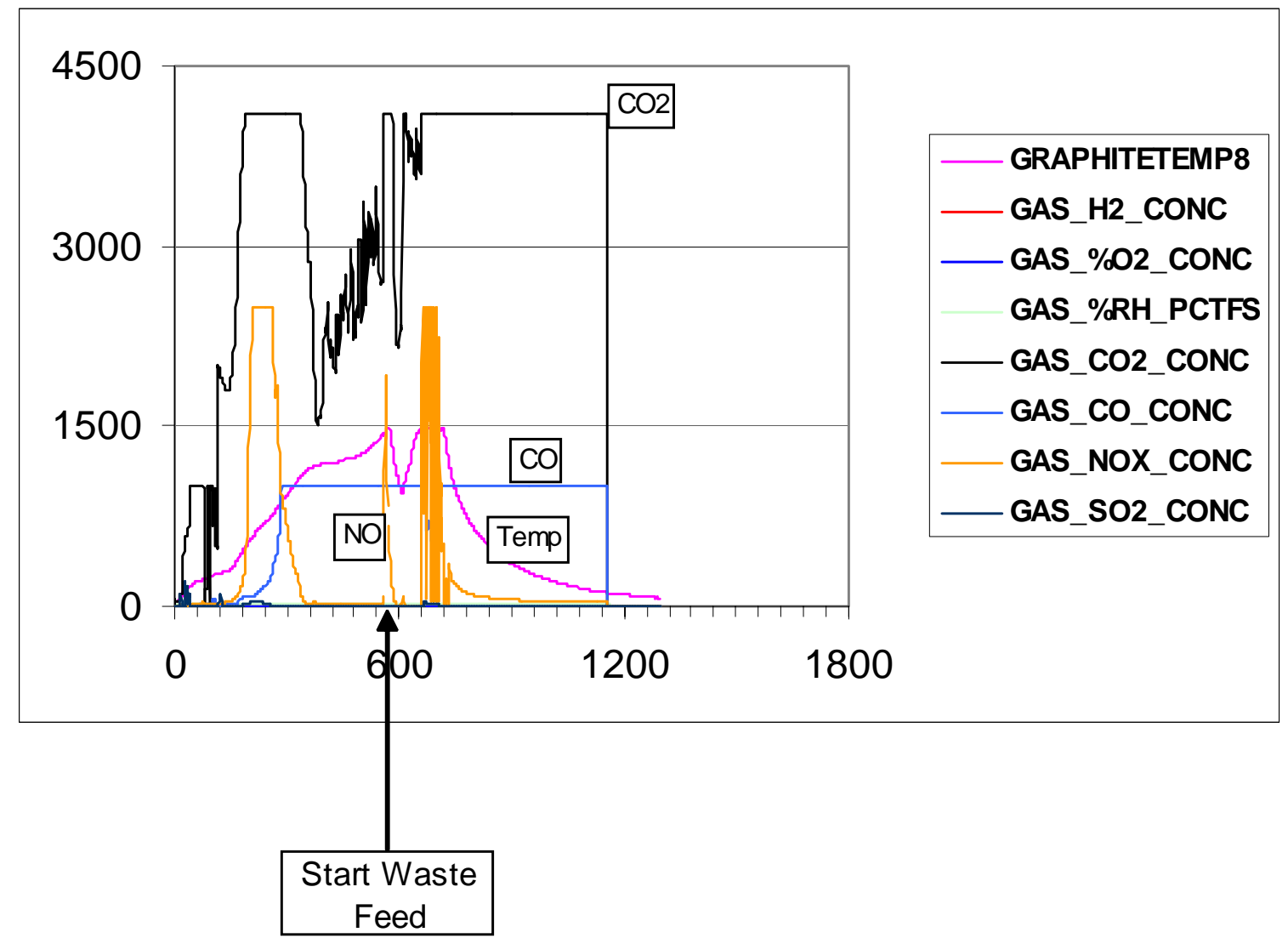

Figure 4-20. Analysis of Graphite Temperature, $\mathrm{H}_{2}, \% \mathrm{O}_{2}, \mathrm{CO}, \mathrm{CO}_{2}, \mathrm{NO}_{\mathrm{X}}$, and $\mathrm{SO}_{2}$ Versus Runtime (min) for Run 4.

It was observed that, unlike Run 2, the $\mathrm{CO}_{2}$ and $\mathrm{CO}$ levels remained high prior to the initiation of the waste feed. From this data, it was concluded that the high levels were a result of the deterioration of the graphite crucible linings. Instead of increasing the dilution gases so that the $\mathrm{CO}_{2}$ and $\mathrm{CO}$ were within a detectable range, it was decided to disregard the carbon oxides and focus on the levels of $\mathrm{H}_{2}, \mathrm{SO}_{2}$, and $\mathrm{NO}$. 


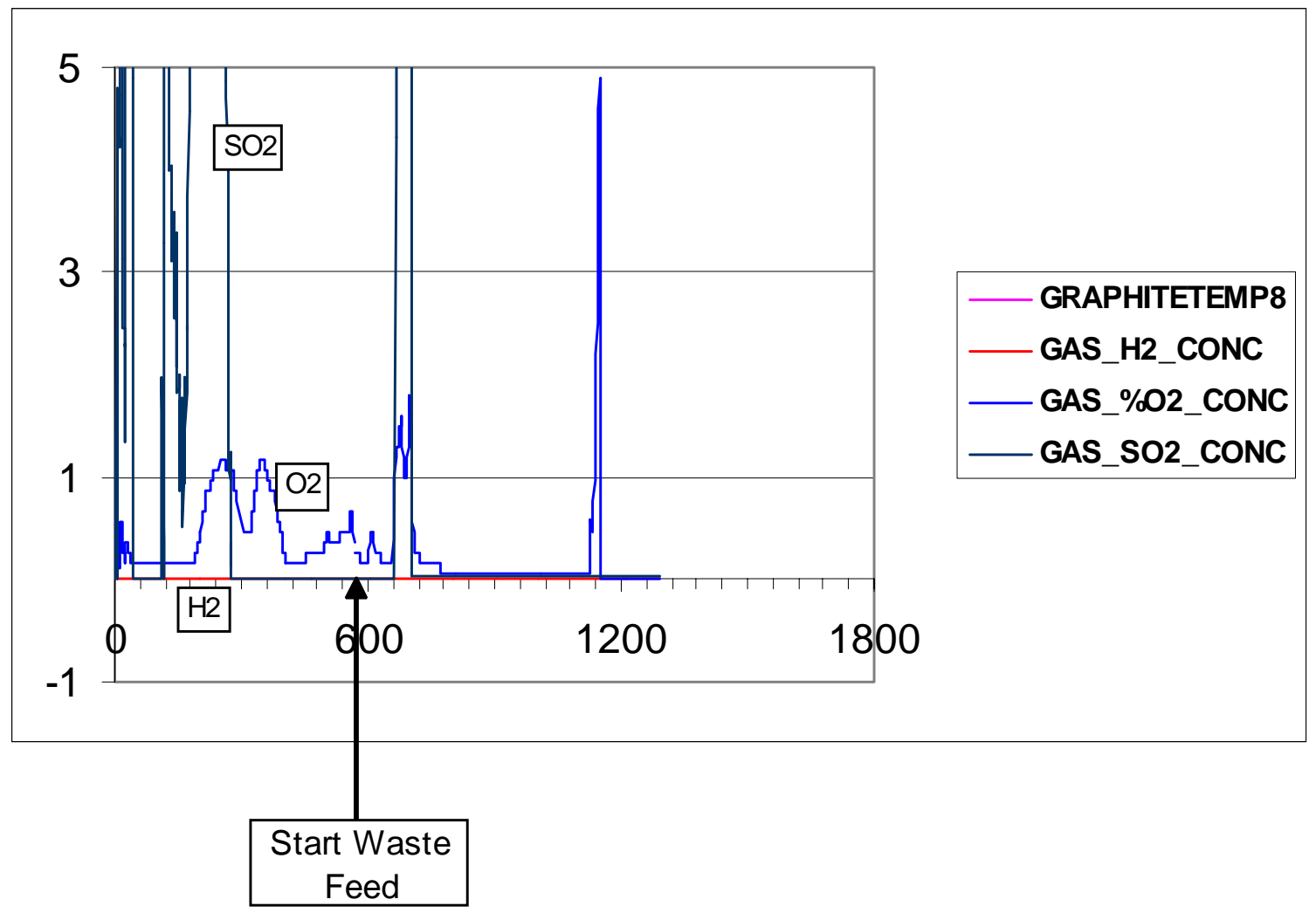

Figure 4-21. Analysis of $\% \mathrm{O}_{2}, \mathrm{H}_{2}$, and $\mathrm{SO}_{2}$ versus Runtime (min) for Run 4

Figures 4-22 and 4-23 show data from the actual balance period. 


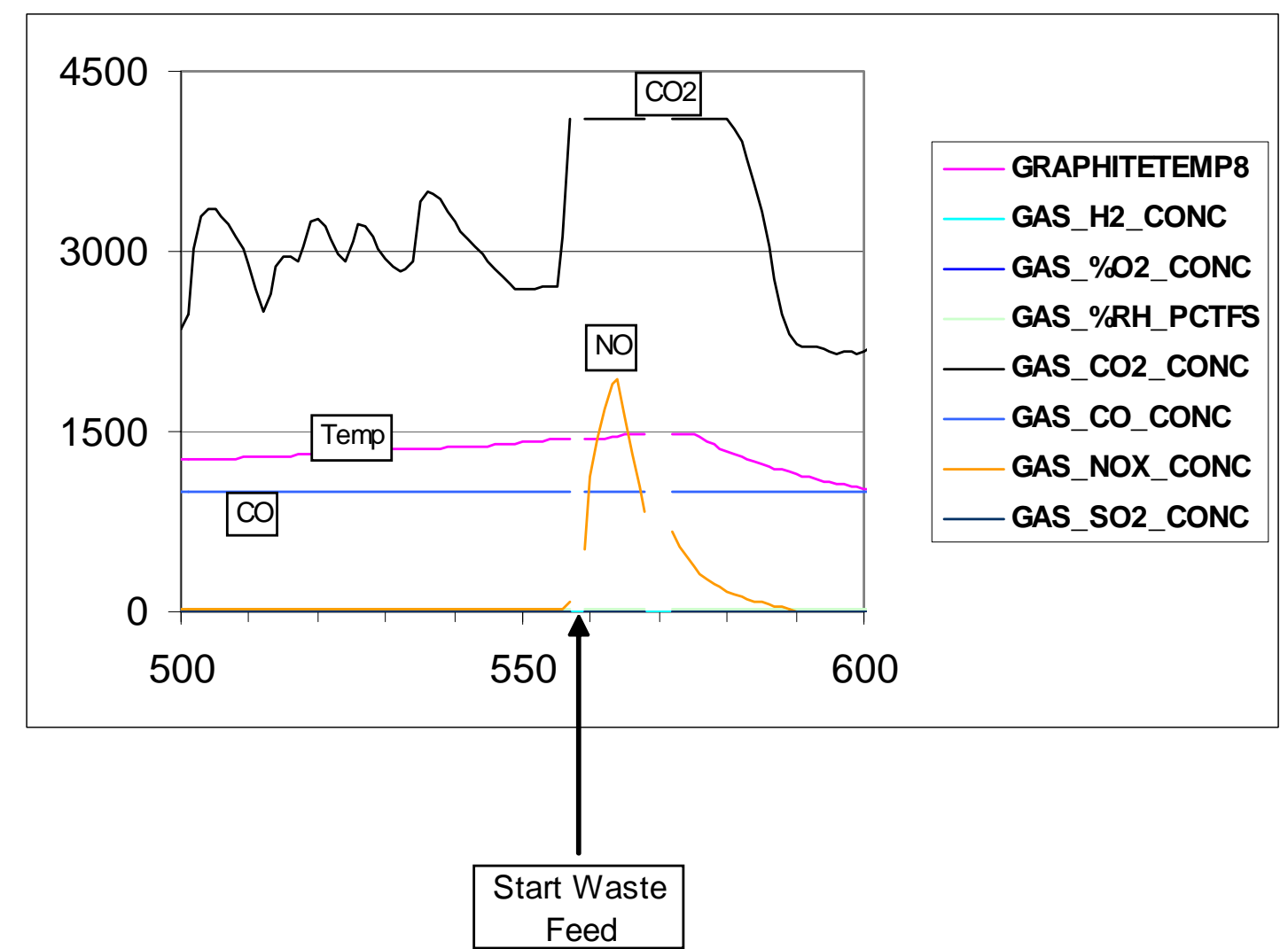

Figure 4-22. Gas Analysis During Balance Period for Run 4.

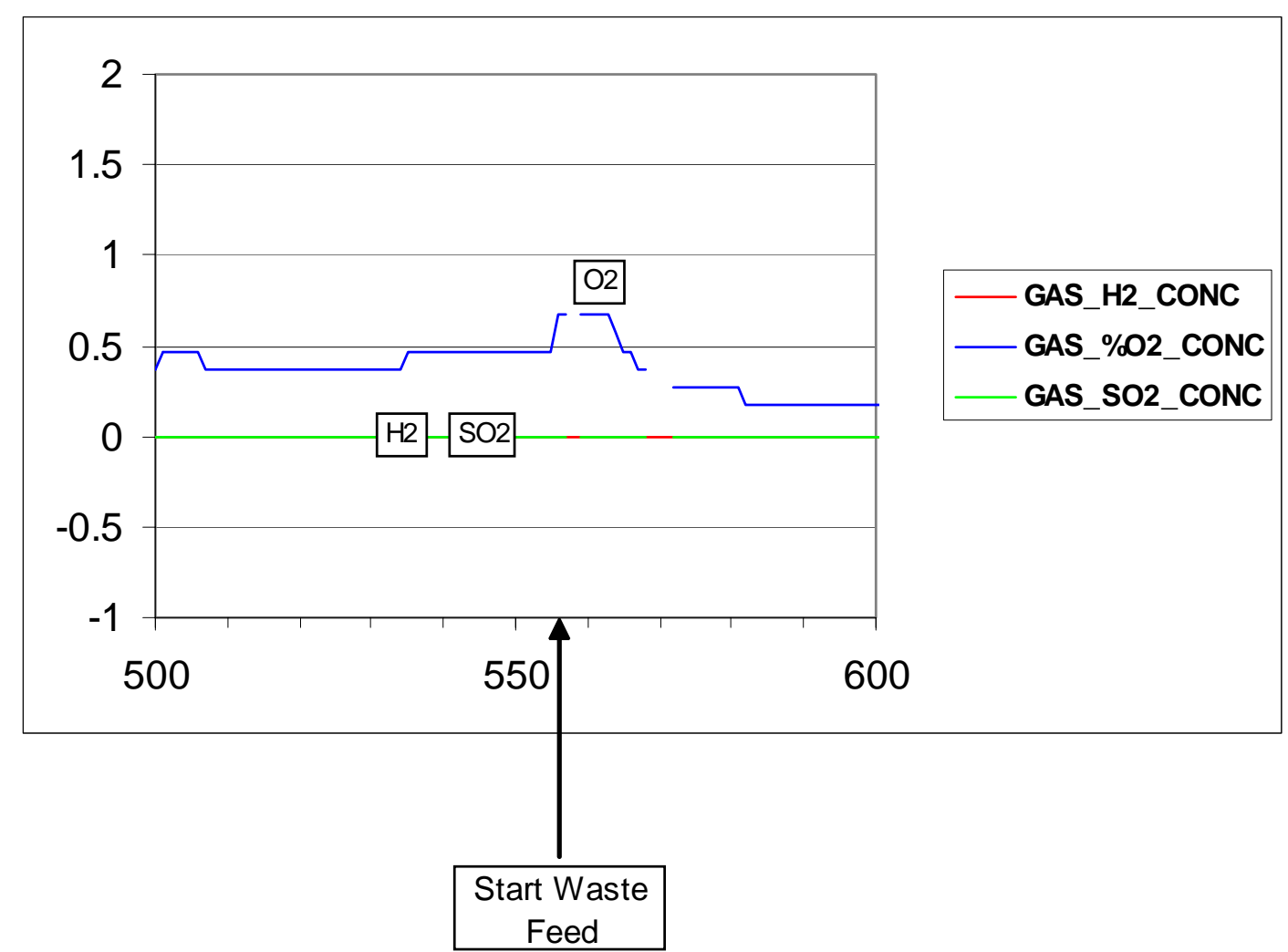

Figure 4-23. Gas Analysis During Balance Period for Run 4 
In addition to the process analyzer data, samples were taken of the scrubber water as shown in Table 4-45. This data was converted to equivalent concentrations as shown in Table 4-46.

Table 4-45. Anion Concentrations of Scrubber Water for Run 4.

\begin{tabular}{|c|c|c|c|c|c|c|}
\hline \multicolumn{7}{|c|}{ Anion Concentrations in Scrubber Water of AVS Run2 Samples in ppm } \\
\hline & \multicolumn{3}{|c|}{ RIC AVS4-2304 } & \multicolumn{3}{|c|}{ RIC AVS4-0041 } \\
\hline & $1^{*}$ & $2^{*}$ & average* $^{*}$ & $1^{*}$ & $2^{*}$ & average* $^{*}$ \\
\hline $\mathrm{F}$ & 0.5781 & 0.5759 & 11.54 & 0.8676 & 0.8388 & 17.06 \\
\hline $\mathrm{Cl}$ & 0.5631 & 0.6042 & 11.67 & 0.7444 & 0.7417 & 14.86 \\
\hline NO2 & 13.94 & 13.59 & 275.3 & 13.11 & 13.13 & 262.4 \\
\hline NO3 & -- & -- & -- & -- & -- & -- \\
\hline SO4 & 14.69 & 14.75 & 294.4 & 15.49 & 15.15 & 306.4 \\
\hline PO4 & -- & -- & -- & -- & -- & -- \\
\hline
\end{tabular}

Table 4-46. Scrubber Water Samples Converted To Concentration Equivalents (ppmv)

\begin{tabular}{|c|c|c|c|c|c|}
\hline \multicolumn{6}{|c|}{ Delta (AVS2:39 - AVS3:30)** } \\
\hline NO2 & 145.09 & 4935.79 & 94.92 & $0.0018(\mathrm{NO})$ & 6315.95 \\
\hline $\mathrm{s}$ & 44.20 & 1503.68 & 28.92 & 0.0008 (SO2) & 2765.96 \\
\hline $\mathrm{CO} 3$ & 239.00 & 8130.78 & 156.36 & 0.0022 & 7976.65 \\
\hline $\mathrm{F}$ & 10.98 & 373.54 & 7.18 & 0.0003 & 1157.24 \\
\hline & Run $11-04-2002$ & urge flow -- & scfm & & \\
\hline
\end{tabular}

A comparison of the calculated predictions for gas concentrations from the DIAL oxide spreadsheet versus the combined process gas analyses and scrubber water sampling is shown in Table 4-47.

Table 4-47. Predicted vs. Measured Gas Concentrations.

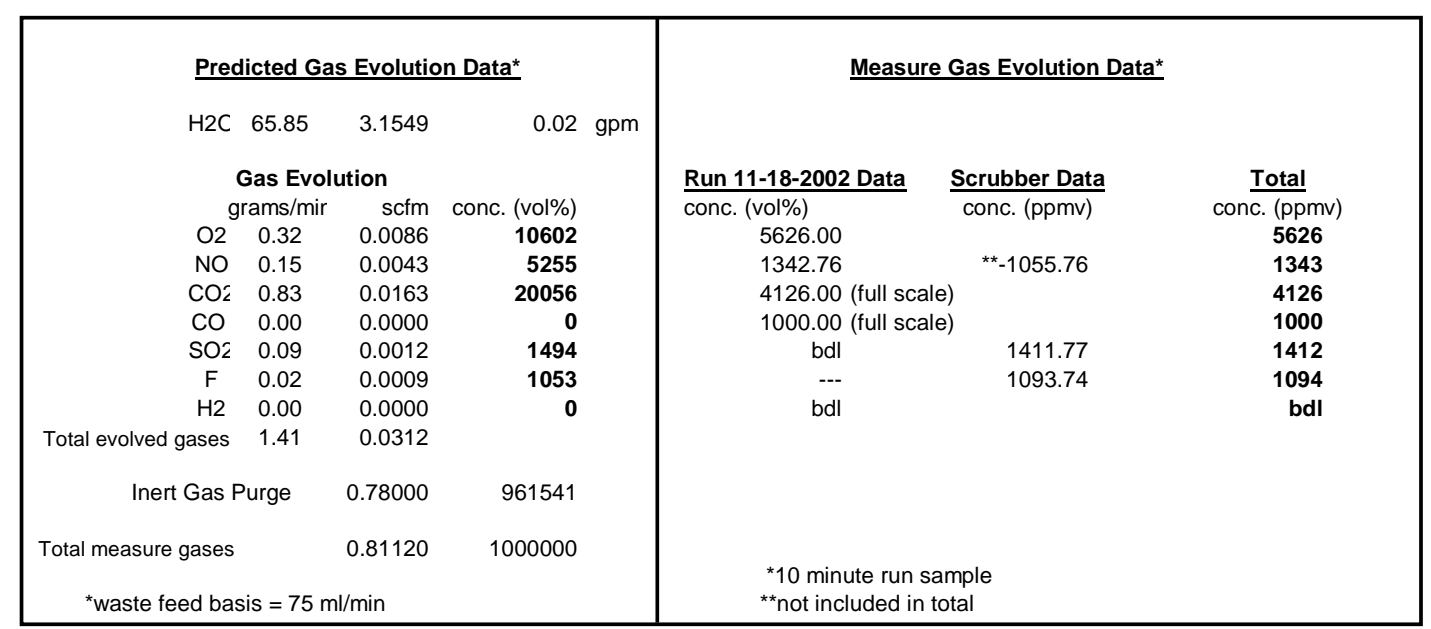


The process gas analyzers performed well during the AVS Run 4 and data was obtained for balance calculations. All species were put on an equivalent concentration basis with respect to the AVS system off-gas flow. Due to high carbon oxide levels prior to the initiation of waste feed, it was decided to concentrate on the detection and measurement of the remaining off-gas components, $\mathrm{H}_{2}, \mathrm{SO}_{2}$, and $\mathrm{NO}$. A comparison of the calculated off-gas components and the total measured components is given in Table 3. As in Run 2, the $\mathrm{SO}_{2}$ and $\mathrm{F}$ measured values approximated the calculated values. The scrubber water NO sample showed questionable value and thus was not included in the total measured value. Because of this the NO measured value was significantly lower than that predicted. $\mathrm{No}_{2}$ was detected during the run. The carbon oxide levels were inaccurate and no comparison can be made. An interesting observation is that the measured $\mathrm{O}_{2}$ level was only $1 / 2$ of the predicted value. This suggests that there was no leakage of air into the AVS system. It also suggests that the free oxygen evolved in the off-gas contributes to the deterioration of the crucible linings. 


\subsection{TTT Experiments}

\section{Test Highlights and General Observations}

The initial matrix of 36 heat treatments was generated and analyzed. Due to the crystallinity determinations made, an additional series of higher temperature heat treatments was performed. All samples generated had some crystalline character. The phases identified include $\mathrm{ZrO}_{2}, \mathrm{ZrSiO}_{4}$, and Fe-bearing spinel.

\section{Test Data}

The crystalline character of the TTT samples was defined by identifying crystal types and concentrations using XRD and SEM analyses. All of the raw data was analyzed and correlated to construct a TTT "nose" diagram. Sufficient data is provided within the text of this document to illustrate and interpret the data analysis and methods used to formulate the TTT diagram. One TTT sample, that is representative of the crystallization phenomena observed, will be diagramed and discussed in detail as an illustrative case of the data analysis followed to generate the TTT diagram. This tactic is intended to streamline discussion and analysis. The TTT sample treated at $1060^{\circ} \mathrm{C}$ for 192 hours is the representative sample chosen for this purpose.

\section{Heat Treatment Procedure}

All TTT samples were batched and melted in the same manner as Large Melt samples, using a molybdenum disilicide element resistance furnace in an air atmosphere. One third of the $294 \mathrm{~g}$ dry batch was added (by visual inspection) to the 500 -cc high-form alumina (99.8\% corundum) crucible and placed in the room temperature melt furnace. The furnace was heated to $700^{\circ} \mathrm{C}$ at $10^{\circ} \mathrm{C}$ per minute and held at $700^{\circ} \mathrm{C}$ for one hour. The furnace was then ramped to $1000^{\circ} \mathrm{C}$ at $5^{\circ} \mathrm{C}$ per minute and held at $1000^{\circ} \mathrm{C}$ for one hour. The furnace was then ramped to $1450^{\circ} \mathrm{C}$ at $5^{\circ} \mathrm{C}$ per minute. As soon as the furnace reached $1450^{\circ} \mathrm{C}, 50 \mathrm{~g}$ (visual estimate) batch charges were added at 20 minute intervals. One hour after the final batch addition, the crucible was removed from the furnace and stirred with a 1/2" diameter quartz rod for 5-10 seconds and then replaced in the furnace. The $1450^{\circ} \mathrm{C}$ dwell period was continued for a total of 3 hours post batch addition. After the 3-hour dwell at $1450^{\circ} \mathrm{C}$, the alumina crucible was removed from the catch crucible and immediately placed in a pre-heated annealing furnace. All annealing furnaces were equipped with calibrated thermocouples - all of which were electronically connected to a PC platform temperature recorder.

Upon completion of the heat treatment, the samples were removed from the annealing furnaces and cooled to room temperature on a steel plate.

The alumina crucible containing the heat-treated sample was visually examined for corrosion, batch/mass loss due to foam overflow, or fractures. Any crucible exhibiting foam overflow or fractures that resulted in mass loss, i.e. fractures that occurred during the melting/heat treatment, was discarded and the experiment repeated. All acceptable samples were then bisected vertically with a diamond saw. The sectioned samples were digitally photographed. As can be observed from the photographs, none of the sample crucibles were shown to have been visibly corroded at the glass melt line. 
Sampling of the crucible sections was performed with video record. The crucible sections were placed in two plastic bags and the wasteform was removed by striking the outer edges of the crucible. The resulting pieces with no visible crucible contact were separated from those with visible crucible adhesion. The SEM samples, one oriented near the top center of the melt, one oriented near the bottom center of the melt, were extracted at this point. This selection was made by mandating a portion of the top melt surface by attached for the "top" sample and a portion of the crucible contact area be attached for the "bottom" sample. The SEM samples were oriented normal to the crucible or melt surface prior to polishing in order to minimize surface phenomena impact on analysis. The pieces with crucible contamination were then placed in two plastic bags and the separation process was repeated as necessary to maximize sample recovery.

The resulting pieces were placed on white paper and mixed thoroughly with metallic forceps. The resulting mound of sample pieces was separated into quadrants. One quadrant was selected for the PCT experiment; the remaining three quadrants were combined for TCLP size grading. All samples extracted were placed in pre-marked plastic bags.

Sample obtained for TCLP was further size reduced with a hammer (in a plastic bag) prior to initiation of the EPA test protocol. Sample obtained for the PCT was also size reduced with a hammer (to reduce the potential for tungsten carbide contamination from the grinder).

Sub-samples analyzed by PCT and TCLP protocols were processed solely at Mississippi State University (MSU). XRD powder was initially sampled and size reduced at MSU, with standard addition, final sample grinding, along with actual XRD analysis at University of Missouri-Rolla (UMR). SEM samples were selected at MSU, with sample mounting and polishing being performed at Graftech (Parma, Ohio) and SEM analysis at UMR.

\section{TTT Data Calculation Case: TTT Isothermal Heat Treatment \\ Temperature $1060^{\circ} \mathrm{C}$ \\ Dwell Time 192 Hours}

For calculation spreadsheet examples, SEM and XRD data descriptions, and crystallinity analysis description, the 192 -hour, $1060^{\circ} \mathrm{C}$ heat treatment was selected as a representative sample. This particular sample was chosen because it represented a comprehensive case, i.e. it was processed at sufficient time and temperature to experience crystalline in-growth of several of the phases observed. This sample was melted in Furnace DIAL-M8-369 and placed in the Annealing Oven \#2 on August 16 (at 1343 military time 08/16/02). The sample was removed from the oven on August 24 (at 1340, 08/24/02). The thermocouple trace for the sample indicated no excursions beyond $\pm 5^{\circ} \mathrm{C}$ (upon thermal equilibration from $1450^{\circ} \mathrm{C}$ ) during the heat treatment period. 


\section{$\underline{\mathrm{PCT}}$}

The PCT was performed on all Time-Temperature-Transformation diagram heat treatment samples. This data set required 9 PCT samples sets to generate. The SRS EA glass was used as a standard glass for this program. The cumulative EA data for this program is presented in Table 4-49. The corresponding strip chart data are presented graphically in Figure 4-24 and 4-25.

\begin{tabular}{|c|c|c|}
\hline \multicolumn{3}{|c|}{ Table 4-49 Cumulative SRS EA Standard Data: PCT Results } \\
\hline $\begin{array}{l}\text { Reference } \\
\text { Project/Document }\end{array}$ & DIAL-RIC-02 & WSRC-TR-92-346 \\
\hline Number of EA Sets & 10 & 12 \\
\hline Total EA Vessels & 20 & 42 \\
\hline Element & \multicolumn{2}{|c|}{$\begin{array}{l}\text { Average } \\
\text { STD +/- }\end{array}$} \\
\hline $\mathrm{B}$ & $\begin{array}{c}598 \\
19\end{array}$ & $\begin{array}{c}587 \\
43\end{array}$ \\
\hline $\mathrm{Li}$ & $\begin{array}{c}191 \\
5\end{array}$ & $\begin{array}{c}190 \\
14\end{array}$ \\
\hline $\mathrm{Na}$ & $\begin{array}{c}1693 \\
49\end{array}$ & $\begin{array}{c}1662 \\
112\end{array}$ \\
\hline $\mathrm{Si}$ & $\begin{array}{c}923 \\
27\end{array}$ & $\begin{array}{c}893 \\
86\end{array}$ \\
\hline Batch ID & Excel Spreadsheet & Comments \\
\hline 1 & EA-PCT0822 & Large Melts \\
\hline 2 & EA-PCT0829 & TTT \\
\hline 3 & EA-PCT0906 & TTT \\
\hline 4 & EA-PCT0906 & TTT \\
\hline 5 & EA-PCT0925 & TTT \\
\hline 6 & EA-PCT0927 & TTT \\
\hline 7 & EA-PCT1009 & TTT \\
\hline 8 & EA-PCT1011 & TTT \\
\hline 9 & EA-PCT1107 & TTT \\
\hline 10 & EA-PCT1115 & TTT \\
\hline
\end{tabular}




\section{EA Glass Benchmark for RIC - 02}

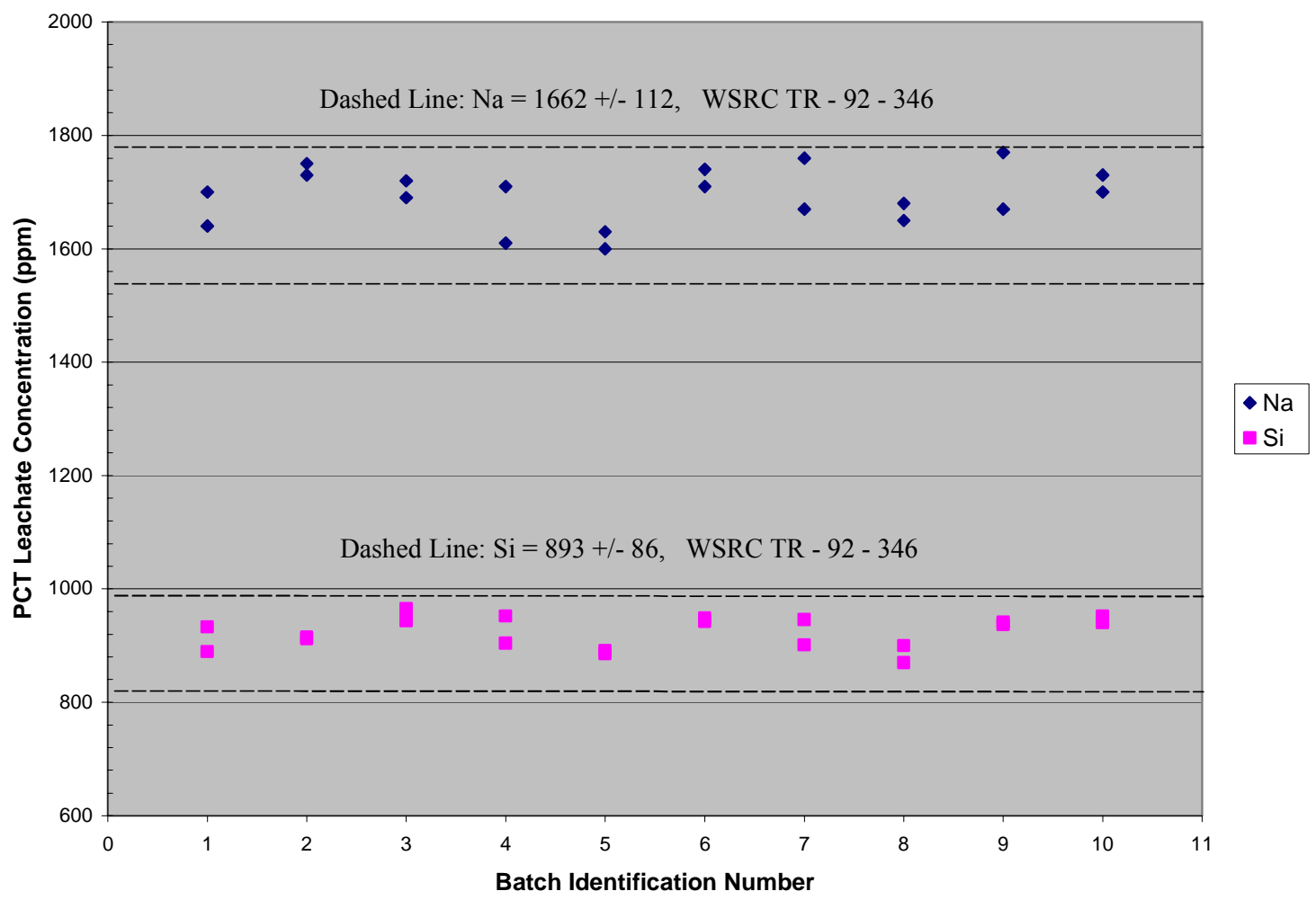

Figure 4-24. Strip Chart Data of the PCT Sodium And Silicon Leachate Concentration for 11 Batches of EA glass. 


\section{EA Glass Benchmark for RIC - 02}

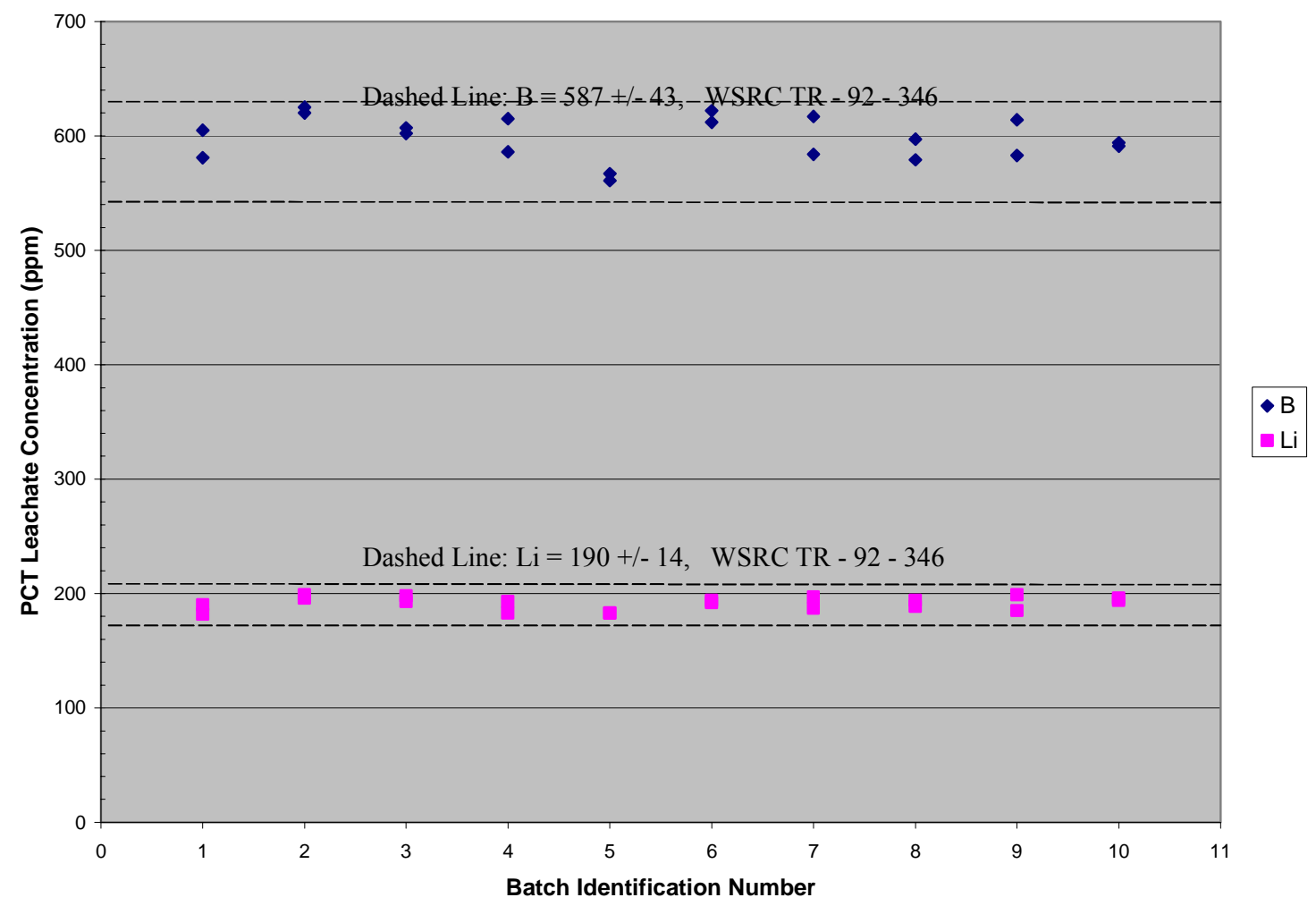

Figure 4-25. Strip Chart Data of the PCT Boron And Lithium Leachate Concentration for 11 Batches of EA Glass 
The PCT results obtained for the Time-Temperature-Transformation diagram heat treatment samples are displayed in Tables 4-50, 4-51 and 4-52. These tables report the leachate concentration (as normalized release - grams glass dissolved per liter solution) values for all elements analyzed. The elements on the three tables were grouped based on the results of PCT test performed on the 60 weight percent Large Melt glass, or LM 60 the composition which was selected for the TTT diagram. One grouping (Group 1) displays the results for alkali elements ( $\mathrm{Li}, \mathrm{Na}, \mathrm{K}, \& \mathrm{Cs}$ ), B, P, Si, and $\mathrm{Sr}$. These elements had high relative leachate concentrations (for the LM 60 sample), and are commonly used as benchmarks for glass durability. Lithium is not present in any AVS project glass, but was analyzed as a check element for the EA glass. The three elements used to directly compare the test results versus the EA glass standard ( $\mathrm{Na}, \mathrm{Si}$, and $\mathrm{B})$ are all in this grouping. Also, it was anticipated that $\mathrm{Na}, \mathrm{B}, \mathrm{Sr}$, or $\mathrm{Si}$ would be most likely to reflect large deviations in normalized release as a function of relative crystallinity and/or formation of specific crystalline species.

The second grouping (Group 2) displays PCT normalized leachate concentrations (g/L) for elements determined to be below detection limit (BDL) in the LM 60 PCT leachate. Elements in this grouping include $\mathrm{Cd}, \mathrm{Ce}, \mathrm{Cu}, \mathrm{La}, \mathrm{Pb}, \mathrm{Se}, \mathrm{Te}, \mathrm{Ti}$, and $\mathrm{Zr}$. Several of these elements have very limited solubility in aqueous solutions (especially near neutral $\mathrm{pH}$ solutions) and were expected to show little or no response as a function of heat treatment.

The third grouping (Group 3) of elements includes Al, As, Ba, Ca, Fe, Mg, Mn, Ni, S, Sb, and $\mathrm{Zn}$. All elements in this set had a measurable concentration in the PCT leachate of $\mathrm{LM}$ 60. Of these species, $\mathrm{Mg}$ and $\mathrm{Sb}$ are relatively soluble and show relative release rates in the same range as alkali and B. Several others are considerably less soluble (ex. Zn, $\mathrm{Fe}$, and $\mathrm{Ni}$ ) in near neutral $\mathrm{pH}$ solutions. 


\begin{tabular}{|c|c|c|c|c|c|c|c|c|c|c|c|c|}
\hline Temperature & \multicolumn{12}{|c|}{ Table 4-50. TTT PCT Data (Alkali, B, P, Si, Sr, Cs) (mg/l) } \\
\hline \multirow{4}{*}{$1200^{\circ} \mathrm{C}$} & $\begin{array}{ll}\text { B } & 0.11\end{array}$ & $\begin{array}{ll}\text { P } & 0.11\end{array}$ & $\begin{array}{ll}\text { B } & 0.10\end{array}$ & $\mathrm{P}$ bdl & $\begin{array}{ll}\text { B } & 0.12\end{array}$ & $\mathrm{P} 0.11$ & $\begin{array}{ll}\text { B } & 0.12\end{array}$ & $\mathrm{P} 0.11$ & B 0.11 & P 0.09 & B 0.11 & $\begin{array}{ll}\text { P } & 0.32\end{array}$ \\
\hline & K 0.12 & Si 0.08 & $\mathrm{~K} 0.18$ & Si 0.08 & $\mathrm{~K} 0.13$ & Si 0.08 & $\mathrm{~K} 0.14$ & Si 0.08 & K 0.21 & Si 0.07 & $\mathrm{~K} 0.14$ & Si 0.07 \\
\hline & $\mathrm{Li}$ bdl & Sr 0.06 & $\mathrm{Li}$ bdl & Sr 0.07 & $\mathrm{Li}$ bdl & Sr 0.06 & $\mathrm{Li}$ bdl & Sr 0.06 & $\mathrm{Li}$ bdl & Sr 0.07 & $\mathrm{Li}$ bdl & Sr 0.07 \\
\hline & $\mathrm{Na} 0.11$ & Cs 0.11 & $\mathrm{Na} 0.14$ & Cs 0.11 & $\mathrm{Na} 0.23$ & Cs 0.11 & $\mathrm{Na} 0.23$ & Cs 0.12 & $\mathrm{Na} 0.18$ & Cs 0.05 & $\mathrm{Na} 0.14$ & Cs 0.10 \\
\hline \multirow{4}{*}{$1060^{\circ} \mathrm{C}$} & $\begin{array}{ll}\text { B } & 0.11\end{array}$ & $\begin{array}{ll} & 0.12\end{array}$ & $\begin{array}{ll}\text { B } & 0.10\end{array}$ & $\begin{array}{ll}\mathrm{P} & \text { bdl }\end{array}$ & $\begin{array}{ll}\text { B } & 0.11\end{array}$ & $\begin{array}{ll}\mathrm{P} & 0.10\end{array}$ & $\begin{array}{ll}\text { B } & 0.11\end{array}$ & $\begin{array}{lll}\mathrm{P} & 0.07\end{array}$ & $\begin{array}{ll}\text { B } & 0.11\end{array}$ & $\begin{array}{ll}\text { P } & 0.09\end{array}$ & $\begin{array}{ll}\text { B } & 0.09\end{array}$ & $\mathrm{P} \quad \mathrm{bdl}$ \\
\hline & K 0.13 & Si 0.08 & K 0.12 & Si 0.08 & K 0.14 & Si 0.07 & K 0.19 & Si 0.09 & K 0.15 & Si 0.08 & K 0.10 & Si 0.09 \\
\hline & $\mathrm{Li}$ bdl & Sr 0.06 & $\mathrm{Li}$ bdl & Sr 0.07 & $\mathrm{Li}$ bdl & $\mathrm{Sr} 0.06$ & $\mathrm{Li}$ bdl & Sr 0.07 & $\mathrm{Li}$ bdl & Sr 0.07 & $\mathrm{Li}$ bdl & Sr 0.04 \\
\hline & $\mathrm{Na} 0.12$ & Cs 0.10 & $\mathrm{Na} 0.11$ & Cs 0.09 & $\mathrm{Na} 0.17$ & Cs 0.14 & $\mathrm{Na} 0.21$ & Cs 0.06 & $\mathrm{Na} 0.18$ & Cs 0.05 & $\mathrm{Na} 0.31$ & Cs 0.08 \\
\hline \multirow{4}{*}{$920^{\circ} \mathrm{C}$} & $\begin{array}{ll}\text { B } & 0.11\end{array}$ & $\mathrm{P} 0.12$ & B 0.09 & $\begin{array}{ll}\mathrm{P} & \text { bdl }\end{array}$ & B 0.11 & $\mathrm{P} \quad 0.10$ & B 0.11 & $\begin{array}{lll} & 0.34\end{array}$ & B 0.11 & P 0.08 & B 0.15 & $\begin{array}{ll}\mathrm{P} & \mathrm{bdl}\end{array}$ \\
\hline & K 0.12 & Si 0.09 & K $\quad 0.14$ & Si 0.09 & K 0.11 & Si 0.08 & $\mathrm{~K} 0.32$ & Si 0.09 & $\mathrm{~K} 0.13$ & Si 0.09 & K 0.07 & Si 0.11 \\
\hline & $\mathrm{Li}$ bdl & Sr 0.07 & $\mathrm{Li}$ bdl & Sr 0.08 & $\mathrm{Li}$ bdl & Sr 0.07 & $\mathrm{Li}$ bdl & Sr 0.07 & $\mathrm{Li} \quad$ bdl & Sr 0.07 & $\mathrm{Li}$ bdl & Sr 0.05 \\
\hline & $\mathrm{Na} 0.14$ & Cs 0.10 & $\mathrm{Na} 0.13$ & Cs 0.09 & $\mathrm{Na} 0.17$ & Cs 0.13 & $\mathrm{Na} 0.15$ & Cs 0.09 & $\mathrm{Na} 0.19$ & Cs 0.06 & $\mathrm{Na} 0.04$ & Cs 0.07 \\
\hline \multirow{4}{*}{$780^{\circ} \mathrm{C}$} & B 0.11 & $\mathrm{P} 0.11$ & B 0.10 & $\begin{array}{ll} & \text { bdl }\end{array}$ & B 0.12 & P 0.09 & B 0.12 & P 0.08 & B 0.12 & P 0.08 & B 0.10 & $\mathrm{P} \quad \mathrm{bdl}$ \\
\hline & K 0.10 & Si 0.09 & K 0.23 & Si 0.09 & K 0.12 & Si 0.08 & K 0.12 & Si 0.08 & K 0.10 & Si 0.09 & K 0.11 & Si 0.09 \\
\hline & $\mathrm{Li}$ bdl & Sr 0.07 & $\mathrm{Li}$ bdl & Sr 0.08 & $\mathrm{Li}$ bdl & Sr 0.07 & $\mathrm{Li}$ bdl & $\begin{array}{ll}\text { Sr } & 0.08\end{array}$ & $\mathrm{Li}$ bdl & $\begin{array}{ll}\mathrm{Sr} & 0.08\end{array}$ & $\mathrm{Li}$ bdl & Sr 0.07 \\
\hline & $\mathrm{Na} 0.15$ & Cs 0.09 & $\mathrm{Na} 0.13$ & Cs 0.09 & $\mathrm{Na} 0.21$ & Cs 0.12 & $\mathrm{Na} 0.22$ & Cs 0.13 & $\mathrm{Na} 0.24$ & Cs 0.09 & $\mathrm{Na} 0.09$ & Cs 0.10 \\
\hline \multirow{4}{*}{$640^{\circ} \mathrm{C}$} & B 0.09 & $\mathrm{P} \quad 0.02$ & B 0.11 & $\mathrm{P} \quad 0.11$ & B 0.10 & $\mathrm{P} \quad 0.02$ & B 0.10 & P 0.01 & B 0.11 & $\mathrm{P} 0.10$ & B 0.10 & $\mathrm{P} \quad \mathrm{bdl}$ \\
\hline & K 0.13 & Si 0.08 & K 0.13 & Si 0.08 & K 0.15 & Si 0.08 & K 0.15 & Si 0.08 & K 0.54 & Si 0.08 & K 0.17 & Si 0.09 \\
\hline & $\mathrm{Li}$ bdl & Sr 0.07 & $\mathrm{Li}$ bdl & Sr 0.07 & $\mathrm{Li}$ bdl & Sr 0.07 & $\mathrm{Li}$ bdl & Sr 0.07 & $\mathrm{Li}$ bdl & Sr 0.07 & $\mathrm{Li}$ bdl & Sr 0.08 \\
\hline & $\mathrm{Na} 0.16$ & Cs 0.11 & $\mathrm{Na} 0.16$ & Cs 0.09 & $\mathrm{Na} 0.17$ & Cs 0.13 & $\mathrm{Na} 0.17$ & Cs 0.10 & $\mathrm{Na} 0.21$ & Cs 0.10 & $\mathrm{Na} 0.19$ & Cs 0.10 \\
\hline \multirow{4}{*}{$500^{\circ} \mathrm{C}$} & B 0.10 & $\mathrm{P} 0.03$ & B 0.11 & $\mathrm{P} \quad 0.11$ & B 0.11 & $\mathrm{P} \quad 0.10$ & B 0.11 & $\begin{array}{ll}\mathrm{P} & 0.10\end{array}$ & B 0.10 & $\mathrm{P} \quad 0.09$ & B 0.09 & $\mathrm{P} \quad$ bdl \\
\hline & K 0.21 & Si 0.08 & K 0.12 & Si 0.08 & K 0.15 & Si 0.08 & K 0.24 & Si 0.08 & K 0.21 & Si 0.08 & K $\quad 0.14$ & Si 0.08 \\
\hline & $\mathrm{Li}$ bdl & Sr 0.07 & $\mathrm{Li}$ bdl & Sr 0.07 & $\mathrm{Li}$ bdl & Sr 0.07 & $\mathrm{Li}$ bdl & Sr 0.07 & $\mathrm{Li}$ bdl & Sr 0.08 & $\mathrm{Li}$ bdl & Sr 0.07 \\
\hline & $\mathrm{Na} 0.17$ & Cs 0.11 & $\mathrm{Na} 0.18$ & Cs 0.09 & $\mathrm{Na} 0.19$ & Cs 0.12 & $\mathrm{Na} 0.20$ & Cs 0.12 & $\mathrm{Na} 0.22$ & Cs 0.07 & $\mathrm{Na} 0.10$ & Cs 0.09 \\
\hline Time (hrs) & \multicolumn{2}{|c|}{0.75} & \multicolumn{2}{|c|}{3} & \multicolumn{2}{|c|}{12} & \multicolumn{2}{|c|}{48} & \multicolumn{2}{|c|}{192} & \multicolumn{2}{|c|}{768} \\
\hline
\end{tabular}




\begin{tabular}{|c|c|c|c|c|c|c|c|c|c|c|c|c|}
\hline Temperature & \multicolumn{12}{|c|}{ Table 4-51. TTT PCT Data (Group 2) (mg/l) } \\
\hline \multirow{5}{*}{$1200^{\circ} \mathrm{C}$} & $\mathrm{Cd} 0.00$ & $\mathrm{~Pb} 0.00$ & $\mathrm{Cd} 0.00$ & $\mathrm{~Pb}$ bdl & $\mathrm{Cd} 0.00$ & $\mathrm{~Pb}$ bdl & $\mathrm{Cd} 0.00$ & $\mathrm{~Pb}$ bdl & $\mathrm{Cd} 0.00$ & $\mathrm{~Pb}$ bdl & $\mathrm{Cd} 0.00$ & $\mathrm{~Pb} 0.00$ \\
\hline & Ce bdl & Se bdl & Ce bdl & Se bdl & Ce bdl & Se bdl & Ce bdl & Se bdl & Ce bdl & Se bdl & Ce 0.01 & Se bdl \\
\hline & $\mathrm{Cr} 0.00$ & Te 0.02 & $\mathrm{Cr} 0.00$ & Te 0.00 & $\mathrm{Cr} 0.00$ & Te 0.01 & $\mathrm{Cr} 0.00$ & Te 0.00 & $\mathrm{Cr}$ bdl & Te 0.01 & $\mathrm{Cr} 0.01$ & Te 0.05 \\
\hline & $\mathrm{Cu} 0.02$ & Ti 0.00 & $\mathrm{Cu} 0.01$ & Ti 0.00 & $\mathrm{Cu} 0.01$ & Ti 0.00 & $\mathrm{Cu} 0.01$ & Ti 0.00 & $\mathrm{Cu} 0.01$ & Ti bdl & $\mathrm{Cu} 0.01$ & Ti 0.00 \\
\hline & La 0.00 & $\mathrm{Zr} 0.00$ & La 0.00 & $\mathrm{Zr} 0.00$ & La bdl & Zr 0.00 & La bdl & $\mathrm{Zr} 0.00$ & La bdl & $\operatorname{Zr} 0.00$ & La 0.00 & $\mathrm{Zr} 0.00$ \\
\hline \multirow{5}{*}{$1060^{\circ} \mathrm{C}$} & $\mathrm{Cd} 0.00$ & $\mathrm{~Pb} 0.00$ & $\mathrm{Cd} 0.00$ & $\mathrm{~Pb}$ bdl & $\mathrm{Cd} 0.00$ & $\mathrm{~Pb}$ bdl & $\mathrm{Cd} 0.00$ & $\mathrm{~Pb}$ bdl & $\mathrm{Cd} 0.00$ & $\mathrm{~Pb}$ bdl & $\mathrm{Cd} 0.00$ & $\mathrm{~Pb} 0.00$ \\
\hline & $\mathrm{Ce}$ bdl & Se bdl & $\mathrm{Ce}$ bdl & $\mathrm{Se}$ bdl & Ce bdl & $\mathrm{Se}$ bdl & $\mathrm{Ce}$ bdl & $\mathrm{Se}$ bdl & Ce bdl & $\mathrm{Se}$ bdl & Ce 0.00 & Se bdl \\
\hline & $\mathrm{Cr} 0.00$ & Te 0.02 & Cr 0.00 & Te 0.01 & Cr 0.00 & Te 0.02 & $\mathrm{Cr}$ bdl & $\mathrm{Te} 0.01$ & $\mathrm{Cr}$ bdl & Te 0.01 & $\mathrm{Cr} 0.00$ & Тe 0.02 \\
\hline & $\mathrm{Cu} 0.05$ & Ti 0.00 & $\mathrm{Cu} 0.01$ & Ti 0.00 & $\mathrm{Cu} 0.00$ & Ti 0.00 & $\mathrm{Cu} 0.01$ & Ti bdl & $\mathrm{Cu} 0.01$ & Ti bdl & $\mathrm{Cu} 0.01$ & Ti 0.00 \\
\hline & La 0.00 & $\mathrm{Zr} 0.00$ & La 0.00 & $\mathrm{Zr} 0.00$ & La bdl & $\mathrm{Zr} 0.00$ & La bdl & $\mathrm{Zr} 0.00$ & La bdl & $\operatorname{Zr} 0.00$ & La 0.00 & $\mathrm{Zr} 0.00$ \\
\hline \multirow{5}{*}{$920^{\circ} \mathrm{C}$} & Cd 0.00 & $\mathrm{~Pb}$ bdl & $\mathrm{Cd} 0.00$ & $\mathrm{~Pb}$ bdl & Cd 0.00 & $\mathrm{~Pb} 0.00$ & Cd 0.00 & $\mathrm{~Pb} 0.00$ & $\mathrm{Cd} 0.00$ & $\mathrm{~Pb}$ bdl & $\mathrm{Cd} 0.00$ & $\mathrm{~Pb} 0.00$ \\
\hline & $\mathrm{Ce}$ bdl & Se bdl & $\mathrm{Ce}$ bdl & $\mathrm{Se}$ bdl & Ce bdl & Se bdl & Ce 0.01 & $\mathrm{Se}$ bdl & Ce bdl & $\mathrm{Se}$ bdl & Ce 0.00 & Se bdl \\
\hline & $\mathrm{Cr} 0.00$ & Te 0.03 & Cr 0.00 & Te 0.02 & $\mathrm{Cr} 0.00$ & Te 0.03 & $\mathrm{Cr} 0.01$ & Te 0.08 & $\mathrm{Cr}$ bdl & Te 0.05 & Cr 0.00 & Te 0.16 \\
\hline & $\mathrm{Cu} 0.01$ & Ti 0.00 & $\mathrm{Cu} 0.02$ & Ti 0.00 & $\mathrm{Cu} 0.00$ & Ti 0.00 & $\mathrm{Cu} 0.01$ & Ti 0.00 & $\mathrm{Cu} 0.01$ & Ti bdl & $\mathrm{Cu} 0.01$ & Ti 0.00 \\
\hline & La 0.00 & $\mathrm{Zr} 0.00$ & La 0.00 & $\mathrm{Zr} 0.00$ & La bdl & $\mathrm{Zr} 0.00$ & La 0.00 & $\mathrm{Zr} 0.00$ & La bdl & Zr 0.00 & La 0.00 & Zr 0.00 \\
\hline \multirow{5}{*}{$780^{\circ} \mathrm{C}$} & $\mathrm{Cd} 0.00$ & $\mathrm{~Pb} 0.00$ & $\mathrm{Cd} 0.00$ & $\mathrm{~Pb}$ bdl & $\mathrm{Cd} 0.00$ & $\mathrm{~Pb}$ bdl & $\mathrm{Cd} 0.00$ & $\mathrm{~Pb}$ bdl & $\mathrm{Cd} 0.00$ & $\mathrm{~Pb}$ bdl & $\mathrm{Cd} 0.00$ & $\mathrm{~Pb} 0.00$ \\
\hline & $\mathrm{Ce}$ bdl & Se bdl & $\mathrm{Ce}$ bdl & $\mathrm{Se}$ bdl & Ce bdl & $\mathrm{Se}$ bdl & $\mathrm{Ce}$ bdl & $\mathrm{Se}$ bdl & $\mathrm{Ce}$ bdl & $\mathrm{Se}$ bdl & Ce 0.00 & Se bdl \\
\hline & Cr 0.00 & Te 0.02 & Cr 0.00 & Te 0.01 & Cr 0.00 & Te 0.02 & Cr 0.00 & Te 0.02 & Cr 0.00 & Te 0.01 & Cr 0.00 & Te 0.06 \\
\hline & $\mathrm{Cu} 0.02$ & Ti 0.00 & $\mathrm{Cu} 0.01$ & Ti 0.00 & $\mathrm{Cu} 0.00$ & Ti 0.00 & $\mathrm{Cu} 0.01$ & Ti 0.00 & $\mathrm{Cu} 0.01$ & Ti 0.00 & $\mathrm{Cu} 0.01$ & Ti 0.00 \\
\hline & La 0.00 & $\mathrm{Zr} 0.00$ & La 0.00 & $\mathrm{Zr} 0.00$ & La bdl & Zr 0.00 & La bdl & $\mathrm{Zr} 0.00$ & La bdl & Zr 0.00 & La 0.00 & Zr 0.00 \\
\hline \multirow{5}{*}{$640^{\circ} \mathrm{C}$} & $\mathrm{Cd} 0.00$ & $\mathrm{~Pb} 0.00$ & $\mathrm{Cd} 0.00$ & $\mathrm{~Pb} 0.00$ & $\mathrm{Cd} 0.00$ & $\mathrm{~Pb} 0.00$ & $\mathrm{Cd} 0.00$ & $\mathrm{~Pb} 0.00$ & $\mathrm{Cd} 0.00$ & $\mathrm{~Pb}$ bdl & $\mathrm{Cd} 0.00$ & $\mathrm{~Pb} 0.00$ \\
\hline & Ce 0.00 & $\mathrm{Se}$ bdl & $\mathrm{Ce}$ bdl & Se bdl & Ce 0.00 & Se bdl & Ce 0.00 & $\mathrm{Se}$ bdl & $\mathrm{Ce}$ bdl & $\mathrm{Se}$ bdl & Ce 0.00 & Se bdl \\
\hline & Cr 0.00 & Te 0.01 & Cr 0.00 & Te 0.02 & $\mathrm{Cr} 0.00$ & Te 0.01 & $\mathrm{Cr} 0.00$ & $\mathrm{Te} 0.01$ & $\mathrm{Cr} 0.00$ & Te 0.01 & Cr 0.00 & Te 0.02 \\
\hline & $\mathrm{Cu} 0.01$ & Ti 0.00 & $\mathrm{Cu} 0.01$ & Ti 0.00 & $\mathrm{Cu} 0.02$ & Ti 0.00 & $\mathrm{Cu} 0.02$ & Ti 0.00 & $\mathrm{Cu} 0.01$ & Ti 0.00 & $\mathrm{Cu} 0.01$ & Ti 0.00 \\
\hline & La bdl & $\mathrm{Zr} 0.00$ & La 0.00 & $\mathrm{Zr} 0.00$ & La bdl & $\mathrm{Zr} 0.00$ & La bdl & $\mathrm{Zr} 0.00$ & La bdl & Zr 0.00 & La 0.00 & Zr 0.00 \\
\hline \multirow{5}{*}{$500^{\circ} \mathrm{C}$} & $\mathrm{Cd} 0.00$ & $\mathrm{~Pb} 0.00$ & $\mathrm{Cd} 0.00$ & $\mathrm{~Pb} 0.00$ & $\mathrm{Cd} 0.00$ & $\mathrm{~Pb}$ bdl & $\mathrm{Cd} 0.00$ & $\mathrm{~Pb}$ bdl & $\mathrm{Cd} 0.00$ & $\mathrm{~Pb}$ bdl & $\mathrm{Cd} 0.00$ & $\mathrm{~Pb} 0.00$ \\
\hline & $\mathrm{Ce} 0.00$ & $\mathrm{Se}$ bdl & $\mathrm{Ce}$ bdl & $\mathrm{Se}$ bdl & $\mathrm{Ce}$ bdl & Se bdl & $\mathrm{Ce}$ bdl & $\mathrm{Se}$ bdl & $\mathrm{Ce}$ bdl & $\mathrm{Se}$ bdl & $\mathrm{Ce} 0.00$ & Se bdl \\
\hline & $\mathrm{Cr} 0.00$ & Te 0.01 & Cr 0.00 & Te 0.02 & Cr 0.00 & Te 0.02 & Cr 0.00 & Te 0.02 & $\mathrm{Cr}$ bdl & Te 0.01 & Cr 0.00 & Te 0.02 \\
\hline & $\mathrm{Cu} 0.01$ & Ti 0.00 & $\mathrm{Cu} 0.01$ & Ti 0.00 & $\mathrm{Cu} 0.01$ & Ti 0.00 & $\mathrm{Cu} 0.01$ & Ti 0.00 & $\mathrm{Cu} 0.02$ & Ti bdl & $\mathrm{Cu} 0.01$ & Ti 0.00 \\
\hline & La bdl & $\operatorname{Zr} 0.00$ & La 0.00 & $\mathrm{Zr} 0.00$ & La bdl & $\operatorname{Zr} 0.00$ & La bdl & $\operatorname{Zr} 0.00$ & La bdl & $\operatorname{Zr} 0.00$ & La 0.00 & Zr 0.00 \\
\hline Time (hrs) & \multicolumn{2}{|c|}{0.75} & \multicolumn{2}{|c|}{3} & \multicolumn{2}{|c|}{12} & \multicolumn{2}{|c|}{48} & \multicolumn{2}{|c|}{192} & \multicolumn{2}{|c|}{768} \\
\hline
\end{tabular}




\begin{tabular}{|c|c|c|c|c|c|c|c|c|c|c|c|c|}
\hline Temperature & \multicolumn{12}{|c|}{ Table 4-52. TTT PCT Data (Group 3) (mg/l) } \\
\hline $1200^{\circ} \mathrm{C}$ & $\begin{array}{c}\text { Al } 0.03 \\
\text { As } 0.07 \\
\text { Ba } 0.01 \\
\text { Ca } 0.07 \\
\text { Fe } 0.00 \\
\text { Mg 0.08 }\end{array}$ & $\begin{array}{c}\text { Mn } 0.01 \\
\text { Ni } 0.00 \\
\text { S } 0.07 \\
\text { Sb } 0.08 \\
\text { Zn } 0.00\end{array}$ & $\begin{array}{c}\text { Al } 0.03 \\
\text { As } 0.07 \\
\text { Ba } 0.01 \\
\text { Ca } 0.08 \\
\text { Fe } 0.00 \\
\text { Mg } 0.07\end{array}$ & $\begin{array}{c}\text { Mn } 0.01 \\
\text { Ni } 0.00 \\
\text { S bdl } \\
\text { Sb } 0.08 \\
\text { Zn bdl }\end{array}$ & $\begin{array}{c}\text { Al } 0.03 \\
\text { As } 0.08 \\
\text { Ba } 0.01 \\
\text { Ca } 0.06 \\
\text { Fe } 0.00 \\
\text { Mg } 0.06\end{array}$ & $\begin{array}{l}\text { Mn } 0.01 \\
\text { Ni } 0.00 \\
\text { S } 0.09 \\
\text { Sb } 0.08 \\
\text { Zn bdl }\end{array}$ & $\begin{array}{c}\text { Al } 0.03 \\
\text { As } 0.06 \\
\text { Ba } 0.01 \\
\text { Ca } 0.07 \\
\text { Fe } 0.00 \\
\text { Mg } 0.06\end{array}$ & $\begin{array}{l}\text { Mn } 0.01 \\
\text { Ni } 0.00 \\
\text { S } 0.09 \\
\text { Sb } 0.08 \\
\text { Zn bdl }\end{array}$ & $\begin{array}{c}\text { Al } 0.03 \\
\text { As } 0.05 \\
\text { Ba } 0.01 \\
\text { Ca } 0.07 \\
\text { Fe } 0.00 \\
\text { Mg } 0.06\end{array}$ & $\begin{array}{l}\text { Mn } 0.01 \\
\text { Ni } 0.00 \\
\text { S } 0.11 \\
\text { Sb } 0.07 \\
\text { Zn bdl }\end{array}$ & $\begin{array}{c}\text { Al } 0.03 \\
\text { As } 0.04 \\
\text { Ba } 0.02 \\
\text { Ca } 0.07 \\
\text { Fe } 0.00 \\
\text { Mg } 0.06\end{array}$ & $\begin{array}{cc}\text { Mn } & 0.01 \\
\text { Ni } & 0.06 \\
\text { S } & 0.10 \\
\text { Sb } & 0.07 \\
\text { Zn } & 0.00\end{array}$ \\
\hline $1060^{\circ} \mathrm{C}$ & $\begin{array}{l}\text { Al } 0.03 \\
\text { As } 0.08 \\
\text { Ba } 0.01 \\
\text { Ca } 0.07 \\
\text { Fe } 0.00 \\
\text { Mg } 0.07\end{array}$ & $\begin{array}{c}\text { Mn } 0.01 \\
\text { Ni } 0.00 \\
\text { S } 0.08 \\
\text { Sb } 0.08 \\
\text { Zn } 0.00\end{array}$ & $\begin{array}{c}\text { Al } 0.03 \\
\text { As } 0.07 \\
\text { Ba } 0.01 \\
\text { Ca } 0.08 \\
\text { Fe } 0.00 \\
\text { Mg } 0.06\end{array}$ & $\begin{array}{c}\text { Mn } 0.01 \\
\text { Ni } 0.00 \\
\text { S bdl } \\
\text { Sb } 0.09 \\
\text { Zn bdl }\end{array}$ & $\begin{array}{c}\text { Al } 0.03 \\
\text { As } 0.07 \\
\text { Ba } 0.01 \\
\text { Ca } 0.07 \\
\text { Fe bdl } \\
\text { Mg } 0.05\end{array}$ & $\begin{array}{c}\text { Mn } 0.01 \\
\text { Ni } 0.00 \\
\text { S } 0.05 \\
\text { Sb } 0.08 \\
\text { Zn bdl }\end{array}$ & $\begin{array}{c}\text { Al } 0.03 \\
\text { As } 0.08 \\
\text { Ba } 0.01 \\
\text { Ca } 0.08 \\
\text { Fe } 0.00 \\
\text { Mg } 0.05\end{array}$ & $\begin{array}{l}\text { Mn } 0.01 \\
\text { Ni } 0.00 \\
\text { S } 0.20 \\
\text { Sb } 0.08 \\
\text { Zn bdl }\end{array}$ & $\begin{array}{c}\text { Al } 0.03 \\
\text { As } 0.07 \\
\text { Ba } 0.01 \\
\text { Ca } 0.08 \\
\text { Fe } 0.00 \\
\text { Mg } 0.05\end{array}$ & $\begin{array}{l}\text { Mn } 0.01 \\
\text { Ni } 0.00 \\
\text { S } 0.12 \\
\text { Sb } 0.08 \\
\text { Zn bdl }\end{array}$ & $\begin{array}{l}\text { Al } 0.03 \\
\text { As } 0.08 \\
\text { Ba } 0.01 \\
\text { Ca } 0.13 \\
\text { Fe } 0.00 \\
\text { Mg } 0.21\end{array}$ & $\begin{array}{cc}\text { Mn } & 0.01 \\
\text { Ni } & 0.00 \\
\text { S } & 0.40 \\
\text { Sb } & 0.07 \\
\text { Zn } & 0.00\end{array}$ \\
\hline $920^{\circ} \mathrm{C}$ & $\begin{array}{c}\text { Al } 0.03 \\
\text { As } 0.08 \\
\text { Ba } 0.01 \\
\text { Ca } 0.09 \\
\mathrm{Fe} 0.00 \\
\mathrm{Mg} 0.08\end{array}$ & $\begin{array}{c}\text { Mn } 0.01 \\
\text { Ni } 0.00 \\
\text { S } 0.09 \\
\text { Sb } 0.09 \\
\text { Zn } 0.00\end{array}$ & $\begin{array}{c}\text { Al } 0.04 \\
\text { As } 0.07 \\
\text { Ba } 0.01 \\
\text { Ca } 0.09 \\
\text { Fe } 0.00 \\
\text { Mg } 0.05\end{array}$ & $\begin{array}{c}\text { Mn } 0.01 \\
\text { Ni } 0.00 \\
\text { S bdl } \\
\text { Sb } 0.09 \\
\text { Zn } \quad \text { bdl }\end{array}$ & $\begin{array}{c}\text { Al } 0.03 \\
\text { As } 0.06 \\
\text { Ba } 0.01 \\
\text { Ca } 0.07 \\
\text { Fe bdl } \\
\text { Mg } 0.04\end{array}$ & $\begin{array}{c}\text { Mn } 0.01 \\
\text { Ni } 0.00 \\
\text { S } 0.07 \\
\text { Sb } 0.08 \\
\text { Zn bdl }\end{array}$ & $\begin{array}{c}\text { Al } 0.03 \\
\text { As } 0.08 \\
\text { Ba } 0.02 \\
\text { Ca } 0.08 \\
\text { Fe } 0.00 \\
\text { Mg } 0.03\end{array}$ & $\begin{array}{cc}\text { Mn } & 0.01 \\
\mathrm{Ni} & 0.00 \\
\mathrm{~S} & 0.12 \\
\mathrm{Sb} & 0.09 \\
\mathrm{Zn} & 0.00\end{array}$ & $\begin{array}{c}\text { Al } 0.04 \\
\text { As } 0.07 \\
\text { Ba } 0.01 \\
\text { Ca } 0.08 \\
\text { Fe } 0.00 \\
\text { Mg } 0.04\end{array}$ & $\begin{array}{c}\text { Mn } 0.01 \\
\text { Ni } 0.00 \\
\text { S } 0.10 \\
\text { Sb } 0.08 \\
\text { Zn bdl }\end{array}$ & $\begin{array}{c}\text { Al } 0.03 \\
\text { As } 0.07 \\
\text { Ba } 0.01 \\
\text { Ca } 0.06 \\
\text { Fe } 0.00 \\
\text { Mg } 0.05\end{array}$ & $\begin{array}{cc}\text { Mn } & 0.01 \\
\text { Ni } & 0.01 \\
\text { S } & \text { bdl } \\
\text { Sb } & 0.07 \\
\text { Zn } & 0.00\end{array}$ \\
\hline $780^{\circ} \mathrm{C}$ & $\begin{array}{c}\text { Al } 0.04 \\
\text { As } 0.08 \\
\text { Ba } 0.01 \\
\text { Ca } 0.08 \\
\text { Fe } 0.00 \\
\text { Mg } 0.08\end{array}$ & $\begin{array}{c}\text { Mn } 0.01 \\
\text { Ni } 0.00 \\
\text { S } 0.09 \\
\text { Sb } 0.09 \\
\text { Zn } 0.00\end{array}$ & $\begin{array}{c}\text { Al } 0.04 \\
\text { As } 0.07 \\
\text { Ba } 0.02 \\
\text { Ca } 0.09 \\
\text { Fe } 0.00 \\
\text { Mg } 0.04\end{array}$ & $\begin{array}{c}\text { Mn } 0.01 \\
\text { Ni } 0.00 \\
\text { S bdl } \\
\text { Sb } 0.09 \\
\text { Zn bdl }\end{array}$ & $\begin{array}{c}\text { Al } 0.04 \\
\text { As } 0.06 \\
\text { Ba } 0.01 \\
\text { Ca } 0.09 \\
\text { Fe bdl } \\
\text { Mg } 0.04\end{array}$ & $\begin{array}{c}\text { Mn } 0.01 \\
\text { Ni } 0.00 \\
\text { S } 0.06 \\
\text { Sb } 0.08 \\
\text { Zn bdl }\end{array}$ & $\begin{array}{cc}\text { Al } & 0.04 \\
\text { As } & 0.07 \\
\text { Ba } & 0.01 \\
\text { Ca } & 0.11 \\
\text { Fe bdl } \\
\text { Mg } 0.04\end{array}$ & $\begin{array}{c}\text { Mn } 0.01 \\
\text { Ni } 0.00 \\
\text { S } 0.06 \\
\text { Sb } 0.09 \\
\text { Zn bdl }\end{array}$ & $\begin{array}{c}\text { Al } 0.04 \\
\text { As } 0.08 \\
\text { Ba } 0.01 \\
\text { Ca } 0.10 \\
\text { Fe } 0.00 \\
\text { Mg } 0.04\end{array}$ & $\begin{array}{c}\text { Mn } 0.01 \\
\text { Ni } 0.00 \\
\text { S } 0.11 \\
\text { Sb } 0.09 \\
\text { Zn } \quad \text { bdl }\end{array}$ & $\begin{array}{l}\text { Al } 0.04 \\
\text { As } 0.09 \\
\text { Ba } 0.01 \\
\text { Ca } 0.08 \\
\text { Fe } 0.00 \\
\text { Mg } 0.03\end{array}$ & $\begin{array}{cc}\text { Mn } & 0.01 \\
\text { Ni } & 0.00 \\
\text { S } & 0.00 \\
\text { Sb } & 0.09 \\
\text { Zn } & 0.00\end{array}$ \\
\hline $640^{\circ} \mathrm{C}$ & $\begin{array}{c}\text { Al } 0.03 \\
\text { As } 0.06 \\
\text { Ba } 0.02 \\
\text { Ca } 0.07 \\
\text { Fe } 0.00 \\
\text { Mg } 0.05 \\
\end{array}$ & $\begin{array}{c}\text { Mn } 0.02 \\
\text { Ni } 0.00 \\
\text { S } 0.07 \\
\text { Sb } 0.07 \\
\text { Zn bdl }\end{array}$ & $\begin{array}{r}\text { Al } 0.04 \\
\text { As } 0.08 \\
\text { Ba } 0.01 \\
\text { Ca } 0.09 \\
\text { Fe } 0.00 \\
\text { Mg } 0.08 \\
\end{array}$ & $\begin{array}{cc}\text { Mn } & 0.01 \\
\text { Ni } & 0.00 \\
\text { S } & 0.09 \\
\text { Sb } & 0.09 \\
\text { Zn } & 0.00\end{array}$ & $\begin{array}{c}\text { Al } 0.04 \\
\text { As } 0.06 \\
\text { Ba } 0.02 \\
\text { Ca } 0.08 \\
\text { Fe } 0.00 \\
\text { Mg } 0.05 \\
\end{array}$ & $\begin{array}{cc}\text { Mn } & 0.02 \\
\text { Ni } & 0.00 \\
\text { S } & 0.09 \\
\text { Sb } & 0.08 \\
\text { Zn } & 0.00\end{array}$ & $\begin{array}{c}\text { Al } 0.04 \\
\text { As } 0.05 \\
\text { Ba } 0.02 \\
\text { Ca } 0.08 \\
\text { Fe } 0.00 \\
\text { Mg } 0.05 \\
\end{array}$ & $\begin{array}{cc}\text { Mn } & 0.02 \\
\text { Ni } & 0.00 \\
\text { S } & 0.09 \\
\text { Sb } & 0.08 \\
\text { Zn } & 0.00\end{array}$ & $\begin{array}{c}\text { Al } 0.03 \\
\text { As } 0.07 \\
\text { Ba } 0.01 \\
\text { Ca } 0.08 \\
\text { Fe } 0.00 \\
\text { Mg } 0.05 \\
\end{array}$ & $\begin{array}{c}\text { Mn } 0.02 \\
\text { Ni } 0.00 \\
\text { S } 0.13 \\
\text { Sb } 0.08 \\
\text { Zn bdl }\end{array}$ & $\begin{array}{l}\text { Al } 0.04 \\
\text { As } 0.08 \\
\text { Ba } 0.02 \\
\text { Ca } 0.10 \\
\mathrm{Fe} 0.00 \\
\mathrm{Mg} 0.05\end{array}$ & $\begin{array}{cc}\text { Mn } & 0.01 \\
\text { Ni } & 0.00 \\
\text { S } & 0.06 \\
\text { Sb } & 0.09 \\
\text { Zn } & 0.00\end{array}$ \\
\hline $500^{\circ} \mathrm{C}$ & $\begin{array}{c}\text { Al } 0.04 \\
\text { As } 0.05 \\
\text { Ba } 0.02 \\
\text { Ca } 0.08 \\
\text { Fe } 0.00 \\
\text { Mg } 0.06 \\
\end{array}$ & $\begin{array}{c}\text { Mn } 0.01 \\
\text { Ni } 0.00 \\
\text { S } 0.09 \\
\text { Sb } 0.08 \\
\text { Zn bdl }\end{array}$ & $\begin{array}{c}\text { Al } 0.03 \\
\text { As } 0.08 \\
\text { Ba } 0.01 \\
\text { Ca } 0.08 \\
\text { Fe } 0.00 \\
\text { Mg } 0.10 \\
\end{array}$ & $\begin{array}{c}\text { Mn } 0.01 \\
\text { Ni } 0.00 \\
\text { S } 0.29 \\
\text { Sb } 0.09 \\
\text { Zn } 0.00\end{array}$ & $\begin{array}{c}\text { Al } 0.03 \\
\text { As } 0.07 \\
\text { Ba } 0.01 \\
\text { Ca } 0.07 \\
\text { Fe bdl } \\
\text { Mg } 0.05 \\
\end{array}$ & $\begin{array}{c}\text { Mn } 0.01 \\
\text { Ni } 0.00 \\
\text { S } 0.06 \\
\text { Sb } 0.07 \\
\text { Zn bdl }\end{array}$ & $\begin{array}{c}\text { Al } 0.03 \\
\text { As } 0.06 \\
\text { Ba } 0.01 \\
\text { Ca } 0.08 \\
\text { Fe bdl } \\
\text { Mg } 0.05 \\
\end{array}$ & $\begin{array}{c}\text { Mn } 0.01 \\
\text { Ni } 0.00 \\
\text { S } 0.05 \\
\text { Sb } 0.07 \\
\text { Zn bdl }\end{array}$ & $\begin{array}{c}\text { Al } 0.03 \\
\text { As } 0.06 \\
\text { Ba } 0.01 \\
\text { Ca } 0.08 \\
\text { Fe } 0.00 \\
\text { Mg } 0.06 \\
\end{array}$ & $\begin{array}{c}\text { Mn } 0.02 \\
\text { Ni } 0.00 \\
\text { S } 0.20 \\
\text { Sb } 0.07 \\
\text { Zn bdl }\end{array}$ & $\begin{array}{c}\text { Al } 0.03 \\
\text { As } 0.08 \\
\text { Ba } 0.02 \\
\text { Ca } 0.08 \\
\text { Fe } 0.00 \\
\text { Mg } 0.05 \\
\end{array}$ & $\begin{array}{cc}\text { Mn } & 0.01 \\
\text { Ni } & 0.00 \\
\text { S } & 0.02 \\
\text { Sb } & 0.07 \\
\text { Zn } & 0.00\end{array}$ \\
\hline Time (hrs) & & & & & & & & & & & & \\
\hline
\end{tabular}


The elements in each grouping are discussed in turn.

\section{Group 1}

Silicon and B, necessarily common to all borosilicate glasses, and $\mathrm{Sr}$ are the most concentrated species in the TTT glass composition. It is observed that for almost all heat treatment times and temperatures, the relative normalized release of $\mathrm{B}>\mathrm{Si}>\mathrm{Sr}$. Also, the normalized release for each specie is quite constant as a function of heat treatment time and temperature. Figures 4-26, 4-27 and 4-28 are graphical representations of the data for these elements. Analysis of the data indicates no appreciable response with respect to $\mathrm{PCT}$ conditions for these three elements. Leachate $\mathrm{pH}$ was also effectively constant $(\mathrm{pH} \sim 8)$ for all times and temperatures. As silica solubility is a strong function of $\mathrm{pH}>9$, this is consistent with the Si release data.

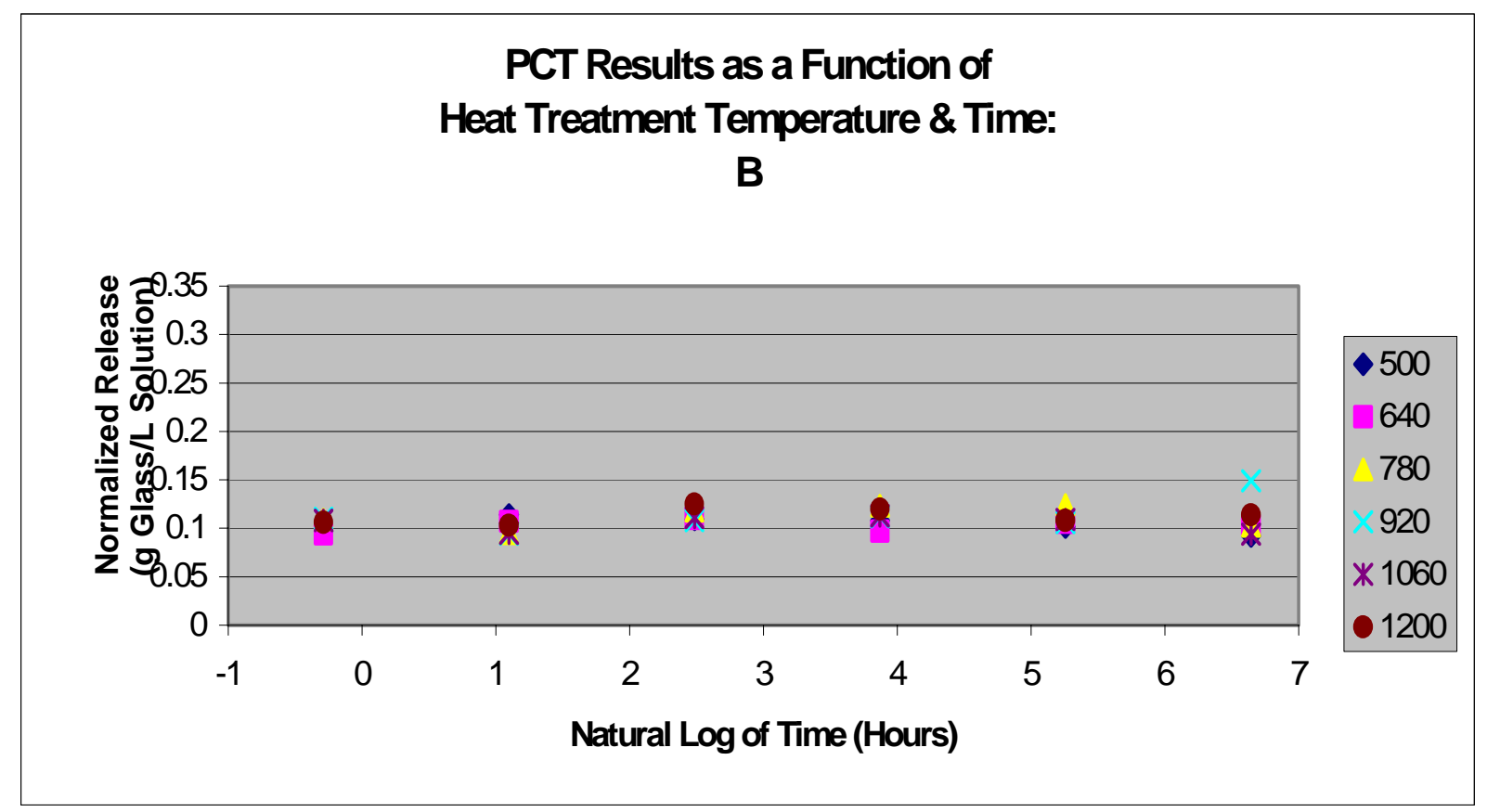

Figure 4-26. PCT Results for Boron 


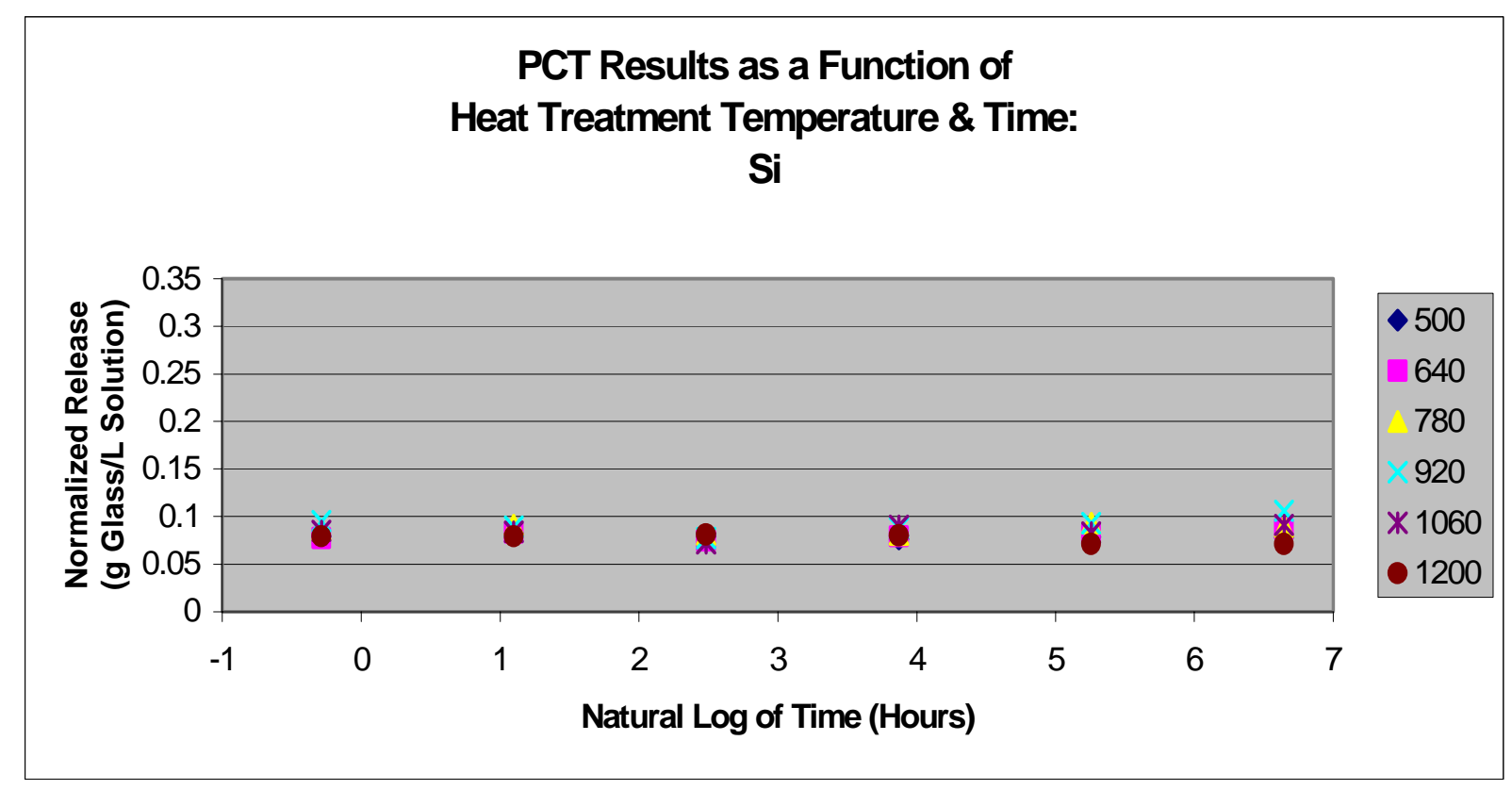

Figure 4-27. PCT Results for Silicon

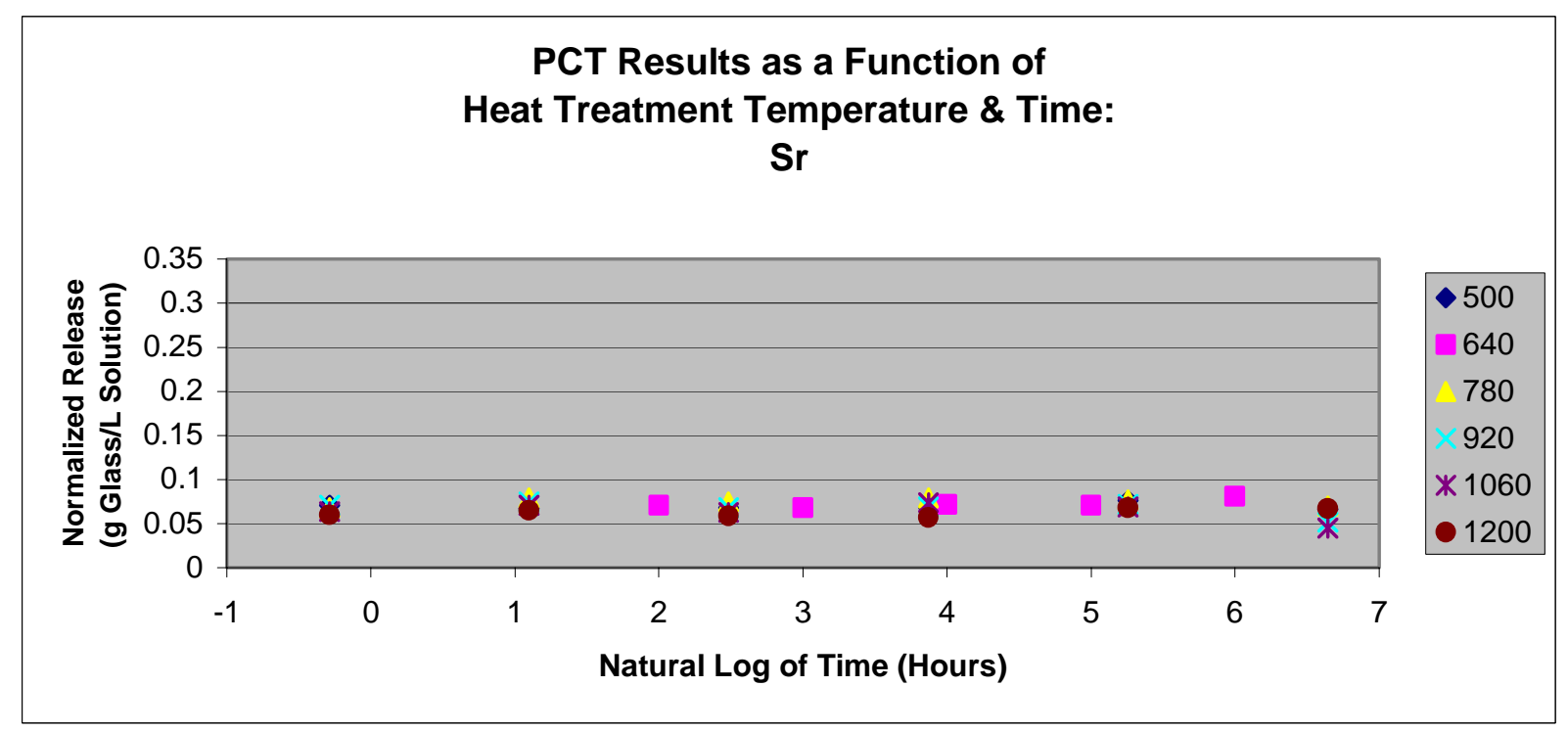

Figure 4-28. PCT Results for Strontium

The alkali elements $\mathrm{Na}$ and $\mathrm{K}$ reflect the highest relative PCT release values for almost every heat-treated sample tested. Normalized $\mathrm{Na}$ and $\mathrm{K}$ release values were considerably higher than corresponding values for $\mathrm{Cs}$. Cs release values are equivalent to values for $\mathrm{Si}$ and B. No consistent data trends are noted for specific temperatures - with a possible exception of the $1060^{\circ} \mathrm{C}$ heat treatments. The sodium release (for the $1060^{\circ} \mathrm{C}$ heat treatments) appears to increase slightly as a function of heat treatment duration. Figure's 4-29, 4-30, and 4-31 are graphical representations of the PCT tests data for Na, K, and 
Cs, respectively. It is observed that no wasteform specie exhibits a PCT response within a factor of 10 of the values for the SRS EA glass.

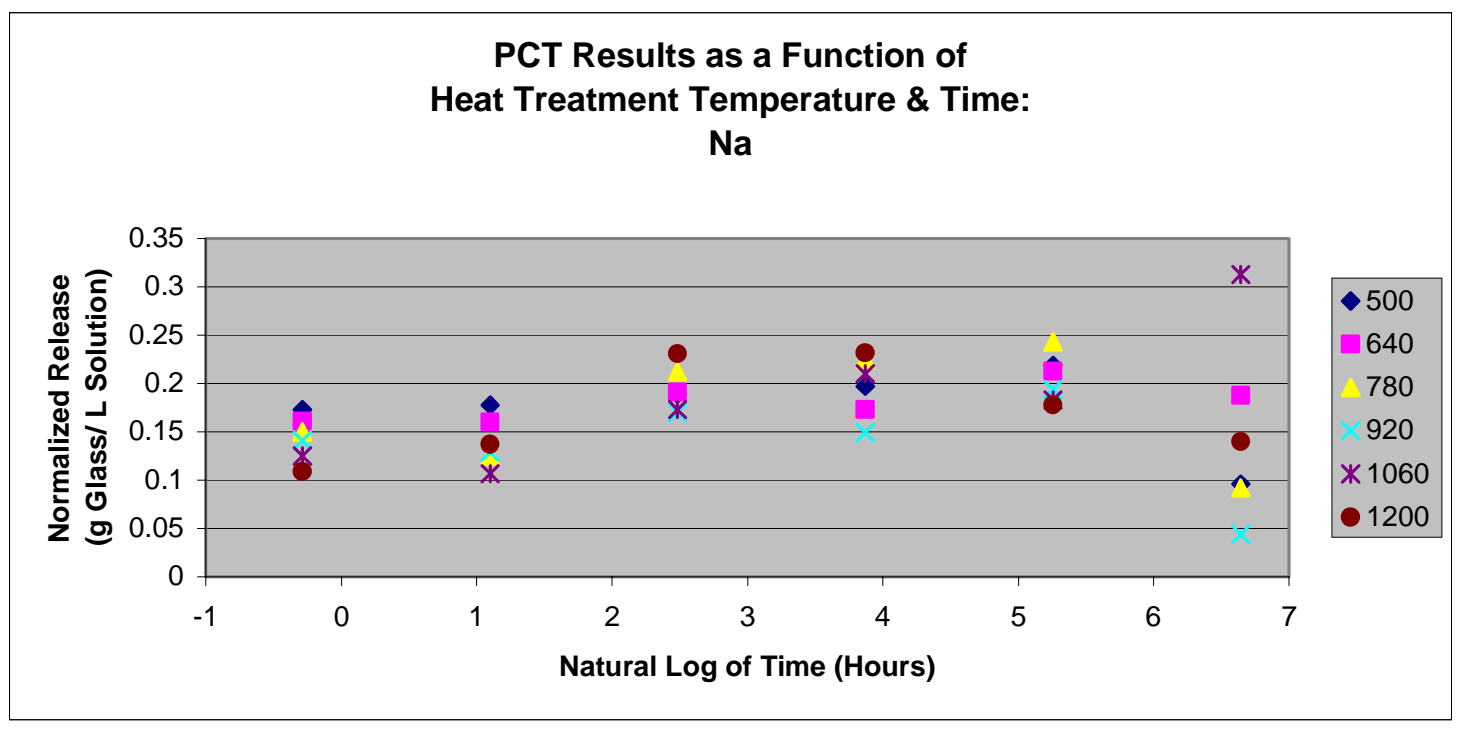

Figure 4-29. PCT Results for Sodium

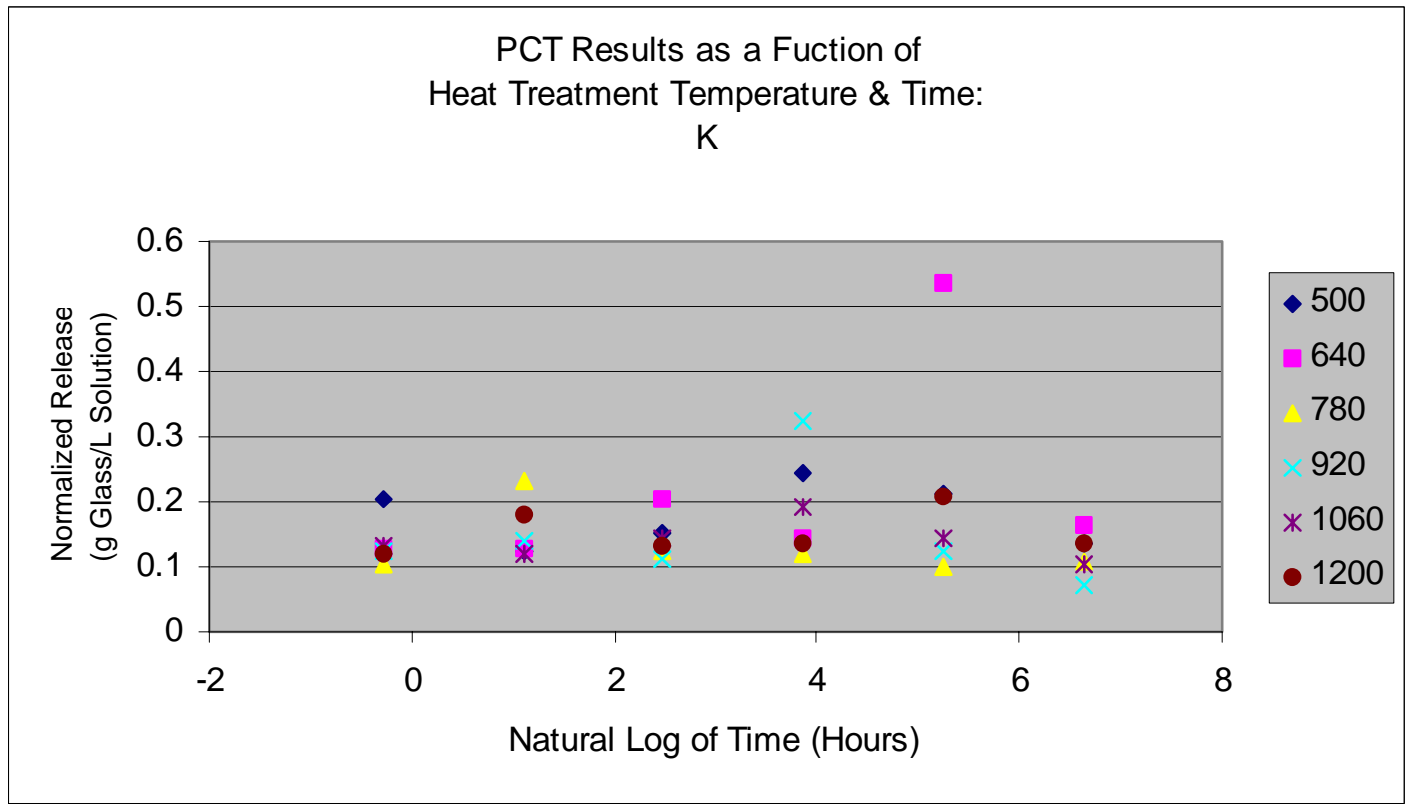

Figure 4-30. PCT Results for Potassium 


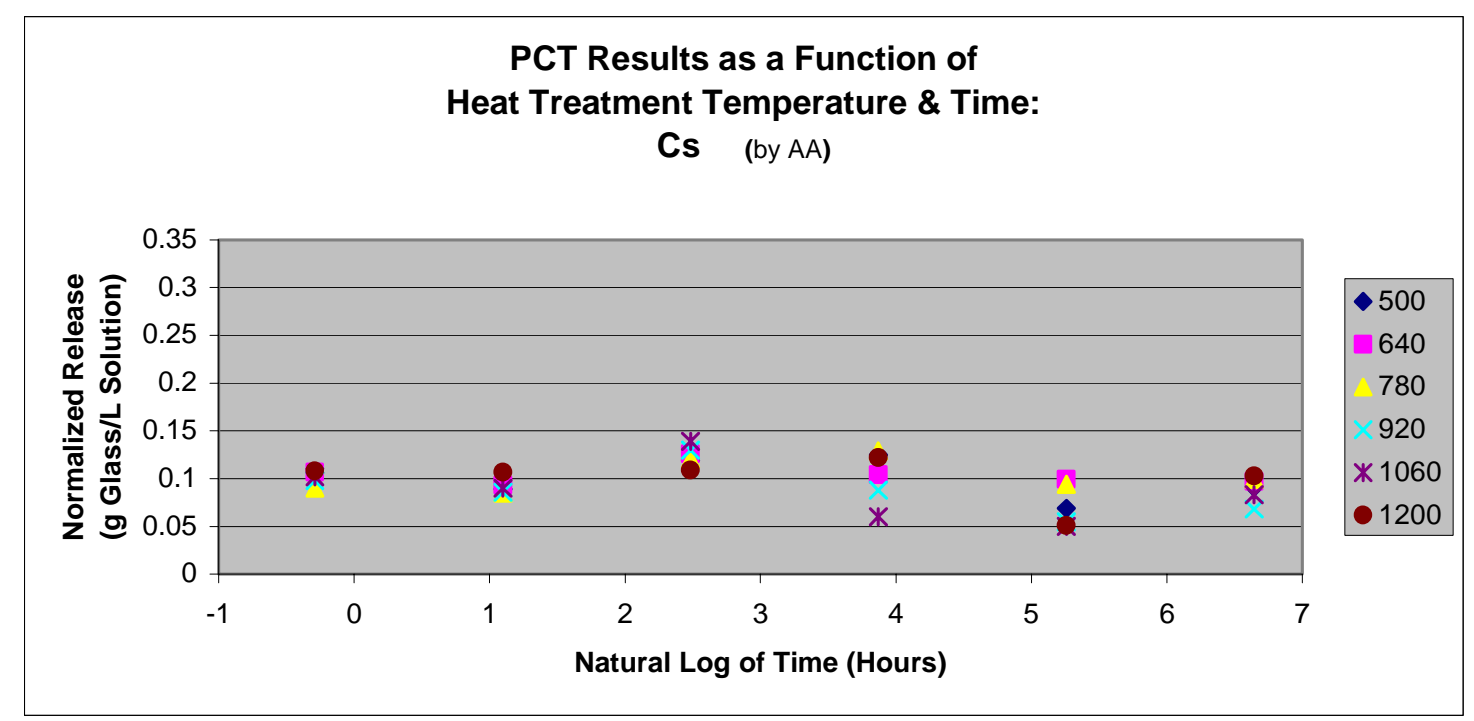

Figure 4-31. AA PCT Results for Cesium

Group 2

The PCT data for Group 2 are presented in Table 4-51. A considerable fraction of the constituents in the AVS LM 60 composition has limited solubility in the PCT leachates taken from the LM 60 glass or the heat-treated samples. However, 2 of the constituents that were BDL in the LM 60 leachate have consistent levels in the leachates of the heat treated samples. Copper and Te are present in small concentration in most heat-treated sample PCT leachates. The normalized release values (nominally $0.01-0.02 \mathrm{~g}$ Glass / liter) are considerably lower than for the more soluble species. Tellurium concentration does appear to greater in the long-term, $920^{\circ} \mathrm{C}$ leachates than for other periods. These values do not approach any SRS EA glass release limit. Tellurium release is plotted in Figure 4-32. 


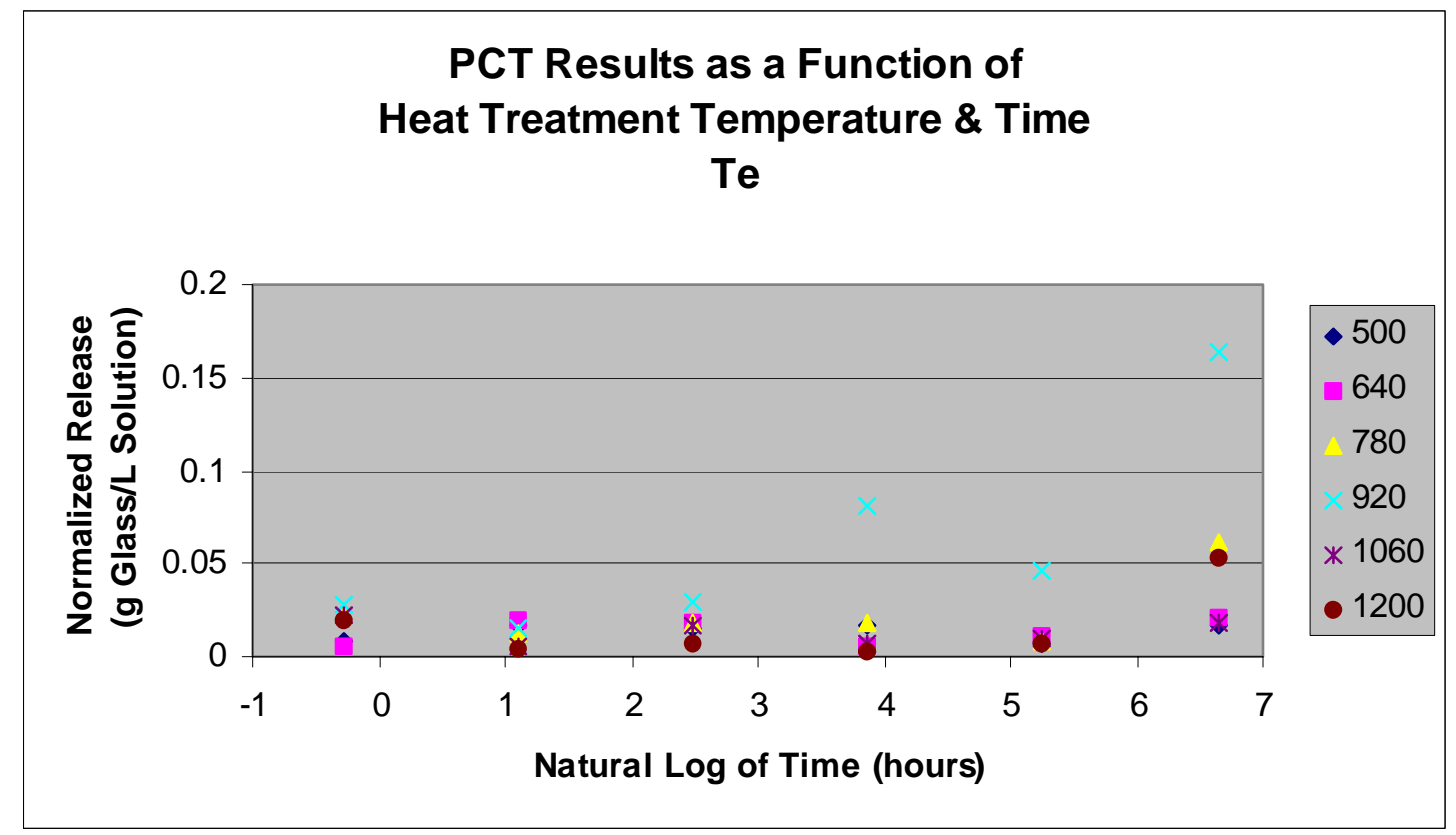

Group 3

Figure 4-32. PCT Results for Tellurium

The PCT Data for Group 3 are presented in Table 4-52. Most Group 3 cations, with the exception of $\mathrm{Zn}, \mathrm{Ni}$, and $\mathrm{Fe}$, have appreciable solubility in the PCT leachates of all heattreated samples. Compared with the data in Tables 4-50 and 4-51, these values are lower to on par with the more soluble species. In general, $\mathrm{Ca}$ has the highest relative release, roughly equivalent to $\mathrm{Si}$ or $\mathrm{Sr}$ (another alkaline earth). In addition, $\mathrm{Mg}$, and $\mathrm{Sb}$ have appreciable release values. The PCT response of no Group 3 species reflects any relationship between heat treatment conditions and chemical durability. The calcium release is plotted in Figure 4-33.

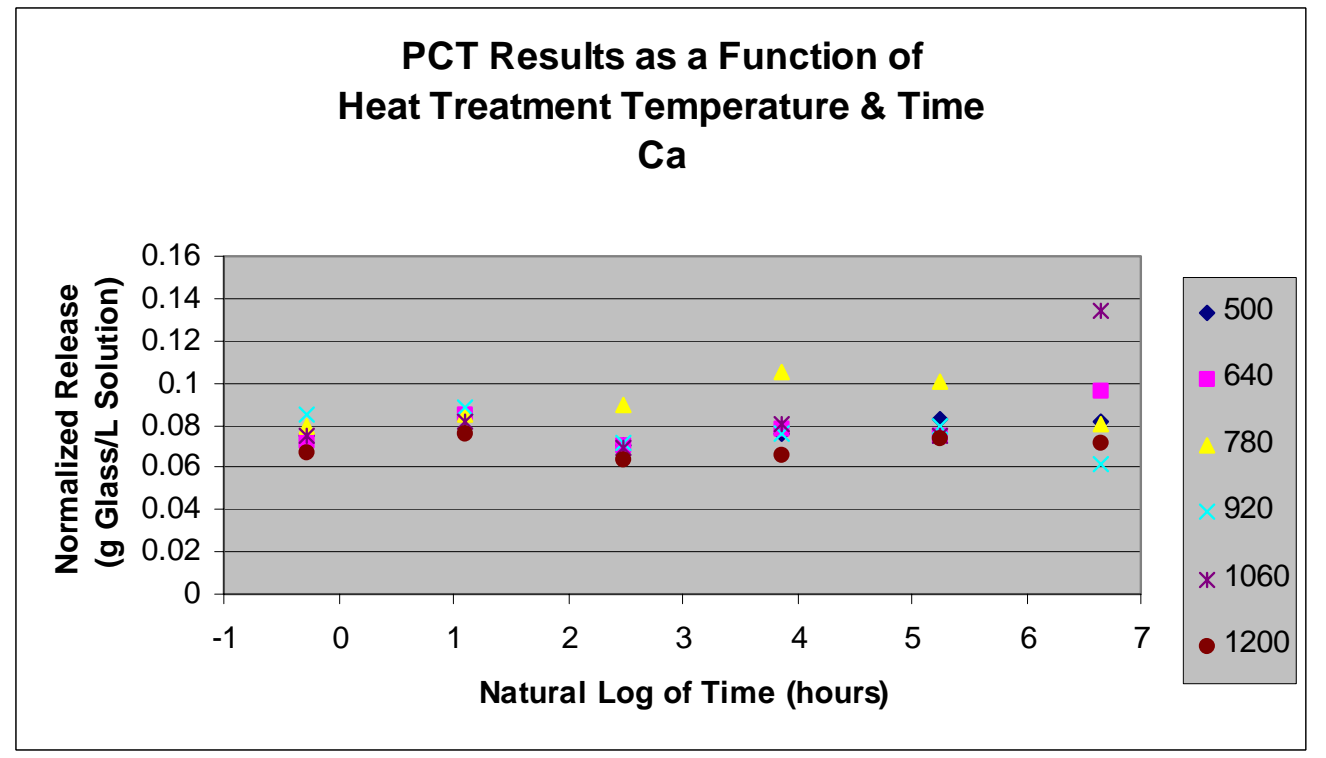

Figure 4-33. PCT Results for Calcium 


\section{TCLP}

The TCLP was performed on all TTT heat-treated samples. As per the DOE approved Detailed Test Plan, the sub-sampling of the crucible material was performed under video record. Six separate batches of TCLP protocols were performed. Extraction solutions were analyzed for the following metals: $\mathrm{As}, \mathrm{Ba}, \mathrm{Cd}, \mathrm{Cr}, \mathrm{Ni}, \mathrm{Pb}, \mathrm{Sb}$, Se, and $\mathrm{Zn}$. The data are presented in Table 4-53.

The release of RCRA species $\mathrm{As}, \mathrm{Ba}, \mathrm{Cr}, \mathrm{Ni}, \mathrm{Pb}, \mathrm{Sb}$, Se, and $\mathrm{Zn}$, as measured in the extraction fluid, were uniformly below the corresponding Universal Treatment Standard (UTS) levels. Cadmium response was strongly influenced by thermal treatment conditions and was determined to be the process-limiting factor. A review of Table 4.4.2.3.1 will show that all samples given an isothermal heat treatment of $1200^{\circ} \mathrm{C}$ had $\mathrm{Cd}$ TCLP response greater than the $0.11 \mathrm{ppm}$ UTS limit. All samples given a heat treatment of $1060^{\circ} \mathrm{C}$ for 3 hours or more also had an excessive $\mathrm{Cd}$ response. A general trend is noted wherein samples given longer duration and/or higher temperature heat treatments are equated with higher Cd release. All samples given $640^{\circ} \mathrm{C}$ or $500^{\circ} \mathrm{C}$ heat treatments (independent of isothermal soak duration) had corresponding $\mathrm{Cd}$ release values under the 0.11 UTS limit. A 3D plot of the Cd release data is provided in Figure 4-34.

It is noted that the $\mathrm{Cd}$ release data for the isothermal soak conditions is greater than observed for the slow cooling rate samples generated to determine optimal composition. Subsequent testing was performed to determine if the isothermal conditions did indeed impact the $\mathrm{Cd}$ release at elevated (above $1200^{\circ} \mathrm{C}$ ) temperatures. The TTT melt and isothermal heat treatment protocol was provided to $10 \mathrm{LM} 60$ batch samples. Heat treatment included 0.75 and 3 hours at $1300^{\circ} \mathrm{C}$ and $0.75,3,48$, and 192 hours at $1340^{\circ} \mathrm{C}$. The TCLP was performed on all samples and the Cd release determined. In all cases, the Cd release was below the UTS limit. These data are provided in Table 4-54.

Analysis of the TCLP data for the 36 TTT samples and the elevated temperature samples, indicates the $1200^{\circ} \mathrm{C}$ temperature range is critical with respect to TCLP Cd release. This is consistent with crystallinity data (discussed later). Rapid initial crystal growth, especially for the transition metal spinel and zirconia, occur in this same region. 


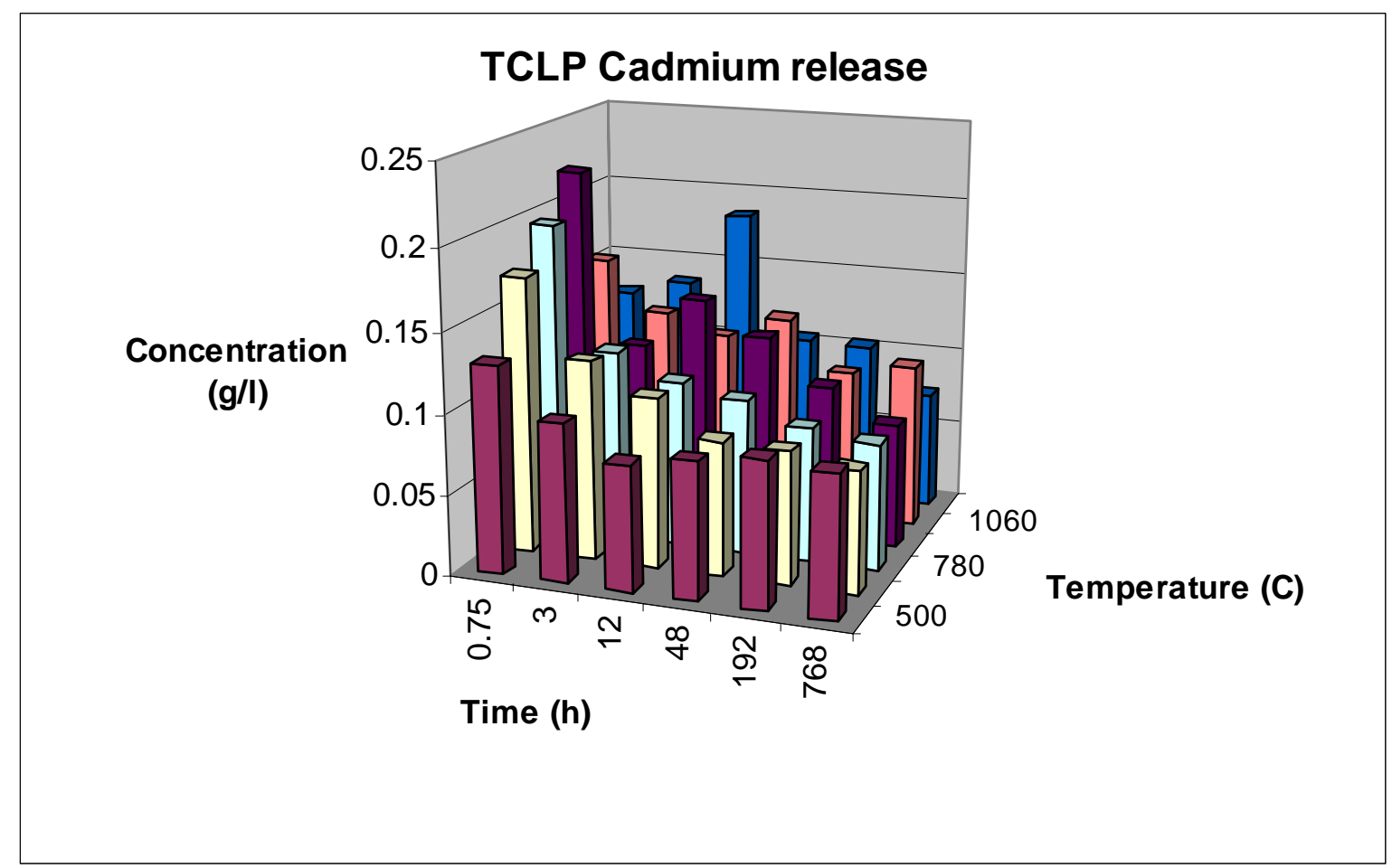

Figure 4-34. Three dimensional representation of the TCLP data for cadmium 


\begin{tabular}{|c|c|c|c|c|c|c|c|c|c|c|c|c|}
\hline Temperature & \multicolumn{12}{|c|}{ Table 4-53. TTT TCLP Data (mg/l) } \\
\hline $1200^{\circ} \mathrm{C}$ & $\begin{array}{ll}\text { As } & 0.01 \\
\mathrm{Ba} & 0.16 \\
\mathrm{Cd} & 0.13 \\
\mathrm{Cr} & 0.00 \\
\mathrm{Ni} & 0.04 \\
\end{array}$ & $\begin{array}{lr}\mathrm{Pb} & 0.06 \\
\mathrm{Sb} & 0.02 \\
\mathrm{Se} & \mathrm{bdl} \\
\mathrm{Zn} & 0.30\end{array}$ & $\begin{array}{c}\text { As } 0.02 \\
\mathrm{Ba} \text { bdl } \\
\mathrm{Cd} 0.17 \\
\mathrm{Cr} \quad 0.00 \\
\mathrm{Ni} \quad 0.04\end{array}$ & $\begin{array}{lr}\mathrm{Pb} & 0.08 \\
\mathrm{Sb} & 0.02 \\
\mathrm{Se} & \text { bdl } \\
\mathrm{Zn} & 0.17\end{array}$ & $\begin{array}{cc}\text { As } & 0.03 \\
\mathrm{Ba} & 0.09 \\
\mathrm{Cd} & 0.20 \\
\mathrm{Cr} & 0.00 \\
\mathrm{Ni} & 0.04 \\
\end{array}$ & $\begin{array}{ll}\mathrm{Pb} & 0.08 \\
\mathrm{Sb} & 0.02 \\
\mathrm{Se} & 0.01 \\
\mathrm{Zn} & 0.30\end{array}$ & $\begin{array}{cc}\text { As } & 0.024 \\
\mathrm{Ba} & 0.041 \\
\mathrm{Cd} & 0.22 \\
\mathrm{Cr} & 0.001 \\
\mathrm{Ni} & 0.030 \\
\end{array}$ & $\begin{array}{ll}\mathrm{Pb} & 0.07 \\
\mathrm{Sb} & 0.02 \\
\mathrm{Se} & 0.01 \\
\mathrm{Zn} & 0.29\end{array}$ & $\begin{array}{ll}\text { As } & 0.02 \\
\mathrm{Ba} & 0.08 \\
\mathrm{Cd} & 0.16 \\
\mathrm{Cr} & 0.00 \\
\mathrm{Ni} & 0.03 \\
\end{array}$ & $\begin{array}{ll}\mathrm{Pb} & 0.08 \\
\mathrm{Sb} & 0.02 \\
\mathrm{Se} & 0.01 \\
\mathrm{Zn} & 0.25\end{array}$ & $\begin{array}{ll}\text { As } & 0.01 \\
\mathrm{Ba} & 0.02 \\
\mathrm{Cd} & 0.13 \\
\mathrm{Cr} & 0.00 \\
\mathrm{Ni} & 0.02 \\
\end{array}$ & $\begin{array}{cc}\mathrm{Pb} & 0.06 \\
\mathrm{Sb} & 0.02 \\
\mathrm{Se} & \text { bdl } \\
\mathrm{Zn} & 0.16\end{array}$ \\
\hline $1060^{\circ} \mathrm{C}$ & $\begin{array}{ll}\text { As } & 0.01 \\
\mathrm{Ba} & 0.18 \\
\mathrm{Cd} & 0.10 \\
\mathrm{Cr} & 0.00 \\
\mathrm{Ni} & 0.03 \\
\end{array}$ & $\begin{array}{lr}\mathrm{Pb} & 0.05 \\
\mathrm{Sb} & 0.02 \\
\mathrm{Se} & \text { bdl } \\
\mathrm{Zn} & 0.21\end{array}$ & $\begin{array}{l}\text { As } 0.01 \\
\text { Ba } 0.01 \\
\text { Cd } 0.13 \\
\text { Cr } 0.00 \\
\text { Ni } 0.04\end{array}$ & $\begin{array}{lr}\mathrm{Pb} & 0.06 \\
\mathrm{Sb} & 0.02 \\
\mathrm{Se} & \text { bdl } \\
\mathrm{Zn} & 0.12\end{array}$ & $\begin{array}{ll}\text { As } & 0.01 \\
\mathrm{Ba} & \text { bdl } \\
\mathrm{Cd} & 0.12 \\
\mathrm{Cr} & 0.00 \\
\mathrm{Ni} & 0.03\end{array}$ & $\begin{array}{cc}\mathrm{Pb} & 0.06 \\
\mathrm{Sb} & 0.020 \\
\mathrm{Se} & \text { bdl } \\
\mathrm{Zn} & 0.13\end{array}$ & $\begin{array}{cc}\text { As } & 0.019 \\
\mathrm{Ba} & 0.009 \\
\mathrm{Cd} & 0.11 \\
\mathrm{Cr} & 0.00 \\
\mathrm{Ni} & 0.03\end{array}$ & $\begin{array}{ll}\mathrm{Pb} & 0.06 \\
\mathrm{Sb} & 0.02 \\
\mathrm{Se} & 0.01 \\
\mathrm{Zn} & 0.13\end{array}$ & $\begin{array}{cc}\text { As } & 0.02 \\
\mathrm{Ba} & 0.03 \\
\mathrm{Cd} & 0.13 \\
\mathrm{Cr} & 0.00 \\
\mathrm{Ni} & 0.03 \\
\end{array}$ & $\begin{array}{ll}\mathrm{Pb} & 0.06 \\
\mathrm{Sb} & 0.02 \\
\mathrm{Se} & 0.01 \\
\mathrm{Zn} & 0.14\end{array}$ & $\begin{array}{cc}\text { As } & 0.01 \\
\mathrm{Ba} & 0.02 \\
\mathrm{Cd} & 0.14 \\
\mathrm{Cr} & 0.00 \\
\mathrm{Ni} & 0.03 \\
\end{array}$ & $\begin{array}{cc}\mathrm{Pb} & 0.07 \\
\mathrm{Sb} & 0.02 \\
\mathrm{Se} & \text { bdl } \\
\mathrm{Zn} & 0.13\end{array}$ \\
\hline $920^{\circ} \mathrm{C}$ & $\begin{array}{ll}\text { As } & 0.01 \\
\mathrm{Ba} & 0.20 \\
\mathrm{Cd} & 0.08 \\
\mathrm{Cr} & 0.00 \\
\mathrm{Ni} & 0.02 \\
\end{array}$ & $\begin{array}{rr}\mathrm{Pb} & 0.04 \\
\mathrm{Sb} & 0.02 \\
\mathrm{Se} & \text { bdl } \\
\mathrm{Zn} & 0.18\end{array}$ & $\begin{array}{ll}\text { As } & 0.01 \\
\text { Ba } & \text { bdl } \\
\text { Cd } & 0.11 \\
\text { Cr } & 0.00 \\
\text { Ni } & 0.03 \\
\end{array}$ & $\begin{array}{lr}\mathrm{Pb} & 0.05 \\
\mathrm{Sb} & 0.02 \\
\mathrm{Se} & \text { bdl } \\
\mathrm{Zn} & 0.08\end{array}$ & $\begin{array}{ll}\text { As } & 0.02 \\
\text { Ba } & \text { bdl } \\
\text { Cd } & 0.10 \\
\text { Cr } & 0.00 \\
\text { Ni } & 0.03 \\
\end{array}$ & $\begin{array}{ll}\mathrm{Pb} & 0.05 \\
\mathrm{Sb} & 0.02 \\
\mathrm{Se} & 0.01 \\
\mathrm{Zn} & 0.08\end{array}$ & $\begin{array}{cc}\text { As } & 0.01 \\
\mathrm{Ba} & 0.02 \\
\mathrm{Cd} & 0.15 \\
\mathrm{Cr} & 0.00 \\
\mathrm{Ni} & 0.03 \\
\end{array}$ & $\begin{array}{cc}\mathrm{Pb} & 0.06 \\
\mathrm{Sb} & 0.02 \\
\mathrm{Se} & \mathrm{bdl} \\
\mathrm{Zn} & 0.12\end{array}$ & $\begin{array}{ll}\text { As } & 0.01 \\
\text { Ba } & \text { bdl } \\
\text { Cd } & 0.11 \\
\text { Cr } & 0.00 \\
\text { Ni } & 0.03 \\
\end{array}$ & $\begin{array}{cc}\mathrm{Pb} & 0.05 \\
\mathrm{Sb} & 0.02 \\
\mathrm{Se} & \mathrm{bdl} \\
\mathrm{Zn} & 0.06\end{array}$ & $\begin{array}{cc}\text { As } & 0.01 \\
\mathrm{Ba} & 0.02 \\
\mathrm{Cd} & 0.18 \\
\mathrm{Cr} & 0.00 \\
\mathrm{Ni} & 0.03 \\
\end{array}$ & $\begin{array}{cc}\mathrm{Pb} & 0.13 \\
\mathrm{Sb} & 0.02 \\
\mathrm{Se} & \text { bdl } \\
\mathrm{Zn} & 0.06\end{array}$ \\
\hline${ }^{780^{\circ}} \mathrm{C}$ & $\begin{array}{ll}\text { As } & 0.01 \\
\mathrm{Ba} & 0.13 \\
\mathrm{Cd} & 0.09 \\
\mathrm{Cr} & 0.00 \\
\mathrm{Ni} & 0.02\end{array}$ & $\begin{array}{rr}\mathrm{Pb} & 0.04 \\
\mathrm{Sb} & 0.02 \\
\mathrm{Se} & \text { bdl } \\
\mathrm{Zn} & 0.16\end{array}$ & $\begin{array}{lr}\text { As } & 0.01 \\
\mathrm{Ba} & \text { bdl } \\
\mathrm{Cd} & 0.08 \\
\mathrm{Cr} & 0.00 \\
\mathrm{Ni} & 0.02\end{array}$ & $\begin{array}{lr}\mathrm{Pb} & 0.04 \\
\mathrm{Sb} & 0.02 \\
\mathrm{Se} & \text { bdl } \\
\mathrm{Zn} & 0.03\end{array}$ & $\begin{array}{cc}\text { As } & 0.01 \\
\mathrm{Ba} & 0.01 \\
\mathrm{Cd} & 0.10 \\
\mathrm{Cr} & 0.00 \\
\mathrm{Ni} & 0.02\end{array}$ & $\begin{array}{lr}\mathrm{Pb} & 0.06 \\
\mathrm{Sb} & 0.02 \\
\mathrm{Se} & \text { bdl } \\
\mathrm{Zn} & 0.06\end{array}$ & $\begin{array}{ll}\text { As } & 0.01 \\
\mathrm{Ba} & \text { bdl } \\
\mathrm{Cd} & 0.13 \\
\mathrm{Cr} & 0.00 \\
\mathrm{Ni} & 0.02\end{array}$ & $\begin{array}{cc}\mathrm{Pb} & 0.09 \\
\mathrm{Sb} & 0.02 \\
\mathrm{Se} & \mathrm{bdl} \\
\mathrm{Zn} & \mathrm{bdl}\end{array}$ & $\begin{array}{cc}\text { As } & 0.02 \\
\mathrm{Ba} & 0.04 \\
\mathrm{Cd} & 0.13 \\
\mathrm{Cr} & 0.00 \\
\mathrm{Ni} & 0.02\end{array}$ & $\begin{array}{ll}\mathrm{Pb} & 0.09 \\
\mathrm{Sb} & 0.02 \\
\mathrm{Se} & 0.01 \\
\mathrm{Zn} & 0.08\end{array}$ & $\begin{array}{cc}\text { As } & 0.01 \\
\mathrm{Ba} & 0.02 \\
\mathrm{Cd} & 0.10 \\
\mathrm{Cr} & 0.00 \\
\mathrm{Ni} & 0.02\end{array}$ & $\begin{array}{cc}\mathrm{Pb} & 0.05 \\
\mathrm{Sb} & 0.02 \\
\mathrm{Se} & \text { bdl } \\
\mathrm{Zn} & 0.07\end{array}$ \\
\hline $640^{\circ} \mathrm{C}$ & $\begin{array}{cc}\text { As } & 0.01 \\
\mathrm{Ba} & \text { bdl } \\
\mathrm{Cd} & 0.09 \\
\mathrm{Cr} & 0.00 \\
\mathrm{Ni} & 0.03\end{array}$ & $\begin{array}{ll}\mathrm{Pb} & 0.05 \\
\mathrm{Sb} & 0.02 \\
\mathrm{Se} & 0.00 \\
\mathrm{Zn} & 0.01\end{array}$ & $\begin{array}{ll}\text { As } & 0.02 \\
\mathrm{Ba} & 0.04 \\
\mathrm{Cd} & 0.08 \\
\mathrm{Cr} & 0.00 \\
\mathrm{Ni} & 0.02\end{array}$ & $\begin{array}{ll}\mathrm{Pb} & 0.04 \\
\mathrm{Sb} & 0.02 \\
\mathrm{Se} & 0.01 \\
\mathrm{Zn} & 0.09\end{array}$ & $\begin{array}{cc}\text { As } & 0.02 \\
\mathrm{Ba} & 0.01 \\
\mathrm{Cd} & 0.09 \\
\mathrm{Cr} & 0.00 \\
\mathrm{Ni} & 0.02\end{array}$ & $\begin{array}{lr}\mathrm{Pb} & 0.04 \\
\mathrm{Sb} & 0.02 \\
\mathrm{Se} & \text { bdl } \\
\mathrm{Zn} & 0.10\end{array}$ & $\begin{array}{cc}\text { As } & 0.01 \\
\mathrm{Ba} & \text { bdl } \\
\mathrm{Cd} & 0.10 \\
\mathrm{Cr} & 0.00 \\
\mathrm{Ni} & 0.02\end{array}$ & $\begin{array}{ll}\mathrm{Pb} & 0.05 \\
\mathrm{Sb} & 0.02 \\
\mathrm{Se} & 0.00 \\
\mathrm{Zn} & \mathrm{bdl}\end{array}$ & $\begin{array}{ll}\text { As } & 0.01 \\
\mathrm{Ba} & \text { bdl } \\
\mathrm{Cd} & 0.10 \\
\mathrm{Cr} & 0.00 \\
\mathrm{Ni} & 0.02\end{array}$ & $\begin{array}{cc}\mathrm{Pb} & 0.05 \\
\mathrm{Sb} & 0.02 \\
\mathrm{Se} & \mathrm{bdl} \\
\mathrm{Zn} & \mathrm{bdl}\end{array}$ & $\begin{array}{cc}\text { As } & 0.01 \\
\mathrm{Ba} & 0.01 \\
\mathrm{Cd} & 0.10 \\
\mathrm{Cr} & 0.00 \\
\mathrm{Ni} & 0.02\end{array}$ & $\begin{array}{cc}\mathrm{Pb} & 0.04 \\
\mathrm{Sb} & 0.02 \\
\mathrm{Se} & \text { bdl } \\
\mathrm{Zn} & 0.09\end{array}$ \\
\hline $500^{\circ} \mathrm{C}$ & $\begin{array}{cc}\text { As } & 0.02 \\
\mathrm{Ba} & \text { bdl } \\
\mathrm{Cd} & 0.09 \\
\mathrm{Cr} & 0.00 \\
\mathrm{Ni} & 0.03 \\
\end{array}$ & $\begin{array}{ll}\mathrm{Pb} & 0.05 \\
\mathrm{Sb} & 0.02 \\
\mathrm{Se} & 0.01 \\
\mathrm{Zn} & 0.03\end{array}$ & $\begin{array}{cc}\text { As } & 0.01 \\
\mathrm{Ba} & 13 \\
\mathrm{Cd} & 0.08 \\
\mathrm{Cr} & 0.00 \\
\mathrm{Ni} & 0.02\end{array}$ & $\begin{array}{lr}\mathrm{Pb} & 0.04 \\
\mathrm{Sb} & 0.02 \\
\mathrm{Se} & \text { bdl } \\
\mathrm{Zn} & 0.17\end{array}$ & $\begin{array}{cc}\text { As } & 0.01 \\
\mathrm{Ba} & 0.01 \\
\mathrm{Cd} & 0.08 \\
\mathrm{Cr} & 0.00 \\
\mathrm{Ni} & 0.02 \\
\end{array}$ & $\begin{array}{lr}\mathrm{Pb} & 0.04 \\
\mathrm{Sb} & 0.02 \\
\mathrm{Se} & \text { bdl } \\
\mathrm{Zn} & 0.11\end{array}$ & $\begin{array}{cc}\text { As bdl } \\
\mathrm{Ba} & 0.01 \\
\mathrm{Cd} & 0.08 \\
\mathrm{Cr} & 0.00 \\
\mathrm{Ni} & 0.02 \\
\end{array}$ & $\begin{array}{cc}\mathrm{Pb} & 0.04 \\
\mathrm{Sb} & 0.02 \\
\mathrm{Se} & \mathrm{bdl} \\
\mathrm{Zn} & 0.11\end{array}$ & $\begin{array}{cc}\text { As } & 0.01 \\
\mathrm{Ba} & \text { bdl } \\
\mathrm{Cd} & 0.10 \\
\mathrm{Cr} & 0.00 \\
\mathrm{Ni} & 0.03 \\
\end{array}$ & $\begin{array}{cc}\mathrm{Pb} & 0.05 \\
\mathrm{Sb} & 0.02 \\
\mathrm{Se} & \mathrm{bdl} \\
\mathrm{Zn} & 0.15\end{array}$ & $\begin{array}{cc}\text { As bdl } \\
\mathrm{Ba} & 0.01 \\
\mathrm{Cd} & 0.07 \\
\mathrm{Cr} & 0.00 \\
\mathrm{Ni} & 0.02 \\
\end{array}$ & $\begin{array}{cc}\mathrm{Pb} & 0.04 \\
\mathrm{Sb} & 0.02 \\
\mathrm{Se} & \text { bdl } \\
\mathrm{Zn} & 0.07\end{array}$ \\
\hline Time (hrs) & \multicolumn{2}{|c|}{0.75} & \multicolumn{2}{|c|}{3} & \multicolumn{2}{|c|}{12} & \multicolumn{2}{|c|}{48} & \multicolumn{2}{|c|}{192} & \multicolumn{2}{|c|}{768} \\
\hline
\end{tabular}




\begin{tabular}{|c|c|c|}
\hline \multicolumn{3}{|c|}{ Table 4-54: TCLP Cd Response for Elevated Soak Temperature Samples } \\
\hline Temperature $\left({ }^{\circ} \mathbf{C}\right)$ & Soak Time (hrs) & Cd Response (ppm) \\
\hline 1300 & 0.75 & 0.085 \\
\hline 1300 & 3 & 0.094 \\
\hline 1340 & 0.75 & 0.077 \\
\hline 1340 & 3 & 0.078 \\
\hline 1340 & 48 & 0.068 \\
\hline 1340 & 192 & 0.046 \\
\hline
\end{tabular}

$\underline{\text { XRD }}$

Qualitative scans were performed with a Scintag PADX diffractometer using a $\mathrm{Cu}$ source with a wavelength of $0.154184 \mathrm{~nm}$ (weighted average of $\mathrm{K}_{\square 1}$ and $\mathrm{K}_{\square 2}$ ). A liguid nitrogen cooled Ge solid-state detector was used to detect the diffracted x-rays. Scans were performed in the step mode over a 2-theta range of 3 to 90 degrees with a step size of 0.03 degrees and a counting time of 1 second. Preparation of the powder samples was performed by DIAL.

Quantitative scans were performed with a Philip's X'Pert MRD diffractometer using a Cu $\mathrm{K}_{\alpha}$ radiation source. Primary optics used on the incident beam side of the instrument include an X-ray mirror (PW3088/60, Philips) which virtually eliminates $\mathrm{Cu} \mathrm{K \alpha}$ lines. Secondary optics used on the diffracted beam side consist of a $0.27^{\circ}$ parallel plate collimator (PW3098/27, Philips) equipped with a flat graphite monochromator (PW3121/00, Philips) in order to reduce the fluorescent radiation reaching the sealed proportional detector (PW3011/20, Philips). To each sample, a known amount $(\sim 10$ $\mathrm{wt} \%$ ) of NIST SRM 676 Alumina powder was added as a quantitative internal standard. The alumina standard was ground with the powdered sample (-200mesh prior to grinding) with a mortar and pestle for five minutes. An X-ray diffraction pattern of this material was obtained in the continuous mode over a range of 3 to $90^{\circ} 2$-theta with a step size of 0.02 degrees and a counting time of 15 seconds. The resulting diffraction patterns were quantified using RIQAS (v. 4.0), a Rietveld refinement software package purchased from Materials Data Incorporated. Crystal structure data for each phase quantified was obtained from the Inorganic Crystal Structure Database (NIST, 2001).

The XRD analyses identified multiple crystalline phases in the heat treatment samples. The crystalline phases observed were consistent with zirconium dioxide $\left(\mathrm{ZrO}_{2}\right.$, monoclinic or tetragonal form), zircon $\left(\mathrm{ZrSiO}_{4}\right)$, or transition metal-rich spinel $\left(\mathrm{Fe}_{3} \mathrm{O}_{4}\right.$, $\mathrm{MnAl}_{2} \mathrm{O}_{4}$, and a Fe/Mn form). All patterns (including the Large Melt and AVS samples) were closely consistent with magnetite. The lower temperature heat treatments $\left(780^{\circ} \mathrm{C}\right.$ and below) displayed crystallization patterns more consistent with $\mathrm{Mn} / \mathrm{Fe}$ spinel and/or $\mathrm{MnAl}_{2} \mathrm{O}_{4}$. This is indicative of a continuous spinel phase in all samples - the more crystalline (higher temperature and longer duration heat treatments) patterns are dominated by the high iron stoichiometry.

A form of zirconia was present in all samples excepting the $0.75,3$, and 12 -hour heat treatments performed at $500^{\circ} \mathrm{C}$. XRD analysis of all 1060 and $1200^{\circ} \mathrm{C}$ heat treatments 
indicate the presence of monoclinic zirconia (except 768 hours at $1200^{\circ} \mathrm{C}$, where zircon is a dominant phase). XRD analysis of the 500,640 , and $780^{\circ} \mathrm{C}$ heat treatments indicate the presence of tetragonal zirconia. Both forms of zirconia were detected in all $920^{\circ} \mathrm{C}$ heat treatments. Zircon formation was detected only in the highest temperature, longest duration heat treatments (192 and 768 hours at $1200^{\circ} \mathrm{C}$ and 768 hours at $1060^{\circ} \mathrm{C}$ ). Table 4-55 a corresponding TTT grid with the XRD phase identification. Included in Table 455 , are the corresponding XRD standard cards for all 6 phases.

With a zirconium rich phase (as zirconia or zircon) present in all samples save the lowest temperature, lowest duration heat treatments, and as zirconium is one of the more difficult oxides to dissolve in glass and the AZ 101 waste has considerable (9-10 weight percent on an oxide basis) zirconia, it was decided to perform additional heat treatments to confirm that the zirconia was completely dissolved in the melt prior to cooling. Heat treatments were performed at $1340^{\circ} \mathrm{C}$ for $0.75,3.48$ and 192 hours and at $1300^{\circ} \mathrm{C}$ for 0.75 and 3 hours. These samples were processed and analyzed as the other 36 TTT samples (same batch material, composition, and protocols). XRD analyses of the samples indicate the $\mathrm{ZrO}_{2}$ is below detectable levels for the 0.75 and 3 hour $1340^{\circ} \mathrm{C}$ heat treatments and the 0.75 hour $1300^{\circ} \mathrm{C}$ heat treatment. Small concentrations of zirconia are present in the longer duration heat treatments. These data indicate that all zirconium batch materials were fully dissolved in the crucible prior to heat treatment.

The multiple spinel phases identified are not concluded to be separate, individual phases, but are provided as the spinel standard XRD patterns most representative of the TTT sample patterns. The XRD identification of the multiple spinel forms appears consistent with the concentration of transition metals and alumina in the wasteform (on the order of 40 percent by mass) 


\begin{tabular}{|c|c|c|c|c|c|c|}
\hline Temp & \multicolumn{6}{|c|}{\begin{tabular}{|l|} 
Table 4-55. XRD Phase Identification \\
\end{tabular}} \\
\hline $1200^{\circ} \mathrm{C}$ & $\begin{array}{l}\mathrm{ZrO}_{2}(\mathrm{~m})^{\mathrm{a}, \mathrm{c}} \\
\mathrm{Fe}_{3} \mathrm{O}_{4}{ }^{\mathrm{d}}\end{array}$ & $\begin{array}{l}\mathrm{ZrO}_{2}(\mathrm{~m}) \\
\mathrm{Fe}_{3} \mathrm{O}_{4}\end{array}$ & $\mid \begin{array}{l}\mathrm{ZrO}_{2}(\mathrm{~m}) \\
\mathrm{Fe}_{3} \mathrm{O}_{4}\end{array}$ & $\mid \begin{array}{l}\mathrm{ZrO}_{2}(\mathrm{~m}) \\
\mathrm{Fe}_{3} \mathrm{O}_{4}\end{array}$ & \begin{tabular}{|l}
$\mathrm{ZrO}_{2}(\mathrm{~m})$ \\
$\mathrm{Fe}_{3} \mathrm{O}_{4}$ \\
$\mathrm{ZrSiO}_{4}{ }^{\mathrm{e}}$
\end{tabular} & $\begin{array}{l}\mathrm{Fe}_{3} \mathrm{O}_{4} \\
\mathrm{ZrSiO}_{4}\end{array}$ \\
\hline $1060^{\circ} \mathrm{C}$ & $\begin{array}{l}\mathrm{ZrO}_{2}(\mathrm{~m}) \\
\mathrm{Fe}_{3} \mathrm{O}_{4}\end{array}$ & $\begin{array}{l}\mathrm{ZrO}_{2}(\mathrm{~m}) \\
\mathrm{Fe}_{3} \mathrm{O}_{4}\end{array}$ & $\begin{array}{l}\mathrm{ZrO}_{2}(\mathrm{~m}) \\
\mathrm{Fe}_{3} \mathrm{O}_{4}\end{array}$ & $\begin{array}{l}\mathrm{ZrO}_{2}(\mathrm{~m}) \\
\mathrm{Fe}_{3} \mathrm{O}_{4}\end{array}$ & $\begin{array}{l}\mathrm{ZrO}_{2}(\mathrm{~m}) \\
\mathrm{Fe}_{3} \mathrm{O}_{4}\end{array}$ & $\begin{array}{l}\mathrm{ZrO}_{2}(\mathrm{~m}) \\
\mathrm{Fe}_{3} \mathrm{O}_{4} \\
\mathrm{ZrSiO}_{4}{ }^{\mathrm{e}}\end{array}$ \\
\hline $920^{\circ} \mathrm{C}$ & $\begin{array}{l}\mathrm{ZrO}_{2}(\mathrm{t})^{\mathrm{b}, \mathrm{f}} \\
\mathrm{ZrO}_{2}(\mathrm{~m}) \\
\mathrm{Fe}_{3} \mathrm{O}_{4}\end{array}$ & $\begin{array}{l}\mathrm{ZrO}_{2}(\mathrm{t}) \\
\mathrm{ZrO}_{2}(\mathrm{~m}) \\
\mathrm{Fe}_{3} \mathrm{O}_{4}\end{array}$ & \begin{tabular}{|l}
$\mathrm{ZrO}_{2}(\mathrm{t})$ \\
$\mathrm{ZrO}_{2}(\mathrm{~m})$ \\
$\mathrm{Fe}_{3} \mathrm{O}_{4}$
\end{tabular} & $\begin{array}{l}\mathrm{ZrO}_{2}(\mathrm{t}) \\
\mathrm{ZrO}_{2}(\mathrm{~m}) \\
\mathrm{Fe}_{3} \mathrm{O}_{4}\end{array}$ & $\begin{array}{l}\mathrm{ZrO}_{2}(\mathrm{t}) \\
\mathrm{ZrO}_{2}(\mathrm{~m}) \\
\mathrm{Fe}_{3} \mathrm{O}_{4} \\
\mathrm{MnAl}_{2} \mathrm{O}_{4}{ }^{\mathrm{g}}\end{array}$ & $\begin{array}{l}\mathrm{ZrO}_{2}(\mathrm{t}) \\
\mathrm{ZrO}_{2}(\mathrm{~m}) \\
\mathrm{Fe}_{3} \mathrm{O}_{4} \\
\mathrm{MnAl}_{2} \mathrm{O}_{4}\end{array}$ \\
\hline $780^{\circ} \mathrm{C}$ & $\begin{array}{l}\mathrm{ZrO}_{2}(\mathrm{t}) \\
\mathrm{Fe}_{3} \mathrm{O}_{4} \\
\mathrm{Mn} / \mathrm{Fe} \\
\mathrm{Spinel}^{\mathrm{h}}\end{array}$ & $\begin{array}{l}\mathrm{ZrO}_{2}(\mathrm{t}) \\
\mathrm{Fe}_{3} \mathrm{O}_{4} \\
\mathrm{Mn} / \mathrm{Fe} \\
\mathrm{Spinel}\end{array}$ & $\begin{array}{l}\mathrm{ZrO}_{2}(\mathrm{t}) \\
\mathrm{Fe}_{3} \mathrm{O}_{4} \\
\mathrm{Mn} / \mathrm{Fe} \text { Spinel }\end{array}$ & $\begin{array}{l}\mathrm{ZrO}_{2}(\mathrm{t}) \\
\mathrm{Fe}_{3} \mathrm{O}_{4} \\
\mathrm{Mn} / \mathrm{Fe} \text { Spinel } \\
\mathrm{MnAl}_{2} \mathrm{O}_{4}\end{array}$ & $\begin{array}{l}\mathrm{ZrO}_{2}(\mathrm{t}) \\
\mathrm{Fe}_{3} \mathrm{O}_{4} \\
\mathrm{MnAl}_{2} \mathrm{O}_{4}\end{array}$ & $\begin{array}{l}\mathrm{ZrO}_{2}(\mathrm{t}) \\
\mathrm{Fe}_{3} \mathrm{O}_{4} \\
\mathrm{MnAl}_{2} \mathrm{O}_{4}\end{array}$ \\
\hline $640^{\circ} \mathrm{C}$ & $\begin{array}{l}\mathrm{ZrO}_{2}(\mathrm{t}) \\
\mathrm{Fe}_{3} \mathrm{O}_{4} \\
\mathrm{Mn} / \mathrm{Fe} \\
\text { Spinel }\end{array}$ & $\begin{array}{l}\mathrm{ZrO}_{2}(\mathrm{t}) \\
\mathrm{Fe}_{3} \mathrm{O}_{4} \\
\mathrm{Mn} / \mathrm{Fe} \\
\mathrm{Spinel}\end{array}$ & $\begin{array}{l}\mathrm{ZrO}_{2}(\mathrm{t}) \\
\mathrm{Fe}_{3} \mathrm{O}_{4} \\
\mathrm{Mn} / \mathrm{Fe} \text { Spinel }\end{array}$ & $\begin{array}{l}\mathrm{ZrO}_{2}(\mathrm{t}) \\
\mathrm{Fe}_{3} \mathrm{O}_{4} \\
\mathrm{Mn} / \mathrm{Fe} \text { Spinel } \\
\mathrm{MnAl}_{2} \mathrm{O}_{4}\end{array}$ & \begin{tabular}{|l}
$\mathrm{ZrO}_{2}(\mathrm{t})$ \\
$\mathrm{Fe}_{3} \mathrm{O}_{4}$ \\
$\mathrm{Mn} / \mathrm{Fe}$ Spinel
\end{tabular} & $\begin{array}{l}\mathrm{ZrO}_{2}(\mathrm{t}) \\
\mathrm{Fe}_{3} \mathrm{O}_{4} \\
\mathrm{Mn} / \mathrm{Fe} \\
\mathrm{Spinel}\end{array}$ \\
\hline $500^{\circ} \mathrm{C}$ & $\begin{array}{l}\mathrm{Fe}_{3} \mathrm{O}_{4} \\
\mathrm{Mn} / \mathrm{Fe} \\
\mathrm{Spinel}\end{array}$ & $\begin{array}{l}\mathrm{Fe}_{3} \mathrm{O}_{4} \\
\mathrm{Mn} / \mathrm{Fe} \\
\mathrm{Spinel}\end{array}$ & $\begin{array}{l}\mathrm{Fe}_{3} \mathrm{O}_{4} \\
\mathrm{Mn} / \mathrm{Fe} \text { Spinel }\end{array}$ & $\begin{array}{l}\mathrm{ZrO}_{2}(\mathrm{t}) \\
\mathrm{Fe}_{3} \mathrm{O}_{4} \\
\mathrm{Mn} / \mathrm{Fe} \text { Spinel }\end{array}$ & \begin{tabular}{|l}
$\mathrm{ZrO}_{2}(\mathrm{t})$ \\
$\mathrm{Fe}_{3} \mathrm{O}_{4}$ \\
$\mathrm{Mn} / \mathrm{Fe}$ Spinel
\end{tabular} & $\begin{array}{l}\mathrm{ZrO}_{2}(\mathrm{t}) \\
\mathrm{Fe}_{3} \mathrm{O}_{4} \\
\mathrm{Mn} / \mathrm{Fe} \text { Spinel }\end{array}$ \\
\hline Time (H) & 0.75 & 3 & 12 & 48 & 192 & 768 \\
\hline
\end{tabular}

a $(\mathrm{m})$ - monoclinic crystalline geometry

${ }^{\mathrm{b}}(\mathrm{t})$ - tetragonal crystalline geometry

${ }^{\mathrm{c}} \mathrm{ZrO}_{2}(\mathrm{~m})$ - powder diffraction file 37-1484

${ }^{\mathrm{d}} \mathrm{Fe}_{3} \mathrm{O}_{4}$ - powder diffraction file 19-0629

${ }^{\mathrm{e}} \mathrm{ZrSiO}_{4}$ - powder diffraction file 06-0266

${ }^{\mathrm{f}} \mathrm{ZrO}_{2}(\mathrm{t})$ - powder diffraction file 79-1771

${ }^{\mathrm{g}} \mathrm{MnAl}_{2} \mathrm{O}_{4}$ - powder diffraction file 24-0507

${ }^{\mathrm{h}} \mathrm{Mn} / \mathrm{Fe}$ Spinel - powder diffraction file 29-0880

Quantification of the crystalline content was performed using the RIQAS 4.0 Rietveld refinement technique. A $10-\mathrm{wt} \%$ amount of SRM $676 \mathrm{Al}_{2} \mathrm{O}_{3}$ was used as an internal standard. The spinel modeled was based on the magnetite structure, with Al being randomly substituted for Fe - based on the quantitative SEM-EDS analyses of the spinel crystals for that heat treatment. This allowed the software to generate a pattern match for the XRD sample. The weight percent of each crystalline phase was calculated versus the concentration of the alumina standard. The residual glass concentration was determined by difference. For this study, 10 percent R-Weighted Pattern, RWP (internal measure of deviation between the generated pattern versus XRD sample pattern), was selected as the maximum acceptable value. In all analyses, the RWP was on the order of 5 percent.

\section{$\underline{\text { SEM }}$}

Sampling of the crucible sections was performed with video record. The crucible sections were placed in two plastic bags and the wasteform was removed by striking the outer edges of the crucible. The resulting pieces with no visible crucible contact were separated from those with visible crucible adhesion. The SEM samples, one oriented near the top center of the melt, one oriented near the bottom center of the melt, were extracted at this point. This selection was made by mandating a portion of the top melt surface be visible for the "top" sample and a portion of the crucible contact area be 
attached for the "bottom" sample. The SEM samples were oriented normal to the crucible or melt surface prior to polishing in order to minimize surface phenomena impact on analysis.

The surfaces were polished at Graftech in a manner consistent with fiber polishing procedures followed at MSU. The samples were mounted in clear epoxy and then ground and polished to a surface finish with alumina grinding media. A Struers Roto-Tool 35 semi-automatic polishing machine was used to perform the surface preparation. All surfaces were prepared consistent with the following sequence of alumina grinding media: $15,12,9,3,1,0.3$ micron. In addition to the TTT samples, a fractured piece of an LM-60 glass (target composition used for the TTT) casting was included on each sample mount. This was performed to minimize surface preparation impacts on the SEM-EDS analysis by ensuring a reference piece would have an identical surface preparation and orientation in the SEM vacuum chamber. This also provided a comparative reference composition for SEM-EDS analyses.

The polished specimens were analyzed using a JEOL T33A SEM. Top and bottom samples were analyzed for all heat treatments. After an initial scan of the samples to evaluate homogeneity, SEM photomicrographs were obtained. Due to the types of crystalline phases present, backscatter images provided relatively sharp delineation between the glassy and various crystalline phases. Photomicrographs were obtained at $200,500,1000$, and 2000X magnification. The machine has an image resolution of about $500 \mathrm{~nm}$. Figure 4-36 shows the microstructure of the TTT sample heat-treated at $1060^{\circ} \mathrm{C}$ for 192 hours at the various magnifications. Figure 4-37 provides a high magnification micrograph that labels the crystalline phases observed for this sample. The EDS spectra for the discrete components observed for this sample are provided in Figures 4-38 through 4-49.

EDS analysis was performed on the glassy and crystalline phases. Multiple phases were identified in all samples. All samples had a glassy matrix and a transition metal spinel phase. A zirconium rich phase was also present in most samples. Each phase identified was analyzed by EDS, where possible. All EDS analyses were performed in duplicate. Two distinct spectra were obtained for all quantitative determinations. In many of the short duration, low heat treatment temperatures, it was not possible to obtain quantitative EDS patterns representative of the crystalline chemistry. This was due to the small size of the crystallites. Nominally, crystals smaller than 1 micron (in one dimension) were not accurately evaluated by the EDS analysis as the EDS spectra was heavily skewed by the surrounding glassy matrix. Spectra of crystals at least 2 microns (in the smallest dimension) were much more accurate and reproducible.

This was especially important for analysis of the zirconia rich phase and for accurate determinations of the stoichiometry of the spinel phases. In many cases, XRD indicated the presence of zirconia, but the SEM-EDS analysis could not identify a corresponding zirconium-rich phase. SEM analyses (as will be discussed later) indicated an aspect ratio of approximately 15:1 for the small, zirconium-rich crystals (on the order of $6600 \times 440$ nanometers or $3000 \times 200$ nanometers). As these crystals grew, the larger needle shaped 
crystals detected by the SEM and subsequent EDS analyses on these crystals supported the identification of zirconia. Likewise, the stoichiometry of the spinel phases was most accurately determined for the higher-temperature (more rapid growth kinetics at $920^{\circ} \mathrm{C}$ and above) and longer duration heat treatment samples.

The formation of zircon, $\mathrm{ZrSiO}_{4}$, in the long-term high temperature heat treatments was detected initially by XRD. Subsequent SEM-EDS analysis confirmed the presence of zircon as shown in Figure 4-50. This is an SEM photomicrograph with EDS phase composition analyses overlain. Four phases with differing contrasts (backscatter imaging) and compositions are denoted. Three phases (spinel, zirconia and residual glass) common to all samples are shown. Additionally, however, there is a light gray (backscatter image contrast) growing at the periphery of all white, needle shaped (zirconia) crystals. This stoichiometry as determined by the EDS is considerably different from that measured for the zirconia phase. The relative silica content is substantially higher, quite consistent with zircon (ideally 33\% silica, 67\% zirconia by mass as $\mathrm{SiO}_{2} \cdot \mathrm{ZrO}_{2}$ ). In contrast, the $\mathrm{SEM}$ analysis of the shorter term (up to 48 hours) heat treatments did not reveal a similar zircon phase as seen in Figure 4-37. It is concluded then, that the zircon phase was nucleated and grown as an interaction between zirconia and the silica rich glassy matrix.

The stoichiometric determinations of the spinel phases were also impacted by the relative size of the crystallites. Heat treatments of lower temperature and time result in smaller crystallites and correspondingly less accurate EDS analysis (i.e. more matrix phase interference). The crystalline species observed in Figures 4-36 and 4-37 (TTT-1060-192) are relatively large, well-defined shapes with large contrasts (by backscatter imaging) evident between species. The EDS spectra obtained from this heat treatment sample, Figures 4-38-4-.4-49 are consistent with transition metal spinel, zirconia, and a glassy matrix. This is consistent with the XRD identification. The spinel phase is dominated by $\mathrm{Fe}_{\mathrm{x}} \mathrm{O}_{\mathrm{y}}$, but also enriched in $\mathrm{Mn}_{\mathrm{x}} \mathrm{O}_{\mathrm{y}}$ and possibly alumina. The zirconia rich phase is common to most of the heat treatments and is uniformly found as needle-shaped crystals. The stoichiometry is dominated by zirconia, with considerably smaller concentrations of alumina and silica. This is likely due to matrix interference, but this is not certain. There is potential for small amounts of alumina or silica and the longer-term or $1200^{\circ} \mathrm{C}$ heat treatments indicate the presence of zircon.

The majority of samples appear to have considerable differences in crystal size and relative concentration as a function of top or bottom orientation in the crucible. Top and bottom sample images of the various heat treatments were taken, and the images shown in Figure 4-36 are representative of the overall trend. The top orientation samples were more prone to larger, more irregular shaped crystals. Bottom orientation crystals were more numerous and had a more regular (consistent) geometry. Due to this inconsistency between top and bottom orientation, the SEM was used primarily for crystalline stoichiometry versus quantification of volume percent crystallinity. The stoichiometry of the various crystalline phases detected is provided in Table 4-56. 


\begin{tabular}{|c|c|c|c|c|c|}
\hline Temp. & \multicolumn{5}{|c|}{ Table 4-56. Relative Crystal Size (SEM Analysis) } \\
\hline $1200^{\circ} \mathrm{C}$ & $\begin{array}{l}\text { Spinel 10-20 } \mu \\
\mathrm{ZrO}_{2} 30-50 \mu^{\mathrm{a}}\end{array}$ & $\begin{array}{l}\text { Spinel } 10-30 \mu \\
\mathrm{ZrO}_{2} \text { up to } 100 \mu\end{array}$ & $\begin{array}{l}\text { Spinel } 10-30 \mu \\
\mathrm{ZrO}_{2} \text { up to } 100 \mu\end{array}$ & $\begin{array}{l}\text { Spinel } 15-50 \mu \\
\mathrm{ZrO}_{2} \text { up to } 100+\mu\end{array}$ & $\begin{array}{l}\text { Spinel } 20-50 \mu \\
\mathrm{ZrSiO}_{4} / \mathrm{ZrO}_{2}{ }^{\text {b }} \text { up } \\
\text { to } 100 \mu\end{array}$ \\
\hline $1060^{\circ} \mathrm{C}$ & 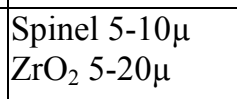 & 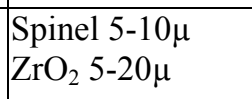 & 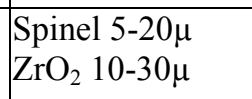 & 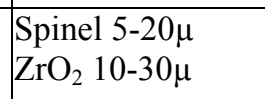 & $\begin{array}{l}\text { Spinel } 5-10 \mu^{\mathrm{c}} \\
\mathrm{ZrO}_{2} 10-30 \mu\end{array}$ \\
\hline $920^{\circ} \mathrm{C}$ & $\begin{array}{l}\text { Spinel } 1-5 \mu \\
\mathrm{ZrO}_{2} 5-10 \mu\end{array}$ & $\begin{array}{l}\text { Spinel } 1-5 \mu \\
\mathrm{ZrO}_{2} 5-10 \mu\end{array}$ & $\begin{array}{l}\text { Spinel 2-5 } \\
\mathrm{ZrO}_{2} 5-10 \mu\end{array}$ & $\begin{array}{l}\text { Spinel } 2-5 \mu \\
\mathrm{ZrO}_{2} 5-10 \mu\end{array}$ & $\begin{array}{l}\text { Spinel 3-5 } \\
\mathrm{ZrO}_{2} 8-12 \mu\end{array}$ \\
\hline $780^{\circ} \mathrm{C}$ & $\begin{array}{l}\text { Crystalline } \\
\text { structures } \\
\text { poorly visible at } \\
1000 X\end{array}$ & $\begin{array}{l}\text { Crystalline } \\
\text { structures poorly } \\
\text { visible at } 1000 \mathrm{X}\end{array}$ & $\begin{array}{l}\text { lrystalline } \\
\text { structures poorly } \\
\text { visible at } 1000 \mathrm{X}\end{array}$ & \begin{tabular}{|l} 
Crystalline \\
structures poorly \\
visible at 1000X
\end{tabular} & $\begin{array}{l}\text { Crystalline } \\
\text { structures visible } \\
\text { at } 1000 \mathrm{X}(1-2 \mu)\end{array}$ \\
\hline $640^{\circ} \mathrm{C}$ & $\begin{array}{l}\text { Crystalline } \\
\text { structures } \\
\text { poorly visible at } \\
1000 X\end{array}$ & $\begin{array}{l}\text { Crystalline } \\
\text { structures poorly } \\
\text { visible at 1000X }\end{array}$ & $\begin{array}{l}\text { Crystalline } \\
\text { structures poorly } \\
\text { visible at } 1000 \mathrm{X}\end{array}$ & $\begin{array}{l}\text { Crystalline } \\
\text { structures poorly } \\
\text { visible at } 1000 \mathrm{X}\end{array}$ & $\begin{array}{l}\text { Crystalline } \\
\text { structures visible } \\
\text { at } 1000 \mathrm{X}(1-2 \mu)\end{array}$ \\
\hline $500^{\circ} \mathrm{C}$ & $\begin{array}{l}\text { Crystalline } \\
\text { structures } \\
\text { poorly visible at } \\
1000 X\end{array}$ & $\begin{array}{l}\text { Crystalline } \\
\text { structures poorly } \\
\text { visible at } 1000 \mathrm{X}\end{array}$ & $\begin{array}{l}\text { Crystalline } \\
\text { structures poorly } \\
\text { visible at } 1000 \mathrm{X}\end{array}$ & $\begin{array}{l}\text { Crystalline } \\
\text { structures poorly } \\
\text { visible at 1000X }\end{array}$ & $\begin{array}{l}\text { Crystalline } \\
\text { structures poorly } \\
\text { visible at 1000X }\end{array}$ \\
\hline Time $(\mathbf{H})$ & 0.75 & 3 & 12 & 48 & 192 \\
\hline
\end{tabular}

${ }^{\mathrm{a}} \mathrm{ZrO}_{2}$ crystals had needlelike geometry. Dimension given for long axis.

${ }^{\mathrm{b}} \mathrm{ZrSiO}_{4}$ only present in immediate contact with zirconia and glassy matrix.

${ }^{\mathrm{c}}$ Spinel appears as fully densified crystals.

The stoichiometric determinations were based on samples with sufficient crystalline formation and size - to minimize matrix of other interference. The EDS compositions provided here are the average of the values obtained for the top and bottom samples of given heat treatments. As spectra are all obtained in duplicate, the values provided in Table 4-57 are the average of four (minimum) sample analyses. Table 4-57 provides the chemical compositions for the three primary crystalline phases present - spinel, zirconia, and zircon. Compositions are provided as elemental weight percent. The analytical uncertainty is on the order of \pm 0.2 weight percent. 


\begin{tabular}{|c|c|c|c|c|c|c|c|c|c|c|c|c|}
\hline \multicolumn{13}{|c|}{ Table 4-57. Relative Crystal Stoichiometry (elemental-wt\%) } \\
\hline Sample & \multicolumn{4}{|c|}{ Zirconia } & \multicolumn{4}{|c|}{ Zircon } & \multicolumn{4}{|c|}{ Spinel } \\
\hline \multirow{4}{*}{ TTT-1200-0.75 } & $\mathrm{Zr}$ & 61.1 & & 1.0 & & & & & $\mathrm{Fe}$ & 43.9 & & 5.0 \\
\hline & $\mathrm{O}$ & 28.8 & $\mathrm{Fe}$ & 4.5 & & & & & $\mathrm{O}$ & 30.8 & $\mathrm{Ni}$ & 2.9 \\
\hline & $\mathrm{Si}$ & 4.0 & $\mathrm{Mn}$ & --- & & & & & $\mathrm{Al}$ & 11.6 & $\mathrm{Si}$ & --- \\
\hline & & & & & & & & & $\mathrm{Mn}$ & 5.8 & & \\
\hline \multirow{4}{*}{ TTT-1200-3 } & $\mathrm{Zr}$ & 61.8 & & 1.0 & & & & & $\mathrm{Fe}$ & 43.4 & $\mathrm{Zn}$ & 4.4 \\
\hline & $\mathrm{O}$ & 28.6 & $\mathrm{Fe}$ & 4.3 & & & & & $\mathrm{O}$ & 31.1 & $\mathrm{Ni}$ & 3.4 \\
\hline & $\mathrm{Si}$ & 4.2 & $\mathrm{Mn}$ & --- & & & & & $\mathrm{Al}$ & 11.4 & $\mathrm{Si}$ & --- \\
\hline & & & & & & & & & $\mathrm{Mn}$ & 5.8 & & \\
\hline \multirow{4}{*}{ TTT-1200-12 } & $\mathrm{Zr}$ & 63.1 & & --- & & & & & $\mathrm{Fe}$ & 43.9 & $\mathrm{Zn}$ & 4.6 \\
\hline & $\mathrm{O}$ & 28.4 & $\mathrm{Fe}$ & 3.9 & & & & & $\mathrm{O}$ & 31.1 & $\mathrm{Ni}$ & 3.1 \\
\hline & $\mathrm{Si}$ & 4.0 & $\mathrm{Mn}$ & --- & & & & & $\mathrm{Al}$ & 10.0 & $\mathrm{Si}$ & 1.6 \\
\hline & & & & & & & & & $\mathrm{Mn}$ & 5.7 & & \\
\hline \multirow{4}{*}{ TTT-1200-48 } & $\mathrm{Zr}$ & 60.5 & & --- & & & & & $\mathrm{Fe}$ & 44.0 & $\mathrm{Zn}$ & 4.3 \\
\hline & $\mathrm{O}$ & 29.2 & $\mathrm{Fe}$ & 4.2 & & & & & $\mathrm{O}$ & 31.0 & $\mathrm{Ni}$ & 3.3 \\
\hline & $\mathrm{Si}$ & 5.1 & $\mathrm{Mn}$ & -- & & & & & $\mathrm{Al}$ & 10.4 & $\mathrm{Si}$ & 1.8 \\
\hline & & & & & & & & & $\mathrm{Mn}$ & 5.1 & & \\
\hline \multirow{4}{*}{ TTT-1200-192 } & $\mathrm{Zr}$ & 62.7 & $\mathrm{Al}$ & --- & $\mathrm{Zr}$ & 38.8 & $\mathrm{Al}$ & --- & $\mathrm{Fe}$ & 43.0 & $\mathrm{Zn}$ & 5.0 \\
\hline & $\mathrm{O}$ & 29.7 & $\mathrm{Fe}$ & 1.2 & $\mathrm{O}$ & 39.0 & $\mathrm{Fe}$ & --- & $\mathrm{O}$ & 31.3 & $\mathrm{Ni}$ & 3.2 \\
\hline & $\mathrm{Si}$ & 6.4 & $\mathrm{Mn}$ & --- & $\mathrm{Si}$ & 22.2 & $\mathrm{Mn}$ & --- & $\mathrm{Al}$ & 9.5 & $\mathrm{Si}$ & 1.7 \\
\hline & & & & & & & & & $\mathrm{Mn}$ & 6.3 & & \\
\hline \multirow{4}{*}{ TTT-1200-768 } & $\mathrm{Zr}$ & 64.2 & $\mathrm{Al}$ & --- & $\mathrm{Zr}$ & 38.9 & $\mathrm{Al}$ & --- & $\mathrm{Fe}$ & 41.5 & $\mathrm{Zn}$ & 4.5 \\
\hline & $\mathrm{O}$ & 29.6 & $\mathrm{Fe}$ & --- & $\mathrm{O}$ & 38.9 & $\mathrm{Fe}$ & --- & $\mathrm{O}$ & 32.0 & $\mathrm{Ni}$ & 2.9 \\
\hline & $\mathrm{Si}$ & 6.0 & $\mathrm{Mn}$ & --- & $\mathrm{Si}$ & 22.0 & $\mathrm{Mn}$ & --- & $\mathrm{Al}$ & 11.1 & $\mathrm{Si}$ & 2.1 \\
\hline & & & & & & & & & $\mathrm{Mn}$ & 5.9 & & \\
\hline \multirow{4}{*}{ TTT-1060-3 } & & & & & & & & & $\mathrm{Fe}$ & 33.2 & $\mathrm{Zn}$ & 4.0 \\
\hline & & & & & & & & & $\mathrm{O}$ & 35.3 & $\mathrm{Ni}$ & 2.0 \\
\hline & & & & & & & & & $\mathrm{Al}$ & 15.8 & $\mathrm{Si}$ & 3.0 \\
\hline & & & & & & & & & $\mathrm{Mn}$ & 6.8 & & \\
\hline \multirow{4}{*}{ TTT-1060-12 } & & & & & & & & & $\mathrm{Fe}$ & 41.3 & $\mathrm{Zn}$ & 4.6 \\
\hline & & & & & & & & & $\mathrm{O}$ & 32.2 & $\mathrm{Ni}$ & 2.4 \\
\hline & & & & & & & & & $\mathrm{Al}$ & 10.3 & $\mathrm{Si}$ & 1.5 \\
\hline & & & & & & & & & $\mathrm{Mn}$ & 7.5 & & \\
\hline \multirow{4}{*}{ TTT-1060-48 } & & & & & $\mathrm{Zr}$ & 40.2 & & & $\mathrm{Fe}$ & 36.7 & $\mathrm{Zn}$ & 4.3 \\
\hline & & & & & $\mathrm{O}$ & 36.1 & $\mathrm{Fe}$ & 4.1 & $\mathrm{O}$ & 33.8 & $\mathrm{Ni}$ & 2.3 \\
\hline & & & & & $\mathrm{Si}$ & 12.5 & $\mathrm{Mn}$ & 2.3 & $\mathrm{Al}$ & 14.7 & $\mathrm{Si}$ & 1.4 \\
\hline & & & & & & & & & $\mathrm{Mn}$ & 6.8 & & \\
\hline \multirow{4}{*}{ TTT-1060-192 } & & & & & $\mathrm{Zr}$ & 39.3 & & 5.1 & $\mathrm{Fe}$ & 50.4 & $\mathrm{Zn}$ & 2.2 \\
\hline & & & & & $\mathrm{O}$ & 37.2 & $\mathrm{Fe}$ & 1.9 & $\mathrm{O}$ & 30.3 & $\mathrm{Ni}$ & 1.2 \\
\hline & & & & & $\mathrm{Si}$ & 14.5 & $\mathrm{Mn}$ & 1.9 & $\mathrm{Al}$ & 10.3 & $\mathrm{Si}$ & 2.0 \\
\hline & & & & & & & & & $\mathrm{Mn}$ & 3.4 & & \\
\hline \multirow{4}{*}{ TTT-1060-768 } & $\mathrm{Zr}$ & & & & & & & & $\mathrm{Fe}$ & 37.9 & $\mathrm{Zn}$ & 4.1 \\
\hline & $\mathrm{O}$ & 28.4 & $\mathrm{Fe}$ & -- & & & & & $\mathrm{O}$ & 33.4 & $\mathrm{Ni}$ & 2.5 \\
\hline & $\mathrm{Si}$ & 4.0 & $\mathrm{Mn}$ & --- & & & & & $\mathrm{Al}$ & 14.7 & $\mathrm{Si}$ & 2.0 \\
\hline & & & & & & & & & $\mathrm{Mn}$ & 5.5 & & \\
\hline
\end{tabular}

Zircon was not identified in the XRD scan of the sample TTT-1060-48, but could be quantified by the SEM-EDS. This is consistent with the relative detection capability of the SEM versus the XRD. 


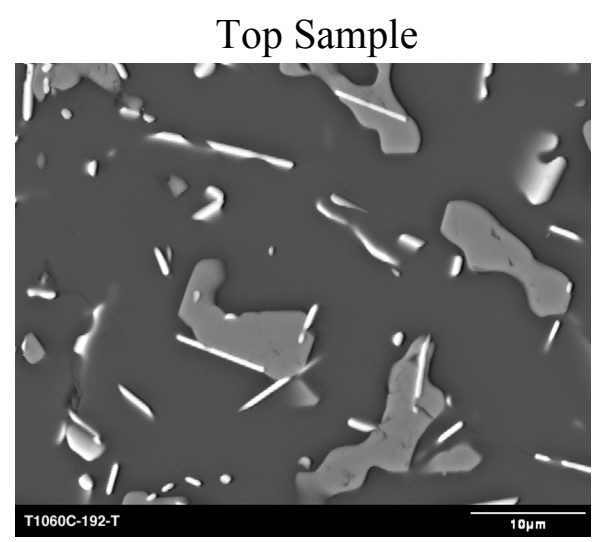

Magnification

Bottom Sample

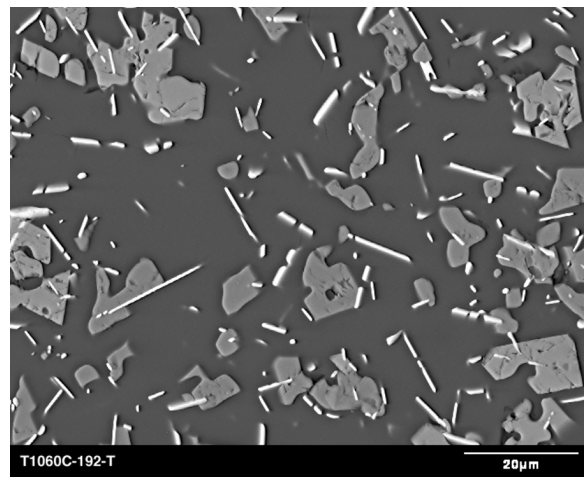

$2000 X$

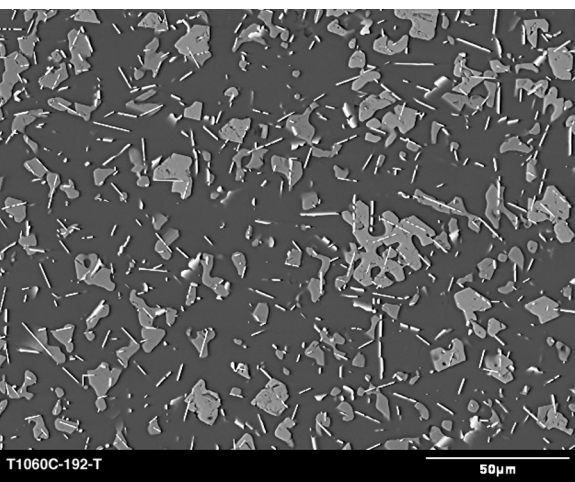

$1000 X$
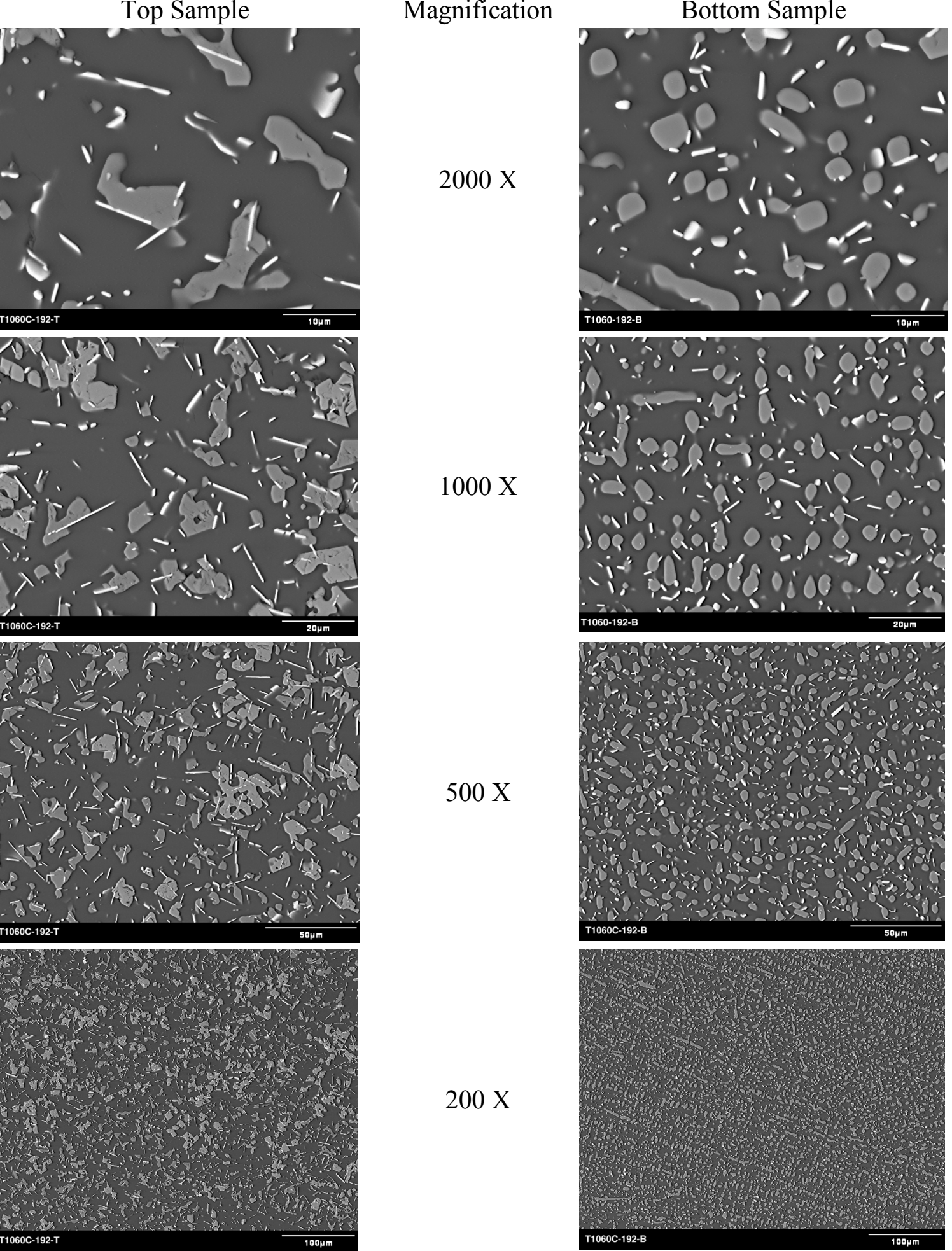

$500 X$

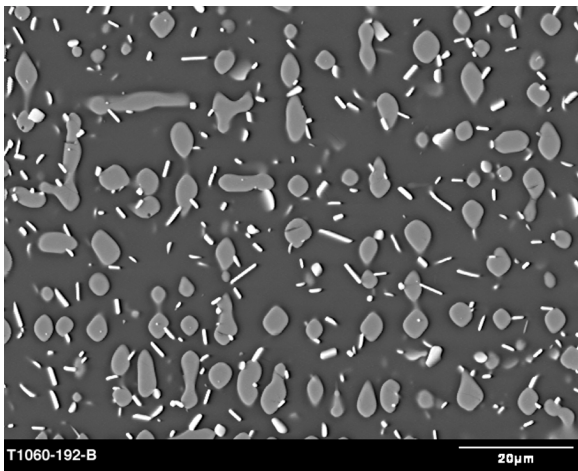

$200 X$

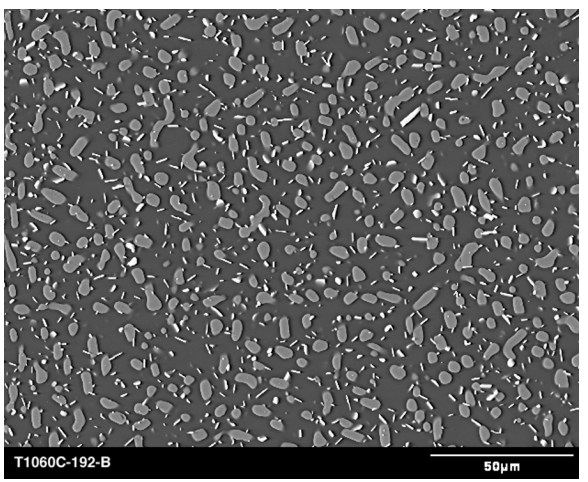

Figure 4-36. SEM Photomicrographs of Sample TTT-1060-192. 
Section 4

Experimental Results and Discussion

Additional Tests of an Advanced Vitrification System (DE-AC26-00NT40801)
Radioactive Isolation Consortium, LLC

Falls Church, VA 22046

www.ricllc.com

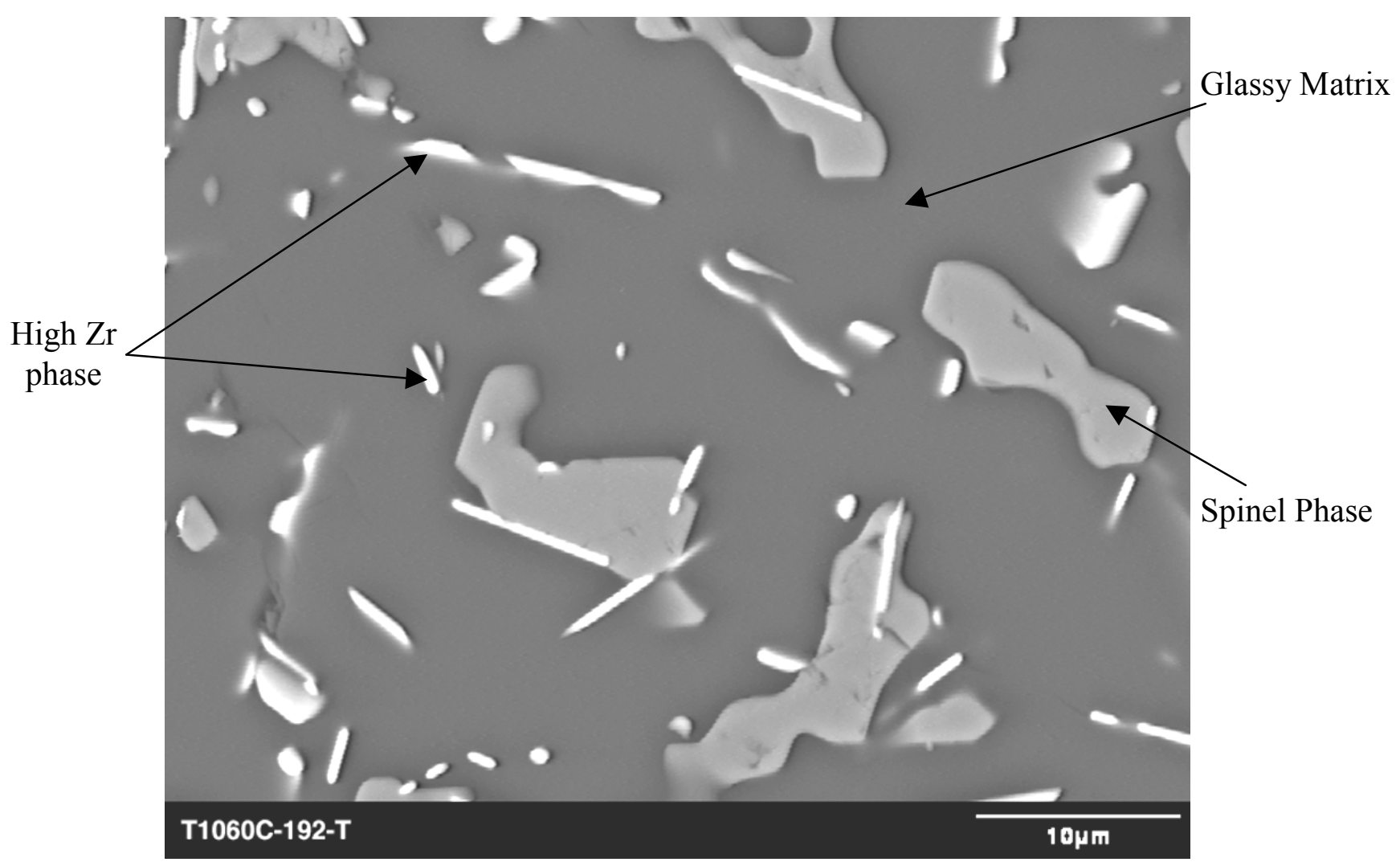

Figure 4-37. SEM Micrograph Illustrating Crystalline Morphology of TTT-1060-192 


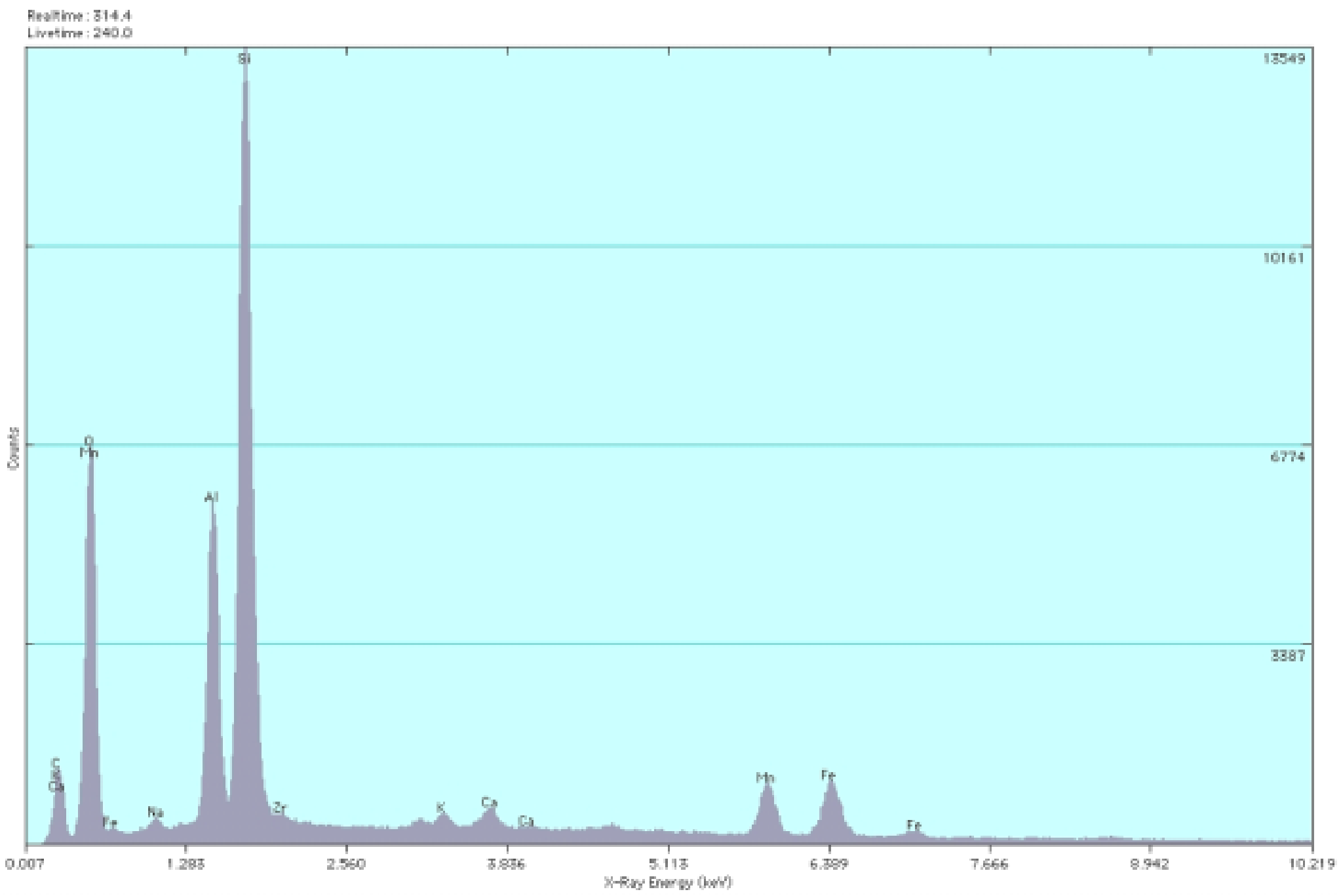

Figure 4-38. TTT-1060-192 SEM-EDS Spectra: Bottom Sample, Glassy Matrix

$1^{\text {st }}$ Replicate 
Rovaltime: 317.9

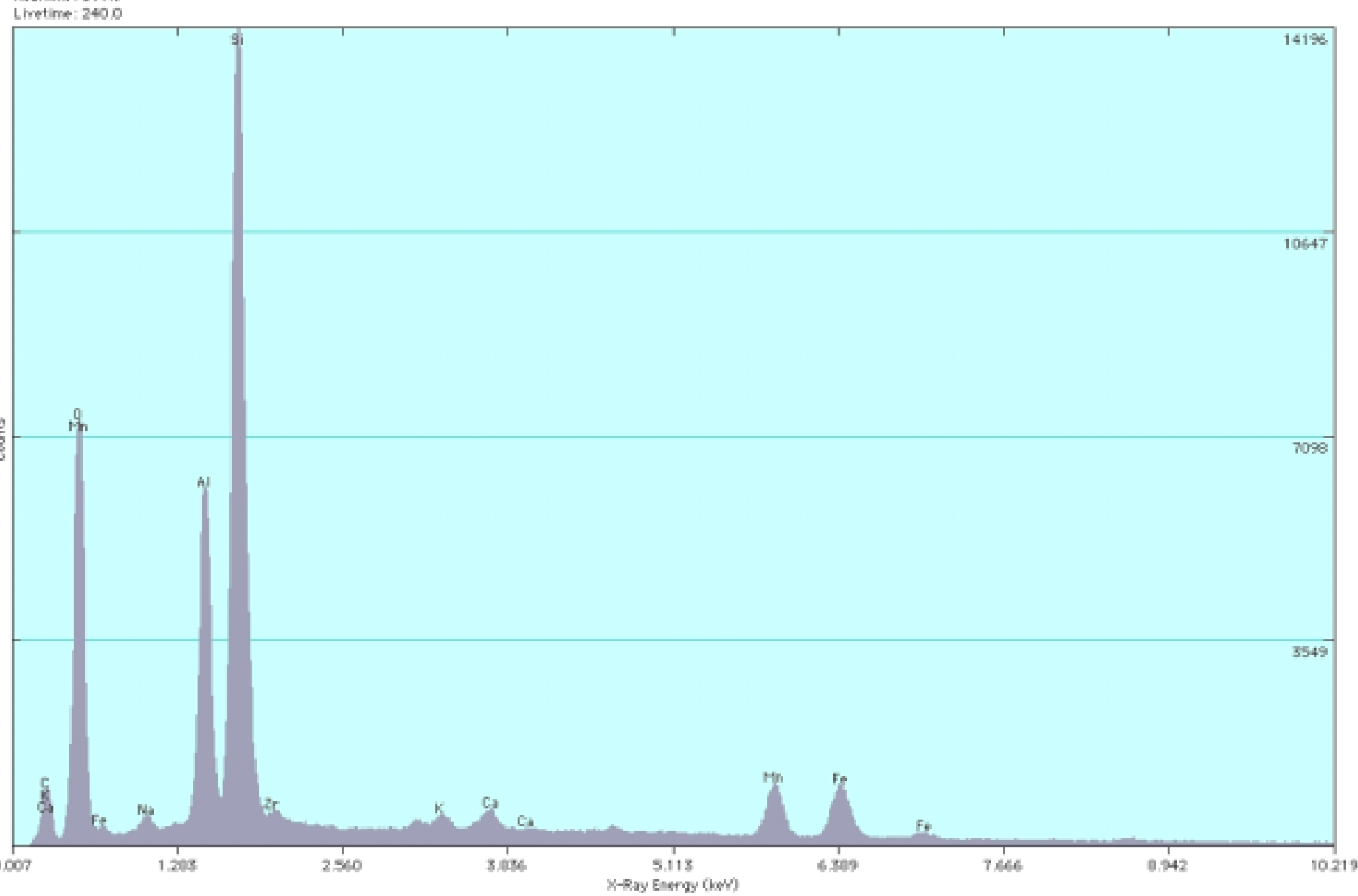

Figure 4-39. TTT-1060-192 SEM-EDS Spectra: Bottom Sample, Glassy Matrix

$2^{\text {nd }}$ Replicate 


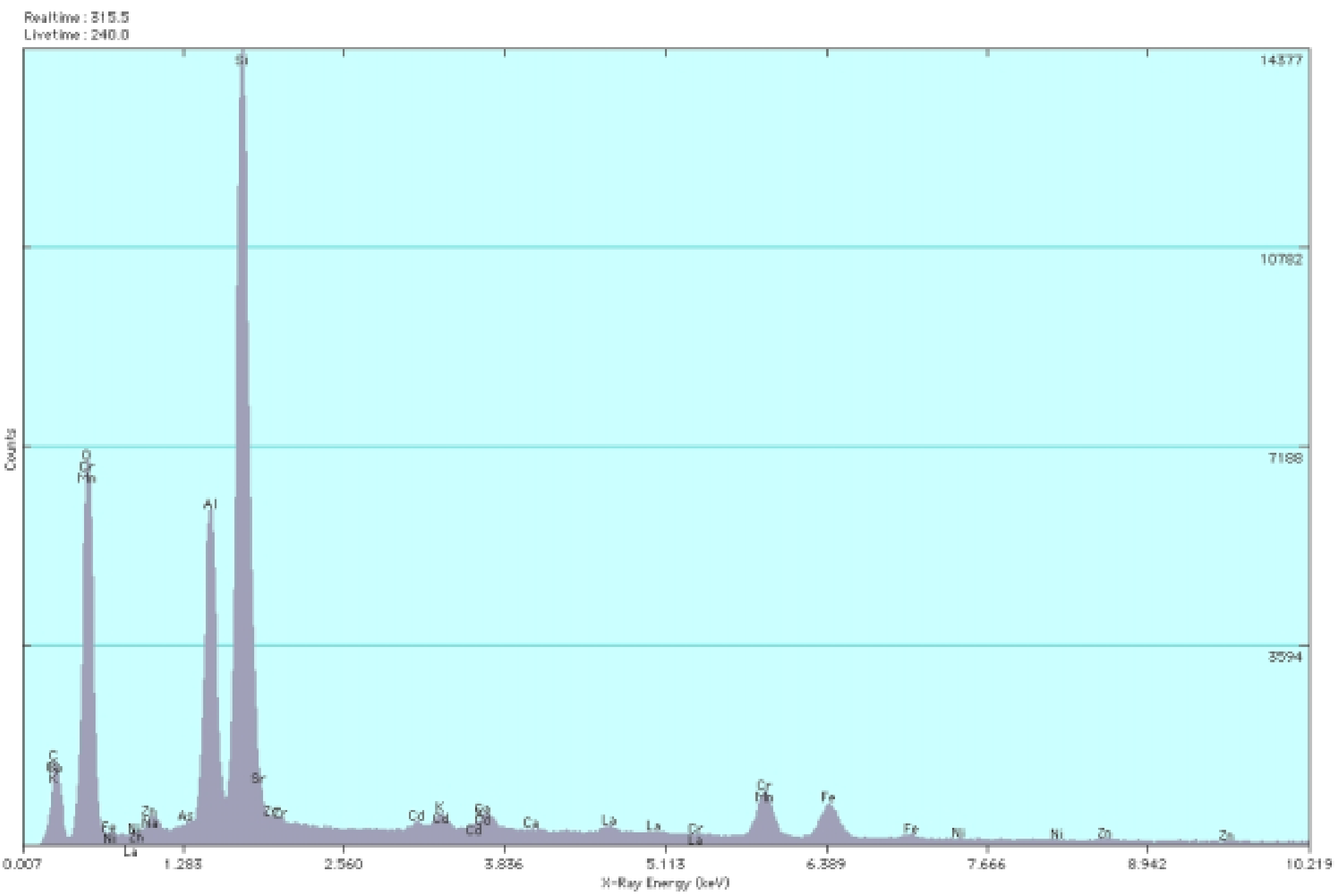

Figure 4-40. TTT-1060-192 SEM-EDS Spectra: Top Sample, Glassy Matrix

$1^{\text {st }}$ Replicate 


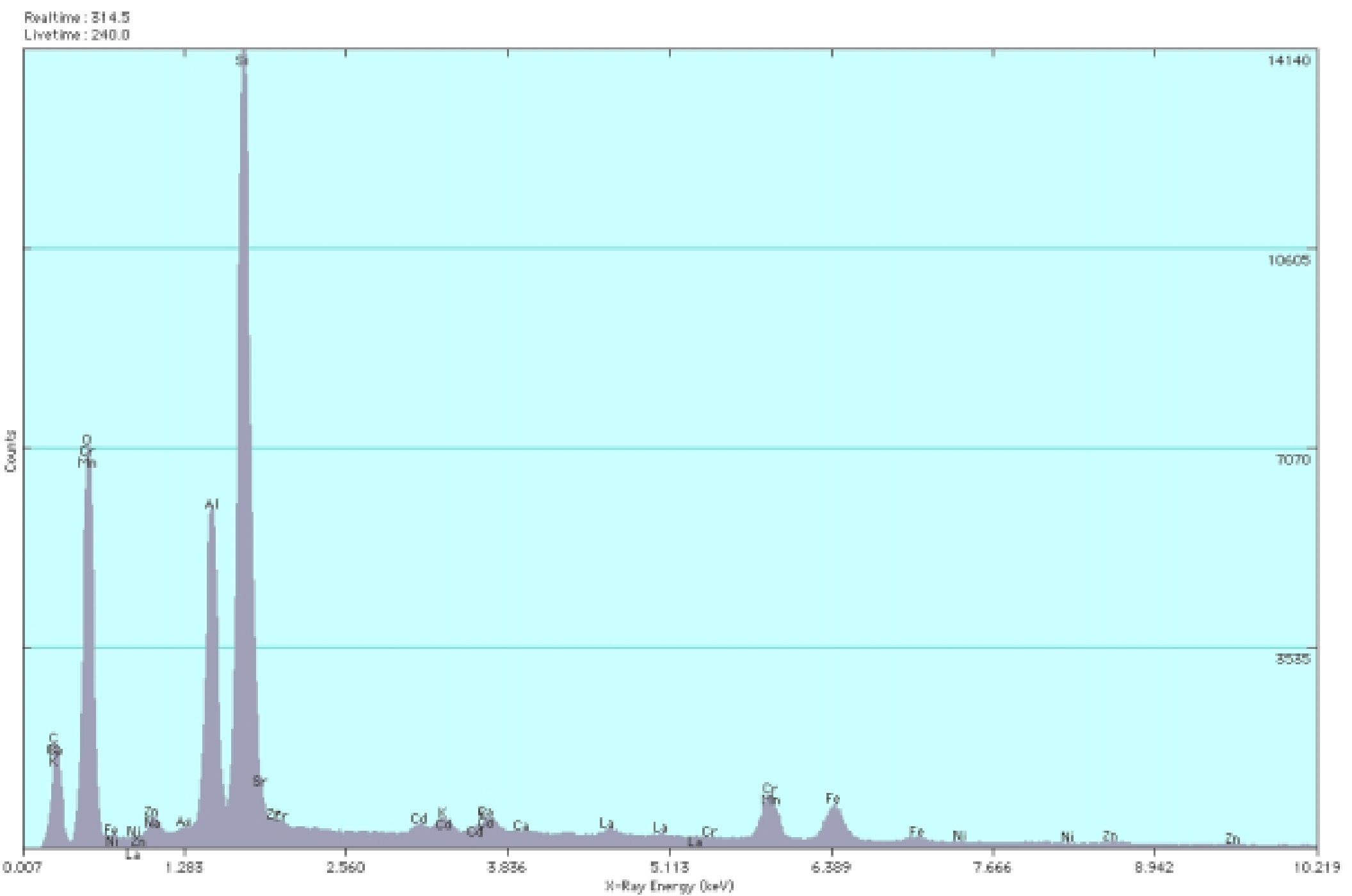

Figure 4-41. TTT-1060-192 SEM-EDS Spectra: Top Sample, Glassy Matrix

$2^{\text {nd }}$ Replicate 


\section{Realtime : 831.1}

Linetime: 240.0

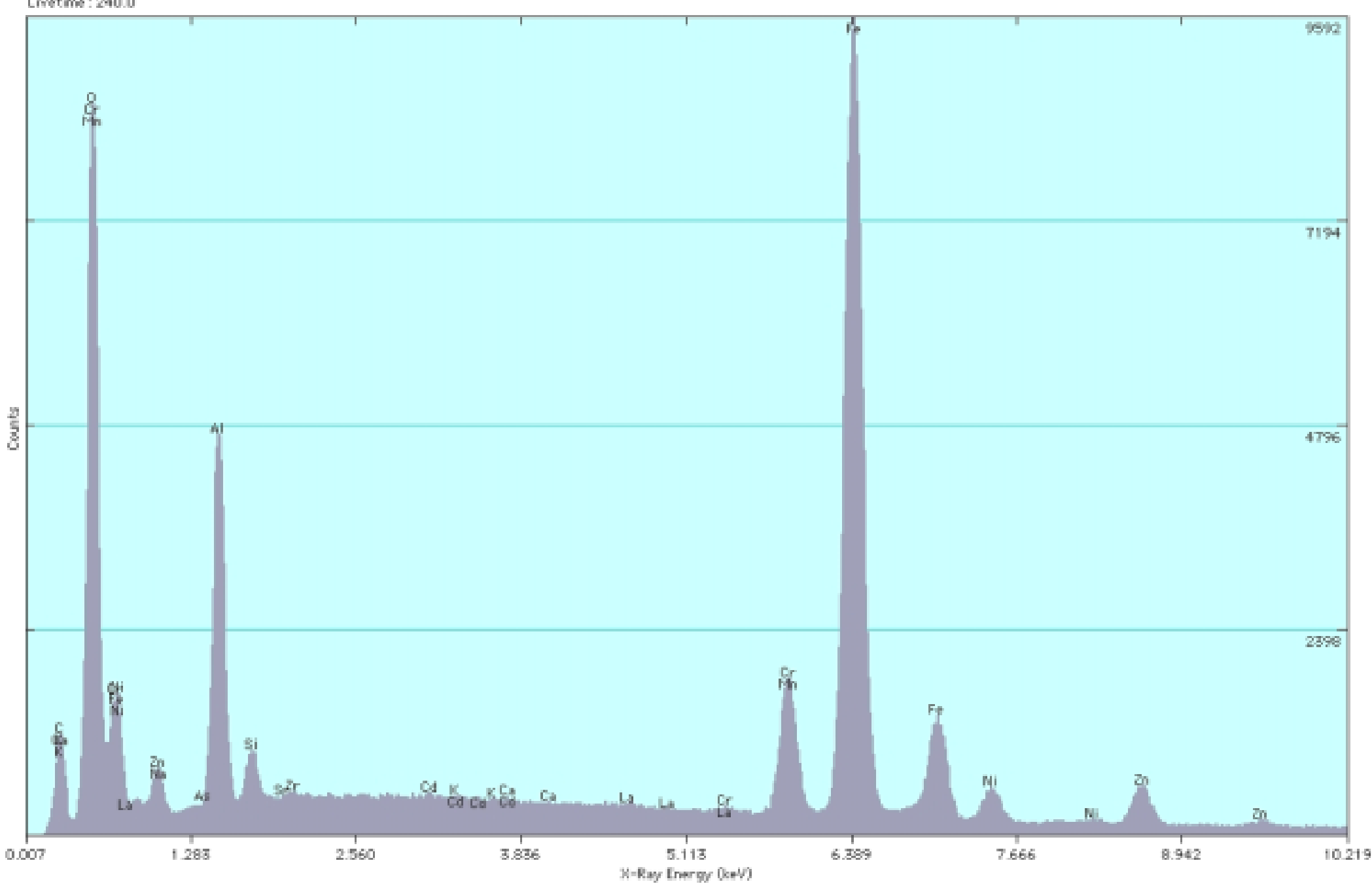

Figure 4-42 TTT-1060-192 SEM-EDS Spectra: Bottom Sample, Spinel Phase

$1^{\text {st }}$ Replicate 


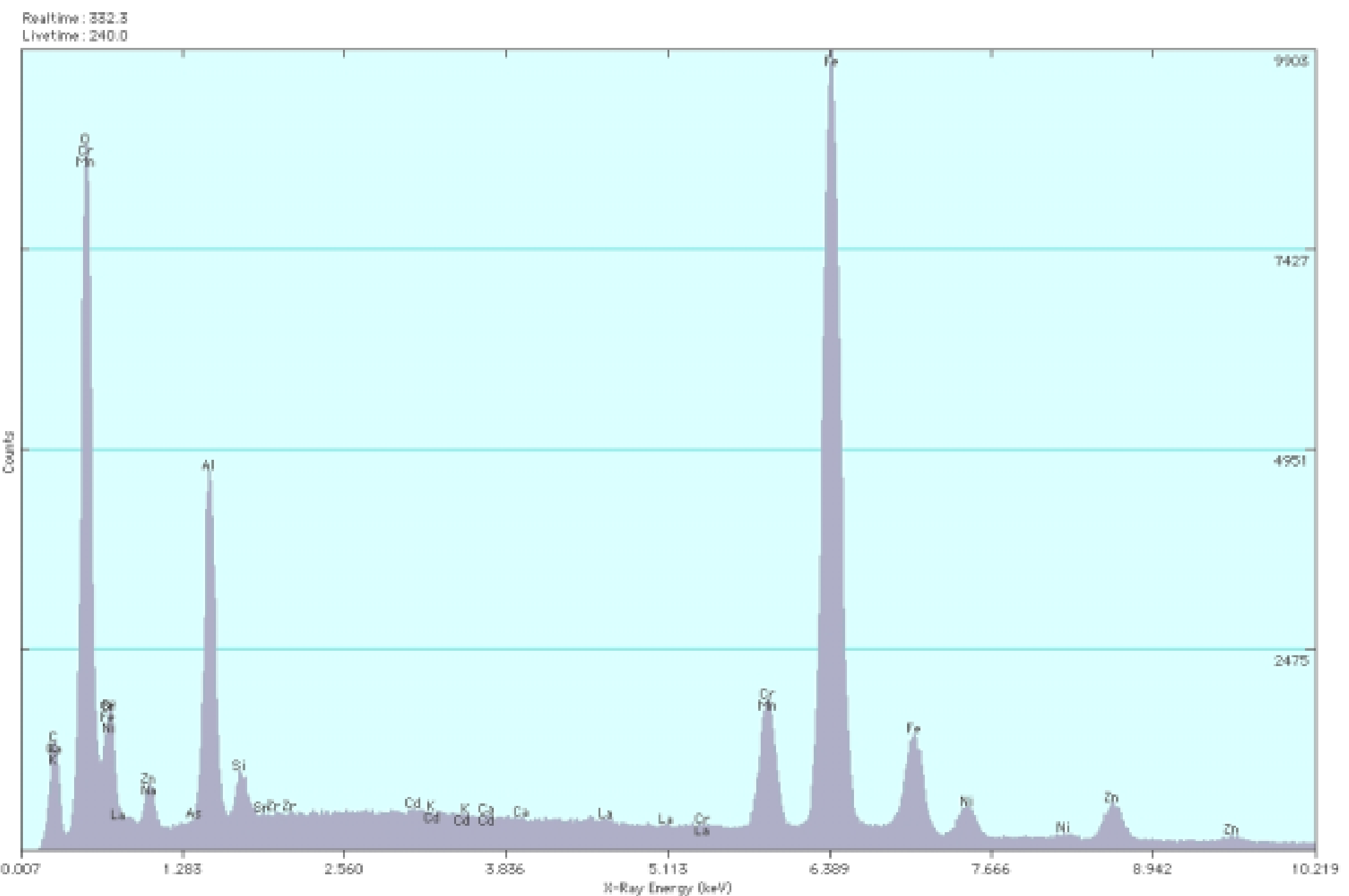

Figure 4-43. TTT-1060-192 SEM-EDS Spectra: Bottom Sample, Spinel Phase

$2^{\text {nd }}$ Replicate 


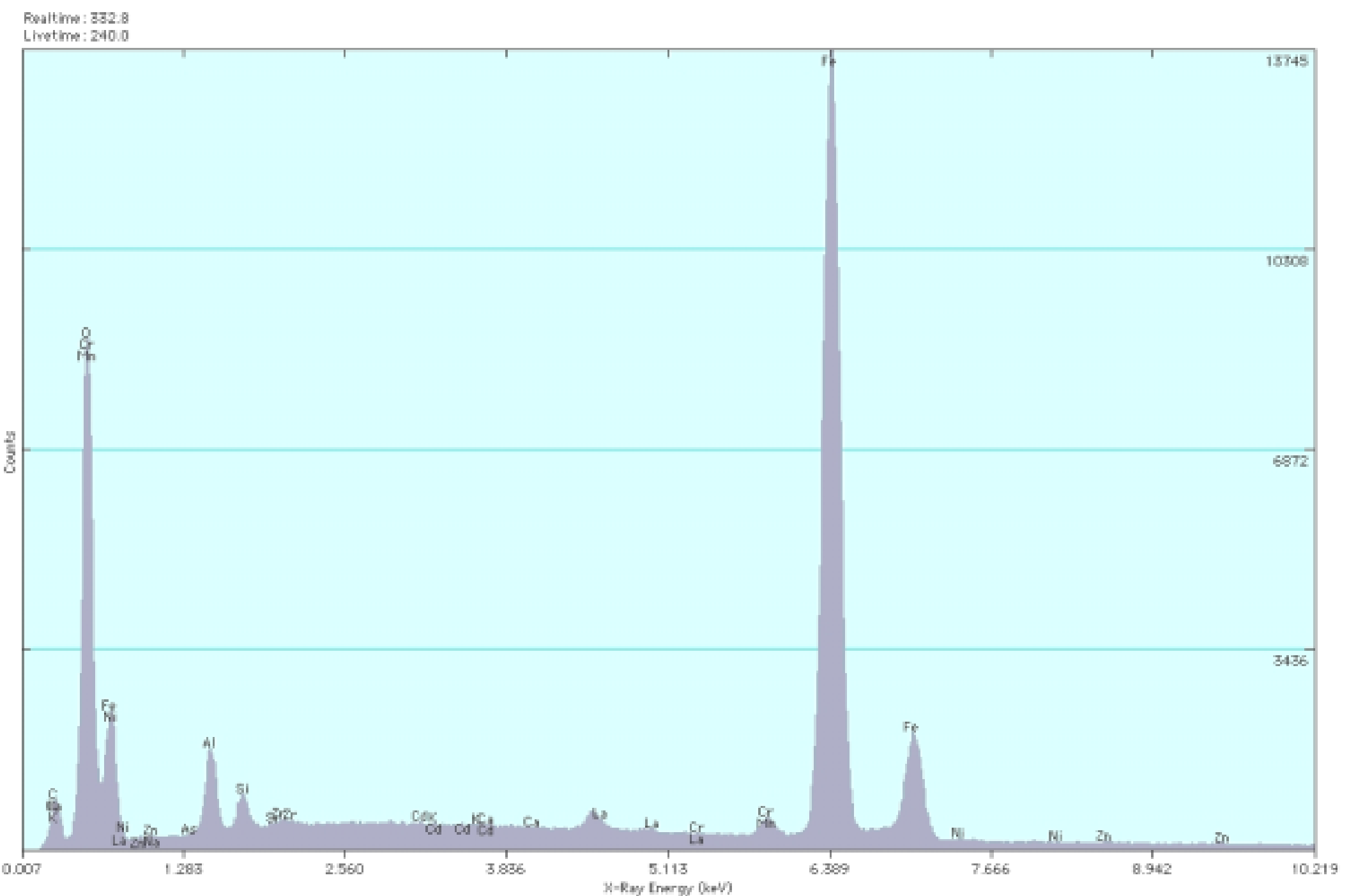

Figure 4-44. TTT-1060-192 SEM-EDS Spectra: Top Sample, Spinel Phase

$1^{\text {st }}$ Replicate 


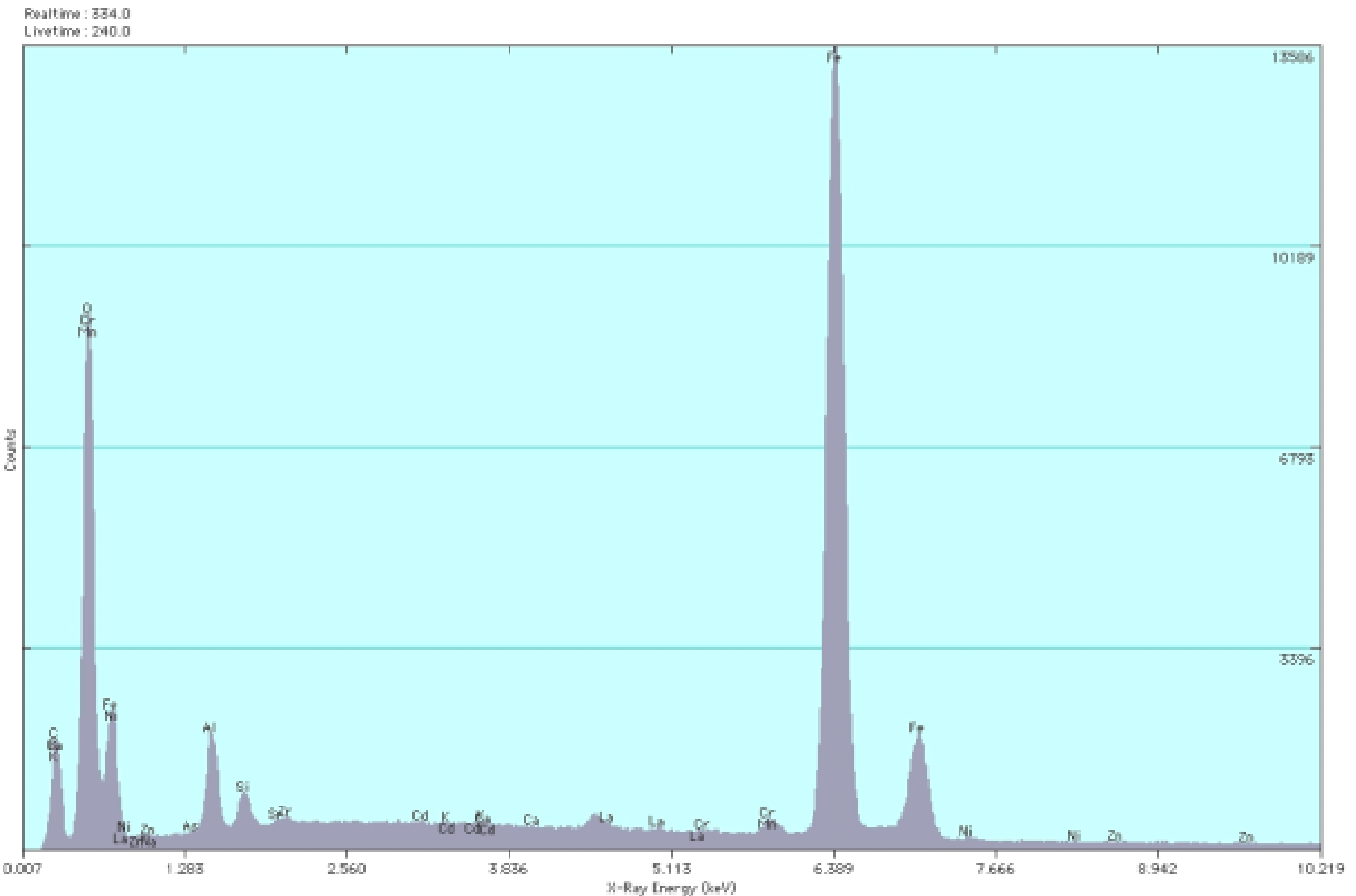

Figure 4-45. TTT-1060-192 SEM-EDS Spectra: Top Sample, Spinel Phase $2^{\text {nd }}$ Replicate 
Realtime : 365.4

Linetion : 240.0

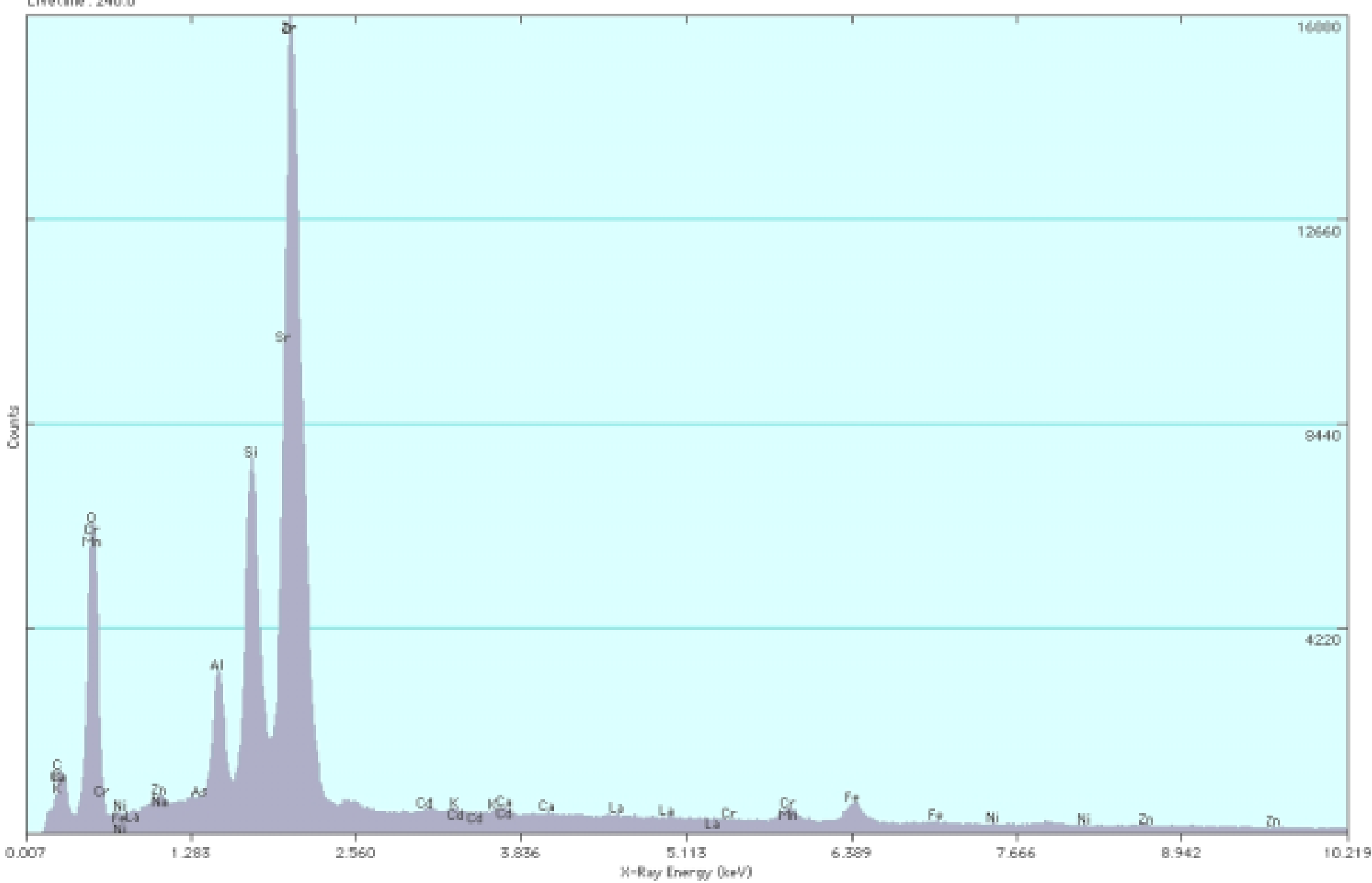

Figure 4-46. TTT-1060-192 SEM-EDS Spectra: Bottom Sample, High Zirconium Phase $1^{\text {st }}$ Replicate 
Res llime: 375.4

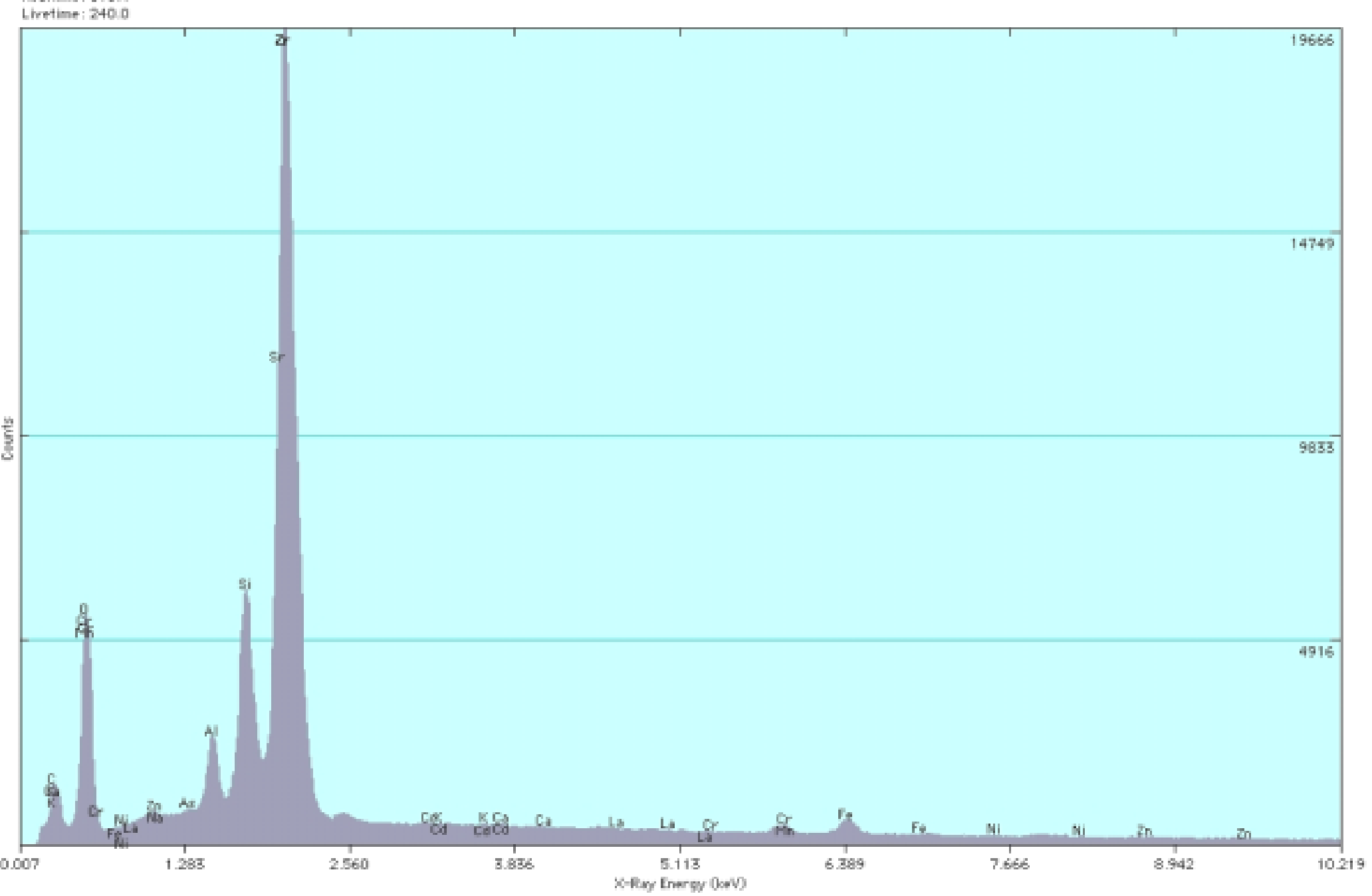

Figure 4-47. TTT-1060-192 SEM-EDS Spectra: Bottom Sample, High Zirconium Phase $2^{\text {nd }}$ Replicate 
Limetime: 240.0

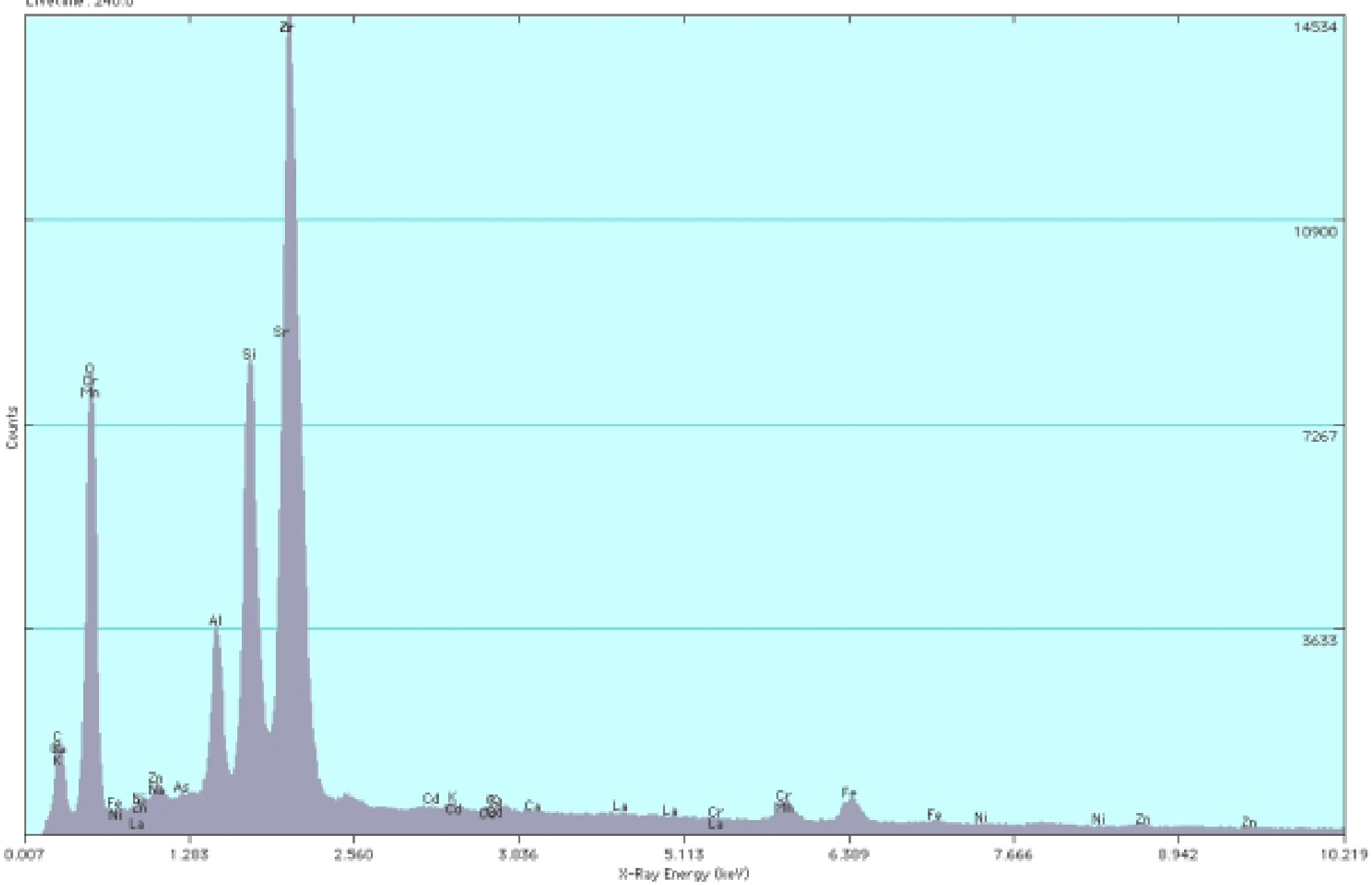

Figure 4-48. TTT-1060-192 SEM-EDS Spectra: Top Sample, High Zirconium Phase

\author{
$1^{\text {st }}$ Replicate
}




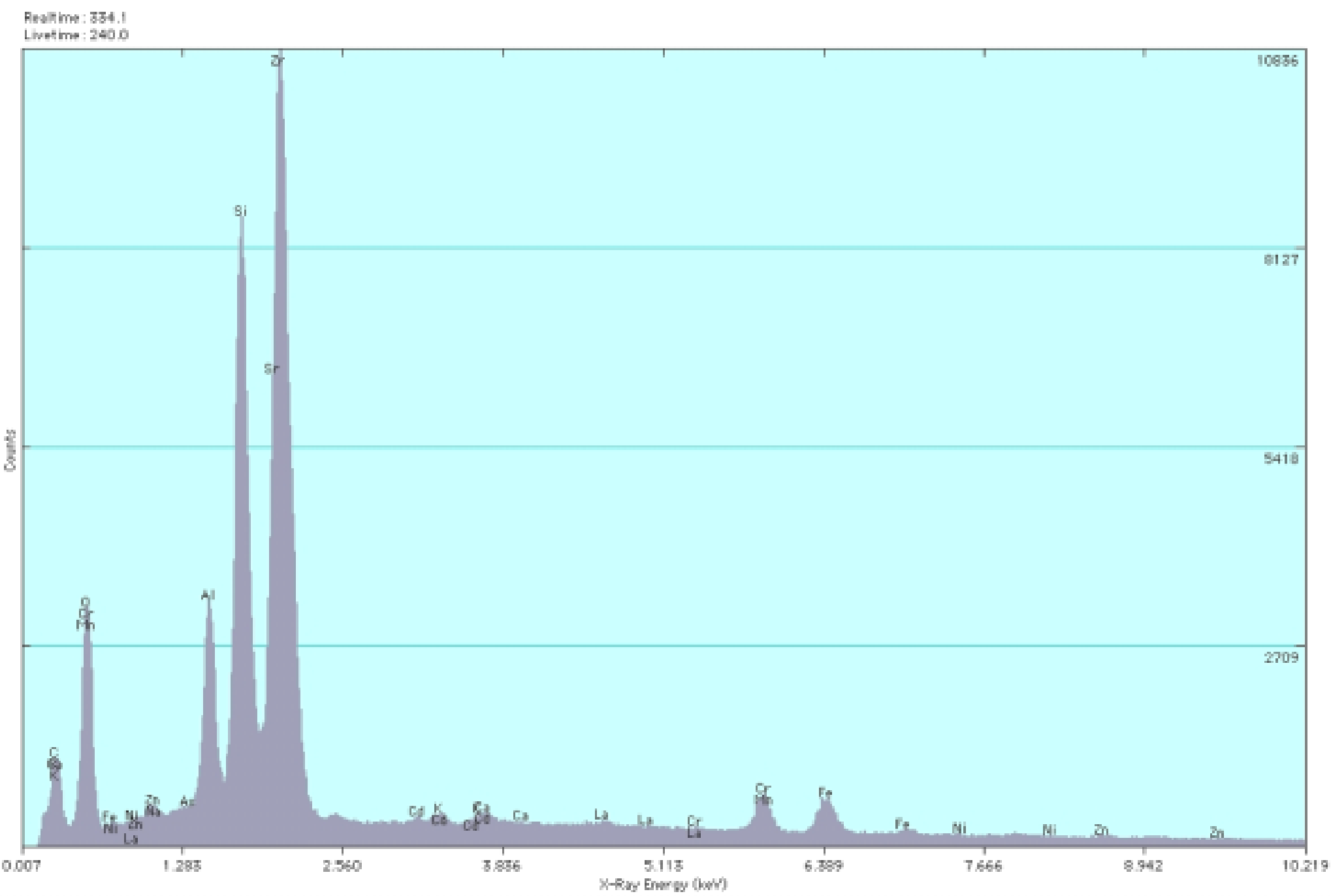

Figure 4-49-. TTT-1060-192 SEM-EDS Spectra: Top Sample, High Zirconium Phase $2^{\text {nd }}$ Replicate 


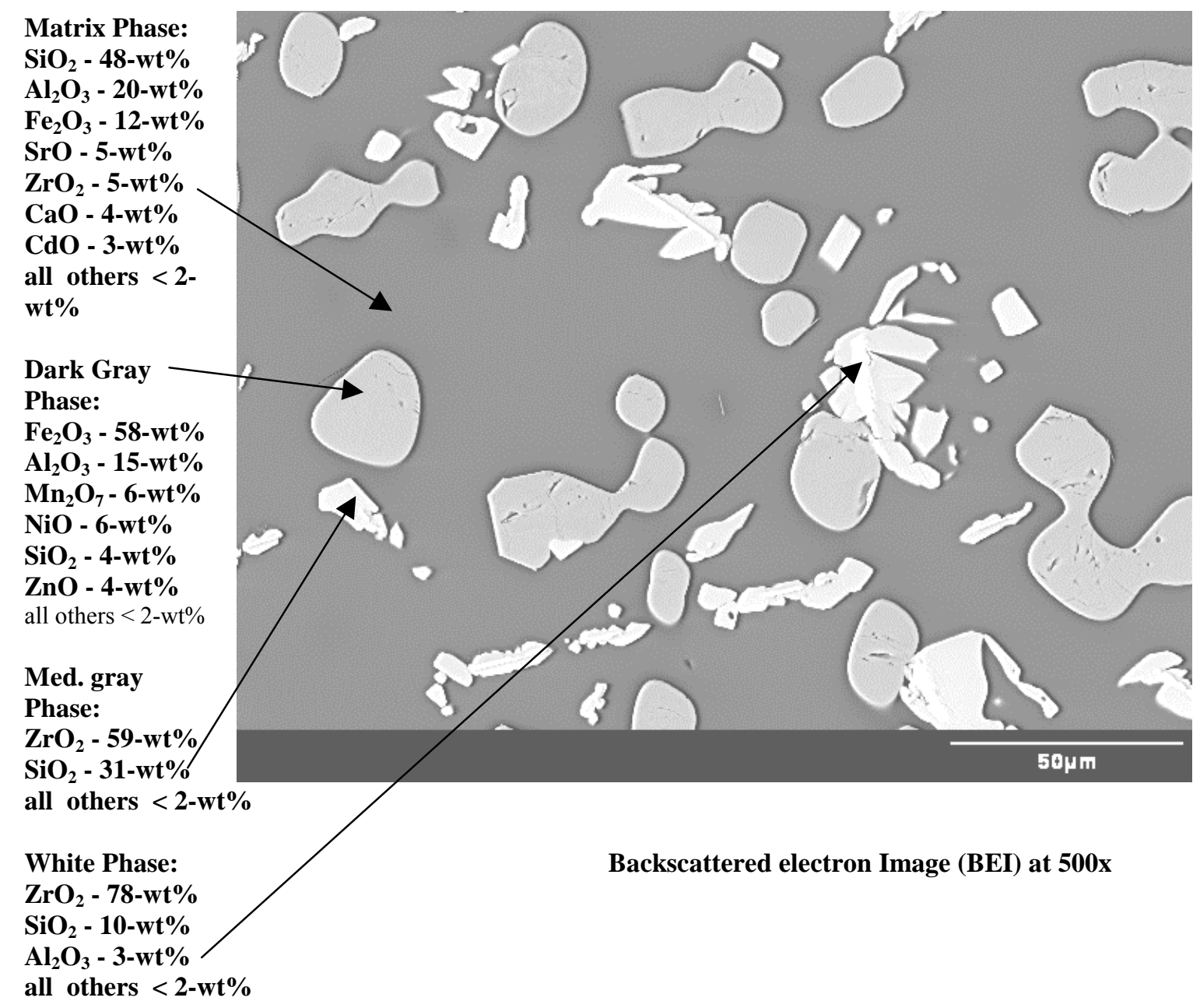

Note: This EDS analysis is for a single image (average of two replicates). Quantitative SEM-EDS data are averages of multiple images (top and bottom orientation samples).

Figure 4-50. SEM Micrograph Illustrating Crystalline Morphology of TTT-1200-192. DIAL Sample $1200^{\circ} \mathrm{C}-192$ hrs 


\section{TTT Diagram}

The TTT diagram was constructed by evaluating the relative crystallinity of the TTT sample Rietveld pattern and calculated weight percent of each phase for the TTT-1060192 sample is shown in Figure 4-51. The phases present, spinel (modeled as $\left.\mathrm{Al}_{0.9} \mathrm{Fe}_{2.1} \mathrm{O}_{4}\right), \mathrm{ZrO}_{2}$, and $\mathrm{ZrSiO}_{4}$ were calculated at 19.2, 5.3, and 0.8 weight percent respectively, with a residual glass phase of 72.3 weight percent. The relative uncertainty of the zircon and zirconia phase concentrations is on the order of 10 percent. The uncertainty of the spinel phase is considered higher due to the variability of spinel composition across the matrix.

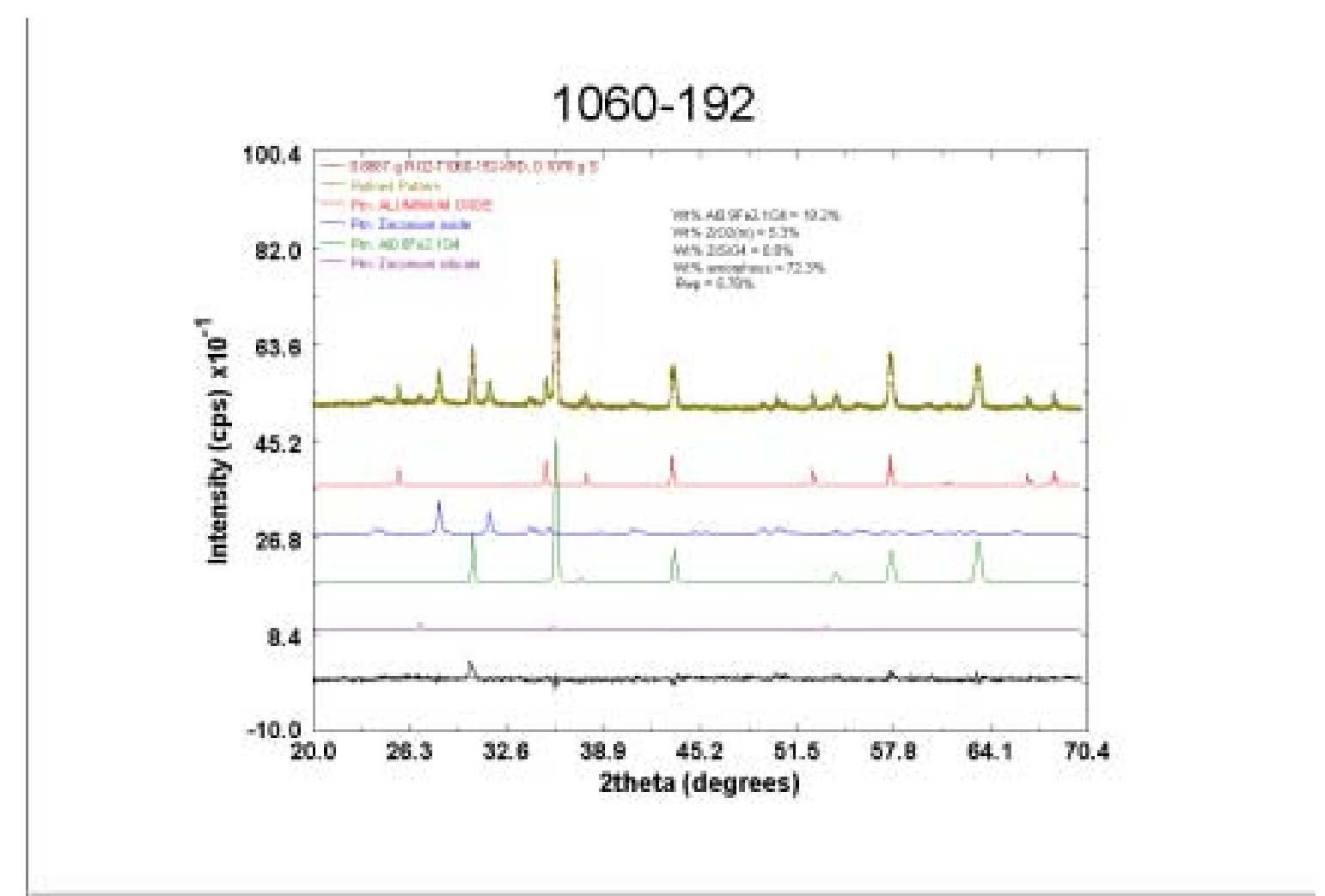

Figure 4-51. Rietveld Analysis of Long-Term XRD Scan of TTT-1060-192.

Figure 4-52 represents a TTT "nose diagram" of the crystalline phases present in the TTT samples. The diagram is plotted as Temperature versus the Natural Log of time in hours. This diagram includes the crystallinity data obtained for the 1300 and $1340^{\circ} \mathrm{C}$ heat treatments as well as the 36 original samples. Table 4-58 provides the logarithmic conversions for the heat treatment intervals. 


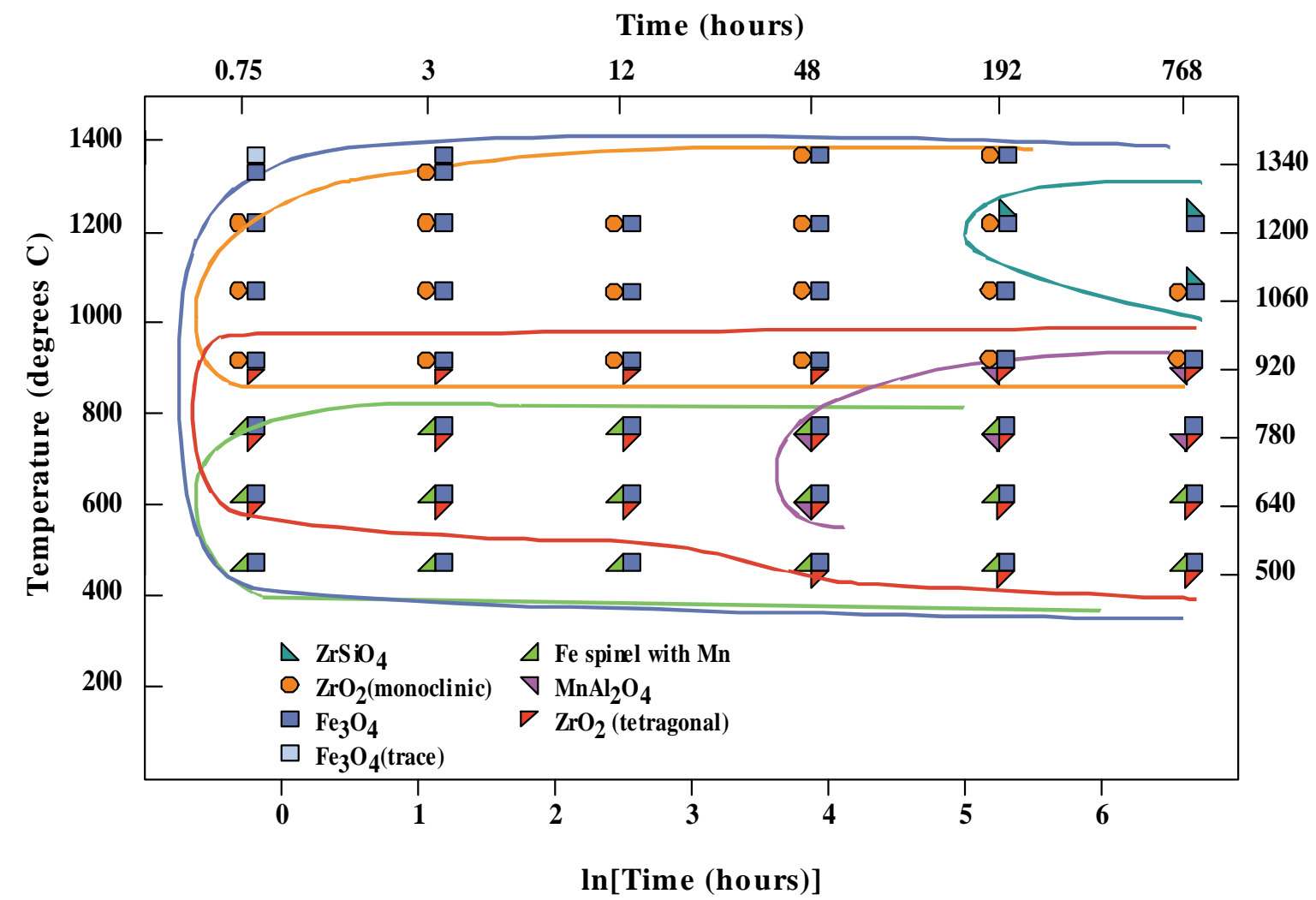

Figure 4-52. Heat Treatment Temperature vs. the Natural Log of Time for the RIC 60-wt\% Simulated AZ-101 Waste Glass as a Function of Crystalline Character

\begin{tabular}{|c|c|c|c|c|c|c|}
\hline \multicolumn{7}{|c|}{ Table 4-58. Corresponding Time and Natural Log T Values. } \\
\hline Time (Hrs) & 0.75 & 3 & 12 & 48 & 192 & 768 \\
\hline Natural Log & -0.29 & 1.10 & 2.48 & 3.87 & 5.26 & 6.64 \\
\hline
\end{tabular}




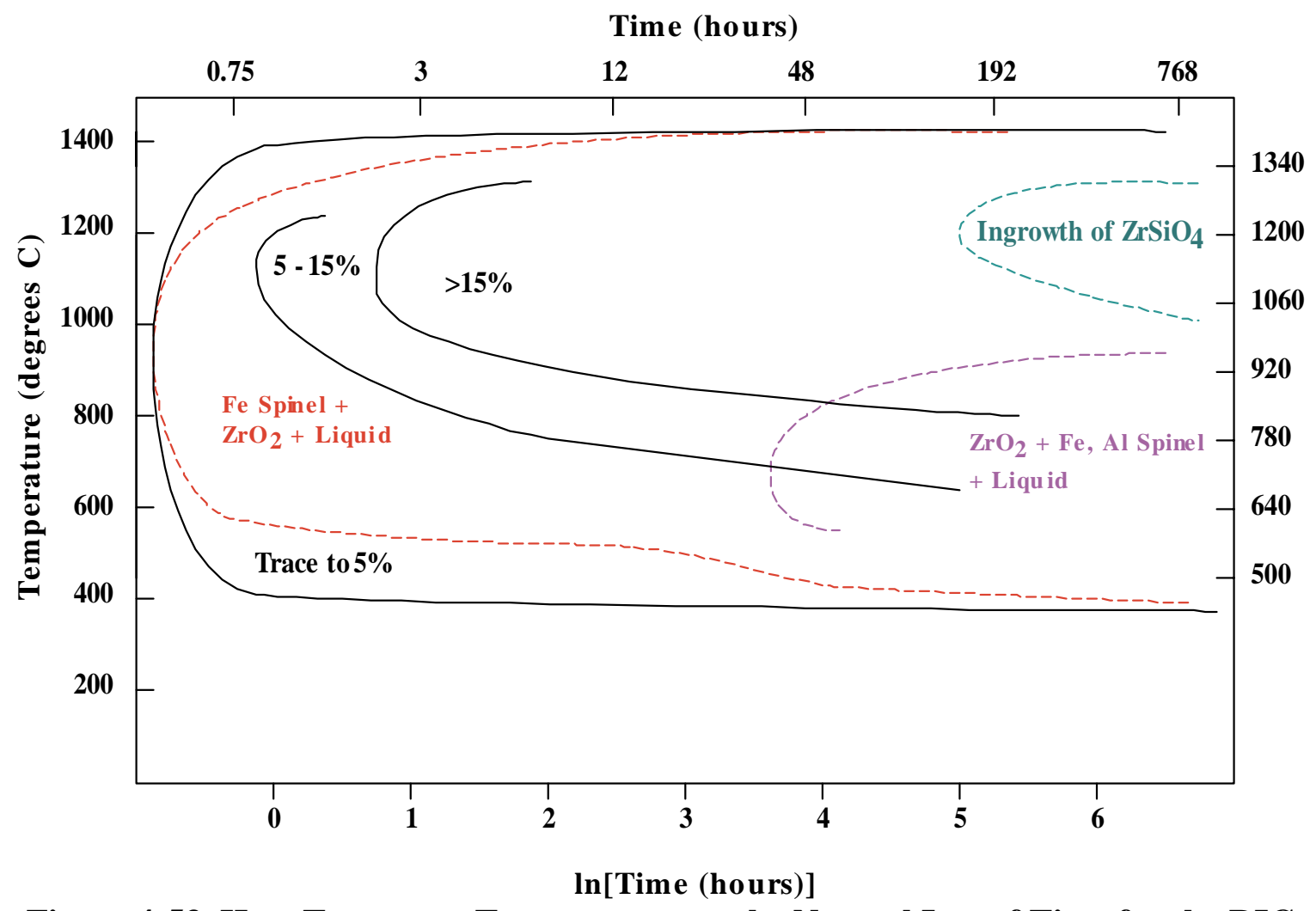

Figure 4-53. Heat Treatment Temperature vs. the Natural Log of Time for the RIC 60-wt\% Simulated AZ-101 Waste Glass Shown as a Function of Percent Crystallinity and Phase Field. 


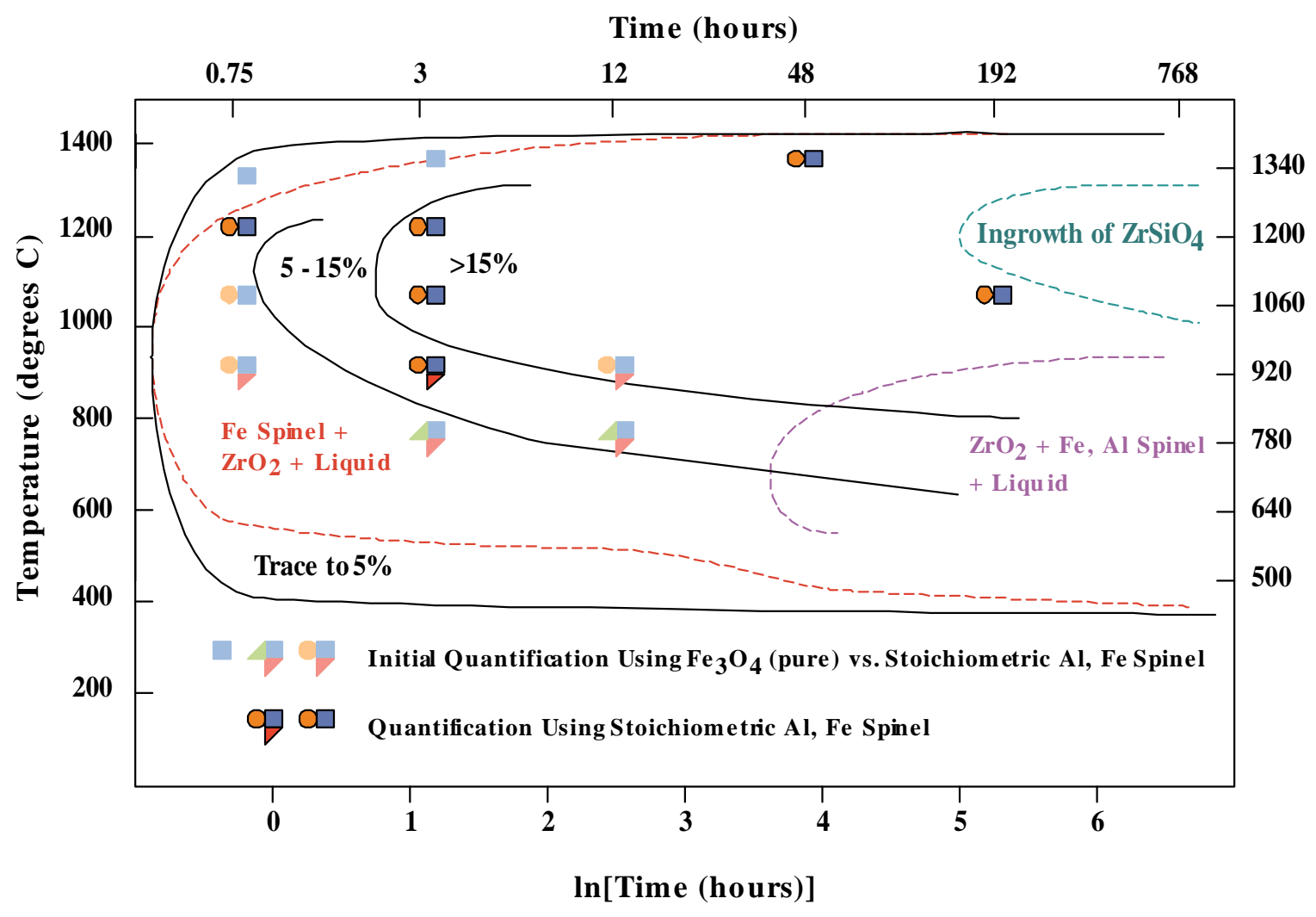

Figure 4-54

\section{Discussion and Results}

The relative size of crystals and the degree of crystallinity was significantly reduced below $920^{\circ} \mathrm{C}$. Likewise, the spinel phases consistent with the XRD of lower temperature heat treatments is not consistent with the samples heat-treated at $920-1200^{\circ} \mathrm{C}$. Analysis of the higher temperature $\left(1300\right.$ and $\left.1340^{\circ} \mathrm{C}\right)$ heat-treated samples give similar XRD patterns to those below $920^{\circ} \mathrm{C}$ with respect to spinel. The samples with the poorest degree of crystallinity are associated with the $\mathrm{Mn} / \mathrm{Fe}$ spinel in addition to magnetite. It appears then, that the $\mathrm{Mn} / \mathrm{Fe}$ spinel is indicative of the initial spinel phase. The samples with maximum crystallinity $\left(920-1200^{\circ} \mathrm{C}\right)$ have spinel compositions more heavily dominated by the iron oxides.

The identification of the $\mathrm{MnAl}_{2} \mathrm{O}_{4}$ spinel phase is noted at a slightly higher temperature region than the $\mathrm{Mn} / \mathrm{Fe}$ spinel. This does not appear to be an initial spinel phase nucleating form the melt. Significant concentrations of alumina and manganese are available for crystallization and their incorporation into the existing spinel crystals is likely.

The only crystalline silicate detected is zircon. This is likely due to the relatively low silica and, especially, alkali concentrations. 
The relative concentration of zirconia approaches 4-5 weight percent in the short-term 1060 and $1200^{\circ} \mathrm{C}$ heat treatments. The corresponding long-term heat treatment samples have over 5 weight percent zirconia and a significant amount (on the order of 1 weight percent) zircon. The target weight percent zirconia in the glass is on the order of 7.5 , therefore, less than $1 / 3$ of the zirconia remains in the residual amorphous phase of the most heavily crystallized samples.

The maximum crystallinity is observed for the $1060^{\circ} \mathrm{C}$ heat treatments. Total crystallinity in excess of 20 weight percent is observed at the three-hour heat treatment duration. The corresponding $1200^{\circ} \mathrm{C}$ heat treatment contained approximately 15 weight percent total crystallinity. 


\subsection{UTS Compliance}

The SOW requires, "Using results from the TCLP tests, the contractor shall determine the leachability of any RCRA-listed components relative to the Universal Treatment Standards in order to demonstrate the feasibility of receiving an exemption from the EPA to delist the AVS waste form.'

\section{Results}

Two laboratory-scale AVS waste forms at a nominal $60 \%$ waste loading [M-1] produced leachate extract concentrations with results comfortably within the Universal Treatment Standards (UTS) for all the elements of concern under the UTS regulation. ${ }^{\text {T }}$ The laboratory-scale tests investigated two vitrified waste product cool-down rates. In the first, a sample was cooled at a rate of $1{ }^{\circ} \mathrm{C} / \mathrm{min}$ (slow cooling). The Cd TCLP release at this rate was $0.073 \mathrm{mg} / \mathrm{L}$. The second sample was rapidly cooled in air and the observed release rate $0.053 \mathrm{mg} / \mathrm{L}$. Both these samples are below the UTS limit of $0.11 \mathrm{mg} / \mathrm{L}$.

The AVS Bench-Scale 4 waste form at essentially the same composition and waste loading produced a leachate extract with only the element cadmium $(\mathrm{Cd})$ statistically indistinguishable from its UTS level. Applying the standard deviation shows a Cd concentration of 0.11 , or the same as the UTS limit. All other elements were well within the UTS criteria.

\begin{tabular}{|c|c|c|c|c|c|c|c|c|}
\hline \multicolumn{7}{|c|}{ TCLP Results } \\
\hline \multirow{2}{*}{ Waste Loading } & \multicolumn{7}{|c|}{ Element Concentration in TCLP Extract (mg/L) } \\
\cline { 2 - 9 } & As & Ba & Cd & Cr & Ni & Pb & Se & Zn \\
\hline & & & & & & & & \\
\hline $\begin{array}{c}\text { 61-wt\% Lab } \\
\text { Scale with Fast } \\
\text { Cooling } \\
\text { (R-02-LM-60) }\end{array}$ & 0.0000 & 0.0136 & 0.0373 & 0.0002 & 0.0214 & 0.0087 & 0.0000 & 0.1001 \\
\hline $\begin{array}{c}\text { 60-wt\% Lab } \\
\text { Scale with } \\
\text { 1C/min Cooling } \\
\text { (Slow Cooling) }\end{array}$ & 0.0012 & 0.0248 & 0.0731 & 0.0004 & 0.0158 & 0.0177 & 0.0000 & 0.0736 \\
\hline Bench-Scale 4 & 0.019 & 0.2 & 0.14 & 0.002 & 0.031 & 0.2 & 0.014 & 0.197 \\
\hline UTS Limit & 5.0 & 21.0 & 0.11 & 0.60 & 11.0 & 0.75 & 5.7 & 4.3 \\
\hline
\end{tabular}

${ }^{1}$ A report on the analysis of the applicability of the UTS to Savannah River glass states, "The DWPF is exempted from UTS standards, since the waste sludge is being treated by a specified technology, e.g. [sic, should probably be viz.] HLVIT, which has been declared by EPA to be BDAT [Best Demonstrated Available Technology]." "Toxic Characteristic Leaching Procedure (TCLP) Testing of Waste Glass and K-3 Refractory: Revisited," C.M. Jantzen and J.B. Pickett, Westinghouse Savannah River Co., Aiken, SC and I. Joseph, GTS Duratek, Columbia, MD, WSRC-MS-99-00335, p. 4.

${ }^{2}$ Universal Treatment Standards are stated in EPA's regulations at 40 CFR 268.48. The "underlying hazardous constituents" listed in $\$ 268.48$ in the AVS AZ-101 waste glass are As, $\mathrm{Ba}, \mathrm{Cd}, \mathrm{Cr}, \mathrm{Ni}, \mathrm{Pb}, \mathrm{Se}$ and $\mathrm{Zn}$. 
An exemption from the EPA to delist the AVS bench-scale waste form is considered feasible for the $60 \%$. The laboratory-scale 60 -wt $\%$ AVS waste form glass provides such full compliance and an exemption should be obtainable based on those results. The Bench-Scale 4 results comply with the UTS for all elements with only the Cd level at a statistically indistinguishable level from its UTS standard.

\section{Discrepancy between Lab and Bench-Scale Tests}

The fact that the bench-scale and laboratory-scale glass leaching performance results were different is unexpected.

Previous testing results on Envelope D yielded consistent results between lab- and benchscale tests. For these tests, there was reasonable consistency of the TCLP results between the $50 \%$ waste loaded glass produced at the laboratory scale and the $50 \%$ waste loaded glass produced at the bench scale as regards $\mathrm{Ag}$ and $\mathrm{Cr}$. $\mathrm{Pb}$ leachate concentration was somewhat reduced at the bench scale in comparison to the laboratory scale. Thus, prior testing does not show evidence of increases in TCLP results from laboratory-scale to bench-scale. On the contrary, this testing tended to confirm the validity of extrapolation from laboratory-scale results to the bench scale.

For the current tests, a comparison of the AZ-101 60-wt\% glass produced at the laboratory scale and the glasses produced at the bench scale indicates that they are similar in chemical composition and uniformity.

Paradoxically the amount of crystallinity in the bench-scale glasses was consistent with a $60-w t \%$ AVS glass annealed at $1200^{\circ} \mathrm{C}$ for 45 minutes to 3 hours. This is evidenced by the results obtained for the preparation of the TTT diagram. The cooling rate indicated by thermocouples on the exterior of the bench-scale graphite container shows no annealing period similar to the TTT at the $1200^{\circ} \mathrm{C}$. Rather, the bench-scale cooling rate evidences a relatively rapid cooling of the container and glass, which is consistent with that of previous tests. The discrepancy between the conclusion based on the TTT data and the conclusion based on the measured cooling rate data is an anomaly, which cannot be resolved by consulting the experimental data record.

The higher TCLP results for the Bench-Scale glass are speculated to be a processing control defect in the bench-scale testing, which, based on prior results, should be correctible at the $60-\mathrm{wt} \%$ waste loading to bring the result into conformance with the laboratory scale results.

Differences between the laboratory-scale test and the bench scale tests are possible causes of the increased TCLP results at the bench scale. These include ---

- Processing control divergence affected intended heating profile;

\footnotetext{
${ }^{3}$ See the Conclusions and Recommendations section for a discussion of the EPA's environmental goals and why the AVS waste form is anticipated to provide further support for for delisting. The AVS waste form is the glass encapsulated within the graphite and alumina and using it for TCLP testing might result in much higher waste loaded glass passing UTS limits.
} 
- TCLP sampling methodology;

- Feed form, namely, slurry feed at the bench scale as opposed to dried feed at the laboratory scale;

- Difference in the feed rate of slurry from the feed rate used the COFFEE slurry feed experiments (the COFFEE glass successfully passed the TCLP test); and

- Leachate equipment or procedural variation.

\section{Processing Control Divergence Affected Intended Heating Profile}

The primary suspected cause of the discrepancy in results from the laboratory scale test to the bench-scale is a process control anomaly discovered after bench-scale testing was complete. The external thermocouples, which were used for process control, showed a melt temperature of about $1510^{\circ} \mathrm{C}$, which is what was intended. However, a comparison with the imaging pyrometer focused on about 1.5 inches diameter of the top melt surface shows temperatures of about $1200^{\circ} \mathrm{C}$. This was an unanticipated substantial divergence from what was desired for the melt temperature of the top surface.

For the joule melter, Hrma et al. found, "The commonly held assumption was that crystals, if they form at all, should dissolve easily in the melter because of the liquidus constraint which guaranteed that the melt temperature was above liquidus in most of the melt volume. This, as the calculation showed, was not the case. The melt circulates within the melter between cool and hot regions so fast that crystals do not have sufficient time to dissolve while in the hot zone. As g result, some steady-state size and concentration of crystals is established." 4

For the AVS hot hohlraum process to work correctly, there should be little temperature difference between the top surface of the melt and the crucible wall temperature. This is controlled by having a feed rate that allows slurry additions to immediately come to temperature due to the high radiant flux. If the feed rate is too fast, the temperature of the melt has a gradient too great to produce the desired melt and convective mixing can occur, which enhances the formation of nucleating agents in the colder elements of the melt. The TTT results show that a glass with more crystallinity has little or no effect on PCT performance, but the same glass has deteriorating TCLP results. This may or may not be due to the crystallinity, but the relatively increased leachability in the bench-scale glass may be due to the unanticipated temperature imbalance created by an excessive slurry feed rate.

\section{TCLP Sampling Methodology}

The sampling methodology used to obtain the glass for leach testing was different for the laboratory-scale tests and the bench scale tests. The bench-scale glass was first sawed into the segments with a band saw over a period of about 30 minutes for test 4 . This cutting methodology was employed to obtain the samples from the locations specified in the contract. Both bench-scale glasses tested were about 5 inches in diameter and from 3 to 4 inches tall. The sawed segments were then hammered to obtain smaller pieces for

\footnotetext{
4 "Settling of Spinel in a High-Level Waste Glass Melter," P. Hrma, Pacific Northwest National Laboratory, Project No. 65422, Sept. 2001, p. 2.
} 
the test. In contrast, the laboratory-scale glass was not sawn, but was broken with a hammer. EPA also admits that the TCLP test doesn't work well for brittle solids, like the sample glass and the sizing methodology in the procedure is specified for fibrous solids. The sensitivity of the particle surface area and geometry of the test samples is discussed further in the Conclusions and Recommendations section of this report.

\section{Feed Form}

The feed form at the laboratory-scale was a dried solid compared to slurry feed at the bench-scale. This may have had a yet unknown impact on the chemistry associated with the melt. However, the results from the COFFEE slurry feed tests do not indicate that the slurry feed form is the likely cause of the discrepancy.

\section{Leachate Equipment or Procedural Variation}

Changes in the sources of supplies for the acid leach solution or in the analytical equipment providing the results are a potential source of the 2 to 3 times increase in all the reported levels of the hazardous constituents in the glass extracts. Initial investigations by DIAL indicate that the results on the blanks suggest this is not the cause.

\footnotetext{
${ }^{5}$ See the Conclusions and Recommendations section for a sensitivity analysis on the sampling procedure.
} 


\section{Results and Discussion - WAPS Compliance}

\section{WAPS Compliance Objective}

In March of 2002, the Department of Energy contracted with RIC ${ }^{\mathbb{1}}$ to perform additional tests of its Advanced Vitrification System using a simulant specified by DOE to be representative of AZ-101 waste. The objective of the testing program is to demonstrate compliance of the maximum waste loaded vitrified product with waste form acceptance criteria given in the DOE Waste Acceptance Product Specifications for Vitrified HighLevel Waste Forms (WAPS). ${ }^{2}$ In particular, five criteria specified in Section 1 (Waste Form Specification) of the WAPS were called for in the Statement of Work.

These are:

1. WAPS Section 1.1.1 Chemical Composition Projections

2. WAPS Section 1.1.2 Chemical Composition During Production

3. WAPS Section 1.3 Specification for Product Consistency

4. WAPS Section 1.4 Specification for Phase Stability

5. WAPS Section 1.5 Hazardous Waste Specification

\section{Approach}

The relevant results of the AZ-101 test program to compliance with the specified WAPS are summarized in this section. The testing program was conducted in accordance with a Final Test Plan developed and approved by DOE. The Final Test Plan and DOE approved Program Management Plan guided the work activities.

To provide a roadmap for the how the work performed under this contract demonstrates compliance of the high temperature, highly waste loaded vitrified AZ-101 waste form

\footnotetext{
${ }^{1}$ Additional Tests of an Advanced Vitrification System," DE-AC26-00NT40801, (January 2002), revised 3/14/02
}

This testing program is an extension of work on the Envelope D waste form to include a second waste form using AZ-101 simulant. The SOW references both waste forms, but this testing and report is directed to the AZ-101 simulant work and the single waste form deliverable resulting from that work: "The objective of this project is to conduct bench-scale vitrification tests using DOE provided waste simulant recipes in order to demonstrate the ability of the existing design Advanced Vitrification System (AVS) test equipment to produce simulated waste forms that meets the technical criteria for immobilized high-level waste (HLW) at DOE sites. The specific objective of the testing is to unambiguously establish whether these bench-scale tests, using waste simulant recipes provided by the DOE, can produce borosilicate glass waste forms that fully comply with the current revision of Waste Acceptance Product Specifications for Vitrified High-Level Waste Forms (WAPS)." The SOW further requires "conduct[ing] one qualification bench-scale test at maximum waste loading." SOW, p.1.

${ }^{2}$ U.S. Department of Energy Office of Environmental Management, Waste Acceptance Product Specifications for Vitrified High-Level Waste Forms - WAPS, EM-WAPS Rev. 02, December 1996.

${ }^{3}$ The SOW specifies, "At a minimum, the following WAPS requirements shall be addressed: 1.1.1 (Chemical Composition Projections), 1.3.1 (Product Consistency Acceptance Criterion), 1.4.1 (Phase Stability Information including Tg and Full TTT diagram) and 1.5 (Hazardous Waste Specification)." SOW, p.6. The SOW has performance requirements beyond the letter of the WAPS, such as UTS compliance and development of a full-scale AVS flow sheet. These other requirements are discussed elsewhere in the report. Pursuant to DOE instructions, this section deals only with WAPS compliance. 
with the WAPS criteria, the experimental results have been correlated with the above cited WAPS criterion. This section correlates the results with WAPS compliance.

\section{Scope}

The Statement of Work limits the WAPS compliance review to the experimental results produced on the laboratory and bench-scale equipments described in the report. ${ }^{-}$More specifically, it does not include WAPS compliance with respect to the extrapolation of the results ${ }^{5}$ to the full-scale AVS process. This is appropriate because the extrapolated results depend on full-scale design specific information, which have been projected, but not verified to the rigors required for such a review.

\section{Compliance}

WAPS Section 1.1.1 Chemical Composition Projections

"In the WQR, the Producer shall project the chemical composition, identify crystalline phases expected to be present, and project the amount of each crystalline phase, for each waste type."

\section{a. Borosilicate Glass (WAPS 1.1) \\ "The waste form is borosilicate waste glass."}

ASTM C162 defines a borosilicate glass as any silicate glass having at least 5-wt\% boron. Bench-Scale 4 glass had a percentage of measured boron content by weight equaling $5.5 \pm 0.2 \mathrm{wt} \%$.

\section{b. Identification and Amount of Crystalline Phases (WAPS 1.1.1) "The Producer shall... identify crystalline phases expected to be present, and project the amount of each crystalline phase”}

The crystalline phases present in the bench-scale product were investigated using both scanning electron microscopy (SEM) and quantitative $\mathrm{x}$-ray diffraction (QXRD). Both methods revealed the presence of two crystalline phases, zirconia and spinel. The figure below shows a SEM of a section from Bench-Scale 4 taken at $200 \mathrm{X}$ magnification. In this figure, the glassy areas are represented by the dark background. The rod-shaped crystals in the figure are crystals of zirconia $\left(\mathrm{ZrO}_{2}\right)$ and the remaining light areas are spinel. The crystalline phase compositions were verified by qualitative energy dispersive $\mathrm{x}$-ray analysis (EDS) of each of the regions.

The relative percentage of each phase was determined from QXRD. Individual peaks in the $\mathrm{X}$-ray diffraction pattern were matched with the appropriate Joint Committee on Powder Diffraction Files (JCPDF) peaks digitally to identify the phases. These phases

\footnotetext{
${ }^{4}$ See fn 1 for the relevant text of the SOW.

${ }^{5}$ While not an inquiry concerning WAPS compliance, it is likely that these results can be used to define pertinent fullscale design criteria such as the cooling rate of the vitrified product.
} 
were quantified by the addition of an alumina standard and the resulting pattern matched using a Rietveld analysis.

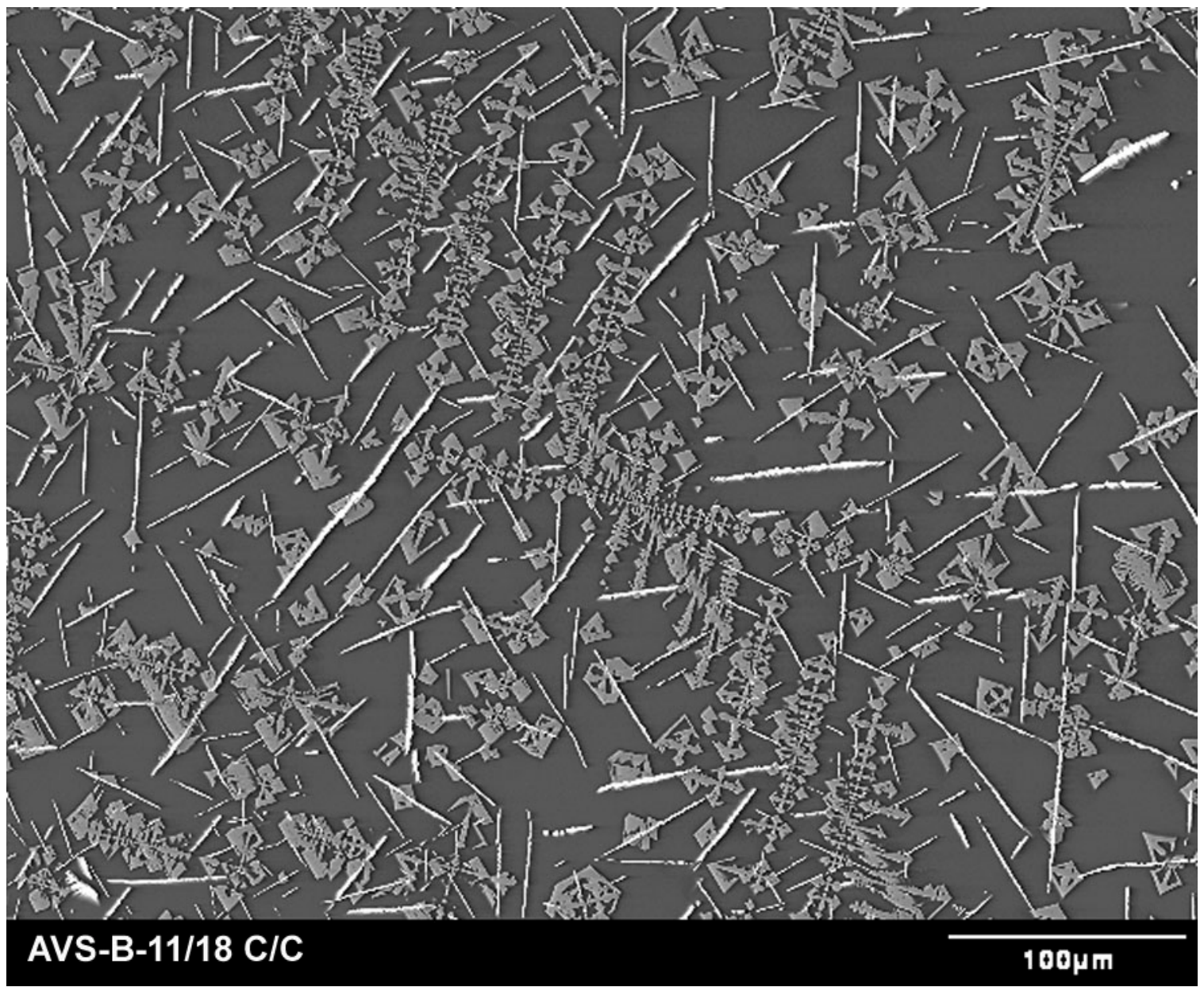

Figure 5-1. Typical Micrograph of Bottom Sample of AVS Bench-Scale 4

The table below lists the percentage of each phase obtained by this method. The average weight percentage of spinel is $10 \% \pm 2 \%$ and zirconia $4 \% \pm 1 \%$.

\section{Chemical Composition During Production (WAPS 1.1.2)}

The Producer shall report the oxide composition of the waste form. The reported composition shall include all elements, excluding oxygen, present in concentrations greater than 0.5 percent by weight of the glass, for each waste type. The Producer shall describe the method to be used for compliance in the WCP. An estimate of the error of the reported composition and the basis for the estimate shall be reported

The bench-scale waste form from AVS Bench-Scale 4 was sampled for composition in six locations (top middle (TM), top side (TS), center middle (CM), center side (CS), bottom middle (BM), bottom side (BS)). Each sample was analyzed in triplicate. For each replicate sample, three dissolution methods were used: microwave digestion $(\mathrm{mw})$, $\mathrm{NaOH} / \mathrm{Na}_{2} \mathrm{O}_{2}$ dissolution followed by nitric acid uptake (fn); $\mathrm{NaOH} / \mathrm{Na}_{2} \mathrm{O}_{2}$ dissolution 
followed by hydrochloric acid uptake ( $\mathrm{fcl}$ ). The resulting solutions were analyzed along with matrix-matched blanks and standards. All cation concentrations (except Cs) were determined using a Perkin Elmer 4300 DVP ICP spectrometer. Cs concentration was determined using by atomic absorption spectroscopy and anions $\left(\mathrm{Cl}^{-}\right.$and $\left.\mathrm{F}^{-}\right)$using ion chromatography. Because of analytical considerations such as high solution blanks, not every dissolution method can be used to determine each element's concentration. The appropriate dissolution method for each element is given below:

$$
\begin{aligned}
& \text { mw - K, Mn, Na, P, Sb, and Zr } \\
& \text { fcl - Al, As, B, B, Ca, Ce, Cr, Fe, K, La, Mg, Mn, P, Pb, S, Sb, Si, Sr, Te, } \\
& \quad \text { Ti, and Zr } \\
& \text { fn- Al, As, B, Ba, Ca, Ce, Cr, Cs, Fe, K, La, Mg, Pb, S, Si, Sr, Te, and Ti }
\end{aligned}
$$

Once the analytical data is obtained, the replicate concentrations are averaged and the standard deviation of the samples obtained. Where elements are listed under multiple dissolution methods, e.g., Al, the results for each dissolution method are averaged. The data are then converted to concentration in the glass on an oxide basis and normalized to 100-wt $\%$. The table below gives the mean elemental composition and variance for each of the six sampling locations along with the waste form average of the vitrified product based on these six samples for Bench-Scale 4. 
Section 5

Results and Discussion - WAPS Compliance

Additional Tests of an Advanced Vitrification System (DE-AC26-00NT40801)
Radioactive Isolation Consortium, LLC

Falls Church, VA 22046 www.ricllc.com

Table 5-2. Elemental Composition of Bench-Scale 4

\begin{tabular}{|c|c|c|c|c|c|c|c|}
\hline Oxide & $\begin{array}{c}\text { Sample } \\
\text { Average } \\
(w t \%)\end{array}$ & $\begin{array}{l}\text { Bottom } \\
\text { Middle } \\
\text { (wt\%) }\end{array}$ & $\begin{array}{c}\text { Bottom } \\
\text { Side } \\
(\text { wt \%) }\end{array}$ & $\begin{array}{l}\text { Center } \\
\text { Middle } \\
(w t \%)\end{array}$ & $\begin{array}{c}\text { Center } \\
\text { Side } \\
(w t \%)\end{array}$ & $\begin{array}{c}\text { Top } \\
\text { Middle } \\
\text { (wt\%) }\end{array}$ & $\begin{array}{c}\text { Top Side } \\
\text { (wt\%) }\end{array}$ \\
\hline $\mathrm{Al} 2 \mathrm{O} 3$ & $17 \pm 7 \pm 0.7$ & $17.6 \pm 0.9$ & $17.9 \pm 0.3$ & $17.9 \pm 0.3$ & $\begin{array}{c}17.77 \pm \\
0.08\end{array}$ & $17.9 \pm 0.4$ & $17.7 \pm 0.4$ \\
\hline As2O3 & $0.06 \pm 0.01$ & $0.06 \pm 0.01$ & $0.06 \pm 0.01$ & $0.06 \pm 0.01$ & $0.05 \pm 0.02$ & $0.05 \pm 0.02$ & $0.06 \pm 0.01$ \\
\hline $\mathrm{B} 2 \mathrm{O} 3$ & $5.5 \pm 0.2$ & $5.5 \pm 0.1$ & $5.5 \pm 0.2$ & $5.6 \pm 0.2$ & $5.47 \pm 0.07$ & $5.5 \pm 0.2$ & $5.48 \pm 0.01$ \\
\hline $\mathrm{BaO}$ & $0.09 \pm 0.00$ & $0.09 \pm 0.00$ & $0.09 \pm 0.00$ & $0.09 \pm 0.00$ & $0.09 \pm 0.00$ & $0.09 \pm 0.01$ & $0.09 \pm 0.00$ \\
\hline $\mathrm{CaO}$ & $0.66 \pm 0.03$ & $0.66 \pm 0.04$ & $0.67 \pm 0.02$ & $0.67 \pm 0.02$ & $0.65 \pm 0.00$ & $0.67 \pm 0.02$ & $0.65 \pm 0.01$ \\
\hline$\overline{\mathrm{CdO}}$ & $0.69 \pm 0.03$ & $0.69 \pm 0.04$ & $0.69 \pm 0.02$ & $0.70 \pm 0.03$ & $0.69 \pm 0.03$ & $0.69 \pm 0.02$ & $0.67 \pm 0.03$ \\
\hline$\overline{\mathrm{CeO} 2}$ & $0.14 \pm 0.01$ & $0.14 \pm 0.01$ & $0.14 \pm 0.00$ & $0.14 \pm 0.00$ & $0.14 \pm 0.00$ & $0.14 \pm 0.00$ & $0.14 \pm 0.00$ \\
\hline $\mathrm{Cr} 2 \mathrm{O} 3$ & $0.21 \pm .024$ & $0.22 \pm 0.02$ & $0.21 \pm 0.01$ & $0.20 \pm 0.01$ & $0.21 \pm 0.02$ & $0.22 \pm 0.01$ & $0.24 \pm 0.01$ \\
\hline $\mathrm{Cs} 2 \mathrm{O}$ & $0.14 \pm 0.01$ & $0.14 \pm 0.00$ & $0.15 \pm 0.00$ & $0.15 \pm 0.00$ & $0.14 \pm 0.00$ & $0.15 \pm 0.00$ & $0.14 \pm 0.00$ \\
\hline $\mathrm{CuO}$ & $0.07 \pm 0.02$ & $0.07 \pm 0.02$ & $0.07 \pm 0.01$ & $0.07 \pm 0.01$ & $0.08 \pm 0.02$ & $0.08 \pm 0.02$ & $0.07 \pm 0.01$ \\
\hline $\mathrm{Fe} 2 \mathrm{O} 3$ & $20.2 \pm 0.9$ & $20 \pm 1$ & $20.4 \pm 0.3$ & $19.93 \pm 0.05$ & $20.4 \pm 0.1$ & $20.4 \pm 0.5$ & $20.5 \pm 0.8$ \\
\hline $\mathrm{K} 2 \mathrm{O}$ & $0.27 \pm 0.01$ & $0.29 \pm 0.02$ & $0.27 \pm 0.01$ & $0.28 \pm 0.02$ & $0.28 \pm 0.05$ & $0.28 \pm 0.04$ & $0.27 \pm 0.06$ \\
\hline La2O3 & $0.62 \pm 0.02$ & $0.62 \pm 0.04$ & $0.62 \pm 0.00$ & $0.63 \pm 0.00$ & $0.62 \pm 0.00$ & $0.62 \pm 0.01$ & $0.61 \pm 0.02$ \\
\hline $\mathrm{MgO}$ & $0.16 \pm 0.01$ & $0.16 \pm 0.01$ & $0.16 \pm 0.00$ & $0.16 \pm 0.00$ & $0.16 \pm 0.00$ & $0.16 \pm 0.01$ & $0.16 \pm 0.00$ \\
\hline $\mathrm{MnO}$ & $5.6 \pm 0.2$ & $5.8 \pm 0.3$ & $5.5 \pm 0.3$ & $5.6 \pm 0.4$ & $5.6 \pm 0.3$ & $5.5 \pm 0.4$ & $5.6 \pm 0.1$ \\
\hline $\mathrm{Na} 2 \mathrm{O}$ & $1.04 \pm 0.02$ & $1.08 \pm 0.01$ & $1.03 \pm 0.01$ & $1.06 \pm 0.01$ & $1.05 \pm 0.01$ & $1.04 \pm 0.01$ & $1.04 \pm 0.01$ \\
\hline $\mathrm{NiO}$ & $1.02 \pm 0.06$ & $1.0 \pm 0.1$ & $1.00 \pm 0.06$ & $0.98 \pm 0.08$ & $1.02 \pm 0.05$ & $1.03 \pm 0.03$ & $1.01 \pm 0.04$ \\
\hline $\mathrm{PbO}$ & $0.32 \pm 0.01$ & $0.31 \pm 0.01$ & $0.31 \pm 0.01$ & $0.32 \pm 0.01$ & $0.31 \pm 0.00$ & $0.32 \pm 0.01$ & $0.31 \pm 0.00$ \\
\hline $\mathrm{Sb} 2 \mathrm{O} 5$ & $0.33 \pm 0.02$ & $0.34 \pm 0.02$ & $0.32 \pm 0.02$ & $0.32 \pm 0.03$ & $0.32 \pm 0.02$ & $0.32 \pm 0.02$ & $0.33 \pm 0.01$ \\
\hline $\mathrm{SeO} 2$ & bdl $^{\mathrm{a}}$ & bdl & bdl & bdl & bdl & bdl & bdl \\
\hline $\mathrm{SiO} 2$ & $31 \pm 1$ & $31 \pm 1$ & $30.9 \pm 0.8$ & $31.1 \pm 0.7$ & $\begin{array}{c}30.74 \pm \\
0.08\end{array}$ & $31 \pm 1$ & $30.7 \pm 0.4$ \\
\hline $\mathrm{SrO}$ & $4.41 \pm 0.2$ & $4.4 \pm 0.3$ & $4.43 \pm 0.03$ & $4.48 \pm 0.05$ & $4.42 \pm 0.06$ & $4.5 \pm 0.1$ & $4.4 \pm 0.1$ \\
\hline $\mathrm{TeO} 2$ & $0.17 \pm 0.01$ & $0.17 \pm 0.00$ & $0.17 \pm 0.02$ & $0.17 \pm 0.02$ & $0.17 \pm 0.02$ & $0.17 \pm 0.03$ & $0.17 \pm 0.01$ \\
\hline TiO2 & $0.17 \pm 0.01$ & $0.17 \pm 0.02$ & $0.17 \pm 0.00$ & $0.17 \pm 0.00$ & $0.17 \pm 0.01$ & $0.17 \pm 0.00$ & $0.17 \pm 0.01$ \\
\hline $\mathrm{ZnO}$ & $1.9 \pm 0.2$ & $1.9 \pm 0.2$ & $1.9 \pm 0.2$ & $1.9 \pm 0.2$ & $1.9 \pm 0.2$ & $1.9 \pm 0.2$ & $1.9 \pm 0.2$ \\
\hline $\mathrm{ZrO} 2$ & $7.2 \pm 0.1$ & $7.3 \pm 0.2$ & $6.8 \pm 0.5$ & $6.8 \pm 0.7$ & $7.0 \pm 0.5$ & $6.7 \pm 0.8$ & $6.9 \pm 0.2$ \\
\hline $\mathrm{P} 2 \mathrm{O} 5$ & $0.24 \pm 0.05$ & $0.17 \pm 0.05$ & $0.16 \pm 0.06$ & $0.19 \pm 0.08$ & $0.18 \pm 0.06$ & $0.17 \pm 0.07$ & $0.2 \pm 0.1$ \\
\hline $\mathrm{SO} 3$ & $0.39 \pm 0.03$ & $0.39 \pm 0.00$ & $0.39 \pm 0.00$ & $0.41 \pm 0.02$ & $0.39 \pm 0.00$ & $0.38 \pm 0.03$ & $0.38 \pm 0.01$ \\
\hline \begin{tabular}{|l|} 
Total \\
\end{tabular} & 100.00 & 100.00 & 100.00 & 100.00 & 100.00 & 100.00 & 100.00 \\
\hline $\begin{array}{l}\text { Waste } \\
\text { Loading } \\
{[\mathrm{M}-1]}\end{array}$ & 60.88 & & & & & & \\
\hline $\begin{array}{l}\text { Waste } \\
\text { Loading } \\
{[\mathrm{M}-2]}\end{array}$ & 62.48 & & & & & & \\
\hline
\end{tabular}

${ }^{\mathrm{a}}$ Below detection limit. 
Using the data given in the table above, the waste loading was calculated using two methods:

- Method-1 (M-1): Waste loading (wt\%) $=[$ (mass of the glass $)-(($ mass of glass formers added $)+($ mass of sodium oxide in the waste, expressed as $\mathrm{Na} 2 \mathrm{O})+$ (mass of silicon in the waste, expressed as $\mathrm{SiO} 2)$ )]/ (mass of the glass).

- Method-2 (M-2): Waste loading (wt $\%)=[$ (mass of the glass $)-($ mass of glass formers added) $] /$ (mass of the glass).

\begin{tabular}{|l|c|c|}
\hline & $\begin{array}{c}\text { M-1 } \\
\text { wt\% }\end{array}$ & $\begin{array}{c}\text { M-2 } \\
\text { wt\% }\end{array}$ \\
\hline Bench-Scale 4 Waste Loading & 60.9 & 62.5 \\
\hline
\end{tabular}

M-1 yields a lower waste loading of the two methods described. M-1 does not allow glass-forming chemicals to be considered when calculating waste loading percentages. Excluded are $\mathrm{SiO}_{2}$ and $\mathrm{Na}_{2} \mathrm{O}$ added during feed preparation or which may be present in the waste simulant prior to feed preparation.

M-2 allows all original constituents of the waste simulant to be considered part of the waste loading. Only those chemicals added to the waste simulant to facilitate vitrification are not included in the waste loading. While yielding a higher waste loading value than M-1, M-2 may provide a more accurate gauge as to the quantity and speed of waste removal from the storage tanks.

This M-1 value for the AZ-101 simulant waste loading is close to the $60-\mathrm{wt} \%$ [M-1] target for the vitrification. Thus, the bench-scale process produces a product with relatively uniform composition and a predictable waste loading.

\section{WAPS Section 1.3 Specification for Product Consistency}

"The Producer shall demonstrate control of waste form production by comparing, either directly or indirectly, production samples to the Environmental Assessment (EA)1 benchmark glass... The consistency of the waste form shall be demonstrated using the Product Consistency Test (PCT). For acceptance, the mean concentrations of lithium, sodium and boron in the leachate, after normalizing for the concentrations in the glass, shall each be less than those of the benchmark glass described in the Environmental Assessment for selection of the DWPF waste form [4]. The measured or projected mean PCT results for lithium, sodium and boron shall be provided...The Producer shall define the statistical significance of the reported data ... One acceptable method of demonstrating that the acceptance criterion is met, would be to ensure that the mean PCT results for each waste type are at least two standard deviations below the mean PCT results of the EA glass". 
The Product Consistency Test (PCT) was run on samples from Bench-Scale 4. The product glasses were sampled in six locations (top middle (TM), top side (TS), center middle $(\mathrm{CM})$, center side $(\mathrm{CS})$, bottom middle (BM), bottom side (BS). Three replicates were taken at each location. The results of the PCT tests are given in the table below.

Table 5-3. Results of PCT Testing on Bench-Scale 4 Vitrified Product

\begin{tabular}{|c|c|l|l|l|l|l|l|c||}
\hline Element & $\begin{array}{c}\text { SRL- } \\
\text { EA }\end{array}$ & $\begin{array}{l}\text { Top } \\
\text { Side }\end{array}$ & $\begin{array}{l}\text { Top } \\
\text { Center }\end{array}$ & $\begin{array}{l}\text { Middle } \\
\text { Side }\end{array}$ & $\begin{array}{l}\text { Middle } \\
\text { Center }\end{array}$ & $\begin{array}{l}\text { Bottom } \\
\text { Side }\end{array}$ & $\begin{array}{l}\text { Bottom } \\
\text { Center }\end{array}$ & $\begin{array}{l}\text { Bench- } \\
\text { Scale 4 } \\
\text { Average }\end{array}$ \\
\hline 7-day PCT & Cormalized Concentration (g/L) \\
\hline $\mathrm{B}$ & 15.15 & 0.10 & 0.10 & .09 & 0.10 & 0.10 & 0.10 & 0.10 \\
\hline $\mathrm{Li}$ & 8.37 & bdl & bdl & bdl & bdl & bdl & bdl & NA \\
\hline $\mathrm{Na}^{*}$ & 10.68 & 0.53 & 0.27 & 0.27 & 0.31 & 0.26 & 0.26 & 0.32 \\
\hline $\mathrm{Si}$ & 3.36 & 0.08 & 0.09 & 0.08 & 0.09 & 0.08 & 0.08 & 0.08 \\
\hline $\begin{array}{l}\mathrm{pH} \text { after 7 } \\
\text { days }\end{array}$ & 11.57 & 7.64 & 7.57 & 7.55 & 7.59 & 7.57 & 7.59 & 7.59 \\
\hline
\end{tabular}

* Na data were adjusted to account for filter contamination

It can be seen from this table that for all samples the mean PCT results for each element are at least two standard deviations below the mean PCT results for the EA glass. As a consistency check a sample of the EA glass was run with each PCT sample and the results obtained were statistically the same as the published values for the SRL-EA class listed in the above table.

In order to assess the effect of variations in the waste loading on PCT performance, laboratory-scale data may be compared with the bench-scale results. Large crucible PCT data were obtained with a range of waste loadings $\pm 5 \mathrm{wt} \%$ on either side of the nominal $60 \mathrm{wt} \%$ loading. The PCT releases from laboratory-scale samples are given in table below.

Table 5-4. PCT Releases from Laboratory-Scale Samples

\begin{tabular}{|c|c|c|c|c|c||}
\hline \multirow{2}{*}{ Element } & \multirow{2}{*}{ SRL EA } & \multicolumn{5}{|c|}{$\begin{array}{c}\text { Measured Waste Loading } \\
\text { (Wt\% [M-1]) }\end{array}$} \\
\cline { 3 - 6 } & & 56 & 59 & 61 & 64 \\
\hline $\mathrm{B}$ & 7-day PCT Normalized Concentration (ppm) \\
\hline $\mathrm{Li}$ & 15.15 & 0.11 & 0.12 & 0.12 & 0.13 \\
\hline $\mathrm{Na}$ & 8.37 & bdl & bdl & bdl & bdl \\
\hline $\mathrm{Si}$ & 10.68 & 0.21 & 0.25 & 0.22 & 0.18 \\
\hline $\mathrm{pH}$ after 7 days & 3.36 & 0.07 & 0.08 & 0.08 & 0.09 \\
\hline \hline
\end{tabular}

These results indicate that, over the range of compositions studied, PCT performance is acceptable as defined above. 


\section{WAPS Section 1.4 Specification for Phase Stability}

(a) $\mathrm{Tg}$

"The Producer shall provide the following data for each projected waste type: The glass transition temperature;”

The glass transition temperature Tg was measured for the Bench-Scale 4 glass. The product glasses were sampled at three locations (top, center and bottom). The Tg was obtained from a DTA scan of the sample and are given in the table below.

Table 5-5. Glass Transition Temperature (Tg) for Bench-Scale Vitrified Product

\begin{tabular}{|l|c|c||}
\hline \multirow{2}{*}{ Location } & \multicolumn{2}{|c|}{ Bench-Scale 4 } \\
\cline { 2 - 3 } & Center & Side \\
& $\begin{array}{c}\text { Tg } \\
\left({ }^{\circ} \mathbf{C}\right)\end{array}$ & $\left({ }^{\circ} \mathbf{C}\right)$ \\
\hline Top & 670 & 660 \\
\hline Middle & 646 & 652 \\
\hline Bottom & 664 & 655 \\
\hline Average & \multicolumn{2}{|c|}{} \\
\hline
\end{tabular}

The table shows that the $\mathrm{Tg}$ results are uniform throughout the glass to within $10^{\circ} \mathrm{C}$. It is estimated that the accuracy of these measurements is $\pm 5^{\circ} \mathrm{C}$.

(b) TTT

"The Producer shall provide the following data for each projected waste type:...A timetemperature-transformation (TTT) diagram that identifies the duration of exposure at any temperature that causes significant changes in either the phase structure or the phase compositions."

Following on the next four pages are a ---

- TTT Diagram for Nominal 60-Wt\% [M-1] Vitrified AZ-101 Simulant (Figure 5-2);

- Diagram of Crystalline Phases Identified in TTT Experiments (Figure 5-3);

- TTT PCT Data for B, Li, Na and Si (Table 5-6); and,

- TCLP Results for TTT Samples (Table 5-7).

\section{TTT Diagram}

The TTT diagram was developed based on a series of quasi-isothermal annealing experiments using AZ-101 simulant vitrified at a nominal waste loading of $60-\mathrm{wt} \%$ [M-1].

The time-temperature regime studied was bracketed by the liquidus temperature $\left(\sim 1350^{\circ} \mathrm{C}\right.$, the highest temperature at which crystals can coexist with the glass at equilibrium) at the high end, and by a temperature below the glass transition temperature, $\mathrm{Tg},\left(658^{\circ} \mathrm{C} \pm 9^{\circ} \mathrm{C}\right)$ on the low end. 
In particular, six temperatures $\left(1200^{\circ} \mathrm{C}, 1060^{\circ} \mathrm{C}, 920^{\circ} \mathrm{C}, 780^{\circ} \mathrm{C}, 640^{\circ} \mathrm{C}\right.$, and $500^{\circ} \mathrm{C}$ were selected for six times $(0.75,12,48,192$ and 768 hours). Crystallinity as well as PCT and TCLP performance was obtained at each of these temperature/time intervals. In addition, limited TTT data was obtained for samples held at $1340^{\circ} \mathrm{C}$ and $1300^{\circ} \mathrm{C}$.

\section{Crystalline Phases}

In all, five separate crystalline phases were identified: $\mathrm{ZrSiO}_{2}$, monoclinic $\mathrm{ZrO}_{2}$, tetragonal $\mathrm{ZrO}_{2}, \mathrm{Fe}_{3} \mathrm{O}_{4}$, trace- $\mathrm{Fe}_{3} \mathrm{O}_{4}$, and Fe-spinel with $\mathrm{Mn}, \mathrm{MnAl}_{2} \mathrm{O}_{4}$. Not all phases were found in all samples. Figure 5.2 gives the distribution of phases found.

Using a Rietveld analysis, the percentage of each phase and the total crystallinity in each sample was determined. Based upon these data a TTT-diagram was constructed as shown in Figure 5.3. Figure 5.3 depicts four isopleths: trace-5\%, 5-10\%, 10-20\% and $>20 \%$. In addition, regions where the in-growth of the various dominate crystalline phases are also shown. PCT performance of all samples was acceptable.

\section{TTT Sample PCT}

The PCT results are given in Table 5-6 and may be compared with the SRL-EA glass results given in Table 5-3. For all samples, the mean PCT results are at least 1 to 2 orders of magnitude below the mean PCT results for the EA glass. Thus, the result for each element is "at least two standard deviations below the mean PCT results of the EA glass."

\section{TTT Sample TCLP}

The TCLP results are given in Table 5-7. It is not required that the thermally annealed samples pass any TCLP criteria. However, the data do indicate that keeping the vitrified product at elevated temperatures for long times may result in changes in the release characteristics of the glass. 


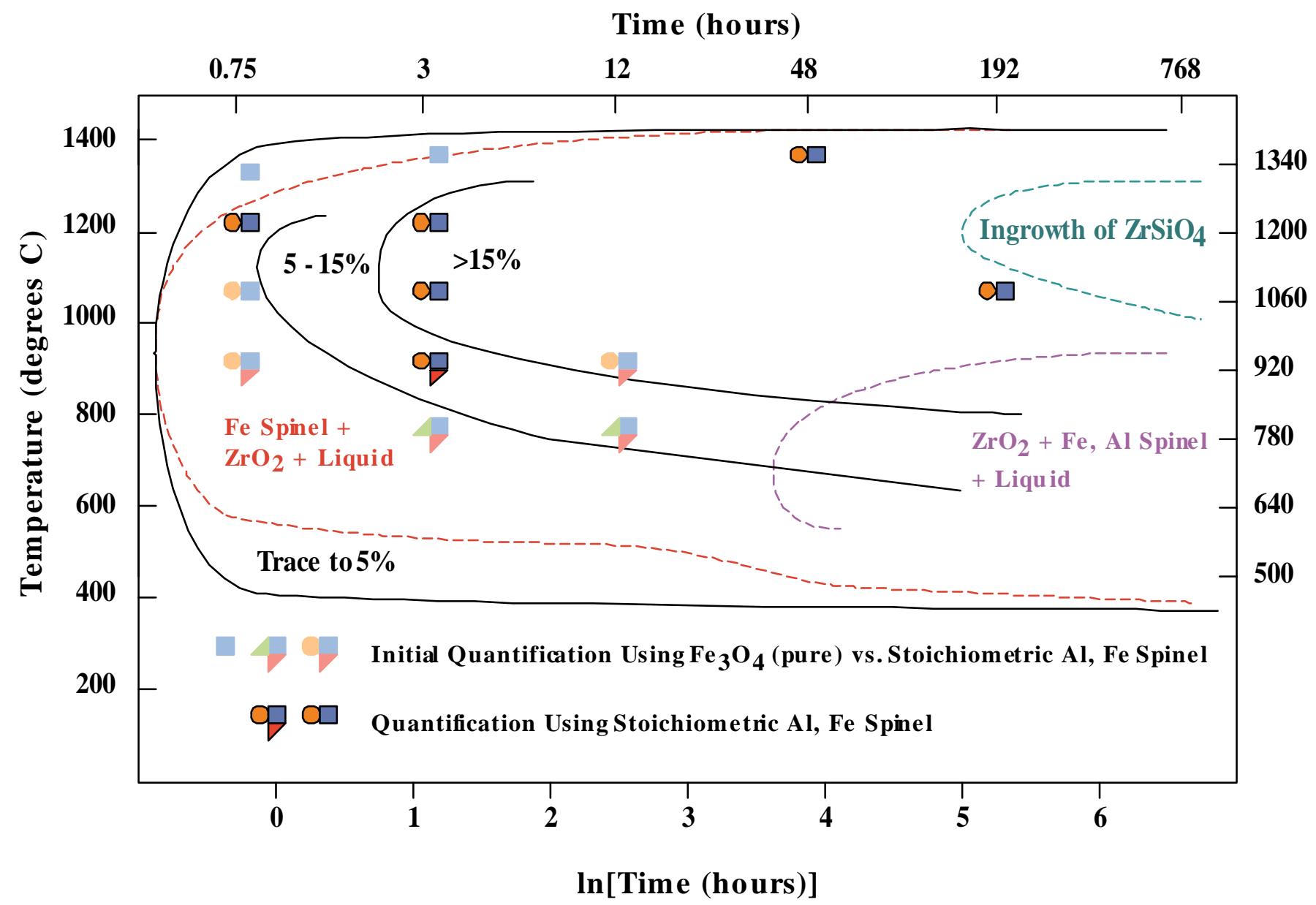

Figure 5-2. TTT Diagram for Nominal 60-Wt\% [M-1] Vitrified AZ-101-Simulant 


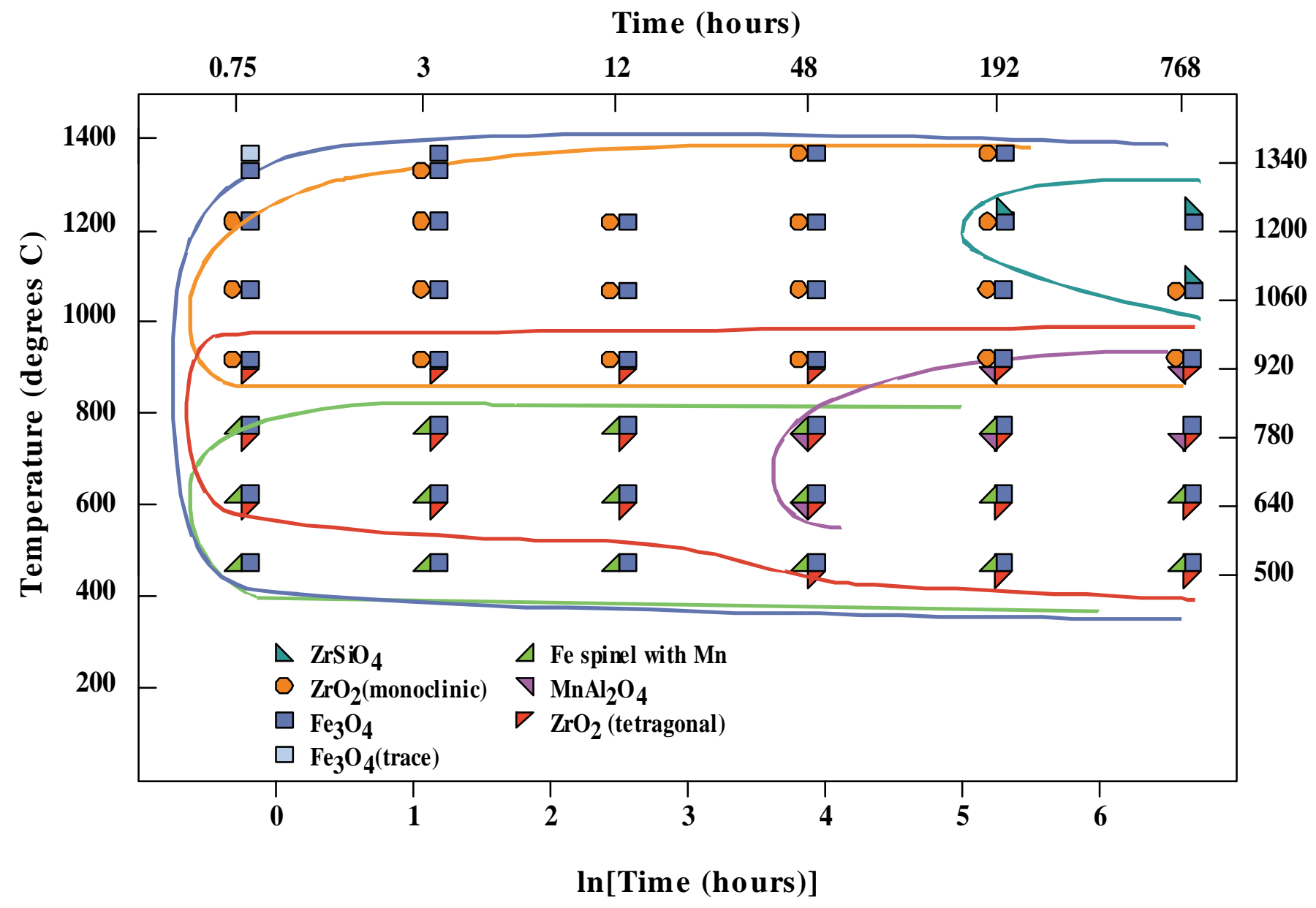

Figure 5-3. Crystalline Phases Identified in TTT Experiments 
Table 5-6. TTT PCT Data for B, Li, Na and Si

\begin{tabular}{|c|c|c|c|c|c|c|}
\hline Temperature & \multicolumn{6}{|c|}{ Concentration (mg/l) } \\
\hline $1200^{\circ} \mathrm{C}$ & $\begin{array}{lr}\text { B } & 0.11 \\
\mathrm{Li} & \text { bdl } \\
\mathrm{Na} & 0.11 \\
\mathrm{Si} & 0.08 \\
\end{array}$ & $\begin{array}{ll}\text { B } & 0.10 \\
\mathrm{Li} & \text { bdl } \\
\mathrm{Na} & 0.14 \\
\mathrm{Si} & 0.08 \\
\end{array}$ & $\begin{array}{cr}\text { B } & 0.12 \\
\text { Li } & \text { bdl } \\
\mathrm{Na} & 0.23 \\
\mathrm{Si} & 0.08 \\
\end{array}$ & $\begin{array}{cr}\text { B } & 0.12 \\
\text { Li } & \text { bdl } \\
\mathrm{Na} & 0.23 \\
\mathrm{Si} & 0.08 \\
\end{array}$ & $\begin{array}{cr}\text { B } & 0.11 \\
\text { Li } & \text { bdl } \\
\text { Na } & 0.18 \\
\text { Si } & 0.07 \\
\end{array}$ & $\begin{array}{cr}\text { B } & 0.11 \\
\mathrm{Li} & \text { bdl } \\
\mathrm{Na} & 0.14 \\
\mathrm{Si} & 0.07 \\
\end{array}$ \\
\hline $1060^{\circ} \mathrm{C}$ & $\begin{array}{cr}\text { B } & 0.11 \\
\text { Li } & \text { bdl } \\
\text { Na } & 0.12 \\
\text { Si } & 0.08 \\
\end{array}$ & $\begin{array}{lr}\text { B } & 0.10 \\
\text { Li } & \text { bdl } \\
\mathrm{Na} & 0.11 \\
\mathrm{Si} & 0.08 \\
\end{array}$ & $\begin{array}{cr}\text { B } & 0.11 \\
\text { Li } & \text { bdl } \\
\text { Na } & 0.17 \\
\text { Si } & 0.07\end{array}$ & $\begin{array}{cr}\text { B } & 0.11 \\
\text { Li } & \text { bdl } \\
\text { Na } & 0.21 \\
\text { Si } & 0.09 \\
\end{array}$ & $\begin{array}{cr}\text { B } & 0.11 \\
\text { Li } & \text { bdl } \\
\text { Na } & 0.18 \\
\text { Si } & 0.08 \\
\end{array}$ & $\begin{array}{cr}\text { B } & 0.09 \\
\text { Li } & \text { bdl } \\
\mathrm{Na} & 0.31 \\
\text { Si } & 0.09 \\
\end{array}$ \\
\hline $920^{\circ} \mathrm{C}$ & $\begin{array}{cr}\text { B } & 0.11 \\
\text { Li } & \text { bdl } \\
\text { Na } & 0.14 \\
\text { Si } & 0.09\end{array}$ & $\begin{array}{cr}\text { B } & 0.09 \\
\text { Li } & \text { bdl } \\
\text { Na } & 0.13 \\
\text { Si } & 0.09\end{array}$ & $\begin{array}{cr}\text { B } & 0.11 \\
\text { Li } & \text { bdl } \\
\text { Na } & 0.17 \\
\text { Si } & 0.08\end{array}$ & $\begin{array}{cr}\text { B } & 0.11 \\
\text { Li } & \text { bdl } \\
\text { Na } & 0.15 \\
\text { Si } & 0.09\end{array}$ & $\begin{array}{cr}\text { B } & 0.11 \\
\text { Li } & \text { bdl } \\
\text { Na } & 0.19 \\
\text { Si } & 0.09\end{array}$ & $\begin{array}{cr}\text { B } & 0.15 \\
\mathrm{Li} & \text { bdl } \\
\mathrm{Na} & 0.04 \\
\mathrm{Si} & 0.11\end{array}$ \\
\hline $780^{\circ} \mathrm{C}$ & $\begin{array}{cr}\text { B } & 0.11 \\
\text { Li } & \text { bdl } \\
\mathrm{Na} & 0.15 \\
\mathrm{Si} & 0.09 \\
\end{array}$ & $\begin{array}{lr}\text { B } & 0.10 \\
\text { Li } & \text { bdl } \\
\mathrm{Na} & 0.13 \\
\text { Si } & 0.09 \\
\end{array}$ & $\begin{array}{cr}\text { B } & 0.12 \\
\text { Li } & \text { bdl } \\
\mathrm{Na} & 0.21 \\
\text { Si } & 0.08 \\
\end{array}$ & $\begin{array}{cr}\text { B } & 0.12 \\
\mathrm{Li} & \text { bdl } \\
\mathrm{Na} & 0.22 \\
\mathrm{Si} & 0.08 \\
\end{array}$ & $\begin{array}{cr}\text { B } & 0.12 \\
\text { Li } & \text { bdl } \\
\mathrm{Na} & 0.24 \\
\text { Si } & 0.09 \\
\end{array}$ & $\begin{array}{cr}\text { B } & 0.10 \\
\text { Li } & \text { bdl } \\
\text { Na } & 0.09 \\
\text { Si } & 0.09 \\
\end{array}$ \\
\hline $640^{\circ} \mathrm{C}$ & $\begin{array}{cr}\text { B } & 0.09 \\
\text { Li } & \text { bdl } \\
\text { Na } & 0.16 \\
\text { Si } & 0.08\end{array}$ & $\begin{array}{cr}\text { B } & 0.11 \\
\text { Li } & \text { bdl } \\
\text { Na } & 0.16 \\
\text { Si } & 0.08\end{array}$ & $\begin{array}{cr}\text { B } & 0.10 \\
\text { Li } & \text { bdl } \\
\text { Na } & 0.17 \\
\text { Si } & 0.08\end{array}$ & $\begin{array}{cr}\text { B } & 0.10 \\
\text { Li } & \text { bdl } \\
\text { Na } & 0.17 \\
\text { Si } & 0.08\end{array}$ & $\begin{array}{cr}\text { B } & 0.11 \\
\text { Li } & \text { bdl } \\
\text { Na } & 0.21 \\
\text { Si } & 0.08\end{array}$ & $\begin{array}{cr}\text { B } & 0.10 \\
\text { Li } & \text { bdl } \\
\mathrm{Na} & 0.19 \\
\mathrm{Si} & 0.09\end{array}$ \\
\hline $500^{\circ} \mathrm{C}$ & $\begin{array}{cr}\text { B } & 0.10 \\
\text { Li } & \text { bdl } \\
\mathrm{Na} & 0.17 \\
\text { Si } & 0.08\end{array}$ & $\begin{array}{cr}\text { B } & 0.11 \\
\text { Li } & \text { bdl } \\
\mathrm{Na} & 0.18 \\
\mathrm{Si} & 0.08\end{array}$ & $\begin{array}{cr}\text { B } & 0.11 \\
\text { Li } & \text { bdl } \\
\mathrm{Na} & 0.19 \\
\text { Si } & 0.08\end{array}$ & $\begin{array}{cr}\text { B } & 0.11 \\
\text { Li } & \text { bdl } \\
\mathrm{Na} & 0.20 \\
\text { Si } & 0.08\end{array}$ & $\begin{array}{cr}\text { B } & 0.10 \\
\text { Li } & \text { bdl } \\
\mathrm{Na} & 0.22 \\
\text { Si } & 0.08\end{array}$ & $\begin{array}{cr}\text { B } & 0.09 \\
\mathrm{Li} & \text { bdl } \\
\mathrm{Na} & 0.10 \\
\mathrm{Si} & 0.08\end{array}$ \\
\hline Time (hrs) & 0.75 & 3 & 12 & 48 & 192 & 768 \\
\hline
\end{tabular}


Table 5-7. TCLP Results for TTT Samples

\begin{tabular}{|c|c|c|c|c|c|c|c|c|c|c|c|c|}
\hline Temperature & \multicolumn{12}{|c|}{ Table 4.4.2.3.1. TTT TCLP Data (mg/l) } \\
\hline $1200^{\circ} \mathrm{C}$ & $\begin{array}{ll}\text { As } & 0.01 \\
\mathrm{Ba} & 0.16 \\
\mathrm{Cd} & 0.13 \\
\mathrm{Cr} & 0.00 \\
\mathrm{Ni} & 0.04\end{array}$ & $\begin{array}{lr}\mathrm{Pb} & 0.06 \\
\mathrm{Sb} & 0.02 \\
\mathrm{Se} & \text { bdl } \\
\mathrm{Zn} & 0.30\end{array}$ & $\begin{array}{ll}\text { As } & 0.02 \\
\mathrm{Ba} & \text { bdl } \\
\mathrm{Cd} & 0.17 \\
\mathrm{Cr} & 0.00 \\
\mathrm{Ni} & 0.04\end{array}$ & $\begin{array}{lr}\mathrm{Pb} & 0.08 \\
\mathrm{Sb} & 0.02 \\
\mathrm{Se} & \text { bdl } \\
\mathrm{Zn} & 0.17\end{array}$ & $\begin{array}{ll}\text { As } & 0.03 \\
\mathrm{Ba} & 0.09 \\
\mathrm{Cd} & 0.20 \\
\mathrm{Cr} & 0.00 \\
\mathrm{Ni} & 0.04\end{array}$ & $\begin{array}{ll}\mathrm{Pb} & 0.08 \\
\mathrm{Sb} & 0.02 \\
\mathrm{Se} & 0.01 \\
\mathrm{Zn} & 0.30\end{array}$ & $\begin{array}{l}\text { As } 0.024 \\
\text { Ba } \\
0.041 \\
\text { Cd } 0.22 \\
\text { Cr } 0.001 \\
\text { Ni } \quad 0.030\end{array}$ & $\begin{array}{ll}\mathrm{Pb} & 0.07 \\
\mathrm{Sb} & 0.02 \\
\mathrm{Se} & 0.01 \\
\mathrm{Zn} & 0.29\end{array}$ & $\begin{array}{ll}\text { As } & 0.02 \\
\mathrm{Ba} & 0.08 \\
\mathrm{Cd} & 0.16 \\
\mathrm{Cr} & 0.00 \\
\mathrm{Ni} & 0.03\end{array}$ & $\begin{array}{ll}\mathrm{Pb} & 0.08 \\
\mathrm{Sb} & 0.02 \\
\mathrm{Se} & 0.01 \\
\mathrm{Zn} & 0.25\end{array}$ & $\begin{array}{ll}\text { As } & 0.01 \\
\mathrm{Ba} & 0.02 \\
\mathrm{Cd} & 0.13 \\
\mathrm{Cr} & 0.00 \\
\mathrm{Ni} & 0.02\end{array}$ & $\begin{array}{ll}\mathrm{Pb} & 0.06 \\
\mathrm{Sb} & 0.02 \\
\mathrm{Se} & \text { bdl } \\
\mathrm{Zn} & 0.16\end{array}$ \\
\hline $1060^{\circ} \mathrm{C}$ & $\begin{array}{ll}\text { As } & 0.01 \\
\text { Ba } & 0.18 \\
\text { Cd } & 0.10 \\
\text { Cr } & 0.00 \\
\text { Ni } & 0.03\end{array}$ & $\begin{array}{lr}\mathrm{Pb} & 0.05 \\
\mathrm{Sb} & 0.02 \\
\mathrm{Se} & \text { bdl } \\
\mathrm{Zn} & 0.21\end{array}$ & $\begin{array}{ll}\text { As } & 0.01 \\
\text { Ba } & 0.01 \\
\text { Cd } & 0.13 \\
\text { Cr } & 0.00 \\
\text { Ni } & 0.04\end{array}$ & $\begin{array}{lr}\mathrm{Pb} & 0.06 \\
\mathrm{Sb} & 0.02 \\
\mathrm{Se} & \text { bdl } \\
\mathrm{Zn} & 0.12\end{array}$ & $\begin{array}{ll}\text { As } & 0.01 \\
\text { Ba } & \text { bdl } \\
\text { Cd } & 0.12 \\
\text { Cr } & 0.00 \\
\text { Ni } & 0.03\end{array}$ & $\begin{array}{l}\mathrm{Pb} \quad 0.06 \\
\mathrm{Sb} \\
0.020 \\
\mathrm{Se} \text { bdl } \\
\mathrm{Zn} \quad 0.13\end{array}$ & $\begin{array}{l}\text { As } 0.019 \\
\mathrm{Ba} \\
0.009 \\
\mathrm{Cd} 0.11 \\
\mathrm{Cr} \quad 0.00 \\
\mathrm{Ni} \quad 0.03\end{array}$ & $\begin{array}{ll}\mathrm{Pb} & 0.06 \\
\mathrm{Sb} & 0.02 \\
\mathrm{Se} & 0.01 \\
\mathrm{Zn} & 0.13\end{array}$ & $\begin{array}{ll}\text { As } & 0.02 \\
\mathrm{Ba} & 0.03 \\
\mathrm{Cd} & 0.13 \\
\mathrm{Cr} & 0.00 \\
\mathrm{Ni} & 0.03\end{array}$ & $\begin{array}{ll}\mathrm{Pb} & 0.06 \\
\mathrm{Sb} & 0.02 \\
\mathrm{Se} & 0.01 \\
\mathrm{Zn} & 0.14\end{array}$ & $\begin{array}{ll}\text { As } & 0.01 \\
\mathrm{Ba} & 0.02 \\
\mathrm{Cd} & 0.14 \\
\mathrm{Cr} & 0.00 \\
\mathrm{Ni} & 0.03\end{array}$ & $\begin{array}{ll}\mathrm{Pb} & 0.07 \\
\mathrm{Sb} & 0.02 \\
\mathrm{Se} & \text { bdl } \\
\mathrm{Zn} & 0.13\end{array}$ \\
\hline $920^{\circ} \mathrm{C}$ & $\begin{array}{cc}\text { As } & 0.01 \\
\text { Ba } & 0.20 \\
\text { Cd } & 0.08 \\
\text { Cr } & 0.00 \\
\text { Ni } & 0.02 \\
\end{array}$ & $\begin{array}{lr}\mathrm{Pb} & 0.04 \\
\mathrm{Sb} & 0.02 \\
\mathrm{Se} & \text { bdl } \\
\mathrm{Zn} & 0.18\end{array}$ & $\begin{array}{ll}\text { As } & 0.01 \\
\text { Ba } & \text { bdl } \\
\text { Cd } & 0.11 \\
\text { Cr } & 0.00 \\
\text { Ni } & 0.03 \\
\end{array}$ & $\begin{array}{lr}\mathrm{Pb} & 0.05 \\
\mathrm{Sb} & 0.02 \\
\mathrm{Se} & \text { bdl } \\
\mathrm{Zn} & 0.08\end{array}$ & $\begin{array}{ll}\text { As } & 0.02 \\
\mathrm{Ba} & \text { bdl } \\
\mathrm{Cd} & 0.10 \\
\mathrm{Cr} & 0.00 \\
\mathrm{Ni} & 0.03 \\
\end{array}$ & $\begin{array}{ll}\mathrm{Pb} & 0.05 \\
\mathrm{Sb} & 0.02 \\
\mathrm{Se} & 0.01 \\
\mathrm{Zn} & 0.08\end{array}$ & $\begin{array}{ll}\text { As } & 0.01 \\
\text { Ba } & 0.02 \\
\text { Cd } & 0.15 \\
\text { Cr } & 0.00 \\
\text { Ni } & 0.03 \\
\end{array}$ & $\begin{array}{ll}\mathrm{Pb} & 0.06 \\
\mathrm{Sb} & 0.02 \\
\mathrm{Se} & \text { bdl } \\
\mathrm{Zn} & 0.12\end{array}$ & $\begin{array}{cc}\text { As } & 0.01 \\
\mathrm{Ba} & \text { bdl } \\
\mathrm{Cd} & 0.11 \\
\mathrm{Cr} & 0.00 \\
\mathrm{Ni} & 0.03 \\
\end{array}$ & $\begin{array}{ll}\mathrm{Pb} & 0.05 \\
\mathrm{Sb} & 0.02 \\
\mathrm{Se} & \text { bdl } \\
\mathrm{Zn} & 0.06\end{array}$ & $\begin{array}{ll}\text { As } & 0.01 \\
\mathrm{Ba} & 0.02 \\
\mathrm{Cd} & 0.18 \\
\mathrm{Cr} & 0.00 \\
\mathrm{Ni} & 0.03 \\
\end{array}$ & $\begin{array}{ll}\mathrm{Pb} & 0.13 \\
\text { Sb } & 0.02 \\
\text { Se } & \text { bdl } \\
\text { Zn } & 0.06\end{array}$ \\
\hline $780^{\circ} \mathrm{C}$ & $\begin{array}{cc}\text { As } & 0.01 \\
\mathrm{Ba} & 0.13 \\
\mathrm{Cd} & 0.09 \\
\mathrm{Cr} & 0.00 \\
\mathrm{Ni} & 0.02 \\
\end{array}$ & $\begin{array}{lr}\mathrm{Pb} & 0.04 \\
\mathrm{Sb} & 0.02 \\
\mathrm{Se} & \text { bdl } \\
\mathrm{Zn} & 0.16\end{array}$ & $\begin{array}{ll}\text { As } & 0.01 \\
\mathrm{Ba} & \text { bdl } \\
\mathrm{Cd} & 0.08 \\
\mathrm{Cr} & 0.00 \\
\mathrm{Ni} & 0.02 \\
\end{array}$ & $\begin{array}{lr}\mathrm{Pb} & 0.04 \\
\mathrm{Sb} & 0.02 \\
\mathrm{Se} & \text { bdl } \\
\mathrm{Zn} & 0.03\end{array}$ & $\begin{array}{ll}\text { As } & 0.01 \\
\mathrm{Ba} & 0.01 \\
\mathrm{Cd} & 0.10 \\
\mathrm{Cr} & 0.00 \\
\mathrm{Ni} & 0.02 \\
\end{array}$ & $\begin{array}{lr}\mathrm{Pb} & 0.06 \\
\mathrm{Sb} & 0.02 \\
\mathrm{Se} & \text { bdl } \\
\mathrm{Zn} & 0.06\end{array}$ & $\begin{array}{ll}\text { As } & 0.01 \\
\text { Ba } & \text { bdl } \\
\text { Cd } & 0.13 \\
\text { Cr } & 0.00 \\
\mathrm{Ni} & 0.02 \\
\end{array}$ & $\begin{array}{ll}\mathrm{Pb} & 0.09 \\
\mathrm{Sb} & 0.02 \\
\mathrm{Se} & \text { bdl } \\
\mathrm{Zn} & \text { bdl }\end{array}$ & $\begin{array}{ll}\text { As } & 0.02 \\
\mathrm{Ba} & 0.04 \\
\mathrm{Cd} & 0.13 \\
\mathrm{Cr} & 0.00 \\
\mathrm{Ni} & 0.02 \\
\end{array}$ & $\begin{array}{ll}\mathrm{Pb} & 0.09 \\
\mathrm{Sb} & 0.02 \\
\mathrm{Se} & 0.01 \\
\mathrm{Zn} & 0.08\end{array}$ & $\begin{array}{ll}\text { As } & 0.01 \\
\mathrm{Ba} & 0.02 \\
\mathrm{Cd} & 0.10 \\
\mathrm{Cr} & 0.00 \\
\mathrm{Ni} & 0.02 \\
\end{array}$ & $\begin{array}{ll}\mathrm{Pb} & 0.05 \\
\mathrm{Sb} & 0.02 \\
\mathrm{Se} & \text { bdl } \\
\mathrm{Zn} & 0.07\end{array}$ \\
\hline $640^{\circ} \mathrm{C}$ & $\begin{array}{ll}\text { As } & 0.01 \\
\text { Ba } & \text { bdl } \\
\text { Cd } & 0.09 \\
\text { Cr } & 0.00 \\
\text { Ni } & 0.03 \\
\end{array}$ & $\begin{array}{ll}\mathrm{Pb} & 0.05 \\
\mathrm{Sb} & 0.02 \\
\mathrm{Se} & 0.00 \\
\mathrm{Zn} & 0.01\end{array}$ & $\begin{array}{ll}\text { As } & 0.02 \\
\text { Ba } & 0.04 \\
\text { Cd } & 0.08 \\
\text { Cr } & 0.00 \\
\text { Ni } & 0.02 \\
\end{array}$ & $\begin{array}{ll}\mathrm{Pb} & 0.04 \\
\mathrm{Sb} & 0.02 \\
\mathrm{Se} & 0.01 \\
\mathrm{Zn} & 0.09\end{array}$ & $\begin{array}{ll}\text { As } & 0.02 \\
\text { Ba } & 0.01 \\
\text { Cd } & 0.09 \\
\text { Cr } & 0.00 \\
\text { Ni } & 0.02 \\
\end{array}$ & $\begin{array}{lr}\mathrm{Pb} & 0.04 \\
\mathrm{Sb} & 0.02 \\
\mathrm{Se} & \text { bdl } \\
\mathrm{Zn} & 0.10\end{array}$ & $\begin{array}{ll}\text { As } & 0.01 \\
\text { Ba } & \text { bdl } \\
\text { Cd } & 0.10 \\
\text { Cr } & 0.00 \\
\mathrm{Ni} & 0.02 \\
\end{array}$ & $\begin{array}{ll}\mathrm{Pb} & 0.05 \\
\mathrm{Sb} & 0.02 \\
\mathrm{Se} & 0.00 \\
\mathrm{Zn} & \text { bdl }\end{array}$ & $\begin{array}{cc}\text { As } & 0.01 \\
\text { Ba } & \text { bdl } \\
\text { Cd } & 0.10 \\
\text { Cr } & 0.00 \\
\text { Ni } & 0.02 \\
\end{array}$ & $\begin{array}{ll}\mathrm{Pb} & 0.05 \\
\mathrm{Sb} & 0.02 \\
\mathrm{Se} & \text { bdl } \\
\mathrm{Zn} & \text { bdl }\end{array}$ & $\begin{array}{ll}\text { As } & 0.01 \\
\mathrm{Ba} & 0.01 \\
\mathrm{Cd} & 0.10 \\
\mathrm{Cr} & 0.00 \\
\mathrm{Ni} & 0.02 \\
\end{array}$ & $\begin{array}{ll}\mathrm{Pb} & 0.04 \\
\mathrm{Sb} & 0.02 \\
\mathrm{Se} & \text { bdl } \\
\mathrm{Zn} & 0.09\end{array}$ \\
\hline $500^{\circ} \mathrm{C}$ & $\begin{array}{ll}\text { As } & 0.02 \\
\text { Ba } & \text { bdl } \\
\text { Cd } & 0.09 \\
\text { Cr } & 0.00 \\
\text { Ni } & 0.03 \\
\end{array}$ & $\begin{array}{ll}\mathrm{Pb} & 0.05 \\
\mathrm{Sb} & 0.02 \\
\mathrm{Se} & 0.01 \\
\mathrm{Zn} & 0.03\end{array}$ & $\begin{array}{ll}\text { As } & 0.01 \\
\text { Ba } & 13 \\
\text { Cd } & 0.08 \\
\text { Cr } & 0.00 \\
\text { Ni } & 0.02 \\
\end{array}$ & $\begin{array}{lr}\mathrm{Pb} & 0.04 \\
\mathrm{Sb} & 0.02 \\
\mathrm{Se} & \text { bdl } \\
\mathrm{Zn} & 0.17\end{array}$ & $\begin{array}{ll}\text { As } & 0.01 \\
\text { Ba } & 0.01 \\
\text { Cd } & 0.08 \\
\text { Cr } & 0.00 \\
\text { Ni } & 0.02 \\
\end{array}$ & $\begin{array}{lr}\mathrm{Pb} & 0.04 \\
\mathrm{Sb} & 0.02 \\
\mathrm{Se} & \text { bdl } \\
\mathrm{Zn} & 0.11\end{array}$ & $\begin{array}{ll}\text { As } & \text { bdl } \\
\mathrm{Ba} & 0.01 \\
\mathrm{Cd} & 0.08 \\
\mathrm{Cr} & 0.00 \\
\mathrm{Ni} & 0.02 \\
\end{array}$ & $\begin{array}{ll}\mathrm{Pb} & 0.04 \\
\mathrm{Sb} & 0.02 \\
\mathrm{Se} & \text { bdl } \\
\mathrm{Zn} & 0.11\end{array}$ & $\begin{array}{ll}\text { As } & 0.01 \\
\text { Ba } & \text { bdl } \\
\text { Cd } & 0.10 \\
\text { Cr } & 0.00 \\
\text { Ni } & 0.03 \\
\end{array}$ & $\begin{array}{ll}\mathrm{Pb} & 0.05 \\
\mathrm{Sb} & 0.02 \\
\text { Se } & \text { bdl } \\
\mathrm{Zn} & 0.15\end{array}$ & $\begin{array}{ll}\text { As } & \text { bdl } \\
\text { Ba } & 0.01 \\
\text { Cd } & 0.07 \\
\text { Cr } & 0.00 \\
\text { Ni } & 0.02 \\
\end{array}$ & $\begin{array}{ll}\mathrm{Pb} & 0.04 \\
\mathrm{Sb} & 0.02 \\
\mathrm{Se} & \text { bdl } \\
\mathrm{Zn} & 0.07\end{array}$ \\
\hline Time (hrs) & \multicolumn{2}{|c|}{0.75} & \multicolumn{2}{|c|}{ 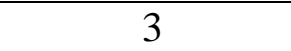 } & \multicolumn{2}{|c|}{12} & \multicolumn{2}{|c|}{48} & \multicolumn{2}{|c|}{192} & \multicolumn{2}{|c|}{768} \\
\hline
\end{tabular}




\section{WAPS Section 1.5 Hazardous Waste Specification}

"The Producer shall determine and report to DOE/RW the presence or absence of any hazardous waste listed in 40CFR261.31 through 40CFR 261.33 [5], in the waste or in any feed stream proposed for storage or disposal. Any RCRA-listed component in a waste shall require the Producer to petition EPA and receive exemption to delist the waste.

The Producer shall perform the appropriate tests and procedures, as described in 40CFR261.20 through 40CFR261.24 [6], using samples from production runs or prototypical specimens to determine if the waste that will be received by $D O E / R W$, for transportation and disposal, has hazardous characteristics. Any waste that is shown to have hazardous characteristics shall be treated to remove such characteristics.

"The Producer shall report and certify in the WQR that the waste is not hazardous, including the absence of any listed components. The characteristic testing methods to be used shall be described in the WCP and the results documented in the WQR. Any modification to these methods needs prior approval from $\mathrm{DOE} / \mathrm{RW}$."

In accordance with the first paragraph of WAPS Section 1.5, the AZ-101 simulant used in this test plan has elemental wastes listed in 40 CFR 261.33, namely arsenic, barium, cadmium, chromium, nickel and lead.

In accordance with WAPS section 1.5, 40 CFR 261.24 states that "A solid waste exhibits the characteristic of toxicity, if, using the Toxicity Characteristic Leaching Procedure (TCLP), test Method 1311 in 'Test Methods for Evaluating Solid Waste, Physical Chemical Methods,' EPA Publication SW-846, the extract from a representative sample of the waste contains any of the contaminants listed in Table 1 of 40 CFR 261.24 at the concentration equal to or greater than the respective values given in that table."

The table below includes the Regulatory Level for the toxic elements in the AZ-101 vitrified surrogate waste product that would be received by DOE/RW and are specified in EPA's Table 1 of 40 CFR 261.24. Also shown are the resultant leachate concentrations and standard deviations obtained from the TCLP test for AVS Bench-Scale 4. 
Table 5-6. TCLP Results for Bench-Scale 4

\begin{tabular}{|l|l|l|l|l|l||}
\hline $\begin{array}{l}\text { EPA HW } \\
\text { No }\end{array}$ & Contaminant & CAS No. & $\begin{array}{l}\text { Table 1 of } \\
\mathbf{4 0} \text { CFR } \\
\mathbf{2 6 1 . 2 4}, \\
\text { Regulatory } \\
\text { Level } \\
(\mathbf{m g} / \mathbf{L})\end{array}$ & $\begin{array}{l}\text { Test 4 } \\
\text { Overall } \\
\text { Average }_{\mathbf{G}} \\
(\mathbf{m g} / \mathbf{L})\end{array}$ & $\begin{array}{l}\text { Test 4 } \\
\text { Standard } \\
\text { Deviation } \\
(\mathbf{m g} / \mathbf{L})\end{array}$ \\
\hline D004 & Arsenic & $7440-38-2$ & 5.0 & 0.019 & \pm 0.009 \\
\hline D005 & Barium & $7440-39-3$ & 100.0 & 0.2 & \pm 0.2 \\
\hline D006 & Cadmium & $7440-43-9$ & 1.0 & 0.14 & \pm 0.03 \\
\hline D007 & Chromium & $7440-47-3$ & 5.0 & 0.002 & \pm 0.001 \\
\hline D008 & Lead & $7439-92-1$ & 5.0 & 0.2 & \pm 0.3 \\
\hline
\end{tabular}

As can be seen from a comparison of the $4^{\text {th }}$ and $5^{\text {th }}$ columns in the above table, "the extract from a representative sample of the waste" does not contain "any of the contaminants listed in Table 1 at the concentration equal to or greater than the respective value [Regulatory Level] given in that table." It can, therefore, be concluded that the vitrified waste product does not exhibit the characteristic of toxicity.

In accordance with 40 CFR 261.20 "A solid waste ... is a hazardous waste if it exhibits any of the characteristics identified in this subpart." Since it does not exhibit the only applicable characteristic of toxicity, then it is concluded that the vitrified waste product is not a hazardous waste under the EPA regulations.

In accordance with WAPS section 1.5, there is a requirement for the "Producer to petition EPA and receive exemption to delist the waste." 40 CFR 260.22 governs petitions to the Environmental Protection Agency (EPA) to exclude a waste produced at a particular facility.

EPA's petition requirements to exclude a waste requires the petitioner to demonstrate---

"that the waste does not meet any of the criteria under which the waste was listed as a hazardous or an acuteely (sic) hazardous waste". Since the waste glass is not a hazardous waste under the EPA regulations, this criterion has been met.

"that regulation under the universal waste regulations of 40 CFR part 273: Is appropriate for the waste or category of waste; will improve management practices for the waste or category of waste; and will improve implementation of the hazardous waste program." Based on the results of the TCLP testing and the finding that the waste glass is not a hazardous waste under the EPA regulations, this criterion has been met.

40 CFR 261.20 further clarifies that the EPA "will grant or deny a petition using the factors listed in 40 CFR 273.81." However, this clarification only applies to waste that is listed as a hazardous waste. 40 CFR 273.81 clarifies that "only the portion of the waste

\footnotetext{
${ }^{6}$ A table showing the extract concentration values for all samples taken from the bench-scale waste glass is included at the end of this section.
} 
stream that does exhibit one or more characteristics (i.e., is hazardous waste) is subject to the universal waste regulations of this part 273." Thus, this section defines a waste that is not classified as hazardous waste as not subject to the section. Therefore, since the waste glass is not a hazardous waste under the EPA regulations, this criterion has been met and the exemption to delist the waste should be granted.

Table 5-7. Bench-Scale 4 TCLP Results

All Segments

\begin{tabular}{|c|c|c|c|c|c|c|c|}
\hline Element & Top Side & $\begin{array}{c}\text { Top } \\
\text { Center }\end{array}$ & $\begin{array}{c}\text { Middle } \\
\text { Side }\end{array}$ & $\begin{array}{c}\text { Middle } \\
\text { Center }\end{array}$ & $\begin{array}{c}\text { Bottom } \\
\text { Side }\end{array}$ & $\begin{array}{c}\text { Bottom } \\
\text { Middle }\end{array}$ & $\begin{array}{c}\text { Bench- } \\
\text { Scale 4 } \\
\text { Average }\end{array}$ \\
\hline $\mathrm{As}$ & $0.018 \pm$ & $0.028 \pm$ & $0.019 \pm$ & $0.016 \pm$ & $0.015 \pm$ & $0.018 \pm$ & $0.019 \pm$ \\
& 0.005 & 0.02 & 0.003 & 0.003 & 0.005 & 0.003 & 0.009 \\
\hline $\mathrm{Ba}$ & $0.2 \pm 0.2$ & $0.15 \pm 0.1$ & $0.2 \pm 0.1$ & $0.2 \pm 0.2$ & $0.2 \pm 0.2$ & $0.1 \pm 0.1$ & $0.2 \pm 0.2$ \\
\hline $\mathrm{Cd}$ & $0.13 \pm 0.03$ & $0.16 \pm 0.02$ & $0.14 \pm 0.03$ & $0.13 \pm 0.04$ & $0.13 \pm 0.02$ & $0.14 \pm 0.03$ & $0.14 \pm 0.03$ \\
\hline $\mathrm{Cr}$ & $0.002 \pm$ & $0.002 \pm$ & $0.002 \pm$ & $0.002 \pm$ & $0.002 \pm$ & $0.002 \pm$ & $0.002 \pm$ \\
& 0.001 & 0.001 & 0.001 & 0.001 & 0.001 & 0.001 & 0.001 \\
\hline $\mathrm{Ni}$ & $0.032 \pm$ & $0.034 \pm$ & $0.032 \pm$ & $0.03 \pm 0.01$ & $0.028 \pm$ & $0.029 \pm$ & $0.031 \pm$ \\
& 0.009 & 0.004 & 0.009 & & 0.008 & 0.009 & 0.007 \\
\hline $\mathrm{Pb}$ & $0.07 \pm 0.01$ & $0.3 \pm 0.3$ & $0.2 \pm 0.2$ & $0.06 \pm 0.02$ & $0.06 \pm 0.01$ & $0.4 \pm 0.5$ & $0.2 \pm 0.3$ \\
\hline $\mathrm{Sb}$ & $0.021 \pm$ & $0.029 \pm$ & $0.022 \pm$ & $0.019 \pm$ & $0.021 \pm$ & $0.021 \pm$ & $0.022 \pm$ \\
& 0.003 & 0.01 & 0.003 & 0.002 & 0.002 & 0.002 & 0.005 \\
\hline $\mathrm{Se}$ & $\mathrm{bdl}$ & 0.022 & $\mathrm{bdl}$ & 0.011 & $\mathrm{bdl}$ & 0.010 & $0.014 \pm$ \\
& & & & & & & 0.007 \\
\hline $\mathrm{Zn}$ & $0.19 \pm 0.07$ & $0.219 \pm$ & $0.20 \pm 0.07$ & $0.19 \pm$ & $0.19 \pm 0.09$ & $0.19 \pm$ & $0.20 \pm 0.06$ \\
& & 0.07 & & 0.06 & & 0.07 & \\
\hline
\end{tabular}




\section{Extrapolation of Experimental Results to a Full Scale AVS Production System}

The SOW requires, "Based on data acquired, the Contractor shall provide a reference chemical and mass balance flowsheet for average and maximum flows that includes the Contractor's projected operation of all full scale equipment required to convert the $D O E$ waste feed provided for the test into filled waste canisters at a production rate of 1.5 metric tons of glass per day. Flow rates shall be based on actual operating time needed to accommodate the appropriate cycle down time and meet the production rate.

"Other information relevant to the viability of the AVS and/or the quality of the final glass product as specifically relates to the Statement of Work objectives."

\subsection{Process Flow Sheet Mass Balance}

The AZ-101 HLW feed slurry contains $28.53-\mathrm{wt} \%$ solid and has a density of $1.248 \mathrm{~g} / \mathrm{cc}$. The frit, that is glass makers, added has a composition of $71.6-\mathrm{wt} \% \mathrm{SiO}_{2}, 23.9-\mathrm{wt} \%$ $\mathrm{H}_{3} \mathrm{BO}_{3}$ and $4.5-\mathrm{wt} \% \mathrm{ZnO}$. Results of laboratory and bench-scale tests a vitrified glass which passes PCT and TCLP requirements is produced containing 60-wt\% [M-1] (62.2$\mathrm{wt} \%[\mathrm{M}-2])$ waste loading and containing $6-\mathrm{wt} \% \mathrm{~B}_{2} \mathrm{O}_{3}$ qualifying for a borosilicate glass.

Using a specified production rate of 1.5 metric tons per day (MT/day) of a finished 60wt $\%$ waste loaded borosilicate glass flowsheets and mass balances for the full-scale AVS process were developed. The standard RIC AVS Module contains 2.5 MT of borosilicate glass for standard $61 \mathrm{~cm}$ and $450 \mathrm{~cm}$ long disposal container. Based on bench-scale testing results, three feed systems have been designed and the appropriate mass balances have been completed. Three feeding/drying methods were considered:

- direct slurry feed into the AVS melter,

- slurry feed after concentration and

- solid feed using an evaporative dryer.

Each of these options is described in turn.

\section{Direct Slurry Feed (Figure 6-1)}

The figure below shows the flowsheet for feeding the AZ-101 slurry directly to the AVS Module melter coming from the HLW treatment plant and after addition of the glassmakers. The concentration of solids (with glass makers) is 37-vol\%. This flowsheet is the simplest and contains the least processing equipment. The processing time in the AVS Module is the longest because of the need to evaporate all the water in the slurry. The processing time, which includes heat-up melting and cool down times, results in a 3day cycle time to complete a $90 \%$ Module fill. To produce a borosilicate glass at a rate of 1.5 MT/D results in moving modules through processing equipment at a rate of 0.6 modules per day. The table following the flowsheet gives the associated mass balance for this option. 


\section{Figure 6-1: Conceptual Flowsheet for Direct Slurry Feed}

Basis: Production Rate 1.5 MT/D - $60 \mathrm{wt} \%$ Waste_oading Borosilicate Glass (BG) 2.5 MT(BG)/AVS Module (Glass Density $=2.95 \mathrm{~g} / \mathrm{cc})^{1} 61 \mathrm{~cm} \mathrm{OD,} 450 \mathrm{~cm}$ Long Throughput 3 Day/Module -90\% Fill by Volume - All Mass Units in MT/D. Direct Slurry Feed - 37vol\% AZ-101 including Frit

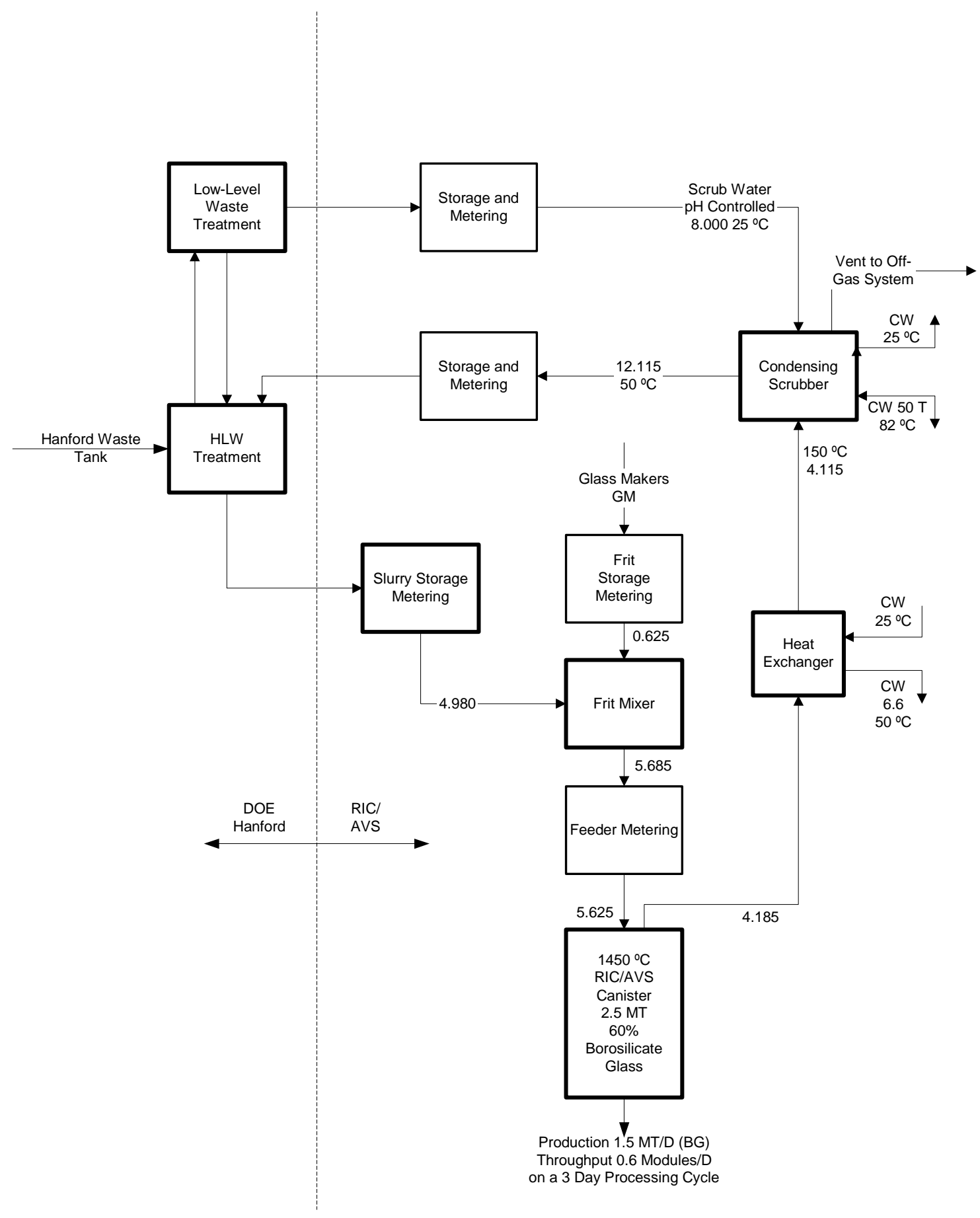

\footnotetext{
${ }^{1}$ Actual glass density at $60-\mathrm{wt} \%$ achieved was $3.2 \mathrm{~g} / \mathrm{cc}$, so this calculation is conservative.
} 
Table 6-1. Mass Balance for Direct Slurry Feed in MT/D

Basis: Production Rate 1.5 MT/D - 60-wt\% Waste Loading Borosilicate Glass (BG) 2.5 MT(BG)/AVS Module (Glass Density = $2.95 \mathrm{~g} / \mathrm{cc}$ ) $61 \mathrm{~cm} \mathrm{OD,} 450 \mathrm{~cm}$ Long Throughput 3 Day/Module -90\% Filled by Volume Direct Slurry Feed - 37-vol\% AZ-101 including Frit

\begin{tabular}{||c|c|c|c|c|c|c|}
\hline \multicolumn{1}{|c|}{ Unit } & \multicolumn{2}{c|}{$\begin{array}{c}\text { Frit } \\
\text { Mixer }\end{array}$} & \multicolumn{2}{c|}{$\begin{array}{c}\text { Scrubber } \\
\text { Condenser }\end{array}$} & \multicolumn{2}{c|}{$\begin{array}{c}\text { RIC/AVS } \\
\text { Melter }\end{array}$} \\
\hline Input/Output & Input & Output & Input & Output & Input & Output \\
\hline Temperature & $\sim 25^{\circ} \mathrm{C}$ & $\sim 25^{\circ} \mathrm{C}$ & $150^{\circ} \mathrm{C}$ & $50{ }^{\circ} \mathrm{C}$ & $25^{\circ} \mathrm{C}$ & $1450^{\circ} \mathrm{C}$ \\
\hline Frit Mixer & & & & & & \\
\hline Slurfy & 4.980 & & & & & \\
\hline Frit $^{2}$ & 0.635 & & & & & \\
\hline Slurry + Frit & & 5.615 & & & & \\
\hline Total & 5.615 & 5.615 & & & & \\
\hline Scrubber Condenser & & & & & & \\
\hline Water Steam & & & 4.000 & & & \\
\hline Non-Condengable & & & 0.115 & & & \\
\hline Scrub Water & & & 8.000 & & & \\
\hline Condenser-Scrubber & & & & 12.115 & & \\
\hline Total & & & 12.115 & 12.115 & & \\
\hline RIC/AVS Module & & & & & & \\
\hline Feed Slurry & & & & & 5.615 & \\
\hline Gasses & & & & & & 4.115 \\
\hline BG Glass & & & & & & 1.500 \\
\hline Total & & & & & 5.615 & 5.615 \\
\hline
\end{tabular}

\section{Slurry Feed after Concentration (Figure 6-2)}

The figure below gives the flowsheet for feeding an AZ-101 slurry with glass makers to the AVS Module after concentrating the HLW in a tank type evaporator to $50 \mathrm{vol} \%$ solids. The purpose of this flowsheet is to increase the rate of processing a Module to a 2day cycle, which reduces the processing equipment. The $50 \mathrm{vol} \%$ value is based on the maximum concentration of slurry that can be safely pumped without clogging the evaporator and transfer lines. The table below the figure gives the associated mass balance for this option.

\footnotetext{
${ }^{2}$ AZ-101 Slurry - 28.53\% Solids, Specific Gravity 1.248 g/cc.

${ }^{3}$ Frit contains $71.6 \%, \mathrm{SiO}_{2}, 23.9 \% \mathrm{H}_{3} \mathrm{BO}_{3}$ and $4.5 \% \mathrm{ZnO}$.

${ }^{4}$ Non-Condensable include $\mathrm{NO}_{\mathrm{X}}, \mathrm{SO}_{\mathrm{X}}, \mathrm{CO}_{\mathrm{X}}$, residual gas removed in alkaline water.

${ }^{5}$ Service water used is assumed two times the total water removed from slurry, which includes free-water, bound water, and hydroxyl water.
} 


\section{Figure 6-2. Conceptual Flowsheet for Slurry Feed after Concentration}

Basis: Production Rate 1.5 MT/D - $60 \mathrm{wt} \%$ Waste Loading Borosilicate Glass (BG) 2.5

MT(BG)/AVS Module (Glass Density =2.95 g/cc) $61 \mathrm{~cm} \mathrm{OD,} 450 \mathrm{~cm}$ Long.

Throughput 2 Day Cycle/Module - 90\% Full by Volume - All Mass Units in MT/D.

Evaporated Feed Concentrated - 50 vol\% Slurry and Frit to AVS Module

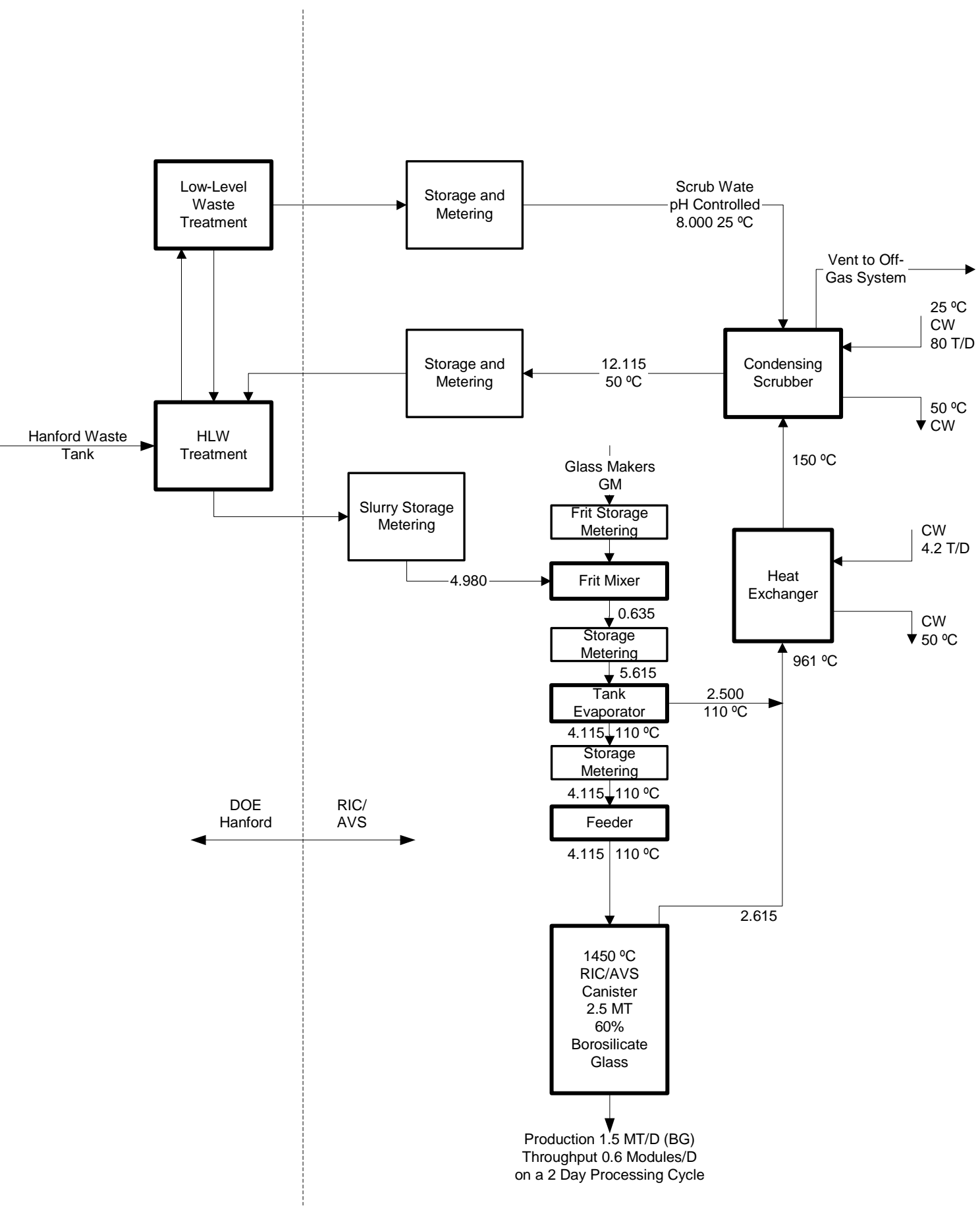


Table 6-2. Mass Balance for Slurry Feed after Concentration in MT/D

Basis: Production Rate 1.5 MT/D - 60-Wt\% Waste Loading Borosilicate Glass (BG) 2.5 MT(BG)/AVS Module (Glass Density = $2.95 \mathrm{~g} / \mathrm{cc}$ ) $61 \mathrm{~cm} \mathrm{OD,} 450 \mathrm{~cm}$ Long. Throughput 2-Day Cycle/Module - 90\% Fill by Volume. Evaporated Feed Concentrated - 50-vol\% Slurry and Frit to AVS Module

\begin{tabular}{|c|c|c|c|c|c|c|c|c|}
\hline \multirow{2}{*}{$\begin{array}{c}\text { Unit } \\
\text { Input/Output } \\
\text { Temperature } \\
\end{array}$} & \multicolumn{2}{|c|}{$\begin{array}{c}\text { Frit } \\
\text { Mixer }\end{array}$} & \multicolumn{2}{|c|}{$\begin{array}{c}\text { Tank } \\
\text { Evaporator }\end{array}$} & \multicolumn{2}{|c|}{$\begin{array}{l}\text { Scrubber } \\
\text { Condenser }\end{array}$} & \multicolumn{2}{|c|}{$\begin{array}{l}\text { RIC/AVS } \\
\text { Melter }\end{array}$} \\
\hline & $\begin{array}{l}\text { Input } \\
25^{\circ} \mathrm{C}\end{array}$ & $\begin{array}{l}\text { Output } \\
25^{\circ} \mathrm{C}\end{array}$ & $\begin{array}{l}\text { Input } \\
25^{\circ} \mathrm{C}\end{array}$ & $\begin{array}{l}\text { Output } \\
110^{\circ} \mathrm{C}\end{array}$ & $\begin{array}{l}\text { Input } \\
150^{\circ} \mathrm{C}\end{array}$ & $\begin{array}{l}\text { Output } \\
50^{\circ} \mathrm{C}\end{array}$ & $\begin{array}{l}\text { Input } \\
110^{\circ} \mathrm{C}\end{array}$ & $\begin{array}{l}\text { Output } \\
1450^{\circ} \mathrm{C}\end{array}$ \\
\hline \multicolumn{9}{|l|}{ Frit Mixer } \\
\hline Slurry & 4.980 & & & & & & & \\
\hline Frit & 0.635 & & & & & & & \\
\hline Slurry + Frit & & 5.615 & & & & & & \\
\hline Total & 5.615 & 5.615 & & & & & & \\
\hline \multicolumn{9}{|l|}{ Tank Evaporator } \\
\hline Slurry + Frit & & & 5.615 & & & & & \\
\hline Free Water Evap. & & & & 1.500 & & & & \\
\hline $50 \%$ Slurry & & & & 4.115 & & & & \\
\hline Total & & & 5.615 & 5.615 & & & & \\
\hline \multicolumn{9}{|l|}{ Condenser/Scrubber } \\
\hline Water & & & & & 4.000 & & & \\
\hline Volatiles from Module & & & & & 0.115 & & & \\
\hline Scrub Water & & & & & 8.000 & & & \\
\hline Scrub + Cond. Water & & & & & & 12.115 & & \\
\hline Total & & & & & 12.115 & 12.115 & & \\
\hline \multicolumn{9}{|l|}{ RIC/AVS Module } \\
\hline $50 \%$ Slurry & & & & & & & 4.115 & \\
\hline Volatiles & & & & & & & & 2.615 \\
\hline BG Glass & & & & & & & & 1.500 \\
\hline Total & & & & & & & 4.115 & 4.115 \\
\hline
\end{tabular}

\section{Solid Feed Using an Evaporative Dryer (Figure 6-3)}

The figure below gives the flowsheet for feeding AZ-101 slurry with glass makers to the AVS Module after drying and removing all the free and bound water in a Porcupine ${ }^{\mathrm{TM}}$ type evaporator dryer operating at $300{ }^{\circ} \mathrm{C}$. The benefit of feeding dried waste to an AVS Module is that there is the least amount of water to be evaporated in the melter so that the rate of glass production is increased and the cycle time is reduced to nominally no more than 2 days. The table below the figure gives the associated mass balance for this option. 
Figure 6-3. Conceptual Flowsheet for Solid Feed Using an Evaporative Dryer

Basis: Production Rate 1.5 MT/D - 60-Wt\% Waste Loading Borosilicate Glass (BG) 2.5 MT(BG)/AVS Module (Glass Density $=2.95 \mathrm{~g} / \mathrm{cc}$ ) $61 \mathrm{~cm} \mathrm{OD,} 450 \mathrm{~cm}$ Long.

Throughput 2-Day Cycle/Module - 90\% Fill by Volume - All Mass Units in MT/D. Dry Feed - RIC AVS Module

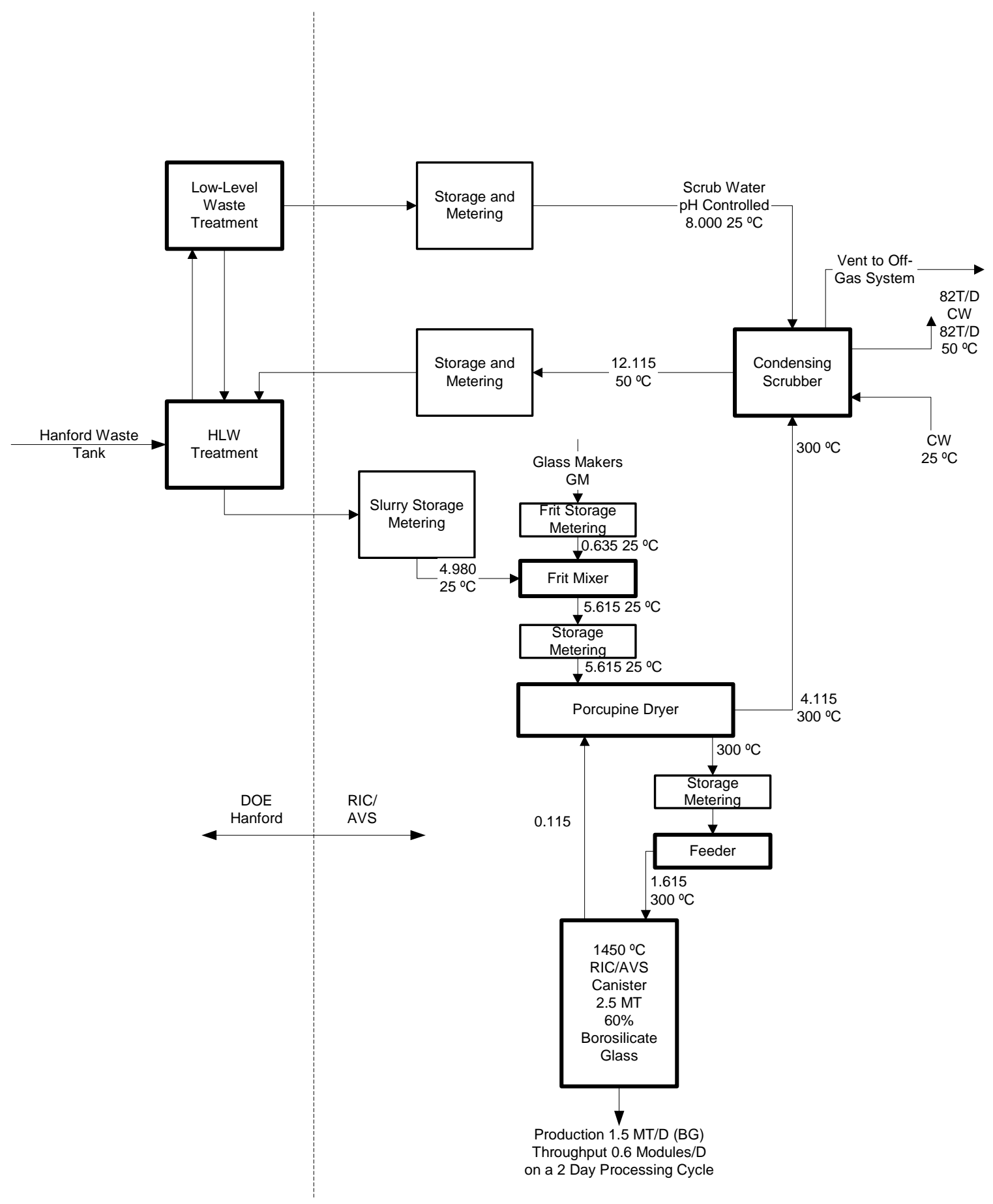


Table 6-3. Mass Balance for Solid Feed Using an Evaporative Dryer in MT/D Basis: Production Rate 1.5 MT/D - 60-Wt\% Waste Loading Borosilicate Glass (BG) 2.5 MT(BG)/AVS Module (Glass Density $=2.95 \mathrm{~g} / \mathrm{cc}$ ) $61 \mathrm{~cm} \mathrm{OD,} 450 \mathrm{~cm}$ Long. Throughput 2-Day Cycle/Module - 90\% Fill by Volume. Dry Feed - RIC AVS Module

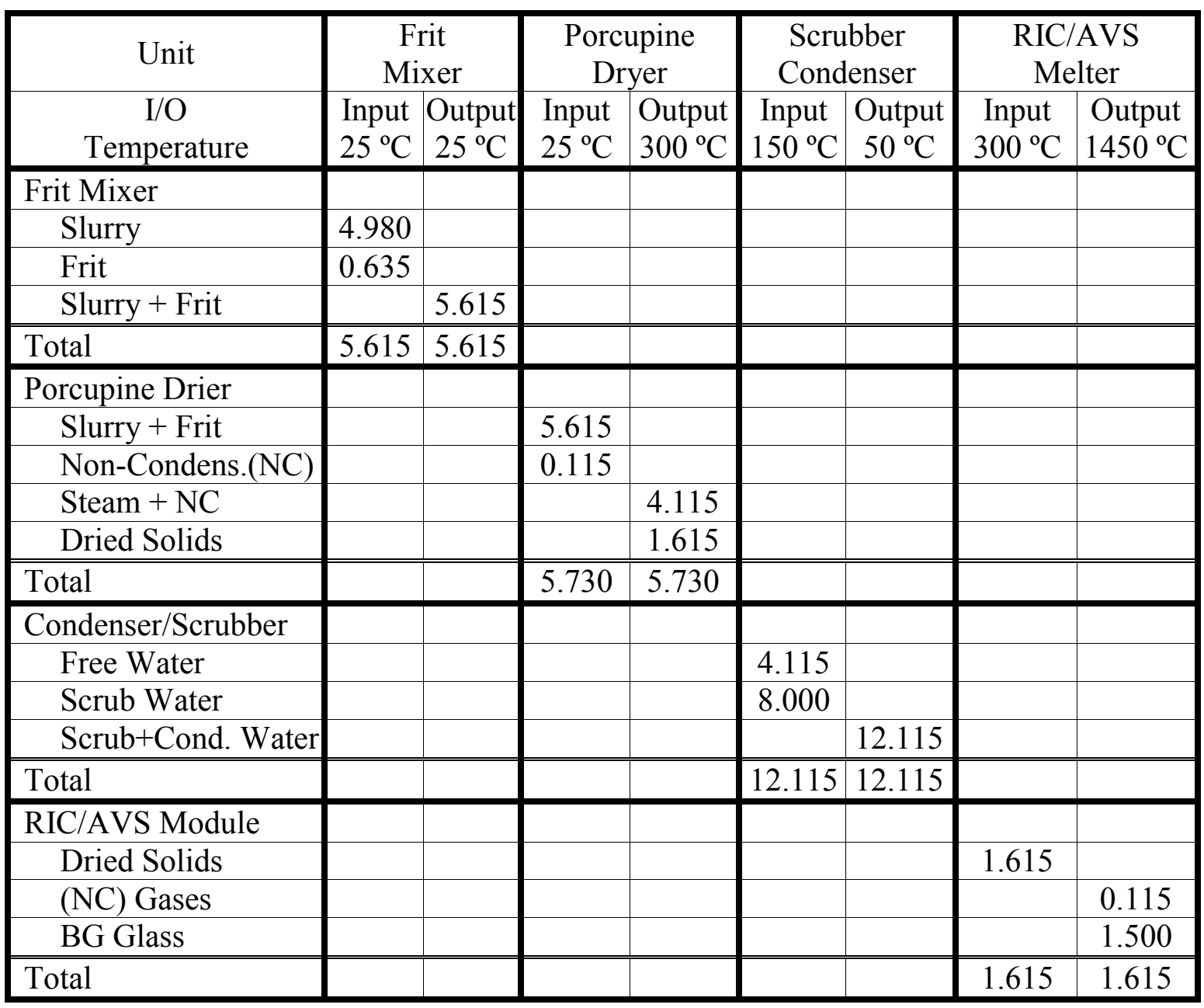

\section{Discussion of Options}

Each of the options presents various benefits, tradeoffs and risks. The first option (direct feeding of slurry and frit) has the benefit of minimal pretreatment components. This option does require a longer processing time in the RIC-AVS module and therefore will require additional processing cells to achieve the required production rate.

The second option (increasing solid concentration to $50 \mathrm{wt} \%$ ) has the benefit of removing a large portion of the water before feeding into the RIC AVS Module. This will reduce the processing time in the RIC AVS Module and thereby reduce the number of process cells required to achieve the specified production rate. This option introduces more complex pretreatment equipment into the RIC-AVS plant. This could cause an increase in the maintenance requirements and required downtime. 
The third option (Porcupine Dryer) removes most of the water from the waste and minimizes the processing time in RIC AVS Module. This option will provide the required production rate with the least amount of process cells in the RIC AVS Facility. The pretreatment system is the most complex of the three options and may require a larger plant to house the equipment and increased maintenance requirements.

\section{Process Times}

The feed to the RIC AVS process is obtained from the HLW pre-treatment plant and stored in storage tanks sized to supply the full capacity of the RIC AVS plant. From the storage tanks, the slurry and frit are fed to a frit mixer at a rate to produce a $60-\mathrm{wt} \%$ waste loading.

The mixed slurry and frit is fed to a metering tank, which meters out the slurry into the RIC AVS Module at a rate based on laboratory tests to fill the Module in 53 hours.

Using the hot hohlraum effect, the melt temperature is held at $1450{ }^{\circ} \mathrm{C}$ (for AZ-101) with the induction coil heater, which for the direct feed flowsheet moves up at the rate of three inches/hr until the module is $90 \%$ filled. The hot hohlraum zone extends about 8 inches. A cool down time of about 19 hours completes the 3-day cycle.

For the 50 vol. \% slurry feed (Figure 6-2) and the dried feed (Figure 6-3) the heated zone moves up at a rate of 5 inches/hour filling for 29 hours and cool down for 19 hours to complete a 2 day cycle.

\section{Process Off-gases}

The gases from the RIC AVS melter, which contains the water vapor from the free-water, bound-water and hydroxyl-water, and the non-condensable NOx, SOx, COx and residual gases are sent to a condenser scrubber.

The condenser scrubber is fed with scrub water obtained from the low-level waste treatment plant. The scrub water is stored and metered to a counter-current scrubbercondenser at a rate, which is twice that of the water removed from the AVS Module container (8.000 MT/D). The $\mathrm{pH}$ of the scrub water is adjusted to alkaline conditions to absorb the NOx, SOx, and COx. Residual vent gases from the scrubber are sent to the off-gas vent system containing HEPA filters.

In the dryer evaporator option, the remaining non-condensable gases from the AVS module passes through the Porcupine dryer-evaporator and joins the rest of the evaporator water sent to the condensing scrubber. Any dust carryover is captured in the dryer and scrubber water, which is recycled to the HLW and LLW pretreatment system to maintain a closed system. 


\subsection{Extrapolating Test Results to Full-Scale AVS Vitrified Product Cooling Rate}

Centerline cooling rates of the vitrified product in the 5 inch bench-scale tests and fullscale AVS Module have been estimated using a combination of experimental data and analytic solutions for transient and steady state heat transfers.

Centerline cooling rates for the full-scale AVS module were previously estimated by assuming that the module was initially filled with molten glass along its entire length, and then allowed to cool by turning off the inductive heating power. The temperature of the outer steel canister was maintained at or near ambient conditions $\left(\sim 50^{\circ} \mathrm{C}\right)$ during the cooling period.

For this case, the cooling process was essentially one-dimensional in the $\mathrm{r}$ direction (the length/diameter of the vitrified log was $>>1$ ). The rate of cooling (and the centerline temperature) was determined by (1) the diameter of the vitrified log, (2) the thermal conductivity of the glass, and (3) the thermal conductivity and thickness of the insulation layer between the graphite/alumina crucible and the outer steel canister. The cool down time of the glass log to the point where the centerline temperature approached ambient temperature was approximately 1 day.

The baseline heating/cooling protocol that has been adopted for the full-scale AVS module is now completely different than that assumed for the previous cooling rate calculations, and results in a much faster centerline cooling rate.

In the present AVS heating/cooling protocols, termed the "Hot Hohlraum Method" (HHM), only the empty portion of the graphite/alumina crucible above the melt surface is inductively heated. The portion of the graphite/alumina crucible below the melt surface is not heated (except minimally by the leakage of magnetic flux from the energized portion of the inductive heating AC coils located above the melt surfaces.

As a result, in the HHM method the feed material introduced into the top of the graphite/alumina crucible is heated by the intense radiant thermal flux in the empty cavity above the melt surface as it falls and joins melted HLW/frit mixture inside the crucible. The radiant thermal flux in the cavity is approximately $40 \mathrm{w} / \mathrm{cm}^{2}$, which supplies the energy to heat up and melt the feed.

The maximum temperature of the melt is then at the surface of the melted material, resulting in a thermally stable condition. The temperature of the vitrified material monotonically decreases with increasing distance below the surface of the melt because the melt is continuously cooled by the thermal conductive losses through the insulation surrounding the graphite/alumina crucible, and by the thermal conductive losses axially downwards through the cooler vitrified log below the melt surface.

In this analysis, estimates of the centerline cooling rate are made from the full-scale AVS using the HHM method, compared to estimate made from previous experiments on the 5 inch bench-scale tests, in which a long-length fully melted region was radially cooled. 


\section{Centerline Cooling Rate for Full-Scale AVS Modules}

Obtaining a 2-dimensional $(\mathrm{r}, \mathrm{z})$ solution for the temperature distribution inside the vitrified (melt plus solid) region of the AVS module will require a numerical computer code model that takes into account radiative and conductive heat transfer. Moreover, such a computer model will have to be bench-marked and validated against experiments at a scale that reproduces the anticipated process and effects.

Since program resources are not yet available for the development and benchmarking of such a computer model, it is necessary to make do with the analytical solutions that can reasonably approximate the heat transfer behavior in the AVS module during the Hot Hohlraum heating process. Rosenhow [Handbook of Heat Transfer, pp 3-115, 1973] provides a one-dimensional solution for the temperature inside a solid cylindrical body that is heated on its upper circular surfaces and cooled along its cylindrical surfaces below. The geometry for this 1-D solution is shown in the Figure 6-4.

The module assumes a non-zero finite thermal conductivity for the body in the $\mathrm{z}$ direction and an essentially infinite conductivity in the radial direction. For our purposes, the thermal conductivity in the $\mathrm{z}$ direction is taken as the volume average of the glass and the graphite/alumina thermal conductivities. The heat transfer coefficient $\mathrm{h}, \mathrm{W} / \mathrm{cm}^{2}{ }^{\mathrm{o}} \mathrm{K}$, for the heat loss from the surface is equivalent to the thermal conductivity of the insulation layer (in $\mathrm{W} / \mathrm{cm}^{2}{ }^{\circ} \mathrm{K}$ ) divided by its radial thickness (in $\mathrm{cm}$ ). No distinction is made between the melt zone and solid zone portions of the vitrified material. The thermal conductivity will be essentially be the same, and there are no convective motions in the melt region.

The $1 \mathrm{D}$ analytic expressions for the temperature distribution as a function of $\mathrm{z}(\mathrm{z}=0$ is the melt surface) below the melt surface is shown in Figure 6-5. The dimensions and thermal conductivities for the full-scale and the 5-inch diameter module are also given.

Figure 6-6 shows T(z) as a function of $\mathrm{z}$ for the full-scale AVS Module for 3 cases: an infinitely long module, a module with an $\mathrm{L} / \mathrm{D}$ ratio (length/diameter) of 1 and a module with an $\mathrm{L} / \mathrm{D}$ ratio of 2 . The temperature distribution for the $\mathrm{L} / \mathrm{D}=2$ case is essentially the same as the $\mathrm{L} / \mathrm{D}=\infty$ case.

The $\mathrm{z}$ distance below the melt surface corresponds to a particular combination of fill rate and time since the material arrives at the surface for the module. For example, at a fill rate of $10 \mathrm{~cm} / \mathrm{hr}$ ( 4 inches $/ \mathrm{hr}$ ), the $\mathrm{z}=10$ centimeter point was at the melt surface 1 hour previously. At a fill rate of 20 centimeter per hour $(8 \mathrm{in} / \mathrm{hr})$, the $\mathrm{z}=10$ point was at the melt surface just $1 \frac{1}{2}$ hour previously. 
Basis: Handbook of Heat Transfer, Rosenhow \& Harnett McGraw Hill (1973); pg. 3-115

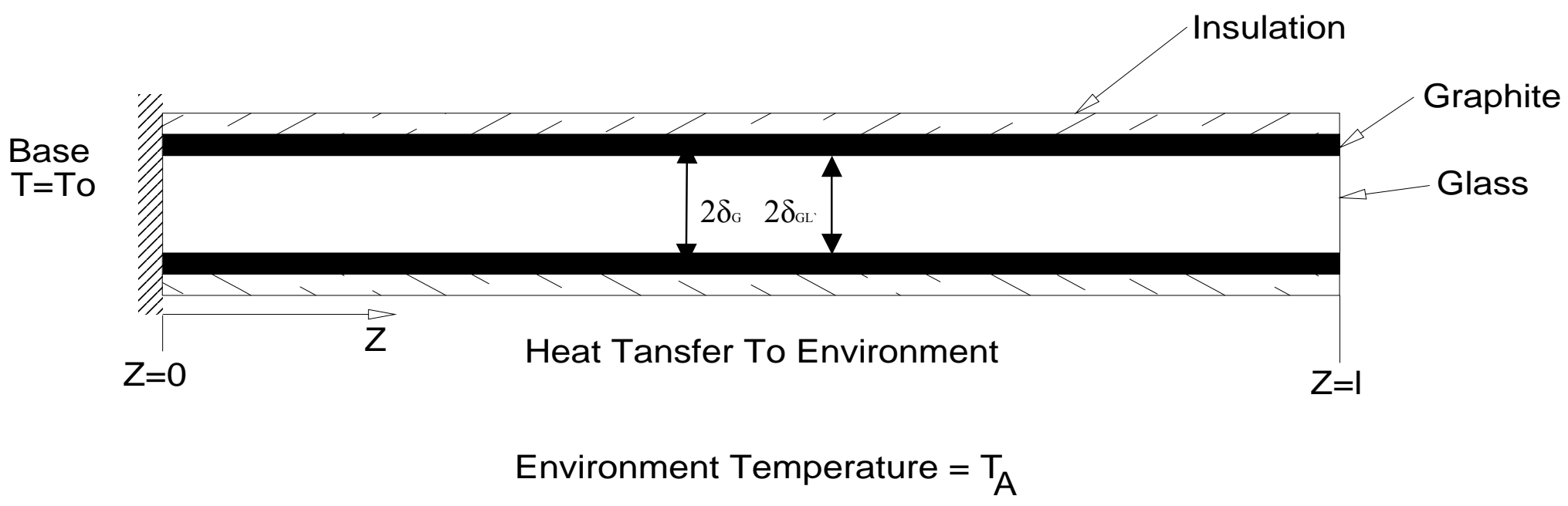

Relationships

Thermal Conductivity [W/cm K, k(insul), k(graphite), k(glass)]

and Parameters

$\mathrm{h}=\mathrm{kINSUL} / \Delta \mathrm{rINSUL}\left(\mathrm{W} / \mathrm{cm}^{\wedge} 2 \mathrm{k}\right) \quad$ Equivalent Heat Transfer Coefficient

$2 \delta_{\mathrm{G}}=\mathrm{OD}$ of Graphite Crucible

$2 \delta \mathrm{GL}=\mathrm{OD}$ of Glass

$\bar{k}=k_{G}\left[1-\left(\delta_{G L} / \delta_{G}\right)^{\wedge} 2\right]+k_{G L}\left(\delta_{G L} / \delta_{G}\right)^{\wedge} 2 \quad$ Volume Average Thermal Conductivity

$m=\sqrt{(h / \bar{k} \delta G)} \mathrm{cm}^{\wedge}-1$

Figure 6-4: Geometry for 1-D Solution from Rosehow 


\section{Very Long Cylinder $\left(1>>\delta_{\theta}\right)$}

$\mathrm{T}_{\mathrm{Z}}=\mathrm{T}_{\mathrm{A}}+\left(\mathrm{T}_{0}-\mathrm{T}_{\mathrm{A}}\right) \mathrm{e}^{(-\sqrt{2} \mathrm{mz})}$

Finite Length Cylinder

$\mathrm{T}_{\mathrm{Z}}=\mathrm{T}_{\mathrm{A}}+\left(\mathrm{T}_{0}-\mathrm{T}_{\mathrm{A}}\right) \cosh [\sqrt{ } 2 \mathrm{ml}(1-\mathrm{z} / \mathrm{l})]$

$\cosh [\sqrt{ } 2 \mathrm{ml}]$

\section{Typical Values}

$\mathrm{k}_{\text {inusl }}=2 \times 10^{-3} \mathrm{~W} / \mathrm{cm} \mathrm{K} \quad \mathrm{k}_{\mathrm{G}}=0.50 \mathrm{~W} / \mathrm{cm} \mathrm{K}$

$\Delta \mathrm{r}_{\text {inusl }}=1 \mathrm{~cm}$

$\mathrm{h}=2 \times 10^{-3} \mathrm{~W} / \mathrm{cm}^{2} \mathrm{~K}$

\section{For 5" Crucible}

$\delta_{\mathrm{G} 1}=3.25 "=8.25 \mathrm{~cm}$

$\delta_{\mathrm{G}}=2.50 "=6.35 \mathrm{~cm}$

$\mathrm{k}=0.25 \mathrm{~W} / \mathrm{cm} \mathrm{K} \mathrm{k}=0.10 \mathrm{~W} / \mathrm{cm}^{\circ} \mathrm{K}$
$\mathrm{k}_{\mathrm{G} 1}=0.02 \mathrm{~W} / \mathrm{cm} \mathrm{K}$

\section{Full Scale Crucible}

$\delta_{\mathrm{G} 1}=28.50 \mathrm{~cm}$

$\delta_{\mathrm{G}}=26.00 \mathrm{~cm}$

Figure 6-5. 1-D Analytical Relationships for Temperature Distributions 
Figure 6-6. Temperature Distribution along Finite Length Cylindrical Crucibles using the HHM Vitrification Method

\begin{tabular}{|l|c|c|c|c|c|c|c|c|}
\hline \multicolumn{2}{|c|}{$\mathrm{L} / \mathrm{D}=\infty$} & \multicolumn{3}{c|}{$\mathrm{L} / \mathrm{D}=1$} & \multicolumn{3}{l|}{$6.1 .1 \quad \mathrm{~L} / \mathrm{D}=2$} \\
\hline $\mathrm{Z}, \mathrm{cm}$ & $\exp (-\sqrt{2} \mathrm{~m} z)$ & $T_{Z}{ }^{\circ} C$ & $\cosh [\sqrt{2 m \ell}]$ & $\cosh \left[\sqrt{2 m \ell}\left(\frac{1-Z}{\ell}\right)\right]$ & $T_{Z}$ & $\cosh [\sqrt{2} m \ell]$ & $\cosh \left[\sqrt{2} m \ell\left(\frac{1-Z}{\ell}\right)\right]$ & $T_{Z}$ \\
& & & & & & & & \\
\\
\end{tabular}

$\begin{array}{rll}\text { Basis: } & \mathrm{h} & =2 \times 10^{-3} \mathrm{~W} / \mathrm{cm}^{2}{ }^{\circ} \mathrm{K} \\ \bar{k} & =0.10 \mathrm{w} / \mathrm{cm}^{\circ} \mathrm{K} \\ \delta_{\mathrm{G} 1} & =28.5 \mathrm{~cm} \\ \mathrm{l} & =\infty, 57.0 \mathrm{~cm}, \text { or } 114.0 \mathrm{~cm} \\ \mathrm{~m} & =2.64 \times 10^{-2}, \sqrt{2} \mathrm{~m}=3.7 \times 10^{-2} \\ \mathrm{~T}_{0} & =1400{ }^{\circ} \mathrm{C} \\ \mathrm{T}_{\mathrm{A}} & =0{ }^{\circ} \mathrm{C}\end{array}$

The figure below shows $\mathrm{T}(\mathrm{z})$ as a function of $\mathrm{z}$ for the full-scale AVS module and for a 5 inch diameter crucible. The two temperature distributions are virtually the same. This is hardly surprising, since the radial thermal conductivity is assumed to be essentially infinite. The only difference between full-scale and 5 inch cases is that their volume averaged thermal conductivities in the $\mathrm{z}$ direction are slightly different, because the volume fractions of glass and graphite are slightly different.

The figure below relates the $\mathrm{T}(\mathrm{z})$ distribution as a function of $\mathrm{z}$ to the time after melting at the surface for 2 fill rates, 4 and 8 inches per hour. The instantaneous centerlinecooling rate in ${ }^{\circ} \mathrm{C} /$ minutes is then readily obtained at any particular temperature or time just by taking the slope of the appropriate curve at that temperature or time.

The limitations of the above analysis are two fold. First, at any given time, the temperature at the centerline will be greater than given by the 1-D analysis, because of the finite thermal conductivity of the vitrified product in the radial direction. The $\square \mathrm{T}$ associated with the radial thermal gradient will increase as the diameter of the module increases.

Second, the analysis is for a steady state temperature distribution, not a transient one in which the vitrified product gives up heat as it continues to move downwards from the surface. This effect is also dependent on the diameter of the module, becoming more important as diameter increases. Rough estimates indicate that while the effect is significant for full-scale modules, it does not alter the estimated cooling rate by a large factor, i.e., $>2$. 


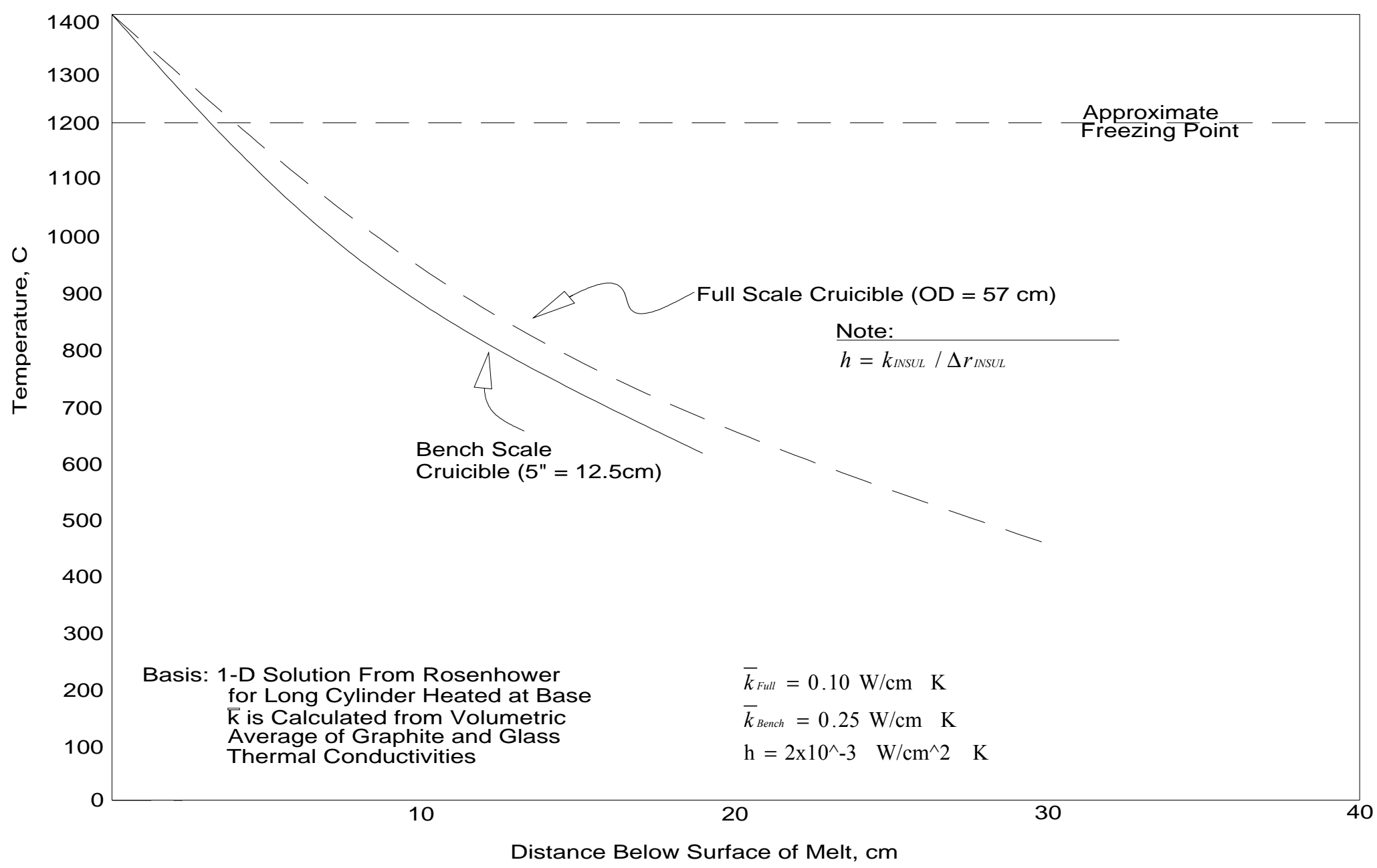

Figure 6-7. Temperature Profile along Crucible for HHM as a Function of Distance Below the Surface of Melt 


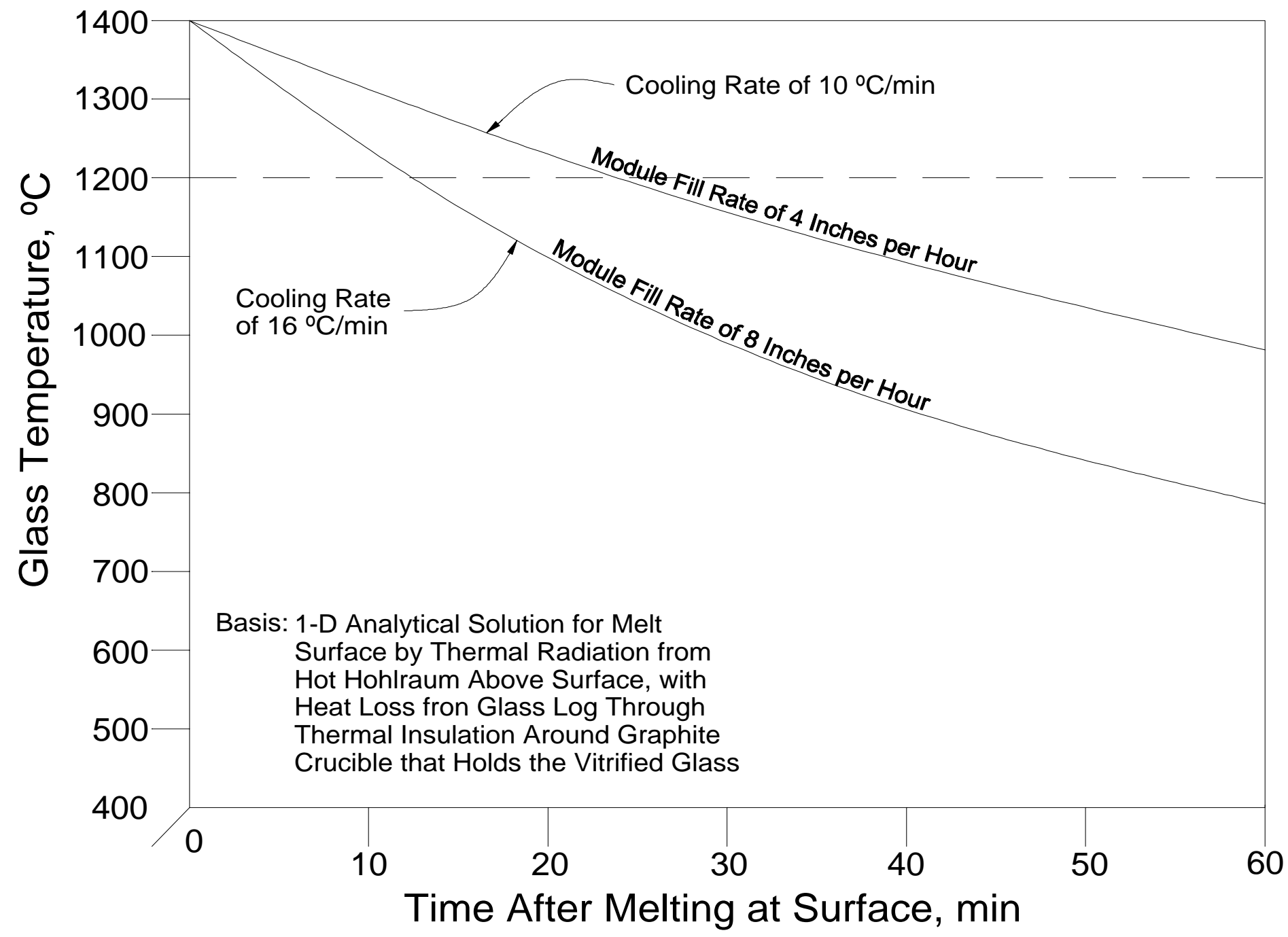

Figure 6-8. Cooling rate for Hot Hohlraum Process for Full-Scale AVS Module 


\section{Centerline Cooling Rates for 5-Inch Bench-Scale Module Based an Experimental Data}

Previous experimental tests of the 5-inch bench-scale test stand can be used to estimate a lower limit to the centerline cooling rates. These tests were carried out by filling the bench-scale module with fully molten HLW/frit material at essentially a uniform melt temperature. The power was then cut-off and the module allowed to cool by heat loss through the enclosing thermal insulation. The figure below shows the temperature of the graphite crucible as a function of time after the induction heating power is terminated. The temperatures shown are for thermocouples 3, 8 and 10 located at 3 different points around the circumference of the crucible corresponds to its center plane. Thermocouples located at other points showed essentially the same temperature/time behavior, indicating a vertically uniform temperature/time profile all over the crucible.

Given this experimental temperature/time behavior, the corresponding centerline temperature/time behavior is derived from 1-D analytical solution for a heat generating cylinder. This solution, taken from Rosenhow (pg.3-109), is given for a cylinder with an internal heat generation $\mathrm{S}\left(\mathrm{W} / \mathrm{cm}^{3}\right)$, radius $\mathrm{r}_{1}(\mathrm{~cm})$, and thermal conductivity $\mathrm{k}(\mathrm{W} / \mathrm{cm}$ $\left.{ }^{\circ} \mathrm{K}\right)$.

To obtain the solution at $\mathrm{T}(\mathrm{r}=0)$, we take the known surface temperature $\mathrm{T}_{\mathrm{A}}$, and an equivalent heat generation rate of $S=\rho C_{p}(d T / d t)$, where $\rho C_{p}$ is the heat capacity in $J / \mathrm{cm}^{3}$ ${ }^{\circ} \mathrm{C}$, and $\mathrm{dT} / \mathrm{dt}$ is the surface cooling rate in ${ }^{\circ} \mathrm{C} / \mathrm{sec}$.

While not strictly correct, since the 1-D solution is for a steady state case, not the actual transient case, the results will be reasonably accurate as long as the temperature difference between the centerline and the surface is small compared to the surface temperature.

As indicated in Figure 6-8 and 6-9, the initial cooling rate of the graphite crucible is $\sim 16$ ${ }^{\circ} \mathrm{C} / \mathrm{min}$, the maximum experienced. At this rate, the temperature difference between the centerline and the surface is only $55^{\circ} \mathrm{C}$, much less than the centerline and the surface temperature of $\sim 1200{ }^{\circ} \mathrm{C}$. As the crucible continues to cool, dT/dt decrease to $\sim 5^{\circ} \mathrm{C} / \mathrm{min}$ resulting in a temperature differences of only $17^{\circ} \mathrm{C}$.

Accordingly, the lower limit to initial cooling rate in the 5 inch bench-scale tests is experimentally determined to be $\sim 16^{\circ} \mathrm{C} / \mathrm{min}$. This is for a crucible initially filled with a $\mathrm{HLW} /$ frit melt at essentially uniform temperature. With the hot hohlraum heating method, the cooling rate will tend to be even greater. 


\section{Centerline TE-3,-8, and -10}

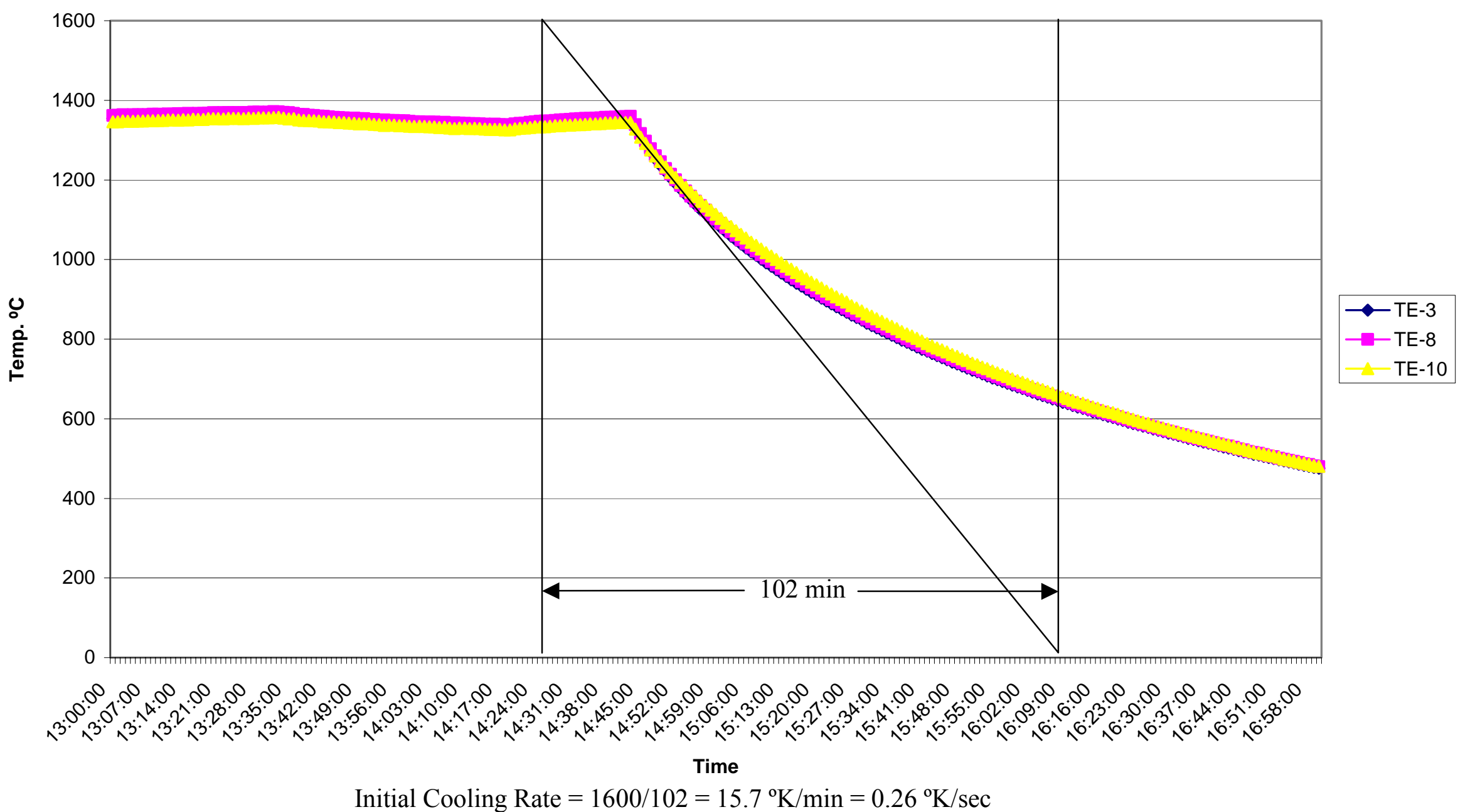

Figure 6-9 
Generating Cylinder (Rosenhow, pg. 3-109)

$$
\left(\mathrm{T}_{\mathrm{r}}-\mathrm{T}_{\mathrm{A}}\right)=1 / 4\left[1-\left(\mathrm{r} / \mathrm{r}_{1}\right)^{2}+2 / \mathrm{B}_{\mathrm{i}}\right]\left[\mathrm{S}\left(\mathrm{r}_{1}\right)^{2} / \mathrm{k}\right]
$$

where: $\mathrm{k}=$ conductivity of glass, $\mathrm{W} / \mathrm{cm}-{ }^{\circ} \mathrm{K}$

$\mathrm{r}_{1}=$ outer radius of glass $\log , \mathrm{cm}$

$\mathrm{S}=$ equivalent heat generation rate, $\mathrm{W} / \mathrm{cm}^{3}$

$\mathrm{r}=$ coordinate of point of in question

$\mathrm{B}_{\mathrm{i}}=\mathrm{hr}_{1} / \mathrm{k}$

Take: $\quad \mathrm{B}_{\mathrm{i}} \rightarrow \infty$

$\mathrm{k} \approx 0.015 \mathrm{~W} / \mathrm{cm}^{-} \mathrm{K}$

$\mathrm{S}=\mathrm{C}_{\mathrm{p}} \rho(\mathrm{dT} / \mathrm{dt}) ; \mathrm{C}_{\mathrm{p}} \rho=2 \mathrm{~J} / \mathrm{cm}^{3}-^{\mathrm{o}} \mathrm{K}$;

$\mathrm{r}=0$ (centerline); $\mathrm{r}_{1}=2.5 \times 2.54=6.3 \mathrm{~cm}$

$\Delta \mathrm{T}=1 / 4[1]\left[2 \mathrm{dT} / \mathrm{dt}\left(\mathrm{r}_{1}^{2} / 0.015\right)\right]$

$=210(\mathrm{dT} / \mathrm{dt})$

\begin{tabular}{|c|c|}
\hline$\underline{\mathrm{dT} / \mathrm{dt}}$ & $\Delta \mathrm{T} /{ }^{\circ} \mathrm{K}$ \\
\hline $1 / 60^{\circ} \mathrm{C} / \mathrm{sec}=\left(1^{\circ} \mathrm{C} / \mathrm{min}\right)$ & 3.5 \\
\hline $1 / 12^{\circ} \mathrm{C} / \mathrm{sec}=\left(5^{\circ} \mathrm{C} / \mathrm{min}\right)$ & 17.5 \\
\hline $1 / 6^{\circ} \mathrm{C} / \mathrm{sec}=\left(10^{\circ} \mathrm{C} / \mathrm{min}\right)$ & 35 \\
\hline $0.26^{\circ} \mathrm{C} / \mathrm{sec}=\left(15.6^{\circ} \mathrm{C} / \mathrm{min}\right)$ & 55 \\
\hline
\end{tabular}

\section{Cooling Rate for 5" Bench-Scale Glass Logs}

- Temperature Measurements of Graphite Crucible after Power is Terminated Show:

- Initial Cooling Rate of $15.6^{\circ} \mathrm{C} / \mathrm{min}\left(0.26^{\circ} \mathrm{C} / \mathrm{sec}\right)$

- Cooling Rate is Essentially Constant Over Entire Surface of Graphite Crucible

- Cooling Rate at Centerline of Glass Log can be Estimated, on Basis of QuasiSteady State Behavior of Equivalent Internal Heat Source

- Glass Log Behaves as Uniform Heat Source with Volumetric Heat Generation Rate of $\mathrm{S}=\rho \mathrm{Cp}[\mathrm{dT} / \mathrm{dt}] \mathrm{W} / \mathrm{cm} 3$

- Assume $(\mathrm{dT} / \mathrm{dt}) \mathrm{Glass} \approx(\mathrm{dT} / \mathrm{dt})$ Graphite; this is valid as long as $\Delta \mathrm{T}$ between centerline and graphite is relatively small

- Use Analytic Solution for Generating Cylinder (From Rosenhow (Handbook of Heat Transfer: $\mathrm{T}_{\mathrm{r}}-\mathrm{T}_{\mathrm{s}}=\left[\mathrm{S}\left(\mathrm{r}_{1}\right)^{2} / \mathrm{k}\right][1 / 4]\left[1-\left(\mathrm{r} / \mathrm{r}_{1}\right)^{2}+2 / \mathrm{B}_{\mathrm{i}}\right]$

With: $\mathrm{B}_{\mathrm{i}} \rightarrow \infty\left[\mathrm{B}_{\mathrm{i}}=\mathrm{hr}_{1} / \mathrm{k}\right]$

$\mathrm{r} \rightarrow 0$ (centerline)

$\mathrm{r}_{1}=$ outer radius of glass $\log , \mathrm{cm}$

$\mathrm{k}=$ conductivity of glass, $\mathrm{W} / \mathrm{cm}-{ }^{\circ} \mathrm{K}$

$\mathrm{S}=\mathrm{C}_{\mathrm{p}} \rho(\mathrm{dT} / \mathrm{dt})$ of glass, $\mathrm{W} / \mathrm{cm}^{3}$ 


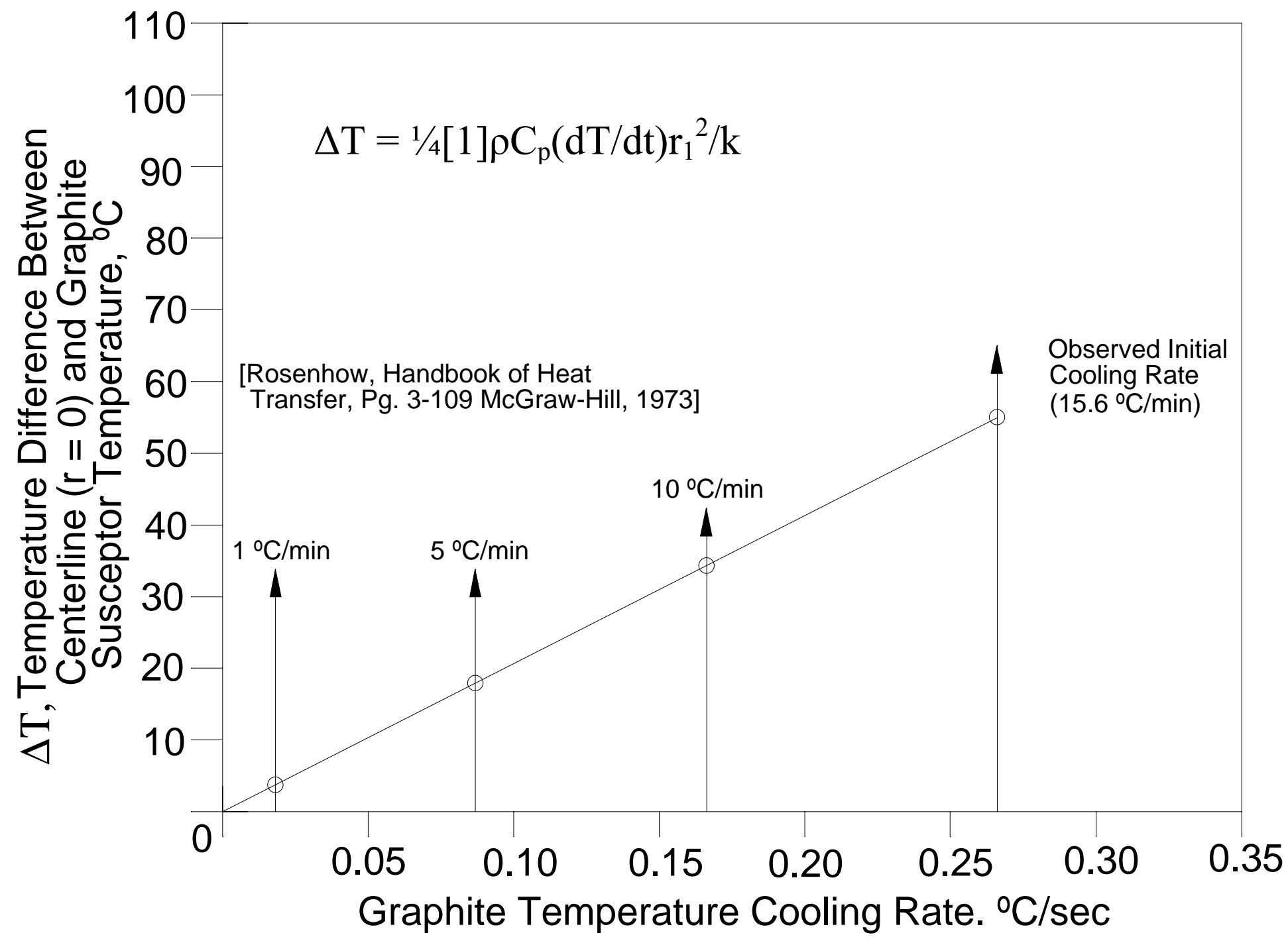

Figure 6-10: $\Delta T$ Between Centerline of 5-Inch Glass Log and Measured Temperature and Measured Temperature of Graphite Crucible as a Function of Cooling Rate 


\section{Cooling Rate Conclusions}

Based on the experimental data, the initial centerline-cooling rate of the vitrified product for the 5 -inch bench-scale test will be on the order of $16^{\circ} \mathrm{C} / \mathrm{min}$. This is considerably faster, by a factor of 16 , then the $1{ }^{\circ} \mathrm{C} / \mathrm{min}$ rate that yields acceptable TCLP performance for cadmium.

Based on a 1-D analytical model the initial cooling rate for the full-scale AVS Module at the centerline will be $\sim 16{ }^{\circ} \mathrm{C} / \mathrm{min}$. The 2 -D model and transient effects will probably reduce this initial cooling rate somewhat, perhaps by a factor of $\sim 2$. However, it will still be much faster than the allowable cooling rate of $1^{\circ} \mathrm{C} / \mathrm{min}$. 


\subsection{Comparison of Vitrified Products from RIC-AVS and Catholic University- VSL}

Comparison of Vitrified Products from RIC-AVS and Catholic University-VSL

The SOW requires the results of this vitrification effort to be compared with that of conventional Joule-melter technology. The DOE has supplied a study conducted by Catholic University's Vitreous State Laboratory (VSL) on AZ-1016 to be used as the basis for this comparison.

The VSL work was not performed in a Joule melter, but in batch melted crucibles in laboratory ovens. The VSL waste glasses were characterized with respect to density, glass transition temperature, crystallinity, TCLP performance, and PCT performance. In addition, a TTT diagram for the vitrified AZ-101 simulant was also prepared.

The VSL report includes a wide variety of glass formulations based on several AZ-101 simulants. The VSL simulant that best matches the AZ-101 composition specified by DOE for the AVS tests is designated HLW98-31. This is the only formulation of AZ-101 simulants that has the same ratio of $\mathrm{Fe}_{2} \mathrm{O}_{3}$ to $\mathrm{MnO}$ as given in the simulant target composition. (The $\mathrm{Fe}_{2} \mathrm{O}_{3}$ to $\mathrm{MnO}$ ratio should not change as the glass forming compounds are added).

The table below is a comparison of the target composition of the simulant (as given by DOE), the composition given in the VSL document VSL-01R250-2 Table 2.5 Column 1 and the DIAL simulant analysis of the AVS simulant. Both the VSL and the DIAL analyses are reasonably close to the target.

6 “Glass Formulation And Testing With RPP-WTP HLW Simulants,” W. K. Kot and I. L. Pegg, Vitreous State Laboratory, The Catholic University of America, Washington, D.C. 20064, February 16, 2001, Rev.0 


\begin{tabular}{|c|c|c|c|}
\hline \multicolumn{4}{|c|}{$\begin{array}{c}\text { Table 6-4. Comparison of VSL and DIAL Analyzed } \\
\text { Simulant with DOE Target }\end{array}$} \\
\hline Oxide & $\begin{array}{l}\text { Target } \\
(\text { wt } \%)\end{array}$ & $\begin{array}{c}\text { VSL } \\
\text { Analyzed } \\
(\mathbf{w t} \%)\end{array}$ & $\begin{array}{c}\text { DIAL } \\
\text { Analyzed } \\
(\mathrm{wt} \%)\end{array}$ \\
\hline $\mathrm{Al}_{2} \mathrm{O}_{3}$ & 24.3 & 23.24 & 23.8 \\
\hline $\mathrm{As}_{2} \mathrm{O}_{3}$ & 0.13 & 0.13 & 0.13 \\
\hline $\mathrm{B}_{2} \mathrm{O}_{3}$ & & $\overline{B D L}$ & BDL \\
\hline $\mathrm{BaO}$ & 0.14 & 0.13 & 0.14 \\
\hline $\mathrm{CaO}$ & 0.81 & 0.78 & 1.34 \\
\hline $\mathrm{CdO}$ & 1.22 & 1.17 & 1.23 \\
\hline $\mathrm{CeO}_{2}$ & 0.27 & 0.26 & 0.25 \\
\hline $\mathrm{Cr}_{2} \mathrm{O}_{3}$ & 0.14 & 0.14 & 0.09 \\
\hline $\mathrm{Cs}_{2} \mathrm{O}$ & 0.27 & 0.27 & 0.28 \\
\hline $\mathrm{CuO}$ & 0.09 & 0.09 & 0.09 \\
\hline $\mathrm{Fe}_{2} \mathrm{O}_{3}$ & 34.1 & 32.63 & 32.9 \\
\hline $\mathrm{K}_{2} \mathrm{O}$ & 0.55 & 0.53 & 0.56 \\
\hline $\mathrm{La}_{2} \mathrm{O}_{3}$ & 1.06 & 1.02 & 1.00 \\
\hline $\mathrm{MgO}$ & 0.21 & 0.20 & 0.28 \\
\hline $\mathrm{MnO}$ & 9.94 & 10.35 & 9.40 \\
\hline $\mathrm{Na}_{2} \mathrm{O}$ & 1.96 & 1.87 & 1.52 \\
\hline $\mathrm{NiO}$ & 1.76 & 1.69 & 1.95 \\
\hline $\mathrm{P}_{2} \mathrm{O}_{5}$ & 0.42 & 0.40 & 0.40 \\
\hline $\mathrm{PbO}$ & 0.50 & 0.48 & 0.54 \\
\hline $\mathrm{SO}_{3}$ & 0.82 & 0.78 & 1.60 \\
\hline $\mathrm{Sb}_{2} \mathrm{O}_{5}$ & 0.69 & 0.60 & 0.50 \\
\hline $\mathrm{SeO}_{2}$ & 0.49 & 0.47 & 0.44 \\
\hline $\mathrm{SiO}_{2}$ & 0.07 & 0.07 & 0.94 \\
\hline $\mathrm{SrO}$ & 7.60 & 7.28 & 7.54 \\
\hline $\mathrm{TeO}_{2}$ & 0.47 & 0.45 & 0.47 \\
\hline $\mathrm{TiO}_{2}$ & 0.21 & 0.20 & 0.28 \\
\hline $\mathrm{ZrO}_{2}$ & 11.7 & 11.78 & 12.60 \\
\hline $\mathrm{U} \mathrm{O}_{2}$ & --- & 2.78 & --- \\
\hline
\end{tabular}

\section{Composition Comparison}

The VSL data were obtained from crucible melts. Therefore, the comparison is made with the results of the AVS Large-Scale Crucible Test Melts.

The table below presents a comparison between the composition of AZ-101 glasses from VSL and DIAL. 
Section 6

Extrapolation of Experimental Results to a Full-Scale AVS Production System

Additional Tests of an Advanced Vitrification System (DE-AC26-00NT40801)

\begin{tabular}{|c|c|c|c|}
\hline \multicolumn{4}{|c|}{$\begin{array}{c}\text { Table 6-5. Composition of HLW-98-31 and DIAL Test } \\
\text { Program Waste Forms }\end{array}$} \\
\hline & \multicolumn{2}{|c|}{ HLW-98-31 } & DIAL Testing \\
\hline & Target & Analyzed & LM-60 Scale 2 \\
\hline $\mathrm{Ag}_{2} \mathrm{O}$ & $0.00 \%$ & $0.01 \%$ & \\
\hline $\mathrm{Al}_{2} \mathrm{O}_{3}$ & $7.40 \%$ & $7.40 \%$ & $16.87 \%$ \\
\hline $\mathrm{As}_{2} \mathrm{O}_{3}$ & $0.04 \%$ & $0.07 \%$ & $0.07 \%$ \\
\hline $\mathrm{B}_{2} \mathrm{O}_{3}$ & $10.00 \%$ & $9.50 \%$ & $6.11 \%$ \\
\hline $\mathrm{BaO}$ & $0.04 \%$ & $0.08 \%$ & $0.08 \%$ \\
\hline $\mathrm{Bi}_{2} \mathrm{O}_{3}$ & $0.00 \%$ & $0.01 \%$ & $\%$ \\
\hline $\mathrm{CaO}$ & $0.25 \%$ & $0.29 \%$ & $0.73 \%$ \\
\hline $\mathrm{CdO}$ & $0.37 \%$ & $0.34 \%$ & $0.69 \%$ \\
\hline $\mathrm{CeO}_{2}$ & $0.08 \%$ & $\mathrm{NA}^{*}$ & $0.15 \%$ \\
\hline $\mathrm{Cl}$ & $0.01 \%$ & NA & \\
\hline $\mathrm{CoO}$ & $0.00 \%$ & $0.02 \%$ & \\
\hline $\mathrm{Cr}_{2} \mathrm{O}_{3}$ & $0.04 \%$ & $0.03 \%$ & $0.16 \%$ \\
\hline $\mathrm{Cs}_{2} \mathrm{O}$ & $0.08 \%$ & NA & $0.17 \%$ \\
\hline $\mathrm{CuO}$ & $0.03 \%$ & $0.04 \%$ & $0.05 \%$ \\
\hline $\mathrm{F}$ & $0.04 \%$ & NA & \\
\hline $\mathrm{Fe}_{2} \mathrm{O}_{3}$ & $10.39 \%$ & $9.64 \%$ & $20.66 \%$ \\
\hline $\mathrm{K}_{2} \mathrm{O}$ & $0.17 \%$ & $0.24 \%$ & $0.37 \%$ \\
\hline $\mathrm{La}_{2} \mathrm{O}_{3}$ & $0.32 \%$ & NA & $0.60 \%$ \\
\hline $\mathrm{Li}_{2} \mathrm{O}$ & $6.00 \%$ & $5.20 \%$ & \\
\hline $\mathrm{MgO}$ & $0.06 \%$ & $0.09 \%$ & $0.16 \%$ \\
\hline $\mathrm{MnO}$ & $3.03 \%$ & $3.63 \%$ & $5.60 \%$ \\
\hline $\mathrm{MoO}$ & $0.00 \%$ & NA & \\
\hline $\mathrm{Na}_{2} \mathrm{O}$ & $6.59 \%$ & $5.68 \%$ & $1.04 \%$ \\
\hline $\mathrm{Nd}_{2} \mathrm{O}_{3}$ & $0.00 \%$ & NA & \\
\hline $\mathrm{NiO}$ & $0.54 \%$ & $0.48 \%$ & $1.14 \%$ \\
\hline $\mathrm{P}_{2} \mathrm{O}_{5}$ & $0.13 \%$ & $0.23 \%$ & $0.20 \%$ \\
\hline $\mathrm{PbO}$ & $0.15 \%$ & $0.19 \%$ & $0.32 \%$ \\
\hline $\mathrm{PdO}$ & $0.00 \%$ & NA & \\
\hline $\mathrm{ReO}$ & $0.00 \%$ & NA & \\
\hline $\mathrm{Rh}_{2} \mathrm{O}_{3}$ & $0.00 \%$ & NA & \\
\hline $\mathrm{RuO}_{2}$ & $0.00 \%$ & NA & \\
\hline $\mathrm{SO}_{3}$ & $0.25 \%$ & NA & $0.37 \%$ \\
\hline $\mathrm{Sb}_{2} \mathrm{O}_{5}$ & $0.21 \%$ & $0.26 \%$ & \\
\hline $\mathrm{SeO}_{2}$ & $0.15 \%$ & $0.06 \%$ & \\
\hline $\mathrm{SiO}_{2}$ & $45.53 \%$ & $44.34 \%$ & $29.94 \%$ \\
\hline $\mathrm{SnO}_{2}$ & $0.00 \%$ & NA & \\
\hline $\mathrm{SrO}$ & $2.32 \%$ & $2.19 \%$ & $4.52 \%$ \\
\hline $\mathrm{Tc}_{2} \mathrm{O}_{7}$ & $0.00 \%$ & NA & \\
\hline $\mathrm{TeO}_{2}$ & $0.14 \%$ & $0.15 \%$ & $0.14 \%$ \\
\hline $\mathrm{ThO}_{2}$ & $0.00 \%$ & NA & \\
\hline $\mathrm{TiO}_{2}$ & $0.06 \%$ & $0.13 \%$ & $0.16 \%$ \\
\hline $\mathrm{Tl}_{2} \mathrm{O}_{3}$ & $0.00 \%$ & $0.05 \%$ & \\
\hline $\mathrm{UO}_{2}$ & $0.00 \%$ & $0.06 \%$ & \\
\hline $\mathrm{V}_{2} \mathrm{O}_{5}$ & $0.00 \%$ & $0.01 \%$ & \\
\hline $\mathrm{WO}_{3}$ & $0.00 \%$ & $0.04 \%$ & \\
\hline $\mathrm{Y}_{2} \mathrm{O}_{3}$ & $0.00 \%$ & NA & \\
\hline $\mathrm{ZnO}$ & $2.00 \%$ & $2.08 \%$ & $1.92 \%$ \\
\hline $\mathrm{ZrO}_{2}$ & $3.56 \%$ & $3.12 \%$ & $7.49 \%$ \\
\hline Total & $100.00 \%$ & $95.66 \%$ & \\
\hline
\end{tabular}




\begin{tabular}{|c|c|c|}
\hline \multicolumn{3}{|c|}{ Table 6-6. Properties of HLW-98-31 vs. AVS Vitrified Waste Form } \\
\hline Parameters & VSL HLW98-31 & DIAL R-02-LM-60 \\
\hline Waste Loading (wt\%[M-1]) & 29.88 & 60 \\
\hline Density $\left(\mathrm{g} / \mathrm{ml}\right.$ at $\left.20^{\circ} \mathrm{C}\right)$ & 2.75 & 3.2 \\
\hline $\begin{array}{c}\text { Glass Transition } \\
\text { Temperature, } T_{g}\left({ }^{\circ} \mathrm{C}\right) \\
\end{array}$ & 458 & 660 \\
\hline Crystallinity & $\begin{array}{c}\text { About } 0.1 \text { vol } \% \text { of high-Fe spinel crystal at } \\
\text { glass crucible interface. }\end{array}$ & $\begin{array}{c}\text { About } 0.5 \text { vol\% of high-Fe spinel with lower } \\
\text { concentration of } \mathrm{ZrO}_{2}\end{array}$ \\
\hline \multicolumn{3}{|c|}{ 7-Day PCT } \\
\hline Element & $\begin{array}{c}\text { Normalized } \\
\text { Concentration }(g / L) \\
\end{array}$ & \\
\hline $\mathrm{B}$ & 0.7259 & 0.12 \\
\hline $\mathrm{Li}$ & 0.5217 & NA \\
\hline $\mathrm{Na}$ & 0.3757 & 0.22 \\
\hline $\mathrm{Si}$ & 0.3154 & 0.08 \\
\hline $\mathrm{pH}$ & 9.84 & 8.0 \\
\hline \multicolumn{3}{|c|}{ TCLP } \\
\hline Element (UTS Limit) & $\mathrm{mg} / \mathrm{l}$ & $\mathrm{mg} / \mathrm{l}$ \\
\hline $\mathrm{Ag}(0.14)$ & $<0.003$ & \\
\hline As (5.0) & $<0.049$ & .0012 \\
\hline $\mathrm{Ba}(21.00)$ & 0.026 & .029 \\
\hline $\mathrm{Cd}(0.11)$ & 0.067 & .073 \\
\hline $\mathrm{Cr}(0.60)$ & 0.023 & .0004 \\
\hline $\mathrm{Pb}(0.75)$ & 0.031 & .0177 \\
\hline $\operatorname{Se}(5.70)$ & 0.086 & .001 \\
\hline
\end{tabular}




\section{Crucible Data}

The most valid comparison of the properties of the VSL vitrified product and the AVS vitrified products is between HLW-98.31 and R-02-LM-60 in as much as they were both crucible tests made with essentially the same simulant. On this basis, R-02-LM-60 has a higher waste loading, a higher density, both pass the PCT tests, and both pass the TCLP tests.

\section{TTT Diagrams}

The TTT diagrams for the two formulations are quite different. This can be seen from a comparison of the above figures. The AVS glass shows a much greater degree of crystallinity throughout the temperature range from liquidus through the glass transition temperature and over the time regime of 1 to 100 hours than does the VSL glass. Crytallinity in the range of trace $-5 \%$ is observed in as short as 0.75 hours in the temperature regime of 1350 to $600{ }^{\circ} \mathrm{C}$ in the AVS glass, while VSL glass shows only trace crystallinity even after several hours at temperature. 


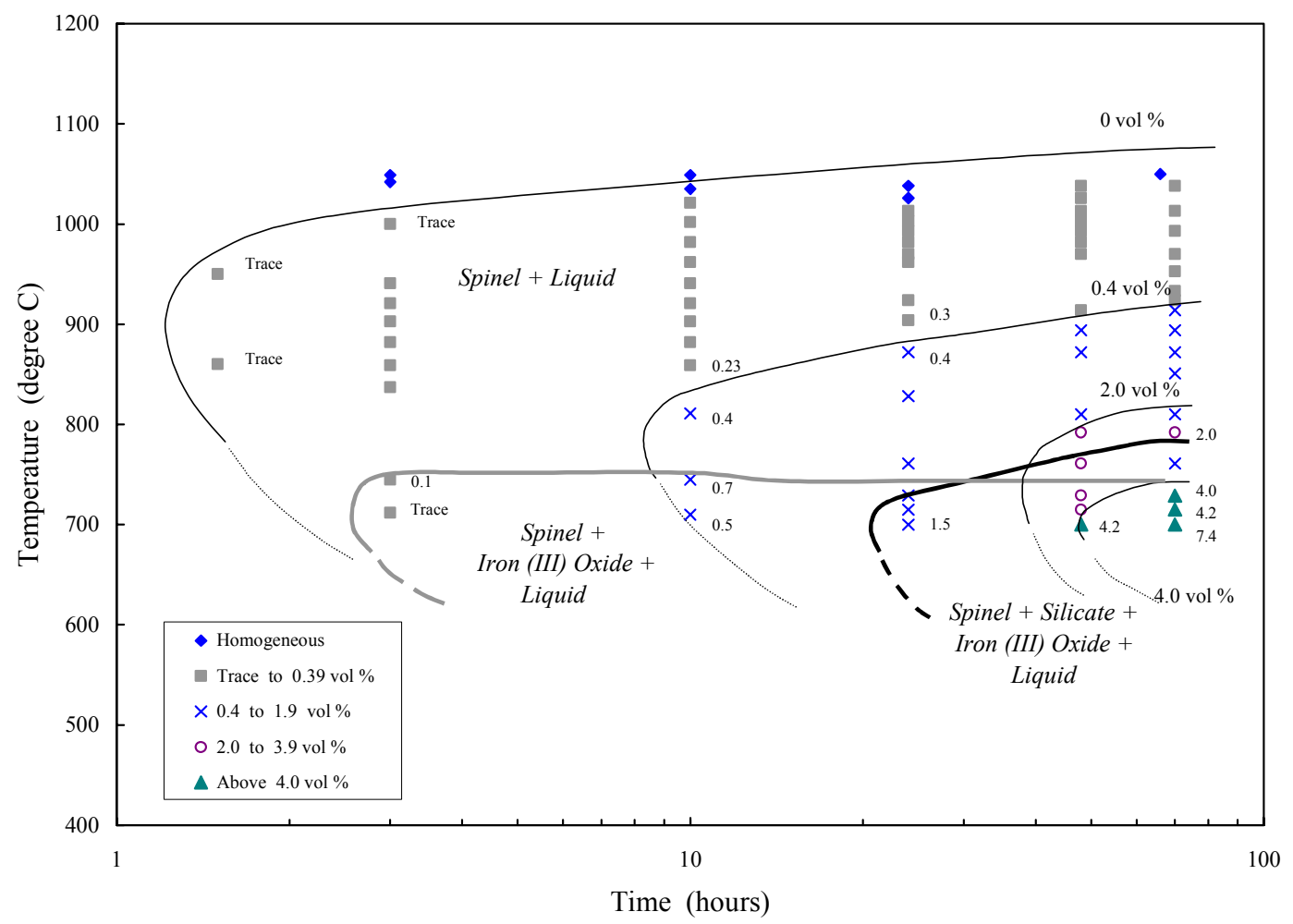

Figure 6-11. Time-Temperature-Transformation Diagram of HLW98-31 Glass

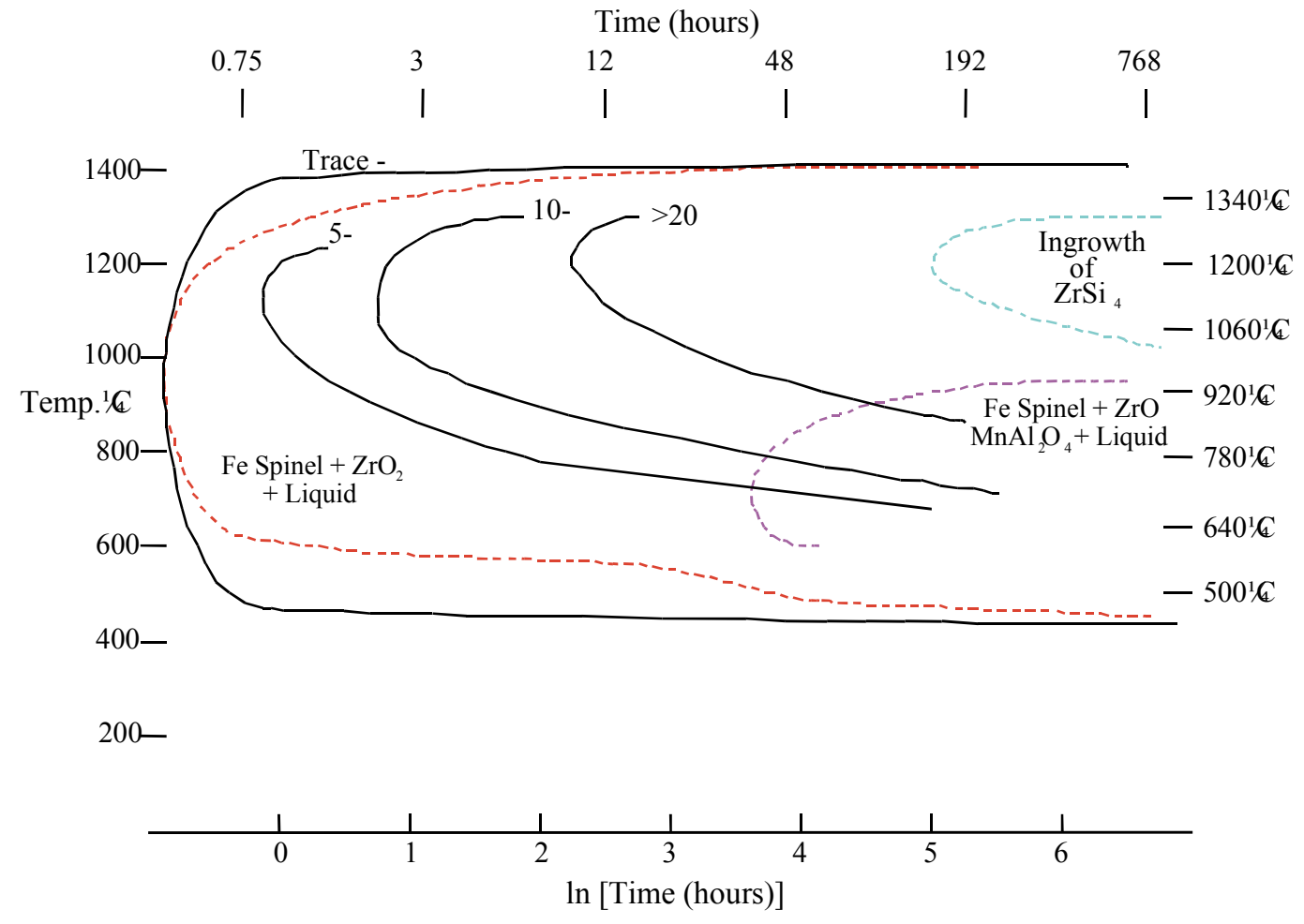

Figure 6-12. Time-Temperature-Transformation Diagram of AVS Glass 


\section{Crystallinity}

Additional types crystals were formed in the AVS TTT study. This is likely due to the higher concentration of $\mathrm{ZrO}_{2}$ in the AVS formulation as a result of the higher waste loading. Crystalline $\mathrm{ZrO}_{2}$ (both monoclinic and tetragonal) as well as $\mathrm{ZrSiO}_{4}$ were found in DIAL TTT samples but absent in the VSL TTT study. Some of these crystals appeared in a time regime longer than that studied by VSL.

While a higher degree of crystallinity as a function of both time and temperature is evident in the RIC TTT study, it is important to recognize that this does not necessarily translate to poorer performance of the vitrified waste. This assessment cannot be made since the VSL study did not include any performance testing of their TTT glasses.

The measurement of how many crystals are formed in per unit volume of glass, how large they are, what their composition is, how rapidly they grow or dissolve, and how quickly they settle to form sludge are important for joule melting. The generation of this data joule melter performance because the crystals (often a mineral called spinel which contains iron nickel, chromium, and other minor oxides), form solid particles that gradually accumulate on the bottom of the joule melter. "Settling of Spinel in a HighLevel Waste Glass Melter," P. Hrma, Pacific Northwest National Laboratory, Project No. 65422, Sept. 2001. For the AVS, accumulation of crystals at the bottom of the melter would not affect melter performance because the AVS melter is used only once. 


\section{PCT and TCLP}

With respect to the RIC AVS study both PCT and TCLP tests were performed on the TTT glasses. All samples showed acceptable PCT performance as shown in the table below.

\begin{tabular}{|c|c|c|c|c|c|c|}
\hline Temperature & \multicolumn{6}{|c|}{ Concentration $(\mathrm{mg} / \mathrm{l})$} \\
\hline \multirow{4}{*}{$1200^{\circ} \mathrm{C}$} & B 0.11 & $\begin{array}{ll}\text { B } & 0.10\end{array}$ & B 0.12 & В 0.12 & B 0.11 & B 0.11 \\
\hline & $\mathrm{Li}$ bdl & Li bdl & $\mathrm{Li}$ bdl & $\mathrm{Li}$ bdl & $\mathrm{Li}$ bdl & $\mathrm{Li}$ bdl \\
\hline & $\mathrm{Na} 0.11$ & $\mathrm{Na} 0.14$ & $\mathrm{Na} 0.23$ & $\mathrm{Na} 0.23$ & $\mathrm{Na} 0.18$ & $\mathrm{Na} 0.14$ \\
\hline & Si 0.08 & Si 0.08 & Si 0.08 & Si 0.08 & Si 0.07 & Si 0.07 \\
\hline \multirow{4}{*}{$1060^{\circ} \mathrm{C}$} & $\begin{array}{ll}\text { B } & 0.11\end{array}$ & $\begin{array}{ll}\text { B } & 0.10\end{array}$ & $\begin{array}{ll}\text { B } & 0.11\end{array}$ & B 0.11 & $\begin{array}{ll}\text { B } & 0.11\end{array}$ & В 0.09 \\
\hline & $\mathrm{Li}$ bdl & $\mathrm{Li}$ bdl & $\mathrm{Li}$ bdl & $\mathrm{Li}$ bdl & $\mathrm{Li}$ bdl & $\mathrm{Li}$ bdl \\
\hline & $\mathrm{Na} 0.12$ & $\mathrm{Na} 0.11$ & $\mathrm{Na} 0.17$ & $\mathrm{Na} 0.21$ & $\mathrm{Na} 0.18$ & $\mathrm{Na} 0.31$ \\
\hline & Si 0.08 & Si 0.08 & Si 0.07 & Si 0.09 & Si 0.08 & Si 0.09 \\
\hline \multirow{4}{*}{$920^{\circ} \mathrm{C}$} & B 0.11 & $\begin{array}{ll}\text { B } & 0.09\end{array}$ & B 0.11 & B 0.11 & B 0.11 & B 0.15 \\
\hline & $\mathrm{Li}$ bdl & $\mathrm{Li}$ bdl & $\mathrm{Li}$ bdl & $\mathrm{Li}$ bdl & $\mathrm{Li}$ bdl & $\mathrm{Li}$ bdl \\
\hline & $\mathrm{Na} 0.14$ & $\mathrm{Na} 0.13$ & $\mathrm{Na} 0.17$ & $\mathrm{Na} 0.15$ & $\mathrm{Na} 0.19$ & $\mathrm{Na} 0.04$ \\
\hline & Si 0.09 & Si 0.09 & Si 0.08 & Si 0.09 & Si 0.09 & Si 0.11 \\
\hline \multirow{4}{*}{$780^{\circ} \mathrm{C}$} & B 0.11 & $\begin{array}{ll}\text { B } & 0.10\end{array}$ & B 0.12 & В 0.12 & B 0.12 & B 0.10 \\
\hline & $\mathrm{Li}$ bdl & $\mathrm{Li}$ bdl & $\mathrm{Li}$ bdl & $\mathrm{Li}$ bdl & $\mathrm{Li}$ bdl & $\mathrm{Li}$ bdl \\
\hline & $\mathrm{Na} 0.15$ & $\mathrm{Na} 0.13$ & $\mathrm{Na} 0.21$ & $\mathrm{Na} 0.22$ & $\mathrm{Na} 0.24$ & $\mathrm{Na} 0.09$ \\
\hline & Si 0.09 & Si 0.09 & Si 0.08 & Si 0.08 & Si 0.09 & Si 0.09 \\
\hline \multirow{4}{*}{$640^{\circ} \mathrm{C}$} & В 0.09 & В 0.11 & В 0.10 & В 0.10 & В 0.11 & В 0.10 \\
\hline & $\mathrm{Li}$ bdl & $\mathrm{Li}$ bdl & $\mathrm{Li}$ bdl & $\mathrm{Li}$ bdl & $\mathrm{Li}$ bdl & $\mathrm{Li}$ bdl \\
\hline & $\mathrm{Na} 0.16$ & $\mathrm{Na} 0.16$ & $\mathrm{Na} 0.17$ & $\mathrm{Na} 0.17$ & $\mathrm{Na} 0.21$ & $\mathrm{Na} 0.19$ \\
\hline & Si 0.08 & Si 0.08 & Si 0.08 & Si 0.08 & Si 0.08 & Si 0.09 \\
\hline \multirow{4}{*}{$500^{\circ} \mathrm{C}$} & B 0.10 & $\begin{array}{ll}\text { B } & 0.11\end{array}$ & $\begin{array}{ll}\text { B } & 0.11\end{array}$ & $\begin{array}{ll}\text { B } & 0.11\end{array}$ & $\begin{array}{ll}\text { B } & 0.10\end{array}$ & $\begin{array}{ll}\text { B } & 0.09\end{array}$ \\
\hline & $\mathrm{Li}$ bdl & $\mathrm{Li}$ bdl & $\mathrm{Li}$ bdl & $\mathrm{Li}$ bdl & $\mathrm{Li}$ bdl & $\mathrm{Li}$ bdl \\
\hline & $\mathrm{Na} 0.17$ & $\mathrm{Na} 0.18$ & $\mathrm{Na} 0.19$ & $\mathrm{Na} 0.20$ & $\mathrm{Na} 0.22$ & $\mathrm{Na} 0.10$ \\
\hline & Si 0.08 & Si 0.08 & Si 0.08 & Si 0.08 & Si 0.08 & Si 0.08 \\
\hline Time (hrs) & 0.75 & 3 & 12 & 48 & 192 & 768 \\
\hline
\end{tabular}

The TCLP performance of the TTT glasses were also acceptable with the exception of some longer heat treated samples where some marginal increase in Cd release above the UTS limits.

Exceeding the UTS levels for heat-treated TTT samples is acceptable since there are no performance criteria relating to annealed samples. Moreover, given the TCLP performance of AZ-101 glasses in the VSL study, there is no reason to expect that a similar behavior would not have been seen in the VSL TTT glasses had they been evaluated. The additional data provides some insight into the consequences of unplanned temperature excursions of the AVS product glass

\section{Processing Implications}

The table below shows waste loading and canister statistics for the VSL and AVS processes. There the mass of waste per canister for each process is calculated, assuming 
an identical outer canister dimension of $61 \mathrm{~cm}$ in diameter and an overall canister length of $4.5 \mathrm{~m}$ for both the Joule-melter pour-type canister and the full-size AVS module.

n spite of the lower internal volume of the AVS canister, at the same fill level, the AVS canister would contain 1.8 times more waste than a pour-type canister from the Joule melter. This is attributed to the higher waste loading and higher density of the AVS glass. Thus, the AVS process is calculated to result in 1.8 times fewer canisters of waste shipped to the repository.

About half as many canisters of waste, costs about half as much for disposal and provides about half the potential leaching surface area available, which enhances environmental protection.

\begin{tabular}{|c|c|c|}
\hline \multicolumn{3}{|c|}{$\begin{array}{l}\text { Table 6-7. Comparison of Joule-Melter Canister Waste Mass with } \\
\text { Full-Size AVS Module Waste Mass, Assuming Overall Canister } \\
\text { Volume of } 61 \mathrm{~cm} \text { Outside Diameter and } 4.5 \mathrm{~m} \text { Height }\end{array}$} \\
\hline Parameters & $\begin{array}{c}\text { Pour-Type Joule Melter } \\
\text { Stainless Canister }\end{array}$ & $\begin{array}{c}\text { Full-Scale } \\
\text { AVS Canister }\end{array}$ \\
\hline Available Fill Volume $\left(\mathrm{m}^{3}\right)$ & $1.224^{\mathrm{a}}$ & $0.941^{\mathrm{b}}$ \\
\hline Fill Level (5) & 90 & 90 \\
\hline Volume Waste Glass $\left(\mathrm{m}^{3}\right)$ & 1.102 & 0.847 \\
\hline Density of Waste Glass & $2.75^{\mathrm{c}}$ & $3.2^{\mathrm{c}}$ \\
\hline Mass of Glass (kg) & 3029 & 2710 \\
\hline Waste Loading wt $\%$ [M-1] & 29.88 & 60 \\
\hline Mass of Waste/canister $(\mathrm{kg})$ & 905 & 1626 \\
\hline Fraction AVS/Joule & & 1.8 \\
\hline
\end{tabular}

a Inside diameter available for filling $59 \mathrm{~cm}(1 \mathrm{~cm}$ canister wall).

b Inside diameter available for filling $52 \mathrm{~cm}$ (canister wall $1 \mathrm{~cm}$; insulation thickness, $1 \mathrm{~cm}$; graphite crucible thickness, $2 \mathrm{~cm}$; alumina, $0.5 \mathrm{~cm}$ ).

c $\quad 2.75 \mathrm{~g} / \mathrm{cc}$ and $3.2 \mathrm{~g} / \mathrm{cc}$ are the glass densities at $20^{\circ} \mathrm{C}$ (see fn 11 for VSL citation), the molten glass density for the AVS glass is $2.95 \mathrm{~g} / \mathrm{cc}$. The plan is to fill the AVS module to a level above $90 \%$ so that cool-down glass volume will be at least $90 \%$.

VSL's HLW98-31 glass had a waste loading of 30.49-wt\%. Correcting the VSL waste loading to subtract the silica and sodium oxide in the waste in order to provide a like number for comparison to the waste loading obtained for the AVS waste loading (DOE Method 1), yields an M-1 waste loading for HLW98-31 of $29.88-w t \%$. Thus, the waste loading for HLW98-31 is approximately a factor of two less $(60-\mathrm{wt} \% / 30-\mathrm{wt} \%)$ than the waste loading used for AVS testing. 


\section{Conclusions and Recommendations}

\subsection{Conclusions}

Based on the results of this work as well as the requirements of the SOW the following conclusions have been reached:

- It is possible to prepare a vitrified AZ-101 borosilicate glass at both the laboratory-scale and the AVS bench scale with a waste loading of $\sim 60 \mathrm{wt} . \%$ [M1] that meets the requirements of the WAPS with respect to composition control, product consistency, toxic release, and crystallinity. Further, as specified by the WAPS, a TTT diagram has been provided to demonstrate the performance of this waste as a function of time and temperature between the liquidus and glass transition temperature.

- Cooling rate for the full-scale process may have to be controlled to comply with crystallinity requirements for the vitrified product.

- With respect to process scale-up of the AZ-101 waste formulation, it was projected that a $1.5 \mathrm{MT} /$ day production rate can be met.

- Comparison of these results with those obtained in support of the Joule melting process at VSL indicate that since a higher waste loading and density can be obtained with the AVS process. the AVS canister would contain 1.8 times more waste than a pour-type canister from the Joule melter at the same fill level, in spite of the lower internal volume of the AVS canister. In both the RIC and VSL study, $\mathrm{Cd}$ release proved to be a critical factor in determining maximum waste loading in the AZ-101.

\subsection{Recommendations - Testing}

Proceed with AVS process development in accordance with the February 2002 Work Plan.

- AVS process development should include waste form testing consistent with the methodology employed to proof test other melter technologies.

- Waste form testing should be undertaken in conjunction with the operation of an up-to-date test stand employing the hot hohlraum heating process developed for the AVS.

- Hot Waste form testing should proceed as described in the February 2002 Work Plan.

- AVS process development testing should include demonstrations and tests of melter production variables in comparison to the WTP Baseline Melter or other competing designs on a Total Life Cycle Costs per Investment basis: e.g. average waste loading translated to number of cans, Annual Operating Costs, Total Operating Efficiency including the replacement cycle for the Baseline Melter. 


\subsection{Recommendations - Environmental}

This section comprises two subsections, which document observations, conclusions and recommendations resulting from the testing program. Included are subsections on a "Specific Method to Prepare TCLP Samples" and "Correcting Deficiencies in Environmental Protection Analysis."

\section{Specific Method to Prepare TCLP Samples}

This subsection documents conclusions from the testing program leading to a recommendation that DOE establish a specific method to prepare TCLP samples and measure the surface area of the sample size. Such a specific method would be consistent with EPA's position and would add credibility to TCLP results performed at different times or by different researchers.

For the bench-scale tests and lab-scale test, the TCLP tests were conducted on pieces smaller than 1 centimeter in the narrowest dimension, as specified by the TCLP Method 1311 test procedure. However, the difference in sample size between the bench-scale and the lab scale introduces an uncontrolled variable inherent in the TCLP test.

The results of the Toxicity Characteristic Leach Procedure (TCLP) test are dependent on a number of test variables that are not well controlled. These uncontrolled variables include:

1. Amount of fines;

2. Size and distribution of fine particles;

3. Shape of fine particles.

The process of preparing samples for TCLP tests can significantly alter the above variables in an unknown and uncontrollable manner, thereby arbitrarily affecting the concentration of the hazardous metals in the TCLP leachate. An illustrative analysis of this is given below.

The concentration of the Ag in the leachate will be proportional to the exposed surface area per gram of vitrified waste. Assuming linear proportionality:

$$
\mathrm{C}_{\mathrm{Ag}}=\mathrm{K}_{\mathrm{D}}(\mathrm{S} / \mathrm{M})
$$

Where:

$$
\begin{aligned}
& \mathrm{C}_{\mathrm{Ag}}=\text { concentration }(\mathrm{ppm}) \\
& \mathrm{K}_{\mathrm{D}}=\text { leach constant } \\
& \mathrm{S} / \mathrm{M}=\text { exposed surface area, } \mathrm{cm}^{2} / \mathrm{gram}
\end{aligned}
$$

The TCLP (Method 1311, Rev. 0, July 1992, Section 7.1.3) states that: "particle size reduction is required, unless the solid has a surface area per gram of material equal to or greater than $3.1 \mathrm{~cm}^{2}$, or is smaller than $1 \mathrm{~cm}$ in its narrowest dimension (i.e., is capable of passing through a $9.5 \mathrm{~mm}$ standard sieve). If the surface area is smaller or the particle size is larger than described above, prepare the solid portion of the waste for extraction by crushing, cutting, or grinding the waste to a surface area or particle size as 
described above.... Note: surface area criteria are meant for 'filamentous' (e.g., paper, cloth, and similar) waste materials. Actual measurement of surface area is not required for material, nor is it recommended. For materials that do not obviously meet the criteria, sample specific methods would need to be developed and employed to measure the surface area. Such methodology is currently not available." (Underlining added for emphasis.)

The TCLP regulations thus directly acknowledge that there is no method for determining the actual surface area in the TCLP tests when solids are prepared by crushing, cutting or grinding, yet the same pass/fail criteria are applied regardless of how the surface area varies.

Depending on the above three uncontrolled variables, the surface area for leaching can vary greatly. Examples are given below.

The surface per gram of 1-centimeter diameter sphere (which is permitted by the test) is:

$$
\mathrm{S} / \mathrm{M}=\left(4 \pi \mathrm{R}^{2}\right) /\left(4 / 3 \pi \mathrm{R}^{3} \rho\right)=3 / \mathrm{R} \rho \mathrm{cm}^{2} / \text { gram }
$$

Where $\mathrm{R}=$ radius of sphere and $\rho=$ density of vitrified waste, $\mathrm{gm} / \mathrm{cc}$.

$$
\begin{aligned}
& \text { Taking } \mathrm{R}=0.5 \mathrm{~cm} \text { and } \rho=3 \mathrm{~g} / \mathrm{cc} \\
& \mathrm{S} / \mathrm{M} \text { Sphere }=3 /(3(.5))=2 \mathrm{~cm} 2 / \mathrm{gm}
\end{aligned}
$$

Now consider the amount, size and shape of the fines associated with cutting and crushing the sample, and how these variables affect the surface area for leaching.

$$
\mathrm{S} / \mathrm{M} \text { Fines }=(3 / 3 \mathrm{Rf}) \mathrm{f}_{\mathrm{f}} \mathrm{fs}
$$

Where $R_{\mathrm{f}}=$ Average radius of fines (= $1 / 2$ Average Diameter)

$\mathrm{f}_{\mathrm{f}}=$ mass fraction of fines relative to large chunks

$\mathrm{f}_{\mathrm{s}}=$ shape factor, area of fines particles relative to area of a sphere of equal diameter

The shape factor for a fine particle that is a circular cylinder of $L / D=2$ is

$$
\mathrm{f}_{\mathrm{S}}=\left[(\pi \mathrm{D})(2 \mathrm{D})+(2)\left(\pi \mathrm{D}^{2} / 4\right)\right] /\left[4 \pi(\mathrm{D} / 2)^{2}\right]=2.5
$$

Table 7-8. Ratio of Surface Area of Fines to

Surface Area of $1 \mathrm{~cm}$ Diameter Sphere

\begin{tabular}{|c|c|c|c|c|c|c|}
\hline & \multicolumn{3}{|c|}{$\mathrm{f}_{\mathrm{s}}=1$ (spheres) } & \multicolumn{1}{c|}{$\mathrm{f}_{\mathrm{s}}=2.5(\mathrm{~L} / \mathrm{D}=2$ cylinder) } \\
\cline { 2 - 7 } & \multicolumn{5}{|c|}{ Average Fine Diameter, microns } \\
\hline $\begin{array}{c}\text { Mass Fraction } \\
\text { of Fines }\end{array}$ & $\mathbf{1 0}$ & $\mathbf{8}$ & $\mathbf{5}$ & $\mathbf{1 0}$ & $\mathbf{7 . 5}$ & $\mathbf{5}$ \\
\hline $\mathbf{5 \times 1 0}$ & 1.0 & 1.25 & 2.0 & 2.5 & 3.1 & 5 \\
\hline $\mathbf{1 \times 1 0} \mathbf{1 0}^{-3}$ & 2.0 & 2.5 & 4.0 & 5.0 & 6.2 & \\
\hline $\mathbf{2} \times \mathbf{1 0}^{-3}$ & 4.0 & 5.0 & 8.0 & 10.0 & 12.5 & 20 \\
\hline
\end{tabular}


Clearly a very small amount of fines, $1 / 2000^{\text {th }}$ of the mass of the solid chunks, will be as or even more important in determining leachate concentrations than the large chunks. Moreover, small changes in the size, shape or amount of fines can change the leachate from a pass to a fail condition.

There are substantial differences in the way that the TCLP samples were prepared from the large-scale and bench-scale tests, and these could significantly affect the metal concentration value.

For example, during the testing, the large-scale melts were hit by a hammer to break-up the product into chunks while the bench-scale melts were cut into chunks by a band saw over a period several hours and then hammered. The band saw cutting operation locally heated the solid melt product to a high temperature, possibly promoting surface crystallization and changing the glass structure. Moreover, the high stresses caused by the band saw probably induced a substantial amount of micro-cracking in the solid making it likely to fracture into a larger amount of fines of smaller average diameter.

The bottom line is that there is no way of knowing how the sample preparation procedure affected the amounts of fines, their size, and their shape, and that these can be of critical importance in whether or not samples pass the TCLP test. There is no guidance on this issue from the TCLP test procedure, and therefore no assurance that the test results really tell whether it is safe or not safe to dispose of the waste product. It also raises into question the validity of any comparison to TCLP results between different testers employing differing sample preparation methodology.

\section{Correcting Deficiencies in Environmental Protection Analysis}

This subsection documents observations, conclusions and recommendations resulting from the testing program relating to the standard analytical regime concerning environmental compliance and environmental performance. A deficiency in applying the standard analytical regime is observed, which potentially leads to decisions compromising the commitment to defense in depth concerning waste form environmental performance. The deficiency also eliminates the potential for higher waste loaded glass and the attendant cost savings from producing even fewer canisters than is possible with the AVS glass under the standard analytical regime.

The AVS waste form is more than the glass material anticipated under EPA's standards and is an innovative technology fitting well within EPA's directive on encouraging innovation. The AVS waste form is a new waste form created by WAPS compliant glass encapsulated in an alumina lined graphite susceptor. The graphite is not merely a container for the glass, but rather the molten glass adheres to the inner surface forming an integral waste form by the welding of glass, alumina and graphite. Thus, the graphite serves as an encapsulator of the high-level waste glass, substantially lengthening the long-term dissolution behavior of the waste form under repository conditions. Since 
graphite and alumina are both already in their final state in terms of corrosion, they are well known to have an expected lifetime in the millions of years. 1

The standard glass performance evaluations required to be performed under the SOW requires the disassembly of the AVS waste form to separate the glass from its encapsulating medium. This process inherently ignores the substantial environmental improvements potentially offered by the AVS waste form.

This seems to be a vestige of the system created to evaluate the waste form obtainable from the joule melter and potentially could encourage the use of poorer performing waste forms.

For example, EPA explains that the TCLP "test was designed to model a theoretical scenario in which a waste is mismanaged by placing it in an unlined landfill containing municipal solid waste. The acetic acid solution in Method 1311 is designed to simulate the result of rainwater infiltrating the landfill, reacting with the municipal solid waste, and then leaching through the waste being tested. The numerical limits for the RCRA toxicity characteristic (40 CFR 261.24) were derived using the same scenario and were set at levels that would prevent the gxpundwater under the landfill from posing a threat to human health and the environment." 2 Thus, while testing the HLW glass in contact with the repository geology would make sense because that is the material in contact with the geology over the long term, the AVS encapsulated waste form would tend to eliminate the presumed potential threat to the human health and environment over the long term.

EPA does not have a closed mind on its specified testing regime or the methodology for treatment, rather EPA indicates an open mind to new compliance treatment methods and evaluation criteria.

From an overall perspective of the EPA's regulations, EPA regulates deep underground direct injection of wastewaters containing hazardous constituents. This is a direct injection of the hazardous constituents to the geology. On the other hand, the vitrification process for high-level radioactive waste will immobilize the hazardous constituents in glass with a direct long-term exposure to the geology. Thus, both the HLWVIT technology standard specified by EPA ${ }^{6}$ and the UTS extract standard also specified by

\footnotetext{
${ }^{1}$ While the Nuclear Regulatory Commission staff has recognized the potential advantages of alumina and graphite for the high level waste, experimental confirmation of the impermeability of the AVS waste form is anticipated to be required to support the generalized knowledge on their actual performance under repository conditions. See e.g., Nuclear Regulatory Commission, Issue Resolution Status Report, Key Technical Issue: Container Life and Source Term, Revision 2 September 1999.

${ }^{2}$ http://www.epa.gov/epaoswer/hazwaste/test/faqs tclp.htm . "Answering 'TCLP QUESTIONS'."

340 CFR 268.40. Savannah River states, "The DWPF is exempted from UTS standards, since the waste sludge is being treated by a specified technology, e.g. [sic, sould probably be viz.] HLVIT, which has been declared by EPA to be BDAT [Best Demonstrated Available Technology].
} 
$\mathrm{EPA}^{\text {G }}$ provide a substantial improvement over direct injection and were created with the recognition that HLW glass would be the leaching medium.

The EPA office responsible for RCRA compliance has established a written policy, which directs staff to "Place a high priority on innovative treatment technologies" to meet the statutory and regulatory goals for land disposal of hazardous materials." directive requires EPA staff to "Routinely Consider Innovative Treatment Technologies Where Treatment Is Appropriate" and "encourages reasonable risk-taking in selecting innovative technologies for treating contaminated soils, sludges, and groundwater." This EPA office further encourages its staff, "When an innovative technology has potential site-specific and/or program-wide benefits, do not be risk averse toward adopting it." The EPA office states, "For actions under RCRA, regulatory staff will be in a position of reviewing proposals from owner/operators, and possibly discussing options with their state counterparts. Program managers should encourage owner/operators to consider innovative approaches and, where appropriate, direct parties to sources of assistance and information."

The directive cites long-standing agency policy to encourage and consider using such innovative technologies at Federal Facilities, which enhances the potential for receiving the exemption to delist the AVS waste form: "An EPA Policy for Innovative Environmental Technologies at Federal Facilities, signed by Administrator Browner in August 1994, documents EPA's commitment to promote the use of Federal facilities as demonstration and testing centers for innovative environmental technologies. Federal facilities offer unique opportunities for the dejelopment and application of both field site characterization and cleanup technologies."

\footnotetext{
${ }^{4} 40$ CFR 268.48.
}

${ }^{5}$ It is generally recognized that the stainless steel container cannot be expected to serve as a long-term barrier, as explained by the Nuclear Regulatory Commission staff: "It is anticipated that the primary cause for engineered barrier degradation under normal conditions (i.e., in the absence of disruptive events, such as seismicity, faulting, or volcanism) will be caused by one or more corrosion processes. Both DOE and the staff evaluated the most likely forms of materials degradation for the candidate container materials of interest (Farmer, et al., 1988; Gdowski, 1991; Cragnolino and Sridhar, 1991, 1992; Geesey, 1993; Sridhar, et al., 1994; U.S. Nuclear Regulatory Commission, 1997; Cragnolino, et al., 1999). These degradation modes include dry-air oxidation of container materials during the initial hot, dry period following emplacement of the WPs in the drifts. After this initial period, the drift wall and container surface temperatures will decrease and the container materials will be subjected to humid-air corrosion and various modes of aqueous corrosion, i.e., general corrosion, localized corrosion, MIC, SCC, and hydrogen embrittlement." Nuclear Regulatory Commission, Issue Resolution Status Report, Key Technical Issue: Container Life and Source Term, Revision 2 September 1999.

${ }^{6}$ OSWER [EPA Office Of Solid Waste And Emergency Response] POLICY DIRECTIVE 9380.0-25, Promotion of Innovative Technologies in Waste Management, Programs Place a Higher Priority on Innovative Treatment and Characterization Technologies.

${ }^{7}$ Id. at 5. 
If testing were authorized using the AVS waste form, rather than requiring removal of the encapsulating graphite and testing only the glass, there would probably be a zero release from material. Although testing the encapsulated waste form was not permitted in the testing, it is well known that graphite encapsulation would preclude contact of the glass with leaching solutions. Thus, if there were no consequent leaching of any hazardous materials in the leachate extract, the AVS waste form would clearly satisfy the UTS waste extract standard. In terms of supporting the purpose of RCRA and the EPA's regulations, use of the AVS waste form would "substantially diminish the toxicity of the waste or substantially reduce the likelihood of migration of hazardous constituents from the waste so that short term and long term threats to human health and the environment are minimized."

Two other environmental benefits to the AVS waste form also go unrecognized by the application of the standard testing regime.

- The first is that current glass leaching evaluation system provides no means to recognize the inherent benefit with the AVS waste form of having twice as much waste in the glass. With twice as much waste, there are half as many canisters of waste, providing half the potential leaching surface area available with the traditional canister.

- The second is that with the encapsulation medium, an even higher waste content in the glass could conceivably pass the TCLP test. This could have 10 to $20 \%$ impact in lowering costs if waste loading could be increased to 70 or $80 \%$. Yet, there is no possibility for considering this if the waste form must be deconstructed and the encapsulating medium removed before TCLP testing.

Based upon the probability of no consequent leaching of any hazardous materials from the AVS waste form using the existing EPA tests, it would serve national environmental policy to demonstrate that the AVS treatment method is a treatment method exceeding current standards for protection of the environment.

It is recommended that testing be permitted using the AVS waste form, rather than requiring that the waste form be de-constructed and the glass tested separately. At the very least, this should be proposed to EPA for consideration. To do otherwise is dysfunctional to the RCRA objectives and tilts the decisional process towards potentially lesser performing waste forms. 


\section{References}

[1] "Waste Acceptance Product Specifications for Vitrified High-Level Waste Forms WAPS," U.S. Department of Energy Office of Environmental Management, EMWAPS Rev. 02, December 1996.

[2] EPA Regulations at 40 C.F.R. Parts 260, 261 and 268.

[3] “Additional Tests of an Advanced Vitrification System," J.R. Powell and M.Reich, Radioactive Isolation Consortium, LLC, January 2002, revised 3/14/02.

[4] “Glass Formulation And Testing With RPP-WTP HLW Simulants," W. K. Kot and I. L. Pegg, Vitreous State Laboratory, The Catholic University of America, Washington, D.C. 20064, February 16, 2001, Rev.0.

[5] "Key Technical Issue:Container Life and Source Term," Nuclear Regulatory Commission, Issue Resolution Status Report, Revision 2 September 1999.

[6] 'AAnswering ‘TCLP QUESTIONS,' Environmental Protection Agency, http://www.epa.gov/epaoswer/hazwaste/test/faqs_tclp.htm

[7] "Promotion of Innovative Technologies in Waste Management, Programs Place a Higher Priority on Innovative Treatment and Characterization Technologies," POLICY DIRECTIVE 9380.0-25, Environmental Protection Agency, Office Of Solid Waste And Emergency Response.

[8] "Toxicity Characteristic Leaching Procedure, test Method 1311 in 'Test Methods for Evaluating Solid Waste, Physical Chemical Methods',' EPA Publication SW846.

[9] "Current Perspectives in Site Remediation and Monitoring, The Relationship Between SW-846, PBMS, and Innovative Analytical Technologies," D.M. Crumbling and Barry Lesnik, EPA Office of Solid Waste and Emergency Response, EPA 542-R-01-015.

[10] “Alternative High-Level Waste Treatments at the INEEL," National Research Council, December 16, 1999.

[11] "Settling of Spinel in a High-Level Waste Glass Melter," P. Hrma, Pacific Northwest National Laboratory, Project No. 65422, Sept. 2001.

[12] "Toxic Characteristic Leaching Proceture (TCLP) Testing of Waste Glass and K-3 Refractory: Revisited," C.M. Jantzen and J.B. Pickett, Westinghouse Savannah River Co., Aiken, SC and I. Joseph, GTS Duratek, Columbia, MD, WSRC-MS-9900335 . 